\title{
CONSTRUCCIÓN DE IDENTIDAD ORGANIZACIONAL DE LOS MANDOS MEDIOS COMO ESPACIO LIMINAL. UN ESTUDIO DE CASO.
}

\author{
Por \\ Diego René Gonzales Miranda
}

Tesis presentada a la

Universidad Autónoma Metropolitana - Unidad Iztapalapa, en cumplimiento con los requisitos para obtener el grado de Doctor en Estudios Organizacionales.

Director

Dr. Luis Montaño Hirose 


\section{A Rafael y Alexandra}

Por aquello que en el pasado fue reconocido, por aquello que lucha por trascender en el futuro, por aquello que somos gracias a la seguridad del presente.

A nuestra liminal identidad... 
La investigación que realicé versó sobre la identidad. El quién soy es dialógico, y por tanto, su respuesta necesita de los demás, se construye en comunidad. El hombre como ser en relación, lo es en tanto encuentra un tú que lo constituye como persona. Así, la respuesta a la pregunta que me planteé en el ámbito organizacional, se logró gracias a muchos otros que me acompañaron en el proceso. Mi reconocimiento y gratitud a todos ellos.

Gracias Prof. Luis por sus consejos, reflexiones, discusiones y sugerencias que me acompañaron a lo largo de todo este proceso y seguirán presentes en mi vida. Gracias por todo lo aprendido y vivido.

Gracias a la Universidad EAFIT (Colombia) por las posibilidades que me brindó para realizar este doctorado que dio luz a esta investigación, en especial al decano, Francisco López y al jefe de departamento, Ricardo Uribe, por su apoyo incondicional. Una mención especial a Rodrigo Muñoz por la disposición y apertura, artífice de mi experiencia intelectual y académica en México.

Gracias a la Universidad Autónoma Metropolitana (México) por acogerme y brindarme la oportunidad de estudiar en su recinto. Gracias Germán por la confianza y dedicación; y cómo no agradecerle a Alejandra, Rosalba y Juan Carlos, por su gentil disposición y colaboración.

Gracias a Comercial Nutresa por su apoyo y apertura en la realización del estudio de caso. A Álvaro Arango, Patricia Garcés y Liliana Crespo como a todos aquellos que gentilmente me colaboraron. Una mención especial a Diego $\mathrm{Paz}^{\dagger}$ por creer en mi proyecto y quien fuera el promotor de realizar la investigación en esta compañía.

Gracias Beatriz por la amistad, consejo, escucha, cercanía, dedicación y por todo lo que me enseñaste. En mucho, esta investigación es gracias a tu apoyo, aliento, confianza y acompañamiento.

Gracias Guillermo por tu gentiliza, calidez, cercanía y amistad. En ti se sintetiza el valor de la palabra cumplida, y en ella, el sostén de toda buena amistad. Aprendí mucho más por fuera de las aulas.

Gracias a Juan Carlos, Mariano y Carmen. Los espacios de diálogo y las discusiones construidas con ustedes me ayudaron a clarificar muchas de las dudas que surgieron.

Gracias Ayuzabet por todo el acompañamiento que me brindaste en este largo, difícil pero enriquecedor camino de la vida y de las ideas.

Por último, y siempre primeros, gracias a mis padres, a René y a María, porque apoyaron siempre mis decisiones y me recalcaron la importancia del estudio. Esta investigación es gracias a ustedes, y también les pertenece. 


\section{TABLA DE CONTENIDO}

INTRODUCCIÓN

UNA PREGUNTA POR LA PROPIA IDENTIDAD QUE SE TORNA PREGUNTA DE INVESTIGACIÓN

CAPÍTULO 1

REVISIÓN DE LA LITERATURA SOBRE LA IDENTIDAD ORGANIZACIONAL 43 INTRODUCCIÓN

1.1. CONTEXTO, IMPORTANCIA Y PROBLEMÁTICA 45

1.2. FUNDAMENTOS 49

1.2.1. Fundamentos disciplinares 49

1.2.1.1. Desde la Filosofía $\quad 49$

1.2.1.2. Desde la Sociología $\quad 51$

1.2.1.3. Desde la Psicología $\quad 57$

1.2.1.4. Desde la Antropología $\quad 59$

1.2.2. Fundamentos ontológicos 60

1.2.3. Fundamentos epistemológicos 61

1.3. CONVERGENCIAS Y DIVERGENCIAS EN TORNO AL CONCEPTO 62

1.3.1. A partir de definición seminal de Albert y Whetten 62

1.3.1.1. El carácter central de la identidad organizacional 62

1.3.1.2. El carácter distintivo de la identidad organizacional 66

1.3.1.3. El carácter continuo de la identidad organizacional 66

1.3.2. Una aproximación de lo que sí es Identidad Organizacional 68

1.3.3. Una aproximación de lo que no es Identidad Organizacional 69

1.4. PARADIGMAS, PERSPECTIVAS Y DISCUSIONES 71

1.4.1. Paradigmas subyacentes al estudio de la identidad organizacional 71

1.4.2. Perspectivas de análisis en relación con la identidad organizacional 74

$\begin{array}{lll}\text { 1.4.2.1. Narración y discurso } & 74\end{array}$

$\begin{array}{lll}\text { 1.4.2.2. } & \text { Construcción identitaria } & 79\end{array}$

1.4.2.3. Regulación y resistencia 83

1.4.2.4. Audiencia e identidad 86

1.4.2.5. Estabilidad y cambio en la identidad organizacional 87

1.4.2.6. Otras perspectivas de análisis 89

1.4.3. Conversaciones en relación con el concepto de identidad organizacional 90 
1.4.3.1. Perdurable 90

1.4.3.2. Autoreferencial e intersubjetiva $\quad 91$

1.4.3.3. Múltiples identidades $\quad 91$

1.4.3.4. Cambio 93

1.4.3.5. Dialogal y relacional 94

1.4.4. Conversaciones en relación con otros términos 95

1.4.4.1. Identidad social 95

1.4.4.2. Identidad e identificación $\quad 97$

1.4.4.3. Identidad personal 98

1.5. DISCUSIÓN: CONSIDERACIONES PARA FUTURAS CONVERSACIONES 99

$\begin{array}{ll}\text { 1.6. A MANERA DE CONCLUSIÓN } & 105\end{array}$

$\begin{array}{ll}\text { CAPÍTULO } 2 & 107\end{array}$

$\begin{array}{ll}\text { MARCO TEÓRICO Y CONCEPTUAL } & 107\end{array}$

$\begin{array}{ll}\text { INTRODUCCIÓN } & 107\end{array}$

2.1. MARCO TEÓRICO: LOS ESTUDIOS ORGANIZACIONALES 108

$\begin{array}{ll}\text { 2.1.1. Contexto y surgimiento } & 108\end{array}$

2.1.1.1. La Segunda Guerra Mundial 109

2.1.1.2. Las protestas de los años 1960 y 1970

2.1.1.3. El triunfo de los mercados $\quad 112$

2.1.2. Una caracterización inacabada 113

$\begin{array}{lll}\text { 2.1.2.1. Ontológico } & 114\end{array}$

2.1.2.2. Epistemológico 116

2.1.2.3. Metodológico 117

2.1.2.4. Acercamientos a una definición 118

2.1.3. Su objeto de estudio 120

2.1.3.1. Un mirada desde el Movimiento de la Contingencia 120

2.1.3.2. La organización, las organizaciones y lo organizando 123

2.1.3.3. Marcos teóricos para el estudio de las organizaciones 126

2.1.4. Su relación con las ciencias sociales y su perspectiva crítica 129

2.1.4.1. En relación con las ciencias sociales $\quad 129$

2.1.4.2. Su perspectiva crítica 131

2.1.5. Reflexiones finales 134

2.2. MARCO CONCEPTUAL 138

2.2.1. Los mandos medios 138

2.2.2. El rol de los mandos medios $\quad 143$

2.2.3. Sobre la identidad personal 144 
2.2.4. Sobre la identidad grupal: lo social, lo colectivo y lo profesional 148

2.2.5. Construcción de identidad organizacional 152

2.3. DISCUSIÓN DE LA PROPUESTA TEÓRICO-METODOLÓGICA 157

2.3.1. La alta dirección y los procesos de institucionalización (tesis) 159

2.3.2. La construcción de sentido de los mandos medios (antítesis) 161

2.3.3. La Identidad Organizacional como una síntesis 163

2.3.4. Un modelo para el análisis teórico y metodológico 168

2.4. A MANERA DE CONCLUSIÓN 176

$\begin{array}{ll}\text { CAPÍTULO } 3 & 178\end{array}$

ASPECTOS METODOLÓGICOS DE LA INVESTIGACIÓN 178

$\begin{array}{ll}\text { INTRODUCCIÓN } & 178\end{array}$

3.1. ALGUNAS CONSIDERACIONES METODOLÓGICAS Y EL DISEÑO GENERAL DE LA INVESTIGACIÓN 180

$\begin{array}{ll}\text { 3.2. EL ESTUDIO DE CASO } & 186\end{array}$

3.3. UNIDAD DE ANÁLISIS Y OBJETO DE ESTUDIO 191

3.4. ACTORES SOCIALES DE LA INVESTIGACIÓN 194

3.4.1. Mandos Medios 194

3.4.2. Directivos 196

3.5. INSTRUMENTOS METODOLÓGICOS 197

3.5.1. Revisión documental 198

3.5.2. Entrevistas semiestructuradas 198

3.5.3. Observación no participante (panorámica) 201

3.6. TRABAJO DE CAMPO: FASES DEL PROCESO INVESTIGATIVO 204

3.6.1. Fase de exploración $\quad 205$

3.6.2. Fase de focalización 206

$\begin{array}{ll}\text { 3.6.3. Fase de profundización } & 207\end{array}$

3.7. SISTEMA CATEGORIAL DE LOS DATOS OBTENIDOS 207

3.7.1. Fase de descripción 209

3.7.2. Fase de interpretación 212

3.7.3. Fase de constitución de sentido y de constitución teórica 222

3.8. RELEVANCIA DE LAS CATEGORÍAS DE ANÁLISIS 222 
3.9. A MANERA DE CONCLUSIÓN 230

CAPÍTULO 4

ESTUDIO DE CASO: COMERCIAL NUTRESA S.A.S. 232

INTRODUCCIÓN 232

4.1. EI GRUPO EMPRESARIAL ANTIOQUEÑO (GEA) 233

$\begin{array}{lll}\text { 4.2. } & \text { GRUPO NUTRESA } & 236\end{array}$

4.3. COMERCIAL NUTRESA 241

4.3.1. Creación 241

4.3.2. Componentes y estructura 244

4.3.3. Visión, misión y valores 246

4.3.4. Cultura Organizacional de Comercial Nutresa 248

4.3.4.1. Dimensiones de la Cultura Organizacional 248

4.3.4.2. Componentes de la Cultura Organizacional 252

4.3.4.3. Evaluación de la Cultura Corporativa de Comercial Nutresa 253

4.3.5. Clima Organizacional 255

4.3.6. Retos y desafíos 255

4.4. CONTEXTUALIZACIÓN DE LA PROBLEMÁTICA DEL ESTUDIO DE CASO EN COMERCIAL NUTRESA S.A.S.

4.4.1. Contextualización a partir de los ejes de referencia 261

4.4.2. El frente comercial: el eslabón tensionante 267

4.5. A MANERA DE CONCLUSIÓN 271

CAPÍTULO 5

RESULTADOS DE LA INVESTIGACIÓN DESDE EL PUNTO DE VISTA DE LOS DIRECTIVOS 272

$\begin{array}{ll}\text { INTRODUCCIÓN } & 272\end{array}$

5.1. PARA LOS DIRECTIVOS, ¿QUIÉNES SON LOS MANDOS MEDIOS? 274

5.1.1. Categorías emergentes $\quad 275$

5.1.1.1. Organizaciones de origen (OO) 275

5.2. CATEGORÍA EMERGENTE PRINCIPAL: LA EFICIENCIA Y LA

RACIONALIDAD INSTRUMENTAL DE LA ADMINISTRACIÓN EN EL TRABAJO

HUMANO 282 
5.2.1. La instrumentalización de la razón: Una revisión al concepto 283

5.2.2. El trabajo humano: escenario de paradojas y contradicciones 294

5.2.3. La autonomía del hombre desde la Teoría Administrativa 302

5.2.4. ¿Una nueva modalidad de ergonomizar (controlar) el alma? 310

5.2.4.1. Una búsqueda de control identitario en negación 319

5.2.4.2. Una autonomía que se subordina 324

5.3. UNA MIRADA ÉTICA A LA ADMINISTRACIÓN 329

5.3.1. La administración y los actos del hombre $\quad 330$

5.3.2. La administración y los actos humanos 332

5.3.3. Una reflexión que invita al diálogo 333

5.4. A MANERA DE CONCLUSIÓN 334

CAPÍTULO 6

RESULTADOS DE LA INVESTIGACIÓN DESDE EL PUNTO DE VISTA DE LOS MANDOS MEDIOS 336

$\begin{array}{ll}\text { INTRODUCCIÓN } & 336\end{array}$

6.1. ¿QUIÉNES SON LOS MANDOS MEDIOS? 339

6.1.1. Categorías emergentes 340

6.1.1.1. Organizaciones de origen (OO) 340

6.1.1.2. Historia personal-profesional-organizacional. 344

6.1.2. Categorías emergentes principales 348

6.1.2.1. Reconocimiento 349

6.1.2.2. Trascendencia 366

$\begin{array}{lll}\text { 6.1.2.3. Seguridad } & 373\end{array}$

6.2. CONSTRUCCIÓN DE IDENTIDAD ORGANIZACIONAL DE LOS MANDOS MEDIOS 382

6.2.1. Una construcción identitaria que se resiste a ser fabricada 383

6.2.2. Lo liminal dentro del ámbito organizacional 388

6.3. LA IDENTIDAD ORGANIZACIONAL EN EQUILIBRIO LIMINAL 404

6.4. A MANERA DE CONCLUSIÓN 413

$\begin{array}{ll}\text { CAPÍTULO } 7 & 417\end{array}$

RECAPITULACIÓN Y REFLEXIONES FINALES 
\begin{tabular}{ll} 
7.1. & COMENTARIOS GENERALES \\
\hline
\end{tabular}

7.2. A NIVEL TEÓRICO 419

7.3. A NIVEL METODOLÓGICO 425

7.4. SOBRE LO ORGANIZACIONAL 430

7.5. LIMITACIONES Y POSIBILIDADES DE INVESTIGACIÓN FUTURAS 440

REFERENCIAS 


\section{ÍNDICE DE TABLAS}

Tabla 1: Definiciones de la Identidad Organizacional desde distintos niveles de análisis

Tabla 2: Paradigmas en relación con la identidad organizacional

Tabla 3: Número de entrevistas a los mandos medios por gerencias y regiones 196

Tabla 4: Preguntas de las entrevistas en relación a las categorías preliminares 200

Tabla 5: Visión general de las fuentes de datos

203

Tabla 6: Preguntas iniciales

211

Tabla 7: Relación objetivos-categorías de análisis

Tabla 8: Relación y clasificación de las categorías de análisis de los mandos medios

Tabla 9: Relación y clasificación de las categorías de análisis de los directivos 218

Tabla 10: Categorías preliminares y emergentes con los resultados en cuanto a la fundamentación y densidad a partir del análisis en el programa Atlas.ti

Tabla 11: Hechos importantes del Grupo Nutresa

Tabla 12: Valores de Comercial Nutresa

Tabla 13: Ritos y celebraciones que desean vivir en la nueva cultura

Tabla 14: Caracterización de los empleados provenientes de diversas compañías del Grupo Nutresa

Tabla 15: Similitudes y diferencias de los empleados provenientes de otras compañías del Grupo Nutresa

Tabla 16: Tendencias de gestión desde 1950 al 2000

Tabla 17: Formas de autorrelación y reconocimiento. Tipo de ofensas morales correspondientes 


\section{ÍNDICE DE GRÁFICAS}

Gráfica 1: Los mandos medios en el centro de los estamentos organizacionales

Gráfica 2: El proceso dialéctico de construcción identitaria

165

Gráfica 3: Modelo de análisis metodológico: aspectos constituyentes de la identidad organizacional de los MM

Gráfica 4: Relación entre la identidad personal y profesional y la identidad organizacional

Gráfica 5: Diseño general de la investigación

Gráfica 6: El espiral del conocimiento y las fases del proceso investigativo

Gráfica 7: Aspectos que interviene en el análisis de los datos

209

Gráfica 8: Segundo sistema categorial: Construcción de IO de los MM

Gráfica 9: Categorías preliminares y emergentes construidas a partir de los mandos medios

Gráfica 10: Categorías preliminares y emergentes construidas a partir de los directivos

Gráfica 11: Construcción de las categorías emergentes de los directivos

Gráfica 12: Construcción de las categorías emergentes de los mandos medios 229

Gráfica 13: Estructura del grupo Nutresa

Gráfica 14: Estructura organizacional de Comercial Nutresa

Gráfica 15: Ritos y celebraciones anteriores

254

Gráfica 16: Categorías preliminares en relación con las dimensiones de los actores sociales de la investigación y la conformación de los ejes de referencia

Gráfica 17: Categorías preliminares y emergentes construidas a partir de los directivos 
Gráfica 19: Categorías preliminares y emergentes construidas a partir de los mandos medios

Gráfica 20: Identidad personal, profesional y organizacional en el tiempo

Gráfica 21: Construcción identitaria de los MM como proceso liminal 


\section{Siglas utilizadas en el documento}

\begin{tabular}{c|l} 
Sigla & \multicolumn{1}{c}{ Significado } \\
\hline GEA & Grupos Empresarial Antioqueño. \\
\hline GN & Grupo Empresarial Nutresa. \\
\hline CN & Comercial Nutresa S.A.S. \\
\hline MG & Modelo de Gobierno de Comercial Nutresa. \\
\hline MM & Mandos medios de Comercial Nutresa. \\
\hline NC & Frente comercial de Comercial Nutresa. \\
\hline OO & Compañía Nacional de Chocolates. \\
\hline CNCH & Organizaciones de origen (directivos y mandos medios). \\
\hline IO & Grupo Empresarial Compañía Nacional de Chocolates. \\
\hline TC & Identidad organizacional. \\
\hline PM & Teoría Crítica. \\
\hline EO & Postmodernismo. \\
\hline TO & Estudios Organizacionales. \\
\hline TA & Teoría Organizacional. \\
\hline OCT & Teoría Administrativa. \\
\hline & Organización científica del trabajo.
\end{tabular}

Las citaciones de textos a partir de la recolección de los datos se enunciarán como sigue: [X \#], en donde la $X$ significa el documento base, y la sigla \#, el número asignado por el investigador a cada documento base. Las siglas de cada documento se presentan a continuación:

\section{Nomenclatura de los documentos base}

\begin{tabular}{c|l} 
Siglas & \multicolumn{1}{c}{ Documento base } \\
\hline MM & Entrevista a un mando medio. \\
\hline D & Entrevista a un directivo. \\
\hline PPMM & Entrevista de la prueba piloto a un mando medio. \\
\hline PPD & Entrevista de la prueba piloto a un directivo. \\
\hline Bit & Bitácora de la investigación (diario de campo). \\
\hline Obs.Par. & Documentos referidos a la observación no participante. \\
\hline Doc & $\begin{array}{l}\text { Archivos documentales de Comercial Nutresa S.A.S. (se } \\
\text { incluyen la documentación oficial, videos, etc.) }\end{array}$
\end{tabular}




\title{
INTRODUCCIÓN
}

\section{UNA PREGUNTA POR LA PROPIA IDENTIDAD QUE SE TORNA PREGUNTA DE INVESTIGACIÓN}

\begin{abstract}
La pedagogía consiste en la práctica de los modos para ayudar a otros a encontrarse; el pedagogo es partero. No lo es el que enseña, función vulgar, sino el que conduce a los otros por sus respectivos caminos hacia sus originales fuentes. Nadie puede enseñar; el hombre llega a la sabiduría por el sendero de su propio dolor, o sea, consumiéndose.
\end{abstract}

Fernando González (2014, pp. 19-20)

En general, una conversación se entiende como un diálogo, en el cual intervienen dos o más personas, alternativamente, sin seguir un plan previo. Mediante esta plática se establece una comunicación y se busca transmitir e intercambiar un conjunto de ideas. Es una interacción donde los interlocutores o partícipes contribuyen a la construcción de un texto, gracias a dicha transferencia. Se diferencia de un monólogo, ya que en este proceso, la construcción depende exclusivamente de un solo individuo; de ahí el carácter dialogal de la conversación.

La construcción del texto dialógico no se realiza simultáneamente, sino que cada interlocutor toma su turno y ocupa su tiempo para expresar sus ideas. Tal proceso no está estipulado en forma rigurosa, pues el intercambio de ideas se lleva a cabo en forma espontánea, de acuerdo con la aparición y creación de argumentos que los actores expresan como fruto del dinamismo propio de la conversación y del tema que se discute. El intercambio de ideas puede girar en torno a varias 
temáticas, y el desarrollo de alguna lleva a otra, sin que necesariamente tengan que estar relacionadas; es decir, es una situación informal que puede variar con facilidad y sin previa organización. No obstante, toda conversación está condicionada por el contexto en medio del cual se encuentran los interlocutores al momento de construir su discurso.

En ese orden de ideas, a continuación se presenta el resultado de una nueva conversación alrededor de la construcción de la identidad organizacional (IO en adelante) de los mandos medios (MM en adelante) de una empresa colombiana de ventas y distribución de alimentos secos. El desarrollo de este diálogo contempló diversas temáticas, todas ellas enmarcadas dentro del proceso de formación investigativa del autor en tanto elaboración de su tesis doctoral.

La conversación se llevó a cabo sobre una variada serie de aspectos de forma y contenido. Se partió de un conjunto de preguntas alrededor de las cuales se construyó el texto, con el fin de llegar a unos acuerdos y definiciones con respecto a un conjunto de objetivos que guiaron las ideas y puntos de vista planteados. Metodológicamente, el diálogo estuvo precedido por una indagación del estado actual de la investigación, a la vez que se le enmarcó dentro de un campo especializado para el análisis de las organizaciones: los Estudios Organizacionales (EO en adelante). Dadas, entonces, las múltiples connotaciones y perspectivas que se encontraron sobre la IO, fue necesario construir un marco teórico-metodológico propio que permitiera delinear los conceptos y permitir con ello una discusión más integrada.

En otro nivel, se planteó un puente entre dicha teoría que se venía conversando y un estudio de caso que posibilitara contrastar lo discutido hasta el momento y, a la vez, indagar y profundizar en la problemática expuesta, con el propósito de aprehender nuevos matices de la conversación gracias al caso particular propuesto. 
Al final de la conversación se obtuvieron resultados que remitieron a nuevos diálogos, para recoger, por último, los frutos de todo el proceso. Efectivamente lo que se expone en el presente documento es una conversación más, pero con unas características que se enmarcan en el rigor académico y la coherencia metodológica, necesarios para una investigación de estas características.

El concepto de la conversación como metáfora ya había sido aplicado por Clegg y Hardy (1996), en la introducción del Handbook of Organization Studies, para aproximarse a la definición de los EO; también para abordar el concepto de IO, por parte de Whetten y Godfrey (1998), en su texto, Identity in Organizations. En tal sentido, cuando en este documento se anuncien apartados sobre conversaciones, estas se entenderán con estas connotaciones.

Ahora bien, antes de presentar los componentes y explicar las relaciones y construcciones conceptuales y teóricas que permitieron el surgimiento del texto dialogal que se expone, es importante contextualizar la conversación. En tal medida, se hace necesario exponer las inquietudes personales del autor-ligadas inexorablemente a cierta historia- que antecedieron y propiciaron la formulación de la pregunta de investigación. El autor, por tanto, se convierte en el primer interlocutor de este diálogo.

La investigación se inició con una pregunta que ha acompañado al autor a lo largo de muchos años como hijo, estudiante, profesional, padre, amigo, profesor; sencillamente, como hombre peregrino: ¿Quién soy? La respuesta remite necesariamente al tema identitario. El interrogante, con fuertes rasgos filosóficos, invita a una introspección con características ontológicas. ¿Cuál es la forma y naturaleza de lo que soy, y por tanto, qué es lo que se puede conocer de mí mismo? Evidentemente, plantear esta cuestión ubica el problema en una disciplina distinta (que puede ser la filosofía o la antropología) a la que hace de marco a esta investigación: el ámbito administrativo y organizacional. Sin embargo, la pregunta adquiere una connotación diferente gracias a la configuración que sufre a partir de la comprensión histórica del autor, lo que permite acercarse a la problemática de 
la investigación y a la pregunta que la sintetiza en el ámbito propiamente organizacional.

La pregunta por lo que se es recorre la vida del individuo, y el trayecto puede ser tan largo como la vida misma en el afán de hallar una respuesta. En ese sentido, bien podría considerársela como una búsqueda, cuya característica primordial pareciera ser lo inalcanzable de su naturaleza. Al momento que se cree haber encontrado la respuesta, esta es tan solo un indicio más para profundizar en ella. Así, la incomprensión pareciera aflorar y el sin sentido de su búsqueda comienza a rondar en quien se atreve a escrutar.

No obstante, la pregunta tiene otra particularidad, es infranqueable. Muchos pueden querer eludirla, evitarla, huir de ella, responderla a medias, darle la espalda, pero de alguna manera, nadie podrá conquistar la realidad que lo rodea sin preguntarse por el sí mismo. Por consiguiente, no se ha hecho nada nuevo y ajeno (quizás tan solo la particularidad de su construcción) a lo que cualquier ser humano persigue en su largo peregrinar. El hacer implica el ser, y este acompaña la acción humana en todas sus dimensiones, donde el obrar refleja la obra del autor y habla de él mismo.

El objetivo de responder la pregunta se ve reflejado en el paso del autor por el estudio de distintas disciplinas. A través de estas se direccionó, por medios académicos, la inquietud por resolver, no siempre de forma explícita, el conflicto propuesto. Peruano de nacimiento, nacionalizado colombiano y residente temporal en México, el autor inició su proceso de formación en universidades públicas y privadas de varios países latinoamericanos. En ese contexto, el desarraigo de un territorio específico, la conceptualización y proyección de vida en un país diferente, y la incorporación reiterada de culturas disímiles, entre otros tantos sucesos, propiciaron, y propician, los cuestionamientos sobre quién es el sujeto que está en este mundo y su proceso de conquista y comprensión de sí mismo. 
La conversación sobre lo que sería la tesis doctoral comenzó, entonces, hace algún tiempo y se contextualiza y circunscribe a una historia en particular. En consecuencia, la investigación se podría considerar como un punto de llegada donde se congregan inquietudes, ideas y experiencias a nivel personal, académico y profesional. Gracias a este trabajo, se encontró un sentido y una posibilidad de profundizar en esas experiencias, a la vez que marcan la apertura de un nuevo proyecto de vida en torno a los temas que la rodean. No obstante, los resultados darán motivo para nuevas interrogantes y futuros proyectos de investigación. La preocupación y el deseo por intentar desvelar los misterios que giran en torno a los fenómenos sociales, los cuales tienen al hombre como centro de sus reflexiones, se vieron reflejados en los inicios de la carrera universitaria del autor, como estudiante -si es que se pudiera determinar una dimensión temporal para esta pregunta-, y se ha prolongado a lo largo de otras dimensiones de su vida hasta llegar a este otro punto de inflexión con la finalización de la presente investigación.

Así pues, esta primera inquietud, que se podría denominar vital, coloca el tema identitario como el aspecto principal de la construcción dialogal de este texto. Alrededor de ese punto girarán otros temas e ideas en el trascurso de la conversación.

Un primer plano, entonces, es la trama de lo propiamente personal, en donde el interrogante se nutre de los aspectos individuales a partir de las propias vivencias y relaciones que se van construyendo. El segundo plano abarca los aspectos personales que intervienen en la conformación de una identidad profesional, con eje en la pregunta quién soy, que se enriquece, en el transcurso, con otras temáticas como los criterios y conocimientos específicos de una profesión determinada. Un tercer plano contextualiza la pregunta por la propia identidad refiriéndola a una organización en donde, a diferencia de las anteriores, los sentidos y significados son impuestos y condicionados de tal modo que el yo soy se relacione con la organización a la cual pertenece el individuo. 
De ahí, entonces, que la pregunta de investigación no se refiera al individuo sino a la identidad que este construye en la organización donde se encuentra. En ese sentido, el tema de la 10 es un proceso que se inicia en forma diacrónica y que conlleva aspectos personales y profesionales. Justamente desde esta perspectiva se abordó la problemática de investigación que se plantea a continuación.

¿Cuál es el problema de investigación? Esta pregunta surge una vez que se han expuesto las inquietudes vitales del autor y las categorías que intervienen al momento de construir una $\mathrm{IO}$ en concreto. Esta interrogante es primordial para toda investigación. La identificación de la primera justifica la existencia de la segunda. A este respecto, abunda la literatura referida a lo que es un problema 0 cómo se plantea, acota o define. Sin embargo, hablar de problema remite a encontrar una solución específica, lo que reduce u omite -sin querer decir con ello que sea eliminada- la parte comprensiva del proceso como tal, antes de adoptar una alternativa de solución o intervención. Por tal consideración, en el trabajo que se presenta se prefiere hablar de problemática, teniendo en cuenta que para un problema se busca su resolución y para una problemática, su comprensión. Este último concepto acompaña todo el desarrollo del diálogo cuyos resultados se presentan en este texto, pues, como se ve a lo largo de este, la conversación buscó comprender antes que resolver el fenómeno social en estudio.

Hablar de problema remite, además y contradictoriamente, a aspectos amplios de la realidad organizacional. El término alude a una síntesis de la realidad organizacional sin explicar los procesos o los componentes que intervienen, los cuales pueden provenir de los mismos actores sociales que la producen 0 propician. En tales circunstancias, la búsqueda de respuestas frente al planteamiento de un problema hace que sean difíciles de encontrar, por lo que es más pertinente hablar de aproximaciones para abordar el problema. Por el contrario, la problemática es más precisa. Enmarcada dentro del problema planteado, a través de las dimensiones espacio-temporales, se preocupa por explicar los componentes que la integran y centra la atención en algún aspecto crucial del problema como tal. Así, la problemática organizacional es una realidad 
social en las organizaciones. Puede ser comprendida y ubicada, y por lo mismo, susceptible de ser sometida a las lógicas del rigor investigativo y a una metodología determinada para afrontarla.

La problematización, por su parte, es otro vocablo que es posible distinguir de los anteriores y que está en relación con estos. La problematización expresa el ejercicio, es decir, la acción de presentar la problemática como objeto de estudio. En palabras de Foucault (1999), es el conjunto de prácticas discursivas y no discursivas que hace que algo entre en el juego de lo verdadero y lo falso, y lo constituye como objeto para el pensamiento. En otras palabras, la problematización es la acción de construir, delimitar y presentar una problemática como un objeto de estudio y, por lo mismo, abre la posibilidad de su investigación dentro del campo de un problema específico.

La problemática remite a la idea de que los hechos o situaciones que la configuran o estructuran no son lineales, no son unicausales, sino que su conformación o, por decirlo así, definición y acotación, se logra a partir de la confluencia de diversos factores cuya integración no siempre está dada en forma congruente y unidireccional; muchas veces, en forma fortuita y carente de alguna lógica matemática racional. Así mismo, dicha estructuración está determinada por dimensiones espacio-temporales, aspectos que hacen que la problemática tenga connotaciones particulares, no universales, ya que depende de la importancia e intensidad que tengan aquellas dimensiones en cuanto a la participación en dicha problemática, pues no siempre será la misma. Por tal razón, se hace necesario profundizar y comprender los factores que intervienen en la problemática, así como las relaciones espacios-temporales que se generen, como paso previo a buscar algún tipo de solución.

En este marco, es esencial entonces crear las condiciones para que exista una investigación viable, identificando y presentando la problemática de la misma. Lo primero por mencionar en esa dirección es el planteamiento de interrogantes. Estos emergen desde el ámbito propiamente organizacional, propiciando el inicio 
de la construcción de la problemática. ¿Qué es la identidad de la organización? ¿Cómo construyen los individuos una $\mathrm{IO}$ dentro de las organizaciones? ¿La IO es aquello que permite caracterizar a una organización con respecto a otras? ¿La IO es algo cambiante o permanente? ¿Cómo se construye una IO específica? ¿Qué elementos intervienen en su construcción?

Con base en los primeros cuestionamientos se comienza a estructurar una problemática en el ámbito organizacional, cuyo foco principal se concentra en la construcción de 10 de los MM. Proceso que se inicia con la institucionalización en las organizaciones como un ejercicio administrativo que busca confinar la identidad a una construcción institucional; por lo tanto, a una variable más de gestión. Ello se realiza con el fin de mantener una uniformidad de pensamiento y comportamiento, a la vez que se relegan la individualidad y particularidad del sujeto a una despersonalizada y eficiente herramienta productiva.

De acuerdo con estos parámetros, el control identitario se logra (o al menos eso se espera) mediante el diseño y la aplicación de estructuras, procedimientos, medidas y objetivos organizacionales. La resistencia a estos mecanismos (catalogados muchas veces como síntomas) busca que sean rectificados mediante la reestructuración del personal o por medio de la implementación de un proceso formativo. Se trata pues de considerar el control como un ejercicio en donde se fabrica la subjetividad (Knights y Willmott, 1989; Barker, 1999; Deetz, 1992, 1994 entre otros). Sin embargo, la búsqueda de regulación identitaria es una modalidad cada vez más intencional de control organizacional, sin decir con ello que sea eficaz cuando aumenten el compromiso o la lealtad de los empleados (Alvesson y Willmott, 2002). Incluso, el efecto que la lealtad produce puede amplificar el cinismo, promover la disidencia o catalizar la resistencia (Ezzamel, Willmott y Worthington, 2000).

Las nuevas formas de control buscan entonces, procesar la subjetividad con el objetivo de constituir trabajadores más adaptables al tiempo que sean capaces de moverse rápidamente entre actividades y tareas con orientaciones diversas. Sin 
embargo, en la práctica, esta fluidez y fragmentación identitaria puede hacer que los empleados sean más vulnerables a la tipificación de las identificaciones corporativas. En este contexto, la fabricación identitaria se convierte en un aspecto más de la gestión en las organizaciones.

Ya que el manejo del interior de las personas es considerado potencialmente menos molesto y más eficaz que las tradicionales formas externas de control administrativo (Alvesson y Willmott, 2002), con la regulación de la identidad se pretende cubrir los efectos intencionales de las prácticas sociales en cuanto a los procesos de construcción y reconstrucción identitaria; en tal sentido se da prioridad a los procedimientos de inducción, capacitación y promoción en las organizaciones. Esta dinámica enmarca el tema identitario en la realidad organizacional.

Ahora bien, ¿por qué centrarse en los MM? La institucionalización de una IO muchas veces desconoce ciertos procesos y antecedentes que los individuos realizan o llevan consigo al momento de ingresar a una organización. Por lo general, se hace caso omiso de una identidad personal (IPer. en adelante) que el sujeto porta al iniciar su vinculación con una compañía y que viene construyendo a lo largo de toda su historia. Las circunstancia familiares, la formación escolar, entre otros muchos aspectos, imprimen en la persona una forma de entender el mundo y la realidad que la circunda; es el proceso de construcción de su personalidad. Así, hay aspectos de índole personal que el empleado trae consigo y que es sumamente difícil de conocer y mucho menos de gestionar. Además, la propia formación profesional, con su respectiva identidad (IProf. en adelante), comienzan a consolidarse, en la mayoría de los casos, antes de vincularse laboralmente a una organización, a menos que un individuo inicie su experiencia laboral a la par que la profesional. Es así como, ante la gran diversidad de carreras profesionales y su diferenciación, las universidades buscan imprimir un sello característico (no siempre efectivo) a cada carrera que ofrecen. Por consiguiente, al igual que ocurre con la IPer., los nuevos empleados llegan a las 
organizaciones con una serie de categorías que les permiten leer la realidad, también de acuerdo con la profesión que estudiaron.

De esta forma, cuando un individuo ingresa a una empresa y con ello se comienza a construir la 10 específica, esta no es más que la continuación de un proceso ya iniciado en el tiempo a partir de la estructuración de una IPer. y una IProf. En efecto, su configuración y estructuración de la identidad personal se inicia desde muy temprana edad. Durante ese transcurso, y en un determinado lapso, el MM comienza a adquirir una IProf., gracias al estudio de una carrera, construida en paralelo y sobre la base de su identidad personal. Una vez que la persona se une a la organización, comienza el proceso de construcción identitario de esa organización, que ha de contar, necesariamente, con las dos primeras. De esta forma, pues, el proceso de construcción identitario se inicia en el pasado, cuando confluyeron dos procesos de construcción identitarios: el personal y el profesional. En consecuencia, la organización no podrá controlar las percepciones y razones con que cuenta el individuo y que hacen parte importante de la significación que tendrán a su nueva vinculación laboral.

Sin embargo, las condiciones para que el MM adquiera una 10 no se cierran con los aspectos mencionados. Tanto su condición particular de encontrarse en el medio de las jerarquías organizacionales como las propias funciones de mediación que realiza abren la posibilidad de mayor maleabilidad ante dicho proceso. De hecho, una reconocida investigación sobre los MM, publicada por Dopson y Stewart (1990), plantea una visión pesimista sobre el futuro de la línea media, al señalar la frustración que deben cargar debido, principalmente, a su situación: de un lado, se encuentran en el medio de una larga línea jerárquica, donde sus decisiones no son tomadas en cuenta ya que se encuentran por debajo de quienes toman realmente las determinaciones relevantes, los directivos. Deben afrontar, además, un conflicto de expectativas entre estos y quienes están ubicados debajo de su línea jerárquica. Un tercer aspecto tiene que ver con su dedicación a las tareas de índole administrativo, ante las cuales los MM terminan por perder su experiencia y conocimiento técnicos, incrementando con ello su 
inseguridad, ya que no poseen un factor diferenciador en específico. Por último, influye el elemento desilusión al no participar de la carrera de ascensos dentro de las organizaciones.

A las anteriores frustraciones se suman predicciones no menos alentadoras para el futuro de los MM. Por ejemplo, la información tecnológica podría influir en las organizaciones para la reducción de los puestos de trabajo, a la par que por el alto requerimiento de conocimientos administrativos, dichos cargos podrían programarse, sistematizarse y estructurarse de manera distinta, lo que implica que no sería necesario requerir de tanta experiencia y creatividad. Todo ello, imposibilitaría las oportunidades para ellos de optar por mejores posiciones y recompensas dentro de las organizaciones.

Mientras una revisión de la literatura sobre la gestión de la línea media saca a la luz estas perspectivas pesimistas, se revela también otro aspecto fundamental: se utilizan referentes para representar la línea media de gestión. Es decir, la imagen espacial del centro evoca la confusión, la complejidad y la ambigüedad de la línea media. El medio se convierte así en un lugar poco envidiable, en donde prima la falta de poder y de control (Ainsworth, Grant y ledema, 2009).

A este aspecto espacial que trae problemas de por sí, se le suma otra peculiaridad de los MM, que es su rol de ser jefe y subordinado a la vez. Si bien las relaciones de subordinación atraviesan y caracterizan a las organizaciones como un elemento inherente y constitutivo de su propia realidad, los MM están expuestos a convivir con una doble situación: son objeto de subordinación y sujetos subordinantes a la vez. Las necesidades de los directivos intermedios se reflejan en dos fuerzas distintas: por un lado, la identificación con el director ejecutivo y sus objetivos de supervivencia y crecimiento, especialmente en los niveles altos de la jerarquía, y por otro lado, el intento de satisfacer su propio impulso para obtener autonomía y conseguir resultados mediante la ampliación de la unidad propia y la balcanización de toda la estructura organizacional. (Mintzberg, 1992, p. 156). 
Según Grison y Worland (2000), los MM se encuentran atrapados en el medio debido a las responsabilidades competitivas y demandas excesivas, tanto de la parte de arriba como de la parte de abajo de la jerarquía. Sus lealtades se dividen entre la alta dirección y la parte operativa. Se mueven con la incertidumbre por el futuro, los procesos de cambio y las decisiones inconsistentes de la alta gerencia. Es una situación que lleva muchas veces a los MM a no tener el poder para tomar decisiones sobre las demandas competitivas que rodean sus responsabilidades. Por tal razón, los MM suelen estar más cercanos de la parte operativa que de los altos directivos, y en esa dinámica:

Ya no se identifican con tanta facilidad con el destino de su empresa, procuran sustraerse a las presiones crecientes de su entorno e incluso adhieren a las críticas más directas que se dirigen contra el nuevo orden económico. [...] En suma, ellos, de quienes hasta aquí se creía que siempre jugarían «a favor», empiezan a «jugar en contra». (Dupuy, 2006, p. 10).

Una vez descritos los aspectos que caracterizan y problematizan la realidad organizacional de los $\mathrm{MM}$, viene ahora la pregunta: ¿por qué relacionarlos con la IO? Como se ha sugerido, la IO de los MM puede ser manejada o incluso diseñada de acuerdo con fines específicos para lograr un cierto control por medio de los procesos de institucionalización. La nomenclatura de los cargos, en el medio de una estructura jerárquica; sus funciones los exponen a transitar por roles contradictorios (jefe-subordinado); su función intermediadora entre los de arriba y los de abajo, y la alta movilidad, son los factores que perfilan una inestabilidad identitaria a partir del conflicto de intereses que tienen que resolver políticamente. Estas razones permean la posibilidad para que, aquellos que ocupan la línea media de gestión, sean inducidos a una fabricación de la subjetividad, sean sometidos a la construcción de una 10 en concreto. No obstante, los actores organizacionales no pueden ser considerados como consumidores pasivos de identidades designadas y diseñadas, por lo que estas no son, necesariamente, aceptadas de manera automática (Ríos, 2003).

La atención está puesta, entonces, en los efectos arbitrarios de las formas de regulación, al tiempo que se consideran las expresiones de resistencia por parte 
de los sujetos y la cuota de subversión que ello implica. En ese marco y según Alvesson y Willmott (2002), la administración es incapaz de gestionar, controlar y definir la identidad del empleado, ya que los MM no son sujetos pasivos a quienes se les pueda moldear con respecto a los fines organizacionales, diseñando para ellos una $\mathrm{IO}$ en particular como parte de su propia identidad. Con ello se entiende que la organización no necesariamente es la entidad con mayor influencia en la construcción de la identidad del individuo. Sin embargo, sí se puede considerar que la regulación de la $\mathrm{IO}$ es un aspecto relevante e influyente que no se ha estudiado lo necesario y es cada vez más importante en el ámbito organizacional (Deetz, 1992; Knights y Willmott, 1989; Kunda, 1992).

Bien se puede decir que esta preocupación por instaurar en el individuo una 10 expresa el predominio de una epistemología positivista y una visión que articula y legitima las formas funcionalistas en el análisis organizacional (Burrel y Morgan, 1979). Al contrario de esta concepción se ha dado paso a un enfoque postmoderno, caracterizado por celebrar la diferencia, lo efímero, la moda y la mercantilización de la cultura. Esta visión se expresa, entre otras cosas:

En la desestabilización de la identidad, como algo dado y relativamente seguro, y un creciente interés en la identidad como objetivo y medio de los esfuerzos de regulación de la Administración. Como mecanismos culturales son introducidos o refinados en un esfuerzo por ganar o mantener el compromiso de los empleados, la involucración y la lealtad en condiciones de disminuir la seguridad del trabajo y la durabilidad del empleo, la gestión de la identidad laboral se vuelve más relevante y crítica dentro de la relación laboral. En estas circunstancias, la identidad organizacional [...] no se le puede suponer o dar por sentado, pero ha sido activamente engendrada o fabricada. (Alvesson y Willmott, 2002, p. 623).

Como se puede observar, la búsqueda de alienación es el objetivo implícito que obliga al sujeto de la línea media a una identificación con la organización de acuerdo con parámetros establecidos por ella misma que garantice -en la medida de lo posible- una mayor eficiencia y la generación de una cultura fuerte. Este propósito se consigue por medio de estrategias para elevar la eficiencia y la competitividad, mientras el individuo debe adaptarse a nuevas condiciones (ideas, modelos y prácticas; formas de solucionar problemas, valores y mitos) y múltiples 
realidades que la organización implanta para su propio beneficio (Pàges, Bonetti, De Gaulejac y Descendre, 1979; Enriquez, 2007).

Las organizaciones definen un espacio geográfico, imaginario y simbólico en el que el sujeto encuentra seguridad, pertenencia y desarrollo, pero también un ámbito de enajenación, exclusión y sufrimiento (Fernández, 2013), un espacio donde el hombre debe encorvar su espalda, al decir de Brunstein (1999). Tal como se comentó ut supra, la construcción de sentido cuenta con una IPer. y una IPro. que son difíciles de considerar, agrupar, identificar y, por lo mismo, gestionar. En dicho proceso de significación, el individuo se encuentra con tensiones entre aquello que es y lo que la organización quiere que sea. Tales tensiones, dependiendo de la construcción de sentido que haga cada individuo, estarán mediados por aspectos del pasado - experiencias con otras organizaciones- y la necesidad de dejar un legado en la organización donde se encuentra en la actualidad.

La organización intenta imponerle al individuo una serie de significados que le conduzcan a obtener un comportamiento óptimo para sus objetivos empresariales. El individuo interioriza la búsqueda de la eficiencia y en torno a ella organiza su práctica y reduce su vida afectiva. De este modo se puede visualizar un individuo que debe callar e interiorizar el discurso oficial que le conduce a buscar una excelencia inalcanzable, ante un sistema organizacional y social que le habla desde una abstracta necesidad de eficiencia (Montaño, 2001).

Pareciera entonces que no hay sujetos sino una masa constituida por aquellos que son moldeados para que funcionen para el sistema (Ham, 2001). Ante una organización en constante transformación, que construye y reconstruye su identidad en un mundo de múltiples realidades, el sujeto puede encontrase con una colonización por los fragmentos de los otros (Gergen, 1992) o con la saturación de las relaciones, derivados de la pérdida del yo y la incoherencia o ambigüedad de la vida cultural organizacional. No obstante, las organizaciones y los sujetos, al modificar e imprimir nuevas características a sus construcciones 
básicas - como es el caso de la identidad - siempre tendrán la posibilidad de la acción y la reinvención en la búsqueda por hacer sentido de sí mismos y su mundo.

Desde una perspectica más teórica, y luego de un poco más de un cuarto de siglo desde su conceptualización, el término IO no está lo suficientemente definido, ni acabada la discusión sobre sus alcances o modelos propuestos. En el campo organizacional han prolifereado definiciones que van desde el nivel individual hasta percepciones de lo que la organización es, basadas en perspectivas institucionalistas o esencialistas qu buscan identificar las características propias de la organización (Ashforth, Rogers y Corley, 2011). Esto ha dado como resultado cacofonía y polisemia en su definición, y aportes al ámbito organizacional, llegando incluso a generar una contradictoria y consecuente situación en donde pareciera que todo es identidad y simultáneamente nada lo es.

Entre los estudios de la identidad que tienen una influencia directa en el control de la organización, se incluyen análisis de fenómenos a nivel institucional y otros fenómenos a nivel macro (Albert y Whetten, 1985; Christensen, 1995; Czarniawska, 1997b), así como los estudios que se concentran en los sujetos y las formas de identificación y subjetivación (Alvesson, 2000; Deetz, 1992). La regulación de la identidad abarca los efectos más o menos intencionales de las prácticas sociales en los procesos de construcción y reconstrucción, sobre los cuales se enfocó esta investigación.

En efecto, el énfasis estuvo puesto en el proceso de construcción identitario de los MM quienes, al igual que los directivos, fueron los otros interlocutores de la conversación que aquí se presenta. El interés de la investigación, por tanto, se centró en el proceso social por medio del cual los MM construyen sentido a su estar en la organización, en diálogo con la parte directiva que busca instaurar en ellos una IO específica. 
En consecuencia, el objetivo de la investigación se puede formular de la siguiente manera: Comprender la construcción de identidad organizacional de los mandos medios en una organización de un grupo empresarial colombiano, con el fin de indagar por el significado que los mandos medios tienen de dicha identidad organizacional, mediante un estudio de caso.

Los objetivos específicos que se desprenden de este objetivo general son: 1) Identificar las características de la organización y de los mandos medios en donde se realizará el trabajo de campo de la investigación doctoral. 2) Identificar dispositivos que la organización emplea para suscitar la incorporación de la identidad organizacional en los mandos medios, en una organización de un grupo empresarial colombiano. 3) Analizar aspectos de la identidad personal y de la identidad profesional que configuran la identidad de los mandos medios, en una organización de un grupo empresarial colombiano. 4) Analizar aspectos de la identidad personal y profesional que configuran una identidad organizacional de los mandos medios, en una organización de un grupo empresarial colombiano. 5) Analizar los aspectos personales así como los profesionales que intervienen en la construcción de la 10 de los $\mathrm{MM}$ en relación con los procesos de institucionalización implementados por los directivos, en una organización de un grupo empresarial colombiano.

¿Qué se tuvo que hacer para cumplir el objetivo de investigación planteado? Lo primero fue enmarcar esta conversación dentro de las conversaciones anteriores, es decir, se buscó conocer en qué va la conversación sobre este tema, qué es lo que se ha dicho sobre la IO. El primer capítulo de esta tesis versa sobre ello. Se realizó una revisión de la literatura referida al tema de la 10 y se discutió la importancia de este concepto y la problemática que gira en torno suyo. Como la problemática está enmarcada dentro de lo propiamente organizacional, se buscaron los fundamentos disciplinares de la IO, a partir de la filosofía, la sociología, la psicología y la antropología. 
A raíz de lo anterior fue necesario precisar los fundamentos ontológicos y epistemológicos de la IO. La diversidad de perspectivas y aproximaciones al término obligó a realizar tal ejercicio, lo que sirvió también para especificar desde qué perspectiva sería abordada el estudio, a la par que se presentaron las convergencias y divergencias en torno al término IO. Desde la definición seminal de Albert y Whetten en 1985 en donde concibieron a la IO como aquello que es central, distinto y perdurable de la organización, han surgido otras conceptualizaciones que discuten y cuestionan esta primera. Junto con ello, y a partir de esta revisión documental, se lograron distinguir una serie de paradigmas, discusiones y controversias que se vienen desarrollando actualmente. Este ejercicio posibilitó identificar en dónde se pueden ubicar los aportes resultantes de la investigación, al concebir la IO como un proceso liminal.

Tal concepción no estaba catalogada dentro de la inicial revisión, lo que implicó una nueva sobre el tema específico. Se encontró que si bien era un aspecto estudiado en el ámbito organizacional, no se había desarrollado a profundidad, sobre todo desde la perspectiva del proceso de construcción como tal.

El capítulo segundo da cuenta de la construcción (definición y delimitación) del marco teórico y conceptual, luego de tener claridad en dónde se inscribe la investigación dentro de los estudios de la identidad de las organizaciones. Más que un marco teórico propiamente, aspecto que se discute con amplitud en el capítulo, los EO son un campo de estudio especializado cuyas características principales son su visión crítica y su mirada pluridisciplinaria. Ya que dicho campo es poco conocido en América Latina, a excepción de México y Brasil, se hizo una presentación de sus fundamentos ontológicos, epistemológicos y metodológicos, ya que todos ellos constituyen las bases desde donde se cimentó la investigación. Junto con ello, se discutieron su objeto de estudio y los marcos teóricos que se inscriben en este campo de conocimiento especializado sobre las organizaciones.

En la segunda parte del apartado que se describe, se detallan los conceptos principales de la investigación: Mandos Medios (MM), construcción de identidad 
organizacional e identidad personal y grupal, en la cual se inscribe la identidad profesional. Llegado a este punto se estuvo frente a un reto teórico-metodológico: plantear y construir un modelo de análisis que permitiera darle sentido a las precategorías y categorías de análisis definidas para la investigación, a la vez que admitiera un análisis de los datos desde el objetivo planteado que es la preocupación por el proceso de construcción en sí mismo. Es así como en este capítulo dos se expone la propuesta teórica de la investigación, que no es otra cosa que la manera en cómo se toma el concepto de IO, y propiamente la 10 de los MM, objeto de estudio del trabajo. Se propone concebirla como una construcción dialógica entre aquello que dicen los directivos que son los $\mathrm{MM}$ y aquello que los MM dicen que son. La IO será el proceso sintético de dicho diálogo. Sobre esta concepción de la IO se desarrolló el modelo metodológico.

Concebir la $1 \mathrm{O}$ como un diálogo entre lo que dicen los directivos que son los MM y aquello que los propios MM dicen que son, configura un conjunto de relaciones que es necesario precisarlas y contextualizarlas. De esta manera, desde el punto de vista de los MM se definieron dos dinamismos: seguridad y significación. Para los directivos, permanencia y cambio. A su vez, estos cuatro componentes están enmarcados en tres ejes contextuales, lo que permite comprender las relaciones existentes entre ellos: eje temporal, eje relacional y eje cultural. Tanto los componentes como los ejes enunciados se explican al final del capítulo, ya que en su conjunto conforman el modelo teórico-metodológico a partir del cual se analizaron los datos.

Ya en el capítulo tres se presentan los aspectos metodológicos de la investigación. En este apartado se describe y explica el proceso investigativo que se llevó a cabo, poniendo énfasis en la construcción de las precategorías y las categorías emergentes. Se presenta el diseño general de la investigación para luego explicar por qué se eligió el estudio de caso como estrategia metodológica para abordar la problemática planteada. Una de las características de los EO es la comprensión de los fenómenos sociales que se inscriben en las organizaciones de forma particular; por ello, no buscan la construcción de una gran teoría o un único 
discurso que intente dar cuenta de toda problemática en forma universal. Por ello, el modelo planteado a nivel metodológico fue diseñado para la problemática definida para el estudio de caso propuesto. En ese sentido, las precategorías y categorías emergentes están enmarcadas dentro de ese contexto específico, por lo que no se pueden generalizar los resultados.

También en este capítulo se precisan dos conceptos considerados de suma importancia para la investigación. La unidad de análisis (primer término) es aquel aspecto en donde se busca encontrar el objeto de estudio (segundo término) para luego analizar y cumplir con el objetivo de la investigación. El objeto de estudio de la investigación se concentra entonces en la 10 de un estamento de la organización —los $\mathrm{MM}$-, buscando comprender aquellos componentes que intervienen en su construcción y, por lo mismo, el sentido que estos le dan a las relaciones que se entretejen entre ellos al momento de constituir una IO. La unidad de análisis, que es el medio por el cual se llega a examinar el objeto de estudio, es la construcción de la $1 O$ de los $M M$ de la organización donde se llevó a cabo la investigación.

Desde el marco teórico construido, la IO se concibe como un proceso dialéctico entre los aspectos que permanecen y otros que cambian. Para detectarlo, se tuvo que identificar las normativas y demás disposiciones que la organización implementa en su intento por generar un sentido de pertenencia e identidad en los MM. Metodológicamente, se recopiló esta información por medio de una revisión documental y entrevistas a los directivos de la organización sede de la investigación. La observación no participante y las entrevistas semiestructuradas ayudaron a obtener los datos necesarios para comprender cómo dichos procesos de institucionalización son apropiados, decodificados y reconstruidos por los MM.

Se realizaron 31 entrevistas a los $\mathrm{MM}$, en ocho regiones del territorio colombiano en donde opera la organización estudiada. Cinco entrevistas a directivos, tres observaciones no participantes y diversa documentación oficial. Toda la información fue sistematizada mediante el programa especializado para 
investigación cualitativa Atlas.ti v.6.2, para su posterior análisis e interpretación. En la última parte del capítulo se presenta el sistema categorial de la investigación; se destacan las categorías emergentes principales para los actores que intervinieron en la investigación (directivos y $\mathrm{MM}$ ): Modelo eficiente de gobierno, reconocimiento, trascendencia y seguridad.

En el cuarto capítulo se expone el análisis del estudio de caso, concibiéndolo como una estrategia de investigación global que involucra el diseño y todos los momentos del proceso investigativo. Es un sistema integrado que centra la atención en la individualidad o particularidad del objeto de estudio, histórica y socialmente contextualizada.

La investigación se realizó en la empresa Comercial Nutresa S.A.S. (CN en adelante), una organización comercial encargada de la distribución y ventas de los productos secos pertenecientes a las principales compañías del Grupo Empresarial Grupo Nutresa (GN en adelante), uno de los más importantes del sector de alimentos de Colombia. La firma fue creada en el año de 2010, a partir de la integración de las áreas de ventas y distribución de algunas de las compañías del GN, conformando una organización con una identidad constituida a partir de otras. Dado que el objeto de estudio de la investigación fueron los MM de $\mathrm{CN}$, el trabajo investigativo se concentró en las unidades de gobierno, llamadas frentes comerciales (FC en adelante) de $\mathrm{CN}$ en cada una de las regiones de Colombia donde operan. Este órgano está conformado por un representante (MM) de cada una de las gerencias de la compañía quienes, a la vez, personifican las áreas funcionales de la organización.

En los capítulos quinto y sexto se presentan los resultados de la investigación. De acuerdo con el modelo teórico-metodológico, la 10 se concibe como un diálogo entre lo que dicen los directivos que son los MM y aquello que los propios MM dicen que son. Así, la 10 de CN, desde el punto de vista de los MM, es producto de un diálogo; por tal razón, no se pueden identificar los componentes que intervienen en la construcción de $1 \mathrm{O}$ de los MM si no se conoce la opinión de los 
directivos; sobre todo, la IO que quieren fabricar en los MM y las maneras como quieren alcanzarlo. Al allegar esta información y a partir del análisis y comprensión de los componentes que intervienen en tal proceso, se pudo entender cómo los MM hacen frente a tales pretensiones empresariales.

En el capítulo cinco se explica esta situación. Se presenta la descripción del proceso reificante que los directivos quieren imponer a los MM en CN. Los resultados permitieron hacer una reflexión en relación con los alcances de la Administración y plantear una nueva modalidad de intervención, la cual busca fabricar y regular una identidad del individuo en relación con la organización. El tipo de acciones se inscribe en una tendencia o conjunto de modas de los últimos tiempos donde se trata de tener injerencia en aspectos más internos del individuo.

En relación con lo anterior, también se profundiza sobre la racionalidad instrumental, que si bien ha sido estudiada en el ámbito administrativo, es pertinente volver a sus fuentes para retomar los postulados más importantes que permitan comprender los alcances de las prácticas manageriales ligadas con la fabricación y control de una IO. En el análisis se emplea el término instrumentalización para expresar el proceso histórico de la Modernidad y en particular de la llustración; se denota así una crítica expresada por la Escuela de Frankfurt hacia el carácter de una razón que pierde objetividad y conciencia de sí, y se presta a legalizar y justificar racionalmente preceptos particulares, despojando al pensamiento de su contenido cognitivo para privilegiar, en su lugar, el cálculo de medios y fines, lo que conlleva a la pérdida del pensamiento reflexivo y crítico.

En el sexto capítulo se describe, analiza y se busca comprender el proceso de construcción identitaria de los MM. Se conceptualizan los tres constructos teóricos hallados a partir del análisis de los datos (reconocimiento, trascendencia y seguridad). Para ello, se recurre a las ciencias sociales, concretamente a la filosofía y a la antropología, en la búsqueda de un mayor entendimiento y alcance en el ámbito organizacional de tales conceptos; sobre todo, con respecto a las 
relaciones que generan y el sentido que tienen para los MM dentro del proceso de construcción identitario que adelantan.

En ese orden de ideas, el lector encontrará en este capítulo, al igual que en el anterior pero en una mayor medida, desarrollos conceptuales basados en otras disciplinas de las ciencias sociales que posibilitaron ahondar en el análisis de los datos. Se optó por mantener estos desarrollos teóricos en los apartados referidos a los resultados, con el fin facilitar al lector seguir la argumentación sin tener que regresarse al capítulo alusivo al marco teórico-conceptual. Aunque la razón más relevante radica en mostrar el propio proceso de construcción del conocimiento como tal, toda vez que los hallazgos de la investigación exigen regresar una y otra vez a los datos y a los marcos teóricos previstos. Si, como en el caso presente, la conceptualización previa no permite una profundización en el análisis de los datos, ese hace necesario, como en efecto ocurrió, recurrir a teorías emergentes que ayuden en la aprehensión de la relación e injerencia que los datos tienen con el objetivo propuesto en la investigación. Tales condicionamientos resaltan el alcance de la mirada pluridisciplinaria para el conocimiento de los fenómenos sociales que se inscriben en las organizaciones. Esto se convierte en unos de los aportes relevantes, a partir de los resultados, de esta investigación.

Como se puede inferir de todo lo anterior, la pregunta de investigación está íntimamente relacionada con el investigador, de ahí que no sea difícil comprender que el autor asume personalmente —con los afectos que esto trae consigo- el proceso de interpretación de los datos. El propio proceso investigativo suscita las reflexiones que el autor expresa, a lo largo del texto, en tonos diversos, de acuerdo con el recorrido que transita durante toda la investigación. De este modo, el espíritu crítico, y la manera como este se manifiesta, recorrerá todo el documento, haciendo énfasis en aquellas realidades que al investigador más le significaron. No se quiere decir con ello que la narración sea un indicador que exprese una mayor importancia que otra sobre la temática; tan solo, la manifestación de una realidad personal que no puede verse desligada del proceso comprensivo propio de la investigación. 
Así las cosas, la primera categoría emergente principal es el reconocimiento. Se refiere al dinamismo que une a los MM con sus organizaciones de origen (OO en adelante). La gestación de las apreciaciones positivas, en donde se reconocen las cualidades de los individuos, proviene de las organizaciones donde antes laboraban los MM, no de la empresa en donde actualmente trabajan. Desde la visión del actual director de la Escuela de Frankfurt, Axel Honneth, los directivos de CN declaran un reconocimiento ideologizado, lo que permite pensar que ellos incurren en una falta moral al no valorar auténticamente las cualidades de los individuos. Lo que hacen es utilizar el reconocimiento -a propósito de la racionalidad instrumental- para buscar que los MM ingresen a un sistema y se adapten a una serie de requerimientos establecidos previamente por la organización.

Sin embargo, existe un reconocimiento en donde las declaraciones de los otros buscan resaltar a la persona como tal $y$, por ende, no procuran algún tipo de comportamiento específico por parte de los individuos. Tal tipo de reconocimiento fue expresado por la OO, y los MM lo recuerdan constantemente. En ese contexto, se descubre un dinamismo que caracteriza a los $M M$, basado en que este reconocimiento implementado por las organizaciones de donde provinieron, consolida y ancla la vida de los MM al pasado. En consecuencia, una manera de resistirse a convertir sus relaciones en herramientas o expresiones reificantes es negándose a dejar de lado, en sus vidas personales y profesionales, a las OO.

La otra categoría emergente principal es la trascendencia. Este constructo expresa el interés de los MM porque su persona, representada en la obra realizada, perdure en el tiempo. La categoría tiene una particularidad: depende del reconocimiento para que se pueda proyectar a futuro. En el capítulo se retoma el concepto expresado por Marcel Mauss de dar-recibir y devolver. Se profundiza en esta idea para explicar cómo el proceso de sentirse reconocido y valorado por las OO lleva a los MM a querer devolver, en una dimensión distinta, dicho reconocimiento, expresado no solo en las manifestaciones positivas hacia ellos, 
sino en aquello que han recibido a lo largo de su estancia en el Grupo Nutresa (GN en adelante).

La trascendencia impulsa a los MM a mirar su futuro próximo de realización tanto a nivel personal, como profesional y organizacional en CN. En otras palabras, la trascendencia suscita una dinámica hacia el futuro, proyectando el quehacer de los MM en la nueva organización. CN se convierte en el espacio de realización, para iniciar de nuevo el proceso de ser reconocidos, aspecto que ya había sido obtenido en las OO. Por estar vinculados laboralmente a $\mathrm{CN}$, los $\mathrm{MM}$ se ven obligados a reiniciar allí el proceso, pues no tienen otra opción. Junto con ello, la trascendencia conlleva el dar más allá del deber, más allá de lo estipulado por el contrato laboral. En un sentido, es un gesto de gratitud, de devolver lo recibido, que trasciende lo meramente organizacional para buscar tener impacto en la sociedad.

Las dos categorías principales descritas —reconocimiento y trascendencia- son dimensiones dirigidas al individuo. Es decir, el interés por el reconocimiento y la necesidad de que la obra trascienda, son situaciones o aspectos que el individuo busca saciar. A diferencia de estas, la tercera categoría principal —seguridad-, si bien tiene una connotación personal, su definición recae sobre las posibilidades que la organización propicia y genera.

La seguridad es, pues, la categoría emergente principal que asegura y blinda el proceso de construcción identitaria, al brindar las garantías personales y estructurales para que la tensa relación laboral se mantenga y no se quiebre o resquebraje. Vale la pena mencionar que tal seguridad se vio cuestionada por los MM. Debido al proceso de restructuración, CN no cumplió con lo que había prometido, de no desvincular a ningún empleado luego de su constitución. La seguridad posibilita la configuración y construcción de una 10 , pero sin ella, el proceso se quiebra o se debilita. 
En síntesis, los constructos antes descritos son los componentes que en sus relaciones estructuran y posibilitan la existencia de una IO: un reconocimiento, que se aferra al pasado; una trascendencia, que busca realizarse a futuro, y una seguridad, que garantiza y sostiene el proceso como tal.

La $1 O$ es un proceso dialéctico entendido como el resultado de un juego interno de relaciones que son las que, en última instancia, constituyen las cosas, a pesar de que aparentemente pueda parecer que los componentes tengan una independencia. Para expresarlo de otro modo, la 10 -en tanto dialéctica- no es fija ni determinada de una vez por siempre, se construye en un constante proceso de transformación. El motor de este cambio es, a la par, tanto su contradicción interna, su limitación y desajuste en relación con su exigencia e intención de totalidad, infinitud y absoluto, como la relación interna en que está inmersa con otra realidad, que aparece como su contrario.

De otra parte, la IO, definida a partir de la configuración de estas tres categorías emergentes, puede considerarse como liminal. A la luz de la propuesta del antropólogo escocés Víctor Turner, los resultados de la investigación permiten sostener que el proceso de construcción de la $1 \mathrm{O}$ de los MM en CN es un proceso liminal y que la IO, como tal, ha de definirse como un proceso en equilibrio liminal. El reconocimiento jalona a los MM a mirar hacia atrás mientras la trascendencia impulsa a otear el futuro, configurando dos fuerzas opuestas que hacen de la 10 el centro del proceso. Desde este punto de vista, la IO es un proceso liminal, no llega a ser una cosa ni la otra, sino que en ella confluyen diversos sentidos y significados construidos por los individuos.

En dicho proceso se logran identificar también dos niveles de análisis que permiten reconocer ciertas jerarquías y, por tanto, límites en la construcción de la IO de CN por parte de los MM. En primer lugar, hay un nivel de análisis conformado por lo propiamente personal - en donde se incluye lo familiar-y lo profesional. Aquellos aspectos que se opongan a los intereses personales y profesionales repercutirán negativamente en el individuo y frustrarán el desarrollo 
constructivo de la IO. En un segundo nivel, se analiza qué es lo organizacional, caracterizado por la seguridad garante que propicia la organización.

De esta manera, la IO se torna en un proceso agónico, tejido por la confluencia de factores contextualizados en tiempo y espacio específicos. Estos, a pesar de su aparente no estructuración, configuran un estado característico e identificable, en donde la 10 se sostiene por las tensiones existentes, particularizada por la presencia de controversias, desencuentros, incumplimientos, frustraciones, tanto como aspiraciones y realizaciones. Esos aspectos, a su vez, se recomponen de acuerdo con los intereses de las partes, generan acuerdos explícitos e implícitos y provocan una tensión que se re-escribe y se re-configura en el dinamismo social y continuo de la experiencia organizacional y de los factores que en ella intervienen.

Finalmente, en el capítulo séptimo se presentan las ideas principales del desarrollo de la tesis a manera de reflexiones finales. Allí se condensan los principales resultados de la investigación, clasificados en cuatro temas: teórico, metodológico, organizacional y vetas para futuras investigaciones. Vale la pena anotar que no es la repetición de los comentarios finales de cada uno de los capítulos, sino la concreción sucinta de las ideas principales desarrolladas a lo largo de todo el documento, a manera de conclusiones.

En la sección dedicada a la discusión de lo organizacional se encuentran las reflexiones que se detienen en aquellos aspectos que ayudan a profundizar en la vida organizacional a partir de la investigación. De hecho, el razonamiento propuesto sobre la 10 de concebirla como un equilibrio liminal, subraya to importante de entender las dinámicas sociales desde los procesos que se inscriben en las organizaciones. En ese sentido y de acuerdo con el texto clásico de los EO, de Clegg y Hardy (1996), la investigación se centró en el organizing, en los procesos sociales como la construcción de identidad organizacional. Así, desde esta dimensión, los resultados de la investigación contribuyen y abonan a la comprensión de lo que se ha dado en llamar organización. 
Tal como se indicó, el estudio realizado giró en torno a una pregunta de investigación: ¿Cómo es el proceso de construcción de identidad organizacional de los mandos medios en Comercial Nutresa? La problemática de investigación se centró en la fabricación, por parte de la dirección y gracias a las nuevas formas de intervención administrativas, de una 10 específica. Frente a tal pretensión, los individuos, y para el caso concreto de la investigación, los MM hicieron frente a tales intensiones y compaginaron una forma de estar en la organización, permitiendo mantener el equilibrio organizacional y, con ello, seguir vinculados a la organización. Así, frente a tales pretensiones, la problemática de investigación es cómo construyen una 10.

A este punto se llega luego de un recorrido de vida. La respuesta a la problemática de investigación no solo se reduce a lo meramente académico, también toca con la experiencia vital del investigador, aspectos que se entrelazan en las distintas facetas identitarias, a la vez que se comprenden estas con el fin de intentar comprenderse a la sombra del trabajo investigativo. No es casual que el autor, a lo largo del proceso de indagación, haya integrado sus características de ser padre, hijo, estudiante y profesor, soltero y esposo. La pregunta vital, como se mencionó al inicio de la introducción, acompañó el proceso. Fue el motor de búsqueda que mantuvo al investigador en el camino trazado para no desviarse. En efecto, lo académico, familiar, personal, profesional y otras facetas de la identidad del sujeto que se pregunta, se encuentran imbricadas e interrogadas, al mismo tiempo, por el propio proceso investigativo y, obviamente, por sus resultados.

La historia del investigador está marcada por la conjunción de varias identidades, tanto a nivel académico como cultural, y por haber podido, también, participar en varios deportes de alto rendimiento por muchos años. La disciplina en el entrenamiento diario, que implica restricciones en lo físico, la comida y los hábitos de sueño, en las amistades y cuidados diversos, entre otras cuestiones, capacitan y perfeccionan al atleta en el deporte que practica. La constancia, tenacidad y confianza en las indicaciones de los entrenadores permiten, además, que los resultados se produzcan. De esta manera, llega el día que sin saber con total 
consciencia o claridad cómo se dan las cosas, el atleta baja su record, el portero logra alcanzar balones que antes no podía o el voleibolista es capaz de rematar en espacios que días antes le parecían imposibles. El entrenamiento fortalece las capacidades del deportista para potenciarlas, para desplegarlas, para desarrollarlas, en otras palabras, para perfeccionarlas. Pasado el tiempo, y ya por fuera de la disciplina de la rutina, el deportista, sin tener ya la necesidad de participar en altas competiciones, ha aprendido el cómo. Ha pasado por la experiencia de vivir las implicancias del arduo entrenamiento y comprende el proceso, de ahí que sea capaz de entenderlo ya sin practicarlo, y por lo mismo, de acompañar a otros en el proceso que inician.

El desarrollo de esta tesis ha sido, con todo, un proceso de aprendizaje al igual que le ocurre al atleta. Así como en el ámbito deportivo, este no ha estado exento de sacrificios, frustraciones, dolores y desengaños. Tal vez, estas mismas circunstancias, el impacto que tienen en la vida del sujeto que las padece, como ocurre en el deporte, es lo que permite una mayor interiorización de lo aprendido. La soledad, incertidumbre, incomprensión, el reconocimiento de los errores y el sinsentido que por etapas atraviesa el investigador en este proceso, conjugan una manera distinta de aprehender la realidad, pasando, necesariamente, por comprenderse a sí mismo de otra manera y en otro lugar. En ello reside, es justo decirlo, el dolor del que habla Fernando González en el epígrafe de esta sección. El camino recorrido, la realidad a la cual se busca comprender mediante un ejercicio investigativo, repercute fuertemente en el investigador, en lo que es, en su misma identidad, propiciando y generando nuevas experiencias que desacomodan lo que se tenía, que interrogan las bases que lo sostenían e invitan a reconstruir su historia nuevamente, sin necesidad de negar lo anterior sino, más bien, contando con ello para re-comprenderlo.

Ahora bien, para aprender hay que despojarse de ciertas cosas y cuestionar otras; de ahí la necesaria valentía para aceptar la nueva realidad e iniciar la etapa de reconstrucción, en un continuum que se asemeja a la vida misma y, por qué no, a la construcción de la propia identidad. Por esto y por muchas otras cosas que 
quedan aún por decir, la pregunta por la propia identidad se tradujo en este caso en pregunta de investigación. No hay problema que no se encarne con el dolor y la alegría que trae en la vida de quien se pregunta. Nadie podrá decirle al otro quién es en su plenitud, sin el proceso solitario, doloroso y, por qué no, alegre, de haberse al menos hecho la pregunta para descubrirse a sí mismo.

En síntesis, lo que se presenta en el texto que tiene en sus manos el lector es una conversación más sobre el tema de la $1 \mathrm{O}$ dentro del ámbito de los EO, enmarcada por las características propias de la realidad organizacional objeto de estudio. Las particularidades de la investigación, entre las cuales se destaca el modelo teóricometodológico propuesto y desarrollado, permiten comprender un poco más los fenómenos que se inscriben en las organizaciones y a ellas mismas. No es algo terminado y blindado de errores y controversias, es un diálogo más en donde se ha hecho énfasis en el proceso metodológico como tal, que en mucho propiciará nuevas conversaciones en este álgido e inconmensurable arenal organizativo. 


\section{CAPÍTULO 1}

\section{REVISIÓN DE LA LITERATURA SOBRE LA IDENTIDAD ORGANIZACIONAL}

\section{INTRODUCCIÓN}

Identidad. El concepto de identidad no es nuevo dentro de las ciencias sociales. La filosofía lo ha abordado desde diversas perspectivas y en distintos contextos históricos, en donde la identidad pareciera ser el resultado de una cierta tendencia de la razón a reducir lo real a lo idéntico, es decir, a sacrificar la multiplicidad de la identidad con vistas a su explicación y como base para la teorización sobre la condición humana. Desde el siglo pasado, la psicología y el psicoanálisis le otorgaron un lugar preponderante en el estudio de los procesos individuales y representó un elemento clave en la comprensión del desarrollo de la personalidad. La propia antropología ha tenido que conformar un cuerpo teórico en torno al problema de la identidad social. Desde luego, no se pueden perder de vista los aportes de otras disciplinas como la sociología, la ciencia política, la lingüística, etc.

La identidad ha desempeñado un papel importante en la teorización de las ciencias sociales, las cuales aportan y tienen injerencia en los estudios de la organización ${ }^{1}$ (Corley, Harquail, Pratt, Glynn, Fiol y Hatch, 2006), ámbito del conocimiento en donde se inscribe la investigación. A pesar del interés académico

\footnotetext{
${ }^{1}$ Ejemplo de ello son las ediciones especiales en revistas internacionales como Academy of Management Review (Vol. 35, No. 2 del año 2010), Human Relations (Vol. 62, No. 3 del año 2009) y Organizations (Vol. 15, No. 1 del año 2008).
} 
que el término identidad despierta, este ha sido objeto de atención dentro del terreno propiamente organizacional hace relativamente unos pocos años (Hatch y Schultz, 2004). La conceptualización propuesta por Stuart Albert y David Whetten (1985), quienes propusieron que la identidad organizacional implicaba aspectos organizacionales que cumplen con los criterios de centralidad, carácter distintivo y continuidad temporal, ha dado paso a nuevas conceptualizaciones. Este trabajo impulsó una ola de investigación y teorización que continúa hasta el presente.

Luego de un poco más de un cuarto de siglo desde su conceptualización, el término $1 \mathrm{O}^{2}$ no está lo suficientemente definido, ni la discusión sobre sus alcances o modelos propuestos, acabados. En el campo organizacional han prolifereado definiciones que van desde el nivel individual hasta percepciones de lo que la organización es, basadas en perspectivas institucionalistas o esencialistas en donde se busca identificar las características propias de la organización (Ashforth, Rogers y Corley, 2011). Esto ha dado como resultado una cacofonía y una polisemia en su definición y en sus aportes al ámbito organizacional, y ha llegado incluso a generar una contradictoria y consecuente situación en donde pareciera que todo es identidad, y simultáneamente nada lo es.

Retomando la definición que Clegg y Hardy (1996) hacen sobre los estudios Organizacionales (EO), "como una serie de conversaciones, en particular de aquellos investigadores organizacionales que contribuyen a constituir las organizaciones mismas por medio de términos derivados de paradigmas, métodos y supuestos, ellos mismos derivados de conversaciones anteriores" (p. 3), se presenta este capítulo en dónde se busca discutir el estado de las conversaciones sobre la IO dentro de los EO. El objetivo es proporcionar un panorama general de las investigaciones referidas a este ámbito dentro de los estudios de la organización, para enmarcar la investigación y los hallazgos obtenidos. Junto con ello, se busca dar a conocer las oportunidades que ofrece este constructo para

${ }^{2}$ Con el fin de recordar el significado de las siglas, se pueden revisar las tablas correspondientes del comienzo. 
comprender y analizar los fenómenos sociales que se inscriben en las organizaciones.

Así, este capítulo se encuentra dividido en seis apartados ${ }^{3}$. En un primer momento se describe la importancia que ha adquirido últimamente el tema de la 10 en el ámbito académico, así como la problemática que lo rodea. En un segundo momento se discutirán los fundamentos disciplinarios, ontológicos y epistemológicos del término, con el ánimo de entender las bases de su inserción dentro del ámbito organizacional, así como los presupuestos para su comprensión e interpretación. Luego, se presenta la discusión, en torno a las convergencias y divergencias que ha generado el concepto primigenio esclarecido por Albert y Whetten en 1985. A continuación se exponen los paradigmas, perspectivas y discusiones que se vienen realizando dentro del marco de la 10 . En un quinto apartado se realiza una breve discusión en torno a lo expuesto, para terminar el capítulo con unas relfexiones finales y horizontes de investigación. De esta manera, se busca delimitar y poner al lector en contexto de las conversaciones que se vienen desarrollonado sobre el tema de investigación.

\subsection{CONTEXTO, IMPORTANCIA Y PROBLEMÁTICA}

El concepto de identidad ha venido extendiéndose en los últimos años a niveles macro de análisis, y se ha convertido en un aspecto fundamental para la comprensión de lo que significa una organización en la sociedad (Albert y Whetten, 1985; Ashforth, Rogers y Corley, 2011; Dutton y Dukerich, 1991; Czarniawska, 1997a; Gioia, Schultz, y Corley, 2000; Hatch y Schultz, 2002). De ahí que el estudio de la 10 sea hoy en día un dominio relevante entre los teóricos e investigadores de las organizaciones.

\footnotetext{
${ }^{3}$ Vale la pena mencionar que de este capítulo se publicaron dos artículos académicos: (1) Gonzales-Miranda, Diego René (2012). Identidad Organizacional: marco teórico para el análisis organizacional. Estudios Interdisciplinarios de la Organización. México. 1 (2). pp. 35-63; y (2) Gonzales-Miranda, D. R., Gentilin, M. y Ocampo, C.A. (2014) La identidad organizacional. ¿En qué va la conversación? Perspectivas y Controversias. En proceso de evaluación.
} 
Basados en la definición de 10 de Albert y Whetten $(1985)^{4}$, los investigadores han abordado el concepto de la 10 explorando sus implicaciones para la vida organizacional en una variedad de entornos. Este creciente interés ha conducido a tomar la IO como una perspectiva importante para analizar diversos temas como la toma de decisiones estratégicas (Dutton y Dukerich, 1991; Elsbach y Kramer, 1996; Gioia y Thomas, 1996; Glynn, 2000; Maitlis y Lawrence, 2003), el cambio organizacional (Chreim, 2005; Martins, 2005; Nag, Corley y Gioia, 2007), mostrar cómo las organizaciones y sus directivos interpretan temas (Dutton y Dukerich, 1991), identifican amenazas (Elsbach y Kramer 1996), perciben y resuelven conflictos (Golden-Biddle y Rao 1997), establecen una ventaja competitiva (Fiol, 1991) y construyen estrategias (Fiol y Huff 1992), por mencionar sólo algunos.

El tema de la $\mathrm{IO}$ es, por tanto, importante a nivel teórico, a la vez que proporciona elementos valiosos para análisis empíricos. Dicho tema brinda formas creativas para comprender una amplia variedad de contextos y fenómenos organizacionales (Alvesson, Ashcraft y Thomas, 2008). Junto con ello, este tema también ha sido abordado a la vez como perspectiva de análisis y como objeto de estudio. En otras palabras, existe una preocupación por lo que "se es", como forma cultural e histórica, y una propensión a tomar la 10 como perspectiva para comprender los problemas y fenómenos sociales presentes en las organizaciones.

Dentro de esta inquietud por el tema identitario, la organización se convierte en un colectivo integrado por diversos aspectos de la identidad, en donde algunos miembros de la organización pueden percibir ajustes, y algunos otros logran distinguir que sus aspectos individuales no encajan en la organización en donde habitan (Kreiner, Hollensensbe y Sheep, 2006a). Para Mead (1934), la identidad

\footnotetext{
${ }^{4}$ Los autores la definen a partir de tres características: 1. Los puntos de respuesta a características que son propias de la organización, es decir, son características consideradas como su esencia. La identidad distingue a la organización con base en algo importante y esencial. Es la característica reconocida como central. 2. Los puntos de respuesta a características que distinguen a una organización de otras. La identidad abarcará características que permitirán una distinción de otras organizaciones. Es la característica reconocida como distintiva. 3. Los puntos de respuesta a características que exhiben cierto grado de igualdad o continuidad a través del tiempo. Es la característica reconocida como perdurable.
} 
es esencialmente el conjunto de creencias y significados que responden a la pregunta ¿quién soy? Al trasladar esta pregunta al ámbito organizacional, quedaría formulada como ¿quiénes somos? (Foreman y Whetten, 2002).

Una de las posibilidades que brinda el término 10 es que permite situar una entidad como tal. Ya sea una organización, grupo o persona, cada organización necesita por lo menos una respuesta preliminar a la pregunta ¿quiénes somos?, para poder interactuar eficazmente con otras entidades a largo plazo. Del mismo modo, otras entidades necesitan por lo menos la respuesta preliminar a la pregunta ¿quiénes son ellos? para realizar esa interacción. La 10 sitúa socialmente, de esta manera, a la organización, al grupo o a la persona (Albert, Ashforth y Dutton, 2000).

Otro aspecto que tiene gran posibilidad para el análisis es el de que los conceptos de identidad e identificación poseen la capacidad de integrar y generalizar. Son términos que viajan fácilmente a través de los distintos niveles de análisis. Transmiten simultáneamente un distintivo y una unidad, lo cual permite al mismo tiempo confusión, multiplicidad y dinamismo, tanto del contenido de lo que es la identidad, como del proceso de su construcción. Identidad (nombre) e identificar (verbo) pueden ser utilizados como conceptos versátiles, marcos teóricos o herramientas que generan posibilidades para el desarrollo teórico (Albert, Ashforth y Dutton, 2000).

Para Kreiner, Hollensensbe y Sheep (2006a), el término identificación se ha entendido en la literatura organizacional a partir de dos significados: en relación con un estado y con un proceso. La identificación como un estado se refiere a la asociación del individuo con un grupo social (una organización, una profesión, etc.). El segundo, como proceso, es el paso de alinear la propia identidad con la de un grupo social. Los autores resaltan que la identidad puede cambiar en este proceso, ya que es cíclica, y no determina cuándo un individuo se llega a identificar con una entidad en particular. 
Las personas desarrollan una gran variedad de procesos de identificación intertextuales entre el yo y el otro en su interacción con sus entornos sociales (Fuller, Hester, Barnett, Frey, Relyea y Beu, 2006). Esto permite una construcción simultánea de la identidad personal como ser humano, y la identidad pública como actor social. $\mathrm{Y}$ dado que tales prácticas articulan lo personal con lo social, analíticamente la noción de identidad puede ser considerada como un concepto puente entre el individuo y la sociedad (Ybema, Keenoy, Oswick, Beverungen, Ellis y Sabelis, 2009). Su potencial de mediación radica precisamente en ese doble carácter, por lo que la identidad puede ser considerada una dialéctica permanente entre la estructura personal y la social.

En este sentido, el estudio de la 10 permite comprender el deseo permanente y subyacente de generar congruencia o encaje de ciertas actitudes y comportamientos personales con lo establecido por la organización. Esto podría implicar también revaluar las creencias fundamentales del individuo, o presionar a la organización para que haga cambios en sus prácticas, pudiendo llevar a reconsiderar la relación misma del individuo con la organización (Foreman y Whetten, 2002).

A pesar de su importancia y de las posibilidades de abonar a la comprensión de los fenómenos organizacionales, Pratt y Rosa (2003) han afirmado que la identidad, como un concepto explicativo, es a menudo usado en exceso, y no ha sido especificado lo suficiente. "El concepto de identidad de la organización está sufriendo una crisis de identidad" (Whetten, 2006, p. 220).

Pratt (2003), haciendo alusión al término IO, afirma que "un concepto que significa todo, no significa nada" (p. 162). Esto constrasta con la definición de Albert y Whetten (1985), los cuales presentaron el concepto como un constructo definido. El mismo Whetten (2006) da cuenta de esta problemática al afirmar que si bien algunos autores proponen la 10 como un conjunto de fragmentos, a menudo incompatibles, otros autores cuestionan esta posición, ya que consideran que al 
concebir la 10 como estable, permite una coherencia consistente con la acción organizativa.

Los diferentes puntos de vista en diferentes momentos de la historia pueden simplemente servir para diferentes propósitos, la falta de un acuerdo universal es, de algún modo, un impedimento para el futuro. De hecho, puede resultar que algunas de las más profundas cuestiones planteadas referidas a la identidad, no se puedan resolver, debido a que su profundidad y densidad serán siempre un enigma. (Whetten, 2006, p. 15).

Es entonces dentro de este contexto que la $1 \mathrm{O}$ es importante para el análisis organizacional. La problemática que subyace remite a una serie de interrogantes: ¿qué es lo que se ha dicho en relación con la 10 ? ¿Cuáles son las principales perspectivas teóricas que los investigadores han utilizado para su estudio? En otras palabras: ¿en qué va la conversación sobre el tema de la IO?

\subsection{FUNDAMENTOS}

A continuación se presentan los fundamentos disciplinares, ontológicos y epistemológicos de la $1 O$.

\subsubsection{Fundamentos disciplinares}

El concepto de IO ha sido desarrollado por la filosofía, por los estudios culturales y por la teoría literaria así como por la psicología, la sociología y la antropología. Es por ello que no es sorpresa que el concepto de identidad organizacional haya encontrado en los estudios organizacionales su espacio y lugar para ser también interrogado. A continuación se presentan los fundamentos disciplinares desde la filosofía, la sociología, la psicología y la antropología.

\subsubsection{Desde la Filosofía}

El término identidad ha sido examinado desde varios puntos de vista. Los más destacados son el ontológico (o metafísico) y el lógico. En el primero se hace referencia a la identidad según la cual toda cosa es igual a ella misma. El segundo es el llamado principio lógico de la identidad, donde éste es considerado el reflejo 
lógico del principio ontológico de la identidad. Esto se expresa en lo siguiente: "si p (enunciado declarativo)...entonces $p$ (lógica de las proposiciones)" ambos sentidos, tanto el ontológico como el lógico, se han entremezclado e incluso confundido con frecuencia.

Según Ferrater Mora (1994) la idea de identidad parece ser el resultado de una cierta tendencia de la razón a reducir lo real a lo idéntico, es decir, a sacrificar la multiplicidad de la identidad con vistas a su explicación. La noción de identidad metafísica fue criticada por Hume pues no estaba de acuerdo con aquellos que afirmaban que hay un yo que es idéntico a sí mismo o idéntico a través de todas sus manifestaciones. Esta idea, afirma, no se deriva de ninguna impresión sensible, dado que penetrar en el yo conllevará a encontrar alguna percepción particular (muchos yos) que terminará convirtiéndose solamente en aces o colecciones del mismo yo. Así, Hume considera el problema de la identidad como insoluble.

En ese orden de ideas, Kant acepta la crítica de Hume al considerar la insolubilidad de la identidad pero sólo cuando se pretende identificar cosas en sí o cuando se funda el término en la persistencia de las múltiples visiones o representaciones del Yo. Sin embargo, considera que la identidad puede asegurarse en la medida en que no es ni física ni metafísica sino trascendental: la conciencia de sí mismo en diferentes momentos.

Siguiendo con Ferrater Mora (1994) los idealistas post-kantianos hicieron un concepto central metafísico en el que la identidad es además de un concepto lógico, el resultado de representaciones empíricas unificadas. Hegel entiende la identidad como un concepto universal, una verdad plena y superior que ha absorbido las identidades anteriores; hay en el principio de identidad-según este autor- más que una identidad simple y abstracta, hay movimiento de la reflexión en el que lo otro surge como apariencia. 
Si bien puede hablarse de un fundamento común de la identidad: "Conveniencia de cada cosa consigo misma", se puede hablar también de identidad en diversos sentidos: Identidad real, identidad racional o formal, incluso muchos autores han hablado sobre el principio psicológico de la identidad, sin embargo, con frecuencia la idea de todas las formas de identidad existentes se pueden reducir a las dos mencionadas anteriormente.

Cuando trató de definir la identidad, Aristóteles observó que ésta se daba en varias formas: Es una unidad de ser, unidad de multiplicidad de seres o unidad de un solo ser tratado como múltiple. Los escolásticos definen varios tipos de identidad: la real, racional, específica, genérica entre otras, pero en términos generales la definen como la "conveniencia de cada cosa consigo misma".

\subsubsection{Desde la Sociología}

El sociológico Erik Erikson enfoca la identidad como el proceso que hace que el núcleo de la individualidad y el núcleo de la comunidad sean uno mismo. La consideración más sociológica de la identidad ha sido iniciada por la escuela de pensamiento del interaccionismo simbólico que muestra cómo son los procesos sociales de construcción de la "identidad social a partir de la distinción entre el yo y ér'. A partir de los años sesenta surgen presupuestos en los que consideran la conciencia de la identidad como un atributo del individuo y esa conciencia se basa en significaciones sociales de rasgos tanto individuales como colectivos, cuya significación constituye un proceso de construcción de sentido en donde todos participan de maneras desiguales.

Por otro lado, Giménez (2000) considera que el concepto de identidad aparace a finales de los años sesenta, aunque sus elementos ya se encuentran presentes en la teoría social anterior. La sociología plantea el estudio de la identidad en dos tradiciones: por un lado, la americana, destaca al sujeto como actor social y la formación de su identidad a partir de la participación en el mundo social; y por el otro lado, la francesa, estudia la identidad como la dimensión subjetiva de las 
representaciónes socialmente elaboradas o el capital cultural que distingue a las clases sociales.

La tradición francesa vincula tambien el estudio de la identidad con los movimientos sociales y las migraciones. La identidad se define a partir de cómo los grupos se representan a sí mismos frente a otros. Durkheim fue el primero en plantear la existencia de representaciones sociales que se expresan en el comportamiento de los individuos. Moscovici retoma esta idea en su teoría de las representaciones sociales, las cuales son campos de conceptos o sistemas de nociones asociadas que sirven para dar cuenta de la realidad y, a la vez, determinan el comportanmiento individual (Giménez, 1996).

En la antropología, se considera que la identidad es un elemento de la cultura internalizada que distingue (Bourdieu) o una representación elaborada por los actores sociales (Moscovici). En ese sentido, la identidad es el lado subjetivo de la cultura considerando su función distintiva. Sin embargo, la identidad no es una especie que se atribuyan los actores sociales a sí mismos; por el contrario, la identidad surge del proceso de intercabio social como una afirmación de razgos que distinguen a un grupo y puede modificarse de acuerdo con la historia de los diferentes grupos o colectivos.

Se pueden distinguir las siguientes controversias (Giménez, 1996) en torno al problema de la identidad:

- La concepción de la idenidad como un proceso social que se juega de distintas formas, sea como una identidad colectiva o como una identidad personal.

- El papel que se les da a los sujetos en tanto se plantean como poseedores de una identidad que los hace distintos a otros.

- Su particiapción en los conflictos, en lugar de enfocarse en las estructuras que los determinan. 
- La exploración de temas como los relatos que elaboran los grupos y el uso estratégico de las identidades.

No obstante, se le ha dado un peso excesivo a las representaciones sociales como el núcleo de la identidad, destacando la parte cognitiva, y un escaso reconocimiento a los valores y las prácticas sociales como los componentes que dan sentido a la identidad (Hernández, 2008).

El Sociólogo norteamericano Charles Horton Cooley (1902) buscó explicar la sociedad $\sin$ excluir lo individual. Es por eso que trató de sintetizar el individualismo y el socialismo en una forma orgánica, evitando caer en perspectivas parciales. "La visión orgánica hace hincapié tanto en la unidad del conjunto y el valor peculiar del individuo, explicando uno por el otro" (Cooley, 1964, p. 36). Este uno por el otro hace referencia al aspecto distributivo (las personas hacen la sociedad) y colectivo (la sociedad hace a las personas) de los aspectos de la vida. Su visión orgánica se sintetiza en el hecho que para él, la sociedad y los individuos no denotan fenómenos separables, sino que son sencillamente aspectos colectivos y distributivos de una misma cosa.

No es posible dividir la psicología social del hombre en aquello que es social y aquello que no lo es. Todo es social en un sentido. Lo social es parte del común de la vida humana. "Todo lo humano acerca de su misma historia tiene un pasado social" (Cooley, 1964, p. 47). En este sentido, Cooley, define el yo en términos sociales. Esto es quizás su mayor contribución a la teoría de la identidad (Hatch y Schultz, 2004). Para Cooley, la idea de identidad es definida por la percepción de cómo nos ven los demás ${ }^{5}$. Plantea a su vez, la idea, promovida recientemente por los postmodernistas, que la identidad es una construcción lingüística: "Que el "Yo" del habla común está envuelto en el hecho que las palabras y las ideas que

\footnotetext{
${ }^{5}$ Es lo que Jane Dutton y Janet Dukerich (1991) definen como imagen. Estos autores proponen que la identidad es reflejada en el espejo de la imagen organizacional.
} 
definen son fenómenos del lenguaje y de la vida comunicativa"6 (Cooley, 1964, p. 180).

Para el también sociólogo norteamericano George Herbert Mead (1934), teórico del interaccionismo simbólico, presenta el yo como dinámico y social, afirmando que la identidad se forma por la interacción social y destaca la internalización de los otros como parte del sí mismo. Mead formula una concepción del sí mismo como un proceso social y, a la vez, una capacidad mental de considerarse a sí mismo como objeto. El sí mismo presupone el proceso social de comunicación entre los humanos; surge con el desarrollo y a través de la actividad social. El sí mismo está dialécticamente relacionado con la mente. Es así que el autor afirma que el yo no es un sí mismo y se convierte en tal cuando la mente se ha desarrollado por medio de un proceso reflexivo. Por medio de la reflexión, los procesos sociales de participación y comunicación son internalizados en la experiencia de los individuos.

Mead (1934) identifica dos aspectos o fases del sí mismo que los llama el yo y el mí. Afirma que ambos son partes de un todo pero separables en cuanto al comportamiento y la experiencia. El "yo" es la respuesta inmediata de un individuo a otro. Es el aspecto no calculable, imprevisible y creativo del sí mismo. Las personas no saben con antelación cómo será la acción el "yo". No se es totalmente consciente del "yo", tan sólo cuando se ha realizado el acto. El yo reacciona contra el mí que es el conjunto organizado de actitudes de los demás que uno asume. Es la adopción del otro generalizado, las personas son conscientes del "mi" pues implica la responsabilidad consciente. El "otro" generalizado es la actitud del conjunto de la comunidad hacia mí.

El autor tiene una concepción moderna de las instituciones sociales, que constriñen a los individuos, a la vez que les capacitan para ser creativos ${ }^{7}$. Albert y Whetten (1985) enfatizan el concepto de yo de Mead para formular la definición de

\footnotetext{
${ }_{7}^{6}$ Bárbara Czarniawska (1997a) discute la identidad organizacional como un fenómeno lingüístico.

${ }^{7}$ Sobre esto se puede consultar también Giddens (1988) y Ritzer (2003).
} 
identidad y las relaciona con la percepciones del sí mismo formado por los otros. La aportación de Mead es considerar que el sí mismo se forma en el proceso de interacción social y de comunicación. El sí mismo puede concebirse como un desarrollo social, al participar en las actividades, y la capacidad de reflexionar sobre las experiencias que internaliza ${ }^{8}$.

El sociólogo y escritor norteamericano Erving Goffman (1989) estudió las unidades mínimas de interacción entre las personas, centrando su atención en grupos reducidos, diferenciándose de esta manera de la mayoría de los estudios sociológicos que se habían hecho hasta el momento a gran escala. Estudió la influencia de los significados y los símbolos de la acción e interacción humana. Plantea el desarrollo de un sí mismo que realiza actuaciones estratégicas dependiendo de los escenarios y recursos disponibles. La identidad para el autor aparece como una construcción subjetiva de los actores sociales y les aporta una capacidad de actuación frente a las estructuras del mundo social.

Goffman equipara la interacción social con el desempeño dramatúrgico. Como una obra de teatro, los actores conspiran con su audiencia para que sean testigos de su desempeño. El trabajo de Goffman sugiere que la identidad es un desempeño y que las habilidades de los actores son relevantes para controlar o manejar las impresiones del desempeño que la identidad deja en los otros. Por lo tanto, los otros en las definiciones de Cooley y Mead viene a ser la audiencia para Goffman dentro de la metáfora que plantea, permitiendo introducir a los stkeholders dentro del debate (Hatch y Schultz, 2004).

Goffman (1989) se aleja de las ideas de Mead sobre el sí mismo, en particular con su análisis de las tensiones entre el yo espontáneo y el mí, las actitudes o constreñimientos sociales. Existe una tensión entre lo que las personas esperan que se haga y lo que se quiere hacer espontáneamente. Las personas actúan para sus audiencias sociales con la finalidad de mantener una imagen aceptable

\footnotetext{
${ }^{8}$ Para Schutz (1974), la actitud reflexiva es la forma como se dota de significado a la acción social.
} 
del sí mismo. En diferentes situaciones (escenarios) los individuos presentan imágenes distintas. Goffman se centró en la dramaturgia como un modelo social que le permite analizar esta presentación. Adoptó una perspectiva de la vida social como si ésta fuera una serie de actuaciones dramáticas que se asemejan a las representadas en el escenario. No creía que el sí mismo fuera una posesión del actor; lo consideraba como el producto de la interacción dramática entre el actor y la audiencia. El autor analizó las situaciones como si las interacciones sociales fueran representaciones, desmenuzando sus distintos componentes y su efecto en la interacción entre el actor y la audiencia ${ }^{9}$. El sí mismo aparece como aquella apariencia que el actor muestra (una máscara) y que manipula para dar cumplimiento al desarrollo de la presentación ${ }^{10}$.

En contraste con Cooley y Mead, la identidad deriva de las formas en que los otros consideran el sí mismo. Goffman, describe no como las imágenes de los otros son transformadas en identidad (propuesto por Cooley y Mead), sino como la identidad puede ser satisfecha comunicándose por los otros a través de la impresión del management. En su texto: “The arts of impression Management”, Goffman no solo describe cómo los individuos impresionan a otros, sino cómo los otros conspiran con el individuo para ayudarlo la mantener satisfecha sus relaciones sociales. Goffman también nota que el contexto de intercambio entre los actores y la audiencia, toma un lugar que provee expectaciones compartidas y da directrices para el desarrollo.

\footnotetext{
${ }^{9}$ En ese sentido, Dubar (2002b) realizó una revisión de los clásicos de la sociología acerca de la identidad y la socialización. Encuentra que la identidad se genera como el resultado de las socializaciones sucesivas, por lo que la socialización es un proceso constante de reconstrucción de identidades ligadas a diversas esferas de la actividad, que cada uno encuentra en el curso de su vida y en la cual aprende a desempeñarse como actor social.

${ }^{10}$ El significado de persona deriva del griego (prosopon) y significa máscara dentro de un drama; luego amplía su significado para referirse a la intimidad, carácter o naturaleza desnuda. Posteriormente, en el derecho romano adquiere un significado de entidad jurídica y moral (personae) que alude a un ser consciente, libre y responsable con derechos y obligaciones. Una discusión amplia sobre estos aspectos se puede revisar en: Dubar (2002a, p. 40 y ss.)
} 


\subsubsection{Desde la Psicología}

J. Locke y D. Hume definen la identidad como un mecanismo psicológico que tiene su principio no en la unidad sustancial del yo, sino en la relación que establece la memoria entre las impresiones continuamente cambiantes: el presente y el pasado. De esta manera, la identidad no es más que una construcción de la memoria. Esta reflexión si bien filosófica, fue acepada sustancialmente por la psicología la cual habla de identidad y crisis de identidad de acuerdo con la solidez o fragilidad de esa construcción haciendo referencia únicamente a la identidad personal, a su existencia continúa a pesar de cambios o funciones (Galimberti, 2002).

Carl Jung realizó algunas reflexiones en torno a una igualdad inconsciente y a priori con los objetos, en este tipo de identidad se establecen ciertos prejuicios ingenuos en donde la psicología de una persona es igual a la de las otras. En cuanto a la identidad consciente, ésta representa la reflexión que hace el sujeto sobre su propia continuidad temporal y su diferencia con los demás.

Henri Tajfel y John Turner (1979) desarrollaron la Teoría de la Identidad Social ${ }^{11}$. Los autores se enfocaron en la identificación dentro y fuera de los grupos, en el etnocentrismo competitivo y en el negativo estereotipo entre los grupos sociales. Proponen una teoría social de identidad contraponiéndola con la entonces idea dominante en la psicología social referida a que la moral del grupo, la cohesión y la cooperación son estrictamente productos de la competencia intergrupal. Tajfel y Turner (1979) observaron que la identidad dentro de los grupos puede operar independientemente de la competición. Otros psicólogos sociales asumen que hay una fuerza motora detrás de la identificación grupal.

\footnotetext{
${ }^{11}$ Teoría que tuvo como objetivo comprender los fundamentos psicológicos de la discriminación entre grupos, compuesta por cuatro elementos: (1) Categorización: se pone a los otros dentro de categorías, es decir, se etiqueta. (2) Identificación: El individuo se asocia con determinados grupos para reafirmar la autoestima. (3) Comparación: Se comparan los grupos, percibiendo un sesgo favorable hacia el grupo al cual el individuo pertenece. (4) Distinción psicosocial: Se espera que la identidad del grupo al cual el individuo pertenece sea a la vez distinta y positivamente mejor que la de los otros.
} 
Sus investigaciones muestran el poder que tiene un grupo pequeño, esto es, el simple nombre de algún miembro del grupo es suficiente para crear distinciones dentro y fuera del grupo, esto sugiere que la construcción de la identidad de las organizaciones juega un rol en la creación de la competencia, lo que investigadores anteriores asumieron como producto de la identidad grupal.

Taifel y Turner proponen una categorización social como la base de la definición de un grupo:

[...] los individuos interesados se definen a ellos mismos y son definidos por otros como un grupo. Podemos conceptualizar un grupo como una colección de individuos quienes se perciben asímismos como miembros de la misma categoría social, comparten las mismas emociones que los envuelven en esta común definición de sí mismos, y logran un cierto grado de consenso social acerca de la evaluación de su grupo y de sus miembros. (Tajfel y Turner, 1979, p. 40).

Los autores creen que la identidad social está basada en el deseo individual para la mejor autoestima mediante los procesos de comparación social por medio de diferencias individuales de sí mismos y la forma positiva o negativa de la evaluación al interior y al exterior de los grupos. Esta diferenciación es explicada mediante la comparación con los otros y significa que dicha distinción está fundamentada por la competición intergrupal.

Marilyn B. Brewer y Wendi Gardner (1996) combinan la distinción entre la identidad personal y social propuesta por Cooley y Mead, con la distinción de Marcus y Goodman (1991) entre independiente e interdependencia. De acuerdo con estos autores, la identidad personal diferencia el self con los otros. La identidad relacional refleja la asimilación individual de los otros en particular y la identidad colectiva refleja la asimilación significativa de los grupos sociales. Brewer y Gardner afirman que estas diferencias coexisten en el mismo individuo, pero se activan en diferentes contextos y en tiempos diferentes. 


\subsubsection{Desde la Antropología}

Inicialmente la identidad étnica era entendida como una concepción del mundo particular exenta de cambios o modificaciones. Posteriormente dicha postura fue deslegitimada, llegando a negar toda posibilidad de entenderse como un conjunto de hechos objetivables y definiéndola entonces como el resultado de la interacción de un grupo humano con otros cuya interpretación debe darse a la luz de las necesidades y conflictos generados a partir de sus relaciones. La identidad debe entenderse en otras palabras, como el resultado de complejas dinámicas históricas, sociales, políticas, económicas, etc., que no puede ser entendida al margen de la manera en cómo grupos humanos con intereses y objetivos específicos la emplean como fuente de legitimidad.

Cuando los Estados Nación definen aquello que los identifica, vigilan el mantenimiento de aquella misma identidad que se habían ocupado de inventar. Para mantener esa unidad identitaria, niegan o vulneran el derecho de las minorías que tienen una identidad propia, por una construida y artificial, pero que nunca lo será por fuerza más de aquella otra que pretende abarcarlas. De manera pues que la identidad -en concreto aquella cuyo núcleo básico es la cultura- es, hoy, el instrumento discursivo por medio del cual las personas y grupos enteros son colocados en desventaja en la vida social, como consecuencia de su asignada incompetencia crónica e insalvable para incorporarse a la vida civil plenamente normalizada.

Lo discutido hasta aquí permite tener un panorama general de los fundamentos disciplinares de la identidad. Es pertinente luego de ello, preguntarse por la naturaleza de aquello que se llama IO, y la manera de abordarla teóricamente. ¿Es la IO una metáfora o una realidad? ¿La IO deriva de un proceso de construcción social o hace referencia a un núcleo esencial? Estas dos interrogantes permiten rastrear los fundamentos ontológicos y epistemológicos de la 10 . 


\subsubsection{Fundamentos ontológicos}

¿Existe realmente la Identidad Organizacional? Tanto la metáfora como la realidad del fenómeno se han utilizado legítimamente para abordar el tema de la IO, sin embargo, ambas se basan en perspectivas disímiles que vale pena profundizar en ellas.

Conceptualizar la IO como metáfora sugiere utilizar el lenguaje para subrayar una semejanza entre las características individuales y las características de la colectividad (Cornelissen, 2002a). Al igual que las personas pueden verse a la luz de su identidad, el colectivo puede verse a la luz de ella. Se usa la identidad como metáfora cuando la dinámica de la organización responde a la siguiente pregunta: ¿Qué es aquello que ve el colectivo como si tuvieran una identidad? Esto permite ver una perspectiva distinta de la común mirada que se tiene de la organización catalogada como una máquina, un sistema abierto, un organismo, etc. (Pratt, 2000). La IO es una metáfora que es utilizada en la teorización sobre cómo las organizaciones son similares y diferentes entre individuos y la colectividad (Gioia, Schultz, y Corley, 2000), y para entender las dimensiones simbólicas de la vida organizacional (Cornelissen, 2002b).

En contraste con esta posición, ver la 10 más allá de una metáfora, permite advertirla como un fenómeno experimentado por los miembros de la organización, percibida por aquellos que están por fuera de ella, convirtiéndose en fundamental para los procesos sociales dentro de los contextos organizacionales. Esta visión colectiva de las identidades, se diferencia de las identidades a nivel individual (aunque conceptualmente relacionadas) por ser capaz de ser modelada como antecedentes y consecuencias de otros procesos sociales y de los resultados. Investigaciones vinculan esta aproximación de la IO con la identificación de la organización (Dutton y Dukerich, 1991; Dutton, Dukerich y Harquail, 1994; Pratt, 1998, 2000), e indaga sobre diferentes aspectos estratégicos del fenómeno (Fiol, 2002; Gioia y Chittipeddi, 1991; Gioia y Thomas, 1996; Glynn, 2000; Glynn y Abzug, 1998; Golden-Biddle y Rao, 1997). 


\subsubsection{Fundamentos epistemológicos}

¿Cómo podemos conocer la Identidad Organizacional? El cuestionamiento se centra ahora en el enfoque epistemológico. ¿Existe la IO como una construcción social de la realidad o como un núcleo esencial, en forma diferente a como los individuos la conciben por medio de los símbolos y el lenguaje? ¿Si la identidad es real y no metafórica, entonces cómo puede es estudiada? Estas preguntas no sólo remiten a preguntarse por la ontología y la teoría que apropia el término identidad, sino que influencia cómo la identidad organizacional es usada como una variable.

Las creencias más fuertes sobre estas interrogantes confluyen en afirmar que la identidad de las organizaciones es un fenómeno contingente, cuyo núcleo o esencia es el resultado de los procesos de construcción social. Hatch (2005) afirma que estos procesos se encuentran en el conocimiento distribuido y/o en la conciencia colectiva de los socios de la organización (stakeholders). Conceptualizar a la organización como una construcción social permanente que se lleva a cabo entre los miembros de la organización, permite que se pueda influir y acceder a los individuos, grupos, equipos de alta dirección y de otros colectivos. Entender la 10 como construcciones narrativas ha logrado que muchos investigadores sustentar -desde diferentes perspectivas- una amplia variedad de características para proveer contextos en donde dichos significados toman sentido (Czarnisawska, 1997).

En contraste, el otro punto de vista sobre este tema trata la 10 como una característica o propiedad que de alguna manera se encuentra dentro de ella misma. Ejemplo de este tipo, es la conceptualización de la organización como un actor social, con un estatus social y jurídico (Scott, 2003; Whetten y Mackey, 2002) cuya identidad se refleja en los tipos de obligaciones contractuales realizados por la organización. Aunque hay alguna variación dentro de este conjunto de concepciones en cuanto a los orígenes de la IO, estas conceptualizaciones abordan a la identidad de la organización como un conjunto de características 
organizativas que existen, que los miembros pueden creer o no, y que se puede experimentar, evaluar, valorar y gestionar.

\subsection{CONVERGENCIAS Y DIVERGENCIAS EN TORNO AL CONCEPTO}

Muchas de las investigaciones han abordado el tema de la identidad organizacional buscando definirla; otras, se han acercado a los fenómenos organizacionales a partir de este concepto para comprender los problemas que se inscriben en las organizaciones. Es por ello que muchas de las investigaciones, dentro de este proceso comprensivo organizacional, aportan elementos y enfoques nuevos para esclarecer el concepto. En ese apartado se discutirá las controversias y los nuevos horizontes que se avecinan alrededor de lo que se denomina: identidad de las organizaciones.

\subsubsection{A partir de definición seminal de Albert y Whetten}

La definición primigenia de Albert y Whetten (1985) sobre aquello que es central, distintivo y constante en la organización, es una propuesta que abre la discusión, más que una definición cerrada y definitiva. Incluso el mismo Whetten en un artículo más reciente (2006) vuelve a formular el concepto de IO con el fin de que éste se pueda distinguir analíticamente de los conceptos relacionados con la cultura organizacional y la imagen. En este artículo, Whetten (2006) busca fortalecer el texto seminal escrito con Albert (1985) en donde enfatiza la definición tripartita como un constructo. Así como este ejemplo muchos otros han interrogado y generado diversas aproximaciones frente aquello que es central, distintivo y duradero en la organización.

\subsubsection{El carácter central de la identidad organizacional}

Es sumamente difícil definir qué es lo central dentro de la organización. Junto con ello, éste término remite a una identidad estructural. ¿Pueden las organizaciones tener más de un centro? Siguiendo a Corley, Harquail, Pratt, Glynn, Fiol, y Hatch (2006) lo central se puede conceptualizar como: 
- Profundidad. Hablar de aquello que es central en las organizaciones requiere implícitamente definir claramente la distinción entre aquello que es superficial y aquello que es fundamental. El concepto de profundidad expresa que las características de la identidad no son tan obvias, y que algunas características pueden ser difíciles de articular ya que están profundamente enraizadas en las creencias de los individuos acerca de la organización, las cuáles pueden ser consideradas como características esenciales (Whetten y Mackey, 2002). Lo esencial puede ser entendido, desde la perspectiva del actor social, como una estructura institucional. Lo esencial se convertiría en el alma de la organización.

- Centralidad compartida. Lo central también puede ser visto como aquello que es compartido por los miembros de la organización.

- Centralidad estructural. Lo central se puede considerar también como aquel nudo que permite que otras características puedan ser articuladas como propias de la organización. La centralidad estructural ha sido descrita por aquellos atributos que están en el centro de los miembros de la organización (Fiol y Huff, 1992; Reger, Gustafson, DeMarie, y Mullane, 1994). Estas características muestran una aproximación ontológica objetivista y una epistemología positivista, en donde se considera a la identidad como poseedora de atributos objetivos capaces de ser identificados y medidos.

¿Cuenta la organización con un solo centro o tiene múltiples centro? ¿Se puede hablar de centros periféricos? ¿Puede una organización tener más de un núcleo? Albert y Whetten (1985), han afirmado que las organizaciones pueden tener al menos dos identidades organizativas. Los autores introducen el concepto dual de identidad. Así, muchas de las organizaciones son híbridos, organizaciones cuya identidad es dual, es decir, se consideran a sí mismas alternativamente, y más aun simultáneamente, como si fuesen dos organizaciones diferentes. Una organización que ya no sólo complejiza su identidad misma sino que problematiza 
la identificación de su estructura y el mismo diseño organizacional. Otros investigadores han adoptado un enfoque similar argumentando que las organizaciones pueden tener múltiples identidades (Fiol, 1991, 2001, Glynn, 2000; Glynn, Barr, y Dacin, 2000; Golden-Biddle y Rao, 1997; Pratt y Foreman, 2000). Sin embargo, el debate continúa en la multiplicidad de identidades de la organización y cómo estas pueden ser conceptualizadas o estructuradas.

La perspectiva de las investigaciones en torno a múltiples identidades depende en gran medida de sus presupuestos epistemológicos. Los esencialistas identifican la identidad de la organización con el alma de una organización o con la esencia fundamental (la parte más profunda de la organización) por lo que encontrar la idea de múltiples identidades es absurdo para ellos. Para estos investigadores, las identidades múltiples son simplemente facetas de una sola identidad. La idea de la multiplicidad es también un problema para los investigadores que se acercan a la identidad de la organización como conocimientos compartidos. Si sus características no son compartidas a través de una organización, ¿puede realmente ser parte de la identidad de una organización? Si las identidades organizacionales son creencias que se tienen en común (como una mente grupal) o creencias acerca de quiénes somos, que son por consenso colectivas, entonces puede ser difícil de conciliar estos planteamientos con una perspectiva de identidad múltiple. Sin embargo, aunque las organizaciones pueden ser capaces de presentar diferentes caras, es poco probable que tan radical configuración de identidades sean fáciles de mantener.

Si las organizaciones tienen más de una identidad, ¿cómo estas identidades se relacionan con los demás? En la actualidad, existen dos tipos de identidades múltiples: identidades híbridas e identidades múltiples como tales. Los dos puntos de vista difieren en sus supuestos sobre el número de posibles identidades que una organización puede mantener o expresar, sobre la naturaleza de su relación.

Identidades híbridas. Tal vez la concepción más común de las múltiples identidades de la organización es la noción de identidades híbridas (Albert y 
Whetten, 1985) o dobles. Identidades híbridas son una combinación de identidades totalmente articuladas que parece que no van de la mano. Albert y Whetten realizan una distinción entre identidades híbridas ideográficas y holográficas. Identidades ideográficas están en manos de grupos específicos en la organización (por ejemplo, departamentos), pero no son comunes a todos los miembros de la organización. Estas identidades se distribuyen o comparten en determinados estamentos de la organización. Ejemplos ilustrativos se pueden ver en las investigaciones de Pratt y Rafaeli (1997), donde estudian la IO de una unidad de rehabilitación, o la de Glynn (2000) que estudia la lucha entre la identidad artística y económica de la orquesta sinfónica. Las identidades holográficas híbridas (Albert y Whetten, 1985), por el contrario, se producen cuando cada una de las múltiples identidades de la organización está en manos de todos los miembros de la organización. Los estudios de Golden-Biddle y Rao (1997) sobre el estudio de una organización no lucrativa de la junta directiva es un ejemplo de ello.

Dos supuestos generales parecen ser comunes al enfoque híbrido. En primer lugar, existe la suposición de que todas las identidades múltiples son identidades duales. Por lo tanto, las organizaciones son limitadas en el número de las identidades múltiples que puede tener o expresar. No pueden tener literalmente todas las cosas en todas las personas. En segundo lugar, este enfoque asume que las identidades múltiples a menudo son inherentemente conflictivas (GoldenBiddle y Rao, 1997; Pratt y Rafaeli, 1997), ya que son elementos que no suelen ir de la mano (Albert y Whetten, 1985).

Identidades múltiples. Pratt y Foreman (2000) examinaron dos dimensiones de las identidades múltiples: la pluralidad y el grado de sinergia. Sugirieron que las organizaciones con múltiples identidades deben considerar cómo mantenerlas bajo un cierto grado de tolerancia, armonía o equilibrio entre ellas. Un enfoque de múltiples identidades propone no sólo que las organizaciones puedan tener más de dos identidades (Fiol, 1991, 2001; Glynn, Barr y Dancing, 2000), sino también que estas diversas identidades no tiene por qué entrar en conflicto con las otras. 
Además, este enfoque sostiene que los conflictos de identidad, si es que existen, puede estar latentes en lugar de manifestarse.

\subsubsection{El carácter distintivo de la identidad organizacional}

Lo distintivo se basa en la comparación, en los juicios de similitud y diferencia entre entidades comparables. Las personas comparan sus organizaciones con las organizaciones de referencia y consideran el grado en que sus atributos o núcleo central lo diferencian de otros similares. "No todos los atributos en una definición de la identidad deben ser distintivos o únicos" (Albert y Whetten, 1985, p. 267), algunos de los atributos en una definición de la identidad en realidad pueden ser similarrd a los atributos de otras organizaciones. En definitiva, se trata de un conjunto distintivo de características que establece una organización a partir de otros. Una tendencia en la literatura sobre la identidad de la organización es poder encontrar el criterio que permita identificar cuando un atributo sobre la identidad es distinto del otro (Elsbach y Kramer, 1996).

\subsubsection{El carácter continuo de la identidad organizacional}

El tercer componente de Albert y Whetten (1985) en su definición consiste en el carácter continuo de la IO. Debido a la forma de entender la identidad de una organización, lo central en su autodefinición (independientemente de cómo se define el centro), se basa en que los cambios de identidad de la organización sólo son interrupciones importantes en la vida organizacional. Por lo tanto, Albert y Whetten examinaron los cambios en la identidad de la organización como algo que ocurre muy lentamente, durante largos períodos de tiempo. A pesar de esta posición (o quizá debido a ella), la relación entre el cambio organizacional y la identidad de la organización ha sido uno de los aspectos más debatidos en la definición original. El cambio es un tema importante en el estudio de las organizaciones, y esto es igualmente cierto en el estudio de la identidad de la organización. 
Luego de la definición de Albert y Whetten (1985) sobre la identidad organizacional, algunos especialistas han llegado tan lejos como para afirmar "Si cambia, no es la identidad" (Whetten y Mackey, 2002). Desde este punto de vista, el investigador se limita a estudiar cómo otros procesos organizativos se relacionan con, y son influenciados por la estabilidad de la identidad de la organización. Algunos ejemplos de los conocimientos obtenidos a través de esta ruta de acceso incluyen la influencia de la identidad de la organización en la toma de decisiones estratégicas y las conductas de los miembros de la junta directiva (Golden-Biddle y Rao, 1997), el potencial de los conflictos que surjan en las instituciones culturales con identidades híbridas (Glynn, 2000), y la influencia de una fuerte identidad de la organización sobre las dimensiones éticas y morales en la toma de decisiones de la organización (Barney, 1998).

Es así que el término $\mathrm{IO}$ ha sido construida como una metáfora fenomenológica, o como una construcción social que objetivamente existe en esencia, y como una propiedad de las organizaciones como actores sociales (Whetten y Mackey, 2002), o un conjunto de entendimientos compartidos (Humphreys y Brown, 2002a; Humphreys y Brown, 2002b).

Investigaciones y teorías apoyan la idea alternativa de que la identidad de la organización puede cambiar y, en algunos casos, podría incluso tener que cambiar (Gioia y Thomas, 1996; Reger, Gustafson, DeMarie, y Mullane, 1994). Hatch y Schultz $(2002,2004)$ propusieron un modelo de $1 O$ destacando la dinámica de los procesos especificados por el cual la 10 surge de la interminable conversación entre los miembros de una cultura organizacional y los stakeholders. Aunque no todas las organizaciones deben cambiar su identidad para sobrevivir o para poner en práctica otros cambios en la organización (Fiol, 2002), otros estudios demuestran el potencial ( $\mathrm{y}$ a veces necesidad) para que el cambio de identidad se produzca. Corley (2005) sugiere que los investigadores investiguen la dinámica de la dirección organizativa de identidad en base a cinco dimensiones: (a) la naturaleza del cambio de identidad (¿Qué está cambiando?), (b) la frecuencia del cambio de identidad (¿Con qué frecuencia se producen cambios?), (c) la velocidad 
del cambio de identidad (¿Cuánto tiempo los cambios que se?), (d) el origen del cambio (¿Cómo surgió la cambio?), y (e) el modo y la unidad de cambio (¿cuáles son los motores del cambio?).

\subsubsection{Una aproximación de lo que sí es Identidad Organizacional}

La identidad organizacional involucra un significado de autoreferenciación (Albert y Whetten, 1985). Las preguntas sobre ¿quién soy? y ¿quiénes somos? capturan la esencia de la identidad en los diferentes niveles de análisis. A nivel organizacional, la identidad captura aquello que dá sentido y significado a sus miembros, es una auto-referenciación en donde el yo es el colectivo. Esta autoreferenciación puede ser tácita o explícita, propia o cedida, o estar mas o menos presente en los individuos (Corley y Gioia, 2003).

Junto con esto, la 10 sirve de contexto y es inherentemente comparativa. Dentro de un determinado contexto social, la organización se puede parecer a unas y diferenciarse de otras. Dentro de un mismo sector industrial las organizaciones tienden a ser evaluadas entre si, a la par que suelen compararse a partir básicamente de sus diferencias y similitudes, aspectos fundamentales para establecer la propia identidad.

Una mirada más estructural o institucional, se basa en estos aspectos contextuales y comparativos. La identidad es típicamente contextualizada en términos de la posición del actor o del rol que son establecidas por un sector industrial específico, el marco social y laboral. En ese sentido, Zuckerman, Kim, Ukanwa, y von Rittmann (2003) definen identidad en términos de la capacidad o habilidad para indicar la pertenencia a una (identidad simple o una identidad enfocada) o más (identidad compleja o una identidad robusta) formas particulares de género.

La 10 envuelve un conjunto de significados compartidos por la colectividad. Esta idea común, problematiza la identidad (Pratt, 2003). Uno de los problemas a 
resolver es la noción de colectividad y quién es incluido en dicho término, ¿son sólo los miembros de la organización o una gama más amplia de stakeholders? (Scott y Lane, 2000a). Otro tema a resolver es ¿qué se entiende o se cree con el término compartir? No está claro si se trata de un agregado (un conjunto de creencias de los miembros acerca de la identidad organizacional) o algun tipo de propiedad gestalt derivada de la dinámica de grupo (Corley, Harquail, Pratt, Glynn, Fiol, y Hatch, 2006).

Por otro lado, hay cierto acuerdo en considerar la 10 como un nivel de construcción colectiva. Sin embargo, las disonancias ocurren acerca de la interacción entre los niveles de analisis: individual y colectivo. Por ejemplo, Whetten y Mackey (2002) argumentan que la 10 es una propiedad de la organización como una entidad o un actor social en donde los compromisos, obligaciones y acciones son definidos por los niveles de la entidad organizacional. La mirada de la 10 es un fenómeno que existe en el nivel del actor social, donde explícitamente se rechaza la idea de unas creencias colectivas acerca de la organización. En una dirección distinta, otros investigadores argumentan que la IO es una comprensión individual acerca de lo que la organización es (Dutton, Dukerich y Harquail, 1994; Harquail y King, 2003; Haslam y Ellemers, 2005). Estas conceptualizaciones de la 10 son el producto de una relación dialéctica entre la colectividad en donde se comparten creencias y la estructura social individual de creencias (Haslam y Ellermers, 2005). De esta manera, se podría decir que existe dos representaciones de la identidad organizacional: la identidad organizacional colectiva y la identidad organizacional construida (Haslam y Ellermers, 2005).

\subsubsection{Una aproximación de lo que no es Identidad Organizacional}

El tema de la 10 , está lejos de ser definida y lograr que tenga una aceptación universal. Muchos autores confunden la noción de 10 con identidad corporativa, imagen organizacional y la reputación. La identidad organizacional es autoreferencial, permite acercarnos a entender ¿quiénes somos? Por el contrario la identidad corporativa y la imagen corporativa envuelve la noción de aspectos 
relacionados con la identidad para audiencias externas (Gioia, Schultz y Corley, 2000), y el tema de la reputación es la visión de cómo la audiencia ve a la organización (Fombrun, 1996; Fombrun y Shanley, 1990). Sin embargo, la confusión en torno al tema de la 10 ocurre también en un nivel más micro. Por ejemplo, el concepto de lo organizativo se refiere a un nivel de abstracción, no a un nivel de análisis (Pratt, 2003). Corley, Harquail, Pratt, Glynn, Fiol, y Hatch (2006) proponen el término 10 para describir algo acerca de una organización como un colectivo, y el término lo organizativo basado en identidad, para describir la parte del auto-concepto que define la conexión con la organización. Mayor confusión causa cuando se usa el término para describir algo que la organización hace (por ejemplo cuando consideran la IO como un objetivo). Es así que varios investigadores proponen el término identificación organizacional como aquel que define el proceso por el cual los individuos llegan a relacionar su propia definición o propio concepto con sus percepciones de la organización (Ashforth y Mael, 1989; Dutton, Dukerich, y Harquail, 1994; Ravasi y van Rekom, 2003).

Junto con ello hay dos conceptos asociados al tema de identidad organizacional que causan confusión. El tema de la Cultura Organizacional se encuentra estrechamente relacionado con el tema de la 10 , a pesar del esfuerzo de los investigadores por tratar de esclarecer las diferencias. En ese sentido, Hatch y Schultz (2002) muestran un modelo para describir cómo la identidad es la relación entre la cultura organizacional y la imagen organizacional, en donde la identidad expresa las creencias culturales a la vez que se convierte en un espejo que los otros tienen de la organización. Al mismo tiempo, la 10 puede envolver valores importantes de la organización, pero la identidad de una organización no es lo mismo que los valores organizacionales. Cuando la identidad organizacional contienen ciertos valores organizacionales, estos valores hacen parte de aquello que es central, distintivo y continuo dentro de las organizaciones.

Otro concepto con el cual se confunde la 10 es con el tema de Clima Organizacional. Éste es definido como la "percepción compartida de cómo son las cosas por aquí" (Reichers y Schneider, 1990, p. 22), en donde se incluye el 
significado que se le dá a un evento. El clima se enfoca en el entorno de trabajo (James y Sells, 1981), como también en la auto-referenciación de la organización en su conjunto. Por otro lado, el clima organizacional se refiere a la percepción compartida acerca de específicas dimensiones de la organización. En ese sentido, no todas las dimensiones de la organización son centrales, distintivas y contínuas. Es decir, que dichas dimensiones de clima no contribuyen a dar un comprensión definitiva de los atributos de identidad. Lo anterior se resume en la siguiente tabla.

\section{Tabla 1: Definiciones de la Identidad Organizacional desde distintos niveles de análisis}

\begin{tabular}{|c|c|c|}
\hline $\begin{array}{c}\text { Nivel de } \\
\text { análisis/Aproximación a la } \\
\text { definición }\end{array}$ & ¿Qué es? & ¿Qué no es? \\
\hline Individual & $\begin{array}{l}\text { La auto-referenciación } \\
\text { comparativa que capturar } \\
\text { aquello que da sentido y } \\
\text { significado a sus miembros. }\end{array}$ & $\begin{array}{l}\text { No es un nivel de análisis que } \\
\text { permita describir y explicar el } \\
\text { comportamiento de los individuos }\end{array}$ \\
\hline Colectivo & \begin{tabular}{lr} 
Conjunto de & \multicolumn{2}{c}{ significados } \\
compartidos por la \\
colectividad, que sirve a su \\
vez como referente \\
comparativo.
\end{tabular} & $\begin{array}{l}\text { No es imagen corporativa, } \\
\text { organizacional, } \\
\text { organizacional, } \\
\text { organizacional. }\end{array}$ \\
\hline
\end{tabular}

Fuente: Elaboración propia.

\subsection{PARADIGMAS, PERSPECTIVAS Y DISCUSIONES}

La discusión en torno a la realidad de la IO, y de la manera de comprenderla, ha permitido que su estudio sea abordado a partir de diversos temas de análisis. A partir de la revisión documental y hemerográfica se identificaron tres paradigmas, cinco perspectivas, y distintas discusiones en relación al concepto mismo de $\mathrm{IO}$, como en relación a otros términos. A continuación se presentan estos hallazgos.

\subsubsection{Paradigmas subyacentes al estudio de la identidad organizacional}

Siguiendo la tipificación de Cornelissen (2006) en donde se concibe la IO como un concepto (Harquail y King, 2010), se pueden distinguir tres paradigmas 0 concepciones acerca de lo que es la IO: (1) El paradigma esencialista de los 
actores sociales, (2) El paradigma de la construcción social, y (3) El paradigma lingüístico-discursivo. Cada uno de estos tres paradigmas tiene su propia comprensión de la IO: un conjunto de características que identifican dichas concepciones, un dispositivo de elaboración cognitiva, y un argumento narrado continuamente.

El paradigma esencialista del actor social concibe la 10 como un objetivo de la entidad organizacional y comprende atribuciones reificadas de aquello que es central, distintivo y perdurable. Se entiende a la organización como un actor social unificado. Los atributos que definen a la organización se describen como características de ella, reflejando su realidad y describiendo las características fijas de la organización (Chreim, 2005). La IO, desde este punto de vista esencialista, entiende a la organización como una entidad en sí misma, como autoreflexiva: "La $\mathrm{IO}$ es un concepto que las organizaciones utilizan para caracterizar aspectos de sí mismas" (Albert y Whetten, 1985, p. 264). Esta perspectiva pone de relieve cómo los miembros de la organización podrían experimentar, evaluar, apreciar y posiblemente administrar estas carácterísticas concretas (Harquail y King, 2010).

Dentro del paradigma de la construcción social, la IO es conceptualizada como un colectivo generalizado y una interpretación sostenida de quienes somos en la organización. Esta interpretación se utiliza como marco para organizar y dirigir la experiencia colectiva, por lo que está sujeta a negociación (Scott y Lane, 2000a) y a las influencias políticas (Rodrigues y Child, 2008). Los argumentos giran en torno al comportamiento colectivo de la organización y sobre qué características son más definitorias que otras, reflejando la perspectiva de cada grupo en la organización (Coupland y Brown, 2004). De esta manera, esta perspectiva es más negociada que la esencialista, y más anclada en la realidad. La IO es una forma de enmarcar e interpretar colectivamente la información (Fiol, 2002). Los miembros de la organización utilizan la IO para comprender sus acciones, establecer expectativas en cuanto su comportamiento e instaurar un punto de referencia para guiar sus acciones en nombre de la organización. 
El paradigma lingüístico-discursivo se centra en el lenguaje y en el papel que este tiene en la construcción de la realidad. La investigación lingüística de este paradigma pone en primer plano el papel de la metáfora (Cornelissen, 2006; Heracleous y Jacobs, 2008), la categorización y el nombre en la construcción de la IO. La construcción de la identidad es un proceso continuo de narración en la que tanto el narrador como el público formulan, editan, aplauden y niegan elementos de la producción narrativa. La investigación discursiva centra su atención en las prácticas de desarrollo-realización, a la vez que subraya el papel del poder y la política, desafiando la hegemonía de un discurso en particular (Humphreys y Brown, 2002b; Coupland y Brown, 2004; Chreim, 2005; Brown y Humphreys, 2006).

Por su parte, Alvesson, Ashcraft y Thomas (2008) plantean que los estudios sobre la IO se han concentrado en diversos campos filosóficos, y proponen otra clasificación: (1) el funcionalista, (2) el intrepretativo y (3) el crítico, este último inspirado por los postestructuralistas. Tomando a Habermas (1972), los autores plantean que existen tres enfoques cognitivos para el conocimiento y que subyacen a la investigación humana: el técnico, el práctico-hermeneútico y el emancipatorio.

El interés técnico se relaciona con la investigación funcionalista, ya que tiene como objetivo desarrollos del conocimiento de relaciones causa-efecto a través del control sobre los recursos naturales y sociales. Este enfoque parece dominar los estudios de la identidad y de la identificación que emanan de la corriente de investigación acerca de la gestión empresarial. Los estudios que tienen un interés cognitivo técnico están interesados en la forma como la identidad y la identificación pueden mejorar potencialmente la eficacia de la organización.

El enfoque práctico-hermenéutico busca una mayor comprensión de experiencias culturales y humanas, o cómo comunicar para generar o transformar el significado. En contraste con el interés técnico, asociado a lo funcional, hay poca preocupación por la utilidad instrumental de estos conocimientos en el desempeño 
organizacional. Lo práctico-hermeneútico se centra en cómo las personas elaboran su identidad a través de la iteracción, o cómo las narrativas del yo tejen significados en concierto con los demás y por fuera de los diversos recursos contextuales que están a su alcance. Desde esta perspectiva interpretativa, la identidad tiene una clave vital para comprenden lo complejo del desarrollo y la dinámica relación entre el yo, el trabajo y la organización.

Por último, la visión emancipatoria tiene una clara orientación crítica. La atención se centra aquí en las relaciones de poder y en las diversas maneras en que los individuos se pueden liberar de las formas de represión que se implementan en las organizaciones. Los investigadores han utilizado el tema identitario para entender las relaciones contemporáneas de control y de resistencia, en especial aquellas acciones que se han orientado a indagar por esas visiones del mundo que sirven para subordinar los cuerpos humanos a los regímenes de gestión.

Estos son los paradigmas que subyacen al estudio de la IO. Ambas clasificaciones tienen puntos en común, y permiten comprender cuál es la naturaleza de la relación entre el conocedor y lo que puede ser conocido, que en este caso será la IO. A continuación, se presentan diversas perspectivas teóricas que se han desarrollado en relación con la IO.

\subsubsection{Perspectivas de análisis en relación con la identidad organizacional}

\subsubsection{Narración y discurso}

A partir de una teoría literaria y una filosofía postestructuralista se argumenta que la identidad, individual y colectiva, es construida a través de la narrativa o el discruso. La caracaterísticas de la narrativa de las identidades tiene sus raíces en el grado en el cual el lenguaje es usado para construir significado, tanto para sí mismo como para los otros. Todo el tiempo se usa el lenguaje para construir identidades y forja discursos a su vez que éstos pueden tomar vida propia al alimentarse de identidades construidas. Esto aporta una clave de la teoría crítica, que mas que definir su propia identidad, los miembros de la organización son 
definidos por las identidades del management o segmentos de la organización construidos para ellos.

Dubar (2002a) plantea que la identidad es algo cambiante que depende de las denominaciones o nombres que se utilizan para designar a los sujetos o colectivos empíricos; la identidad no puede afirmarse como una esencia o sustancia fija. La identidad se formula a partir de las operaciones linguísticas puestas en juego: la diferenciación (como singular de alguien) y la generalización (como el nexo común). La identidad depende entonces, de los recursos simbólicos utilizados para establecer identificaciones con grupos o comunidades del mundo social. De aquí, entonces que sea necesario considerar otras dos formas de identidad -más allá de la comunitaria y societaria- en que los individuos establecen identificaciones.

La forma de identidad narrativa se refiere a la manera en que el individuo es capaz de organizar un relato describiendo su trayectoria vital, los incidentes que la modificaron, pero también considerar futuro proyectos y un plan de vida. Ricoeur (1996) realizó un examen filosófico de la identidad narrativa y las paradojas que suscita, como el mantener una identidad a pesar de los cambios físicos. Afirma que la identidad se juega entre la comunidad y el cambio en las personas. La continuidad se encuentra en la mismidad del cuerpo y el carácter que pueden permanecer semejantes a lo largo del tiempo. En tanto, el cambio corresponde al desarrollo de la ipseidad (sí mismo) y el mantenimiento de la palabra que se reacomodan en la trama narrativa de una vida. La identidad se expresa como una narrativa que le da coherencia a los diversos episodiso de una vida y en la que se muestran los proyectos asumidos.

Se da sentido a las identidades personales en la misma forma en que se narra la identidad de los personasje de un relato. En estos relatos se comprende a los personajes por medio de la trama, lo que les sucede, los propósitos y proyectos que adoptan y aquello que hacen. De manera similiar, el individuo genera un sentido de identidad personal al recitar relatos de lo que ha sido su vida. En 
ambos casos, la identidad no es una estructura fija o una sustancia, las identidades son cambiantes y móviles. La identidad narrativa toma lugar en el movimiento del relato, en la dialéctica entre el orden y el desorden, en el encadenamiento de los episodios de un relato y otro (Ricoeur, 1996).

La identidad narrativa opera como mediación entre la identidad social y la singularidad del individuo; al contar la historia se está articulando estos dos polos aparentemente opuestos. Ricoeur (1996) afirma que los humanos se apropian del tiempo mediante la narración, la cual trata de cursos de acción organizados en determinadas tramas narrativas. Ya que cada cultura tiene un repertorio de relatos distintos, la identidad narrativa comprende un aprendisaje de distintas historias y la apropiación de aquellos elementos adecuados para contar la historia.

Bruner (1991) examina estas ideas para explicar la forma en que las narrativas personales engarzan con aquellas proporcionadas por cada cultura. Afirma que los individuos, al construir significados y narrativas, utilizan sistemas simbólicos que les preceden, los cuales se encuentran arraigados en el lenguaje y en la cultura. Estos sistemas constituyen un tipo de herramientas culturales que hacen del usuario un partícipe de la comunidad. Bruner afirma que el sentido de la agencia del yo deriva de la sensación de poder iniciar y llevar a cabo actividades por su cuenta. Lo que caracteriza a la persona humana es la construcción de un sistema conceptual que organiza un registro de encuentros agenciales con el mundo, un registro que está relacionado con el pasado pero que también está extrapolado hacia el futuro. La habilidad para construir narraciones y entenderlas es crucial en la construcción de las vidas y de un lugar para enfrentar el mundo del individuo.

Ya en el ámbito organizacional, Czarniawska (1997a) analiza la responsabilidad del sector público para interrogar la eficiencia de las prácticas de negocios (cultura de la empresa). En base a un estudio longitudinal en organizaciones públicas en Suiza, la autora muestra cómo la identidad se despliega (desarrolla) mediante procesos narrativos, emergiendo a partir de la interacción entre los actores. Siguiendo a Czarniawska, la identidad es un continuo proceso de narración donde 
tanto el narrador como la audiencia, formulan, editan, apluden y rechazan varios elementos de las producciones narrativas. Presenta un caso de responsabilidad organizacional de amenzas a la identidad de forma externa (es un trabajo paralelo al de Dutton y Dukerrich (1991) y Elsbach y Kramer (1996)). Expone una versión dinámica de la identidad en las definiciones y re-definiciones sobre la franqueza, diferenciación, reflexitividad e individualidad. Su tabajo se le podría considerar como un complemento al trabajo de Hatch y Scultz (2002).

Alvesson y Wilmott (2002) muestran las maneras o formas que usan los managers la cultura para transformar la identidad organizacional a travez de una identidad regulada, esto es, actos que definen a la persona, su moral y valores, conocimiento y técnicas; caracaterización del grupo, reglas de juego y la construcción social dentro del contexto de la organización. Para estos autores, los intentos por parte de los managers por regular la identidad está siendo realizada por el uso de prácticas discursivas. El énfasis está en el uso de este sofisticado discurso para influir los sentimientos de los trabajadores a travez de una identidad con el trabajo, usando su influencia organizacional de narrativas para formar, reparar, mantener, fortalecer o revisar sus sentimos del yo. El punto central de los autores es cómo la identidad sirve como regulación y opresión en las organizaciones. Consideran también, cómo los procesos de regulación sirven para liberar a individuos que trabajan en una nueva área, flexible y decentralizada. Este tipo de organizaciones promueven la micro emancipación de los nuevos empleados por buscar redefinir su trabajo, técnicas y valores organizacionales, con sus propios propósitos.

La IO es entendida como un discurso (Whetten, 2006), o la construcción por medio de narrativas de aquello que es central, duradero y distintivo en una organización (Albert y Whetten, 1985). Es una conversación que se construye socialmente y puede incluir individuos internos y externos (Brown, 2006; Hatch y Schultz 2002; Scott y Lane, 2000a). Al respecto, Sillince y Brown (2009) afirman que la IO es un constructo social retórico en donde las organizaciones representan lo que los directivos quieren o dicen que es. 
McAdams (1996) afirma que las identidades narrativas que construyen las personas, representan los esfuerzos por llegar a un acuerdo con el "pasado reconstruido, con el presente percibido y con el futuro anticipado" (p. 307), en el sentido de que proporcionan un sentido de unidad, y mejoran las contradicciones y multiplicidades de la modernidad. Sin embargo, para Brown y Humphreys (2006) tales unidades son esencialmennte contigentes y frágiles, espacios temporales de clasificación. Para Beech (2008) el proceso de construcción identitario es el resultado de una combinación de escribirse uno mismo, estar escrito por otros y tratar de escribirse uno mismo en la historia de los otros. Para Clarke, Brown y Hope-Hailey (2009), en cambio, las identidades están a disposición de los individuos en forma subjetiva mediante autonarrativas que operan a través de monólogos internos y por medio de la interacción con los otros. También es un proceso de absorción y personalización de una narrativa general (Coupland y Brown, 2004; Slay y Smith, 2011) limitada por la estructura de la duración de dicha narrativa (Gabriel, 2003).

Ybema (2010) se acerca a la identidad a partir del discurso buscando trasladar la teorización de la relación entre las categorías temporales, la identidad colectiva y el cambio organizacional. Para este autor, el eje central de análisis y de exploración reside en la manera en que las personas construyen su identidad colectiva en el discurso organizacional cotidiano. En este sentido, para Ybema, Keenoy, Oswick, Beverungen, Ellis y Sabelis (2009), y Ellis e Ybema (2010), el análisis del discurso de la identidad abarca una amplia variedad de métodos y enfoques, pero como mínimo, un marco o perspectiva discursiva de identidad situada y constituida por las prácticas de hablar y escribir. El énfasis está invariablemente en cualquier discurso de la identidad (Thomas y Linstead, 2002; Hardy, Lawrence y Grant, 2005), en el hablar de identidad (Snow y Anderson, 1987) o en las narrativas de identidad (Czarniawska, 1997a; Brown A. D., 2006; Thomas y Davies, 2005).

El discurso de la identidad es fundamental en los intentos de establecer, legitimar o desafiar las relaciones dominantes de poder y estatus (Ball y Wilson, 2000). De 
este modo, para Ybema, Keenoy, Oswick, Beverungen, Ellis y Sabelis (2009), el posicionamiento discursivo subraya la idea de que la construcción de la IO puede ser una medida del proceso neutral o benigno, en donde participan las emociones, los juicios y aprobaciones, es decir, dicho proceso implica las maniobras sociales y juegos de poder.

\subsubsection{Construcción identitaria}

La construcción de la $\mathrm{IO}$ es un proceso cognitivo permanente, iterativo, encarnado por los empleados, quienes se basan en múltiples modalidades para asimilar la realidad organizacional, con la capacidad de acercarse a ella de diversas maneras, que evocan a la vez diferentes perspectivas a partir de tal experiencia (Harquail y King, 2010). La construcción de IO por un miembro de la organización se basa en el procesamiento, examinación, interpretación y expresión de la información incorporada, que es formal y no formal, oficial y no oficial, simbólica y material, así como la información que se comparte es colectiva, interpersonal y específica a ese individuo. Junto con esto, la conceptualización de la lO por parte del individuo se configura no sólo a partir de estímulos físicos y experiencias, sino tambien de hábitos socialmente construidos y de las acciones intencionales de gestión para elaborar ciertas creencias acerca de lo que es una organización (Humphreys y Brown, 2002a).

A pesar de existir una serie de estudios sobre la construcción de la 10 (por ejemplo, Fiol, 2002; Humphreys y Brown, 2002b; Coupland y Brown, 2004; Denissen, 2010; Brown y Lewis, 2011), y que algunos investigadores se ocupan de alguna faceta sobre la formación de identidad en las organizaciones (Czarniawska y Wolff, 1998; Corley y Gioia, 2004; Clegg, Rhodes y Kornberger, 2007) no ha habido ningún estudio exhaustivo acerca de cómo las identidades organizacionales se forman en sus inicios (Gioia, Price, Hamilton y Thomas, 2010). Para estos autores, sólo tres trabajos han estudiado la formación de la lO per se: Czarniawska y Wolff (1998); Clegg, Rhodes y Kornberger (2007); Corley y Gioia (2004). Cada uno de ellos aborda tan sólo algunos aspectos de la 
construcción de $\mathrm{IO}$, pero, en su conjunto, son un buen punto de partida para una consideración más holística de la formación de 10.

Estos tres estudios sobre la formación de la 10 sugieren que el proceso de participación, tanto por alcanzar legitimidad a través de procesos miméticos como por la construcción de algunas dimensiones de carácter distintivo en el campo organizacional, requieren de un contexto externo receptivo para esos esfuerzos. Estas conclusiones están en estrecha relación con investigaciones que sugieren la importancia de la pertenencia a grupos, industrias u organizaciones. Al respecto, Suddaby y Greenwood (2005) señalan que la identidad reclama mayor legitimidad dentro de contextos amplios.

Para Gioia, Price, Hamilton y Thomas (2010), estas investigaciones ofrecen, sin embargo, sólo una visión limitada de la forma de interacción como estos procesos podrían afectar la actual formación de IO. La búsqueda de legitimidad es, por ejemplo, una explicación funcional de por qué algunos miembros de la organización participan en la construcción de la identidad, pero no explica cómo es el proceso. Para estos autores, el conocimiento del proceso comprensivo de la formación de la $\mathrm{IO}$ es aún limitado e incipiente.

A nivel individual, Linstead y Thomas (2002) tienen caracterizado el proceso de formación de la identidad como la gestión de la tensión entre las demandas presentadas por las respuestas al continuo cuestionamiento sobre ¿qué es lo que la organización espera de mí? y ¿qué es lo que yo quiero ser en el futuro? La primera pregunta tiene que ver con la propia identidad como actor social dentro del espacio propiamente organizacional. La segunda está en relación con la construcción social de la identidad personal. Sin embargo, estas cuestiones no son discretas sino que están inextricablemente entrelazadas. Desde el ámbito propiamente organizacional, estas preguntas también representan, para estos autores, las dos perspectivas dominantes para el estudio de la IO: la construcción social y la visión del actor social sobre la identidad, ambas expresadas en dos preguntas de investigación fundamentales: ¿Cómo los miembros de una naciente 
organización desarrollan una comprensión colectiva de quiénes son en la organización?; y ¿cómo una nueva creación de organización desarrolla un sentido de sí misma como un actor social en su campo o industria?

La visión constructivista de la 10 implica la negociación por parte de sus miembros de los significados compartidos sobre lo que somos para la organización, centrando la atención en los esquemas interpretativos que los miembros construyen colectivamente para proporcionar un significado a su experiencia organizacional (Gioia, Schultz y Corley, 2000; Whetten D. A., 2006). Ravasi y Schultz (2006) observaron que esta visión implica un énfasis en los procesos de construcción de sentido asociados a la construcción social de la identidad como significado y significados de estructuras que son negociadas intersubjetivamente entre los mismos miembros de la organización (Fiol, 1991). De tal forma, la IO es progresiva, compleja, recursiva, reflexiva y en permanente construcción (Ybema, Keenoy, Oswick, Beverungen, Ellis y Sabelis, 2009), negociada por los miembros de la organización por medio de las interacciones que sostienen entre sí y con la participación de partes interesadas externas (Coupland y Brown, 2004; Hatch y Schultz, 2002), dejando de lado las pretenciones de linealidad y causalidad rígidas para abrir espacios en la comprensión de la complejidad de su construcción (Simpson y Carroll, 2008).

En este sentido, la estabilidad de la identidad es, en gran medida, algo transitorio, ya que su construcción será discursiva, emergente e inmersa en un proceso continuo de reconstrucción, por lo que la estabilidad será un logro momentáneo o una ficción resistente (Simpson y Carroll, 2008). Del mismo modo, tanto individual como colectivamente, desde la visión de los fundadores (Rodrigues y Child, 2008) y de las repetidas negociaciones en varios niveles (Ybema, Keenoy, Oswick, Beverungen, Ellis y Sabelis, 2009), de las reclamaciones de las decisiones de la organización como entidad (Whetten D. A., 2006) y de la legitimación de un valor, todos forman parte del juego en el proceso necesario de construcción identitaria. 
De acuerdo con la visión del actor social, la IO es, sin embargo, una propiedad de la organización como una entidad o actor social (King, Felin y Whetten, 2010), y es perceptible principalmente por las formas de compromiso y las acciones que se toman (Corley, Harquail, Pratt, Glynn, Fiol y Hatch, 2006). Whetten (2006) llamó a estos compromisos las notificaciones de identidad, o referentes, que significan la autodeterminación y la autodefinición de la organización en el espacio social. Dentro de él, la 10 tambien es contextualizada y se convierte en un fenómeno comparativo que identifica a la organización y la diferencia de otras (Glynn y Abzug, 2002). King, Felin y Whetten (2010) afirman que desde el punto de vista de una organización como actor social, el camino por recorrer depende de su propia historia. En ausencia de ella, los miembros dibujan en sus propias historias personales a otras organizaciones con el fin de tener un referente para decidir qué acciones y compromisos se pueden apropiar, a la vez que encuentran importantes elementos en el proceso de formación de la 10 , que correspondían a la búsqueda de la distinción óptima esencial para decidir el proceso de ser iguales y diferentes al mismo tiempo. De esta forma, las construcciones de identidad no están libres de contradicciones y elementos provenientes de este proceso, y pueden incluso socavar el proceso mismo de construcción (Alvesson y Robertson, 2006).

Para Beech (2011), la construcción de la IO ha sido concebida como una interacción de co-construcción entre los individuos y las estructuras sociales (Ybema, Keenoy, Oswick, Beverungen, Ellis y Sabelis, 2009). La co-construcción se desarrolla en interacción entre la identidad del propio individuo (su propia noción de quién es él) y la identidad social (la noción de esa persona en discursos externos, instituciones y cultura) (Watson, 2009). Pero también hay que anotar que si bien es una construcción, esta tiene que parecer creíble para sus miembros, sin pasar por una estricta prueba de realidad rigurosa (Albert y Whetten, 1985). En relación con lo anterior, Sluss y Ashforth (2007) ofrecen un modelo conceptual para integrar el proceso de construcción en el cual confluyen lo personal, las relaciones interpersonales y los niveles colectivos basados en los roles. 
Se ha utilizado el enfoque del constructivismo social para el estudio de las identidades organizacionales (Cornelissen, 2006; Ravasi y Schultz, 2006). Las identidades se reconstruyen mediante la acción simbólica y la interacción social en contextos sociales (Cunliffe, 2002). Esto es importante ya que se convierten en el marco de posibilidades para que las personas puedan crear y reconocer el sentido de sus acciones. En este tenor, el proceso de construcción identitaria es gradual, en donde el sujeto llega a darse cuenta de que las cosas son distintas debido a un punto de inflexión que conduce a una expectativa por un nuevo significado. Las transformaciones de la identidad se producen cuando hay una desalineación, sorpresa, shock, disgusto, ansiedad, tensión, desconcierto, cuestionamiento de sí mismo, y la persona se ve obligada a reconocer que no es la misma que era antes. Esto es similar a volverse a escribir a sí mismo.

\subsubsection{Regulación y resistencia}

Las estrategias de regulación de la 10 representan los esfuerzos de gestión destinados a influir en la manera como los empleados resuelven los conflictos por las yuxtaposiciones entre los valores y las expectativas generadas en las organizaciones (Hackley y Kover, 2007). Directores contemporáneos están cada vez más atentos a cómo se puede ejercer el control a través de la fabricación de la subjetividad (Watson, 1994). La literatura crítica ha proporcionado aportes sobre estos tipos de control y sus posibles abusos (Sveningsson y Alvesson, 2003). Sin embargo, los investigadores se quejan de la escasez de estudios que examinan cómo las empresas pueden ayudar a los empleados a hacer frente a las múltiples demandas identitarias (Down y Revely, 2009; Gotsi, Andriopoulos, Lewis y Ingram, 2010).

Otras investigaciones sugieren que las estrategias de gestión han pasado de un enfoque de control tecnocrático (a través de la estandarización y supervisión en forma directa) a los intentos por buscar influir en las creencias de los trabajadores, dejándose ver controles a nivel normativo, ideológico e identitario (Karreman y Alvesson, 2004; Ainsworth y Hardy, 2008). En este sentido, algunas 
investigaciones sugieren que los controles sobre los empleados, incluidos los directivos, buscan colonizar el interior para crear selfs de ingeniería (Kunda, 1992), selfs del diseño (Casey, 1995) o selfs del empresarismo (Brown y Humphreys, 2006). Así, el aspecto regulatorio es considerado como una forma de control normativo que busca gestionar los interiores de los trabajadores de manera que sean flexibles y comprometidos con la organización porque se identifican con ella. El manejo del interior de las personas es considerado potencialmente menos molesto y más eficaz que las tradicionales formas externas de control administrativo (Alvesson y Willmott, 2002).

La regulación de la identidad denota estrategias destinadas a influir en el trabajo con la intención de apoyar las metas de la organización. Mediante discursos y prácticas, y la frecuencia e intensidad de su aplicación, se busca influir en los empleados. Estas estrategias pretenden prescribir la forma en que los miembros deben pensar en sí mismos y en su trabajo. Las funciones administrativas están encaminadas a localizar a los empleados dentro de una estructura, ayudando a crear, mantener y transformar sus identidades (Alvesson y Willmott, 2002).

En esta dirección, uno de los componentes fundamentales de la 10 serán los conflictos, ya que tendrán que negociar su propia identidad con otros grupos dentro de la organización (Kelman, 2006). Sobre esto y a pesar del gran potencial que tiene el concepto identitario para acercarse a comprender los fenómenos organizacionales, no ha sido aún estudiada en forma sistemática cómo la gestión de la identidad puede ayudar a resolver intransigencias y facilitar sostenidamente la armonía intergrupal (Fiol, Pratt y O’Connor, 2009).

Para Alvesson y Willmott (2002), los esfuerzos por regular la identidad se centran en cuatro aspectos: (1) El empleado: ayudar a definir directamente al individuo y/o a otros relacionados con él. (2) Orientaciones de la acción: proporcionar un vocabulario específico de los motivos y los valores (por medio de cuentos, arquetipos, selección de personal, actividades sociales) a través de los cuales los empleados pueden construir un significado de su trabajo y el desarrollo de 
habilidades. (3) Las relaciones sociales: aclarar categorizaciones grupales y afiliaciones, especificando la ubicación jerárquica. (4) La escena: establecer claramente las reglas de juego que delimita el contexto (por ejemplo, las del mercado o la industria).

Desde una perspectiva crítica, las investigaciones presentan estos esfuerzos de control como un medio para alcanzar cierta hegemonía (Alvesson y Willmott, 1996). Así, la resistencia normalmente prevalece cuando los directivos tratan de ejercer un amplio control sobre la mentalidad de los empleados. Las estrategias de control son vistas como un problema porque las personas necesitan que se les controle para que subordinen su voluntad a la organización como un colectivo (Alvesson y Willmott, 2002).

Mientras que algunos estudiosos han sugerido que la gestión de la lO es una función importante de liderazgo (Voss, Cable y Voss, 2006), se ha argumentado que estas construcciones discursivas pueden ser a veces altamente resistentes a las intervenciones de gestión dirigidas a la integración, la agregación, la participación o la eliminación (Pratt y Foreman, 2000). Dado que las identidades de las organizaciones pueden ser adaptativamente inestables (Gioia, Schultz y Corley, 2000; Vaara, Tienari, Piekkari y Santti, 2005; Vaara, Kleymann y Seristo, 2004) y, por lo tanto, mutables dentro de las restricciones, no es claro entonces que el individuo pueda ser manejado por las élites directivas de manera programada y predecible. Es por ello por lo que se puede afirmar que la hegemonía como una forma de control, nunca es completa (Brown y Humphreys, 2006).

En relación con el proceso de construcción de IO, también se han explorado los esfuerzos de la gestión por fabricar subjetividad (Alvesson y Willmott, 2002) y la resistencia de las personas (Collinson, 2005), que buscan cambiar de un yo actual, a una identidad aspiracional (Thornborrow y Brown, 2009), o para visualizar e identificar una identidad laboral impuesta con el fin de considerar el sí mismo como auténtico (Costas y Fleming, 2009). La subjetividad del trabajador es vista 
como producto de los mecanismos disciplinarios y de las técnicas de vigilancia y poder estratégicas.

El enfoque dialógico explica cómo es posible generar un tipo de resistencia gracias a la transformación del significado a través del diálogo interior y del uso potencial de los significados del contexto lingüístico para formar contra-narrativas y contra-discursos (Beech, 2008). El reto es analizar cómo quedan promulgados estos procesos en la construcción de un nuevo significado. En este sentido, el diálogo podría conducir a reforzar o rechazar la construcción de la identidad, o a generar puntos de encuentro entre los extremos.

Es así como los empleados, frente a estas estrategias de regulación, pueden generar resistencia al buscar perseverar en elementos que valoran de una 10 en particular (Ravasi y Schultz, 2006). Así, cuando los empleados se sienten amenazados, o se encuentran a la defensiva o inseguros, las estrategias de regulación de la identidad pueden amplificar el cinismo y la resistencia (Kosmala y Herrbach, 2006), a la vez que pueden ser contraproducentes y alienantes, impidiendo la innovación por la homogeneidad que se promueve. A esta reacción por parte de los empleados, se le ha llamado desidentificación (Costas y Fleming, 2009; Beech, 2011).

\subsubsection{Audiencia e identidad}

El concepto de identidad organizacional tambien ha estado relacionado con temas referidos con la comunicación gerencial y en general, con los medios de comunicación dentro de las organizaciones. Elsbach y Kramer (1996) consideran los efectos de los rangos de los sistemas dentro de las organizaciones, centrándose en cómo las comparaciones y las amenzas afectan a los miembros de la organización en la IO. Los autores estudian las ocho mejores escuelas de negocios según la revista Business Week. Investigan la responsabilidad de los miembros de estas escuelas para percibir la identidad organizacional frente a las amenazas. Los resultados de la investigación presenta la evidencia de cómo la 
audiencia organizacional tiene injerencia sobre la organización y cómo los miembros perciben la identidad en sus organizaciones. El estudio es una aplicación de las ideas de Ginzel, Kramer y Sutton (1993) y la teoría social presentada por Ashforth y Mael (1989). Sugiere que los rankings se convierten en una amenaza para la identidad y definen dos dimensiones para percibir esta amenaza. La primera, en cómo los miembros definen lo central de la organización, distintivo y duradero de sus cualidades. La segunda, es la amenaza que plantea localizar la posición de la escuela en el estatus jerárquico. Los resultados indican que los miembros tienden a responder aspectos de su identidad que no son mencionados en la revista. Esta investigación revela las dinámicas cognitivas que ocurren entre los miembros de la organización y las audiencias, en la configuración de la identidad organizacional.

Cheney y Christensen (2001) examinan los efectos de la organización en sus intentos por influenciar a los otros y cómo dicho intento terminar por afectar a los mismos miembros. Los autores argumentan que la distinción entre identidad e imagen está desapareciendo debido también a la superposición de las prácticas internacionales y la comunicación externa, así como el uso de los medios de comunicación basados en la publicidad para influir en los empleados a través del marketing interno. Estos autores sostienen que si bien las organizaciones que adoptan estas prácticas siguen afirmando que están comunicando a sus entidades externas, resultados de investigación redefinen estas prácticas como autocomunicación. La teoría de estos autores es que la auto-comunicación confirma la auto-definición de la organización (identidad) y se reproducen internamente las imágenes que los managers quieren que se perciba desde afuera de la organización. Lo de afuera se refleja al interior por medio de una comunicación auto-referencial.

\subsubsection{Estabilidad y cambio en la identidad organizacional}

Se conceptualiza la identidad como un proceso en lugar de una construcción estática. Gioia, Schultz y Corley (2000) explicitan los cambios en la definición de 
Albert y Whetten de la identidad como duradera, por un enlace de identidad para un cambio organizacional. Los autores argumentan que la identidad es inestable $y$ adaptativa. Ya que las organizaciones utilizan las mismas etiquetas para describir cómo son por décadas, sus identidades pareciera que no siempre estan cambiando. Sin embargo, la 10 cambia por el hecho de que los significados e interpretaciones de las etiquetas utilizadas para describir sí cambian constantemente. Los autores afirman que estos cambios en la interpretación permiten a las organizaciones adaptarse a cambios en el entorno, preservando el sentido sobre si misma, un estado que los autores lo definen como inestabilidad adaptativa.

Afirman, a su vez, que la imagen organizacional está empezando a crecer en la sociedad post-industrial, la cual crea mucha más condiciones inestables para la construcción de identidad, forzando a las organizaciones a adaptar su identidad al siempre fluctuante percepción externa y a las expectativas. Basándose en el concepto de imagen (propuesto por Dutton y Dukerich (1991) y Alvesson (1990)) los autores muestran cómo la interdependencia entre identidad e imagen, activa un proceso de comparación (Tajfel y Turner (1986)) entre variaciones sobre cómo pensamos que somos y cómo piensan ellos que somos, dejando a la organización con diferentes caminos para responder sobre la base de impresiones transitorias. Los autores discuten las limitaciones de la adaptación de identidad, argumentando que si bien los procesos de construcción de identidad y de la imagen son cada vez más interdependientes, cada uno de ellos mantiene un núcleo de independencia.

Hatch y Schultz (2002) describen la identidad organizacional como un conjunto interrelacionado de procesos (expresión, impresión, duplicación y reflejo) a través del cual, tanto la cultura organizacional y las imágenes influyen en la identidad organizacional y vice-versa. Estos procesos representan la identidad organizacional como dinámica, todavía capaz de ofrecer una sensación de estabilidad a su público. Siguiendo a Mead (1934), argumenta que la propia identidad emerge en un proceso donde participan el mi (cómo los otros te ven) y el yo (cómo te sabes a ti mismo). 
Los autores proponen analogias organizacionales con los conceptos de Mead (1934): yo, como cultura organizacional; y mi, como imagen organizacional. El texto ofrece un modelo de identidad organizacional el cual emerge de los procesos en donde la cultura organizacional y la imagen de los stakeholders juegan un papel influeyente. Los autores definen los procesos de conexión de identidad como imagen reflejo (basados en Dutton y Dukerich, 1991) e impresión (basados en Goffman, 1989) y ambas conecciones de identidad a la cultura como reflejo y expresión. El modelo de los autores da cuenta de la estabilidad y el cambio. En su modelo diagnostican dos disfunciones dinámicas de las identidades (el narcisismo y la hiper adaptación) en términos de disfunciones entre cuatro procesos. Esto trae a cuenta la similitud entre la organización narcisista y la noción de organización ideal de Schwartz (1987) y la organización como asi misma seductora de Cheney y Christensen (2001).

\subsubsection{Otras perspectivas de análisis}

Las cinco perspectivas aquí expuestas fueron las más relevantes como resultado de la revisión. No obstante, existen muchas otras que también tienen una relevancia importante dentro del campo de los EO, concretamente desde la temática de la IO. Entre ellas se encuentran: 10 y psicoanálisis (Driver, 2009; Roberts, 2005; Harding, 2007); contracciones y conflictos (Foreman y Whetten, 2002; Kreiner, Hollensensbe y Sheep 2006b; Fiol, Pratt y O'Connor, 2009), entre otros.

En el ámbito regional, son pocas las investigaciones referidas al tema de la IO. En una de ellas, y que enmarca el estudio de este tema a nivel Latinoamericano, García de la Torre (2007), relaciona la IO con el de la cultura, a la vez que considera que la identidad es la fuente ontológica de aquella. En un trabajo anterior, Carvajal (2005), plantea el problema de la existencia de las organizaciones, y los criterios para establecer su identidad. En términos generales, el tema de la IO no se ha desarrollado tanto como el de Cultura Organizacional, de 
ahí que el tema identitario sea una agenda pendiente también a nivel regional (Ferreira, 2010).

Terminar este acápite, mencionando el texto de Etkin y Schvartein (1997) Identidad de las organizaciones. Invarianza y cambio, en donde los autores proponen los temas de la invarianza y el cambio como ejes centrales de su propuesta, afirmando a su vez, que la identidad es el factor primordial para la invarianza, y proponiendo algunas dimensiones de la identidad (tiempo, tamaño, localización, tangibilidad, etc.) para su estudio.

\subsubsection{Conversaciones en relación con el concepto de identidad organizacional}

\subsubsection{Perdurable}

Para Driver (2009), la definición seminal de IO ha tardado en entenderse como una construcción unitaria que ejerce una fuerza considerable por mantener una 10 constante y coherente en el tiempo. Otros investigadores consideran esta construcción unitaria como una esencia unitaria, la cual es estable, aunque más de lo que pareciera (Scott y Lane, 2000b; Corley, Harquail, Pratt, Glynn, Fiol y Hatch, 2006). Incluso, si bien el proceso de adaptación a las demandas ambientales -lo cual es crucial para el éxito de la organización (Gioia, Schultz y Corley, 2000; Brown y Starkey, 2000; Corley y Gioia 2004; Corley, Harquail, Pratt, Glynn, Fiol y Hatch, 2006) - se considera igualmente importante, y a veces más, para retener esta identidad unitaria que proporciona el reconocimiento (Whetten 2006), la legitimidad y la ventaja competitiva.

Es de este modo como el concepto de $\mathrm{IO}$ ha sido construido como una metáfora fenomenológica, o como una construcción social que objetivamente existe en esencia, y por lo mismo perdura, y como una propiedad de las organizaciones como actores sociales, o un conjunto de entendimientos compartidos (Humphreys y Brown, 2002a; Humphreys y Brown, 2002b). 


\subsubsection{Autoreferencial e intersubjetiva}

La IO esencialmente consiste "en un significado de autoreferencia [...] acerca de los intentos de la entidad por definirse a sí misma" (Corley, Harquail, Pratt, Glynn, Fiol y Hatch, 2006, p. 87). Estos significados autoreferenciales, que son siempre contextualizados e inherentemente comparativos, pueden ser tácitos o explícitos, se puedan dar por sentado o ser conscientemente trabajados (Clarke, Brown y Hope-Hailey, 2009; Thornborrow y Brown, 2009). Este proceso de autoreferenciación no es otra cosa que la forma en que una organización esta comúnmente representada (Sillince y Brown, 2009).

Para algunos autores, la 10 es un fenómeno intersubjetivo (Clegg, Rhodes, y Kornberger, 2007) que reside en la percepción e interpretación de sus miembros o grupos de interés (Hatch y Schultz, 2002). Para Ravasi y Schultz (2006), la IO es definida a partir de esquemas interpretativos que los miembros de la organización construyen colectivamente con el fin de proporcionar un sentido a su experiencia.

\subsubsection{Múltiples identidades}

La identidad se encuentra compartida por todos los miembros de la organización. Es por eso que la identidad se va a desarrollar y se va a manifestar por medio de múltiples capas o dimensiones en las definiciones de los miembros de una misma organización cuando éstos definen quiénes son.

Pratt y Rafaeli (1997) investigaron cómo la vestimenta en un hospital de rehabilitación revela una multiplicidad de interpretaciónes de varios subgrupos asociados a un código de vestimenta. Siguiendo a Tajfel y Turner (1979) y a Ashford y Mael (1989), los autores definen la identidad social como las autocategorizaciones que los individuos usan para denotar su sentido de pertenencia. Sin embrago, enfatizan cómo estas auto-categorizaciones están insertas en unos supuestos culturales y valores que utilizan la autodefinición del símbolo organizacional del vestido para revelar las múltiples capas de significados 
inherentes a toda identidad social. Los autores (utilizando la definición de Albert y Whetten (1985) de un híbrido identitario) exponen la tensión entre el hospital local y las demás identidades profesionales que están detrás del debate por la vestimenta.

Karen Golden-Biddle y Hayagreeva Rao (1997) realizaron un estudio empírico de cómo el proceso de construcción de identidad influencia la accion organizacional (se puede comparar este estudio con el de Dutton y Dukerich (1991) y el de Pratt y Rafaeli (1997)). En ese estudio, los autores, ofrecen una descripción de cómo la IO está amenzada, reparada y preservada por las acciones organizacionales que involucran los altos ejecutivos y la junta de directivos en una organización sin fines de lucro. En esta descripción, los autores señalan la propuesta teórica de Goffman sobre la distinción entre frontstage and backstage. Similar a lo que hicieron Pratt y Rafaeli (1997), los autores enmarcan el conflicto y las múltiples construcciones de identidad dentro de un contexto organizativo. Usan los conceptos de holográficos y de identidades híbridas (Albert y Whetten, 1985) para analizar las tensiones entre la identidad del voluntario y la identidad de familiares y amigos en una organización del tercer nivel. El caso muestra como el individuo y la identidad organizacional están interconectados mediante procesos identitarios.

Autores como Carter y Mueller (2002), y Foreman y Whetten (2002), han reconocido que las organizaciones pueden tener múltiples identidades. Se considera que la $1 \mathrm{O}$ es múltiple cuando los miembros de la organización realizan dos o más afirmaciones acerca de lo que es la organización. Para Sillince y Brown (2009) esta comprensión de las identidades se debe a una aproximación desde la retórica (Carter y Mueller, 2002; Collinson, 2005), en donde se analiza cómo el reconocimiento y las afirmaciones sobre la identidad pueden contribuir a los esfuerzos por explicar con más detalles el comportamiento de las organizaciones. Aunque la noción de identidad múltiple es frecuente en la literatura, la falta de consenso en cuanto a su significado compromete su utlidad como un constructo teórico (Foreman y Whetten, 2002). 
Para Sillince y Brown (2009), la mirada desde la retórica en la concepción de una IO múltiple tiene al menos tres implicaciones importantes para la teorización y la investigación en este campo: (1) El reconocimiento de las identidades múltiples sugiere que existe la necesidad de reconsiderar la ampliamente mencionada suposición de que las organizaciones tienden a comunicarse en forma coherente. En este sentido, se pueden presentar muchos yos en una organización. (2) El reconocimiento de varias identidades responde a una visión clara sobre lo que sus miembros son, son sinónimo de o deberían ser con el objetivo de promover la identificación, es decir, conducentes a promover procesos activos de integración y sentimientos de pertenencia. (3) La concepción de la 10 como múltiple ofrece nuevas ideas para teorizar en este campo, en la medida en que las identidades son estables y duraderas (Albert y Whetten, 1985), dinámicas (Gioia, Schultz, y Corley, 2000), o adaptativas (Brown y Starkey, 2000).

En ese mismo sentido, la 10 está en una constante desestabilización por la producción de nuevos textos, en los cuales la identidad está sujeta a una reconstrucción continua, por lo que dicha reconstrucción puede que sea muy diferente, mientras que en otros, el cambio sea casi imperceptible (Chreim, 2005; Nayak, 2008). Es conocido que los psicólogos han aceptado que las personas tiene múltiples identidades, y más recientemente también se ha afirmado que los individuos tienen un repertorio de identidades que se hacen prominentes en diversos roles y contextos. Asimismo, los individuos tienen "múltiples conceptualizaciones acerca de quiénes somos" (Pratt y Foreman, 2000, p. 19), sobre la base de factores tales como la historia personal o la posición en la jerarquía de la organización (Corley, 2004).

\subsubsection{Cambio}

La literatura ha contribuido a enmarañar la comprensión de la IO, emergiendo los conceptos de cambio y pluralidad como posibles fuentes de tensión, en vez de acercarse a ella como algo estático e inmutable. La identidad se conceptualiza como fluida y maleable (Kreiner, Hollensensbe y Sheep, 2006b), impermanente y 
fragmentaria (Bendle, 2002), múltiple y contextual (Alvesson, 2000). Las identidades se construyen continuamente y son reconstruidas al negociarse constantemente a través de procesos de identificación y diferenciación.

Las identidades emergen de la interacción y de la negociación, y comparten procesos de sentido. Esas interpretaciones ocurren y están contextualizadas e infuenciadas por el entorno, de manera tal que las interacciones entre los miembros externos y los miembros internos de la organización contribuyen a la formación de identidades (Gioia, Schultz y Corley, 2000). Esto evita considerar la IO como algo estático o esencial, aproximándose a la 10 a través de performances. Esta idea extiende la teorización de la identidad como un proceso dialéctico de ser-siendo y de llegar a ser (Tsoukas y Chia, 2002; Clegg, Kornberger y Rhodes, 2005), lo que quiere decir que en vez de ser la 10 algo ontológicamente seguro, surge del proceso de organización de la misma organización. En otras palabras, está en constante cambio. Las identidades no son estáticas u existen objetivamente, sino que se construyen discursivamente en forma fluida y constante (Brown y Humphreys, 2006).

\subsubsection{Dialogal y relacional}

La identidad tiene un carácter esencialmente relacional (Ybema, Keenoy, Oswick, Beverungen, Ellis y Sabelis (2009). Las identidades pueden surgir de las articulaciones de las similitudes y las diferencias, lo que implica la separación discursiva del yo y el otro, apareciendo una parte intrínseca del proceso en la cual se llega a comprender lo que uno es, a partir de las nociones acerca de lo que no se es, y por extensión, quiénes son, y quiénes son los demás. Como argumenta Jenkins (2004), "la construcción social de la identidad es una cuestión de establecer y significar las relaciones de similud y diferencia" (p. 5), más que imponer límites aparentemente arbitrarios de crear y definir la alteridad.

Este diálogo puede ser construido de diversas formas, centrándose, por ejemplo, en discursos dramatúrgicos y también dentro de las llamadas luchas discursivas 
(Alvesson y Deetz, 2000). Las expresiones de los demás pueden llegar a ser asimiladas en uno mismo y convertirse en un mismo sentido. Desde esta concepción, trabajos como los de Cunliffe (2002) se han centrado en el discurso de los administradores como práctica que actua e interactúa con otros, es decir, la identidad es un proceso que es resultado de, al mismo tiempo que permite el diálogo como tal.

Lo dialógico es considerado como un concepto puente entre el individuo y la sociedad. Su potencial mediático radica en su doble carácter, que refracta lo que puede ser visto como una dialéctica permanente entre la estructura personal y la social. Por esta razón, los estudios de la identidad prestan atención simultáneamente a ambas definiciones, a las autodefiniciones y a las definiciones de los demás (Ybema, Keenoy, Oswick, Beverungen, Ellis y Sabelis, 2009), para que la identidad pueda ser sujeto y pueda ser vista también como un proceso activo de trabajo discursivo en relación con otros hablantes. En esta interrelación discursiva "la organización no sólo construye al empleado, sino que el empleado construye la organización" (Gabriel, 1999, p. 190).

Utilizando esta concepción dialogal, Foreman y Whetten (2002) proponen entender la 10 como la conjunción de la comparación entre la percepción de la identidad actual de una organización (creencias sobre el carácter existente de la organización), con sus expectativas en términos ideales (creencias sobre lo que es deseable, informado por los mismos miembros) y cómo la brecha o congruencia de la identidad resultante (la distancia cognitiva entre la identidad actual e ideal) afecta de manera significativa el nivel de involucramiento de los empleados.

\subsubsection{Conversaciones en relación con otros términos}

\subsubsection{Identidad social}

La identidad es entendida como un proceso en donde es construida y reconstruida travéz de una interacción dinámica en la que la persona es arrojada a una identidad de otros (Karreman y Alvesson, 2001) y busca proyectar una 
identidad al mundo exterior (Brown, 2001), o adquirir los comportamientos, símbolos y las historias de una identidad (Sims D., 2003). Estas interacciones implican un diálogo entre la auto-identidad interior y la social-identidad exterior (Watson, 2009). La identidad social se compone de las proyecciones de los demás hacia uno mismo, las proyecciones del yo hacia los demás y las reacciones a las proyecciones recibidas (Beech, 2008). Así, la identidad social es un espacio o lugar en donde las personas recurren y se imponen por discursos externos. La auto-identidad es la visión interiorizada del self en donde las personas tratan de mantener una narrativa particular (Watson, 2009).

Para Ybema, Keenoy, Oswick, Beverungen, Ellis y Sabelis (2009) la identidad social es una versión de la agencia-estructura dialéctica en acción, es decir, el proceso mediante el cual el agente individual constituye y es constituido por sus derechos sociales entorno a los discursos disponibles para ello y lo que los rodean. Para Gioia, Price, Hamilton y Thomas (2010) en cambio, las organizaciones son colectivos sociales porque la sociedad trata a las organizaciones como si fuesen personas, asignándoles estatus legal como actores sociales colectivos.

Desde la perspectiva del actor social, la 10 es esencialmente un conjunto de notificaciones institucionales que explícitamente articulan la organización y es a su vez, lo que representa. Lo importante de este punto de vista es que el lugar de la IO no reside principalmente en la interpretación de sus miembros, sino en las reivindicaciones institucionales asociadas con la organización (Corley, Harquail, Pratt, Glynn, Fiol y Hatch, 2006; Whetten D. A., 2006). Para Ravasi y Schultz (2006) esta concepción de IO tiende a enfatizar la función interpretativa (sensegiving) de la identidad, uniendo la construcción de identidad con la necesidad de proveer una guía coherente en cómo los miembros de una organización deben comportarse y como otras organizaciones deben relacionarse con ellos (Whetten, 2006). 


\subsubsection{Identidad e identificación}

Para Kreiner, Hollensensbe y Sheep (2006a) el término identificación se le ha entendido en la literatura organizacional a partir de dos significados: en relación a un estado y a un proceso. La identificación como un estado se refiere a la asociación del individuo con un grupo social (una organización, una profesión, etc.). El segundo (como proceso) es el paso de alinear la propia identidad con la de un grupo social. Los autores resaltan que la identidad puede cambiar en este proceso ya que es cíclica, y no determina cúando un individuo se llega a identificar con una entidad en particular.

La construcción de la 10 es un proceso crítico del proceso de identificación organizacional. Los individuos construyen una 10 y evalúan la resonancia y concordancia entre su conceptualización de $1 \mathrm{O}$ y sus propias identidades. Junto con ello, y dentro de este proceso, obtienen la posibilidad de poder definirse a sí mismos dentro de la organización (Alvesson y Robertson, 2006; Dutton, Dukerich y Harquail, 1994; Holmer-Nadesan, 1996). Un empleado se identifica con una organización cuando experimenta una concordancia entre su construcción de $1 \mathrm{O}$ y su propia auto-construcción (Dutton, Dukerich y Harquail, 1994), estableciéndose diferentes tipos de identificación a partir de este proceso (Kreiner y Ashforth, 2004). La identificación con la organización aparece cuando las creencias de un individuo sobre lo que es la organización se auto-referencian o se auto-definen consigo mismo (Pratt, 1998).

Para Sluss y Ashforth (2007) la identidad relacional responde a la pregunta: ¿Cuál es la naturaleza de nuestra relación?, y la identificación relacional a: ¿Cuánto tengo internacionalizado esa identidad como parte de mi mismo? Usando estos términos, los autores ofrecen un modelo conceptual para integrar el proceso de construcción en el cual confluye lo personal, las relaciones inter-personales, y los niveles colectivos basados en los roles. 


\subsubsection{Identidad personal}

A nivel individual, Linstead y Thomas (2002) caracterizan el proceso de formación de la identidad como la gestión de la tensión entre las demandas presentadas frente a las preguntas que continuamente se plantean: ¿Qué es lo que quiere la organización de mi? y ¿qué es lo que quiero ser a futuro?. La primera pregunta tiene que ver con la propia identidad como actor social dentro del espacio organizacional, mientras que la segunda tiene que ver con la construcción social de una identidad personal. Sin embargo, ambas estan inextricablemente entrelazadas, a la vez que expresan las dos perspectivas dominantes en el estudio de la IO: la construcción social y los puntos de vistas de los actores sociales (Gioia, Price, Hamilton y Thomas, 2010).

Las identidades personales son negociadas, creadas, amenazadas, reforzadas, reproducidas y revisadas, a través del proceso de construcción como tal, siendo encarnadas en dicha interacción (Alvesson, Ashcraft y Thomas, 2008). Y con respecto a la forma $\mathrm{y}$ al fondo, las identidades personales necesariamente recurren a discursos sociales disponibles o a narrativas sobre quíen uno puede ser y cómo se debe actuar, por lo que algunos individuos pueden tener un apoyo institucional mas fuerte y acceso a ciertos recursos materiales mas que otros (Thomas y Davies, 2005).

De esta manera, la identidad individual se compone de los aspectos del self que surgen de las características personales, asi como de las categorías sociales en las que el individuo afirma estar vinculado (Tajfel y Turner, 1986). Sin embargo, hay que precisar que los individuos no son meros receptores pasivos de identidades que provienen de entidades sociales. Éstos son capaces de reconocer las implicaciones y exigencias de las organizaciones, grupos y otras entidades sociales (Kreiner, Hollensensbe y Sheep, 2006b).

Así, la identidad personal está compuesta por múltiples aspectos que varian en accesibilidad y relevancia a través de diversas situaciones, de las cuales algunos 
son mas importantes y estables, mientras que otros están sujetos a la interpretación y cambios permanentes (Kreiner, Hollensensbe y Sheep, 2006b).

\subsection{DISCUSIÓN: CONSIDERACIONES PARA FUTURAS CONVERSACIONES}

Lo discutido lleva a preguntarse por la posibilidad que tiene la IO de considerarse como un fenómeno que pueda ser deconstruido en un conjunto de componentes generalizables como la orientación moral, las preferencias de riesgo, 0 clasificaciones de estado (Brickson, 2000). Aunque Albert y Whetten (1985) propusieran que las "dimensiones seleccionadas para definir el carácter distintivo de una organización puedan ser muy ecléctico" (p. 268), a muchos académicos les gustaría ser capaces de comparar la identidad de una organización con las identidades de las otras. Las primeras investigaciones versaron sobre la posibilidad de encontrar una identidad única en cada organización o si hay un conjunto de dimensiones de 10 que se puedan generalizar en todas las organizaciones. Si hay dimensiones generalizables, entonces se debe tener en cuenta los atributos de centralidad, distinción y duración, revisadas anteriormente.

La idea de que cada organización tiene una identidad única es el enfoque en donde se evalúa la identidad de una organización con dimensiones sugeridas por los miembros de la organización a sí mismos (por ejemplo, con la técnica de rejilla, Gustafson y Reger, (1998)). Por lo tanto, la identidad de una organización no es necesariamente o directamente comparables con la identidad de otra organización. El enfoque de los que buscan generalizar las dimensiones de la identidad de la organización es una perspectiva ética, en la que los investigadores identifican los atributos que les interesan y evalúan la solidez de estos atributos en una organización con respecto a otras.

Las posiciones teóricas, ontológicas y epistemológicas a través de las cuáles uno se acerca a una construcción, son fundamentales para toda investigación, y en el tema de la 10 , no va a ser la excepción. Sin esta claridad, pueden surgir 
confusiones en los niveles de análisis. Por ejemplo, cuando los investigadores definen la identidad de la organización como una construcción social, pero luego tratan de medir los atributos globales y sus dimensiones (mezclando aspectos positivistas y subjetivistas) las conclusiones pueden ser confusas y perder su carácter de validez.

Una cuestión fundamental será cómo en el trabajo de campo co-mantener múltiples perspectivas sobre la identidad de la organización y al mismo tiempo, acumular conocimientos para aclarar el ámbito de la identidad de la organización objeto de estudio. Sería un error concluir que un solo enfoque es el correcto. Hay varias rutas para el estudio de la identidad de la organización, cada uno con su propia base de supuestos y de destino. Identidad de la organización es una construcción en torno al cual existen profundos desacuerdos y diferencias que no pueden ser reconciliadas, y sin embargo hay una gran promesa para su construcción.

Según (Corley, Harquail, Pratt, Glynn, Fiol y Hatch, 2006), la discusión anterior permite avanzar hacia una concepción socio-cultural de la identidad. En primer lugar, destacan la concepción de la identidad como un proceso inacabado y abierto, que los sujetos están obligados a realizar para enfrentar los cambios del mundo moderno. La identidad constituye una interface entre lo individual y lo social; lo que somos es en buena medida la forma cómo actuamos y lo que decimos en los distintos ámbitos del mundo social. En segundo lugar, la identidad es algo inserto en el mundo cotidiano y se le puede tomar como punto de partida en lo que dicen los sujetos de sí mismos, y por el otro, la forma en que participan de las prácticas cotidianas. Se trata de concebir la identidad como una herramienta que es utilizada de acuerdo con las actividades en que participa el sujeto e incluso, que se improvisa según los contextos y los recursos (económicos, sociales, simbólicos) disponibles. La identidad es vivida y encarnada por las personas de acuerdo con su participación en las prácticas sociales. La identidad tiene entonces, un carácter relacional en tanto permite decir quién es uno y situarse en relación con las otras personas en un contexto social. La identidad 
supone un otro frente al cual se construye y tiene un carácter cambiante, adaptable a los contextos o ámbitos de experiencia en que actúan los sujetos.

Tercero, la construcción de la identidad es un trabajo que se realiza en las prácticas situadas al participar de cierta manera en las actividades y simultáneamente en el pensamiento como un habla interna y la generación de un sí mismo capaz de orquestar distintas voces. La construcción de la identidad es un proceso de autoformación al participar y entrar en contacto con las prácticas y significados culturales. En la medida que se conoce más ámbitos de la experiencia se generan nuevas capacidades de ser y pensar que se entroncan y permiten apropiarse de los mundos culturales. Las personas y actividades que se efectúan en lugares específicos proporcionan recursos identitarios a los sujetos en formación.

Cuarto, es importante destacar el desarrollo de capacidades reflexivas y de auto descubrimiento que desarrollan los sujetos al participar de las prácticas y discursos socio-culturales que conforman un ámbito de experiencia o mundo figurado. Las concepciones del sí mismo implican una capacidad reflexiva, al tomarse como objeto de sí mismo y sus experiencias. La construcción de identidad supone al sí mismo como un proceso social, que se encarna en el sujeto, y el desarrollo de su capacidad de reflexionar sobre el mundo cultural. Las personas a lo largo de su vida pueden tener distintas identidades, incluso contradictorias, que son objeto de una reflexión y adquieren una coherencia en las narrativas biográficas.

Un aspecto más por considerar es el hecho de disponer distintos enfoques teóricos sobre la identidad permite visualizarla y comprenderla en su carácter dinámico y multiforme de acuerdo con las prácticas que el sujeto busca afiliarse y de su conocimiento para participar de las mismas.

Lo comentado en este capítulo ha contribuido a mostrar las diversas conversaciones que se vienen realizando en torno al tema de la IO. Se busca con 
ello promover la conversación y mostrar los principales paradigmas, perspectivas y discusiones que forman parte de los actuales diálogos sobre este tema. Los resultados de la revisión no sólo permiten develar algunas conversaciones acerca de la 10 sino que enmarcan un estado de la discusión para seguir impulsando debates y controversias, a la vez que delimitan y contribuyen a presentar un panorama general sobre el tema para aquellos investigadores que quisieran profundizar en él.

La IO ha sido reconocida y establecida como un importante concepto dentro de los EO (Brown, 2001), y últimamente ha sido vista como un constructo de creciente importancia (Ashforth, Rogers y Corley, 2011). Aunque la definición seminal de Albert y Whetten (1985) de aquello que es central, distintivo y perdurable aún es válida y es retomada por los investigadores para sus trabajos, esta ha sufrido una serie de cambios y desarrollos en los últimos años. Diferentes investigadores han partido de distintos paradigmas y diversas perspectivas teóricas para interpretar estos atributos, configurando un controversial diálogo acerca de lo que la IO es o debería ser. A continuación, se presenta una tabla en donde se resume lo discutido. 


\section{Tabla 2: Paradigmas en relación con la identidad organizacional}

\begin{tabular}{l|l|l|l}
\multicolumn{1}{c|}{$\begin{array}{c}\text { Paradigmas } \\
\text { Items }\end{array}$} & \multicolumn{1}{|c}{ Esencialista } & \multicolumn{1}{c}{ Constructivista } & \multicolumn{1}{c}{ Discursivo } \\
\hline $\begin{array}{l}\text { Concepción de } \\
\text { la IO }\end{array}$ & $\begin{array}{l}\text { Es un atributo o } \\
\text { característica capaz de ser } \\
\text { gestionada. }\end{array}$ & $\begin{array}{l}\text { Es un colectivo } \\
\text { generalizado y una } \\
\text { interpretación } \\
\text { sostenida a partir de la } \\
\text { cual se comprenden } \\
\text { las acciones. }\end{array}$ & $\begin{array}{l}\text { Es una metáfora } \\
\text { construida } \\
\text { narrativamente en } \\
\text { donde no prevalece } \\
\text { un único discurso. }\end{array}$ \\
\hline $\begin{array}{l}\text { Concepción de } \\
\text { la } \\
\text { organización }\end{array}$ & $\begin{array}{l}\text { Es una entidad en sí misma, } \\
\text { auto-reflexiva. }\end{array}$ & $\begin{array}{l}\text { Es una construcción } \\
\text { social. }\end{array}$ & $\begin{array}{l}\text { Es un constructo } \\
\text { discursivo. }\end{array}$ \\
\hline $\begin{array}{l}\text { Enfoques } \\
\text { cognitivos }\end{array}$ & $\begin{array}{l}\text { De la mano del } \\
\text { funcionalismo, se centra } \\
\text { técnicamente en las } \\
\text { relaciones causa-efecto para } \\
\text { mejorar la eficacia de la } \\
\text { organización. }\end{array}$ & $\begin{array}{l}\text { A partir de una mirada } \\
\text { interpretativa, busca la } \\
\text { comprensión del } \\
\text { proceso de } \\
\text { construcción a través } \\
\text { de la práctica } \\
\text { hermenéutica. }\end{array}$ & $\begin{array}{l}\text { Tiene una orientación } \\
\text { crítica al buscar } \\
\text { emancipar al hombre, } \\
\text { denunciando la } \\
\text { subordinación y el } \\
\text { control al que es } \\
\text { sometido por los } \\
\text { regímenes de gestión. }\end{array}$ \\
\hline $\begin{array}{l}\text { Perspectivas } \\
\text { teóricas }\end{array}$ & $\begin{array}{l}\text { Regulación y resistencia. } \\
\text { Estabilidad y cambio. }\end{array}$ & $\begin{array}{l}\text { Construcción } \\
\text { identitaria. }\end{array}$ & $\begin{array}{l}\text { Narración y discurso. } \\
\text { Audiencia e identidad. }\end{array}$
\end{tabular}

Fuente: Elaboración propia.

Lo central, distintivo y duradero de la IO ha dado paso a lo dinámico e inestable (Gioia, Schultz, y Corley, 2000), a las múltiples facetas en las cuales no hay una unidad singular (Brickson 2000; Pratt y Foreman 2000; Essers y Benschop, 2007). Esto ha permitido que las conversaciones en torno a la IO sean disímiles, variadas y muchas veces contradictorias. Sin embargo, la investigación teórica y empírica sobre los procesos de construcción de identidad, podrían considerarse relativamente recientes (Kornberger y Brown, 2007; Sillince y Brown, 2009), a pesar de que "el concepto de identidad es clave para entender las organizaciones modernas" (Gioia, Schultz y Corley, 2000, p. 78). No obstante, hay poco acuerdo sobre lo que el concepto de 10 denota, o si existe una metodología para estudiarlo. Incluso, y retomando a Harquail (2004), se podría afirmar que la anarquía aún reina en el concepto de $\mathrm{IO}$. 
Frente a la diversidad de voces relacionadas con el concepto mismo de 10 , al paradigma que subyace a dicha conceptualización, y de las relaciones que tiene con otros términos, el abordaje de la 10 como objeto de estudio, así como perspectiva teórica para el análisis organizacional, requiere y exige claridad conceptual y epistemológica para no caer en inconsistencias metodológicas y teóricas, reto de todo investigador que tenga su interés de estudio en este campo de conocimiento.

Si bien es cierto que algunas distinciones importantes se han elaborado, las herramientas analíticas, tanto a nivel conceptual como su aplicación a nivel metodológico, son relativamente escasas y no permiten dar cuenta del proceso de construcción identitario como tal. Un ejemplo de ello es que aún no se ha abordado plenamente cómo los conceptos de identidad y cultura se relacionan entre sí, cuáles son sus puntos de similitud y diferencia, y el potencial que tienen para ofrecer una contribución analítica distinta a los EO. Otro aspecto aún por abordar son las posibilidades que tiene la 10 para comprender, tanto a nivel teórico como empírico, las relaciones de la organización con el medio ambiente, y las repercusiones en relación con la legitimidad, la reputación y la atracción de inversores, por mencionar tan sólo algunas vetas de futuras investigaciones.

La aplicabilidad del concepto de identidad a múltiples niveles de análisis y su capacidad para integrar conocimientos analíticos a nivel micro, medio y macro, subraya aún más su potencial de convertirse en un constructo integrador. Como Albert, Ashforth y Dutton (2000) han argumentado: "el poder de la identidad y la identificación se deriva de la capacidad integradora y generadora de estos constructos" (p. 13). El reto estará entonces en encontrar formas de desarrollo y despliegue de conceptos de identidad que sean atractivas a través de los límites científicos sociales tradicionales, para ofrecer la posibilidad de múltiples tipos de análisis perspicaces, siendo a la vez lo suficientemente bien definidos para promover una comprensión más profunda de la compleja realidad organizacional. 


\subsection{A MANERA DE CONCLUSIÓN}

Las conceptualizaciones de lo que es la IO, y los alcances que tiene para el análisis organizacional, están lejos de ser un tema cerrado. Kenny, Whittle y Willmott (2011) en un reciente texto sobre identidad y organizaciones, ponen en debate la importancia de este tema, como aspecto primordial y relevante para la comprensión de los fenómenos organizacionales. Por ello, en este documento se ha buscado presentar en qué va la conversación sobre el tema de la 10 dentro de los estudios de la organización. Con esto se ha querido hacer eco a las distintas voces e intereses que se vienen desarrollando alrededor del tema, abriendo de esta manera el espacio para nuevas discusiones y propiciando un mayor conocimiento de lo que es lo organizacional y lo que se circunscribe a esta afirmación.

La revisión ha permitido mostrar tres paradigmas, y algunas perspectivas teóricas para el análisis organizacional. Si bien el paradigma constructivista y el enfoque narrativo-discursivo vienen teniendo una importancia considerable (Humphreys y Brown, 2002b; Coupland y Brown, 2004; Driver, 2009; Ybema, 2010), la revisión muestra que la construcción o configuración de la 10 no sólo se restringe a estos procesos discursivos. Los conocimientos cognitivos (Harquail y King, 2010), así como los aspectos de construcción en organizaciones en evolución, con gran influencia de los procesos propiamente institucionales, ofrecen a los sujetos posibilidades de configurar una $1 \mathrm{O}$ en particular (McKendrick, Jaffee, Carroll y Khessina, 2003). A ello hay que sumarle que estas construcciones tambien se pueden encontrar en los mismos procesos organizacionales, lo que implica que la estructura subyace a muchos de los fenómenos de organización humana (Hsu y Hannan, 2005; Labianca, Fairbank, Thomas, Gioia y Umphress, 2001).

Adicionalmente, es preciso recalcar que la construcción de la IO es un trabajo que se realiza en las prácticas situadas, al participar de cierta manera en las actividades, y simultáneamente en el pensamiento como un habla interna y la generación de un sí mismo capaz de orquestar distintas voces. La construcción de 
la identidad es un proceso de autoformación al participar y entrar en contacto con las prácticas y significados culturales. En la medida en que se conocen más ámbitos de la experiencia, se generan nuevas capacidades de ser y pensar que se entroncan y permiten apropiarse de los mundos culturales. De esta manera, las personas y las actividades que se efectúan en lugares específicos proporcionan recursos identitarios a los sujetos que buscan configurar una $\mathrm{IO}$.

Aunado a lo anterior, y como parte de las reflexiones finales de esta revisión, causa cierto asombro que el tema de la 10 , a partir de la documentación revisada, prácticamente no esté ligado al tema cultural. No hay referencias o desarrollos en donde se relacionen la 10 con la cultura organizacional, más allá de que los investigadores citan textos o investigaciones sobre ese ámbito. A esto se le suma la gran variedad de temas y marcos teóricos en los cuales se toma la 10 como objeto de estudio, así como perspectiva teórica para el análisis de los fenómenos organizacionales. Así pues, se podría pensar que la IO pareciera tener la importancia y la relevancia suficientes para ser considerada como una corriente de estudio en sí misma. 


\section{CAPÍTULO 2}

\section{MARCO TEÓRICO Y CONCEPTUAL}

\section{INTRODUCCIÓN}

En este capítulo se presenta el marco teórico y se precisan los conceptos que se utilizan en la investigación; además, se expone la propuesta teórica con la que se abordó el trabajo investigativo. El tema de la identidad junto con el de organización son términos muy conocidos y vienen siendo estudiados desde distintas corrientes y disciplinas, lo cual hace necesario precisarlos y dar a conocer al lector cómo se entendió cada uno de ellos en esta investigación. Esto es de suma importancia para mantener la coherencia teórica y, por lo mismo, el rigor académico y la validez de los resultados. En este sentido, la precisión o conceptualización estará acompañada de cierta discusión, y no se repetirá lo dicho en el capítulo anterior referido a la revisión de la literatura (a excepción de algunos aspectos referidos a la construcción de $1 \mathrm{O}^{12}$ ).

El marco teórico de esta investigación se inscribe en un campo de estudios especializado en el estudio de las organizaciones denominado: Estudios Organizacionales (EO en adelante). En la primera parte de este capítulo se realiza una contextualización histórica de los EO, para luego discutir sus dimensiones ontológicas, epistemológicas y metodológicas, así como su objeto de estudio y los marcos teóricos que se inscriben en este campo de conocimiento. Se destacan su

\footnotetext{
${ }^{12}$ Con el fin de recordar el significado de las siglas, se pueden revisar las tablas correspondientes del comienzo.
} 
carácter pluridisciplinario y su postura crítica como características propias. Este apartado termina con una reflexión en torno a las posibilidades que tienen los EO de aportar, desde la comprensión y reflexión, al carácter funcional y práctico de la administración, y la importancia de divulgar este campo de conocimiento comprensivo para el estudio de las organizaciones en América Latina.

En la segunda parte se precisan los conceptos principales de la investigación, como son: mandos medios (MM), construcción de identidad organizacional e identidad personal y grupal, en la cual se inscribe la identidad profesional. En el último apartado se expone la propuesta teórica de la investigación, que no es otra cosa que la manera como se tomará el concepto de IO, y propiamente la IO de los MM, objeto de estudio de este trabajo. Se propone concebirla como una construcción dialógica entre aquello que dicen los directivos que son los MM y la concepción de 10 que ellos tienen. La 10 será el proceso sintético de dicho diálogo. Este modelo teórico sirvió además como modelo metodológico, por lo que se precisarán los aspectos que intervinieron en él.

\subsection{MARCO TEÓRICO: LOS ESTUDIOS ORGANIZACIONALES. UN CAMPO DE CONOCIMIENTO COMPRENSIVO PARA EL ESTUDIO DE LAS ORGANIZACIONES ${ }^{13}$}

\subsubsection{Contexto y surgimiento}

Ubicar y determinar puntualmente el surgimiento de los EO es una tarea compleja, tanto como su misma definición y constitución. No obstante, existen algunos hechos o hitos históricos que los contextualizan, los cuales tienen estrecha relación con la aparición de nuevas ideas y concepciones en torno a la organización, es decir, el mundo de las ideas tiene huellas geográficas que explican su aparecimiento y transformación. Siguiendo a March $(2007)^{14}$, existen

\footnotetext{
${ }^{13}$ A partir de este apartado se publicó un artículo académico: Gonzales-Miranda, D.R. (2014). Los Estudios Organizacionales. Un campo de conocimiento comprensivo para el estudio de las organizaciones. INNOVAR. En prensa.

${ }^{14}$ Para este apartado se tomarán principalmente las ideas de este autor, cuya aproximación desde el punto de vista norteamericano, tiene un claro sesgo hacia la Teoría de la Organización, cuyas bases epistemológicas y metodológicas distan de las de los EO. No obstante, el recuento que
} 
tres acontecimientos significativos en el siglo $\mathrm{XX}$ que moldearon las características propias del campo de los $\mathrm{EO}^{15}$. Estos son los siguientes:

\subsubsection{La Segunda Guerra Mundial}

La Segunda Guerra Mundial (1939-1945) trajo una profunda devastación económica e intelectual a Europa, por lo que su reconstrucción tuvo un proceso lento. Si bien había algunos académicos europeos importantes que estaban trabajando en los estudios de las organizaciones antes del periodo de la postguerra, no fue hasta bien avanzada la década de 1970 que los estudios de las organizaciones lograron tener una importancia destacada. Esta recuperación lenta contrastó con la de Norteamérica, ya que allí en este mismo periodo de tiempo ella fue relativamente rápida, expandió las instituciones norteamericanas con su política económica a otras latitudes, y permitió igualmente la inmigración de académicos de Alemania, Austria y el resto de Europa Central ${ }^{16}$.

Esta invasión intelectual permitió el florecimiento de académicos y estudiosos en Estados Unidos, que según March (2007) fueron alrededor de 100 veces más de los que se tenía en ese momento. Es en este escenario en el que en 1965 Rand McNally publicó el Handbook of Organizations, en donde sus contribuyentes fueron toda una generación de estudiosos de la postguerra, profundamente influenciados por el entrelazamiento de una conducta científica desarrollada en

presenta March ilustra el surgimiento del estudio de las organizaciones, de ahí su pertinencia y valía para retomarlo. Sin embargo, esta contextualización no es la única. Se pueden revisar otras clasificaciones, como la de Westwood y Clegg (2003), Reed (1996), Ibarra (2003, 2006), Ibarra y Montaño (1990), Barba, Montaño y Solís (1999), entre otros.

${ }^{15}$ Es importante destacar que para el autor se puede encontrar a los precursores de los EO en Asia y en África, con contribuciones sobre las organizaciones desarrolladas en Europa después del Renacimiento y de la Reforma a través de los años 1930 sobre los cimientos de las incipientes disciplinas sociales y la ingeniería humana. Algunos de estos precursores de las organizaciones modernas incluyen a científicos sociales como Durkheim, Marshall, Michels, Mosca, Pareto, Smith y Weber; complementados con los ingenieros europeos Fayol y Urwick, y los norteamericanos Gulick, Mayo, Dewey, Parker Follet y Taylor. Para March (2007), estos personajes fueron los pioneros, pero antes de la Segunda Guerra Mundial, los precursores del campo de los EO fueron básicamente europeos.

${ }^{16}$ Para March (2007), Adolf Hitler permitió la llegada a Norteamérica de pensadores que nacieron en Europa Central y llegaron a Estados Unidos escapando de la persecución. Algunos de estos grandes contribuyentes al estudio de las organizaciones en Norteamérica fueron: Blau, Heider, Lewin, Machlup, Morgenstern, Schumpeter, Schütz, Friedrich A. von Hayek, entre otros. 
América del Norte. Esta posguerra incluye una larga lista de estudiosos de las organizaciones, no sólo de refugiados procedentes de Europa Central sino de otros académicos como: Richard M. Cyert, Robert Dubin, Alvin W. Gouldner, Mason Haire, Robert Merton, W. Richard Scott, Philip Selznick, Herbert A. Simon, Karl E. Weick, por mencionar sólo algunos.

En este sentido, se puede afirmar junto con Barba, Montaño y Solís (1999, p. 78) que "Estados Unidos es el país en donde se desarrolla históricamente el estudio de las organizaciones". Luego de la Revolución Industrial en Inglaterra (18801930), Norteamérica no solo se benefició con la llegada de muchos estudiosos de las organizaciones de Europa Central, sino que, fruto de la hegemonía política y económica, sajona y protestante ${ }^{17}$ (básicamente calvinista), allí se privilegió la preservación y el aumento de la individualidad por medio de la propiedad privada. El modelo organizacional norteamiericano se vió influenciado por el pensamiento práctico de estos inmigrantes, en el que la acumulación del capital era signo de elección divina (Hopenhayn, 2001).

\subsubsection{Las protestas de los años 1960 y 1970}

Los EO europeos, al igual que los de América del Norte, desarrollaron una identidad académica propia, siendo influenciados fuertemente los primeros por la expansión que se produjo en décadas posteriores de los movimientos contracultura y de protesta de los años 1960 y 1970 . Estos movimientos crearon un ambiente intelectual propio de las universidades europeas, caracterizado según March (2007, p. 14) por:

\footnotetext{
${ }^{17}$ La Iglesia Protestante surge a partir de la escisión de la Iglesia Católica en el siglo XVI. Sus principales representantes fueron Martín Lutero y Juan Calvino. Para el protestantismo la única regla de fe es la Escritura interpretada privadamente, rechazando la jerarquía de la Iglesia Católica. Existen algunas diferencias entre ambos: Ios luteranos no admiten visibilidad ni jerarquía alguna de la Iglesia, mientras que los calvinistas sostienen que la Iglesia es en parte visible y aceptan a los presbíteros como delegados del pueblo cristiano. Ya en el plano más económico, los luteranos honraron el trabajo apreciando el oficio y el valor (no en el sentido monetario) que esto tenía para la comunidad. En cambio, para los calvinistas, el valor del trabajo se centraba en la capacidad de acumular dinero. Lo individual pasó a convertirse en algo deseado y socialmente aceptado.
} 
- Una oposición a la intervención norteamericana en Vietnam y a la hegemonía estadounidense en general.

- Apoyo a la sensibilidad feminista, a la retórica y a la perspectiva histórica.

- Una crítica radical (principalmente marxista) de la sociedad y de las ciencias sociales.

- El post-estructuralismo, la post-modernidad y la cosmovisión social constructivista.

- Un entusiasmo romántico sobre el futuro de la sociedad.

En las primeras dos décadas luego de la Segunda Guerra Mundial, muchos académicos europeos como Michel Crozier, Walter Goldberg, David Hickson, Derek Pugh se interesaron en sus propias organizaciones regionales para estudiarlas. Sin embargo, el impacto económico y político negativo de la guerra fue mucho mayor en Europa que en América del Norte, por lo que tanto la recuperación económica como la académica fue más lenta. Esto repercutió en el hecho de que la expansión académica europea de los EO se produjo con un equipo y en un lugar diferentes, en un tiempo distinto y con un retraso notable en comparación con Estados Unidos (March, 2007). En la década de 1970 a 1980, numerosos centros de investigación y reconocidos académicos interesados en las organizaciones comenzaron a hacerse visibles. Entre ellos: Mats Alvesson, Nils Brunsson, John Child, Stewart Clegg, Barbara Czarniawska, Erhard Friedberg, Cornelio J. Lammers, Bruno Latour, Niklas Luhmann, Johan P. Olsen.

En este tiempo se vivió un ambiente pesimista frente a la ciencias sociales, considerándolas como un instrumento de la opresión capitalista (March, 2007). Este pesimismo se trasladó al sistema académico, a los negocios, a la ciencia, a las matemáticas y a los números, al progreso y a todo aquello que se pudiera asociar con América del Norte, pero sobre todo, a los métodos cuantitativos y la forma matemática teórica, que eran características de la época anterior. 
Los efectos de la postguerra se vieron reflejados en un primer momento en los estudios de las organizaciones en el interés en los métodos cuantitativos de investigación, en la difusión institucional de las poblaciones, en la organización demográfica, en la toma de decisiones, en el procesamiento de la información, en el estudio de redes, en el aprendizaje, en la evolución y en las estructuras comparativas. En un segundo momento, estos efectos se vieron reflejados en investigaciones cualitativas sobre la cultura, sobre estudios de género, sobre el sentido de las decisiones, sobre la construcción social y sobre el estudio del poder (March, 2007) ${ }^{18}$.

\subsubsection{El triunfo de los mercados}

La caída del imperio soviético en 1991 significó el triunfo del capitalismo (como apertura de los mercados) tanto en el sistema económico como en la base intelectual del pensamiento social, que ya se había iniciado a principios de los años ochenta con la llegada del neoliberalismo. Este hecho influyó en las universidades europeas y norteamericanas en su papel opositor desarrollado sobre todo en las facultades o escuelas de humanidades más que en las escuelas o facultades de negocios o de ingeniería. Durante la mayor parte del siglo XX tanto en Europa como en Estados Unidos- esta oposición se desarrolló sobre la base del marxismo. Esto se vino abajo cuando el imperio soviético se derrumbó. El marxismo como instrumento y símbolo de oposición perdió fuerza, y fue reemplazado por un nuevo programa de reforma social.

En América del Norte y en Europa estos acontecimientos tuvieron unas repercusiones en los EO, expresadas en lo siguiente: (1) Un efecto sobre los investigadores que arribaron durante la década de 1970 a 1980, y los efectos académicos que se reprodujeron en ellos. Un ejemplo de esto es que la búsqueda de la verdad no podía ser parte del espíritu de la investigación, ya que ésta no

\footnotetext{
${ }^{18} \mathrm{Al}$ respecto se puede revisar la polarización y el debate entre varios reconocidos investigadores dentro del campo de los EO sobre estos temas. Esto quedó registrado en la revista Organization Studies en el año de 1988 (volumen 9) en su primer número. Hickson y Kieser (1988) hacen una breve introdución a la participación de Hinings, Clegg, Child, Aldrich, Donaldson, Reed, entre otros.
} 
existía en el sentido previsto por la mayoría de los académicos tradicionales. (2) Los nuevos radicales, en su gran mayoría jóvenes, eran liberales, por lo que encontraron en esta apertura una forma de organización revolucionaria tanto en el sector privado como en el público. Las investigaciones se centraron en encontrar nuevos usos a los instrumentos de organización de los mercados, buscando el éxito tanto a nivel individual como organizacional. De esta manera, los jóvenes de la década de 1950 fueron atraídos por las ciencias; los jóvenes estudiosos de la década de 1970, por las humanidades, y los de la década de 1990, por los mercados (March, 2007). Así, el liderazgo, las fusiones y adquisiciones, la contratación externa y el espíritu empresarial se convirtieron en los principales temas de investigación.

Una tercera consecuencia (3) fue que los EO se habían vuelto menos vulnerables a la incidencia intelectual debido a su ubicación en instituciones relativamente estables tanto en Norteamérica como en Europa. Los dos primeros hechos históricos habían promovido los EO como un nuevo campo de conocimiento. Esto fue cuestionado en los años de 1980 a 1990 por la contrarrevolución fruto de la caída del imperio soviético, amenazando con enajenar y aislar a los estudiosos de las organizaciones y a sus herederos.

Para Ibarra (2006) esta apertura de mercados y la racionalidad que la acompañó, modificaron la concepción de la organización, "propiciando el análisis sistemático de los problemas específicos de organización, gobierno y desempeño, que ocuparán paulatinamente un lugar mas relevante en las agendas de investigación de las disciplinas sociales" (p. 89).

\subsubsection{Una caracterización inacabada}

Luego de haber presentado el anterior contexto histórico del surgimiento de los EO, se presenta una propuesta para caracterizar los EO. Esta se realizará con base en tres dimensiones (Guba y Lincoln, 1994): lo ontológico, que hace referencia a cuál es la forma y naturaleza de la realidad y, por tanto, qué es lo que 
se puede conocer de ésta; lo epistemológico, que hace referencia a cuál es la naturaleza de la relación entre el conocedor y lo qué puede ser conocido; y lo metodológico, que hace alusión a cómo puede el conocedor encontrar lo que él cree que puede ser conocido. Al final de este apartado se discutirán brevemente una serie de definiciones de los EO, siempre con el ánimo de abrir la discusión y no esclarecer acríticamente un campo de conocimiento que se encuentra en proceso de construcción y divulgación.

\subsubsection{Ontológico}

La realidad que se aborda dentro del campo de los EO es la organización misma. En este sentido, la reflexión girará en torno a su concepción, que está mediada básicamente por dos aproximaciones: aquellos que afirman que las organizaciones son reales y, por ende, se aproximan al realismo afirmando que el mundo existe independientemente de la percepción que se tenga de él (Moore, 1903; Russell, 1929); y las otras perspectivas de aquellos que no comparten esta posición. Entre ellas ${ }^{19}$ : Subjetivista (Kuhn, 1970; Lincoln y Guba, 1985), Constructivista Social (Berger y Luckman, 2008), y sobre todo - dentro de los estudios propiamente de la organización- las llamadas Postmodernas 0 Postpositivistas (Alvesson y Deetz, 1999; Burrel, 1979; Clegg, 1990; Deetz, 2000).

Los realistas reconocen que las observaciones que hacen, y cualquier evidencia de la realidad, se filtran necesariamente a través de los sentidos, métodos de medición, y el contexto socio-cultural en el que se lleva a cabo la investigación (Boal, Hunt y Jaros, 2003). De esta manera, los fenómenos del mundo, y con ellos el de las organizaciones, son vistos como dependientes de la capacidad de comprender la manera en que los individuos dan forma al mundo desde el interior de sí mismos por medio de los sentidos. Así, el realismo convive también con una gran carga subjetiva y contingente.

\footnotetext{
${ }^{19}$ Se puede revisar el trabajo de Fleetwood (2005) en donde, desde el punto de vista del realismo crítico, resalta ciertas ambigüedades y errores que comete la posmodernidad al querer construir una ontología social.
} 
Ahora bien, la organización no solo se puede entender como una entidad social concreta (ya sea socialmente construida o no), con carácter duradero y con una serie de características y tendencias, sino también como un espacio en donde confluyen distintos fenómenos sociales. Teniendo en cuenta esto, la organización es un proceso interminable de fabricación, más que una cosa sólida y estática. En este sentido, los EO estudian las organizaciones no solamente desde el punto de vista empírico sino como "el análisis sostenido de los impulsos organizativos genéricos que dan forma contemporánea a los modos de análisis, códigos de conducta, gestos sociales, uso del vestido, gestos, posturas, reglas del derecho, disciplinas del conocimiento y así sucesivamente" (Chia, 2003, p. 98).

Para Chia (2003), cuatro son las consecuencias que tiene esta dimensión en los EO: (1) Del énfasis modernista que le daba primacía ontológica a la substancia, a la estabilidad, al orden, a la regularidad y la forma, se pasa a una ontología influenciada por Heráclito ${ }^{20}$, en la cual se subraya el proceso, la indeterminación, el flujo, el sin-forma y el cambio incesante. Se hace énfasis entonces en una orientación metafísica que hace hincapié en una primacía ontológica de naturaleza cambiante, en un proceso continuo. (2) A partir de lo primero (ontología que resalta el proceso), se deduce que el lenguaje, y en particular las actividades de denominación y representación simbólica, permiten una ordenación y estructuración sistemática del mundo. Los nombres, símbolos, conceptos y categorías ayudan a objetivar las experiencias, y al hacerlo, permiten hacer un mundo más estable, predecible y habitable. (3) El compromiso con un devenir supone la transformación de la simetría conceptual entre lo consciente y lo inconsciente, entre lo visible y lo invisible, entre la presencia y la ausencia, es decir, aquello que está en proceso de, canalizando la atención en el proceso como tal, en aquello que no está de un lado ni del otro. No se trata de centrarse en los extremos, sino en el matiz que se encuentra a lo largo de ellos. (4) En vez de

\footnotetext{
${ }^{20}$ La propuesta de Heráclito, en la expresión todo cambia, permite comprender la posibilidad del paso de un estado a otro. Si bien la unidad tiene un lugar importante en su doctrina, es una unidad compuesta de diversidad, en la que el cambio no es sólo una apariencia.
} 
pensar en términos de explicaciones causales, se opta por un enfoque procesual de análisis.

\subsubsection{Epistemológico}

Desde la dimensión epistemológica, los EO tienden a tomar posición por el constructivismo y no por el positivismo sociológico ${ }^{21}$, que había primado en un primer momento en el estudio organizacional. Este positivismo, en su forma moderna, se ha aplicado en las organizaciones en un intento por comprender a los individuos que se encuentran en su interior (Blau y Schoenherr, 1971; Hannan y Freeman, 1989), haciendo uso de las relaciones causales, es decir, de los patrones que se repiten a través del tiempo (Donaldson, 2003). De esta manera, la generalización y la determinación constituyeron los componentes básicos de la teoría positivista de la organización (Burrel y Morgan, 1979).

El constructivismo considera, en cambio, que las personas crean la sociedad (Berger y Luckmann, 2008) y sus estructuras constitutivas como son las organizaciones, a pesar que no sólo se reducen a ello. La organización no existe como entidad supraindividual, sino sólo cuando sus miembros desempeñan sus funciones e interactuan construyéndose socialmente. En este sentido, con el constructivismo se busca develar aquellos aspectos sociales que se encuentran olvidados. Al estudiar los procesos de construcción se comprende cómo las mismas organizaciones surgen o desaparecen (Czarniawska, 2003), y —desde un punto de vista mas crítico- es volver a los orígenes de las organizaciones y de las formas organizativas, a fin de desreificar a la misma organización (Burrell y Morgan, 1979).

A diferencia de los EO, la TO promueve una epistemología que valide el conocimiento, la cual tiene que ser consistente con el realismo naturalista que asevera que es posible estudiar un fenómeno usando los enunciados de las

${ }^{21}$ Comte (1853) trató de crear un cuerpo de conocimientos sobre la sociedad de forma analógica a las ciencias naturales, por lo que el único conocimiento auténtico era el científico, pilar básico para la construcción de un pensamiento preciso y correcto, pero al mismo tiempo, utilitario y pragmático. 
ciencias naturales (McKelvey, 1997). La TO busca que sus resultados sean capaces de ser comparados con los fenómenos que estudia, de ahí que necesite cierto grado de precisión. Al respecto, Lex Donaldson (2003) afirma que el positivismo es el mejor enfoque para el análisis organizacional. Inspirado en el modelo de las ciencias naturales -expresa el autor-, el positivismo busca producir un conocimiento superior al sentido común. Con ello intenta explicar la acción humana y la estructura social, causada por factores objetivos que fungen como restricciones externas con las cuales las personas se enfrentan. Desde esta perspectiva, la orientación positivista es aliada del funcionalismo estructural y social, y por ende de la administración. Las estructuras de la organización, por ejemplo, se explicarían desde su obligatoriedad y capacidad para adaptarse a situaciones contingenciales tales como el tamaño de la organización y la estrategia, o frente al hecho de evitar o no disfunciones, como puede ser por ejemplo, el bajo desempeño de la organización.

Así, el positivismo aspira a promulgar generalizaciones de amplio alcance. Las organizaciones y los comportamientos de los sujetos, presentan regularidades, patrones que se repiten a través del tiempo. Detrás de estos patrones hay causas y efectos que se relacionan, por lo que un determinado efecto producirá una causa específica. De esta manera, la generalización y el determinismo se convierten en aspectos centrales de la teoría de la organización positivista (Burrel y Morgan, 1979).

\subsubsection{Metodológico}

Desde el punto de vista metodológico, lo primero por decir y considerar es que los hechos científicos no existen por sí mismos, esperando ser descubiertos por los investigadores. Un hecho científico es una construcción abstraída de una realidad compleja y entrelazada por medio de definiciones arbitrarias y clasificadas de acuerdo a un criterio en particular e indefinido de posibilidades (Knorr Cetina, 2005; Latour y Woolgar, 1979). Así, los procesos de selección de un problema o de una hipótesis, su delimitación, el alcance del estudio, la definición y 
clasificación de los datos pertinentes para la configuración del problema, implican una opción, una decisión por parte del investigador (Myrdal, 1958). Se debe, por tanto, reconocer la participación del investigador dentro de la dinámica de construcción, no como un observador neutral, sino como un cómplice implicado.

Derivado de ello, desde los EO no se buscará la mejor manera de hacer las cosas, sino que se afirmará que existen múltiples formas de hacer las cosas. Debido a esto, el enfoque ya no estará en la universalidad del método, sino en el particular y específico camino del conocimiento comprensivo propio a cada organización. De lo impersonal y descontextualizado del proceso, se pasa al reconocimiento de lo propio, de lo único e individual que cada organización trae consigo.

Por otro lado, los argumentos metodológicos en las ciencias sociales son los argumentos acerca de la práctica discursiva, es decir, del lenguaje, y éste nunca es neutral. Inevitablemente cautiva al lector por una interpretación posible dentro de un conjunto infinito de posibilidades alternativas (Case, 2003). Las preguntas de investigación dentro de los EO se dirigen esencialmente a la búsqueda de comprensión de procesos organizacionales y a la manera en que se realizan las interacciones entre los diversos factores que intervienen en ellos. Esto lleva a afirmar que los EO tienden a reconstruir e interpretar procesos complejos de significados. En ese sentido, los EO buscarán la captación y reconstrucción de significados, con una mayor utilización de lenguaje conceptual y con un modo de captar información flexible y desestructurada, un procedimiento más inductivo que deductivo y con una orientación holística y concretizadora (Hancké, 2009; Breweton y Millward, 2001; Shankar Pawar, 2009).

\subsubsection{Acercamientos a una definición}

¿Qué son los EO? La respuesta no va a estar exenta de discusiones y controversias. Se puede afirmar que los EO no son un cuerpo de conocimiento que busque una teoría universal que ilumine los procesos y las acciones de los actores, —su misma denominación como estudios así lo sugiere — sino conocer y 
comprender las pluri-racionalidades que no sólo se encuentran en las empresas sino en toda organización. De ahí que sea más conveniente llamarlos un campo de conocimiento más que una ciencia o disciplina coherentemente estructurada.

Al respecto, Westwood y Clegg (2003), a partir de las discusiones de Bill McKelvey (2003) y Mihaela Kelemen y John Hassard (2003), sostienen cuatro razones por las cuales se podría afirmar que los EO no podrían ser considerados una disciplina. (1) La epistemología positivista tiene graves deficiencias en la explicación de lo que ocurre en las organizaciones. (2) Las realidades organizacionales son complejas y diversas, de tal forma que la representación unidimensional no es apropiada para su estudio. (3) La sociedad actual se enfrenta a una evidente crisis moral en relación con los viejos criterios técnicamente racionales para la decisión y elección, basados en la eficacia y la utilidad. (4) Los EO buscan contribuciones académicas a partir de estudios particulares, por lo que no pretenden la creación de grandes teorías y discursos.

Una primera aproximación sobre lo que son los EO la dan Clegg y Hardy (1996) en la introducción al "Handbook of Organization Studies":

\begin{abstract}
Definir hoy Estudios Organizacionales, no es una tarea fácil. Nuestro enfoque es conceptualizar los Estudios Organizacionales como una serie de conversaciones, en particular de aquellos investigadores organizacionales que contribuyen a constituir las organizaciones mismas por medio de términos derivados de paradigmas, métodos y supuestos, ellos mismos derivados de conversaciones anteriores. (Clegg y Hardy, 1996, p. 3).
\end{abstract}

Estas conversaciones abren la posibilidad para que distintas disciplinas puedan estudiar las organizaciones, de ahí que los EO contengan una pluralidad de paradigmas $^{22}$ (Hatch y Schultz, 1997). De esta manera, la proliferación de múltiples discursos asegurará que un paradigma no domine o sustituya a los

\footnotetext{
22 Un paradigma es un conjunto de creencias compartidas y de supuestos sobre el mundo. Funge de contexto a las teorías dentro de un área particular del conocimiento, sirviendo a su vez como referente para agruparlas y clasificarlas. Kuhn (1970) los define como "logros científicos universalmente reconocidos que, por un tiempo, ofrecen problemas y soluciones modelo para una comunidad de practicantes" (p. viii). Los paradigmas rigen el progreso de lo que se denomina ciencia normal, en la cual la obra del científico se dedica a la articulación y a la aplicación amplia del paradigma aceptado que, en sí mismo, no se cuestiona ni se critica.
} 
demás, y que "las voces de la disidencia y el clamor de las alternativas compitan por un espacio auditivo" (Burrell, 1996, p. 645), apartándose de la gran teorización única y eficiente para resolver los problemas organizacionales.

En suma, los EO como campo de conocimiento dedicado al análisis de las formas de organización y a las acciones y medios de gobierno, suponen una atención muy marcada sobre los sistemas y procedimientos que regulan la acción, pero comprendiendo siempre que ellos son producto de relaciones y procesos sociales altamente contingentes, a partir de lo que constituye, organiza y transforma la realidad (Ibarra, 2006). Desde los EO, la organización se convierte en el instrumento del sujeto, es decir, los EO estudian al individuo dentro de la organización, por lo que se recobra su carácter social con base en una perspectiva no instrumental $\left.\right|^{23}$.

Teniendo esto presente, se pasa a discutir el objeto mismo de los EO -ya introducido en el apartado sobre sus dimensiones ontológicas- a partir de dos aspectos. El primero, el aporte que al respecto ofreció el Movimiento de la Contingencia, y el segundo, la definición de Organización en sus tres acepciones a partir de la propuesta de Clegg y Hardy (1996).

\subsubsection{Su objeto de estudio}

\subsubsection{Un mirada desde el Movimiento de la Contingencia}

A partir de los estudios de Woodward (1975), Pugh (1997), Burns y Stalker (1961) y Lawrence y Lorsh (1973), principales exponentes del Movimiento de la Contingencia (movimiento que se inscribe dentro de la llamada Teoría de la Organización ${ }^{24}$ ), se incorporaron otras categorías de análisis distintas a las que

\footnotetext{
${ }^{23}$ Sobre la fundación de los EO se puede revisar Montaño (2013) en donde el autor hace una breve reseña del inicio de los EO en Europa a la vez que introduce un aspecto importante de sus características como es la crítica. Sobre ella se profundizará más adelante en este mismo capítulo. ${ }^{24}$ Para ver un panorama sobre las diversas maneras de concebir el desarrollo de la Teoría de la Organización, se puede consultar: Clegg, Hardy y Nord (1996); Clegg y Dunkerley (1980); Hall (1996); Hatch (1997); Ibarra y Montaño (1992); Mouzelis (1975); Perrow (1991); Pfeffer (1992, 2000); Reed (1996); Silverman (1975), entre otros.
} 
hasta ese momento habían concentrado la atención en los estudios de la organizaciones, creando una divergencia caracterizada básicamente por realizar estudios de varias organizaciones, por la utilización de métodos cuantitativos y por la posibilidad de generalizar a partir de los resultados empíricos obtenidos (De la Rosa, 2007). Se cuestiona la propuesta taylorista del one best way, para afirmar con la expresión all depends que no hay una mejor forma de hacer las cosas sino muchas mejores formas, tantas como organizaciones existan (Montaño, 1994).

Básicamente, y contrario a lo que la misma Teoría de la Organización pretendía, los resultados de sus principales representantes pusieron la atención en la organización como tal. En efecto, al estudiar el contexto (conjunto de circunstancias temporales que rodean a una organización, y sin las cuáles no se podría comprender los fenómenos que se inscriben en su interior) y el entorno o ambiente (aspectos económicos, sociales, culturales, morales, etc., que circunscriben a una organización concreta), el referente de la organización quedó como objeto de estudio propio en las investigaciones de los principales representantes de este movimiento. Las organizaciones se convirtieron en el interés $\mathrm{y}$ en el objeto de estudio, pues sobre ellas recaen los factores contingentes. Junto con esto, el intento de construir un gran y único discurso es reemplazado por lo particular y específico, es decir, por la singularidad. Al no existir ya posibilidades de universalizar los conocimientos, la organización comenzó a ser considerada como objeto de estudio, en cuyo interior los fenómenos sociales inscritos buscarán ser comprendidos antes que solucionados.

Esto se corrobora en el caso de algunas de las investigaciones realizadas. Por ejemplo, Woodward (1975), al estudiar las organizaciones, encuentra que sus estructuras no están relacionadas con el tamaño, con el tipo de industria o el éxito mismo de la empresa; sino con el tipo de tecnología. Así, cada tipo de organización tiene una forma de organización específica, y a cada estructura le corresponde un sistema productivo específico, o sea, organizaciones con similares sistemas de producción, tienen estructuras similares. 
Por otro lado, Pugh, y otros (1963), o grupo de Aston ${ }^{25}$, usaron el análisis factorial para determinar las variables que mejor definen la estructura de la organización y su contexto interno, descubrieron que la estructura de la organización (la especialización, la estandarización, la formalización, la centralización, la configuración) está en función de las variables contextuales (historia, edad, tamaño, misión, tecnología, etc.).

A su vez, Burns y Stalker (1961), descubrieron que las organizaciones aptas para el cambio estaban caracterizadas por la baja especialización y diferenciación de sus funciones, por su alto nivel de polivalencia, por su ajuste y continua redefinición de las tareas de los individuos a través de la interacción, por su alto nivel de responsabilidad para resolver los problemas sin consultar al superior, por su alto compromiso con la tarea de trabajo y por contar con una red de autoridad, control y comunicación. Estas características rompieron con el pensamiento predominante de la época, caracterizado por el excesivo control y centralización.

Desde otra perspectiva, Lawrence y Lorsh (1973) plantearon que a mayor complejidad ambiental, mayor es el grado de diferenciación interna de la empresa, y viceversa. De modo que para alcanzar la eficiencia, las organizaciones se ven obligadas a encontrar una forma particular para su adaptación. Son estos autores los que introducen el término Teoría de la Contingencia: "A base de examinar y comparar algunos selectos estudios actuales, hemos intentado sacar a la luz las posibilidades de un nuevo enfoque basado en la investigación al que, provisionalmente, hemos dado el nombre de teoría contingente de la organización" (Lawrence y Lorsch, 1973, pp. 202-203).

\footnotetext{
${ }^{25}$ El Grupo de Aston fue constituido inicialmente por un grupo de investigadores que desarrollaron una compleja investigación a mediados de la década de los 60. Sus trabajos supusieron la apertura de una línea de investigación ampliamente aceptada, y que fue continuada a lo largo de los años por otros investigadores que no formaron parte del grupo original. El Grupo de Aston afirma que es necesario considerar conjuntos de variables que caractericen las actividades y el desarrollo organizativo, ya que la organización estructura sus actividades en función de las contingencias que debe afrontar. Por tal razón, a esta corriente se le denomina Movimiento de la Contingencia. Los fundadores de este grupo son los autores del texto de 1963.
} 
Así, el Movimiento de la Contingencia, al plantear la noción contingencial de la organización, permite distinguir tres posibles fronteras o espacios en donde encontrar el objeto de estudio que se va a investigar: (1) Por un lado, la organización en sí misma, ya que en su interior las acciones de los individuos en el cumplimiento de sus funciones la configuran como un objeto de estudio, al igual que los procesos sociales y las formas cómo están organizados los distintos elementos que coexisten allí. (2) Aquellos aspectos por fuera de la organización, que la influyen y configuran. Son los distintos contextos que van determinando la organización, y que permiten comprender los procesos que la estructuran y modifican, y (3) La relación entre las dos anteriores, es decir, el objeto de estudio es la relación entre los aspectos contingenciales y la organización como tal, en donde se resalta la injerencia, la tensión y el equilibrio dinámico entre el medio ambiente que rodea la organización y ésta como tal.

\subsubsection{La organización, las organizaciones y lo organizando}

La caracterización brevemente descrita en los apartados anteriores, aunada a los resultados generales del llamado Movimiento de la Contingencia, centra la atención en la organización como objeto de estudio de los EO. Si bien esto podría parecer algo obvio y sencillo de entender, abre la discusión sobre esta realidad por estudiar.

Ejemplo de ello son las discrepancias acerca del inicio de la teorización sobre las organizaciones, en donde hay múltiples aproximaciones. Para Michael Reed (1996), fue Saint-Simon el primer teórico de la organización, ya que fue el pionero en identificar el lugar que ocupaban los patrones de la moderna organización, identificando sus características distintivas, su influencia y significación en la emergente sociedad. En cambio, para Scott (1992), la emergencia del campo organizacional puede aproximarse a la traducción en inglés de la obra de Weber y luego de Michels, así como a los trabajos que de ello derivaron en la Universidad de Columbia con Merton. Al mismo tiempo, en la ahora Universidad de Carnegie Mellon, un equipo multidisciplinario liderado por Simon enfatizó sus estudios en la 
comprensión de la toma de decisiones. Posteriormente, una perspectiva de racionalidad limitada (March y Simon) sustituyó esta visión para reemplazarla por una de múltiples racionalidades (Cyert y March). Scott (1992) afirma que hasta ese momento se puede hablar de un área de identificación fortalecida incluso en la investigación empírica que sustenta su legitimidad en sus bases ancestrales, como Maquiavelo, Saint Simon, Marx y Weber, y más recientemente por Taylor, Barnard, Mayo, Gilbreth y Parker Follet. Para el autor, tres libros proveen una integración y mayor interés al campo organizacional: March y Simon (1958), Etzioni (1986) y Blau y Scott (1962), en donde incluye también la revista Administrative Science Quarterly, fundada en 1956.

La organización, por otro lado, no corresponde ya a estructuras ordenadas y estables, sino a los movimientos que dan lugar a su conformación y adaptación permanentes. La condición de modernidad ha dejado de ser ese orden estructurado fundamentado en la norma, para reconstruirse como ese proceso persistente de recreación de estructuras, producto del flujo entre agentes diversos (Ibarra, 2006). Sin pretender esclarecer las controversias que giran actualmente en torno a este concepto, los términos de organizaciones (objetos empíricos), organización (discursos teóricos) y organizando (proceso social), propuestos por Clegg y Hardy (1996), ayudan a adentrarse en el objeto de estudio de los EO ${ }^{26}$.

Las organizaciones existen como objetos reales dentro de un contexto sociocultural específicos. Tienen una historia, pasan por un proceso de constitución determinado y se diferencian de otras organizaciones. Sin embargo, esto no significa que todas los individuos vean lo mismo de una organización. Al acercarse a las organizaciones, los investigadores eligen una serie de interpretaciones y representaciones, definiendo así el sentido propiamente empírico. Poder darles sentido a las organizaciones en términos particulares es siempre un efecto del

\footnotetext{
26 Vale la pena aclarar y resaltar que las tres formas de apreciar la organización no son excluyentes o complementarias, sino incluyentes y principales; es decir, al momento de acercarse a estudiar una organización, si bien en algunos casos los tres conceptos pueden ser válidos para acotar aquello que se quiera estudiar y dependiendo del objetivo de la investigación, uno de ellos primará.
} 
privilegio teórico permitido por ciertas formas de ver, ciertos términos del discurso y sus representaciones conversacionales. Al mismo tiempo, estos términos de representación ya son formas de no ver, formas de no distinguir otras representaciones conversacionales, por ende, formas de no aceptar otros posibles atributos de las organizaciones (Clegg y Hardy, 1996).

Dado esta representación, las características prominentes no son atributos de la organización, sino que son el efecto de la interacción recíproca de distintas visiones de ellas. Es decir, que la visión es organizada (que no necesariamente tiene que converger con otras miradas) en el mundo empírico de las organizaciones. Es por ello que algunos autores afirman que las organizaciones no existen porque son un concepto, no una construcción (Arnott, 2002).

En la segunda acepción, la organización también es vista como discursos teóricos que sirven de marcos conceptuales para estudiar los fenómenos que acontecen en una empírica y real organización. Las discusiones en torno a su constitución o caracterización y a las relaciones que tienen en su interior también pueden ser abordadas desde un punto de vista meramente teórico, sin necesidad de contar una organización empírica para su estudio. Y es que la organización se ha visto paulatinamente reforzada en las últimas décadas por la incorporación de distintas connotaciones en la región, habiendo sido caracterizada como ambigua y, por lo tanto, inexistente (Barnard, 1948). Para Ibarra (2006) el uso del vocablo organización permitió al menos dos efectos en el ámbito organizacional: (1) Posibilitó la sustitución de otros como el de corporación o monopolio o el de burocracia, que eran fuertemente cuestionados por sectores de la sociedad, al asociarlos al poder del dinero y a la intervención estatal desmedida. (2) Al utilizar este concepto suficientemente real y abstracto se eliminaron las diferencias sustantivas que existen entre entidades tan diversas por su naturaleza y función social (March y Simon, 1977), haciendo equivalentes y comparables realidades distintas. 
En lo referente a la concepción de la organización como lo organizando, se entiende la organización como un proceso social en constante construcción. Esto tiene como trasfondo que la organización se deriva de los efectos estabilizadores del discurso, es decir, no tiene realidad extralingüística. La organización es una abstracción conceptual que se convierte en hábitos, permitiendo así su estudio. En ese sentido, dicha rutinización es realizada por los individuos, pero también como efecto de la organización de las realidades y fenómenos que abarca el concepto en sí. Así, la identidad del individuo-agente se construye en el acto mismo de la organización (Chia, 2003).

\subsubsection{Marcos teóricos para el estudio de las organizaciones}

Los EO no reclaman para sí mismos una posición privilegiada en el estudio de las organizaciones. Por el contrario, al promover la participación y el compromiso de múltiples disciplinas y perspectivas teóricas, narrativas, prácticas o de otros paradigmas, no se está frente a un campo de conocimiento hermético, sino frente a un campo permeable, y a que desde el aporte de otras perspectivas teóricas y visiones se puedan ahondar y comprender los fenómenos que se inscriben en las organizaciones. Lejos de ser exclusivos, los EO son inclusivos (Clegg y Hardy, 1996) y de esta forma buscan movilizar el acercamiento de diversas disciplinas como un lugar de paso (Callon 1986) en el estudio de las organizaciones.

Los marcos teóricos, así como los temas estudiados u objetos de investigación, son sumamente diversos. Algunos ejemplos de los distintos temas de interés $u$ objetos de estudio - siguiendo la discusión realizada a partir de la propuesta de organización de Clegg y Hardy (1996)—, pueden ser: (1) objetos empíricos: descripción de la práctica en la utilización de verduras como ingrediente gastronómico en un restaurante de alta cocina, para mostrar la complicidad entre el agente y la estructura (Gómez y Bouty, 2011), la relación entre la investigación sobre la poesía y la actualidad de ésta en el trabajo, con el fin de comprender las relaciones que tiene con la ira (Fraiberg, 2010); el modelo de las características del trabajo para abordar el diseño de trabajo virtual (Gibson, Gibbs, Stanko, Tesluk 
y Cohen, 2011); (2) discursos teóricos: un documental de una aerolínea inglesa que permite reflexionar sobre las condiciones sociales, económicas y culturales que subyugan a la sociedad (Wood y Brown, 2011), el estudio comparativo entre japonenses y holandeses en torno al concepto de consenso (Noorderhaven, Benders y Keizer, 2007); (3) procesos sociales: los procesos de los expatriados para formar lazos que permitan la adaptación al contexto cultural desconocido (Farh, Bartol, Shapiro y Shin, 2010), el proceso de reconciliación a partir de la relación castigo-perdón, como un elemento eficaz en el restablecimiento de las relaciones afectivas (Abramson y Senyshyn, 2010).

Como se puede notar, existe una gran diversidad y variedad de objetos de estudio, incluso se podría afirmar que es poco lo que se puede dejar de analizar y estudiar en el ámbito organizacional. No obstante, estos objetos de estudio son abordados desde una gran diversidad de perspectivas teóricas que incluso pueden ser opuestas entre ellas. Según De la Rosa y Contreras (2007), algunas de ellas, comunmente asociadas a los $\mathrm{EO}$, son ${ }^{27}$ : Cultura en las organizaciones $y$ análisis transcultural, Nuevo Institucionalismo, Teorías de la ambigüedad organizativa, Análisis estratégico y poder en las organizaciones, Ecología organizacional, Psicoanálisis en las organizaciones, Antropología de las organizaciones, Organizaciones posmodernas, Aprendizaje y conocimiento organizacional, Análisis posmoderno de las organizaciones y Cambio.

Otro punto de referencia para conocer los marcos teóricos dentro de los EO se puede encontrar en el Handbook of Organizations Studies (Clegg, Hardy y Nord, 1996), en cuyos capítulos se desarrollan diversas temáticas que sirven para el análisis de los temas de interés, fenómenos organizacionales u objetos de estudio. Por otro lado, en una reciente investigación, Gonzales-Miranda, Gentilin, Ocampo

${ }^{27}$ Estos autores desarrollan un cuadro sintético de los EO a partir de las siguientes variables: Conceptos o ideas relevantes, autores relevantes, concepción metafórica de la organización, elemento de la organización emblemático del enfoque, nivel de análisis y aspectos metodológicos. Por tal razón, este trabajo es ilustrativo para introducir al lector en el tema. 
y Sierra $(2012)^{28}$, no sólo se corroboró la actualidad de los marcos teóricos de los EO, sino la gran importancia que vienen adquiriendo dentro del ámbito académico para el estudio de los fenómenos organizacionales en los últimos doce años a nivel mundial.

Así, el campo de los EO es heterogéneo por la gran participación de numerosos enclaves que tienen estilos diferentes, orientaciones y creencias. No se integra ni por la teoría compartida, ni por la perspectiva compartida, ni siquiera por una tolerancia compartida para múltiples perspectivas. Conserva una substancia intelectual, geográfica y un discurso propio, con enclaves separados que persisten en sus propios mundos del discurso y en la formación de un campo común únicamente caracterizado paradójicamente por la diversidad (March, 2007).

La breve contextualización de este campo de conocimiento, expuesta en el primer apartado, ubica también su surgimiento como una respuesta alternativa a la Teoría de la Organización.

[...] se trata de un proyecto de origen europeo que intentó vencer tanto la hegemonía estadounidense de la Teoría de la Organización como ampliar el espectro social analítico de la organización, recurriendo de manera más constante al pensamiento crítico. No obstante, dicho esfuerzo quedó fuertemente anclado en territorio anglosajón, presentado algunas dificultades de comunicación con el resto de países europeos. (Montaño, 2004, p. 9).

En este sentido, los EO retomarán críticamente la propuesta teórico-metodológica de la Teoría de la Organización para el estudio organizacional. Sin embargo, y luego de este breve recorrido, hay dos aspectos que identifican propiamente los EO: Su relación con las ciencias sociales y su perspectiva crítica.

\footnotetext{
${ }^{28}$ El objetivo de la investigación, a partir de una revisión hemerográfica, fue clasificar e identificar tendencias, autores, temáticas y marcos teóricos actuales en el análisis organizacional.
} 


\subsubsection{Su relación con las ciencias sociales y su perspectiva crítica}

\subsubsection{En relación con las ciencias sociales}

La diversidad de perspectivas teóricas lleva a delimitar los EO como un campo de conocimiento que se vale de las ciencias sociales para la comprensión de los fenómenos sociales que se inscriben en las organizaciones. En este sentido, es un campo abierto, un receptor de múltiples racionalidades, las cuales permitan explicar y comprender antes que resolver problemas organizacionales específicos de corte operativo y funcional.

Como se mencionó líneas arriba, los aspectos propios de los EO no están exentos de debates, interrogantes y controversias. Esta característica específica de la pluridisciplinariedad no va a ser la excepción. La discusión se centra en los conceptos de interdisciplinariedad, multidisciplinariedad y transdisciplinariedad. No se busca zanjar las diferencias, ni mucho menos tomar una postura que acote las polémicas. Tan sólo afirmar que los EO tienen en su espíritu la participación de diversas disciplinas y campos de conocimiento.

En la investigación interdisciplinaria, los investigadores pertenecen a diversas disciplinas. A pesar de ello, logran ponerse de acuerdo en la formulación de un plan de acción y en la contribución de cada cual, es decir, el proyecto es común a todos y se tiene un mismo objetivo (Repko, 2012). Hay una auténtica integración de resultados y los aportes son revisados, redefinidos y reestructurados para construir una integración sistémica a partir del objetivo planteado (Meeth, 1978). Para Khapova y Arthur (2011), esto permite una mayor variación en las metodologías, un programa de investigación más amplio, diseños de investigación más longitudinales y, fruto de lo anterior, intercambios interdisciplinarios más instructivos.

En la investigación multidisciplinaria, los investigadores pertenecen también a diversas disciplinas, y cada uno es prácticamente independiente en su trabajo, por lo que le es prescindible conocer el trabajo de los demás. Por lo tanto, no existe 
propiamente una integración (Repko, Szoztak y Buchberger, 2013), y si la hay, está presente en una introducción que busque unir las aproximaciones de por sí disímiles, en donde se aclaran los términos conceptuales utilizados de manera unívoca por todos. Sin embargo, la explicación del fenómeno estudiado es propia de cada disciplina.

La investigación transdisciplinaria va más allá de las dos primeras (de la inter y de la multi), y se caracteriza por una completa integración teórica y práctica. Según Lattuca (2001), es la aplicación de teorías, conceptos o métodos de diferentes disciplinas con el objetivo de desarrollar una síntesis general. La transdisciplinariedad atraviesa los límites disciplinarios para ser aplicados a muchos campos de conocimiento. Este tipo de investigación es poco común hoy en día por lo complejo de su implementación, en donde los esfuerzos para que esto se dé recaen sobre todo en los investigadores en el compromiso de construir un colectivo de conocimiento.

La participación de diversas racionalidades en la comprensión de los fenómenos sociales presentes en las organizaciones, se contrapone a la monodisciplinariedad, ejemplificada por la excesiva especialización propia de la modernidad. En la medida en que las organizaciones se vuelven más complejas estructuralmente (que no se refiere necesaria y exclusivamente al tamaño de la organización sino a las dinámicas e interacciones que acontecen en su interior), es cada vez más improbable que una sola disciplina tenga el conocimiento suficiente para abordar los problemas. La modernidad, como resultado de la modernización, se basa en una diferenciación funcional creciente de los fenómenos; la posmodernización y posmodernidad ${ }^{29}$, en cambio, se distinguen justamente por el proceso inverso (Clegg, 1990).

\footnotetext{
${ }^{29} \mathrm{Si}$ bien es posible ubicar los EO como una perspectiva postmoderna, dicho aspecto no se va a desarrollar a profundidad en este apartado. Sin embargo, es pertinente acotar dicho término. El concepto de postmodernidad, ya es en sí mismo complejo. Sería lógico pensar que lo postmoderno se refiere a aquellos aspectos o posturas que surgen luego de la modernidad; sin embargo, esto no es tan sencillo. Para Linstead (2004), la existencia de la postmodernidad es constante en el tiempo
} 
Sobre esto, Lash (1988) utiliza el término desdiferenciación, en oposición a la diferenciación burocrática, y con ello pretende explicar el cambio de un modelo rígido a uno flexible; del consumo de masa, al consumo en nichos; del determinismo tecnológico, a las opciones tecnológicas; del trabajo descalificado, al polivalente, que se desarrollan en una compleja fragmentación de formas de relación, como la subcontratación y las redes. Es en relación con esta nueva manera de concebir las organizaciones, y por la misma transformación que estás tienen, que los EO apoyados en las ciencias sociales aportarán en la comprensión de los fenómenos sociales en las organizaciones, dejando de lado la unicidad de un único discurso propio de una excesiva especialización.

Esto es coherente con la misma definición de estudios. No se busca una sola teoría o un gran único discurso, sino que el término denota en sí mismo la pluralidad (Repko, 2012), en el cual diversas perspectivas teóricas ayudan a comprender con mayor profundidad el fenómeno estudiado. No se trata de encasillar los EO en alguno de los tres tipos de investigación antes referidas, pero sí afirmar que por su historia, surgimiento y sus dimensiones epistemológicas y metodológicas, los EO son un campo inclusivo en donde la pluridisciplinariedad complementa y aporta a comprender los fenómenos organizacionales estudiados.

\subsubsection{Su perspectiva crítica}

Fruto de lo anterior, la visión crítica no podrá ser ajena como elemento constitutivo propio de los EO. Dada la participación de diversas, y muchas veces disímiles, miradas teóricas, la visión crítica de los fenómenos sociales en las organizaciones será un aspecto particular presente en las investigaciones que opten por la perspectiva de los EO. La noción de crítica implica al menos dos significados comunes dentro de las investigaciones referidas al ámbito organizacional: se habla

más que sustitutiva de una época; simultáneamente preexiste a lo moderno, y sin embargo, es cognoscible sólo a través de la modernidad y después de ella. El postmodernismo es, en última instancia, aquello que escapa a todos los regímenes de orden y significación con los cuales se pretende capturar y representar la realidad. Resalta el caos, lo ambivalente, lo paradójico y ambiguo, lo no estático, la problemática de la existencia humana, y por lo tanto, busca desarrollar formas de significado respondiendo a las perplejidades de la naturaleza. 
de crítica al referirse a una sentencia o evaluación, generalmente negativa, centrada en algunos aspectos del objeto o de la práctica, y segundo, existe una cierta noción científica de crítica referida a la práctica de investigación teórica en un área temática específica llevada a cabo por eruditos en el tema. En términos generales, ser crítico es estar informado para poder establecer juicios sobre los actores y sus acciones cotidianas, promoviendo una actitud más reflexiva sobre dicho actuar (Messner, Clegg y Kornberger, 2008).

Tanto la Teoría Crítica (TC en adelante) como el postmodernismo (PM en adelante) pueden ser considerados como perspectivas que comparten aspectos convergentes y divergentes para comprender las organizaciones. Las investigaciones dentro del ámbito organizacional como managerial a partir de estas dos perspectivas no son tan recientes como se cree. La TC comenzó a estar presente en el estudio de las organizaciones a finales de los 70 y principios de los 80, mientras que el PM surgió a finales de los 80 (Alvesson y Deetz, 1999). Estas dos perspectivas surgen a partir de la desilusión de los modelos modernistas, modelos representados sobre todo por Occidente.

La TC, en sentido amplio, constituye una crítica radical a la sociedad contemporánea, caracterizada por la explotación, la represión, las relaciones asimétricas de poder, la comunicación distorsionada y la falta de conciencia. La TC, en sentido estricto, se refiere a la llamada Escuela de Frankfurt ${ }^{30}$. Dentro de

\footnotetext{
${ }^{30}$ La Escuela de Frankfurt es la denominación de una corriente de pensamiento neomarxista dentro del marxismo occidental, que formula como aportación fundamental la teoría crítica frente a la teoría tradicional marxista. En la Escuela de Frankfurt se engloban las investigaciones de varios filósofos, sociólogos, psicólogos y economistas pertenecientes o cercanos al Instituto de Investigación Social de la Universidad de Frankfurt, fundado por Felix Weil en 1923. Sus principales representantes son Max Horkheimer, Theodor W. Adorno, Herbert Marcuse, Erich Fromm, Jürgen Habermas y Axel Honneth, entre otros. La escuela de Frankfurt es uno de los centros de irradiación del pensamiento más influyentes del siglo XX. En muchos aspectos filosóficos, políticos, jurídicos y sociológicos, expresa la crisis de la cultura que se vive desde la segunda mitad del siglo XIX a consecuencia del desencanto de la razón y el embate de la dialéctica hegeliana. La TC está relacionada comúnmente con la Escuela de Frankfurt (para algunos autores ambas expresiones son sinónimos), en términos de que son un programa de reflexión filosófica, investigación social y orientación social y política. La intención de los representantes de dicha escuela, "era la de desarrollar una reflexión filosófica, social y política articulada en un trabajo interdisciplinario con las ciencias sociales, y orientada por una intención crítica y emancipadora frente a las penurias imperantes en las sociedades modernas" (Leyva,
} 
los EO, la pretensión de la TC es aspirar a sociedades y lugares de trabajo libres de dominación. Por su lado, el PM es mucho más difícil de delimitar. Dentro de las ciencias sociales, el término describe un estado de ánimo social, un periodo histórico lleno de grandes cambios sociales y organizacionales, y un conjunto de enfoques. Se enfatizan las investigaciones referidas a aspectos más relevantes de los ámbitos político y social, el uso de las concepciones de fragmentación, la textualidad y la resistencia dentro de los EO.

Tanto la TC como el PM critican el iluminismo de la modernidad y su promesa de sujeto autónomo progresivamente emancipado por el conocimiento adquirido a través del método científico. En el discurso, se atribuía a la modernidad la emancipación del mito, de la autoridad y de los valores tradicionales, a través del conocimiento, la razón y las oportunidades basadas en la capacitación y el desarrollo individual. A pesar de que reconocen parcialmente las potencialidades del iluminismo y de la modernidad (Habermas, 1984), critican sus grandes relatos basados en categorías universales abstractas; el uso de la razón como instrumento de dominación y hegemonía; la mistificación del progreso, la ciencia y la tecnología; la destrucción del medio ambiente; la promesa incumplida de emancipación humana y la exclusión social generada sistemáticamente.

La TC y el PM abren nuevas discusiones. Concretamente la TC muestra cómo el modernismo está basado en mitos, y ha adquirido una autoridad arbitraria, una vida social subordinada a la racionalidad tecnológica y ha protegido los intereses de un nuevo grupo dominante (Horkheimer y Adorno, 1979). En este sentido, para ambas perspectivas, el trabajo fundamental consistirá en responder a una dominación social, caracterizada por el resultado de la ciencia, la industrialización y la comunicación o información tecnológica, como el desarrollo positivo de capacidades pero también como formas peligrosas de dominación.

2005, p. 8). Para una mayor profundización se puede consultar el texto de Martin Jay (1974), el cual en términos de Wiggershaus (2010) "continúa siendo la única presentación histórica de gran amplitud de la Escuela de Fráncfort” (p. 17). 
Las respuestas de cada perspectiva develan, además, diferencias. La TC ve el proyecto de la modernidad como una enfermedad, y vislumbra esperanzas en reconstruir y recobrar algunas propuestas para redireccionar el futuro. En cambio, los postmodernistas anuncian la muerte de ese proyecto y proclaman la ausencia de un futuro inimaginable. La TC se ha enfocado en el sesgo y cierre del discurso histórico a través de la reificación, la universalización de los intereses sectoriales, el dominio de la razón instrumental y la hegemonía. El PM, en cambio, en el lado oscuro de la llustración, concretamente en la destrucción del medio ambiente y personas nativas, su exclusión y las consecuencias de los efectos oscuros de la razón y del progreso. Cabe resaltar que el PM no encuentra viable ese proyecto, ya que este es inherentemente problemático. Busca encontrar las voces no iluminadas, las posibilidades humanas que la propia llustración suprime. El hombre, entendido como un sujeto humano con una identidad coherente con reglas naturales y una autonomía potencial, es declarado muerto, y en su lugar se le considera descentrado, fragmentado y clasificado. La resistencia es una manera alterna de leer al sujeto, lo cual constituye la base esencial de la reforma y la revolución política de la postmodernidad.

Sin querer clasificar los EO dentro de una de estas dos líneas o posturas críticas, es preciso resaltar que en términos generales este campo de conocimiento da primacía a una actitud crítica frente a la realidad organizacional que estudia. Un debate aún pendiente, pero que se menciona con el propósito de contextualizar al lector y como ejemplo de las controversias que giran en torno a los EO, es diferenciarlos de los Critical Management Studies (ver: Alvesson y Willmott, 2003; Kelemen y Kostera, 2002; Grey y Willmott, 2005; Fernández Rodríguez, 2007), asunto que podría ser un buen ejercicio académico y que propiciaría nuevas conversaciones en el estudio organizacional.

\subsubsection{Reflexiones finales}

Este texto ha querido ser un documento introductorio a los EO. Se han presentado algunas de las controversias y diferencias de este campo de conocimiento, a la 
vez que ha querido mostrar las particularidades que se consideran como propias. Si bien los EO están todavía en construcción y muchos investigadores se acercan a él con definiciones aún inacabadas, es posible afirmar que se trata de una nueva perspectiva para la comprensión de los fenómenos organizacionales, cuya riqueza se encuentra en esa pluridisciplinariedad y en su perspectiva crítica, aspectos relevantes tanto para la investigación como para la intervención organizacional. En este sentido, los EO se convierten en un campo reflexivo y crítico que puede abonar a la formación en administración, al considerar no sólo los aspectos técnicos de la organización, sino también al centrar la atención en los efectos sociales que producen su operación, dándoles importancia capital a las formas de gobierno desde las que son conducidas las conductas (Ibarra, 2006).

Por otro lado, se puede catalogar el período moderno como el detonador de las primeras prácticas racionales para la dirección de las grandes empresas que empiezan a gestarse en el siglo XVIII, es decir, que los primeros esbozos de la Teoría Administrativa se empiezan a generar cuando la racionalidad instrumental ${ }^{31}$ adquiere liderazgo histórico. Así, la administración comenzó a simbolizar el nuevo modo de gobierno, en cuya racionalidad, la organización científica transformará la naturaleza humana; a la par que esta categoría de razón se convertirá en sinónimo de libertad, justicia y erradicación de la ignorancia (Reed, 1996). Es así como la administración se sustentará en dos racionalidades: la instrumental y la económica.

Fruto de estas dos racionalidades, la Administración se caracteriza por pretender resolver los problemas organizacionales con el fin de buscar la rentabilidad de los recursos invertidos. Por su misma naturaleza, la prescripción le será algo primordial y constitutivo; es por ello que la comprensión y la posibilidad de recurrir

\footnotetext{
${ }^{31}$ La construcción de la categoría de razón instrumental se abre camino en el periodo de la llustración. Max Horkheimer y Theodor Adorno ubican que es en el momento de exaltación de la razón, cuando comienza un proceso que lleva a presentarla con independencia, subjetivación y pragmatismo. El concepto razón instrumental parte de la crítica que realiza Horkheimer (2002) a la sociedad capitalista, ya que, siguiendo el discurso de Carlos Marx, ve dentro de dicha sociedad el germen del individualismo, del poder exacerbado, del interés por lo material y, en general, de un carácter de dominio frente a la naturaleza y la humanidad.
} 
a marcos teóricos pluridisciplinarios, así como contar con una perspectiva crítica, no serán características de la Administración, y lejos de marcar diferencias irreconciliables, e incluso discursos antagónicos, se propone los EO como un campo especializado que puede complementar la formación en Administración, en donde se busque una formación integral tanto en la intervención como en la comprensión, dado que a mayor comprensión de los fenómenos por estudiar, las acciones direccionadas a intervenir las organizaciones tendrán un sustento comprensivo que eleve las posibilidades de una gestión eficiente.

La organización es un entretejido de situaciones diversas, que lejos de buscar un común denominador a manera de cierta universalización, presenta rasgos particulares propios de cada organización, circunscrita por una historia y un tiempo específicos. Este carácter social hace que en la organización se entrecrucen diversas lógicas de acción en donde múltiples actores propugnan por disímiles proyectos sociales, y por lo mismo, distintas interpretaciones del sentido institucional, reflejando intereses particulares, como también ilusiones, fantasías y angustias (Montaño, 2004). De esta manera, el significado de la organización no es perceptible, sino que los fenómenos ahí presentes se convierten en lo ininteligible, aquello que pugna por sobresalir, pero que escondido en la dinámica de la creación humana, se oculta en forma latente. El esfuerzo académico se concentrará entonces por hacerlo inteligible, y por tanto, hacer comprensible 10 organizacional.

Junto con lo anterior, es pertinente, (luego de la discusión realizada) preguntarse: ¿a qué hace referencia la perspectiva organizacional de los EO? Sin querer establecer un condicionamiento que reduzca las posibilidades de considerar otros elementos para el análisis, se sugieren algunos aspectos que pueden ayudar a delimitar la respuesta a esta pregunta $^{32}$ : (1) Se podría pensar que las investigaciones realizadas bajo esta perspectiva hacen referencia a la literatura enmarcada dentro ella, con el ánimo de seguir la reflexión sobre las

\footnotetext{
${ }^{32}$ Al respecto se puede revisar: Contreras y De la Rosa (2013) y De la Rosa (2011).
} 
organizaciones en el punto en donde éstas estén. Lo cual no implica una exhaustiva revisión, más sí reconocer los principales autores y conversaciones ya realizadas dentro del tema específico de estudio. (2) Identificar el objeto de estudio dentro de las tres acepciones de organización antes referidas (organization, organizations, organizing). Sobre esto es importante revisar los diferentes handbooks que se han publicado sobre los diversos temas de estudio dentro de los EO. (3) Que los resultados de las investigaciones permiten ahondar en la comprensión de la misma organización, es decir, pueden brindar nuevos conocimientos sobre el objeto de estudio abordado. (4) Por último, la aproximación comprensiva y crítica como elemento fundamental. Esto no quiere decir que desde los EO no se puedan realizar procesos de intervención; sin embargo, lo comprensivo prima sobre lo prescriptivo, a manera de complemento y sustento, incluso como proceso previo a la intervención como tal.

Los elementos antes descritos pueden ayudar a clarificar que no toda investigación que se realice en una organización posee una perspectiva organizacional, o concretamente pueda ser considerada dentro del campo de los EO. Esto es importante, ya que el carácter abierto e inclusivo, y la dificultad de delimitar ciertas características de los EO, accede a que se corra el riesgo de perder el rigor y la consistencia metodológica dentro de este campo de conocimiento (Palmer, Dick y Freiburger, 2009).

Por otro lado, los EO carecen aún de relevancia para América Latina (lbarra, 2006). Para este mismo autor, esto se debe, entre otras cosas, a la ausencia de referentes históricos específicos que impiden otorgar un sentido más dinámico al mismo concepto de organización. A lo anterior habría que sumarle, la preponderancia de la visión funcionalista dentro del ámbito organizacional frente a otras visiones que tienen un reconocimiento mas institucionalizado, como lo es la misma Administración, pero sobre todo, por el carácter propio de los EO. En efecto, la pluridiciplinariedad y la perspectiva crítica exigen una apertura a la diversidad de opiniones, al disenso, a la controversia, al debate, a la disputa, al 
trabajo en comunidad de investigadores que propicien nuevas conversaciones, etc., aspectos difíciles de lograr.

En una investigación ya citada, en donde se realizó una revisión hemerográfica a nivel mundial del estudio de las organizaciones, se encontró que sólo el $0.37 \%$ de los autores son latinoamericanos ${ }^{33}$ (Gonzales-Miranda, Gentilin, Ocampo y Sierra, 2012). Este es un dato sumamente dicente para cuestionar el papel que tiene Latinoamérica en el estudio organizacional a nivel mundial, y los aportes que pudiera dar al conocimiento y a la investigación de la realidad regional latinoamericana. Es preciso señalar que esto no quiere decir que no exista un desarrollo importante a nivel latinoamericano escrito en idioma español o portugués sobre los EO, tan sólo resaltar que a nivel internacional, en donde el lenguaje escrito preponderante es de lengua anglosajona, la presencia de autores procedentes de instituciones latinoamericanas es prácticamente inexistente.

Por último, lo desarrollado en este apartado busca alentar la discusión sobre este campo de conocimiento comprensivo para el estudio organizacional. No son posturas cerradas, sino que se ha presentado una conversación más, que de seguro podrá ser interrogada, cumpliendo en sí mismo una de las caracteristicas de los EO. Pero se busca con ello continuar con el diálogo y participar en nuevas conversaciones, con el fin de dar a conocer los EO en la región y profundizar un poco más en el conocimiento que se tiene de las organizaciones.

\subsection{MARCO CONCEPTUAL}

\subsubsection{Los mandos medios}

Una primera definición de los MM la da Mintzberg (1992): "[son] aquellos empleados de la organización que se encuentran en la jerarquía de la autoridad por debajo del director jefe comprendiendo todos los niveles hasta llegar a

\footnotetext{
${ }^{33}$ La revisión de los 5.509 artículos en diez de las principales revistas a nivel mundial en el estudio de las organizaciones, consideró la institución educativa que el autor referenció en el artículo publicado. En ese sentido, no se tomó propiamente, ni necesariamente, la nacionalidad del autor.
} 
aquellos que tratan directamente con los operarios" (p. 31). Otros autores se aproximan a esta definición, afirmando que los MM están localizados debajo de los directivos y la primera línea de supervisión jerárquica de las empresas (Wooldridge, Schmid y Floyd, 2008; Raes, Heijltjes, Glunk y Roe, 2011). Sin embargo, este término también se puede traducir como ejecutivos. Para Dupuy (2006) "se trata en efecto, de quienes gozan de ese status aunque no encuadren a nadie, pero sobre todo de los individuos a los que se les confía, al menos en teoría, una misión de encuadramiento, y que ocupan una posición intermedia entre la dirección de la empresa y el conjunto de sus asalariados" (p. 9).

En relación con lo anterior no se puede dejar de mencionar un texto sobre los ejecutivos (les cadres, que bien pueden ser considerados como MM) de Luc Boltanski (1982). En este libro, el autor busca entender qué caracteriza a este grupo a partir de los elementos que tienen en común. Para ello comienza por deconstruir la realidad para mostrar la heterogeneidad del grupo, profundizando en la historia de su creación prestando especial atención al proceso de inclusión y exclusión que llevó a su formación. El autor termina por reconstruir el dinamismo de unificación que les permitió emerger y persistir. Sin embargo, esta agrupación e identificación de los llamados ejecutivos no sólo es el resultado del destino técnico o económico, sino de la movilización de tecnologías sociales múltiples que los logran identificar y clasificar. Es luego de un gran trabajo colectivo que este grupo social se logra plasmar en las instituciones en donde cobran una existencia a partir de su jerarquía y sentido de pertenencia.

Otros autores definen a los MM de una forma más general, considerándolos como aquellos que tienen una responsabilidad directa sobre los subordinados por fuera de la alta dirección (Potosky, 2008). Definir a los MM a partir del lugar que ocupan en la organización, atrapa a los MM en el medio, y propicia un conflicto entre las demandas que la organización les exige y la necesidad de buscar, al mismo tiempo, cooperación para llevar a cabo sus funciones, experimentando una falta de poder para realizar las acciones competitivas que rodean sus responsabilidades (Grison y Worland, 2000). 
Aunada a lo anterior, hay una particularidad que identifica a los MM, y es ser enlaces entre el ápice estratégico y la base operativa (Mintzberg, 2000), uniendo los requerimientos de los directivos y las demandas de la fuerza operativa (Grison y Worland, 2000). Para Wooldridge, Schmid y Floyd (2008), los MM sirven también como interface entre los actores organizacionales y aquellos dominios de la organización que se encuentran desconectados, y en este sentido, son agentes de cambios potenciales. De este modo los $\mathrm{MM}$ se convierten en una pieza central dentro de los actores organizacionales, revelando sus propias demandas por los requerimientos y lealtades tanto de los directivos como de los operarios (Grison y Worland, 2000). Junto con ello, los MM pasaron de ser considerados como un recurso para la alta dirección, cuya función era básicamente el control, a apoyar las actividades empresariales, ya que se encuentran en una mejor posición para formar entendimientos compartidos sobre las capacidades de la organización (Wooldridge, Schmid, y Floyd, 2008).

Dentro de los intentos por definir a los MM, siempre a partir de la posición que ocupan en la organización, existe una reciente preocupación por la relación que estos generan con la alta dirección. Así, algunos autores caracterizan la interface entre los MM y la alta dirección como un lugar en el cual los mundos separados de ambos se interceptan, caracterizándose por una alternancia de episodios de contacto durante cada interacción o procesos de interfaces, en donde los altos ejecutivos y los MM actúan independientemente sobre la base de supuestos, expectativas y roles (Raes, Heijltjes, Glunk y Roe, 2011).

A la definición centrada en el lugar que ocupan los MM dentro del organigrama, se le suma una serie de tareas o funciones que se les asignan a ellos: no solo tienen que evitar y solucionar los conflictos internos e interdepartamentales, sino que tienen que escuchar los problemas personales de sus subordinados. La atmósfera positiva y las relaciones personales son un medio para que los MM cumplan los objetivos dados, si esto no es suficiente, ellos recurrirán a la autoridad. En cualquier caso, ellos (los MM) consideran este tipo de actividades como parte de 
su rol y una forma legítima de asumir responsabilidades por los errores que cometen sus subordinados (Delmestri y Walgenbach, 2005).

A esto se añade que los MM cumplen una función básica de intermediación. En efecto, por estar en el centro, los MM ejercen una función de vinculación que tiene repercusión en la estructura organizacional. Los MM se convierten en un corredor de flujo de recursos y de información ${ }^{34}$ de otros actores, con la capacidad de poder mediar (Ainsworth, Grant y ledema, 2009) y, con ello, ejercer el poder formal que tienen. Shi, Markoczy y Dess (2009) consideran el corretaje como una de las principales funciones de los MM. Lo definen como el proceso mediante el cual un actor media el flujo de recursos de información entre dos o más actores que no están directamente conectados. Estos autores asumen que el objetivo de los MM es contribuir al proceso estratégico, y que el uso de sus relaciones de corretaje permite difundirla información a través de los distintos niveles jerárquicos de la organización. En el rol de corretaje, un individuo media en el flujo de fuentes de información entre otros actores que no están conectados entre las divisiones o las pequeñas unidades de negocio ${ }^{35}$.

Por otro lado, los MM pueden actuar mejor como facilitadores que como creadores de conocimiento entre los trabajadores y los altos directivos (Riege y Zulpo, 2007). Los altos directivos en firmas exitosas tienden a creer que las competencias básicas de su compañía son ambigüas, mientras que los MM tienen una visión clara de lo que constituyen las competencias de la organización (Wooldridge,

\footnotetext{
${ }^{34}$ Aunque la teoría de los procesos de información ha sido raramente usada para explicar las interacciones entre los altos directivos y los MM, la lógica de esta teoría sugiere que las decisiones estratégicas serían mayores cuando la información de los MM es exitosamente incorporada a la formulación de la estrategia, pues dicha información tiende a ser marcadamente diferente a la de los altos directivos (Raes, Heijltjes, Glunk y Roe, 2011).

${ }^{35}$ Según Shi, Markoczy y Dess (2009), la función de corretaje se descompone en cinco roles: (1) Coordinador: cuando los MM asumen el papel de bróker entre los miembros de su grupo. Un MM puede facilitar información entre dos compañeros, incluso si las partes pertenecen al mismo subgrupo. (2) Cosmopolita: cuando un MM lucha entre dos vicepresidentes de una organización matricial. (3) Representativo: Los MM pueden delegar a uno de sus compañeros la comunicación de información y negociar intercambios. (4) Guardián: los MM pueden actuar como guardianes entre los compañeros de su grupo y manipular la información que viene de afuera. (5) Enlace: cuando ninguno de los tres miembros en la triada (nivel superior, medio e inferior) pertenece al mismo grupo. El MM une niveles de administración más bajos con los de los altos directivos.
} 
Schmid y Floyd, 2008). Esto se debe a que gracias a la delegación de las responsbilidades a los niveles jerárquicos más bajos y cercanos a ellos, los MM tienen un conocimiento holístico del trabajo, aspecto que ayuda a enfocarse sobre todo en la resolución de problemas (Delmestri y Walgenbach, 2005).

Atendiendo las emociones negativas de los subordinados, los MM causan cambios en las respuestas emocionales de ellos, previenen reacciones potencialmente incendiarias y facilitan implementaciones de corrección más sosegadas al aplicar adecuadamente lo que de otra manera sería una estrategia desagradable (Wooldridge, Schmid y Floyd, 2008). El desarrollo de sentimientos positivos y la capacidad de poder conservarlos frente a la negatividad y al temor asociados a algún cambio estratégico, es una contribución central de los MM para la formulación de la estrategia.

Lo dicho hasta el momento se vislubra en la siguiente gráfica, en donde se explicita la relación de los $\mathrm{MM}$ con los otros estamentos de la organización, resaltando su lugar de estar en el centro.

\section{Gráfica 1: Los mandos medios en el centro de los estamentos organizacionales}

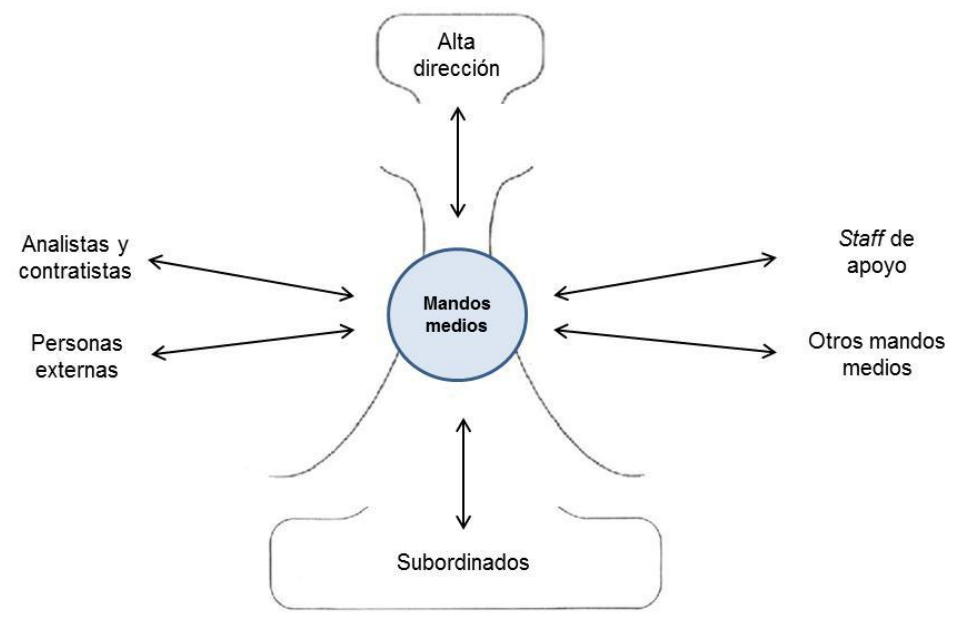

Fuente: Mintzberg, 2000. 


\subsubsection{El rol de los mandos medios}

Luego de definir a los MM, es pertinente precisar lo siguiente: la construcción de la IO de los MM es el objeto de estudio de la investigación, centrando la atención en el oficio que realizan en la organización. Si bien dicho oficio estará mediado por la propia identidad personal y la profesional, los MM realizarán una serie variada de funciones y, por lo mismo, serán catalogados y caracterizados por cada organización de manera particular, aspectos que dependen igualmente del espacio-temporal en donde la organización se encuentre.

Esta consideración permite reflexionar acerca del concepto de rol y su relación con la identidad. Para McCall y Simmos (1966), la identidad entendida como un rol es un lenguaje dramático que los individuos diseñan por sí mismos cuando ocupan posiciones sociales específicas. Esta identidad-rol se deriva de la visión imaginativa que una persona tiene de sí misma. Por otro lado, la concepción microinstitucional de Elsbach (2002) ayuda a aclarar la relación conceptual entre la institucionalización de la identidad y el rol.

Sobre el particular, se da por sentado el valor institucional de la identidad, ya que representa una normativa cognitiva con un componente emocional que antecede a los roles específicos decretados. Los roles pueden ser considerados como recursos, pero sólo en la medida en que existe una identidad institucionalizada, en donde los actores sociales puedan referirse a ella con el fin de negociar el rol que van a ejercer. Los sujetos negocian los roles día a día, y de diversas maneras los incorporan a su ser, a la vez que la formación misma de su ser se ve influenciada por estos roles. Sin embargo, los sujetos también pueden utilizar las identidades institucionalizadas como símbolos con el fin de apoyar la negociación de los roles en estas interacciones cotidianas (Delmestri, 2006). Estas identidades no son neutrales, sino que tienen un impacto en la identidad personal del sujeto.

Así, el rol de las identidades constituye la fuente principal de los planes de acción de una persona y, por lo tanto, puede influir en su vida cotidiana. Esta influencia se 
manifiesta (para McCall y Simmos) en: (1) la manera en la cual una persona valora su desempeño de los roles actuales; (2) por medio del mí, la identidad-rol proporciona un marco de referencia para las evaluaciones de los propios pensamientos y sentimientos con respecto a su desempeño; (3) el rol de las identidades da sentido a la rutina diaria, al determinar las interpretaciones de las situaciones, eventos y de otras personas con las cuales se interactúa, y (4) el rol de las identidades no sólo proporciona planes de acción y sistemas de clasificación, sino que también ayuda a determinar los objetivos del entorno, las etiquetas que se le dan y sus significados.

Por otro lado, y desde la Teoría de la Identidad, Stryker y Statham (1985) comparten la hipótesis interaccionista simbólica de que los seres humanos tienen la posibilidad de elección, aunque muchas veces las opciones se ven limitadas por la estructura social o la interacción social. Los seres humanos son, por tanto, proactivos, y no simplemente reactivos. Su teoría se centra en la relación recíproca entre el individuo y la estructura social más amplia, y entre grupos de individuos y la sociedad. La Teoría de la Identidad de Stryker $(1980,1987)$ consiste en un ordenamiento jerárquico de las identidades, diferenciando cada una de acuerdo con su relevancia y compromiso. De esta manera, el individuo no se compromete con una identidad, sino con una identidad pertinente para cada relación. La relevancia de la identidad se refiere entonces a la ordenación de las identidades en una jerarquía, de tal manera que cuanto mayor sea el posicionamiento de una identidad particular, mayor será la probabilidad de su activación. El compromiso en la relación se centra en la posición que posee una determinada persona dentro de una red de relaciones sociales.

\subsubsection{Sobre la identidad personal}

Al igual que la identidad, concebida en términos generales, la identidad personal ${ }^{36}$ tiene muchas concepciones y es necesario precisar el concepto. Una primera

\footnotetext{
${ }^{36}$ En la literatura referida al tema, se suele usar también el término identidad individual. Para efectos de esta investigación, se tomarán ambos términos en forma indistinta.
} 
aproximación la dan McCall y Simmos (1966) al definirla como las clavijas en la que las identidades sociales y las biográficas se pueden colgar. Si un individuo no puede ser reconocido en una ocasión y en otra como la misma persona, no se podrían construir relaciones sociales, y por lo mismo, no existirían identidades sociales. Para estos autores ambos tipos de identificación son de vital importancia en el proceso de interacción humana ${ }^{37}$. Es así como las identidades personales llevan expectativas de la interacción presente y futura en relación con los otros.

En relación con lo anterior, la Teoría de la Identidad Personal deriva en términos generales de los principios del interaccionismo simbólico de Mead (1934) $)^{38}$. Para Stryker (1991) cuatro son las premisas que sostienen la propuesta general de esta teoría: (1) Las personas son actores y reactores. (2) La acción humana y las interacciones se forman sustancialmente por las definiciones de los actores, y estas se basan en los significados compartidos surgidos de las interacciones entre sí. (3) Los significados y conceptos que las personas tienen sobre sí mismas son cruciales para el proceso que produce sus acciones e interacciones. (4) Al igual que otros significados, las autoconcepciones están modeladas en el curso de la interacción con los demás y son, en gran medida, los resultados de las respuestas de los demás a la persona.

37 Thoits y Virshup (1997) coinciden al tratar las identidades personales como identificadores únicos.

${ }_{38}$ Mead (1934), teórico del interaccionismo simbólico, identifica dos aspectos o fases del self que los llama el yo y el mí. Afirma que ambos son partes de un todo pero separables en cuanto al comportamiento y la experiencia. El yo es la respuesta inmediata de un individuo a otro. Es el aspecto no calculable, imprevisible y creativo del self. Las personas no saben con antelación cómo será la acción del yo. No se es totalmente consciente del yo, tan sólo cuando se ha realizado el acto. El yo reacciona contra el mí que es el conjunto organizado de actitudes de los demás que uno asume. Es la adopción del otro generalizado, las personas son conscientes del mí pues implica una responsabilidad consciente. El otro generalizado es la actitud del conjunto de la comunidad hacia mí. Mead concibe entonces la sociabilización como el proceso mediante el cual los hábitos comunes de la comunidad se internalizan en el individuo o actor. Es un proceso esencial puesto que las personas no logran tener un self ni se construyen en genuinos miembros de la comunidad hasta que no puedan responder a sí mismas al igual que lo hace el resto de la comunidad. Considera que las instituciones deberían definir lo que las personas han de hacer sólo en un sentido amplio y general, de tal modo que dejen espacio para que la individualidad y la creatividad se desarrollen libremente. 
Por otra parte, la identidad personal también se ha relacionado con el tema del rol. Así, Foote (1951) rechaza las teorías de la motivación y aspectos basados en el determinismo biológico (la persona es impulsada desde adentro) y cultural (la persona es impulsada desde el exterior), y promueve una posición a favor de una psicología social de la motivación. Toma la idea de Cooley en donde identidad y sociedad se complementan, promoviendo una teoría de la motivación basada en el lenguaje y la identificación ${ }^{39}$. De esta manera, el lenguaje es visto como un poderoso ingrediente en la motivación, ya que ayuda a dar forma al comportamiento al permitir una interpretación significativa de él, etiquetando a su vez, sus acciones pasadas con el fin de formular resultados presentes y futuros.

En los años 70, aparece otra teoría, denominada Teoría del Control Afectivo (ACT por sus siglas en inglés), cuyos representantes son: Heise (1977); MacKinnon (1994) y Smith-Lovin y Heise (1988). El núcleo de esta teoría consiste en la desviación de los sentimientos fundamentales y transitorios o situacionales producidos por la interacción con algún evento. Las personas se comportan con el fin de experimentar sentimientos de conformidad con las identidades que están tratando de confirmar en una situación en particular (identidad situada). Las emociones que experimentan en este proceso señalan hasta qué punto están teniendo éxito o fracaso en esa confirmación. Si a través de una acción una persona es incapaz de mantener los sentimientos situacionales adecuados, esta

\footnotetext{
${ }^{39}$ El Sociólogo norteamericano Charles Horton Cooley (1902) buscó explicar la sociedad sin excluir lo individual. Es por eso que trató de sintetizar el individualismo y lo social en una forma orgánica, evitando caer en perspectivas parciales. "La visión orgánica hace hincapié tanto en la unidad del conjunto y el valor peculiar del individuo, explicando uno por el otro" (Cooley, 1964, p. 36). Este uno por el otro hace referencia al aspecto distributivo (las personas hacen la sociedad) y colectivo (la sociedad hace a las personas) de los aspectos de la vida. Su visión orgánica se sintetiza en el hecho que para él, la sociedad y los individuos no denotan fenómenos separables, sino que son sencillamente aspectos colectivos y distributivos de una misma cosa. No es posible dividir la psicología social del hombre en aquello que es social y aquello que no lo es. Todo es social en un sentido. Lo social es parte del común de la vida humana. "Todo lo humano acerca de su misma historia tiene un pasado social" (Cooley, 1964, p. 47). En este sentido, el autor define el yo en términos sociales. Esto es quizás su mayor contribución a la teoría de la identidad (Hatch y Schultz, 2004). Para Cooley, la idea de identidad es definida por la percepción de cómo nos ven los demás. Plantea a su vez, la idea, promovida recientemente por los postmodernistas, que la identidad es una construcción lingüística: "Que el "yo" del habla común está envuelto en el hecho que las palabras y las ideas que definen son fenómenos del lenguaje y de la vida comunicativa" (Cooley, 1964, p. 180).
} 
persona va a reformular la definición de acuerdo con la situación concreta con el fin de adaptarse. Las emociones personales brindan una señal particular dentro de las experiencias contextuales que las ayudan a definir su situación. Esta concepción está en estrecha relación con la Teoría del Control de Identidad (Burke, 1991; Burke y Stets, 1999). Al igual que la ACT, esta teoría también hace énfasis en entender la identidad no como el resultado del estado de un individuo o rasgo característico, sino como un proceso continuo. Burke (1991) la describe "como una operación continua de ajuste, el bucle de retroalimentación en donde los individuos continuamente ajustan el comportamiento a seguir a partir de su evaluaciones congruentes con sus estándares de identidades o referencias" ( $p$. 840).

Retomando lo dicho, y con ánimo de ir clarificando esta discusión en torno al concepto de identidad personal, es necesario proponer una definición. Aquello que hace único a alguien, es la primera aproximación desarrollada. Vale la pena profundizar en ello partiendo del concepto de unicidad. Se puede entender como unicidad aquello que soporta una identidad, como la fotografía que tienen los demás de un individuo, o el conocimiento de su ubicación espacial dentro de una red de parentesco. Solo una persona a la vez puede encajar dentro de la imagen que otra persona pueda estar examinando y que llenó los requisitos del pasado al igual que los actuales. Por otro lado, la noción de unicidad también se refiere al hecho de que si bien la mayoría de los hechos aplicables a un individuo se le pueden aplicar a otro, se advierte que en ninguna otra persona se encuentra combinada la totalidad de los hechos que caracterizan a esa persona como tal. Así, la identidad personal se entiende, en términos de Goffman (2010), como:

las marcas o soportes de la identidad, y la combinación única de los ítems de la historia vital, adherida al individuo por medio de esos soportes de su identidad. La identidad personal se relaciona, entonces, con el supuesto de que el individuo puede diferenciarse de todos los demás, y que alrededor de este medio de diferenciación se adhieren y entrelazan, como en los copos de azúcar, los hechos en la melosa sustancia a la cual pueden adherirse aun otros hechos biográficos. (p. 78-79). 
En este pequeño recorrido se ha buscado aclarar los conceptos que giran en torno al tema de la identidad personal. Proceso similar se hará con las identidades basadas en grupos.

\subsubsection{Sobre la identidad grupal: lo social, lo colectivo y lo profesional}

Existen dos formas generales de ver la identidad desde el punto de vista social. Una proviene de la sociología, que es la Teoría de la Representación propuesta por Goffman (2010); y la otra, desde la Psicología Social Europea, representada por Tajfel (1981).

Desde esta última visión, los psicólogos que utilizan la teoría de las identidades sociales, conciben la identidad social como una herramienta cognitiva que las personas utilizan para participar, clasificar y ordenar su entorno social y el lugar que ocupan en él. Es por ello que les interesa examinar el efecto de determinados miembros de los grupos al definirse a sí mismos. Recurren a la identidad social y a la autodefinición para combinarlas, buscando explicaciones sobre los conflictos entre los grupos. De hecho, la Teoría de la Identidad Social fue desarrollada originalmente para explicar los prejuicios y la gran escala de conflictos entre grupos religiosos, étnicos, políticos y/o nacionales. Sin embargo, Tajfel (1981) utilizó la Teoría de la Identidad Social para desarrollar una psicología más social (valga la redundancia), como una manera de hacerle frente al sesgo individualista de la psicología americana (Thoits y Virshup, 1997). El disgusto se concentraba en la incapacidad para explicar las calamidades sociales a gran escala.

Por otro lado, la Teoría de la Identidad Social se incorpora a la teoría de la propia configuración (self-categorization) (Turner, Hogg, Oakes, Reichser y Wetherell, 1987), la cual busca hacer de la identidad social no sólo la base cognitiva del comportamiento del grupo, sino también el mecanismo que hace posible ese comportamiento. Para Tajfel (1981) la identidad social es: 


\begin{abstract}
Una parte del auto-concepto del individuo que se deriva del conocimiento de un grupo(s) social(es), junto con el valor y el significado emocional que los afilia [...] El supuesto es que, por muy rica y compleja que sea la visión de los individuos sobre sí mismos en relación con su mundo circundante [...] muchos aspectos de esta visión son aportados por los miembros de ciertos grupos o categorías sociales. Algunas de estas visiones son más relevantes que otras, y otras pueden variar en relevancia con el tiempo en función de una variedad de situaciones sociales. (p. 255).
\end{abstract}

Por extrapolación, la identidad social puede ser vista como aquella que abarca dos dimensiones interrelacionadas: el nivel del grupo y el del individuo. Sin embargo, para Tajfel, su interés no era explicar el conflicto intergrupal y la competencia a través de lo intraindividual y del proceso interpersonal, sino explorar entre los grupos los procesos psicológicos.

Desde la Teoría de la Representación, el sociólogo y escritor norteamericano Erving Goffman (1989) estudió las unidades mínimas de interacción entre las personas, centrando su atención en grupos reducidos, diferenciándose así de la mayoría de los estudios sociológicos que se habían hecho hasta el momento a gran escala. Estudió la influencia de los significados y los símbolos de la acción e interacción humanas. Plantea el desarrollo del self que realiza actuaciones estratégicas dependiendo de los escenarios y recursos disponibles. La identidad, para el autor, aparece como una construcción subjetiva de los actores sociales y les aporta una capacidad de actuación frente a las estructuras del mundo social.

Goffman equipara la interacción social con el desempeño dramatúrgico. Como una obra de teatro, los actores conspiran con su audiencia para que sean testigos de su desempeño. El trabajo de Goffman sugiere que la identidad es un desempeño y que las habilidades de los actores son relevantes para controlar o manejar las impresiones que dicho desempeño deja en los otros. Goffman (1989) se aleja de las ideas de Mead sobre el self, en particular del análisis de las tensiones entre el yo espontáneo y el mí. Existe una tensión entre lo que las personas esperan que se haga y lo que se quiere hacer espontáneamente. Las personas actúan para sus audiencias sociales con la finalidad de mantener una imagen aceptable del self. 
Es así como en diferentes situaciones (escenarios) los individuos presentan imágenes distintas. Goffman se centró en la dramaturgia como un modelo social, adoptando una perspectiva de la vida social como si esta fuera una serie de actuaciones dramáticas que se asemejan a las representadas en el escenario. No creía que el self fuera una posesión del actor; lo consideraba como el producto de la interacción dramática entre el actor y la audiencia. Este autor analizó las situaciones como si las interacciones sociales fueran representaciones, atomizando sus distintos componentes y su efecto en la interacción entre el actor y la audiencia. El self aparece como aquella apariencia que el actor muestra (una máscara) y que manipula para dar cumplimiento al desarrollo de la presentación.

La identidad en relación con los grupos también se puede ver desde el punto de vista de la identidad colectiva. Este tema fue desarrollado por Alberto Melucci, un sociólogo social europeo, el cual considera la identidad colectiva como una herramienta conceptual para comprender el desarrollo de lo micropolítico, la acción colectiva y los movimientos sociales. Como tal, es un proceso mediante el cual un conjunto de individuos interactúa para crear un sistema compartido de identidad y acción, que enmarca cognitiva y emocionalmente a través de relaciones activas con los demás (Melucci, 1989). El autor la define como:

Una definición interactiva y compartida producida por un número de individuos (o grupos a un nivel más complejo) y en relación con las orientaciones de la acción y el campo de las oportunidades y limitaciones en el que la acción se llevará a cabo. Por interactiva y compartida quiero decir que estos elementos se construyen y negocian a través de un proceso recurrente de la activación de las relaciones que unen a los actores. (Melucci, 1989, p. 70).

El programa de este sociólogo tiene tres características fundamentales: (1) la colectividad tiene continuidad en el tiempo y trata de adaptarse a su entorno social y político, (2) una colectividad se diferencia y se distingue de otras colectividades, y (3) la colectividad es capaz de reconocerse y ser reconocida por otros (Melucci, 1989, pp. 70-71). En este sentido, la identidad colectiva se construye y negocia a través de una activación repetida de las relaciones que unen a todos los individuos a determinados grupos. Polleta y Jasper (2001) afirman que la identidad colectiva 
es la conexión cognitiva, moral y emocional de una persona con una comunidad en general, la categoría, la práctica o la institución. Desde un colectivo, la identidad es una percepción de un estado compartido o en relación.

A diferencia de la identidad social, que es esencialmente un concepto a nivel individual basado en supuestas características de un grupo o una categoría a la que uno está apegado, la identidad colectiva es un distintivo a nivel de grupo. Melucci (1989) sostiene que los movimientos sociales construyen redes sumergidas de la cultura política que se entrelazan con la vida cotidiana y ofrecen nuevas expresiones de la identidad que desafían las representaciones dominantes de la situación de status quo social y político. Lo que hace interesante el concepto de identidad social, es que puede pasar a convertirse en una identidad colectiva gracias al proceso por el cual los miembros del grupo comparten mutuamente otros aspectos cognitivos y emocionales de una identidad social, que a su vez pueden movilizarse a la acción a través del surgimiento de una identidad colectiva en particular. De este modo, se puede afirmar que las identidades sociales son a los individuos como las identidades colectivas son a los grupos.

Teniendo como referente lo discutido sobre las identidades grupales, y tal como se hizo en el apartado sobre identidad personal, falta por definir el concepto de identidades profesionales. Este concepto estaría dentro de una identidad colectiva, a la vez que retoma aspectos ya discutidos de lo individual.

Así, la identidad profesional son aquellas normas identitarias que distinguen a un colectivo no sólo dentro de un sistema de acción laboral específico, sino también biográfico, de acuerdo a la trayectoria que tengan dentro de su vida laboral. Las identidades profesionales son para los individuos formas socialmente reconocidas de identificarse mutuamente en el ámbito del trabajo y del empleo (Dubar, 2002a). En este sentido, Barba, Montoya y Vásquez (2010) prefieren hablar de comunidades profesionales, distinguiendo cuatro características: autonomía, ideología, acceso a centros de poder y consolidación de una cultura profesional 
interna. Para estos autores, estos cuatro elementos se conjugan para consolidar una comunidad profesional, en donde la identidad permite consolidar su posición social y sentido, tanto de su actividad profesional como de su misma vida.

Así pues, el estudio de la identidad profesional se puede incorporar al estudio de la identidad personal, definido por Gecas y Burke (1995) como "los diversos significados unidos a sí mismo y a los demás" (p. 42). Para estos autores, la identidad personal permite la fijación en un lugar por parte de un individuo dentro de la sociedad gracias a las relaciones con los otros, implicados en el significado que los individuos adoptan de sí mismos. Es así como la pertenencia a una profesión influye en la autodefinición y en las formas como los demás piensan en una persona. Por lo tanto, la identidad profesional se puede definir como el conjunto de atributos, creencias y valores que las personas utilizan para definirse a sí mismas en tareas y habilidades especializadas, y la educación basada en profesiones o vocaciones (Ibarra, 1999; Slay y Smith, 2011).

\subsubsection{Construcción de identidad organizacional}

La construcción de la IO es un proceso cognitivo permanente, iterativo, encarnado por los empleados, quienes se basan en múltiples modalidades para asimilar la situación de la organización, con la capacidad de acercarse a ella de diversas maneras a través de información que evocan a su vez diferentes perspectivas de experiencia (Harquail y King, 2010). La construcción de IO por un miembro de la organización se basa en el procesamiento, examen, interpretación y expresión de la información incorporada, que es formal y no formal, oficial y no oficial, simbólica y material, así como la información que se comparte es colectiva, interpersonal y específica a ese individuo. Junto con esto, la conceptualización de lo que es la IO por parte del individuo se basa no sólo en estímulos físicos y experiencias, sino también en hábitos socialmente construidos, y por las acciones intencionales de gestión para elaborar ciertas creencias acerca de lo que es una organización (Dutton, Dukerich y Harquail, 1994; Humphreys y Brown, 2002a). 
El enfoque de la identidad como perfeccionamiento se extiende a la teorización de la identidad como un proceso de llegar a ser (Chia 1996; Tsoukas y Chia 2002), lo que sugiere que, en lugar de ser ontológicamente segura, la identidad surge del proceso de organización (Clegg, Rhodes y Kornberger, 2007). En ese sentido, se puede entender que exista una identificación del individuo con la organización, pero los niveles o grados de identificación no podrán platearse como sistémicos, sino como un proceso de estructuración y configuración dentro del entramado complejo de estructuras, subjetividades y acciones, permitiendo que puedan presentarse reconfiguraciones que retomen códigos de identidades anteriores que en su reestructuración tengan una connotación de autonomía, no por el voluntarismo de los agentes sino por los cambios en prácticas y estructuras (Sainsaulieu, 1996) ${ }^{40}$.

A nivel individual, Linstead y Thomas (2002) tienen caracterizado el proceso de formación de la identidad como la gestión de la tensión entre las demandas presentadas por las respuestas al continuo cuestionamiento sobre ¿Qué es lo que la organización espera de mi? y ¿Qué es lo que yo quiero ser en el futuro? La primera pregunta tiene que ver con la propia identidad como actor social dentro del espacio propiamente organizacional. La segunda pregunta tiene que ver con la construcción social de una identidad personal. Sin embargo, estas cuestiones no son discretas sino que están inextricablemente estrelazadas. Desde el nivel propiamente organizacional, estas preguntas tambien representan las dos perspectivas dominantes para el estudio de la IO: la construcción social y la visión del actor social sobre la identidad ${ }^{41}$, ambas reflejadas en dos preguntas de investigación fundamentales: ¿Cómo los miembros de una naciente organización desarrollan una comprensión colectiva de quiénes son en la organización?; y

\footnotetext{
${ }^{40}$ En su obra: L'identité au travail. Les effets culturels de l'organisation, el autor, en la edición de 1985 con un nuevo prefacio, presenta en cuatro modelos culturales el número de identidades ideales observadas en las empresas y propone los apelativos que se han convertido en clásicos: retiro, fusión, negociación y afinidad.

${ }^{41}$ Esta última no se desarrolla en este apartado. Se puede revisar el capítulo referido a la revisión de la literatura para recordar sus características.
} 
¿cómo una nueva creación de organización desarrolla un sentido de sí misma como un actor social en su campo o industria?

La visión constructivista de la identidad implica la negociación por parte de sus miembros de los significados compartidos sobre lo que somos para la organización, colocando la atención en los esquemas interpretativos que los miembros construyen colectivamente para proporcionar un significado a su experiencia organizacional (Gioia, Schultz y Corley, 2000; Whetten D. A., 2006). Ravasi y Schultz (2006) observaron que esta visión implica un énfasis en los procesos de construcción de sentido asociados a la construcción social de la identidad como significado y significados de estructuras que son negociadas intersubjetivamente entre los miembros de la organización (Fiol, 1991). De esta manera, la 10 es progresiva, compleja, recursiva, reflexiva y en permanente construcción (Ybema, Keenoy, Oswick, Beverungen, Ellis y Sabelis, 2009), negociada por los miembros de la organización por medio de sus interacciones entre sí, y con la participación de las partes externas interesadas (Hatch y Schultz, 2002; Coupland y Brown, 2004), dejando de lado las pretenciones de linealidad y causalidad rígidas para abrir espacios a comprender lo complejo de su construcción y comprensión (Simpson y Carroll, 2008).

En este sentido, la estabilidad de la identidad es, como mucho, algo pasajero, ya que su construcción será discursiva, emergente e inmersa en un proceso continuo de reconstrucción, por lo que la estabilidad será un logro momentáneo o una ficción resistente (Simpson y Carroll, 2008). Del mismo modo, tanto individual como colectivamente, desde la visión de los fundadores (Rodrigues y Child, 2008), de las repetidas negociaciones en varios niveles (Ybema, Keenoy, Oswick, Beverungen, Ellis y Sabelis, 2009), de las reclamaciones de las decisiones de la organización como entidad (Whetten y Mackey, 2002; Whetten D. A., 2006) y de la legitimación de un valor (DiMaggio y Powell, 1983), todos estos elementos están en juego en el proceso necesario de construcción identitaria. 
Para Beech (2011), la construcción de la 10 ha sido concebida como una interacción de coconstrucción entre los individuos y las estructuras sociales. La coconstrucción se desarrolla en la interacción entre la identidad del propio individuo (su propia noción de quién es él) y la identidad social (la noción de esa persona en discursos externos, instituciones y cultura) (Watson, 2009). Pero también hay que anotar que si bien es una construcción, esta tiene que parecer creíble para sus miembros, sin pasar por una estricta y rigurosa prueba de legitimidad (Albert y Whetten, 1985).

Se ha utilizado el enfoque del constructivismo social para el estudio de las identidades organizacionales (Cornelissen, 2006; Ravasi y Schultz, 2006). Las identidades se reconstruyen mediante la acción simbólica y la interacción social en contextos sociales (Cunliffe, 2002); esto es importante ya que se convierten en el marco de posibilidades para que las personas puedan crear y reconocer el sentido de sus acciones. En este tenor, para Strauss (1996), el proceso de construcción identitaria es gradual, en donde el sujeto llega a darse cuenta de que las cosas son distintas debido a un punto de inflexión que conduce a una expectativa por un nuevo significado. Para este autor, las transformaciones de la identidad se producen cuando hay una desalineación, sorpresa, shock, disgusto, ansiedad, tensión, desconcierto, cuestionamiento de sí mismo, y la persona se ve obligada a reconocer que no es la misma que era antes. Esto es similar a volverse a escribir a sí mismo (Goffman, 1974).

A pesar de existir una serie de estudios sobre la construcción de la 10 (por ejemplo, Fiol, 2002; Humphreys y Brown, 2002b; Coupland y Brown, 2004; Denissen, 2010; Brown y Lewis, 2011), y que algunos investigadores se ocupan de alguna faceta sobre la formación de la identidad en las organizaciones (Czarniawska y Wolff, 1998; Corley y Gioia, 2004; Clegg, Rhodes y Kornberger, 2007), no ha habido ningún estudio exhaustivo acerca de cómo las identidades organizacionales se forman en sus inicios (Gioia, Price, Hamilton y Thomas, 2010). Para estos autores, sólo tres trabajos han estudiado la formación de la 10 per se: Czarniawska y Wolff (1998); Clegg, Rhodes y Kornberger (2007) y Corley y 
Gioia (2004). Cada uno de ellos aborda tan sólo algunos aspectos de la construcción de la IO, pero, en su conjunto, son un buen punto de partida para una consideración más holística de la formación de la IO.

Czarniawska y Wolff (1998) estudiaron dos universidades. Una de ellas alcanzó el éxito porque logró adquirir una identidad que estaba en sintonía con su ámbito institucional, por lo que fue reconocida como una de nosotras por las otras universidades de la región. La otra universidad no tuvo tal reconocimiento, ya que siguió siendo una extraña en su ámbito institucional. Los casos comparativos no se ocupan de los detalles del proceso de formación de la 10 que se llevó a cabo en las dos universidades, pero ofrecen algunas pistas sobre dos importantes aspectos en este proceso. En primer lugar, los casos sugieren que la nueva organización puede tratar de imitar las organizaciones existentes. En segundo lugar, la forma cómo las nuevas organizaciones se presentan a sí mismas a sus audiencias externas puede ser crítica, no para la formación de sus identidades, sino para su supervivencia.

Del mismo modo, Clegg, Rhodes y Kornberger (2007) señalaron que la construcción de 10 se produce en un contexto más amplio que el de la industria en donde la organización compite, por lo que la 10 se define con referencia a aquellos que son rivales y a los que no lo son. Basados en su estudio del desarrollo de empresas del negocio del coaching, estos autores argumentaron que los miembros se comprometen con las obras de contrucción de 10 no para su propio bien, sino para facilitar la formación de legitimidad como el respaldo y el apoyo de las acciones de su organización y de sus objetivos. Sus hallazgos sugieren que la resolución de la ambigüedad es una parte importante del proceso de formación de la 10.

Corley y Gioia (2004) estudiaron una empresa que trató de establecerse como una entidad independiente luego de salir dentro de las 100 mejores empresas según la revista Fortune. Los autores encontraron que el conocimiento más importante para la comprensión de la IO era hacer frente al problema de la ambigüedad de la IO y 
definir cuál iba a ser su dominio competitivo. Encontraron también que los intentos de seguimiento de los líderes, la elección de nuevos referentes para la industria y las discrepancias entre la identidad y la construcción externa de la imagen, fueron factores importantes para el establecimiento de la IO.

Estos tres estudios sobre la formación de la 10 sugieren que el proceso de participación, tanto por alcanzar legitimidad a través de procesos miméticos como por la construcción de algunas dimensiones de carácter distintivo en el campo organizacional, requiere de un contexto externo receptivo para dichos esfuerzos. Estas conclusiones están en estrecha relación con investigaciones que sugieren la importancia de la pertenencia a grupos, industrias u organizaciones. Al respecto, Suddaby y Greenwood (2005) señalan que una identidad reclama una mayor legitimidad dentro de contextos amplios.

\subsection{DISCUSIÓN DE LA PROPUESTA TEÓRICO-METODOLÓGICA}

La investigación considera que la $\mathrm{IO}$ es un fenómeno cultural que se inscribe dentro de las organizaciones, es decir, es capaz de ser explicada por los miembros de la organización. Junto con lo anterior, no se parte de considerar esencias particulares, y por lo mismo, inamovibles de la identidad, sino como construcciones sociales en las organizaciones. En este sentido, no se puede hablar de una identidad sino de identidades, en la medida en que cada sujeto esclarece aquello central, distintivo y perdurable en la organización (Albert y Whetten, 1985).

La investigación se abordó desde una postura interpretativa, la cual contrasta con la mirada funcionalista (Kenny, Whittle y Willmott, 2011). En esta dirección, y rescatando la dinámica propia del sujeto que construye y da sentido a la realidad organizacional en el cual se encuentra inmerso, la 10 será una construcción dialéctica resultado del diálogo entre la mirada funcionalista con pretensiones de regulación por parte de la dirección, y la construcción de sentido por parte de los sujetos. Por lo anterior, es necesario explicar y enmarcar brevemente lo dialéctico. 
Georg Wilhelm Friedrich Hegel (1770-1831) ${ }^{42}$ propone el término dialéctica para comprender la realidad. Esto expresa la extrema oposición de Hegel a toda interpretación incompleta de la realidad y del conocimiento. El carácter dialéctico de lo real significa que cada cosa es lo que es, y sólo llega a serlo en interna relación, unión y dependencia con otras cosas y, en último término, con la totalidad de lo real. La dialéctica muestra que los hechos son el resultado de un juego interno de relaciones que son justamente las que constituyen las cosas, a pesar de que estos hechos aislados posean cierta independencia. Así, lo particular remite al todo, y sólo puede comprenderse gracia a ese todo.

Pero este carácter dialéctico no sólo significa que tenga una relación interna, sino, que cada cosa sólo es lo que es en un proceso continuado (Adorno, 1974). Así, la realidad no es fija ni determinada de una vez y para siempre, sino que está en un constante proceso de transformación y cambio, regida y movida por la contradicción, internamente relacionada y constituida como oposición de contrarios.

La estructura y esencia de la dialéctica es un todo complejo constituido por tres momentos o aspectos implicados entre sí:

- Lo que se ha llamado tesis (el aspecto o momento abstracto o intelectual). Suele interpretarse la tesis como una afirmación cualquiera, una realidad, un concepto. Pero esta afirmación lleva en su entraña un contrario, ya que la realidad no es estática, sino dinámica.

- Lo que se ha llamado antítesis (el aspecto o momento dialéctico o negativo -racional). Suele interpretarse como la negación de la afirmación anterior, ya que es esa contradicción el motor de la dialéctica.

\footnotetext{
${ }^{42}$ Esta aproximación e interpretación de la propuesta hegeliana es, por decirlo así, la más auténtica. No es la separación de la tesis, antítesis y síntesis; términos que, por otro lado, Hegel nunca utilizó. No se puede afirmar que existe una obra única en donde esté contemplada la visión tripartita del filósofo alemán. El desarrollo de su propuesta dialéctica se encuentra en diferentes obras. Sin embargo, se puede revisar la Enciclopedia de la Ciencias Filosóficas (Hegel, 2005) para encontrar una síntesis. Lo que se expone a continuación es tomado de este documento.
} 
- Lo que se ha llamado síntesis (el aspecto o momento especulativo o positivo - racional). Suele interpretarse como la superación del conflicto, la negación de la negación anterior. La tesis y la antítesis son a la vez eliminadas y conservadas, es decir, elevadas a un plano superior. La síntesis conserva todo lo positivo que había en los momentos anteriores. Por eso, la síntesis es enriquecimiento y perfección, es la seguridad de que la realidad está en constante progreso.

Teniendo esto presente, la propuesta teórica concibe la 10 como un proceso de construcción dialéctica entre los directivos (qué dicen que son los MM para $\mathrm{CN}$ ) y los MM (quiénes somos para $\mathrm{CN}$ ). A continuación, se pasa a explicar cada uno de los componentes de esta construcción identitaria.

\subsubsection{La alta dirección y los procesos de institucionalización (tesis)}

Es pertinente precisar que este diálogo de autorreferenciación no sólo alude a la relación de la alta dirección con los MM. Los procesos de institucionalización no únicamente vienen de arriba hacia abajo dentro de la estructura organizacional, de ahí que se hable de la organización como tal, y no exclusivamente de la alta dirección. Sin embargo, para la investigación y de acuerdo al modelo teóricometodológico propuesto, se tomarán a los directivos como los actores sociales que buscan imponer una determinada IO a los MM. Este aspecto que se discutirá más profundamente en el capítulo tres referido a los aspectos metodológicos.

Por un lado, la organización buscará fabricar la identidad de los MM, utilizando para ello una serie de estrategias y discursos legitimados, no sujetos a algún tipo de cuestionamiento, para construir una subjetividad que esté acorde con los objetivos organizacionales. La legitimación se realiza mediante el proceso de institucionalización, entendido como "un proceso socialmente integrado por el cual nos movemos de algo que es difuso, inestable y desestructurado a algo más acordado, estable e integrado" (Selznick, 2000, p. 280), que difícilmente es cuestionado. 
Los procesos de institucionalización se pueden también abordar desde un punto de vista menos macro. Zucker (2001) se preocupa por los procesos de institucionalización en las relaciones interpersonales, pero dentro de un contexto sociocultural como son las organizaciones. Para este autor, la institucionalización es el proceso por medio del cual los actores individuales transmiten lo que socialmente se define como real, y al mismo tiempo, en cualquier punto del proceso el significado de un acto se puede definir, más o menos, como una parte dada por hecho de esta realidad social.

Esto permite pensar la organización como una institución en sí misma en la medida en que las prácticas organizacionales se transmiten socialmente, a la vez que facilita comprender la transmisión y legitimación de las normas y los procesos internos. Los directivos de la organización buscarán institucionalizar ciertos procesos referidos a la identidad, como una forma de regulación organizacional.

Para Jepperson (2001) "La institución representa un orden o patrón social que ha alcanzado cierto estado o propiedad; la institucionalización indica el proceso para alcanzarlo [...] Por lo tanto, una institución es un patrón social que revela un proceso de reproducción particular" (p. 195). La institución es un patrón a seguir; pero es seguido porque es construido socialmente. De esta forma, la institución no sólo es construida sino que construye. Así pues, una noción abstracta de institución e institucionalización es útil en tanto concepto que permite entender procesos de la realidad social y organizacional.

Dentro de este contexto polémico y disímil referido al tema de la institución y la institucionalización, es preciso centrarse en el proceso mismo de la institucionalización. Berger y Luckman (2008) proponen que la institucionalización se origina en una habituación, definida como la repetición de una pauta de comportamiento que es aprendida por el que la ejecuta. Así, una pauta puede volver a ejecutarse de la misma manera y con economía de esfuerzo en el futuro. A esto le sigue un proceso de objetivación, donde se generaliza el conocimiento de receta; las instituciones se experimentan como existentes, como si tuvieran una 
realidad propia que se presenta al sujeto como un hecho externo y coercitivo. Finalmente, la sedimentación socializa, mediante sistemas de signos, la abstracción, para hacerla accesible a la comunidad y solo de esta manera existe la posibilidad de que las experiencias se transmitan de una generación a otra o de una colectividad a otra.

El proceso de institucionalización propuesto por Berger y Luckman (2008) es importante porque abre el espacio para reconocer que los hábitos implican pautas de comportamiento, las cuales generan tipificaciones, es decir, ciertos esquemas que permiten afrontar diversas situaciones. "La realidad social de la vida cotidiana, [dicen los autores], es así aprehendida a través de un continuum de tipificaciones que se vuelven progresivamente anónimas" (1997, p. 51). El rol es justamente la expresión acabada de la institucionalización. "La institucionalización aparece cada vez que se da una tipificación recíproca de acciones habitualizadas por tipos de actores" (1997, p. 76).

\subsubsection{La construcción de sentido de los mandos medios (antítesis)}

De otra parte, y siguiendo con los otros partícipes del diálogo, los MM construyen una identidad en el ámbito organizacional. Las normas, reglas y demás directrices son interpeladas, asimiladas y dotadas de sentido. A este proceso, dentro de este diálogo, es al que se le llama construcción. Gracias a ella, los MM tienen la posibilidad de elegir, a pesar de estar limitados muchas veces por la estructura social (Bauman, 2010). Esto los convierte en actores activos y no simplemente en reactivos (Stryker y Statham, 1985). Es en este sentido en el que los MM pueden ordenar jerárquicamente las identidades de acuerdo con una relevancia o compromiso para cada relación en la que se encuentren. En este contexto, la IO de los MM estará mediada por la organización y por las relaciones que en ella se produzcan y actúen como referentes.

Esta construcción, por lo tanto, no será estática, sino dinámica, combinando aspectos que permanecen y otros que cambian. Burke (1991) la describe "como 
una operación continua de ajuste, el bucle de retroalimentación en donde los individuos continuamente ajustan el comportamiento a seguir a partir de su evaluaciones congruentes con sus estándares de identidades o referencias" (p. 840). Entonces, se puede definir la identidad como aquello que hace único a alguien, ya que el proceso constructivo es propio de cada sujeto. La unicidad consiste en la dotación de sentido fruto del proceso, en la conjugación propia de los elementos que se deben considerar. Esta unicidad estará, además, sujeta a un entorno, el cual la va redefiniendo y delimitando.

Este sentido, siguiendo a Berger y Luckmann (2008), "se constituye en la conciencia humana; en la conciencia del individuo, que está individualizado en un cuerpo vivo [...] y ha sido socializado como persona" (pp. 30-31). La conciencia toma sentido en la medida en que dirige su atención hacia un objeto. "Este objeto intencional está constituido por los múltiples logros sintéticos de la conciencia y aparece en su estructura general, ya sea en la percepción, la memoria o la imaginación; alrededor del núcleo, del tema del objeto intencional, se extiende un campo temático delimitado por un horizonte abierto" (p. 31).

La construcción de sentido para los MM en esta investigación es la conciencia de las vivencias que les propician las acciones que tratan de promover en ellos una IO. Es el conjunto de experiencias suscitadas gracias a este tipo de acciones de la organización, y que los MM interpretarán y configurarán.

Una perspectiva social construccionista sobre la 10 sugiere que los miembros de una organización se basan en la comprensión relativamente compartida acerca de las características centrales y distintivas de su organización para dar sentido a su experiencia laboral (Gioia, 1998). La investigación dentro de esta tradición ha examinado cómo los miembros desarrollan entendimientos colectivos de su organización y cómo estos acuerdos afectan los cambios organizativos (Corley y Gioia, 2004; Fiol, 1991) y las decisiones estratégicas (Gioia y Thomas, 1996). En conjunto, estos estudios muestran cómo las identidades organizativas son el resultado de la interacción de múltiples actores, entre los grupos de profesionales 
(Glynn, 2000; Pratt y Rafaeli, 1997) y los niveles jerárquicos (Corley y Gioia, 2004; Fiol, 2002) que intentan dar forma a la construcción significado de otros para "dar sentido" (Gioia y Chittipeddi, 1991, p 442.) con el fin de lograr el consenso en torno a su conceptualización preferente de la realidad organizacional.

\subsubsection{La Identidad Organizacional como una síntesis}

La IO no se implementa per se. Requiere de un diálogo con los actores sociales (MM). Es fruto de este diálogo. Los MM buscarán darles sentido a las diversas manifestaciones que la dirección propone e impone. Aquí es donde se va estructurando una $\mathrm{IO}$, la cual requiere de una interpretación y dotación de sentido. Así, se propone que la misma IO es una dialéctica constante, resultado de una visión sintética entre la organización y los sujetos ( $\mathrm{MM}$, entre otros). En este sentido, no se podría hablar de una única 10 , sino de una conglomeración de significados compartidos que vislumbran una serie de características particulares y comunes.

El enfoque dialógico explica cómo es posible generar un tipo de resistencia gracias a la transformación del significado a través del diálogo interior y el uso potencial de los significados del contexto lingüístico para formar contra-narrativas y contra-discursos (Beech, 2008). El reto es analizar cómo quedan promulgados estos procesos en la construcción de un nuevo significado. De este modo, el diálogo podría conducir a reforzar o rechazar la construcción de la identidad, o a generar puntos de encuentro entre estos dos extremos.

La investigación parte de una aproximación existencialista o constructivista de la identidad, es decir, no hay esencias sino existencias contingentes, rechazando diferencias a priori y permanentes en los individuos. "Lo que existe son modos de identificación, variables en el curso de la historia colectiva y de la vida personal, afiliación a diversas categorías que dependen del contexto" (Dubar, 2002a, p. 12). Estas formas de identificación son de dos tipos: identidades para los otros (externas), que son las identificaciones atribuidas por los otros; y las identidades 
para sí (internas), que son las identificaciones reivindicadas por uno mismo. La relación entre los dos procesos de identificación es lo que se conoce como formas identitarias, es decir, sistemas apelativos, históricamente variables que vinculan las identificaciones por y para los otros, y las identificaciones por y para uno mismo.

Estas formas identitarias se dividen en formas espaciales de las relaciones sociales (eje de relaciones) y en formas societarias llamadas formas de temporalidad (eje biográfico). La combinación de estos dos ejes es lo que Dubar (2002a) Ilama formas identitarias, que no es otra cosa que el proceso de identificación de los individuos en relación con los otros y durante su vida. A una identificación particular que cruza estos ejes, se le conoce como configuración identitaria.

Esta dinámica configura el estudio de la $1 \mathrm{O}$ dentro de un eje relacional y temporal (Dubar, 2002a) que distinguirá al sujeto como tal, a la vez que generará una resistencia a la institucionalización. En este sentido, no necesariamente los directivos diseñan o planean racionalmente la institucionalización de la identidad, sino que esta se da dentro de un proceso social ya explicado líneas arriba. La regulación de la identidad convierte al sujeto en un ente más, en un instrumento intercambiable que sirve para unos fines por fuera de sí, relegando la unicidad a un totalitarismo igualitario de eficiente productividad. La resistencia consistirá dentro de esta relación de autoridad y poder- en construir una identidad, o en la aparente y cínica $\mathrm{IO}$ a la cual estarán presionados a asentir, y con la cual tienen que dialogar. Lo anterior se vislumbra en la siguiente gráfica: 


\section{Gráfica 2: El proceso dialéctico de construcción identitaria}

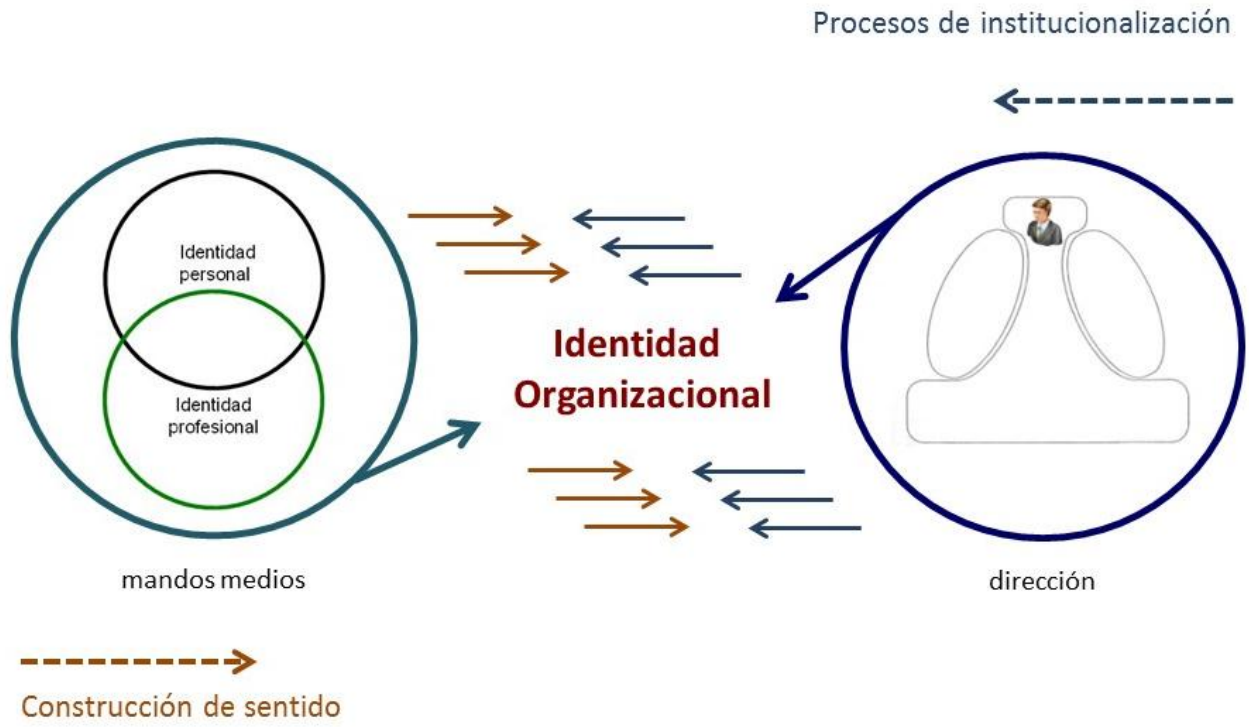

Fuente: Elaboración propia.

De concebir la IO como un proceso de construcción social que se realiza en las organizaciones gracias a la interacción de los sujetos sociales inscritos en ellas, se desprende también que la investigación enfatizará que hay grados de permanencia y de devenir (cambio). Así, se pueden encontrar elementos que están más predispuestos a permanecer y otros a cambiar, sin que esto sea insalvable. Mientras que unos aspectos de la identidad son más centrales (Rousseau, 1998; Gabriel, 1999), otros aspectos de la identidad están sujetos a la interpretación y al cambio (Kreiner, Hollensensbe y Sheep, 2006b). En el ámbito organizacional, las organizaciones también pueden desarrollar más de una identidad o varios aspectos de la identidad a través del tiempo (Albert y Whetten, 1985). Esto sucede a menudo porque las organizaciones se desarrollan en tamaño, al adquirir otras empresas, o para responder a las amenazas externas.

Los principales exponentes de las ideas de permanencia y cambio son Parménides de Elea y Heráclito de Éfeso, respectivamente. Para el primero, el ser es, el no ser no es. El ser es inmutable, perenne e inactivo, considerando lo 
múltiple y el cambio como mera apariencia. El devenir, por tanto, queda excluido del Ser. Heráclito plantea el cambio como principio de la realidad, como lo único permanente $^{43}$ en sí mismo. No hay esencias eternas, todo está sometido al cambio. Esta propuesta permite muchos más abordajes e incluye desde un principio la dialéctica, ya que está fundada en la relación entre opuestos o, más específicamente, por la posibilidad del paso de un estado a otro. Si bien la unidad tiene también un lugar importante en su doctrina, se trata de una unidad distinta a la de Parménides: es una unidad compuesta de diversidad, en la que el cambio no es sólo una apariencia. "La naturaleza es cambio porque es proceso, pero en el proceso hay unidad" (Racinero, 1994, p. 77). Heráclito, basado en su experiencia del mundo real que percibe en constante cambio, asume el devenir como principio regente de la realidad, y así se pasa del ser como algo dado, eterno e inmutable, al ser como proceso. Este cambio de perspectiva implica que todas las deducciones parmenideanas citadas anteriormente se subvierten, y lo que desde ese punto de vista resultaba impensable se vuelve, no sólo posible, sino intrínseco a la realidad.

Así, la identidad es una constante interacción entre la permanencia y el cambio. La identidad es un proceso como tal, término que también ha sido usado para explicar la IO. Recientes estudios convergen en inferir que desde la visión crítica y postmoderna se presentan las nociones de identidad flexible y múltiples identidades. En contraste con las primeras investigaciones, los actuales estudios

\footnotetext{
${ }^{43}$ Desde los filósofos de la naturaleza este tema ya había sido abordado. Es así como buscando respuestas a su realidad, el hombre comienza a preguntarse el porqué de los fenómenos, con el fin de poder comprender, y en esa comprensión poder ser el dueño y señor de la naturaleza que lo rodea. La necesidad de descifrar su entorno, es buscar darle una explicación a su propia existencia. Esto se verá con mayor fuerza en Heráclito, Demócrito y Anaxágoras. Para el primero, el arge será el cambio, el devenir. Observa que todas las cosas se transforman de tantas maneras, que proclama que todo es cambio. "En el momento que llevamos la mano a una cosa, esta ha dejado ya de ser lo que era. Lo que existe, cambia, por el hecho de ser" (Maritain, 1981, p. 36). Demócrito busca algo fijo y estable, y lo encuentra en la cantidad geométrica pura, sin cualidades (sin color, sin olor, sin sabor) y que no contiene sino la extensión en las tres dimensiones del espacio. Todo se explica por el lleno que confunde con el ser y por el no-lleno que es el vacío. Anaxágoras nota que el principio material de que están constituidas todas las cosas deberá de estar compuesto por toda la diversidad de seres que de él se han de ir formando: si todo no estuviera en todo, nada podría provenir de nada. Por lo tanto, cree que ese principio consiste en una mezcla infinita de todas las naturalezas y de todas las cualidades, de modo que cada partícula corpórea contiene en sí elementos de todos los demás.
} 
se focalizan en la forma como las organizaciones expresan sus diferentes identidades en distintos contextos y por variados propósitos. Como resultado, en vez de definir lo que es la identidad, estas investigaciones presentan un lugar transitorio del ejercicio del poder o una política para perseverar o adquirir poder en el futuro (Hatch y Schultz, 2004).

En este sentido, la 10 puede verse como una construcción constante entre aquellos aspectos que permanecen y otros que cambian.

La idea de muchos estudios es que la identidad es un flujo y es múltiple. El resultado es el retorno hacia la idea paradojal y adelantada de sociólogos y psicólogos que la identidad es a la vez un proceso dinámico que se despliega [deviene] en el tiempo y una fuente de estabilidad [permanece] para aquellos que dependen de ella. (Hatch y Schultz, 2004, p. 5).

La propuesta es que ambas nociones, de permanencia y de cambio, están imbricadas, no se contradicen entre sí y representan la posibilidad de comprender una identidad en proceso, es decir, en constante construcción. En estos términos, toda IO (la cual es manifestada por los actores sociales que se encuentran en la organización) siempre es presente, actual -en el sentido planteado por Aristóteles, de estar en acto en lugar de ser mera potencia ${ }^{44}$ _. La identidad es lo que se es, en presente, pero es a su vez expresión de un proceso de construcción que proviene del pasado. Entonces, la identidad es la construcción de sentido autoreferencial, que encuentra sus bases en lo pasado para expresarse en el presente. Así, la IO se construye por antonomasia.

Por tanto, la 10 es el resultado de una doble operación lingüística: diferenciación y generalización. La primera define la diferencia, incidiendo en la singularidad en relación con otras organizaciones, es decir, la $1 \mathrm{O}$ es la diferencia. La segunda es la

\footnotetext{
${ }^{44}$ Este gran pensador, cuya influencia constituye uno de los pilares de Occidente, introduce el concepto de potencia y acto para explicar la realidad. La potencia es aquello que teniendo la capacidad para, aún se encuentra dormido, es decir, posee aquellos elementos constitutivos que le permiten mutar o realizar la esencia de su existencia, pero todavía no se realiza, todavía no se desarrolla. El acto es la realización concreta de la potencia, es su culmen, la perfección. Aquellos elementos constitutivos que lo caracterizan y lo individualizan, se realizan, se despliegan, se perfeccionan y realizan aquello que estaban llamados a ser.
} 
que busca definir el nexo común a una serie de elementos diferentes de otros, la IO es la pertenencia común. Estas dos operaciones están en el origen de la paradoja de la identidad: lo que hay de único es lo que hay de compartido. Para enfrentar esta paradoja es necesario considerar el elemento común a estas dos operaciones: la identificación del otro y por el otro. Así, no hay identidad sin alteridad. Al igual que las alteridades, las identidades varían históricamente y dependen del contexto para su definición (Dubar, 2002a).

\subsubsection{Un modelo para el análisis teórico y metodológico}

La atención de la investigación estuvo puesta en el proceso identitario como tal, por lo que una pregunta de rigor metodológico es: ¿Qué factores intervienen en la construcción de la $\mathrm{IO}$ de los MM? Este interrogante lleva a realizar una distinción entre los niveles en que cada uno de estos factores han sido definidos y abonan en la construcción de la $1 \mathrm{O}$. Se está frente a un reto metodológico que consiste en crear y estructurar un modelo ${ }^{45}$ de análisis que permita estudiar la construcción de la 10 de un estamento de la organización, el cual incorpore un dinamismo dialógico y sea capaz, además, de agrupar procesos colectivos de construcción. Por esto, se propone considerar (a nivel teórico) lo siguiente:

Desde el punto de vista del individuo (para el estudio de caso, los MM), existen una serie de fuerzas internas, o dinamismos de orden psicológico que configuran

\footnotetext{
${ }^{45}$ Siguiendo a Walliser (2002), el término modelo tiene una aplicación propia en muchas de las disciplinas, como son la física teórica, las ingenierías, la economía, las ciencias políticas, entre otras. En términos generales, se puede considerar un modelo como una simplificación de la realidad, en la cual se pueden distinguir tres funciones: (1) La formalización de los modelos valoriza su papel explicativo, combinando una función figurativa y demostrativa de los enunciados, cualquiera sea su nivel de abstracción y su estado de deducción. (2) La validación de los modelos evidencia su carácter ideal, el cual combina aproximaciones de las hipótesis y solidez de las conclusiones, ya sean probadas por proyección sobre los hechos o por inducción a partir de los datos. (3) La utilización de los modelos pone de manifiesto su aspecto contractual, que combina irrealismo de las condiciones y simulación de las consecuencias, ya sean movilizadas con fines argumentativos o más operacionales. En este sentido y para los objetivos de esta investigación, "un modelo posee un poder explicativo si permite deducir de "leyes" genéricas aplicadas a "contextos" específicos ciertas "propiedades" específicas del sistema estudiado" (Walliser, 2002, p. 41).
} 
una identidad, una manera de estar en el mundo (Parkinson, 2003). Estas fuerzas son:

- La seguridad psicológica: Se manifiesta en el deseo de ser amado; esto no sólo se refiere a un nivel afectivo, sino a una seguridad a todo nivel, que implica en última instancia el enfrentar la vida sin el miedo paralizante de perderla. El estar bien de salud, tener los bienes materiales necesarios para vivir, la estabilidad laboral, etc., son ejemplos de ello.

- La necesidad de significación: Es la necesidad de dar sentido y orientación a la propia existencia y de encontrar una recta valoración de ella. Es la necesidad de amar que se expresa como una tendencia a desplegarse, a realizarse como ser humano. Realizar labores de impacto, ascender laboralmente, buscar una mejor calidad de vida, son algunos ejemplos.

La propuesta plantea una perspectiva psicodinámica emergente de la IO. En este sentido, se estudia la IO no sólo para comprender procesos sociales, tales como la identificación, sino para entender cómo se satisfacen las necesidades psicológicas y emocionales. El modelo propicia el conocimiento de los recursos que los individuos están utilizando para satisfacer tales necesidades psicológicas (Harquail y King, 2010).

Por otro lado, y desde el punto de vista de la organización, hay aspectos que permanecen y otros que cambian. Las normas, los procesos de control, el mismo código laboral, tendrán una tendencia a permanecer en el tiempo. Por el contrario, otros aspectos - muchos de ellos propiciados por el mercado o por las mismas estrategias internas - tenderán a cambiar. Ejemplo de ello son las políticas, el personal, la misma ejecución de la estrategia, etc. El dinamismo que se está buscando presentar es la realidad del cambio. Para que algo cambie, debe de existir algo que permanezca en el entendido que es necesario un referente inmóvil que permita afirmar que dicho cambio aconteció. En otras palabras, concebir a la organización representada por sus directivos desde las dimensiones temporales 
de permanencia y cambio, es subrayar que el análisis de la construcción de una IO es dinámico, a la vez que toma postura al alejarse de una visión esencialista de la 10 .

Si se relaciona lo dicho con la configuración identitaria propuesta por Dubar (2002a), las dimensiones de seguridad y permanencia conforman el eje relacional, y las de significación y cambio el eje temporal. De esta manera, cada uno de estos aspectos, tanto a nivel individual (seguridad y significación) como organizacional (permanencia y cambio), se entrecruzan mutua y constantemente. Hay que aclarar que el modelo que se presenta busca ser dinámico y que integre en la medida los componentes que hacen parte de la construcción de la 10 de una compañía. Así, se quiere delimitar dichas interacciones presentando algunos aspectos generales que luego serán acotados a partir del trabajo de campo, pero sobre todo, del sentido que los actores le den a sus relaciones.

Se entiende que la identidad del individuo se estructura, de forma latente y constante, junto con la identidad personal y profesional. Las identidades individuales y organizacionales incluyen múltiples aspectos, a veces conceptualizados como subidentidades (Ashforth, 2001), o múltiples identidades (Thoits y Virshup, 1997; Ashforth y Johnson, 2001). En este orden de ideas, un individuo puede tener múltiples identidades personales y sociales a la vez, siendo a la vez padre, hijo, ingeniero, extrovertido, estudioso, malicioso, etc.

Para Markus y Wurf (1987), estos enfoques no son necesariamente incompatibles. Al hablar de identidad individual, estos enfoques se activan en una situación social concreta. Estos autores reconocen la identidad como una combinación de aspectos en lugar de una totalidad integral, es decir, lo individual incluye autoconcepciones de uno mismo, vinculadas a las circunstancias sociales en donde se circunscriben. Así, la identidad del individuo se compone de las características personales como de las categorías sociales (Tajfel y Turner, 1986; Deaux, 1993; Graafsma, Bosma, Grotevant y De Levita, 1994). De este modo, aspectos interdependientes de la identidad personal se pueden integrar a los 
aspectos de la 10 , mientras que otros pueden ser diferenciados o excluidos (Kreiner, Hollensensbe y Sheep, 2006b).

Si bien la investigación se centró en la 10 , esta se construye en un diálogo con los MM, de ahí que sea necesario tener en cuenta aspectos que intervienen de manera personal en los MM en dicho proceso de construcción. Lo latente hace referencia a que no se puede dividir lo personal de lo profesional. Tal división se hace por cuestiones metodológicas, en el entendido de que dicha diferenciación permitió explicar qué aspectos tanto de lo personal como de lo profesional entran en relación con la 10 .

El individuo buscará saciar sus necesidades de seguridad y significación, y para ello encontrará en la organización aspectos tanto permanentes como variantes que lo ayuden a cumplir con tal objetivo, enmarcados en un contexto temporalbiográfico $^{46}$ (¿quién soy para los otros?) y relacional-espacial (¿quién soy para mí?) específicos.

El objetivo no es, sin embargo, dar un sentido único a los MM a partir de analizar el proceso de construcción identitaria. Mills (1970) les pide a los científicos sociales que permitan un análisis de los aspectos de la vida contemporánea, que ayuden a los individuos a ser más conscientes de la conexión entre "los patrones de sus propias vidas y el curso de la historia del mundo" (p. 9). Se necesita esa asistencia porque los individuos normalmente no definen los problemas que tienen que soportar en términos de cambio histórico y la contradicción institucional. El autor quiere "entender lo que está pasando en el mundo, y para entender lo que está sucediendo en sí mismos en los puntos de la intersección entre la biografía y la historia dentro de la sociedad" (1970, p. 14). Y es que la identidad es la continuidad en el tiempo y en el espacio de la autointerpretación reflexiva del actor (Giddens, 1991).

\footnotetext{
${ }^{46} \mathrm{Si}$ bien los referentes de la identidad, rasgos y competencias organizativas son inherentemente ambiguas y susceptibles de cambiar con el tiempo, este nivel de ambigüedad puede ser tolerado dentro de las referencias al discurso organizacional (Czarniawska, 1997a).
} 
El imaginario permite construir al individuo quién soy realmente en el pasado, presente y futuro, entonces es traído al ahora dándole forma a través de las narrativas (Alvesson, Ashcraft y Thomas, 2008; Sveningsson y Alvesson, 2003) (Taylor, 1989). Es decir, el imaginario no es simplemente una invención personal, se promulgó a través de aspectos sociales e instituciones que reflejan relevancias locales y relaciones de poder (Holstein y Gubrium, 2000).

A los dos ejes contextuales expuestos líneas arriba (temporal-biográfico y ralacional-temporal), se les suma el eje cultural en forma referencial, en el entendido de que los aspectos regionales-culturales también intervienen en el proceso (se puntualiza el hecho de que el tema cultural se tomó de esta manera, ya que un análisis tan sólo de este aspecto puede convertirse en una tesis doctoral en sí misma).

Alvesson y Berg (1992) afirman que es necesario entender los niveles de análisis del objeto que se va a estudiar dentro del ámbito cultural, porque: (1) Evita la confusión en los niveles de análisis. Un asunto es hablar de la cultura a nivel individual y otro a nivel organizacional, por ejemplo. (2) Evita la confusión de equiparar las características de la cultura administrativa (management) con la cultura organizacional, en tanto se ignore la posibilidad de que existan diversas culturas en la organización en los diversos niveles de análisis. Y (3) Poder diferenciar los objetivos en cada nivel. Esto posibilita la aplicación de propuestas teóricas en cada uno de ellos.

Para esta investigación se consideró que hay dos niveles: lo individual (Identidad personal de los MM) y lo grupal (Identidad organizacional de los MM y la Identidad 
profesional de los MM) ${ }^{47}$. Estos mismos autores (Alvesson y Berg, 1992) proponen los siguientes niveles de cultura ${ }^{48}$ :

1. Cultura en las sociedades y naciones. Se considera el fenómeno cultural a un nivel macro. Se busca incluir la historia en profundidad, las creencias religiosas y culturales dentro del análisis de las organizaciones. Otro objetivo en este nivel es considerar cómo lo social, lo cultural y lo económico influyen en la sociedad y, por ende, en las organizaciones.

2. Culturas regionales y locales. Se considera el territorio, la jurisdicción administrativa, el comercio y lo étnico. Se entiende que se puede diferenciar una región particular, distrito o ciudad, ya que interactúan dentro de una misma área geográfica.

3. Las culturas de las industrias o sectores sociales. Se considera que las industrias tiene una perspectiva de cultura particular y diferenciada.

4. Cultura organizacional y corporativa. En este nivel se considera que la cultura es un conjunto, un fenómeno colectivo. Se entienden las características de la organización como un todo, de ahí que se le etiquete con una o más particularidades. En este nivel se suelen usar los conceptos de cultura administrativa o cultura del negocio.

5. Subculturas funcionales a nivel organizativo. En este nivel se encuentran la cultura administrativa (management), en donde se entiende que el sistema cultural afecta la orientación del negocio corporativo. Las ideas, creencias y valores de los directivos caracterizan el comportamiento de la organización. La cultura empresarial es usada también para describir la cultura administrativa.

\footnotetext{
${ }^{47}$ Whetten (2006) afirma que estos modelos en donde se relaciona lo individual y lo organizacional, como los de Selznick (1957) y los de Czarniawska (1997b), son esfuerzos para demostrar los papeles a nivel individual y organizacional que cumple el actor en relación con su responsabilidad social y con las necesidades de autogobierno que requiere.

${ }^{48}$ En el capítulo dedicado al análisis de la información, se especificará cómo se encaró este eje referencial dedicado a la cultura.
} 
6. Grupos sociales en la organización. Esta categoría de análisis se basa en las características culturales de los grupos sociales, más que en el cumplimiento de las funciones.

7. Culturas profesionales. Describe cómo diversos grupos ocupacionales piensan, actúan y funcionan. La profesión no se limita al marco de una organización dada, sino que va más allá de sus límites. El factor decisivo son las ideas y la experiencia de lo que son los valores y las formas de comprensión. Los objetivos son compartidos y los individuos se identifican con ellos.

Así pues, se presenta un modelo metodológico inacabado, el cual permitió considerar las variables y factores que intervinieron en el proceso de construcción identitario. En este sentido, cada uno de los dos ejes (relacional y temporal) fue analizado tanto para los MM como para la organización en cada una de sus dimensiones (siendo el eje cultural transversal al proceso); a la vez que se tuvo que identificar aquellos aspectos que propician seguridad y significación a los MM, como aquellos aspectos permanentes y cambiantes de la organización. Lo anterior se plasma en la siguiente gráfica. 


\section{Gráfica 3: Modelo de análisis metodológico: aspectos constituyentes de la identidad organizacional de los MM}

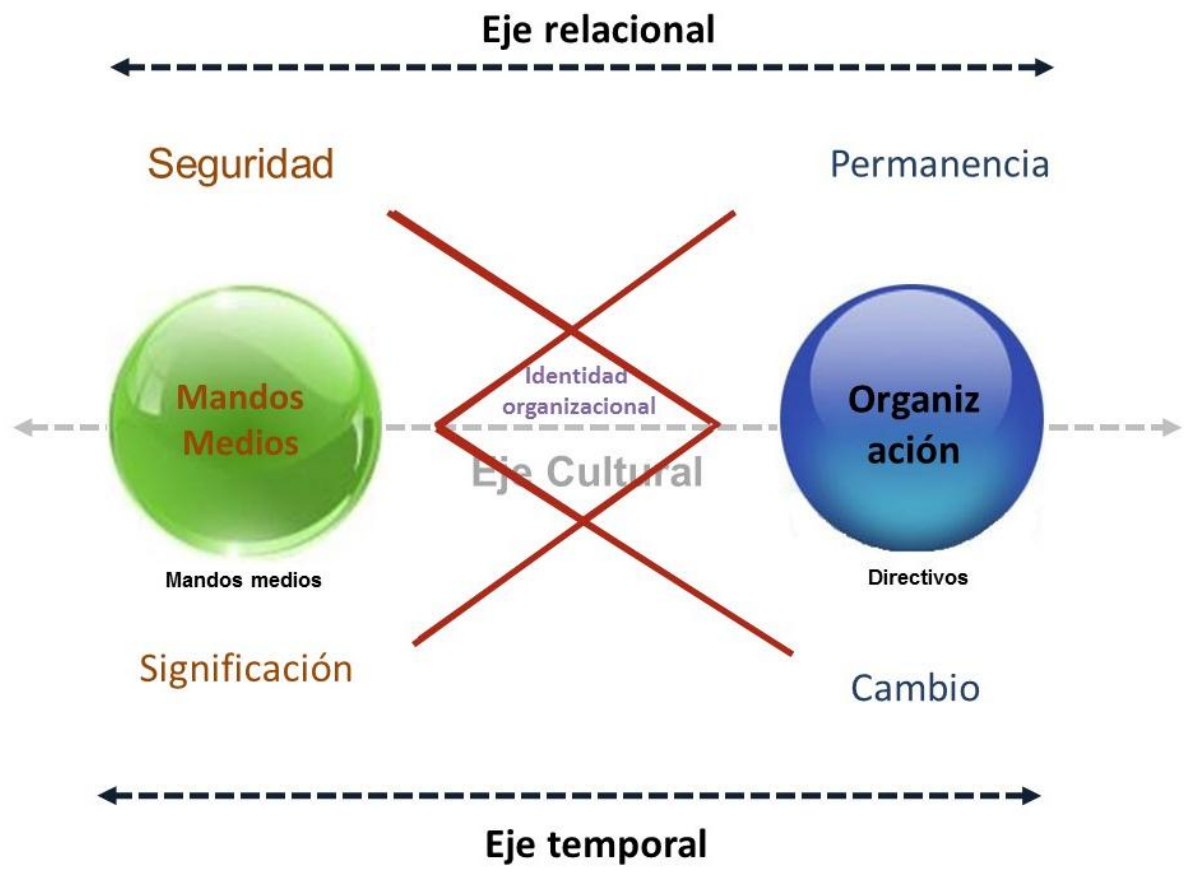

Fuente: Elaboración propia.

El modelo de análisis metodológico consta de lo siguiente: dos actores sociales (los MM de CN, y los directivos de $C N$ ); dos dimensiones de análisis para los MM (seguridad y significación), y dos dimensiones de análisis para los directivos de la organización (permanencia y despliegue).

Vale la pena aclarar también que la investigación centró su atención en las relaciones entre la $\mathrm{IO}$ y las identidades personales y profesionales. El impacto en la identidad personal, como profesional, así como la relación de estas con la IO, son aspectos latentes que también participan en el proceso de construcción identitaria. Con esto se busca centrar la atención en estas interfaces entre las identidades, o aspectos de la identidad, en los individuos y entre estos y las organizaciones. Relación que no se ha abordado lo suficiente dentro de este tema de conocimiento en los EO (Kreiner, Hollensensbe y Sheep, 2006b). No fue el objetivo inicial de esta investigación centrar la atención en la identidad personal, ni 
en la profesional, ni la relación entre ambas, más sí en la relación que dichas identidades tienen con la IO. En este sentido, la misma IO de los MM es la construcción en sí misma de una serie de sentidos y significados. Esto se aclara en la siguiente gráfica:

\section{Gráfica 4: Relación entre la identidad personal y profesional y la identidad organizacional}

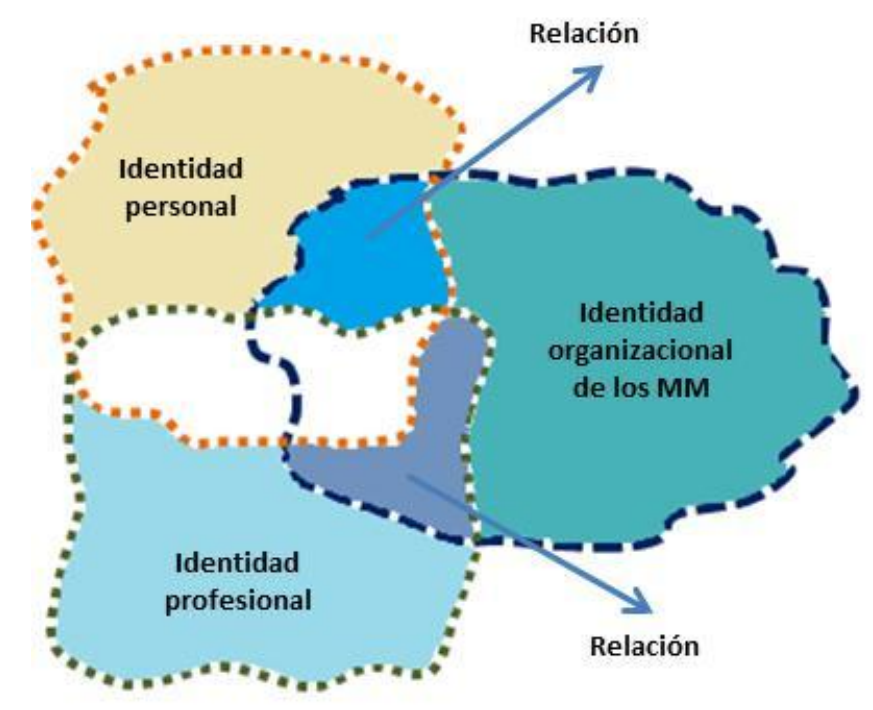

Fuente: Elaboración propia.

Como lo muestra la gráfica, hay ciertos aspectos de la identidad personal y profesional que escapan a lo propiamente organizacional, así como hay otros que se encuentran en la intersección de los tres, que en un primer momento no se consideraron para la investigación. Sin embargo, una de las tres categorías emergentes principales (seguridad) surgió de allí. Esto se explicará y profundizará en los capítulos referidos a los hallazgos.

\subsection{A MANERA DE CONCLUSIÓN}

Este capítulo ha querido mostrar al lector una primera aproximación a los EO, destacando su visión crítica y su perspectiva pluridisciplinar. Ambos elementos han sido tomados en cuenta en el marco conceptual, así como en la propuesta 
teórica y metodológica. Por ello, la constante referencia a las ciencias sociales para explicar y acotar los conceptos, ha sido un común denominador en este capítulo. Vale la pena aclarar sobre esto último, que no ha sido la intención desarrollar los conceptos desde las otras disciplinas, sino apoyarse en ellas, para ampliar y precisar el conocimiento aplicado dentro del ámbito propiamente organizacional.

Para la investigación se propuso una concepción propia de la IO. Junto con ello, se diseñó un modelo metodológico propio. Si bien ambas propuestas deberían estar en la parte metodológica, por ser propuestas aplicadas al trabajo de campo específico, se optó por ubicar el modelo en este capítulo, para centrar la atención del capítulo metodológico al proceso como tal, logrando que capítulo no se extienda en demasía. Es preciso subrayar que ambos aspectos son un aporte importante de las tesis que anteceden a los resultados como tales. Es reflejo, a la vez, de las posibilidades que brinda la 10 para construir nuevas perspectivas y modelos de análisis que permitan comprender los fenómenos organizacionales y el proceso de construcción identitario.

La propuesta teórica permitirá triangular la interpretación de los datos relevados, tarea que se hará en los capítulos posteriores. En esto radica la importancia de la puntualización, así parezca un tanto excesiva, que se tuvo que realizar en este capítulo. Junto con ello, haber enmarcado la investigación dentro del campo de conocimiento de los EO, ha permitido comprender el porqué de optar por una investigación de carácter comprensivo a partir de una metodología cualitativa. Asimismo, el marco teórico conceptual muestra cómo es posible integrar las ciencias sociales a la investigación realizada desde el punto de vista organizacional. 


\section{CAPÍTULO 3}

\section{ASPECTOS METODOLÓGICOS DE LA INVESTIGACIÓN}

\section{INTRODUCCIÓN}

La metodología es un aspecto crucial dentro de toda investigación. No sólo sirve de puente entre la teoría y el ejercicio propiamente empírico sino que en su interior reposa el corazón de la investigación, que no es otra cosa que el proceso metodológico como tal. En este sentido, la formación del investigador se esculpe en dicho proceso, puesto que, en efecto, la investigación no es ajena al investigador. La misma perspectiva de análisis de los datos está influenciada por la interpretación que el investigador hace de ellos. A su vez, la pregunta seminal o vital de investigación comúnmente es un interrogante que el investigador tiene como propio, y que su resolución no sólo responde a una inquietud académica sino que acerca al investigador a un conocimiento mayor de su vida e identidad dentro de ese contexto social-histórico específico en que él se encuentra. Esta investigación ha sido ejemplo de ello. No hay un deslinde entre pregunta e investigador, sino más bien, una estrecha relación, que si bien podrá tener diversos grados, propicia e impulsa el camino por recorrer, en donde el mismo investigador es cuestionado como individuo de cara a dicho interrogante.

Este capítulo es un espacio para narrar y describir el proceso investigativo que se vivió. No llega a ser propiamente una memoria metodológica ${ }^{49}$, pero sí busca

\footnotetext{
49 "La memoria metodológica sitúa las inquietudes existenciales del investigador por encima del sentimiento, la intuición y los recuerdos, pero en consonancia con ellos. La memoria metodológica
} 
mostrar el cómo se llegaron a definir y realizar ciertos aspectos metodológicos, es decir, busca dar cuenta del proceso de aprendizaje con los aciertos y desaciertos que se vivieron a lo largo de este. Con este propósito, se ha explicado y argumentado cada uno de los pasos, no sólo como aspecto propio del rigor investigativo, sino para que esta experiencia pueda servir para orientar el proceder frente a una investigación de carácter cualitativo.

En este apartado no se ha profundizado entre lo cualitativo y lo cuantitativo, sino que se ha priorizado la descripción del proceso como tal. No obstante, se han justificado los aspectos metodológicos de la investigación al presentar su estrategia general, la cual tuvo un enfoque cualitativo que buscó acercarse al fenómeno elegido a partir de un estudio de caso.

Para dar cuenta de lo anterior, el capítulo está dividido en 9 apartados. En el primero se presentan algunas consideraciones generales de la investigación, referidas sobre todo a su carácter constructivista, y se explica a grandes rasgos su diseño general. En el segundo se presenta el estudio de caso aplicado al caso de estudio específico de la investigación, no sin antes hacer una breve discusión en torno a él. En el tercer apartado se discuten la unidad de análisis y el objeto de estudio de la investigación, en donde se esclarecen los términos, ya que todo el sistema categorial de la investigación y el análisis de los datos tuvieron como ejes esos conceptos.

En el cuarto se presentan y justifican los actores sociales que intervinieron en la investigación, para luego pasar a comentar los instrumentos metodológicos que se emplearon. En el quinto apartado se presentan y explican los instrumentos metodológicos aplicados. En el sexto apartado se explica el trabajo de campo realizado a partir de tres momentos o pasos. El séptimo apartado explica el

es un instrumento del que se sirve el investigador para recordar, expresar y representar, con cierto rigor, todo lo aprendido en la inmersión de mundos posibles en el camino del conocimiento; la memoria metodológica da existencia racional y presencia concreta a las preguntas, a los objetivos, al trabajo de campo, a las técnicas de procedimiento, a los hallazgos de una investigación" (Uribe, 2006, p. 43). 
sistema categorial, aspecto fundamental para entender cómo se analizó e interpretó la información construida con los actores sociales. En el penúltimo apartado se explica la relevancia de las categorías de análisis construidas, esto con el objetivo de mostrar cómo se construyeron y la relevancia que éstas tuvieron para la investigación. El capítulo termina con una breve reflexión final, realizada a manera de conclusión, sobre el proceso de planeación y ejecución de la estrategia metodológica.

\subsection{ALGUNAS CONSIDERACIONES METODOLÓGICAS Y EL DISEÑO GENERAL DE LA INVESTIGACIÓN}

La pregunta de investigación $u$ objeto de esta investigación se dirige esencialmente a la búsqueda de comprensión de procesos organizacionales (construcción de $\mathrm{IO})^{50}$ y a la manera en que se realizan las interacciones entre los diversos actores (MM y directivos) que intervienen en esos procesos. Ahora bien, las preguntas fueron planteadas aceptando como supuesto básico que este trabajo investigativo es un intento de reconstrucción e interpretación de los datos construidos a partir de la información de los actores, de ahí que una perspectiva o enfoque posible haya apuntado hacia una metodología cualitativa, cuyo objetivo se dirige a la captación y reconstrucción de significados, con una mayor utilización de lenguaje conceptual y metafórico ${ }^{51}$, con un modo de captar información flexible y desestructurada, un procedimiento más inductivo que deductivo y con una orientación holística y de concreción (Hancké, 2009; Breweton y Millward, 2001; Shankar Pawar, 2009).

\footnotetext{
${ }^{50}$ Con el fin de recordar el significado de las siglas, se pueden revisar las tablas correspondientes del comienzo.

${ }^{51}$ Una reflexión sobre la metáfora a raíz de las reflexiones de Ricoeur y Derrida y que explica la naturaleza del lenguaje que utiliza, la expresa por Jean-Luc Amalric: "Así, en toda metáfora auténticamente creadora hay una conexión íntima entre ficción y redescripción de lo real, pero dado que esta conexión sólo se expresa en el enunciado metafórico, ella no es verdaderamente eficaz y consistente sino a través de la actividad interpretante del lector. Al proyectar el mundo del enunciado metafórico, éste último pasa del sentido a la referencia metafórica y ve su propio mundo refigurado. Percibimos mejor, entonces, lo que podría ser el alcance filosófico de una metáfora: debido a que ella es ante todo una metáfora interpretada y porque realiza una redescripción del mundo del lector la metáfora viva es susceptible de participar en la tarea filosófica de la comprensión de sí" (Amalric, 2012, p. 90).
} 
Esta investigación tuvo como perspectiva teórico-metodológica los Estudios Organizacionales $^{52}$. Su postura ontológica, epistemológica, así como sus propuestas metodológicas ya fueron desarrolladas, presentadas y discutidas en el capítulo respectivo. Esto indica la posición del investigador para las dimensiones ontológicas, epistemológicas y metodológicas. No obstante, es preciso profundizar en algunas de ellas, sobre todo a nivel epistemológico, con el propósito de mantener coherencia teórica y metodológica con los resultados que se presentarán en los capítulos posteriores.

Lo primero por decir es que la fabricación del conocimiento en una organización es posible gracias al aspecto social que se encuentra en su interior. Desde el constructivismo, el hecho social, como aspecto fáctico, es visto como un problema de fabricación. Así, este proceso de conocimiento se construye: "Más que considerar los productos científicos como algo que de alguna manera captura lo que es, los consideraremos como selectivamente extraídos, transformados y construidos a partir de lo que es" (Knorr, 2005, p. 56).

Una perspectiva constructivista social de la IO sugiere que los miembros se basan en la comprensión relativamente comunes de las de las características centrales y distintivas de su organización para dar sentido a su experiencia laboral (Gioia, 1998). La investigación dentro de este ámbito se ha enfocado en cómo los miembros comprenden colectivamente su organización y cómo sus acuerdos afectan los cambios organizativos. Colectivamente, estos estudios muestran cómo la identidad de las organizaciones es el resultado de la interacción de múltiples agentes (Gioia, 2000), que tratan de dar forma a la construcción de significado de otros, para "dar sentido" (Gioia y Chittipeddi, 1991, p. 442), con el fin de lograr el consenso en torno a su conceptualización preferente de la realidad organizacional.

Lo segundo es que la complejidad del objeto de estudio planteado (construcción de $\mathrm{IO}$ de los $\mathrm{MM}$ ) admite hacer una pequeña reflexión epistemológica sobre cómo

\footnotetext{
${ }^{52}$ Se puede revisar el capítulo dos referido al marco teórico-conceptual para revisar sus principales líneas de desarrollo, qué elementos los caracterizan y los diferencian de otros.
} 
acercarse a comprender un proceso dinámico y en constante construcción, como es el de la IO. Para ello, el Enfoque de la Configuración ${ }^{53}$ puede ayudar — sin decir que éste va a ser el lente teórico de análisis- a resolver aspectos del planteamiento metodológico para abordar la pregunta de investigación formulada. Este nos dice que:

\begin{abstract}
Usamos el término "configuración de la organización" para denotar alguna multitud de constelaciones, de conceptos que son características específicas que suelen comúnmente ocurrir juntos. Numerosas dimensiones de los ambientes, las industrias, tecnologías, estrategias, estructuras, culturas, ideologías, grupos, miembros, procesos, prácticas, creencias, y los resultados han decidido agruparse en configuraciones, arquetipos, o gestalts. Las configuraciones pueden ser representadas en tipologías elaboradas conceptualmente o capturadas en las taxonomías de forma empírica. Estas pueden ser situadas en múltiples niveles de análisis, representando patrones comunes a través de los individuos, grupos, departamentos, organizaciones o de redes de organizaciones. (Meyer, Tsui y Hinings 1993, p. 1175).
\end{abstract}

Lo que busca este enfoque es justamente romper los marcos lógicos positivistas y lineales para intentar, desde esa multitud de constelaciones, encarar esta complejidad que se pretende abordar. No se trata entonces sólo de caracterizar o clasificar, sino de capturar e integrar conceptos a partir de las relaciones de análisis y del proceso que esto lleva. Es, en gran medida, reconocer que así como la organización está sujeta a una serie de cambios que son fruto de su ambiente y contexto, y que no se pueden tipificar modélicamente a la más eficiente organización, los actores o sujetos sociales inmersos en estas mismas organizaciones no sólo están presentes sino que son capaces de generar acciones concretas que modifican la vida misma de la organización.

\footnotetext{
${ }^{53}$ El Enfoque de la Configuración centra su atención en los procesos, en aquella realidad que se está dando, en la dinámica misma en que se configuran los componentes que la integran. Esto se relaciona estrechamente con el objetivo de investigación, el cual busca comprender un proceso en particular, que para este caso es la construcción de 10 de los MM de una empresa específica. En ese sentido, es pertinente retomar sus postulados para encarar el problema planteado. Por otro lado, el Enfoque de la Configuración podría ser considerado como un método de análisis, en el entendido de que sus supuestos teóricos permiten tener una posición comprensiva de un aspecto de la realidad a estudiar. Sin embargo, la investigación se suscribe dentro de un programa de doctorado que tiene sus propias bases ontológicas, epistemológicas y metodológicas, como son los EO, por tanto, es un método que abona a la comprensión del desarrollo de la investigación, pero que las bases están cimentadas en los EO. Junto con lo anterior, la IO es un tema que ha sido abordado dentro de los EO, pero no lo suficiente; de ahí el interés particular en profundizar en ella, y así propiciar un mayor conocimiento en este campo especializado en el estudio de las organizaciones.
} 
De esta manera, el Enfoque de la Configuración no sólo rescata las diversas lógicas de relaciones que se encuentran en las organizaciones, sino también los individuos y las interacciones entre ellos. Esto último permite un análisis más holístico que integre diversas y complejas categorías. Permite, además, ver la problemática no solo desde una visión estática sino también dinámica, tratando de acercase a la realidad tal cual es, y al hombre como transformador de ella, es decir -y en términos de De la Garza (2001)- aproximarse a una realidad dadadándose. De este modo, la construcción de identidad está inscrita en variables contingentes y ambientales, las cuales, a su vez, repercuten fuertemente en los actores sociales, haciendo que la realidad no sea estática sino que se vaya dando en un continuum proceso de configuración ${ }^{54}$.

De acuerdo con lo anterior, el diseño de la propuesta de investigación se desarrolló desde un enfoque cualitativo, por considerarlo el más apropiado para responder a la pregunta de investigación planteada. Junto con ello, la misma pregunta auspicia la utilización del constructivismo como lente epistemológico, lo que se verá reflejado en los aspectos metodológicos. Así, se pueden vislumbrar cinco etapas que se encuentran estrechamente relacionadas y que no se convierten en compartimentos estancos, sino que en el ir $y$ venir, propio de la investigación cualitativa, se irán construyendo y redefiniendo.

La primera etapa se refiere a la formulación de la problemática. En ella, y a partir de la primera inquietud académica y experiencia vital del investigador, se plantea la problemática de la investigación. Luego de discutir y someter este primer planteamiento a diversos grupos académicos tanto en México como en Colombia, en los programas de Doctorado en Estudios Organizacionales (UAM-I, México) y en el Doctorado en Administración (EAFIT, Medellín), y hacer las correcciones y ajusten respectivos, se formuló definitivamente el problema de investigación.

\footnotetext{
${ }^{54}$ Hay una gran diferencia entre el Enfoque de la Configuración y la Teoría de la Contingencia.
} Sobre esto último se puede revisar el capítulo dos de este documento. 
La construcción del marco teórico y de la estrategia metodológica están íntimamente relacionadas. El marco teórico propuesto, que no puede ser otro que el de la Identidad Organizacional, discute la posibilidad de ser construido por parte de un estamento de la organización como son los MM. Así pues, la unidad de análisis son los $\mathrm{MM}$ de $\mathrm{CN}$, para lo cual se plantea una propuesta teórica de análisis ya discutida, en la cual se entiende que la 10 es un proceso dialéctico entre aquellos aspectos que permanecen y otros que cambian, devienen o se despliegan. En este sentido ( $\mathrm{y}$ esto forma parte de la tercera fase referida al trabajo propiamente de campo), fue necesario identificar aquellas normativas y demás disposiciones que la organización implementa en su intento por generar en los MM un sentido de pertenencia e identidad. Para lograrlo, se recopiló esta información por medio de una revisión documental y de entrevistas a los directivos de los MM. La observaciones no participantes y las entrevistas semiestructuradas ayudaron a obtener la información en vistas a comprender cómo los procesos de institucionalización son apropiados, decodificados y reconstruidos por los MM.

Con la información construida se procedió a la etapa del análisis. Para ello, se construyeron categorías de análisis y se contrastaron con el modelo teórico para poder interpretar los datos (Galeano 2004). Dado el carácter de la investigación, lo más oportuno y pertinente para el proceso de análisis e interpretación fue hacerlo desde una mirada comprensiva. Luego se procedió a realizar el informe final de la investigación, en donde se destacaron los nuevos aportes teóricos y metodológicos que arrojó la investigación. El diseño general de la propuesta de investigación se presenta a continuación en la gráfica 5 : 


\section{Gráfica 5: Diseño general de la investigación}

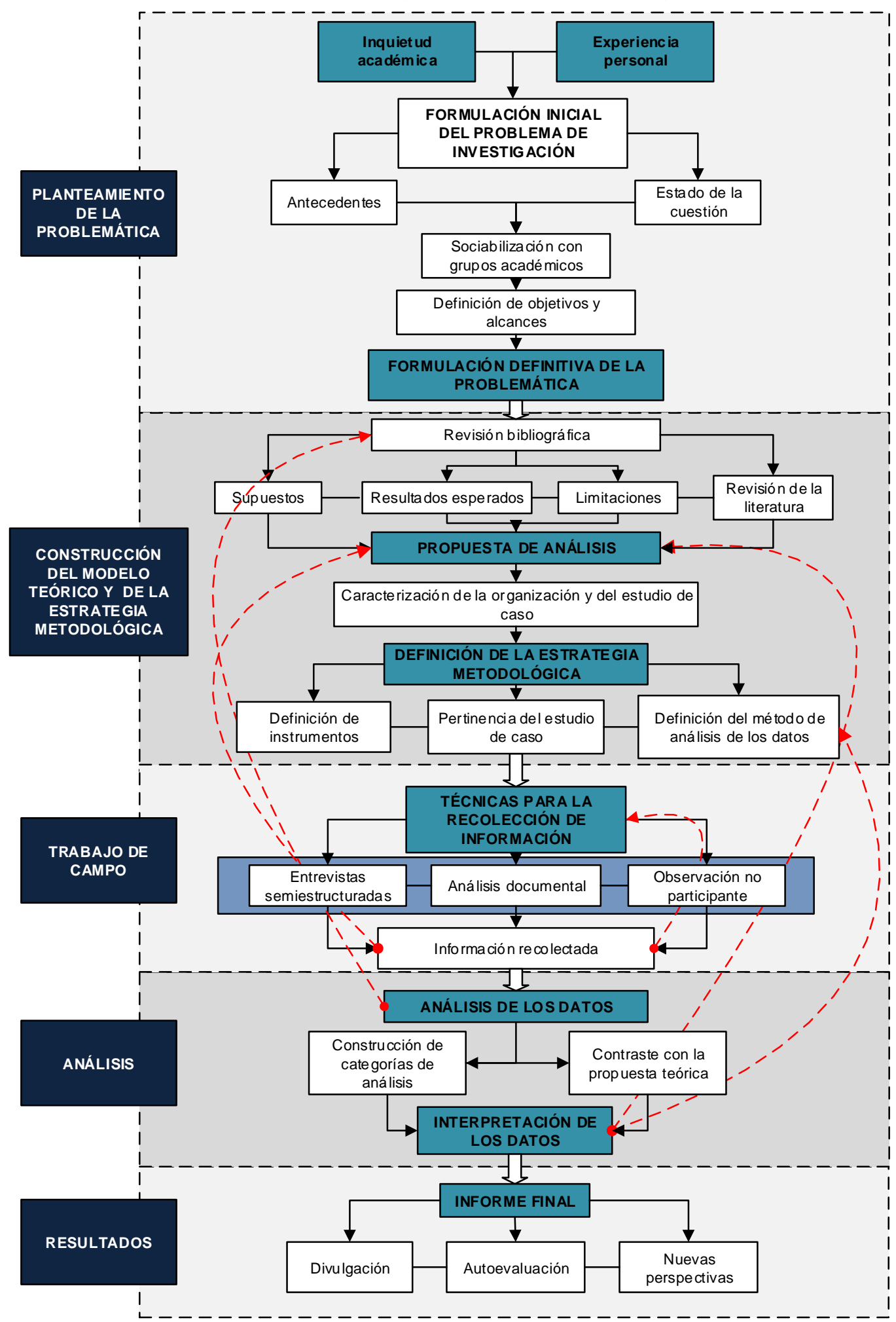

Fuente: Elaboración propia. 


\subsection{EL ESTUDIO DE CASO}

La técnica del estudio de caso se inserta normalmente en la perspectiva cualitativa de investigación social, pero no está necesariamente agotada por lo cualitativo (Gunderman Kröll, 2008; Galeano, 2009). "Algunos estudios de casos son cualitativos, otros no [...] no es una elección metodológica, sino una elección de un objeto a estudiar. Nosotros elegimos estudiar un caso. $Y$ podemos estudiarlo de muchos modos" (Stake, 1994, p. 236). En este sentido, lo que define un estudio de caso es su interés centrado en casos particulares, no su naturaleza metodológica.

Para Galeano (2009), el estudio de caso, dentro del marco de una investigación cualitativa, se inserta en la investigación naturista, intensiva, holística y heurística; en donde su lógica como estrategia se deriva de la propuesta cualitativa de la investigación social. "Su objetivo es comprender el significado de una experiencia, e implica el examen intenso y profundo de diversos aspectos de un mismo fenómeno" (p. 66). "Es un examen de un fenómeno específico, como un programa, un evento, una persona, un proceso, una institución o un grupo social" (Pérez Serrano, 1994). Así, un caso es un suceso o aspecto social localizado en un espacio y un tiempo específicos, y que es objeto de interés de un estudio.

Gunderman Kröll (2008) afirma que hay dos concepciones básicas de los estudios de caso, relacionadas en cómo se conciben las mismas ciencias sociales. La primera entiende el estudio de caso no como un conjunto de procedimientos metodológicos, sino como la especificidad de un objeto de estudio. De esta forma, el estudio de caso no es una elección metodológica de una estrategia de investigación, sino la escogencia de un objeto para ser estudiado. En la segunda concepción, el estudio de caso es un medio para la investigación social, no un objeto de estudio. En este sentido, el estudio de una entidad particular se realiza para alcanzar una comprensión más desarrollada de algún problema más general o para ampliar una teoría. 
Siguiendo con esta discusión, el estudio de caso ha sido visto como una estrategia de investigación comprensiva (Yin, 1994), pero también ha sido tomado no tanto como una opción metodológica, sino como una opción de objeto a estudiar; es decir, el investigador escoge un caso para estudiarlo y lo puede hacer de distintas maneras (utilizando herramientas cualitativas, cuantitativas o sus combinaciones) (Stake, 1995). A fin de cuentas, el estudio de caso es un método entre otros, posible de emplear en los Estudios Organizacionales de manera versátil y creativa, según los intereses y las opciones epistemológicas, metodológicas y teóricas del investigador (Gundermann, 2001).

Para Stablein (1996), en los Estudios Organizacionales actualmente existen tres tipos de estudios de caso: (1) el etno-caso, generalmente conocido como etnografía, orientada a representar la realidad de los participantes nativos; (2) los casos que generan teoría, orientados a las proposiciones teóricas generalizables, y (3) los casos ejemplares, orientados a la acción. Desde esta perspectiva, el concepto actual de estudio de caso aún utiliza las herramientas etnográficas, al considerar que la etnografía es una forma de investigación social que se caracteriza por el énfasis en la exploración de la naturaleza de un fenómeno social concreto, por la tendencia a trabajar con datos no estructurados, por el énfasis en investigar un número pequeño de casos, quizás uno solo, pero en profundidad, y por el análisis de datos que implica la interpretación de los significados y funciones de las actuaciones humanas, expresadas por descripciones explicativas (Atkinson y Hammersley, 1994, citados por Rodríguez Gómez, Gil Flores y García J., 1996).

Profundizando en esto último, la etnografía puede ser vista como un informe o un texto, cuyo rango antropológico se ha revestido de las características del género llamado realismo etnográfico: simulacro de objetividad, sensación de creación de un mundo, presencia narrativa no intrusiva del etnógrafo, focalización en la vida cotidiana, exclusión de personajes particulares y extrapolación estilística de datos particulares (la tipicidad: típica reunión, ritual típico...), embellecimiento por medio de una jerga, representación del discurso nativo (uso de terminología nativa), la creación de efectos de verdad (inserción de testimonios personales, hacer decir), 
la organización textual (seguir a los actores, meditar sobre un suceso), etc., (Marcus y Cushman, 1982, citados por Gutiérrez y Delgado, 1999).

Para esta investigación, un estudio de caso se concibió como una estrategia de investigación global que involucra no sólo el diseño sino todos los momentos del proceso investigativo.

En esencia, el término estudio de caso se refiere a la recolección, el análisis y la presentación detallada y estructurada de la información sobre un individuo, un grupo o una institución. La información proviene de diversas fuentes e incluye usualmente las visiones de los mismos sujetos. (Galeano, 2009, p. 68).

Un caso entonces, es considerado como algo específico, un sistema integrado con patrones de conducta consistentes (Stake, 1994, Gundermann, 2001).

El estudio de caso propone la construcción de un modelo de conocimiento que unifique la experiencia y la realidad humana y focalice su indagación en torno a las prácticas y acciones de los seres humanos, miradas en sus relaciones internas y externas. (Galeano, 2009, p. 69).

Se trata, en suma, de un espacio de significaciones históricamente producidas, que necesitan más de la interpretación comprensiva que de medición estadística, un espacio en el cual el sujeto crea ininterrumpidamente aquellas condiciones sociohistóricas que, a su vez, estructuran su propia vida. (Serrano Blasco, 1997, p. 204).

Se consideró que la estrategia global del estudio de caso es la más pertinente para realizar la investigación, ya que se centra en la individualidad como una conquista creativa, discursivamente estructurada, históricamente contextualizada y socialmente producida, reproducida y trasmitida (Galeano, 2009). Si bien no se pretende una generalización de conocimientos, sino la búsqueda de la particularización efectiva, es decir, la profundidad de la comprensión de lo particular de una organización; el estudio de caso abre la posibilidad para construir teoría a partir de los hallazgos encontrados y, en este sentido, se convierte en una nueva posibilidad de aprendizaje para no quedarse en un conocimiento centrado exclusivamente en lo particular, sino para expandir lo aprendido a otros ámbitos más amplios (Eisenhardt, 1989; Eisenhardt y Graebner, 2007). 
En relación con lo anterior, Yin (1994) afirma que la generalización analítica le permite al investigador generalizar un conjunto particular de resultados a alguna teoría más amplia. Así, y en términos del mismo autor, una teoría que se desarrolla previamente al estudio de caso, puede ser utilizada como una plantilla en donde se compare los resultados empíricos del estudio de caso. En ese sentido, si bien el estudio de caso se centra en la particularidad del objeto de estudio, los resultados del mismo no sólo se circunscriben a la realidad específica analizada, sino que puede arrojar luces a otras problemáticas organizacionales. Esto será un aspecto a corroborar de la presente investigación, ya que para responder a la pregunta planteada se creó y diseñó un modelo teóricometodológico para el estudio de caso específico, el cual podría ser utilizado en futuras investigaciones referidas al tema de la $1 O$.

La investigación se realizó mediante esta modalidad en la compañía Comercial Nutresa S.A.S., empresa dedicada a la venta y distribución de productos no perecederos del Grupo Nutresa. Su elección para realizar el estudio de caso se debió a un criterio de acceso a la información, como aspecto fundamental para justificar esta elección. Además, y siguiendo a Stake (1995), el criterio de maximizar el aprendizaje a partir del estudio de caso es también sumamente importante. Este aprendizaje se adquiere de situaciones atípicas, en donde aquello que se sale de lo normalmente establecido o predecible, se convierte en fuente de conocimiento y comprensión, que incluso puede llevar a modificar ciertas generalidades teóricas previas (Stake, 1995; Galeano, 2009) ${ }^{55}$.

En ese sentido se mencionan algunos aspectos que muestran que la organización elegida fue la apropiada ${ }^{56}$ para el estudio de caso:

\footnotetext{
${ }^{55}$ Para Galeano (2009), el potencial de aprendizaje se da de acuerdo a su facilidad de acceso, que posibilite una combinación de procesos, programas, personas, interacciones o estructuras, relacionados con los temas de investigación; la factibilidad de establecer una buena relación con los temas de la investigación; la facilidad de permanecer en el lugar por el tiempo que sea necesario, y la posibilidad de asegurar la calidad y credibilidad del estudio.

${ }^{56}$ En el siguiente capítulo se profundizará en la organización objeto de estudio. En este capítulo tan sólo se hará referencia a la organización para explicar los aspectos propios de este capítulo metodológico.
} 
- Su reciente creación (marzo del 2011) ha dificultado la consolidación de una IO propia. Su constitución a partir de la integración del personal comercial de varias empresas pertenecientes al mismo grupo (GN), con una trayectoria muy fuerte y reconocida en el Valle de Aburrá, Antioquia, Colombia, no ha permitido la construcción de una identidad propia por el apego que los MM tienen a sus $\mathrm{OO}$.

- La creación de CN implicó una nueva forma de organización y de gobierno. La estructura comercial de cada uno de los cinco negocios desapareció para constituir una nueva y única empresa comercializadora de los productos secos del GN. A partir de ello, se cambió el modelo de gobierno. Se pasó de una estructura piramidal, a una matricial, en donde en cada una de las ocho regiones en Colombia, el gobierno recae sobre un equipo conformado por cada uno de los representantes de las ocho gerencias (ver capítulo cuatro sobre $\mathrm{CN}$ ). De esta manera, la administración de las regiones es mediada no por la identidad de la nueva compañía, sino por las formas de ser y actuar de las compañías de donde provienen sus integrantes.

- Los MM, al provenir de estas compañías del grupo, operan de acuerdo a parámetros preestablecidos, fruto de la fuerte identificación con las compañías de origen. A su vez, estos MM desconocen algunas de las nuevas políticas que viene implementando la nueva compañía CN. Esto se traduce en un problema de comunicación entre la alta dirección y la base operativa. Junto con ello, en lo que lleva la empresa de creada, han tenido dos restructuraciones, lo cual ha implicado el despido de $50 \mathrm{MM}$.

- Para Chia (1996), la IO se logra, y por lo tanto se le puede estudiar, cuando se interrumpen los procesos históricos de las organizaciones y se llega a un alto en el camino, así sea temporal, como puede ser un proceso de 
restructuración como lo tuvo $\mathrm{CN}$. Junto a esto, el autor sugiere que las identidades configuran una dialéctica de ser y devenir (Chia 1996; Tsoukas y Chia 2002; Clegg, Kornberger y Rhodes, 2005), que están siempre en constante cambio. En este tenor, para Whetten (2006), el tema de la IO se oberva, por medio del discurso, más fácilmente durante períodos de agitación organizativa. De este modo, las nuevas compañías configuran un entorno especialmente relevante para estudiar la $I O$, porque su institucionalización relativamente incipiente hace que el proceso de formación de la IO sea particular y especialmente visible. En este contexto, la 10 se puede considerar en términos de una obra identitaria que los gerentes utilizan para establecer un sentido de identidad para las organizaciones. Dada la realidad de $\mathrm{CN}$, este es otro argumento para considerar que dicha organización es propicia para la investigación.

\subsection{UNIDAD DE ANÁLISIS Y OBJETO DE ESTUDIO}

El término unidad de análisis está fuertemente identificado con la metodología cuantitativa. Una definición la da Pérez Serrano (1994):

Es la unidad de trabajo en el análisis estadístico utilizado en la respuesta a un problema de investigación. Una unidad de análisis se traduce siempre en un índice que representa la medida de una variable. Dicha variable puede venir representada por objetos, individuos o por clases de individuos o grupos de objetos y/o individuos. Así, por ejemplo, se denomina unidad de análisis a la unidad de muestreo, es decir, a cada elemento de la muestra. (p. 226).

Sin embargo, el término también es utilizado desde el enfoque propiamente cualitativo. Para Mendizábal (2006, p. 87) es "aquello sobre lo cual se estudiará". Para esta investigación, se entenderá unidad de análisis como aquel aspecto en donde se buscará encontrar el objeto de estudio para luego analizar y cumplir con el objetivo de la investigación. El objeto de estudio de la investigación se concentra entonces en la IO de un estamento de la organización, como son los $\mathrm{MM}$ de $\mathrm{CN}$, buscando comprender aquellos elementos que intervienen en su construcción y, por lo mismo, el sentido que les dan a las relaciones que se entretejen entre estos elementos al momento de constituir una IO. 
La unidad de análisis y el objeto de estudio se encuentran íntimamente relacionados. Por medio de la unidad de análisis se llega a estudiar el objeto de estudio, o visto de otra manera, en la unidad de análisis se encuentra el objeto de estudio. Por otro lado, el marco teórico, que es la 10 , se convierte en la perspectiva de análisis para abordar la investigación, a la vez que conforma parte de su objeto de estudio. Al estudiar la $1 \mathrm{O}$ de los MM, la perspectiva teórica es lente y objeto de estudio a la vez. A través del caso particular de $\mathrm{CN}$ se buscó recomprender el concepto de 10.

La investigación transitó por diversos momentos de naturaleza simultánea y cíclica, algo propio de la metodología cualitativa (Flick, 2008a, 2008b), permitiendo con ello que la ruta metodológica fuera determinada por múltiples construcciones e interpretaciones (Galeano, 2004). El proceso de construcción giró en torno al objeto de estudio de la investigación: construcción de 10 de los MM de CN. Alrededor de dicho objeto giraron las reflexiones y discusiones en tres momentos que podrían clasificarse en exploración, focalización y profundización (Galeano, 2004).

Así, los procesos del proceso investigativo, como son la definición del problema de investigación, el marco teórico, la estrategia metodológica, etc. (que también se les podría llamar componentes del proceso metodológico en la construcción del conocimiento), giraron en torno a este objeto de estudio, el cual se convirtió en el eje de todos los procesos. Al girar los procesos en torno a él, se configuró un espiral de conocimiento, en donde, si bien pareciera que se regresa al mismo punto, la profundidad y el conocimiento adquirido hacen que dicho proceso sea distinto en la medida en que el conocimiento sobre el objeto de estudio avance, haciendo que el punto de llegada sea totalmente diferente. Es por ello que por cada ciclo de aprendizaje, fruto de esta interacción, el cuestionamiento inicial se fue enriqueciendo y perfeccionando mediante una continua retroalimentación de idas y venidas. 


\begin{abstract}
Es justamente la metodología de la investigación la que se constituye en ese "miembro intermediario" que hace "el enlace y el pasaje de la una a la otra", es decir, es el puente o eslabón que permite el ir y venir entre el conocimiento teórico acumulado previamente y su aplicación y validación práctica al momento de llevar a cabo en forma crítica, una indagación concreta, ya sea para generar conocimiento básico, tecnológico o de intervención. (Pacheco Espejel y Cruz Estrada, 2010, p. 58).
\end{abstract}

Esto se ha representado en una especie de espiral, que vista de lado permite observar las fases del proceso investigativo, en donde el objeto de estudio es el eje. Visto desde el cenit, se observa la espiral del conocimiento con los procesos que lo circundan. Lo anterior se vislumbra en el siguiente esquema:

\title{
Gráfica 6: El espiral del conocimiento y las fases del proceso investigativo
}

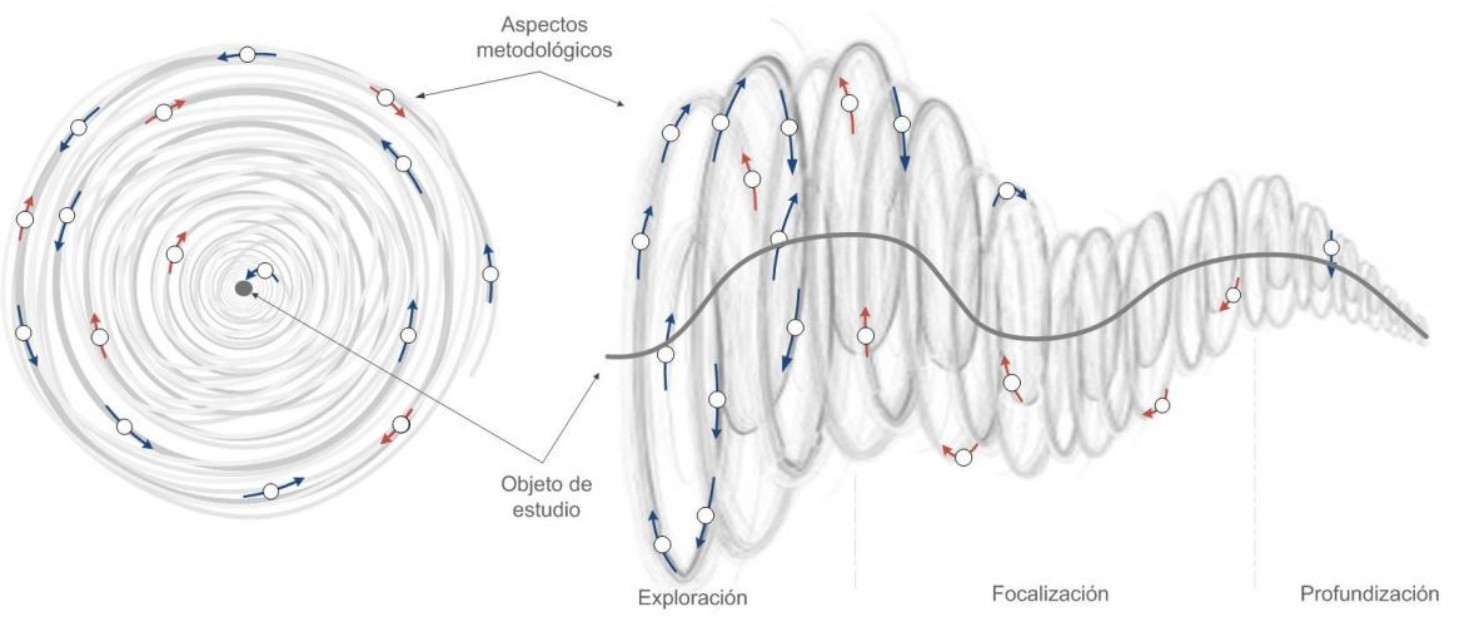

Fuente: Elaboración propia.

El propósito de la gráfica es mostrar la relación entre los componentes del proceso metodológico, el objeto de estudio y las fases del proceso metodológico. Así, los componentes giran en torno al objeto de estudio en una espiral que permite el ir y venir del conocimiento en la investigación cualitativa. En este sentido, al momento de regresar en el proceso, no es que se esté retrocediendo en la comprensión del fenómeno social estudiado, sino que se vuelve para profundizar y, de esta manera, el punto de llegada no será el mismo que el de partida, como lo trata de graficar la espiral. De esta manera, las mismas fases del proceso se van centrando y concentrando, haciendo que los círculos sean cada vez más pequeños, en la medida en que el proceso avanza. Así, en la etapa de 
exploración, los círculos serán más grandes, y se irán reduciendo hasta llegar a la fase de profundización.

\subsection{ACTORES SOCIALES DE LA INVESTIGACIÓN}

\subsubsection{Mandos Medios}

La investigación no consideró a todos los MM de la organización, sino que, y de acuerdo con la información recolectada, se buscó identificar particularidades o patrones comunes en el proceso de identificación a partir de la caracterización previa de una serie de aspectos propuestos en el modelo metodológico de análisis. Por tanto, no se puede afirmar que existe una única manera por la cual los MM construyen su 10, sino que la investigación aplicó dicho proceso de construcción a una organización en particular $(\mathrm{CN})$, a la vez que no todos los MM de dicha organización podrán verse identificados en su totalidad por el proceso de construcción identitaria que se pretende esclarecer. Es por ello por lo que fue necesario identificar aquellos sujetos que ocupan la línea media y que fueran los más significativos ${ }^{57}$ para realizar el trabajo de campo.

Adicionalmente, la investigación buscó centrarse en las relaciones que construyen los individuos (MM) y dotan de sentido su estar en el mundo y, para el estudio de caso, su estar en la organización. Si bien es cierto que los MM ocupan un lugar de permanente interrelación dentro de la estructura organizacional con otros estamentos (ápice estratégico, base operativa, otros MM), la construcción de 10 que desarrollan se centra en las relaciones $y$, por lo mismo, en la autoreferenciación que con ellos se elabora. En este sentido, no fue necesario entonces estudiar la construcción de la 10 de los otros estamentos de la organización.

\footnotetext{
${ }^{57}$ Los actores más significativos son aquellos que por su trayectoria, cargos y funciones, historia en la compañía, pertenencia a los FC, entre otros aspectos pueden dar razón, en mayor profundidad y claridad del proceso de construcción identitario que adelantan.
} 
Según la estructura de $\mathrm{CN}$ y la definición de lo que en esta investigación se entiende como $\mathrm{MM}$, explicada ya en el capítulo referido al marco teórico y conceptual, y enmarcada dentro del contexto organizativo del estudio de caso, los MM podrían ser los directores, jefes y coordinadores, ya que estos tres cargos se encuentran en la línea media de gestión. Esta clasificación es sumamente amplia, por lo que la selección de los MM se acotó a aquellos que forman parte del frente comercial.

El frente comercial (FC) es un equipo de trabajo conformado por los representantes de algunas de las gerencias del Comité de Presidencia de CN en cada una de las regiones en Colombia. Esta estructura de gobierno emula a la del Comité de Presidencia, pero sin la presencia de una cabeza jerárquica, por lo que la toma de decisiones es consensuada entre sus miembros. Es un consejo u órgano de gobierno regional conformado por los representantes de las regiones de cada una de las gerencias de la empresa. Dicho órgano es el encargado de tomar las decisiones y aplicar las estrategias definidas por cada una de las compañías del GN que CN se encarga de comercializar.

Debido a que cada una de las gerencias tiene una estructura distinta, no en todos los frentes comerciales se encuentran representadas. Sin embargo, hay algunas, como las gerencias de los canales comerciales — sobre todo el canal tradicional-, que debido a su importancia dentro de la empresa, sí están presentes en todos los frentes. En general, se entrevistaron $31 \mathrm{MM}$ de las 8 regiones administrativas de $\mathrm{CN}$ en Colombia. A estas 8 regiones hay que agregarles la sede central, la cual se encuentra en Antioquia. Bogotá, por ser una región con mucho volumen de ventas, se divide en tres: Norte, sur y una región dedicada exclusivamente a la cadena de autoservicios. El número de entrevistas por gerencias y regiones se muestra en la siguiente tabla. 


\section{Tabla 3: Número de entrevistas a los mandos medios por gerencias y regiones}

\begin{tabular}{|c|c|c|c|c|c|c|c|c|c|c|}
\hline $\begin{array}{l}\text { Regiones } \\
\text { Gerencias } \\
\end{array}$ & $\begin{array}{c}\text { Of. } \\
\text { Central }\end{array}$ & $\begin{array}{c}\text { Sur- } \\
\text { occidente }\end{array}$ & Costa & $\begin{array}{l}\text { Bog. } \\
\text { Norte }\end{array}$ & $\begin{array}{l}\text { Bog. } \\
\text { Sur }\end{array}$ & $\begin{array}{l}\text { Bog. } \\
\text { Auto. }\end{array}$ & Ant. & $\begin{array}{c}\text { Santande- } \\
\text { res }\end{array}$ & $\begin{array}{c}\text { Tolima- } \\
\text { Huila }\end{array}$ & TOTAL \\
\hline C. Tradicional. & 3 & 1 & 3 & 1 & 1 & & 1 & 1 & 1 & 12 \\
\hline $\begin{array}{l}\text { C. Grandes } \\
\text { Cadenas. }\end{array}$ & 2 & & & & & & & & & 2 \\
\hline $\begin{array}{l}\text { C. } \\
\text { Autoservicios. }\end{array}$ & 1 & & & & & 2 & 1 & & 1 & 5 \\
\hline Logística & & & & & 2 & & 1 & 1 & 1 & 5 \\
\hline Planeación & 1 & & & & & & & & & 1 \\
\hline $\begin{array}{ll}\text { Cultura } & y \\
\text { Desarrollo } & \end{array}$ & & 1 & 1 & & & & & & & 2 \\
\hline $\begin{array}{l}\text { Servicios } \\
\text { Comerciales. }\end{array}$ & & 1 & 1 & & 1 & & & 1 & & 4 \\
\hline TOTAL & 7 & 3 & 5 & & 7 & & 3 & 3 & 3 & 31 \\
\hline
\end{tabular}

Fuente: Elaboración propia.

\subsubsection{Directivos}

Para la investigación, los directivos fueron aquellos que conforman el Comité de Presidencia de CN, es decir, los ocho gerentes y el presidente de la compañía. De estas nueve personas se entrevistaron a los gerentes de ventas de los tres canales: Tradicional, Autoservicios y Grandes Cadenas, a la Gerente de Cultura y Desarrollo y al Presidente de la Compañía.

La elección de estos actores se debió básicamente a que $\mathrm{CN}$ es una empresa comercializadora y de ventas, por lo que los gerentes de los tres canales tienen una mayor incidencia en la línea media de gestión. De hecho, en la constitución de $\mathrm{CN}$ se definen a los tres canales como de mayor importancia, y a las otras gerencias, como soporte de ellos.

Vale la pena aclarar que la unidad de análisis de la investigación, tal como se explicó líneas arriba, son los MM de CN. Los directivos fueron incluidos dentro de la investigación básicamente por lo siguiente: (1) Debido al marco teórico elegido para la investigación, concretamente en cuanto a la concepción de IO como un diálogo, por lo que era necesario tener la otra parte de la conversación, es decir, ¿qué dicen los directivos que son los MM? Para poder comprender el proceso de 
construcción de la 10 de los MM, era preciso entonces conocer la otra parte de la conversación emitida justamente por los directivos. (2) Una segunda razón se debe a que la información oficial de la compañía en cuanto a su proceso de constitución y creación, se basa únicamente en documentos informales, es decir, no hay un informe formal, un texto oficial en donde se describa la constitución de la nueva compañía. Fue necesario, por lo tanto, entrevistar a los directivos para reescribir la historia y, con ello, tener los elementos necesarios para la comprensión del fenómeno que se estudió. (3) Hay una tercera razón que tiene que ver con las implicaciones que pudiera tener tomar en cuenta a los subordinados de los MM. Si bien se afirma que no sólo los directivos influyen en los MM en la construcción de una $\mathrm{IO}$, su inclusión afectaría la recolección y construcción de los datos, el alcance de la investigación e irremediablemente obligaría a adentrarse en categorías conceptuales de otro orden, ampliando los objetivos de la investigación. Su exclusión se debió básicamente al modelo teórico-metodológico propuesto, y en el entendido que los procesos de institucionalización y control identitario están sobre todo influenciados y dirigidos por la alta dirección.

\subsection{INSTRUMENTOS METODOLÓGICOS}

Para obtener la información de los MM se utilizaron entrevistas semiestructuradas y observación no participante, y para el ápice estratégico (directivos), la revisión documental, observación no participante y entrevistas semiestructuradas. La atención estuvo puesta en las relaciones de los MM con los directivos. Las relaciones de los MM dentro del entramado tejido organizacional estructura un rol, el cual integra dichas relaciones. Esto es, el rol llamado MM está entrelazado por tres tipos de relaciones que establecen a su vez tres roles distintos: con los jefes, con los subordinados y con otros MM. Así, los MM son jefes, subordinados y pares a la vez. En este sentido, la investigación sólo consideró la relación con la dirección, como estamento que busca institucionalizar una 10 particular. 
Los procesos de institucionalización, entre ellos el de la IO, son impartidos por los directivos a toda la organización en su conjunto. Así, todos los estamentos están sometidos a ellos. Cada uno de estos procesos tendrá su propio proceso de construcción, el cual necesariamente estará mediatizado por aspectos relacionales y temporales (Dubar, 2002a), definiendo procesos y construcciones disímiles. Lo importante será entonces la autoreferenciación que los MM hacen de sí mismos y de la organización, así como de los procesos de institucionalización que por medio de los otros actores se manifiesten.

Dada la vasta gama de definiciones en torno a los instrumentos metodológicos, es preciso definir cada uno de ellos, para luego explicar brevemente qué o a quién se aplicó, cuándo y por qué.

\subsubsection{Revisión documental}

En la búsqueda de comprensión de los procesos organizacionales, el análisis e interpretación de la palabra escrita es un elemento fundamental. En la investigación se utilizó esta herramienta para obtener la información de cómo los procesos de institucionalización son implementados en la organización. Por ello, se puso especial cuidado en aquellos documentos oficiales que reflejaban tal intención. Bryman (1989) menciona que el análisis de textos es un elemento significativo en la investigación social, y Ruiz (2007) afirma que la lectura de un texto es el más amplio, universalizado y valioso de los modos actuales de obtener información en una investigación. En este trabajo se entiende como análisis documental, a las acciones comprendidas desde la lectura, el análisis de contenido y la interpretación de textos o documentos relacionados con la organización, y las preguntas de investigación planteadas.

\subsubsection{Entrevistas semiestructuradas}

La entrevista es una de las herramientas metodológicas más importantes y popularizadas de la investigación cualitativa (Ruiz, 2007). Las entrevistas fueron 
enfocadas a los directivos de los MM y a los MM, con el fin de obtener información del proceso de institucionalización de la IO, así como de la construcción de sentido que sobre este proceso realizan los MM. Vista como un proceso de comunicación, en el transcurso del cual ambos actores (entrevistador y entrevistado) pueden influirse mutuamente (Alvesson, 2011), es decir, una interacción creadora y captadora de significados, la entrevista es un proceso en el que entrevistador y entrevistado construyen activamente una versión del mundo (Silverman, 1975).

En este trabajo se utilizó la entrevista individual semiestructurada, es decir, una entrevista que se basó en un guión o protocolo básico, con los principales aspectos que iban a ser considerados durante su duración. Las entrevistas fueron grabadas (previa autorización) en su totalidad para garantizar la fiabilidad (Eisenhardt y Bourgeois, 1988). Junto con ello, a lo largo de la recopilación de los datos, se trató de minimizar el sesgo de entrevista a través de la diversidad informante, el anonimato y la confidencialidad (Huber y Power, 1985). Se procedió con las entrevistas hasta llegar a una etapa en que las entrevistas adicionales no brindaban o revelaban nuevas categorías o relaciones, o sea, se logró la saturación teórica (Strauss y Corbin, 2008).

La entrevista semiestructurada permitió generar confianza y disminuir el riesgo de la utilización de juicios preconcebidos y de valor, aumentando las posibilidades de acercamiento a la realidad percibida por el entrevistado. Las entrevistas fueron asumidas más como una conversación que como un interrogatorio, con una intervención mínima de parte del investigador y con la flexibilidad suficiente como para incluir temas no considerados con anterioridad.

Las preguntas fueron estructuradas de acuerdo con las cuatro categorías preliminares: identidad personal, identidad profesional, identidad organizacional y procesos de institucionalización. Las tres primeras dirigidas a los MM, y la última a los directivos. A continuación se relacionan algunas de las preguntas base con cada una de las categorías preliminares definidas en el modelo teóricometodológico. 


\section{Tabla 4: Preguntas de las entrevistas en relación a las categorías preliminares}

\begin{tabular}{|c|c|}
\hline $\begin{array}{l}\text { Categorías preliminares } \\
\text { (actores sociales) }\end{array}$ & Preguntas \\
\hline $\begin{array}{l}\text { Identidad personal } \\
\text { (Mandos medios) }\end{array}$ & $\begin{array}{l}\text { - ¿Cuáles son sus anhelos, sus aspiraciones? } \\
\text { - ¿Qué importancia tiene su autorrealización? } \\
\text { - ¿Qué decisiones importantes ha tenido que tomar en } \\
\text { - ¿Cuál es el proyecto de vida que tiene? } \\
\text { - ¿Cómo quiere que lo recuerden? } \\
\text { - ¿Qué aspectos personales se han desarrollado } \\
\quad \text { trabajando para la compañía? ¿Cuáles no? }\end{array}$ \\
\hline $\begin{array}{l}\text { Identidad profesional } \\
\text { (Mandos medios) }\end{array}$ & $\begin{array}{l}\text { - ¿Qué lo llevó a elegir su profesión? } \\
\text { - ¿Cuál es la relación entre los valores familiares y la } \\
\text { profesión que eligió? ¿Cómo se relacionan? } \\
\text { ¿Cómo incide la profesión que usted tiene en su } \\
\text { trabajo? ¿Qué particularidades de su profesión aportan } \\
\text { a la compañía? }\end{array}$ \\
\hline $\begin{array}{l}\text { Identidad organizacional } \\
\text { (Mandos medios) }\end{array}$ & $\begin{array}{l}\text { - ¿Qué atributos caracterizan a la empresa? ¿Qué es } \\
\text { - ¿Qmercial Nutresa? } \\
\text { - ¿Qué características tienen los mandos medios? } \\
\text { - ¿daptarse a la nueva empresa? } \\
\text { ¿Qué ha tenido que hacer, a nivel profesional, para } \\
\text { - ¿Qué hay de la organización de donde usted proviene } \\
\text { en esta nueva compañía? y, ¿en usted? } \\
\text { - Si yo le preguntara a otro empleado (directivo) de la } \\
\text { organización, quién es usted, ¿qué me diría? } \\
\text { - Si cambio la pregunta y digo, ¿cómo debería ser?, } \\
\text { ¿qué me contesta? ¿Qué es lo que no podría decir de } \\
\text { usted? } \\
\text { - ¿Cómo ha sido su experiencia en todo este proceso? }\end{array}$ \\
\hline $\begin{array}{l}\text { Procesos de institucionalización } \\
\text { (Directivos) }\end{array}$ & $\begin{array}{l}\text { - ¿Cuáles son las características de CN? } \\
\text { - ¿Qué características considera que han permanecido y } \\
\text { han cambiado en CN de la organización de donde } \\
\text { usted proviene? } \\
\text { - ¿Cuáles son las principales dificultades que encuentra } \\
\text { - ¿Qué acciones está implementando CN para construir } \\
\text { una identidad propia? } \\
\text { - ¿Qué acciones toma como directivo en su quehacer } \\
\text { - ¿otidiano para generar una IO en los MM? } \\
\text { - ¿Qué qué dimensiones del ser dirige estas acciones? } \\
\text { profesional? acciones están dirigidas a nivel } \\
\text { - ¿Qué tipo de acciones están dirigidas a nivel personal? } \\
\text { ¿Cuál es el papel que cumplen los MM en esta } \\
\text { construcción identitaria? }\end{array}$ \\
\hline
\end{tabular}

Fuente: Elaboración propia. 


\subsubsection{Observación no participante (panorámica)}

La observación participante se refiere a la recolección de información que realizan los investigadores durante un período de tiempo extenso en el campo, suficiente para observar un grupo, sus interacciones, comportamientos, ritmos, cotidianidades (Galeano, 2009). Para Gutiérrez y Delgado (1999, p. 144) existen ciertas condiciones para aplicar la observación participante:

- El investigador debe ser un foráneo a su objeto de investigación.

- Debe convivir integradamente en el sistema que va a estudiar.

- La integración del analista será maximizada y funcional, sin dejar de ser por ello un analista externo.

- El investigador debe escribir una monografía etnográfica empleando el género del realismo etnográfico.

- Debe dar por finalizada la circulación del texto y la interpretación con la monografía dirigida a la comunidad académica.

Uno de los medios básicos con que el hombre se mantiene en contacto con los otros y con la realidad, es la observación. Este sentido primordial del hombre también está implícito de manera importante en las actividades de investigación. Ruiz (2007) menciona que la observación es el modo más espontáneo y antiguo de recoger información; es el proceso de contemplar sistemática y detenidamente cómo se desarrolla la vida social, sin manipularla ni modificarla, tal cual ella discurre por sí misma.

Para Sánchez (2001), la ciencia comienza con la observación, e involucra la interacción social entre investigador e informantes en el medio de éstos, además de recoger datos de manera sistemática y no intrusiva (Taylor y Bogdan, 1996). Se trata entonces de observar de manera fenomenológica y reflexiva, sin juicios, los elementos y procesos que ocurren en el caso estudiado. Mediante el uso de esta técnica se buscó conocer el lugar y el contexto específico de los informantes, 
tratando de comprender cómo interpelan, interpretan y viven los procesos de institucionalización de la IO.

Cabe resaltar que en el sentido estricto de las definiciones antes mencionadas, no se realizaron observaciones participantes, básicamente por el tiempo en que participó el investigador de las actividades, sino más bien observaciones no participantes o panorámicas, ya que

El investigador no participa por completo en la vida social del grupo al que observa, no es un «participante completo» sino que «participa como observador». La diferencia básica entre ambos comportamientos estriba en que aquí, tanto el investigador como los «observados» saben, son conscientes de los objetivos y planes del investigador, cosa que no sucede cuando éste participa por completo. (Ruiz, 2007, p. 135).

Se redactaron tres documentos de información a partir de las observaciones no participantes realizadas en una actividad que se denomina Despliegue de la estrategia. Esta consiste en la presentación por parte de los cinco negocios del Grupo Nutresa: Galletas, Chocolates, Pastas, Cárnicos y Café, las estrategias de mercadeo para cada una de las marcas de todos los productos de estas empresas para el 2013. Esta actividad se realizó en cada una de las ocho regiones y fue presentada por el presidente de cada una de las compañías, acompañado por su gerente de mercadeo y algunos asistentes, a los MM de CN (directores, jefes y coordinadores).

Es necesario aclarar aquí que el contexto en que se realizaron es muy importante dado que era el espacio para sociabilizar las estrategias de mercado por parte de las empresas miembro del grupo y que $\mathrm{CN}$ tiene la responsabilidad de distribuir y vender. En esto se ahondará en el capítulo referido al análisis de los datos. A continuación se presenta la tabla 5 en donde se resumen los instrumentos utilizados, a la vez que se especifica la fecha en que se aplicaron y la justificación de su uso. 
Tabla 5: Visión general de las fuentes de datos

\begin{tabular}{|c|c|c|c|}
\hline Fuente de datos & ¿Qué? ¿Quién? & ¿Cuándo? & ¿Por qué? \\
\hline Archivos documentales & $\begin{array}{l}\text { - Memoria de creación de Comercial } \\
\text { - } \text { Lutresa. } \\
\text { (128) oftura de todos los comunicados de Comercial } \\
\text { Nutresa vía intranet. } \\
\text { - Informe de evaluación de la cultura } \\
\text { corporativa de Comercial Nutresa. } \\
\text { - Informe de evaluación del clima } \\
\text { organizacional de Comercial } \\
\text { Nutresa. } \\
\text { - Informe del análisis de las } \\
\text { compañías de donde provienen los } \\
\text { empleados de Comercial Nutresa. } \\
\text { - entrevistas a empleados de la } \\
\text { organización en la etapa de } \\
\text { exploración. } \\
\text { - } 2 \text { videos institucionales. } \\
\text { - } 1 \text { canción institucional. } \\
\text { Bitácora de trabajo. }\end{array}$ & $\begin{array}{l}\text { - El contacto con la organización objeto de } \\
\text { estudio: Comercial Nutresa S.A.S. se } \\
\text { realizó en agosto del } 2012 \text {. } \\
\text { A partir de agosto de } 2012 \text { se inició la fase } \\
\text { de exploración y se tuvieron varias } \\
\text { reuniones y entrevistas con los directivos y } \\
\text { empleados para ir construyendo el estudio } \\
\text { de caso. } \\
\text { - Las reuniones de formalización de la } \\
\text { investigación culminaron con la aprobación } \\
\text { del proyecto de investigación por parte del } \\
\text { Comité de Presidencia de la compañía. El } \\
\text { plazo de compromiso para la entrega del } \\
\text { informe a dicho comité fue para noviembre } \\
\text { del } 2013 \text {. } \\
\text { La bitácora de trabajo se desarrolló a lo } \\
\text { largo de todo el trabajo de campo, desde la } \\
\text { exploración y definición de la organización y } \\
\text { el objeto de estudio de la investigación, } \\
\text { hasta el final del análisis de la información. }\end{array}$ & $\begin{array}{l}\text { - CN es una empresa relativamente joven, } \\
\text { pero vieja en su planta de personal. } \\
\text { Fundada en el 2010, CN está constituida } \\
\text { por el área comercial de los productos } \\
\text { secos del Grupo Nutresa. Esta reciente } \\
\text { constitución hizo que prácticamente no } \\
\text { existieran documentos oficiales, por lo } \\
\text { que se hicieron necesarias las entrevistas } \\
\text { a los directivos. } \\
\text { La gran mayoría de la documentación } \\
\text { está en una presentación electrónica, } \\
\text { mas no hay documentos formales } \\
\text { oficiales. Esta realidad se traslada no sólo } \\
\text { a la constitución de la misma compañía } \\
\text { sino a. todas las gerencias en donde los } \\
\text { informes de las consultoras que se } \\
\text { contrataron son más bien un resumen de } \\
\text { los resultados que la explicación del } \\
\text { desarrollo completo de la intervención. }\end{array}$ \\
\hline Observación no participante & $\begin{array}{l}\text { - observaciones en los } \\
\text { lanzamientos del Despliegue de la } \\
\text { Estrategia en dos ciudades de } \\
\text { Colombia (Medellín y Barranquilla). }\end{array}$ & $\begin{array}{l}\text { - Las observaciones se realizaron entre el } 13 \\
\text { de febrero y el } 7 \text { de marzo del } 2013 \text { en las } \\
\text { ciudades de Medellín y Barranquilla. }\end{array}$ & 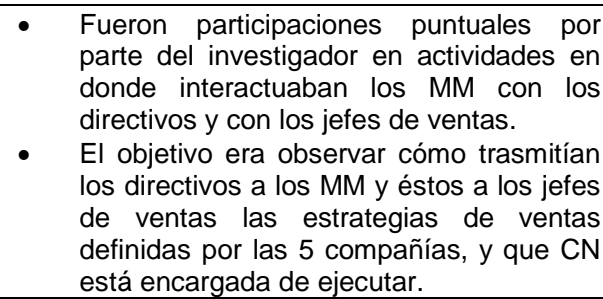 \\
\hline $\begin{array}{l}\text { Entrevistas } \\
\text { semiestructuradas (MM) }\end{array}$ & $\begin{array}{l}\text { - } 31 \text { entrevistas a MM en } 8 \text { ciudades } \\
\text { de Colombia. }\end{array}$ & $\begin{array}{l}\text { - Las entrevistas se realizaron entre el } 22 \text { de } \\
\text { enero del } 2013 \text { y el } 11 \text { de julio del } 2013 .\end{array}$ & $\begin{array}{l}\text { - Son los actores objeto de estudio de la } \\
\text { investigación. Por medio de las } \\
\text { entrevistas se obtuvieron los datos para el } \\
\text { posterior análisis y construcción de } \\
\text { sentido. }\end{array}$ \\
\hline $\begin{array}{l}\text { Entrevistas } \\
\text { semiestructuradas } \\
\text { (Directivos) }\end{array}$ & $\begin{array}{ll}- & 5 \text { entrevistas a los directivos de } \mathrm{CN} \\
\text { (presidente y } 4 \text { gerentes). }\end{array}$ & $\begin{array}{l}\text { - Las entrevistas se realizaron entre el } 22 \text { de } \\
\text { enero del } 2013 \text { y el } 7 \text { de julio del } 2013 .\end{array}$ & $\begin{array}{l}\text { - Como parte del marco téorico era } \\
\text { necesario obtener la información sobre lo } \\
\text { que los directivos piensan de los MM y la } \\
\text { IO que quieren promover. }\end{array}$ \\
\hline
\end{tabular}

Fuente: Elaboración propia. 
En lo referente a la sistematización de los datos, estos fueron categorizados utilizando el programa especializado para investigación cualitativa Atlas.ti v.6.2. El promedio de duración de la entrevistas a los MM fue de 56 min., y para los directivos fue de $54 \mathrm{~min}$. En total fueron $34 \mathrm{~h}$. y $38 \mathrm{~min}$. de grabación, para un total de 37 documentos de trabajo de entrevistas de aproximadamente 629 páginas que fueron analizadas. Todas las entrevistas fueron grabadas y transcritas, a excepción de una, que fue difícil su redacción por haber sido la única que fue realizada vía Skype ya que debido a un problema de conexión la entrevista no pudo ser grabada, pero sí se tomó nota de ella.

Todos los documentos construidos a partir de las observaciones no participantes, así como los documentos audiovisuales y de la revisión documental, fueron también sistematizados, codificados y luego ingresados al software para su posterior análisis. Cabe resaltar que las distintas reuniones previas al inicio en propiedad del trabajo de campo también fueron grabadas. Muchas de ellas sirvieron para construir el caso como tal, pero no fueron consideradas como insumo de información para el posterior análisis de la información.

\subsection{TRABAJO DE CAMPO: FASES DEL PROCESO INVESTIGATIVO}

Siguiendo a Galeano (2004), el proceso de investigación cualitativa se puede dividir en tres momentos: exploración, focalización y profundización. Estos tres momentos no son lineales, sino más bien simultáneos y cíclicos, permitiendo definir la ruta metodológica que orienta el proceso como tal, propiciando construcciones e interpretaciones de los datos relevados. Considerando esta clasificación se describen a continuación los diferentes procesos y actividades que se realizaron, no sin antes explicar brevemente en qué consiste cada uno de estos momentos.

- Fase de exploración: se entra en contacto con el problema o situación que se investiga. Se trabaja con datos sueltos sin mucha coherencia ni 
articulación, impresiones, sensaciones, intuiciones, que adquieren sentido en la medida en que la investigación avanza.

- Fase de focalización: centra el problema estableciendo relaciones con el contexto. Se agrupa, clasifica y se concretan aspectos o dimensiones para definir lo relevante y lo irrelevante.

- Fase de profundización: se reconfigura el sentido de la acción social, interpretar desligándose de la experiencia concreta que dio sentido para construir nuevos conceptos, categorías, teorías.

\subsubsection{Fase de exploración}

La fase de exploración se inició al entrar en contacto con la organización objeto de estudio (agosto de 2012). Se tuvo una primera reunión con la Gerente de Cultura y Desarrollo Organizacional, en donde se presentó la propuesta inicial tanto a nivel teórico como metodológico. En esta primera reunión, en la cual estuvo presente la directora de Desarrollo de Capital Humano, se aprobó el proyecto al encontrar que los resultados de la investigación podían aportar a la compañía, concretamente al área de Cultura y Desarrollo. Se sugirió introducir el tema cultural como un aspecto importante dentro de la realidad de la compañía, ya que era en las regiones en donde se habían presentado los principales problemas, producto de las reestructuraciones y la conformación misma de la nueva organización.

Se tuvo una segunda reunión con la Gerente de Cultura y Desarrollo, en donde se explicó en términos generales el proceso de constitución de $\mathrm{CN}$, detallando los pormenores y haciendo énfasis en los MM, concretamente, en lo que había significado para la compañía las dos restructuraciones realizadas en noviembre del 2011 y marzo del 2012. Se acordó que se debía validar la propuesta frente al Comité de Presidencia (consejo de gobierno de la empresa, presidido por el presidente y conformado por los ocho gerentes de cada una de las áreas de la compañía), para lo cual se hicieron una serie de recomendaciones referidas sobre todo a la forma como se debía presentar la propuesta, enfatizando en la practicidad de la propuesta y los compromisos que se debían cumplir. Junto con 
ello, se acordó tener una cita con la directora de comunicaciones y gestión del cambio. En esa reunión, se explicaron el modelo y la filosofía que utilizan para comunicar las distintas disposiciones y normas estipuladas a nivel de presidencia y del corporativo.

En diciembre del 2012, se presentó a la Compañía CN el proyecto de investigación. Hubo algunos comentarios referidos a incluir las regiones de los Santanderes y Huila-Tolima. Luego fue aprobado. Posteriormente, se inició todo el proceso de relevamiento y construcción de la información a partir de la revisión documental.

En enero del 2013 se realizó la prueba piloto. Para ello se prepararon tres instrumentos dirigidos a los actores sociales de la investigación. Por un lado, las entrevistas semiestructuradas, con las cuales se entrevistaron a dos MM. Uno proveniente de la Compañía de Galletas Noel y, el otro, de la Compañía Nacional de Chocolates. Se entrevistó también a un directivo, al Gerente del Canal Mayorista, el cual proviene de Noel.

Luego de este proceso, y fruto del análisis de los resultados de la prueba piloto, salieron a la luz una serie de aspectos por ajustar, sobre todo en lo referido al componente profesional. Esto permitió ajustar los instrumentos metodológicos y profundizar en el modelo teórico de acuerdo con la realidad que mostraba el estudio de caso. Junto con ello Igualmente se validó también la estructura del documento para las observaciones no participantes.

\subsubsection{Fase de focalización}

Esta fase la constituye el proceso de aplicación de los instrumentos de recolección de información ya ajustados, hasta el análisis y construcción de sentido de los datos. Se incluyen en esta fase las entrevistas a los FC en cada una de las regiones de Colombia en donde tiene operación comercial $\mathrm{CN}$, las entrevistas a los directivos, las observaciones realizadas y el trabajo de documentación 
revisado. Algo importante por anotar es que para poder obtener cierta información en cuanto a la creación de $\mathrm{CN}$ y los criterios que se tuvieron en cuenta para las estructuraciones, así como para el manejo de toda la información brindada por $\mathrm{CN}$, se firmó un acuerdo de confidencialidad entre el investigador y el representante de la compañía. De esta manera, se tuvo acceso a información reservada, e importante para el análisis de los datos.

Este proceso constituyó la construcción del sistema categorial, y el ajuste de las categorías y subcategorías para el análisis. Aquí se presentan las versiones finales de los procesos, así como un resumen de ellos. La fase terminó con la sistematización de los datos relevados mediante los instrumentos de recolección.

\subsubsection{Fase de profundización}

La fase de profundización correspondió al proceso de definición de cada una de las categorías y subcategorías presentes en la investigación, así como la explicación y el análisis de las categorías emergentes. Esta fase termina con el análisis y la triangulación teórica de las categorías emergentes y, por lo mismo, con los hallazgos de la investigación.

Vale la pena resaltar que luego construir las categorías emergentes principales de la investigación (reconocimiento, trascendencia y seguridad) se presentaron los resultados preliminares al Comité de Presidencia de CN. Esto con el fin de realizar una retroalimentación con la alta dirección.

\subsection{SISTEMA CATEGORIAL DE LOS DATOS OBTENIDOS}

El esquema base del sistema categorial que a continuación se presenta, es tomado de Galeano Marín y Aristizábal Salazar (2008). Un sistema categorial es el conjunto de categorías con sus relaciones que guían la investigación y apoyan el análisis de los datos (Vélez y Galeano, 2000; Galeano, 2004). En este sentido, la construcción del sistema categorial refleja el cumplimiento de los objetivos de la 
investigación. Pero también muestra el desarrollo de la construcción de sentido de los datos y, con ello, expone al lector parte del proceso formativo vivido por el investigador, en cuanto al proceso interpretativo se refiere.

Dado que el sistema categorial es un conjunto de categorías, es imprescindible definir dicho término. Este se entiende como:

Ordenadores epistemológicos, campos de agrupación temática, supuestos implícitos en el problema y recursos analíticos. Como unidades significativas dan sentido a los datos, permiten reducirlos, compararlos y relacionarlos. [Son] una construcción para ordenar el mundo vivido, y al mismo tiempo como una visión anticipada de dicho mundo. (Alvarado, 1993, p. 274).

Dentro de los procesos de investigación cualitativa es propio reconstruir el sentido que los actores sociales de la investigación materializaron en los textos sociales. Se trata entonces de develar un sentido que se encuentra oculto, de ahí que se requiera de un proceso de interpretación (reconstrucción hermenéutica). Este proceso de construcción tiene tres ejes: (1) El investigador, quien toma posición frente a las pretensiones de validez de los actores sociales, a la vez que realiza el proceso de construcción de sentido a partir de su propia historia y conocimiento, claro está, inscrito también dentro de un contexto cultural e histórico determinado. (2) El marco teórico que sirve de lente para el análisis. Esta teoría recae sobre la unidad de análisis de la investigación. (3) El trabajo de campo. Son los datos recolectados, organizados, sistematizados y debidamente categorizados.

El proceso de investigación cualitativa articula, para esta investigación, estos tres ejes en un intento por ser coherentes con un método interpretativo y comprensivo. Así, este proceso se realiza en forma de espiral con base en tres fases, tomando como referente a Alvarado $^{58}$ (1993, pp. 273-274), como se muestra en la gráfica 7. Cada uno de estas fases se definirá en forma breve para luego explicar su aplicación en el proceso metodológico desarrollado para la investigación.

\footnotetext{
${ }^{58}$ La definición de cada una de estas fases es tomada de este autor en cada uno de los acápites siguientes. Posterior a estas definiciones, se explica el proceso realizado para el caso concreto de CN.
} 


\section{Gráfica 7: Aspectos que interviene en el análisis de los datos}

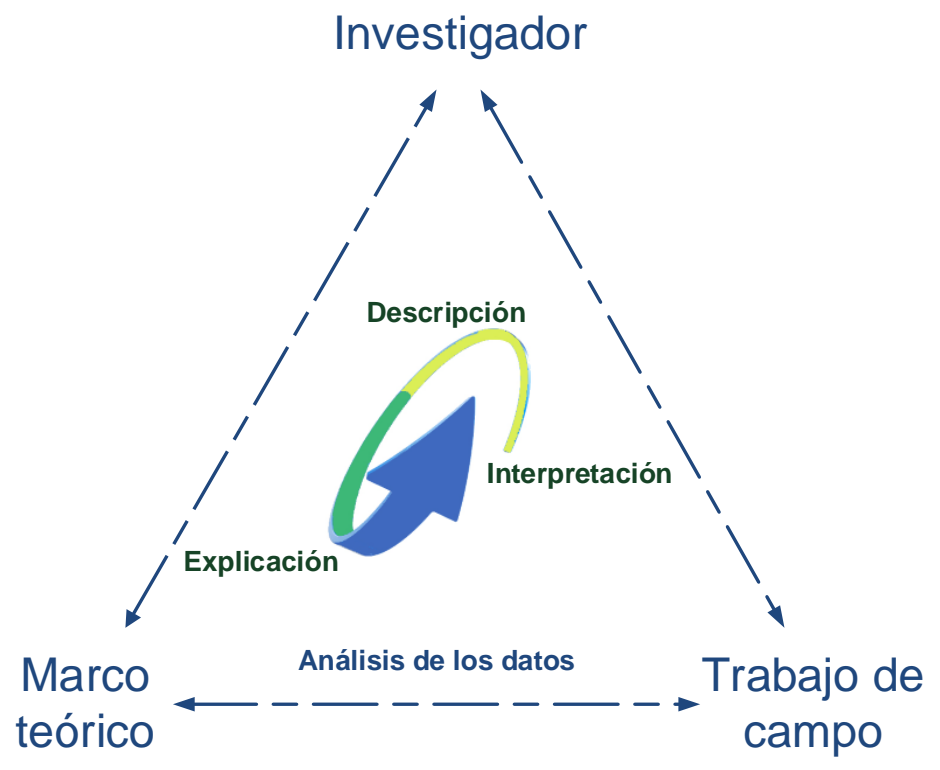

Fuente: Elaboración propia.

\subsubsection{Fase de descripción}

Parte de una serie de interrogantes generales que el investigador tiene sobre la intencionalidad de la comunicación de los actores sociales frente a determinadas vivencias. Las maneras particulares que adquieren estos interrogantes dependen de entrada de la propia experiencia del investigador, de las comprensiones previas sobre el fenómeno social, de la teoría acumulada en torno al entramado social y cultural que contextualiza el fenómeno que se quiere estudiar.

Estas preguntas orientan las primeras estrategias de trabajo, como son la definición de los instrumentos de recolección de información. Buscan con ello que se garantice la observación tanto de lo evidente como de lo no evidente, lo consensual y lo contradictorio, lo repetitivo y lo diferente, lo público y lo privado, tratando de identificar aquellos detalles que se puedan constituir en pistas para el análisis. Estos datos suelen presentarse en forma inconexa, sin sentido y desarticulados. Se buscará encontrar tendencias que permitan, en términos descriptivos, y progresivamente, identificar y llenar el contenido de las categorías que sirven de eje al ordenamiento de la información. 
Al inicio de la investigación, las categorías surgieron de todo el proceso indagatorio, fruto de una primera revisión documental, conversaciones con expertos y trabajo reflexivo con colegas, profesores, amigos y con el director de la tesis doctoral. En este sentido, las primeras categorías aparecen a partir de intuiciones, datos sueltos, conceptos imprecisos sin mucha coherencia ni articulación, sensaciones, deseos y concepciones que comenzaron a adquirir sentido a medida que la investigación avanzaba y el conocimiento propio de la organización objeto de estudio crecía. Es por ello por lo que a este grupo de categorías se les puede llamar propiamente precategorías o categorías preliminares, ya que son definidas previas al trabajo de campo.

Fue muy importante el conocimiento indagatorio que se tuvo con CN. Los primeros contactos se realizaron por medio de un empleado con un cargo importante, que años antes había trabajado con el investigador. De hecho, por iniciativa de él y luego de conocer el proyecto de investigación, fue que se tocaron las puertas de $\mathrm{CN}$. Fue en este momento en el que se iniciaron los primeros acercamientos, y también la validación de las categorías preliminares. Es importante además que dentro de la modalidad del estudio de caso, fue imprescindible conocer la realidad de la organización en la cual se iba a realizar la investigación, en el entendido de que los supuestos teóricos y metodológicos tenían que ser ajustados a una realidad concreta y específica, por lo que dichas conjeturas tuvieron que ser concordadas y organizadas de acuerdo con la realidad concreta que se iba a investigar.

Las precategorías en esta primera etapa fueron: identidad organizacional, identidad personal, identidad profesional y procesos de institucionalización identitarios. Todas ellas son fruto de un inventario inicial de preguntas, las cuales se presentan en la siguiente tabla: 


\section{Tabla 6: Preguntas iniciales}

\begin{tabular}{|c|c|c|c|}
\hline $\begin{array}{c}\text { Identidad } \\
\text { Organizacional de los } \\
\text { MM }\end{array}$ & $\begin{array}{c}\text { Identidad } \\
\text { Profesional de los } \\
\text { MM }\end{array}$ & $\begin{array}{l}\text { Personal } \\
\text { s MM }\end{array}$ & $\begin{array}{c}\text { Proceso de } \\
\text { institucionalización } \\
\text { identitario de los MM }\end{array}$ \\
\hline $\begin{array}{l}\text { - ¿Cuál es la IO de los } \\
\text { - ¿Cu? } \\
\text { ¿Cuál es el proceso } \\
\text { de construcción de } \\
\text { IO de los MM? } \\
\text { - ¿Qué elementos } \\
\text { intervienen en la } \\
\text { construcción de la } \\
\text { IO? } \\
\text { - ¿Hay elementos que } \\
\text { permanecen en el } \\
\text { tiempo, y que formen } \\
\text { parte de la IO? } \\
\text { ¿Qué elementos de } \\
\text { la IO cambian?, y si } \\
\text { lo hacen, ¿se puede } \\
\text { hablar de una IO } \\
\text { como tal? ¿Qué es aquello que } \\
\text { ¿Quace superficial o } \\
\text { handamental a una } \\
\text { organización? } \\
\text { ¿Cuál es el criterio } \\
\text { que permite } \\
\text { identificar cuándo un } \\
\text { atributo sobre la } \\
\text { identidad es distinto } \\
\text { del otro? }\end{array}$ & $\begin{array}{lll}\text { - } & \text { ¿Qué es la } \\
\text { identidad } & \\
\text { profesional? } & \\
\text { - } & \text { ¿Qué } & \\
\text { elementos } & \\
\text { forman parte de } \\
\text { la identidad } \\
\text { profesional? } & \\
\text { - ¿Cuál es } & \text { la } \\
\text { relación entre la } \\
\text { IO y } & \text { la } \\
\text { identidad } & \\
\text { profesional? } & \\
\text { ¿Cómo } & \text { se } \\
\text { relaciona la lO } \\
\text { con la historia } \\
\text { del individuo? } \\
\text { ¿Qué } & \\
\text { elementos de la } \\
\text { identidad } & \\
\text { profesional } & \text { se } \\
\text { negocian en el } & \text { el } \\
\text { proceso } & \text { de } \\
\text { construcción de } & \text { de } \\
\text { una IO? } & \end{array}$ & $\begin{array}{l}\text { - ¿Qué es la } \\
\text { identidad } \\
\text { personal? } \\
\text { ¿Qué elementos } \\
\text { forman parte de } \\
\text { la identidad } \\
\text { personal? } \\
\text { - ¿Cuál es la } \\
\text { relación entre la } \\
\text { IO y la identidad } \\
\text { personal? } \\
\text { ¿Qué elementos } \\
\text { de la identidad } \\
\text { personal se } \\
\text { negocian en el } \\
\text { proceso de } \\
\text { construcción de } \\
\text { una IO? ¿Cómo logra el } \\
\text { individuo dentro } \\
\text { de } \\
\text { organización la } \\
\text { seguir siendo él } \\
\text { mismo? ¿En qué } \\
\text { cambia? ¿En } \\
\text { qué es en lo que } \\
\text { está dispuesto a } \\
\text { ceder? }\end{array}$ & $\begin{array}{l}\text { - ¿Cómo es el } \\
\text { proceso de } \\
\text { institucionalización } \\
\text { identitaria? ¿Quién } \\
\text { lo planea? ¿Quién lo } \\
\text { ejecuta? } \\
\text { - ¿Es posible fabricar } \\
\text { una identidad para } \\
\text { los MM dentro de la } \\
\text { organización? } \\
\text { - ¿Cómo hacen los } \\
\text { empleados frente a } \\
\text { la resistencia que } \\
\text { genera dicho } \\
\text { proceso? ¿Qué } \\
\text { estrategias } \\
\text { desarrollan? } \\
\text { ¿Es posible fabricar } \\
\text { una IO propia? } \\
\text { ¿Cuánto influye la } \\
\text { relación con los } \\
\text { empleados da la } \\
\text { fabricación de una } \\
\text { IO? }\end{array}$ \\
\hline
\end{tabular}

Fuente: Elaboración propia.

En esta primera etapa, las precategorías están estrechamente relacionadas con los conceptos teóricos, incluso se podría decir que surgen a partir de ellos. En este sentido, se entiende que la $1 O$ de los MM como individuos dentro de la organización pasa necesariamente por comprender la relación entre la identidad personal con la profesional. En esta primera etapa del sistema categorial, aún no hay categorías emergentes (pues no se ha realizado aún el trabajo de campo) y la atención no está puesta todavía en las relaciones como tales. No se tiene como referente el concepto de 10 concebida como un diálogo, ni mucho menos la 
historia de la creación de la organización en donde se realizó la investigación, en la cual las organizaciones de origen de este grupo empresarial serán un factor primordial para el análisis de los datos.

\subsubsection{Fase de interpretación}

La interpretación es el proceso que permite la reconstrucción teórica, la recontextualización del fenómeno, el desligue del fenómeno (como vivencia) de su objetivación (como texto, como representación simbólica) para que el propio actor social pueda reconstruir esta relación superando el camino del extrañamiento que le ha impedido reconocerse en dicha objetivación. (Alvarado, 1993, p. 275).

Esta fase se caracteriza por la búsqueda permanente de relaciones que puedan expresar hipótesis cualitativas; relaciones que encuentran su origen en constataciones previas y se constituyen en sí mismas en nuevas constataciones. Es en esta fase en donde se caracteriza la circularidad del proceso interpretativo, a la vez que se van estableciendo nuevas relaciones entre las categorías definidas en la etapa anterior.

Luego de hacer la revisión documental de CN, y realizar las entrevistas piloto de la investigación, se construyó un nuevo conjunto de categorías, fruto de las primeras intuiciones surgidas del trabajo de campo indagatorio y del marco teórico utilizado para esta investigación. Este nuevo conjunto se presenta en la siguiente gráfica ${ }^{59}$ :

\footnotetext{
${ }^{59}$ Se presenta el segundo sistema categorial con el cual se realizó el análisis e interpretación de los datos. El primer sistema categorial no se presenta en el trabajo para no extender la lectura y hacer tediosa la comprensión del proceso investigativo.
} 


\section{Gráfica 8: Segundo sistema categorial: Construcción de IO de los MM}

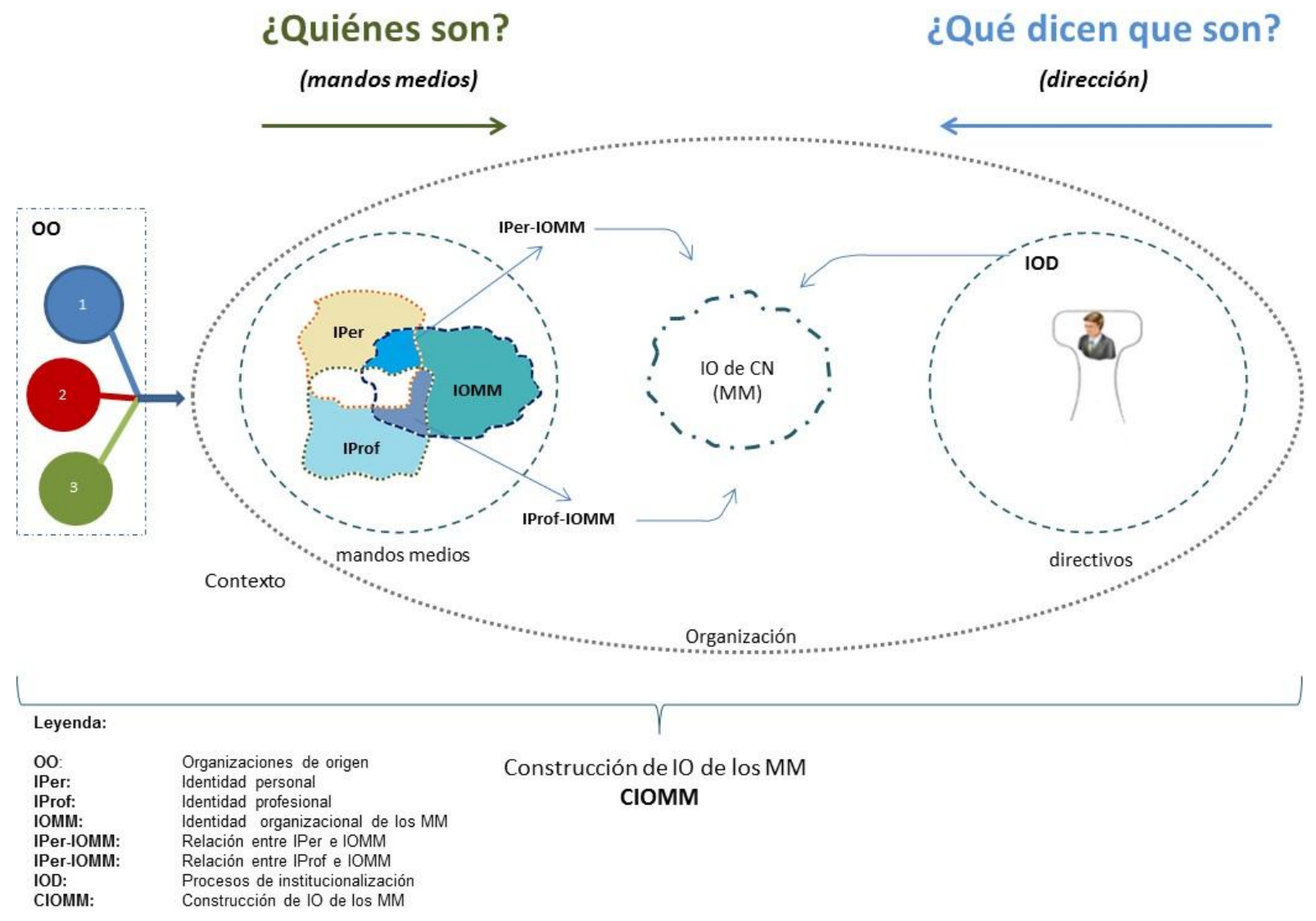

Fuente: Elaboración propia.

Ya en este segundo sistema categorial se incluyeron las organizaciones de origen, las cuales tienen gran incidencia en la construcción de la IO de los MM. Junto con ello, se anexa la concepción de los directivos que buscan estructurar, articular y ejecutar ciertos procesos para fabricar una subjetividad dentro de la organización. En esta fase, se incluyeron también las relaciones entre la identidad personal y profesional con la identidad organizacional de los MM, así como la concepción de lo que para esta investigación se entiende como IO, que no es más que un diálogo entre la unidad de análisis (MM) y los directivos. Es el diálogo fruto de las interrogantes: “¿Quiénes son los MM?” y “¿Qué dicen que son los MM?” De este modo, surgen tres categorías emergentes. Dos de dichas relaciones (IPer.-IOMM y IProf.-IOMM) y una como resultado del diálogo: IO de los MM. La investigación 
no tuvo como objetivo descubrir cuál es la $\mathrm{IO}$ de los $\mathrm{MM}$, aunque sí se discutirá este punto como categoría de análisis, sino el proceso de construcción de dicha IO. La pregunta se centró en el cómo y no en el cuál, enfatizando en el proceso y en la mirada comprensiva de la realidad organizacional estudiada.

En este punto, y como producto del carácter circular $^{60}$ de la investigación, fue necesario precisar los objetivos específicos para contrastarlos con la propuesta inicial de la investigación. Al realizar un estudio de caso, la realidad de la problemática organizacional identificada en la organización objeto de estudio permitió descubrir la particularidad de esa organización, con la manifestación de una problemática que si bien fue propuesta en forma teórica, cobró vida en forma individual y propia, y bajo condiciones y contextos específicos. A continuación, se presenta la relación entre los objetivos y las categorías de análisis de acuerdo con el segundo sistema categorial antes discutido.

${ }^{60}$ Al respecto, Alvarado (1993) afirma que la investigación tiene una característica circular propia de carácter interpretativo, "que implica un movimiento del todo a la parte incomprendida y de ésta al todo" (p. 275). 


\section{Tabla 7: Relación objetivos-categorías de análisis}

Objetivo general de la investigación

Comprender la construcción de identidad
organizacional de los mandos medios en una organización de un grupo empresarial colombiano, con el fin de indagar por el significado que los mandos medios tienen de dicha identidad organizacional, mediante un estudio de caso.

\begin{tabular}{l} 
Objetivos específicos de la investigación \\
\hline Identificar las características de la organización y de \\
los mandos medios en donde se realizará el trabajo \\
de campo de la investigación doctoral.
\end{tabular}

Identificar dispositivos que la organización emplea para suscitar la incorporación de la identidad organizacional en los mandos medios, en una organización de un grupo empresarial colombiano.

Analizar aspectos de la identidad personal y de la identidad profesional que configuran la identidad de los mandos medios, en una organización de un grupo empresarial colombiano.

Analizar aspectos de la identidad personal y profesional que configuran una identidad organizacional de los mandos medios, en una organización de un grupo empresarial colombiano.

Analizar los aspectos personales así como los profesionales que intervienen en la construcción de la $\mathrm{IO}$ de los $\mathrm{MM}$ en relación con los procesos de institucionalización implementados por los directivos, en una organización de un grupo empresarial colombiano.

Fuente: Elaboración propia.

Una vez realizado este ejercicio, se procedió a analizar la información recolectada. Es en este momento cuando surgen las categorías emergentes propias del trabajo de campo. Siguiendo a Galeano (2004, p. 41), se procedió a clasificar estas categorías en descriptivas, explicativas e interpretativas. Esta autora las define de la siguiente manera:

- Descriptivas: Emergen del primer contacto con los datos recolectados. Atribuyen un contenido a un segmento del texto. Son términos utilizados por los participantes en la investigación, y se emplean como categorías de expresiones textuales de los actores o sustantivas, denominación creada 
por el investigador apoyado en rasgos que son posibles de identificar en los datos recogidos y apropiados.

- Explicativas: Apuntan a temas que el investigador descubre como recurrentes o que aparecen con un mismo significado. Este tipo de categorías pueden ilustrar una teoría que emerja de los resultados del análisis.

- Interpretativas: Suponen la postura del investigador frente a unos temas particulares. Son construcciones teóricas, conceptualizaciones para organizar los datos, y que pueden vincular dos o más categorías.

Vale la pena aclarar que según esta propuesta de clasificación de la autora, las categorías preliminares estarían catalogadas como explicativas por estar íntimamente ligadas con la teoría. Sin embargo, a partir de estas precategorías se configuró un conjunto de categorías descriptivas surgidas del análisis de los datos; estas categorías permitieron una clarificación y reconstrucción de sentido de las categorías explicativas (preliminares), y de la misma relación entre ellas. Por último, surgen cinco categorías interpretativas principales: (1) reconocimiento, (2) trascendencia, (3) seguridad, que dan lugar a la (4) IO de los MM, y (5) los procesos de institucionalización. El objetivo de la investigación (construcción de IO de los $\mathrm{MM}$ ) no está representado en una categoría en particular, sino que todo el proceso investigativo da cuenta de él, y por lo mismo, permite el cumplimiento del objetivo trazado por la investigación. El conjunto de categorías se presenta a continuación en las tablas 8 y 9.

Las gráficas - tanto de los MM como de los directivos- en donde se explicitan las subcategorías como las relaciones entre ellas, se presentarán en los apartados correspondientes a cada actor social de la investigación, con el objetivo de mostrar visualmente la correspondencia dentro del modelo de análisis. 
Tabla 8: Relación y clasificación de las categorías de análisis de los mandos medios

\begin{tabular}{|c|c|c|c|c|c|c|c|}
\hline $\begin{array}{l}\text { Categorías } \\
\text { explicativas }\end{array}$ & $\begin{array}{c}\text { Categorías } \\
\text { descriptivas }\end{array}$ & $\begin{array}{l}\text { Categorías } \\
\text { explicativas }\end{array}$ & Categorías descriptivas & $\begin{array}{c}\text { Categorías } \\
\text { descriptivas }\end{array}$ & $\begin{array}{c}\text { Categorías } \\
\text { interpretativas }\end{array}$ & $\begin{array}{c}\text { Categorías } \\
\text { interpretativas }\end{array}$ & $\begin{array}{l}\text { Objetivo de la } \\
\text { investigación }\end{array}$ \\
\hline \multirow{5}{*}{$\begin{array}{l}\text { Organizaciones } \\
\text { de Origen (OO) }\end{array}$} & \multirow{5}{*}{$\begin{array}{ll}\text { - } & \text { Reconocimiento } \\
\text { - } & \text { Desapego } \\
\text { - } & \text { Adecuación } \\
\text { - } & \text { Relaciones } \\
\text { - } & \text { Desernalismo } \\
& \text { Deseño }\end{array}$} & $\begin{array}{l}\text { Identidad } \\
\text { Personal (IPer.) }\end{array}$ & $\begin{array}{l}\text { Seguridad } \\
\text { - } \quad \text { Estabilidad familiar } \\
\text { Significación } \\
\text { - } \quad \text { Reconocimiento } \\
\quad \text { personal } \\
\end{array}$ & & \multirow{6}{*}{ 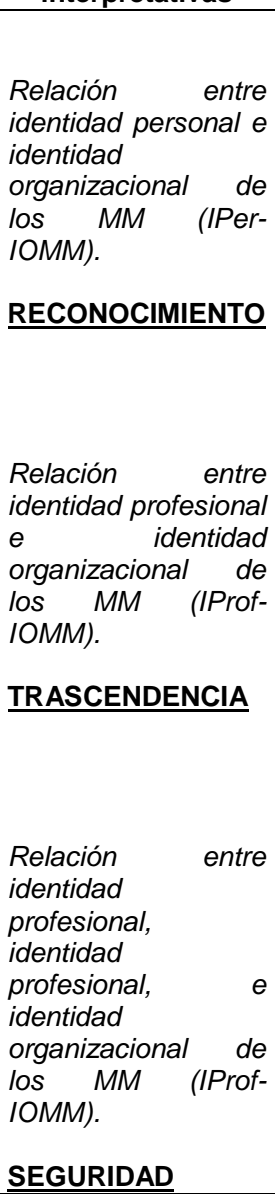 } & \multirow{6}{*}{$\begin{array}{l}\text { IO de los MM } \\
\text { (CPMM). }\end{array}$} & \multirow{6}{*}{$\begin{array}{l}\text { Construcción de } \\
\text { IO de los MM } \\
\text { (CIOMM) }\end{array}$} \\
\hline & & & $\begin{array}{ll}- & \text { Atributos de CN } \\
\text { - } & \text { Dar-recibir-devolver }\end{array}$ & & & & \\
\hline & & $\begin{array}{l}\text { Organizacional } \\
\text { de los MM } \\
\text { (IOMM) }\end{array}$ & $\begin{array}{l}\text { - Críticas al modelo de } \\
\text { gobierno de CN }\end{array}$ & $\begin{array}{ll}\text { - } & \text { Descualificación } \\
\text { - } & \text { Poder y jerarquía } \\
\text { - } & \text { Adecuación }\end{array}$ & & & \\
\hline & & \multirow{2}{*}{$\begin{array}{l}\text { Identidad } \\
\text { Profesional } \\
\text { (IProf.) }\end{array}$} & $\begin{array}{l}\text { Seguridad } \\
\text { - } \quad \text { Estabilidad } \\
\text { profesional } \\
\text { Significación } \\
\text { - } \quad \text { Trascendencia } \\
\text { - } \quad \text { Formación profesional } \\
\text { - } \quad \text { Reconocimiento } \\
\quad \text { profesional }\end{array}$ & & & & \\
\hline & & & $\begin{array}{l}\text { Transversal } \\
\text { - } \quad \text { Rol de los MM }\end{array}$ & $\begin{array}{ll}\text { - } & \text { Críticas a la of. } \\
\text { central. } & \\
\text { - } & \text { Necesidad de } \\
& \text { autonomía } \\
\text { - } & \text { Relación con la } \\
\text { estrategia } \\
\text { - Alineación- } \\
\text { institucionalización }\end{array}$ & & & \\
\hline & & $\begin{array}{l}\text { Historia } \\
\text { Prof-Org }\end{array}$ & $\begin{array}{ll}\text { - } & \text { Identificación temprana } \\
\text { - } & \text { Motivación familiar } \\
\text { - } & \text { Renuncias } \\
\text { - } & \text { Relación con lo laboral }\end{array}$ & & & & \\
\hline
\end{tabular}

Fuente: Elaboración propia. 


\section{Tabla 9: Relación y clasificación de las categorías de análisis de los directivos}

\begin{tabular}{|c|c|c|c|c|c|}
\hline $\begin{array}{c}\text { Objetivo de } \\
\text { la } \\
\text { investiqación }\end{array}$ & $\begin{array}{c}\text { Categorías } \\
\text { interpretativas }\end{array}$ & $\begin{array}{c}\text { Categorías } \\
\text { interpretativas }\end{array}$ & $\begin{array}{c}\text { Categorías } \\
\text { descriptivas }\end{array}$ & $\begin{array}{c}\text { Categorías } \\
\text { descriptivas }\end{array}$ & $\begin{array}{c}\text { Categorías } \\
\text { explicativas }\end{array}$ \\
\hline & & $\begin{array}{l}\text { ¿Quiénes son } \\
\text { los mandos } \\
\text { medios? }\end{array}$ & $\begin{array}{l}\text { Críticas al modelo de } \\
\text { gobierno } \\
\text { - Poder y jerarquía } \\
\text { - } \quad \text { Descualificación }\end{array}$ & & \\
\hline \multirow[t]{3}{*}{$\begin{array}{l}\text { Construcción } \\
\text { de } 10 \text { de los } \\
M M(\text { (CIOMM). }\end{array}$} & $\begin{array}{l}\text { MODELO } \\
\text { EFICIENTE DE } \\
\text { GOBIERNO } \\
\text { Críticas al } \\
\text { modelo de } \\
\text { gobierno } \\
\text { Atributos de } \\
\text { CN }\end{array}$ & & & $\begin{array}{ll}- & \text { Buscar } \\
& \text { conductas } \\
& \text { determinadas } \\
\text { - } & \text { Estrategias de } \\
\text { institucionaliza } \\
\text { ción } \\
\text { - Dificultades en } \\
\text { la } \\
\text { implementació } \\
\mathrm{n}\end{array}$ & $\begin{array}{l}\text { Procesos de } \\
\text { institucionalización }\end{array}$ \\
\hline & & & $\begin{array}{l}\text { ¿Quiénes son los } \\
\text { MM? }\end{array}$ & & \\
\hline & & & Atributos de CN & & \\
\hline
\end{tabular}

Fuente: Elaboración propia.

En los capítulos referidos a los hallazgos (capítulos cinco y seis) se definen cada una de las categorías identificadas. Se aclara que no sólo es la definición conceptual de cada una de ellas a partir del análisis de los datos, sino la reconceptualización teórica, que es parte de la interpretación y construcción de sentido de los datos. Lo que se presenta a continuación es la versión final, depurada y sintetizada, de la categorización tanto para los MM como para los directivos, las cuales constaron de tres versiones anteriores. Antes de mostrar gráficamente cada una de ellas se aclara lo siguiente:

\section{Desde los mandos medios}

1. Fueron tres las precategorías: IOMM, IPer. e IProf. Estas tres categorías fueron constituidas a partir del modelo teórico-metodológico, y por lo mismo tienen una fuerte correspondencia con el marco teórico-conceptual.

2. Las categorías emergentes fueron cinco: Hist. Per-Prof-Org; OO; Reconocimiento, Seguridad y Trascendencia. 
3. Las dos primeras categorías emergentes, y a la vez explicativas, fueron transversales a todo el proceso, pero en forma distinta. La primera (Hist. PerProf-Org) influencia las tres precategorías, por lo que es transversal a todas ellas por las relaciones que genera con ellas, en el sentido de buscar una coherencia entre lo personal, lo profesional y lo organizacional, y lo será también a las emergentes e interpretativas. La segunda (OO) influencia no sólo a los MM sino también a los directivos. Es la fuerte referencia e identificación que tienen con las OO, por lo que la IO tomará de ellas algunos aspectos y la resistencia a dejarlas, y también caracterizará el proceso de construcción identitario.

4. Las categorías emergentes principales, desde el punto de vista de los MM, son: Reconocimiento, Seguridad, Trascendencia y la 10 de CN. Estas categorías son el resultado de la investigación y dialogarán con las de los directivos.

Las categorías desde esta dimensión se presentan en la siguiente gráfica. 


\section{Gráfica 9: Categorías preliminares y emergentes construidas a partir de los mandos medios}



\section{RECONOCIMIENTO}

Reconocimiento personal

Reconocimiento

Renuncia

Relación con lo laboral

\section{SEGURIDAD}

Estabilidad familiar

Formación personal

Estabilidad profesional

Formación profesional

Atributos de $\mathrm{CN}$

Relación con lo laboral

TRASCENDENCIA

Trascendencia

Reconocimiento profesional

Identificación temprana

Motivación familiar

Dar-recibir-devolver

Formación profesional

Fuente: Elaboración propia.

\section{Desde los directivos}

1. Las categorías preliminares o precategorías fueron: Críticas al modelo de gobierno (MG); ¿Quiénes son los MM?; Atributos de CN y Procesos de institucionalización.

2. Las categorías emergentes o hallazgos de la investigación fueron: Organizaciones de Origen (OO), ¿Quiénes son los MM?, Modelo eficiente de Gobierno. Estas tres categorías no se desarrollarán en este capítulo sino en el referido a la presentación de los resultados de la investigación (capítulo cinco). 
3. Al igual que en los $M M$, la categoría OO influencia la configuración del proceso de categorización, por lo que será desarrollada posteriormente, para poder comprender el papel y la relación que tienen con las otras dos categorías emergentes.

4. La categoría emergente principal es: Modelo eficiente de gobierno.

Las categorías desde esta dimensión se presentan en la siguiente gráfica.

\section{Gráfica 10: Categorías preliminares y emergentes construidas a partir de los directivos}
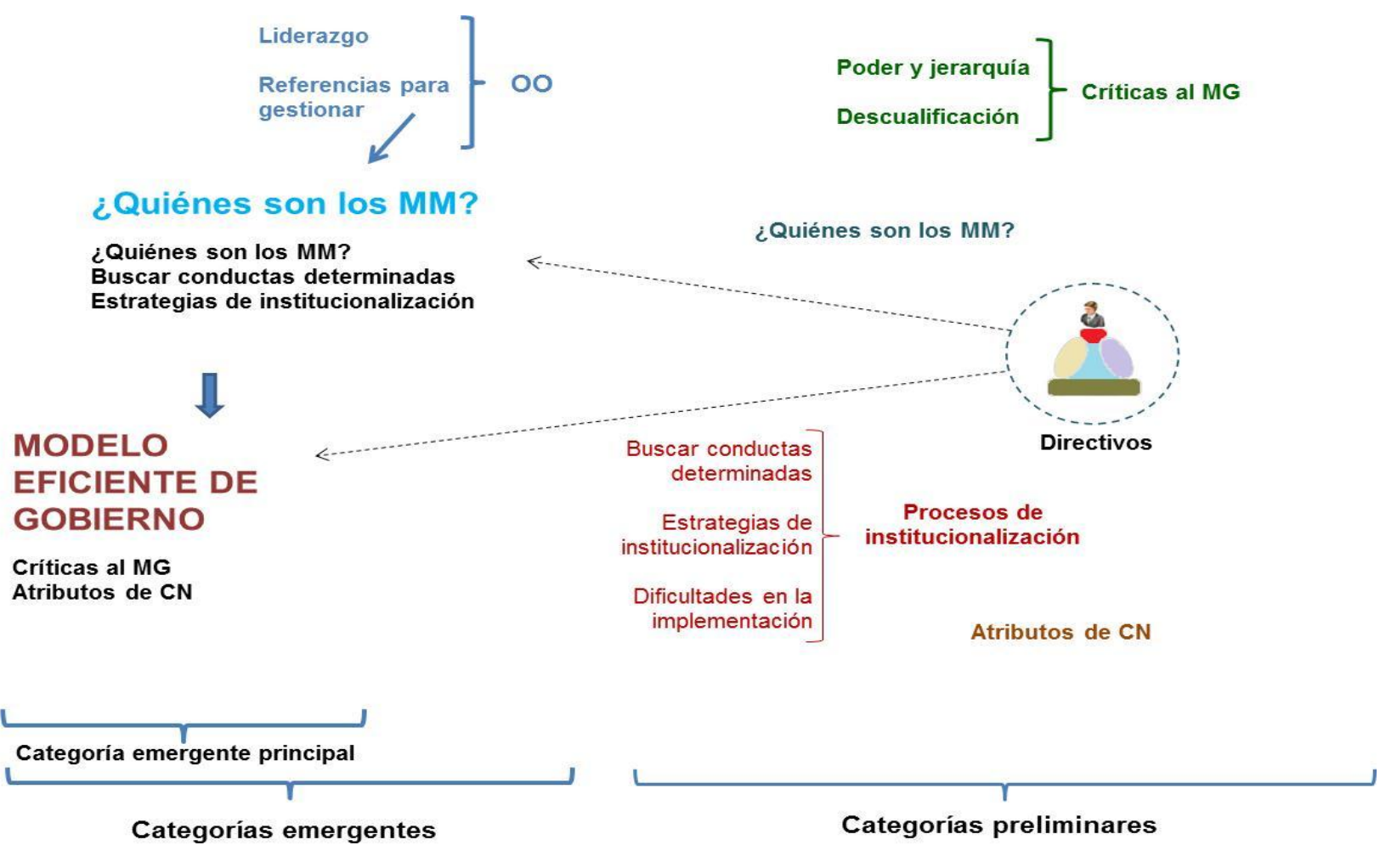

Fuente: Elaboración propia. 


\subsubsection{Fase de constitución de sentido y de constitución teórica}

En esta etapa final del ciclo comprensivo se articulan los argumentos desligándolos de lo empírico del fenómeno que les dio origen, conservándolos en el nivel de representaciones. Para Alvarado (1993), es aquí donde se puede adentrar en el terreno de la inferencia que totalice una visión paradigmática, semántica y pragmática del sentido reconstruido frente a un fenómeno social o cultural $^{61}$.

Este proceso se desarrolla en forma dialéctica y mediado por la reflexión crítica, en donde se buscan relaciones de nivel más complejo, más lejanas de la evidencia empírica, asociadas a la inferencia teórica. Se busca develar los hilos conductores que articulan y les dan coherencia discursiva a los argumentos interpretativos. Esto permite ir construyendo un entramado de relaciones que dan lugar a nuevos conceptos, nuevas comprensiones sobre la parte incomprendida.

Dado que esta fase se convierte en el análisis propiamente de las categorías emergentes, y con ello de los resultados de la investigación, este análisis se realizará en los capítulos referidos a los resultados de la investigación.

\subsection{RELEVANCIA DE LAS CATEGORÍAS DE ANÁLISIS}

La información fue organizada para su análisis a través del software especializado para investigación cualitativa Atlas.ti en su versión $6.2^{62}$. Las categorías

\footnotetext{
${ }^{61}$ Es paradigmática en cuanto se refiere a las múltiples relaciones que expresan una manera particular y valorativa de mirar el fenómeno; es semántica en cuanto remite al problema de la construcción de significados globales, y es pragmática en cuanto vincula de manera simultánea los anteriores elementos con los problemas de sentido de la existencia, la forma de ser y de expresarse del fenómeno en cuestión (Alvarado, 1993).

${ }^{62}$ Atlas.ti es un programa computacional para la investigación cualitativa, el estudio y el análisis de los datos diseñado por Thomas Murh a finales de los ochentas, basándose en la propuesta de construcción teórica de Glaser y Strauss (1967). Este software permite expresar el sentido circular del análisis cualitativo, otorgando la posibilidad de incorporar secuencialmente los datos sin la necesidad de recoger todo el material en un mismo tiempo. Por esta razón, permite llevar a cabo el muestreo teórico necesario para realizar el análisis para la construcción de teoría. Existen otros
} 
preliminares, así como las emergentes fueron analizadas y relacionadas entre sí para su análisis e interpretación a partir del cruce con los otros dos componentes (el investigador y el marco teórico) ya explicado en el capítulo tres referido a los aspectos metodológicos. Ahora se explican los conceptos de fundamentación y densidad para luego pasar a presentar el análisis de las categorías tomando como referente dichos conceptos.

Como se comentó en el capítulo referido a los aspectos metodológicos las categorías no son sólo palabras sino que engloban y cobijan ideas, conceptos, percepciones e interpretaciones. Este proceso de construcción el Atlas.ti lo refleja por medio de la asignación y ubicación de dos números entre paréntesis de llaves, como, por ejemplo: $\{3-5\}$ : el primer número (3) significa el número de citas que han sido codificadas con dicha categoría, y representa la relevancia e importancia de la misma (groundedness: fundamentación, solidez, validez), y el segundo número (5), el número de otras categorías que están conectadas con ésta en la estructura que se va creando, y expresa el grado de densidad teorética de la misma, y por lo tanto, contiene o expresa un mayor grado de abstracción (Martínez, 2001).

Evidentemente, estos dos conceptos básicos, la fundamentación o "validez" de una categoría, es decir, el hecho que representa "algo real" externo a nosotros constatado en muchas citas, y el grado de la densidad teorética de la misma, es decir, la multiplicidad de relaciones o enlaces que tiene con otras categorías (que indica que es un nodo importante), constituyen dos conceptos filosóficos clásicos (extensión y comprehensión de los conceptos), es decir, la amplitud que abarca un concepto y la profundidad semántica del mismo. (Martínez, 2001, p. 5).

Los métodos interpretativos no comienzan su desarrollo con una teoría preconcebida, excepto si se quiere desarrollar una ya existente. En ese sentido, los conceptos o hipótesis son elaborados a partir de los datos a lo largo de la investigación. Una característica fundamental de este enfoque metodológico es su carácter circular (Flick, 2008a, 2008b), obligando al investigador a abordar el

software como: Ethnograph, el HyperResearch, el Nud*dist, el QRS Nvivo, el Folio Views. Sin embargo, para Martínez (2001) el Atlas.ti es el mejor, más completo y fácil de usar de todos. 
proceso completo de la investigación a partir de los nuevos pasos y su relación entre la interpretación de los datos y la selección del material empírico.

Para el caso de esta investigación se construyeron unas categorías preliminares (precategorías) a partir del modelo teórico-metodológico, cuya conceptualización fue fruto de la revisión documental y de los primeros acercamientos a la problemática planteada. Esto permitió la identificación de las precategorías que sirvieron para la construcción de las categorías emergentes, que son propiamente los hallazgos de la investigación. Las categorías emergentes fueron construidas a partir de las categorías preliminares. Se buscó agrupar las ideas y los significados que los actores sociales le dan a las relaciones que emergen del proceso de construcción identitario.

Con la presentación de las categorías preliminares y las emergentes se quiere subrayar la importancia que tienen y las posibilidades que prestan para hacer una reflexión entre ellas con el objetivo de poder elevar el conocimiento de lo investigado a un nivel teórico, sin querer con ello decir, que esto es una justificación para pensar en el surgimiento de una nueva teoría sobre el tema de IO. Sólo es mostrar estos resultados luego del análisis que se realizó por medio del software especializado, con el ánimo de mostrar - y justificar a la vez- las relaciones y los hallazgos que se presentan en los dos siguientes capítulos. En la tabla 10 se presentan todas las categorías (preliminares y emergentes) con los resultados de ambas dimensiones: 


\section{Tabla 10: Categorías preliminares y emergentes con los resultados en cuanto a la fundamentación y densidad a partir del análisis en el programa Atlas.ti}

MANDOS MEDIOS (MM)

CATEGORÍAS

\section{Preliminares}

1.1. IOMM

Atributos de $\mathrm{CN}$

Dar-recibir-devolver

Críticas al MG

Descualificación

Poder y jerarquía

1.2. IPer.

Estabilidad familiar

Reconocimiento personal

Formación personal

1.3. IProf.

Estabilidad profesional

Trascendencia

Formación profesional

Reconocimiento profesional

Rol de los MM

- Críticas a la of. central

- Necesidad de autonomía

- Relación con la estrategia

- Alineacióninstitucionalización

\section{Emergentes}

2.1. Hist.Per-Prof-Org

Identificación temprana

Motivación familiar

Renuncias

Relación con lo laboral

2.2. Organizaciones de origen (OO)

Reconocimiento

Desapego

Adecuación

Relaciones

- Paternalismo

- Desempeño

3. Emergentes principales

RECONOCIMIENTO

SEGURIDAD

TRASCENDENCIA
DIRECTIVOS

\section{CATEGORÍAS}

\section{Preliminares}

$\{0-5\} \quad$ 1.1. Críticas al modelo de Gobierno (MG)

$\{36-2\}$

$\{18-2\}$

$\{8-6\}$

Poder y jerarquía

1.2. ¿Quiénes son los mandos medios (MM)?

$\{7-2\} \quad 1.4$. Atributos de CN

\{26-3\} Referentes para gestionar
$\{8-5\}$

$\{5-1\}$

$\{6-1\}$

$\{1-7\}$

$\{12-2\}$

$\{8-2\}$

$\{7-2\}$

$\{26-3\}$

$\{0-10\}$

\{7-2\}

$\{30-1\}$

$\{20-2\}$

$\{9-3\}$

$\{11-2\}$

$\{23-2\}$

$\{0-7\}$

$\{0-11\}$

$\{0-10\}$

Fuente: Elaboración propia. 
En el cuadro anterior se presentan todas las categorías construidas para esta investigación. Se dividen básicamente en tres: Preliminares, emergentes y emergentes principales. Las primeras son construidas a partir de las primeras intuiciones del investigador a las que se suman la revisión documental y los primeros acercamientos que se tuvieron en el estudio de caso como tal. Hay que aclarar que cada una de ellas se explica a su vez, a partir de otras categorías preliminares que las integran. Las segundas son las categorías emergentes o interpretativas. Éstas son construidas a partir del análisis de los datos, surgen a partir de ellos. Es el conjunto de significados que el investigador ha logrado sintetizar en una frase o palabra a la cual se le resignifican otras definiciones a partir de los datos obtenidos. Se les da un nuevo significado surgido del sentido que los actores sociales y el mismo investigador construyen en el proceso de interpretación. Para esta investigación se destacaron algunas categorías, que siendo emergentes, se les ha catalogado como principales. Estas representan los componentes con los cuales los MM construyen una 10 en $\mathrm{CN}$, en ese sentido, expresan los hallazgos de la investigación. La construcción de las categorías emergentes principales se basó en las preliminares y en las emergentes no principales, en el entendido que estas últimas fueron transversales al proceso. Por tal razón, no tienen una importancia menor en los resultados de la investigación, pero en un nivel distinto a las principales.

Retomando los conceptos de fundamentación y densidad teorética se ejemplifica el significado de los símbolos numéricos que expresan estas dos nociones utilizando algunas categorías. Por ejemplo, la categoría descualificación goza de 36 proposiciones o citas que a partir de los instrumentos de recolección de la información se han logrado identificar como pertenecientes a esa categoría. El número uno (densidad teorética), indica a su vez, que esta categoría es utilizada una vez para definir otra categoría. Esto expresa la importancia o relevancia que tiene esta categoría para construir otra sostenida por todas las proposiciones que se agrupan en ella. A su vez, esta misma categoría (descualificación) contribuye a construir una categoría descriptiva preliminar llamada IOMM (identidad 
organizacional de los MM). Así, esta última categoría se define a partir de todo el grupo que la compone, —que bien se les podría denominar como subcategorías(Atributos de CN, Dar-recibir-devolver, Críticas al MG, Descualificación, y Poder y jerarquía). Ya que son cinco categorías que la componen, los números 0 y 5 indican que no hay ninguna proposición asociada a ella, y que le están asociadas cinco categorías, es decir, esta categoría (IOMM) es construida con base en otras cinco categorías. Se aclara que no necesariamente una sub-categoría está asociada a una categoría de un nivel superior, sino que puede formar parte de otra.

En relación con lo anterior, es imperativo precisar que si bien las categorías emergentes principales, que conforman los hallazgos de la investigación tanto desde el punto de vista de los directivos como de los MM, son los componentes que permiten comprender el proceso de construcción identitario de los MM. No son compartimentos estancos que no se relacionan unos con otros, sino que por el contrario, se entrelazan y mantienen una estrecha relación. Esto es importante ya que en el afán de profundizar en las categorías emergentes principales, el análisis se tomará por separado en un primer momento (esto se realizará en los capítulos referidos a los hallazgos), para luego hacer explícita su integración. Es por ello, y dentro de esta misma aclaración, que para cada categoría emergente principal se ha buscado profundizar a partir de unos marcos teóricos específicos, con el ánimo de tener una mayor claridad y posibilidad de profundizar en el análisis. Se desarrollará esta teoría en la parte de hallazgos, debido a que la construcción de las categorías emergentes surgieron de la interpretación de los datos y no estaban previstas con anterioridad. Se optó por incluirla dentro de los hallazgos para ser coherentes con el proceso investigativo como tal, y porque su lectura previa al análisis, ayuda al lector en la comprensión del análisis que se hará posteriormente. 
Para ilustrar las relaciones entre las distintas categorías y la construcción de las categorías emergentes principales se presentan las gráficas que muestran dichas relaciones a partir de los resultados que arroja el software Atlas.ti.

\section{Gráfica 11: Construcción de las categorías emergentes de los directivos}

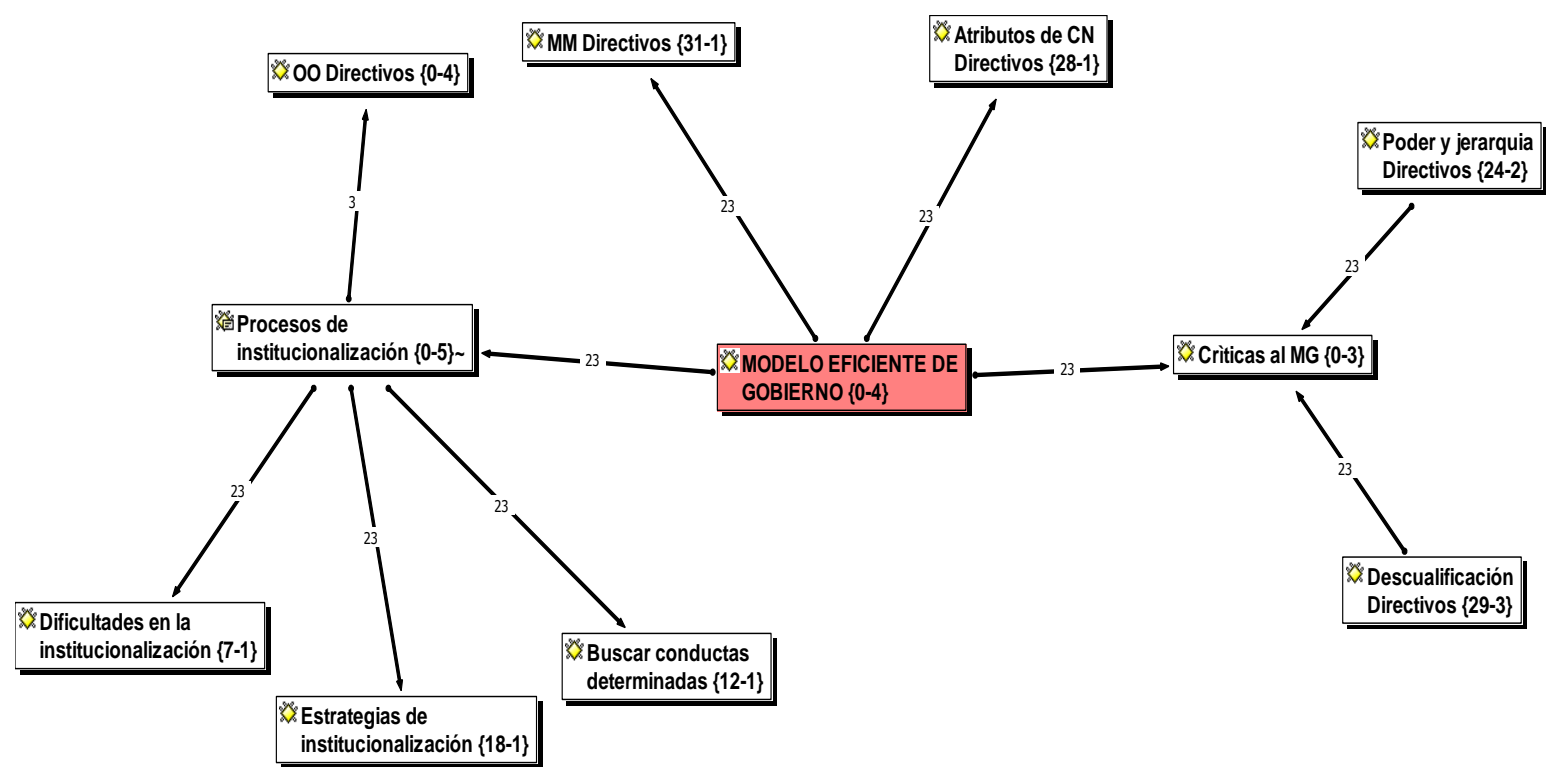

Fuente: Elaboración propia. 


\section{Gráfica 12: Construcción de las categorías emergentes de los mandos medios}

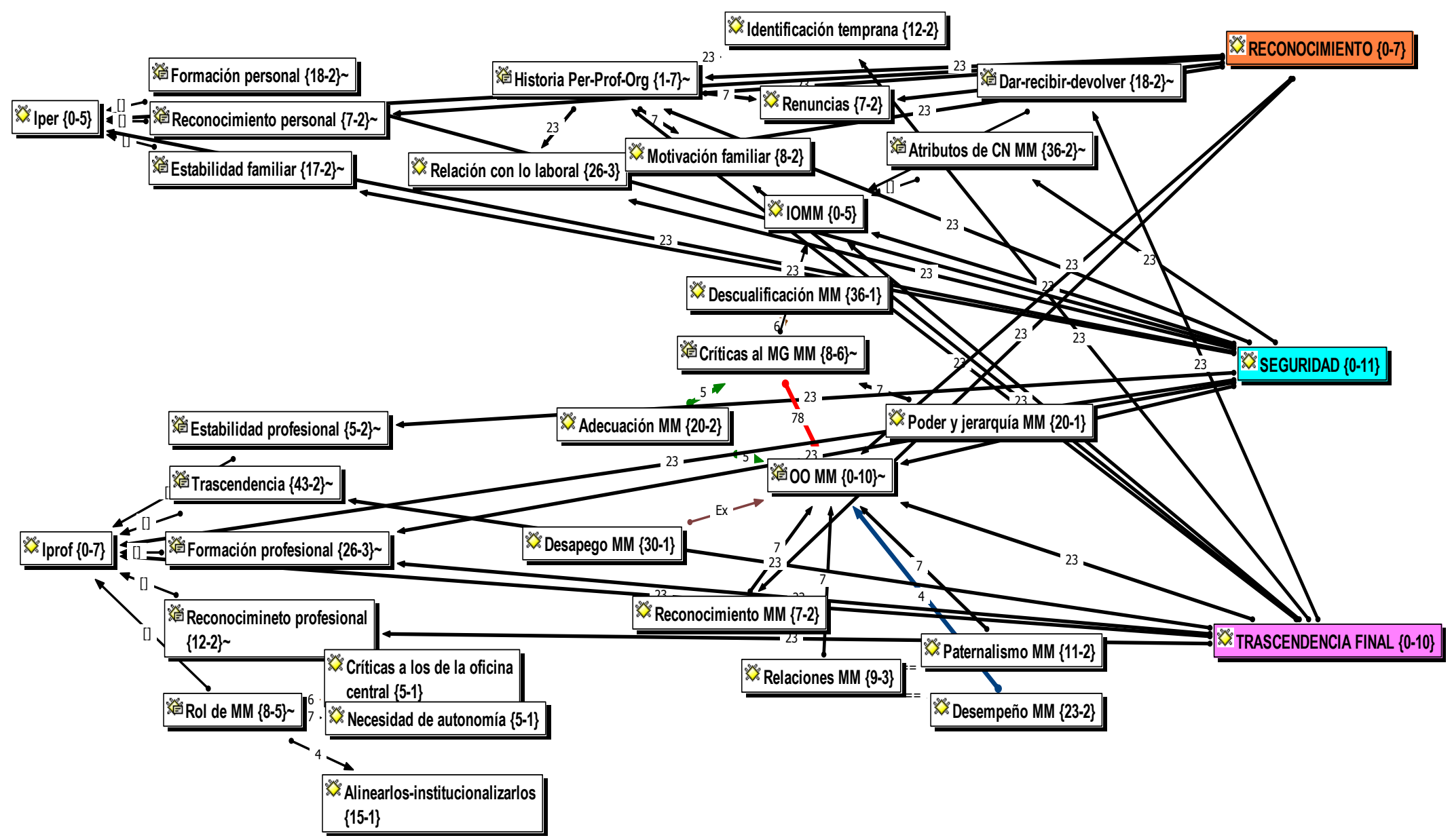

Fuente: Elaboración propia. 
Las cuatro categorías preliminares: Críticas al modelo de gobierno, ¿Quiénes son los mandos medios?, Proceso de institucionalización, Atributos de CN, permiten explicar y comprender otras categorías a la vez que le sirven de fundamento para su conceptualización. La manera como son explicadas por los actores ayuda a acotar la realidad al concepto que estas categorías expresan apropiando conceptualmente el estudio de caso abordado. En el caso de la primera categoría, son 54 proposiciones que la fundamentan, y por lo tanto tres categorías emergentes requieren de ella para explicarse. En ese sentido, la clarificación conceptual desde los resultados de la investigación, en contraste con lo expuesto en el marco teórico-conceptual se convierten en elementos importantes por los matices y precisiones conceptuales que en la realidad del caso de estudio de aplican y constituyen sentido para los actores sociales de la investigación.

\subsection{A MANERA DE CONCLUSIÓN}

A nivel metodológico, muchas son las discusiones acerca de los conceptos que giran en torno al camino recorrido, optado y definido para llevar a cabo la investigación. Desde el esclarecimiento de por qué hacer un estudio de caso, hasta las mismas definiciones de cada uno de los instrumentos utilizados, la diversidad de aproximaciones y conceptualizaciones hace que la definición del mismo camino investigativo sea difícil, incluso más de lo debido, en el entendido de que la atención de la investigación está puesta en el análisis e interpretación de los datos, lo que se desarrollará en el capítulo posterior.

No obstante, se buscó plasmar y acompañar al lector en el camino transitado por considerar que dicho proceso fue una experiencia enriquecedora y de mucho aprendizaje. Se aprende sobre investigación, investigando, y dicha experiencia no sólo debiera quedar escrita para fines netamente académicos sino como un texto a manera de remembranza para el mismo investigador, texto al que pueda recurrir para aprender de los errores y de los aciertos. Sobre esto, no hay una única y 
mejor manera de hacer las cosas, sencillamente se elige un camino en forma coherente y se justifica esa elección. Esto es lo que se ha pretendido hacer en este capítulo.

Uno de los frutos del aprendizaje, y que se quiere subrayar, es la firme convicción de que no hay una estrategia metodológica al margen de un marco teórico claro y consistente. No hay metodología sin teoría. Mantener la coherente relación entre ambas ha significado para esta investigación, una de las formas de sostener la solidez metodológica y, en ese sentido, mostrar la fiabilidad de la investigación.

Se ha hecho mucho énfasis en el sistema categorial, aspecto crucial de la investigación, de una manera muy descriptiva. El análisis y la reflexión en torno a los aspectos metodológicos se realizarán en el capítulo destinado a los hallazgos. En este capítulo se ha mostrado el proceso de construcción de sentido a partir de las categorías definidas. Este proceso, que pocas veces se presenta en un informe final de tesis, ha sido también un aprendizaje valioso y, por ello, no exento de dificultades. El constante diálogo con colegas con más experiencia en este proceso, y la constante discusión acerca de su construcción, permitieron clarificar el proceso y estructurar el sistema categorial que se ha presentado en este capítulo. 


\section{CAPÍTULO 4}

\section{ESTUDIO DE CASO: COMERCIAL NUTRESA S.A.S.}

\section{INTRODUCCIÓN}

En este capítulo se describe la organización en donde se realizó el estudio de caso: Comercial Nutresa S.A.S. Fundada como Cordialza Colombia en marzo del 2010, cambia de nombre a Comercial Nutresa (abril 2011), luego de que el Grupo Nacional de Chocolates, del cual hacía parte, hiciera lo propio y pasase a llamarse Grupo Nutresa $(\mathrm{GN})^{63}$.

La información que aquí se presenta se basa primordialmente en la documentación oficial (informes, comunicados, entrevistas, etc.) relevada en la etapa de exploración de la investigación. El objetivo del capítulo es hacer una breve descripción de CN poniendo en conocimiento del lector su creación y su vinculación con el Grupo Empresarial Antioqueño (GEA en adelante) y el papel que cumple dentro del GN. En ese sentido, no es menester profundizar históricamente, ni detallar los diversos procesos que se dieron en su creación y constitución, sino, enmarcar al lector dentro de la empresa en donde se realizó la investigación, concretamente en la situación que vivieron los MM.

Esta descripción permite a su vez, conocer los problemas que se han presentado en todo el proceso de constitución, y dentro de él, los retos y desafíos con los

${ }^{63}$ Con el fin de recordar el significado de las siglas, se pueden revisar las tablas correspondientes del comienzo. 
cuáles ha tenido que enfrentar la alta dirección para poder construir una IO propia, dentro de la cual, los MM juegan un papel importante.

En el último apartado se contextualiza la problemática de la investigación con el estudio de caso. Se analiza la situación particular de CN, y por ende la de los MM, en los dos ejes propuestos por el modelo teórico-metodológico (relacional y biográfico) identificando las categorías que están en relación con ellos, configurando así, el marco contextual con el cual se analizaron los datos. Junto con ello, se describe el FC como el espacio en donde los MM construyen una IO, a la vez que se resaltan las circunstancias que caracterizan a este órgano de gobierno subrayando el sentido que los MM le dan a las relaciones que se entretejen en este espacio laboral.

\subsection{EI GRUPO EMPRESARIAL ANTIOQUEÑO (GEA)}

En los años 70's se inicia la estrategia de un grupo de empresarios antioqueños por proteger los intereses de los pequeños accionistas frente a los claros intereses de un grupo de empresarios bogotanos (Carlos Ardila Lülle, Julio Mario Santo Domingo y Jaime Michelsen Uribe, entre otros) de querer apoderarse de las empresas símbolos de la región de Antioquia, Colombia. Es así que en 1972, Adolfo Arango Montoya, presidente de Cementos Argos; Jorge Molina Moreno, presidente de Suramericana, y Samuel Muñoz Duque, presidente de Nacional de Chocolates, veían con preocupación cómo un grupo de empresarios capitalinos adquirieran acciones para hacerse de un porcentaje mayoritario de participación de las empresas antioqueñas (Gallo, 2011).

Para Londoño (2004) ocurrieron dos hechos significativos que aceleraron el proceso de constitución del llamado Grupo Empresarial Antioqueño (GEA). (1) Carlos Ardila Lülle tomó el poder de Postobón en 1968 a partir de Gaseosas Lux. (2) El mismo Ardila Lülle se apoderó, en 1973, de la textilera insigne de la región: Coltejer. En sus primeras decisiones sacó de la Junta Directiva a Samuel Muñoz y 
a Jorge Molina. A estos dos hechos emblemáticos le siguieron la compra, a partir de 1978, de importantes porcentajes de acciones de reconocidas empresas antioqueñas como Nacional de Chocolates, Suramericana, Argos, Coltabaco, Fabricato, Cadenalco, Cine Colombia y Simesa, entre otras.

Todo esto motivó a Santiago Mejía Olarte y a Ricardo Ángel Villa a promover una primera reunión que tuvo lugar el 28 de marzo de 1978 en Proantioquia, con la participación de doce destacados empresarios cuyo objetivo era crear un movimiento en defensa de la sociedad anónima y del patrimonio industrial de Antioquia. Se cita a continuación un texto de apertura de dicha reunión:

Antioquia ha logrado crear una serie de empresas en las diferentes áreas cuyos beneficios han irrigado a todo el país: fuente de empleo, halago para la formación del mercado de capitales, transferencia de tecnología, aprendizaje y dominio de sistemas modernos de mercadeo, formación de clase administrativa y dirigente, etc., todo lo cual promovió en forma eficiente el desarrollo nacional y condujo a la elevación del nivel de vida de los colombianos...

La sociedad anónima abierta, que hizo posible la canalización del ahorro de la comunidad para ejecutar en Medellín grandes realizaciones que la nación admira y presenta como fruto de la vocación creadora de los colombianos, se ve amenazada por procedimientos de grupos financieros audaces, poseedores de gran capacidad de maniobra. Éstos, con inversiones cuantiosas y el empleo de métodos no ortodoxos pero legales, pagando precios en apariencia altos si se atiende al rendimiento directo de aquéllas en dividendos por porcentaje muy minoritario de las acciones de una compañía, pueden hacerse a su dominio (...) semejante proceder será, en muy breve término, funesto para el sistema de la sociedad anónima (...) Antioquia se encuentra en la obligación de defender ese patrimonio, que es también su posibilidad para enfrentar el futuro; y para convenir qué acciones se emprenden se ha citado a quienes tienen en sus manos la responsabilidad de las principales industrias del departamento. (Londoño en Londoño, 2004, pp. 51-52).

Se formó un primer comité coordinado por Fabio Rico Calle, presidente en ese entonces de Colcafé. Ese mismo año se iniciaron las negociaciones para retomar el control de las empresas antioqueñas. La estrategia de lo que algunos historiadores y columnistas denominaron como Sindicato Antioqueño, era el cruce de acciones entre las compañías miembro, o que algunos denominan el enroque paisa. Este consistía en configurar un capital para comprar acciones no sólo de las tres empresas emblemáticas del GEA (Cementos ARGOS, Suramericana de 
Seguros, y Compañía Nacional de Chocolates), sino también de otras, con el objetivo de tener margen de maniobra con el fin de negociar con los accionistas mayoritarios de dichas empresas. Hay otra estrategia que tiene relación con la anterior denominada: incorporación (Álvarez, 2003). Ésta consistía en la compra de empresas preexistentes vinculadas al mismo negocio mediante dos procedimientos: el pago en dinero o bienes, o el pago en acciones de la compañía compradora.

Para el actual presidente de Argos, José Alberto Vélez: "Nacimos como resultado de una maniobra realizada por un grupo de compañías de esta región, que querían protegerse de tomas agresivas durante los años setenta y tempranos ochenta [...] Nos mantuvimos unidos para sobrevivir estos embates de la mafia y ahora seguimos unidos para evitar las mismas tomas por parte de empresas extranjeras" (Schipani, 2012, p. 32).

Es así que el GEA se conforma por un grupo de empresas agrupadas en tres grandes sectores: alimentos, asegurador-financiero y cemento. Este grupo de empresas conocidas y reconocidas sobre todo en la región de Antioquia, Colombia, como el Sindicato Antioqueño, se desenvuelven en los últimos años, con criterios más o menos homogéneos en las coyunturas en donde se inscriben (Álvarez, 2003). Hay que aclarar que el GEA no tiene una figura formal o jurídica sino que es más bien una agrupación informal de un grupo de empresas antioqueñas que comparten una serie de principios y políticas. Para uno de los expresidentes (recientemente reemplazado en abril del 2014) de una de la compañías miembro, Carlos Piedrahita -expresidente del Grupo Nutresa (antiguamente Compañía Nacional de Chocolates)-, el GEA "es más un constructo filosófico; cuando los tres nos reunimos, [hace mención a los presidentes de las otras dos compañías claves del GEA: Argos y Suramericana] lo hacemos para tomar café como amigos y compartimos ideas sobre cómo deben administrarse los negocios" (Schipani, 2012, p. 32). 
Se crea entonces una estructura de participación accionaria cruzada entre las empresas del GEA, por algunos considerada como el keiretsu japonés, es decir, una serie de relaciones empresariales ligadas entre sí (Schipani, 2012). Es dentro de este conglomerado en donde se inscribe la compañía en donde se realizó el trabajo de campo de la investigación: Comercial Nutresa, empresa perteneciente al ahora Grupo Nutresa, antes Ilamada Compañía Nacional de Chocolates. Luego de realizar esta contextualización se procede a hacer lo propio con el GN.

\subsection{GRUPO NUTRESA}

La creación de la $\mathrm{CNCH}$ (actual $\mathrm{GN}$ ) es un ejemplo de este proceso de incorporación, brevemente discutido en el apartado anterior. Esto lo describe detalladamente Álvarez (2003) como sigue: Don Gabriel Ángel y su padre Alejandro Ángel, por medio de la empresa Ángel López \& Cía., fundaron la Compañía Nacional de Chocolates en 1920. Esta fue el fruto de la incorporación de: La Compañía Industrial de Chocolates de Francisco Arango V., Chocolate Águila de Santiago Londoño, El trébol de Enrique Cardona, el Yunque, San Bernardo, Sansón, La Compañía, de Enrique Montoya y La Herradura.

El 12 de abril de 1920 fue fundada con el nombre de Compañía de Chocolates Cruz Roja, para luego adoptar el nombre de Compañía Nacional de Chocolates en 1924. Su producto único era el chocolate de mesa. En 1933 se formó una nueva empresa denominada Fábricas de Galletas y Confites Noel formada con aportes de la Nacional de Chocolates y de la Fábrica de Galletas y Confites, fundada en 1916. Esto sería el primer paso de una relación empresarial que sería más adelante base para la construcción del Grupo de Alimentos, hoy Grupo Nutresa.

Algunos de los hechos más importantes del Grupo Nutresa se resumen en la siguiente tabla:

Tabla 11: Hechos importantes del Grupo Nutresa 


\begin{tabular}{|c|c|}
\hline AÑO & HECHOS IMPORTANTES \\
\hline 1916 & $\begin{array}{l}\text { - Fundación de la Fábrica Nacional de Galletas y Confites que posteriormente se convertiría } \\
\text { en la Fábrica de Galletas y confites Noel. }\end{array}$ \\
\hline 1920 & $\begin{array}{l}\text { - Fundación de la Compañía Nacional de Chocolates Cruz Roja, que posteriormente se } \\
\text { convertiría en Compañía Nacional de Chocolates S.A. }\end{array}$ \\
\hline 1933 & $\begin{array}{l}\text { - Alianza Cía. Nacional de Chocolates se hace accionista de Galletas Noel mediante el } \\
\text { aporte de maquinaria para fabricar golosinas y la marca DUX. Este es el primer paso para } \\
\text { la conformación del grupo empresarial que se tiene hoy en día. } \\
\text { - Creación de la marca Sello Rojo, para comercializar café tostado y molido, como } \\
\text { estrategia de diversificación de ingresos de la Cía. Nacional de Chocolates. }\end{array}$ \\
\hline 1958 & - Creación de la marca Colcafé, para la comercialización de café soluble. \\
\hline 1960 & $\begin{array}{l}\text { - Fusión de dos filiales de la Nacional de Chocolates, Chocolate Sansón y Chocolates } \\
\text { Chaves, Santa Fe y Tequendama, dando origen a Industria Colombiana de Café S.A. - } \\
\text { Colcafé. } \\
\text { - Adquisición nacional del negocio cárnico por parte de Galletas Noel, que posteriormente } \\
\text { se consolidaría a través de la empresa Industria de Alimentos Zenú S.A.S. y Alimentos } \\
\text { Cárnicos S.A.S. }\end{array}$ \\
\hline 1968 & $\begin{array}{l}\text { - Adquisición nacional de la fábrica de café: La Bastilla, como complemento al negocio de } \\
\text { café de Colcafé. Esta compañía luego se transformaría en Tropical Coffee Company } \\
\text { S.A.S. }\end{array}$ \\
\hline 1970 & $\begin{array}{l}\text {-Adquisición de Frigorífico Continental en Barranquilla y Frigorífico Suizo en Bogotá, } \\
\text { complementando la presencia del negocio cárnico en Colombia. }\end{array}$ \\
\hline 1978 & $\begin{array}{l}\text { - La Nacional de Chocolates y Galletas Noel participaron en el "Movimiento en defensa de } \\
\text { la sociedad anónima y del patrimonio industrial de Antioquia" que dio origen a lo que, en } \\
\text { su momento, se denominó el Sindicato Antioqueño. }\end{array}$ \\
\hline 1980 & $\begin{array}{l}\text { - Adquisición nacional de Molino Santa Marta S.A. como proveedor de harina de trigo para } \\
\text { el Negocio de Galletas. } \\
\text { - Fundación de Tecniagro S.A. como proveedor especializado de carnes seleccionadas } \\
\text { para el Negocio Cárnico. }\end{array}$ \\
\hline 1993 & $\begin{array}{l}\text { - Fundación de Dulces de Colombia S.A., como parte del proceso de especialización de los } \\
\text { negocios que se comienza a desarrollar en la década de los } 90 .\end{array}$ \\
\hline 1995 & $\begin{array}{l}\text { - Fundación de la primera empresa comercializadora en el exterior: Corporación } \\
\text { Distribuidora de Alimentos S.A. - Cordialsa, en Ecuador. } \\
\text { - Fundación de la empresa distribuidora en Venezuela, hoy denominada Cordialsa } \\
\text { Venezuela S.A. } \\
\text { - Fundación de Proveg Ltda., con lo cual el Negocio Cárnico entra al segmento de } \\
\text { vegetales enlatados. }\end{array}$ \\
\hline 1996 & $\begin{array}{l}\text {-Adquisición internacional de Industrias Alimenticias Hermo de Venezuela S.A., la primera } \\
\text { operación industrial fuera de Colombia, fortaleciendo al Negocio Cárnico. }\end{array}$ \\
\hline 1997 & $\begin{array}{l}\text { - Adquisición nacional de Productos Alimenticios Doria, líder en Colombia en pastas } \\
\text { alimenticias, por parte de Cía. Nacional de Chocolates y sus empresas vinculadas. }\end{array}$ \\
\hline 1999 & - Venta del $30 \%$ de Galletas Noel a Danone, como socio estratégico. \\
\hline 2000 & $\begin{array}{l}\text { - Fundación de Novaventa S.A., empresa dedicada a la venta de los productos de las } \\
\text { compañías de alimentos en "canales alternativos" como venta directa a través de } \\
\text { catálogos y máquinas dispensadoras. }\end{array}$ \\
\hline 2002 & $\begin{array}{l}\text { - Adquisición nacional de Rica Rondo Industria Nacional de Alimentos S.A., consolidando el } \\
\text { liderazgo del negocio cárnico en Colombia. } \\
\text { - Escisión de la actividad industrial de Industrias Alimenticias Noel, dándole origen a } \\
\text { InverAlimenticias Noel con inversiones en los negocios de Galletas, Cárnico y Golosinas } \\
\text { de Azúcar. } \\
\text { - Escición de la actividad industrial de Cía. Nacional de Chocolates, dándole origen a }\end{array}$ \\
\hline
\end{tabular}


Inversiones Nacional de Chocolates S.A. con inversiones en los negocios de Chocolates, Café y Pastas y una participación en InverAlimenticias Noel S.A.

- Fundación de la compañía distribuidora en México, Cordialsa México, complementando la red creada en Ecuador y Venezuela.

- Adquisición internacional de las plantas de galletas y chocolates de Nestlé en Costa Rica, dándole origen a Compañía Nacional de Chocolates DCR y a Compañía de Galletas Noel de Costa Rica.

2004

- Adquisición internacional de activos de distribución en Puerto Rico que dieron origen a

Cordialsa Boricua Empaque Inc.

- Fundación de las compañías distribuidoras, de la red Cordialsa, en Estados Unidos, Panamá, Costa Rica, Nicaragua, Guatemala, El Salvador y Honduras.

- Adquisición del 30\% de Galletas Noel que poseía Danone.

- Inversiones Nacional de Chocolates S.A. absorbe a InverAlimenticias S.A., resultando en

2005 una matriz dueña del 100\% de los negocios Cárnico, Galletas, Chocolates, Pastas y Café.

- Adquisición nacional de Pastas Comarrico, líder de la categoría en la costa atlántica colombiana.

- Adquisición nacional del 94\% de Setas Colombianas S.A., que complementa al negocio cárnico en un segmento en el cual es líder en Colombia.

- Inversiones Nacional de Chocolates S.A. cambia de denominación por Grupo Nacional de Chocolates S.A., reflejando la nueva estructura y visión de sus negocios.

- Adquisición nacional de Meals de Colombia, empresa líder y reconocida por su cultura e innovación, incursionando en el Negocio de Helados.

- Adquisición internacional de Galletas Pozuelo en Costa Rica, empresa líder en Centro América.

2006

- Adquisición internacional de Blue Ribbon empresa de alto reconocimiento en el Negocio Cárnico en Panamá.

- Fundación de Servicios Nacional de Chocolates S.A., el centro de servicios compartidos del Grupo Nutresa.

- Fundación del Grupo Nacional de Chocolates, con el propósito de concentrar los esfuerzos de las compañías del Grupo en su contribución al desarrollo económico y social de la comunidad.

- Adquisición nacional de Mil Delicias, que participa en el segmento de platos listos congelados, complementando el avance de Zenú con la línea de Sofia Express.

2007 - Adquisición internacional de los activos de Good Foods, dando origen a la Compañía Nacional de Chocolates de Perú, con participación en los negocios de Chocolates, Galletas y Golosinas.

- Fusión de las redes de distribución Cordialsa y Pozuelo en Nicaragua y Panamá, logrando mayor eficiencia y efectividad comercial.

- Adquisición internacional de Ernesto Berard S.A., del Negocio Cárnico, complementando la presencia de Blue Ribbon en el mercado panameño.

2008 - Fundación del Centro de Investigación en Nutrición, Salud y Bienestar Vidarium que posteriormente se transforma en la Corporación que lleva su mismo nombre

- Fundación de un Joint Venture de La Recetta en conjunto con Alpina, para atender de forma especializada al segmento institucional en Colombia.

- Fusión de Galletas Pozuelo con Galletas Noel de Costa Rica.

2009 -Adquisición internacional de Nutresa S.A. de C.V., en México, que participa con marcas de alto reconocimiento en el Negocio de Chocolates.

- Fundación de Cordialsa Colombia, empresa especializada en la comercialización de los productos de los Negocios de Chocolates, Galletas, Café y Pastas en Colombia.

2010 -Adquisición Nacional de Industrias Aliadas, compañía dedicada a la producción de café soluble y de extractos de café para exportación.

- Adquisición internacional de Fehr Holdings, LLC, en Estados Unidos. Empresa dedicada a la producción y comercialización de galletas dulces, a través de dos plataformas de producción ubicadas en Texas y Oklahoma. 
-Adquisición de Helados Bon, empresa líder en el negocio de helados en la República Dominicana

- Grupo Nacional de Chocolates S.A. cambia de denominación a Grupo Nutresa S.A., representando todas las categorías de alimentos y empresas del grupo y el vínculo de las marcas con la nutrición.

Fuente: Grupo Nutresa, página oficial, consultada el 26 de diciembre de 2012.

Actualmente el GN tiene seis categorías de negocios: carnes frías, galletas, chocolates, café, helados y pastas. Cada una de ellas representada por muchas empresas insignes antioqueñas. Tiene un portafolio de más de 70 marcas, distribuidas en 12 países de la región con 8 plantas. Estos productos están presentes en 65 países de la región, con 30,000 empleados (6,100 fuera de Colombia). Según su expresidente, Carlos Piedrahita, en el 2011, el Grupo Nutresa facturó US\$2.800 millones y casi US\$ 834 millones de dólares por fuera de Colombia (Schipani, 2012).

La estructura del GN es la siguiente: 


\section{Gráfica 13: Estructura del grupo Nutresa}

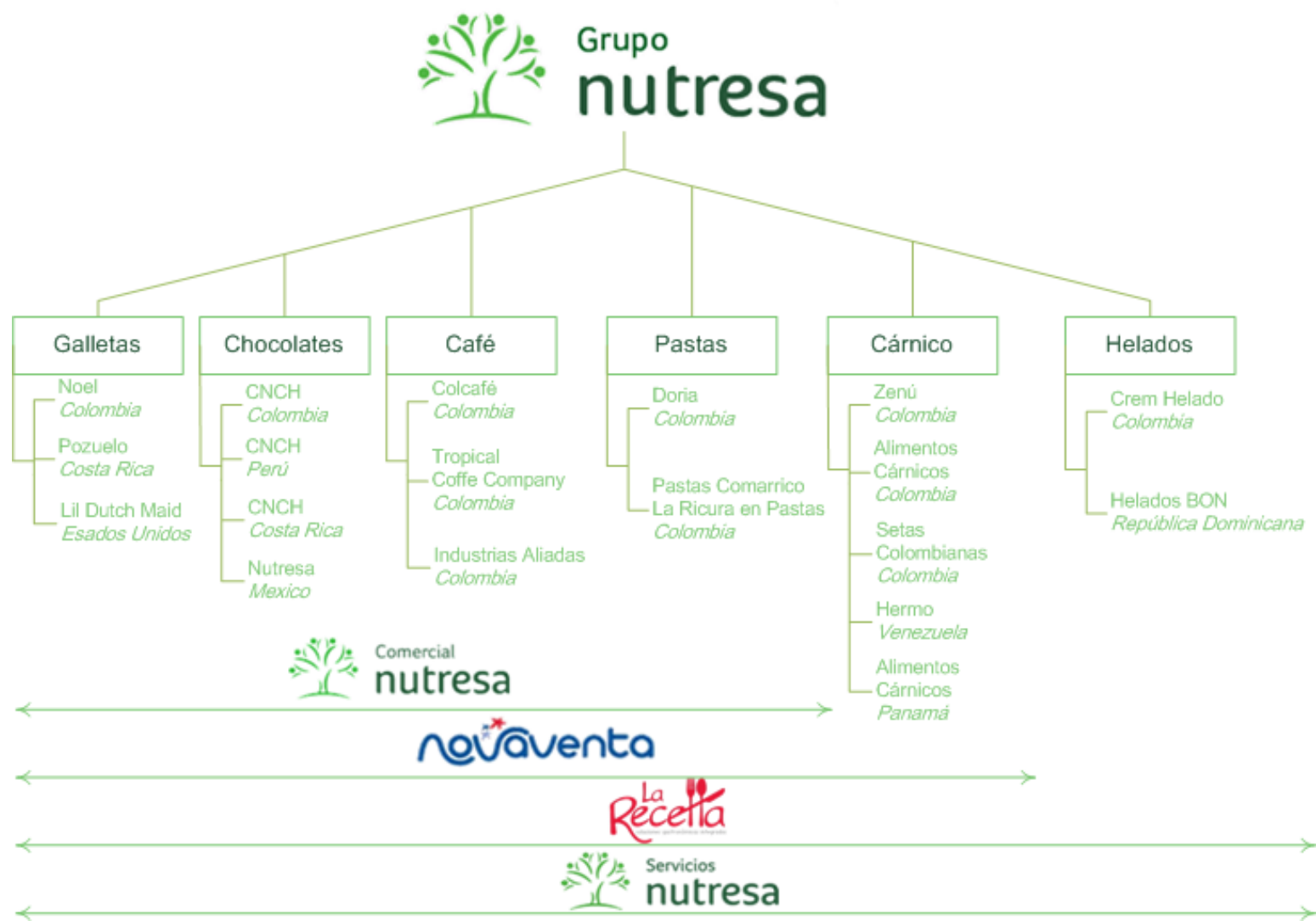

Fuente: Grupo Nutresa, página oficial, consultada el 26 de diciembre de 2012.

EI GN es un grupo empresarial de alimentos con un amplio portafolio de productos distribuidos en seis rubros (galletas, chocolates, café, pastas, cárnicos y helados). Cuenta con una estructura de servicios que tiene la función de soportar la promoción, venta y distribución de los productos y marcas del grupo. Comercial Nutresa $(\mathrm{CN})$ se encarga de la distribución y venta de los productos secos de los cuatro primeros rubros en Colombia. Nonaventa, compañía de canales alternativos que hace parte del GN, constituida en el año 2000, tiene a su cargo la comercialización de productos de la compañías del Grupo, a través de dos canales: Venta Directa (venta por catálogo) y Venta al Paso (máquinas dispensadoras de snacks y máquinas de café). La Recetta, compañía creada y respaldada por el GN y Alpina especializada en clientes institucionales y de grandes volúmenes (hoteles, ejército, cadenas de restaurantes, etc.) en donde se 
les ofrece soluciones integradas a las necesidades. Es la responsable de distribuir los productos del grupo a aquellos clientes que procesan alimentos. Y por último, Servicios Nutresa, que se encarga del soporte técnico a nivel contable y de los procesos de gestión humana de todo el GN.

La Compañía Nacional de Chocolates $(\mathrm{CNCH})$, migra a llamarse Grupo Nutresa en el 2011 con el objetivo de mostrar un nombre que vaya más acorde con el giro del negocio, el cual no sólo de dedicaba a la producción y venta de chocolates, sino al sector alimentos. La idea con este cambio, es que los futuros inversionistas tuvieran una mayor claridad sobre los alcances misionales y el portafolio de la compañía. Nutresa hace referencia a nutrición, que junto con los conceptos de bienestar y salud, terminan por consolidar la identidad del Grupo de Alimentos. Este proceso de cambio no fue algo fácil debido a la gran aceptación y posicionamiento de marca que tenía la Compañía Nacional de Chocolates en toda Colombia, y sobre todo en Antioquia.

\subsection{COMERCIAL NUTRESA}

\subsubsection{Creación}

La creación de CN se realizó el 1 de marzo del 2010 con el nombre de Cordialsa Colombia S.A.S., empresa perteneciente a la Compañía Nacional de Chocolates (posteriormente Grupo Nutresa), con el objetivo de encargarse de la distribución y venta de los productos secos de cinco compañías del Grupo Nutresa (Noel, Nacional de Chocolates, Colcafé, Pastas Doria, Pastas Comarrico). Cordialsa se le denominó a la nueva compañía porque era el nombre que se le daba a la empresa que distribuía los productos del GN en el exterior. Como esta empresa se iba a encargar de hacer la distribución en Colombia, se le denominó Cordialsa Colombia.

El objetivo inicial de esta nueva empresa era lograr una mayor eficiencia y sinergia en la distribución de los productos secos del grupo. Junto con ello, Colombia se 
convertía en un lugar sumamente atractivo para empresas extranjeras, por lo que se preveía el ingreso de potenciales e importantes competidores en el sector de alimentos (Fritolay, Nabisco, Colombina (dulces y golosinas), Nestlé); y las marcas regionales (fuertes en chocolates, en café, por ejemplo). Muestra de ello son los casos siguientes: Fritolay con 36 mil puntos de ventas; Kraft, que luego de comprar Cadbury Adams, tienen 50 mil puntos de ventas nuevos dentro del canal tradicional, el cual a su vez le sirve de distribuidor a Oreo; Nestlé, con 45 mil puntos de ventas en Colombia. Además de lo dicho, están las marcas propias como Éxito o Carrefour las cuales compiten con precios muy bajos. Junto con lo anterior, el alto desarrollo del país, como la firma de los tratados de libre comercio, configuraba un escenario competitivo frente al cual había que tomar ciertas medidas.

El canal de distribución fuerte de la compañía siempre había sido el de la distribución tradicional, es decir, las tiendas y los minimercados. Con el ingreso de grandes competidores, se pensó que el canal que más se afectaría sería el de las grandes cadenas, sin embargo, las empresas competidoras comenzaron a introducir su portafolio de productos mediante otros canales de distribución que no necesariamente eran los propios. De esta manera, el GN, tenía que hacer frente a un embate agresivo de estrategias que buscaban quitarle participación en el mercado.

El inicio de las discusiones sobre la creación de lo que se convertiría en la nueva empresa de distribución y ventas, se dio por iniciativa de los vicepresidentes de Compañía Nacional de Chocolates, Compañía de Galleras Noel y Pastas Doria. Para ello se realizan una serie de visitas a Brasil, Argentina y México, siendo ésta la más beneficiosa (septiembre del 2008), ya que dió origen al actual modelo comercial. Luego de ello, se decidió buscar un acompañante del proceso de consolidación del nuevo proyecto comercial. Es así que se contrata a Booz \& Co., como empresa consultora para realizar esta tarea. 
El GN le encargó la creación de la nueva empresa al actual presidente de Pasta Dorias, el Sr. Fabián Andrés Restrepo Z. El hecho de tener un gerente de proyecto que no perteneciera a ninguna de las dos empresas más grandes del GN que intervenían en el proyecto $(\mathrm{CNCH}$ y Noel) permitió que se salvaran más fácilmente algunos temas políticos, sin embargo, en algunos casos, fue una desventaja momentánea pues primaban las voces de los negocios con mayor peso en las ventas. Incluso el actual presidente de CN, Álvaro Arango, no pertenecía al Grupo Nutresa.

Se define el nuevo modelo comercial, el cual albergará todos los canales y se convertirá en el brazo comercial de los portafolios secos de todas las empresas del grupo empresarial (GN). Se le quiso dar un enfoque nuevo, que se le denomina multilatino. El modelo de implementación fue gradual, planificando el lanzamiento en cada una de las regiones de Colombia en forma secuencial. Esto, con la intención de tener tiempo para realizar la sensibilización e ir monitoreando el proceso.

La primera opción en cuanto a la constitución de la nueva empresa fue crear tres empresas comercializadoras, una para el canal tradicional, otra para el canal moderno y otra para encargarse de la distribución. Sin embargo, se desiste de esta idea, ya que tal división podría debilitar el grupo. Es así que luego se procedió a constituir la estructura organizacional de la nueva compañía, para lo cual se utilizó el modelo de planeación estratégica con oferta de valor diferenciada. De este ejercicio, surge la visión del negocio, su misión y valores organizacionales, los cuales acompañarán la creación de un nuevo modelo comercial y de una nueva cultura organizacional propia. La estructura se definió de la siguiente manera: tres gerencias dedicadas a las ventas en los tres canales (Tradicional, Autoservicios y Grandes Cadenas); y cinco gerencias de soporte (Logística Comercial, Desarrollo de Clientes, Servicios Comerciales, Cultura y Desarrollo Organizacional, y Planeación Comercial). El plazo para la implementación del nuevo modelo comercial fue trazado para un año. 
La metodología que se decidió aplicar para la implementación fue la de sustitución, con el objetivo de fortalecer la cultura organizacional propia desde el inicio. El lanzamiento, 1 de marzo del 2010 (conocido como el día D), se realizó a nivel nacional, para ello se convocaron a todos los empleados, y se realizó un llamado primer ritual de participación masiva.

La salida en vivo de la primera regional (la región colombiana llamada eje cafetero), se realizó el 1 de septiembre de $2010^{64}$. Esta salida en vivo incluyó todas las oficinas centrales de la compañía, la regional Eje Cafetero y el canal Grandes Cadenas. Con esto comenzaron seis ciclos de 180 días a partir de los cuales se dió la implementación de las restantes siete regionales a nivel nacional. En su orden las salidas en vivo fueron: Ibagué, 1 de noviembre de 2010; Cali, 1 de febrero de 2011; Bogotá, 1 de abril de 2011; Bucaramanga, 1 de Junio de 2011; Costa, 1 de agosto de 2011, y Medellín, 3 de octubre de 2011.

\subsubsection{Componentes y estructura}

$\mathrm{CN}$ se define como un sistema organizacional especializado en ventas y distribución que tiene dos componentes: uno técnico y otro humano. El componente técnico está constituido por una oferta de valor diferenciado, a partir de la segmentación, focalización y especialización de los clientes. El componente humano busca una transformación personal de sus empleados, los cuales llama colaboradores. Esta transformación requiere que los empleados encuentren el sentido de sus vidas, por lo que se busca que sean seres humanos que en su actuar dentro de la compañía puedan trascender. La estrategia humana se basa en el autodesarrollo, autogestión, autobienestar y automotivación. Lo que se busca es que los empleados generen su propia transformación personal, el desarrollo del ser en el entendido que puedan alcanzar lo que buscan.

\footnotetext{
${ }^{64}$ La priorización de la salida en vivo de cada una de las regionales se debió al criterio de tamaño en ventas, capacidad de personas frente al cambio y distribución. El tiempo de implementación de un año se pensó más por el proceso de gestión del cambio, buscando que este no fuese muy extenso.
} 
Aquí tenemos 24 segmentos. Esto nos permite poder llegar a tener una oferta de valor diferenciada con unas agrupaciones que tienen más o menos homogeneidad, no tanta dispersidad. Hay muchos tipos de tiendas entonces el poder segmentarlas hace que se atienda mejor las necesidades. Esa segmentación está dividida en 3 ejes: Segmentación por necesidad, segmentación por valor y segmentación por potencial. ¿Y eso que posibilita? Cumplir mejor con las expectativas que tienen los clientes con un proveedor del negocio de consumo masivo. (D5).

La estructura de $\mathrm{CN}$ está conformada por una dirección central que opera en la ciudad de Medellín, Colombia y cuenta con aproximadamente 180 empleados. Ahí operan las 8 gerencias y la presidencia de la compañía. La operación nacional está estructurada en 8 regionales:

1. Suroccidente (Cali, Pereira, Armenia, Manizales, Pasto y Popayán)

2. Costa (Barranquilla, Valledupar, Santa Marta, Cartagena, Montería y Sincelejo)

3. Bogotá Norte (distritos + Tunja oriente y occidente)

4. Bogotá Sur (distritos + Villavicencio y Yopal)

5. Bogotá autoservicios (distritos + Villavicencio y Tunja)

6. Antioquia

7. Santanderes (Cúcuta)

8. Tolima - Huila (Ibagué, Neiva y Florencia)

CN se estructura a partir de estas 8 gerencias que a su vez lideran una serie de cargos dependiendo de las necesidades de cada región. Un ejemplo de los cargos y la manera en cómo está constituida la línea jerárquica de $\mathrm{CN}$ se ilustra a continuación. 


\section{Gráfica 14: Estructura organizacional de Comercial Nutresa}

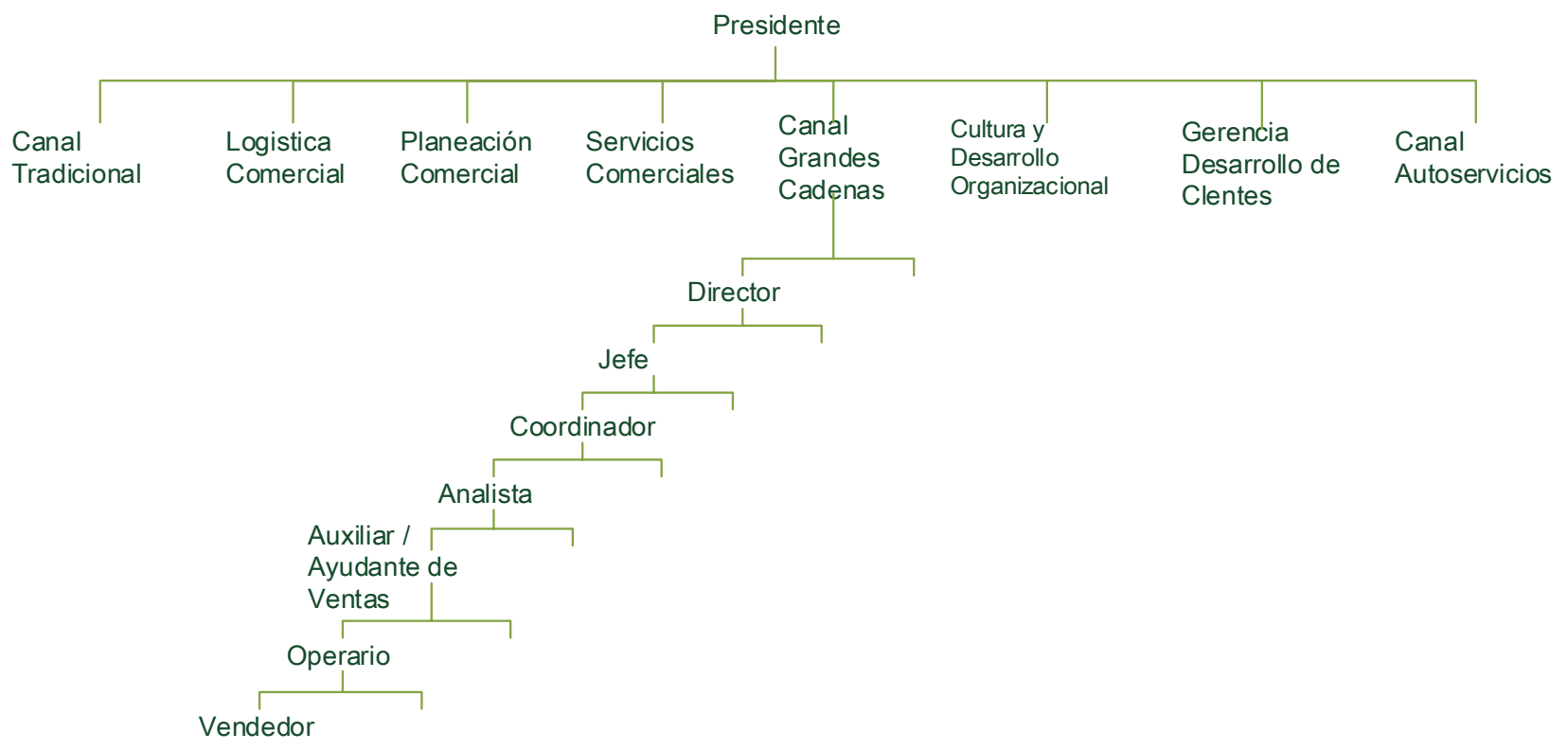

Fuente: Elaboración propia

\subsubsection{Visión, misión y valores}

La visión de CN es:

En el 2015 seremos el mejor socio para nuestros clientes.

La misión de $\mathrm{CN}$ es:

Somos un equipo humano apasionado por el cliente, entregándole con excelencia la mejor propuesta de valor y garantizando la visión de los negocios de Grupo Nutresa.

Los valores de $\mathrm{CN}$ se presentan en la siguiente tabla ${ }^{65}$.

${ }^{65}$ Los comportamientos observables para cada uno de los valores de CN, fueron definidos y redactados por la misma compañía mediante un proceso de participación conjunta. Por tal razón, se ha mantenido el estilo de escritura en primera persona. 


\section{Tabla 12: Valores de Comercial Nutresa}

\begin{tabular}{|c|c|c|}
\hline NOMBRE & DEFINICIÓN & COMPORTAMIENTOS OBSERVABLES \\
\hline Respeto & $\begin{array}{l}\text { Reconocemos y } \\
\text { valoramos la diversidad, } \\
\text { somos únicos y } \\
\text { valiosos. }\end{array}$ & $\begin{array}{l}\text { - Escuchamos a los demás y estamos abiertos al } \\
\text { diálogo constructivo. } \\
\text { - Somos amables, puntuales y oportunos, la cortesía } \\
\text { es una de nuestras principales características. } \\
\text { - Actuamos con honestidad porque cumplimos con } \\
\text { las normas y políticas establecidas. } \\
\text { - Cuidamos el medio ambiente, aportamos con } \\
\text { empeño por desarrollar a la comunidad y lograr la } \\
\text { - Rostenibilidad de nuestro negocio. } \\
\text { - Reconocemos nuestros errores con humildad y } \\
\text { trabajamos por superarlos. }\end{array}$ \\
\hline $\begin{array}{l}\text { Vocación de } \\
\text { servicio }\end{array}$ & $\begin{array}{l}\text { Trabajamos con } \\
\text { entusiasmo y espíritu } \\
\text { colaborativo, } \\
\text { desarrollando soluciones } \\
\text { oportunas que superan } \\
\text { las expectativas de } \\
\text { nuestros clientes. }\end{array}$ & $\begin{array}{l}\text { - Generamos relaciones de confianza y cercanía con } \\
\text { nuestros clientes. } \\
\text { - Buscamos permanentemente soluciones al cliente. } \\
\text { - Atendemos con amabilidad y oportunidad las } \\
\text { necesidades del cliente interno y externo. } \\
\text { - Buscamos permanentemente anticipar y superar } \\
\text { las necesidades del cliente. } \\
\text { - Cumplimos lo que prometemos. } \\
\text { - Mantenemos informados a nuestros clientes sobre } \\
\text { el progreso de sus requerimientos y verificamos su } \\
\text { satisfacción. }\end{array}$ \\
\hline Pasión & $\begin{array}{l}\text { Amamos y disfrutamos } \\
\text { intensamente nuestros } \\
\text { sueños y realizaciones; } \\
\text { con entusiasmo y alegría } \\
\text { hacemos que las cosas } \\
\text { pasen. }\end{array}$ & $\begin{array}{l}\text { - Buscamos el progreso permanentemente. } \\
\text { - Nos trazamos metas claras y retadoras. } \\
\text { - Somos positivos, entusiastas y alegres. } \\
\text { - Somos persistentes para alcanzar los objetivos. } \\
\text { - Nos gozamos la vida. }\end{array}$ \\
\hline $\begin{array}{l}\text { Gestión de } \\
\text { innovación y } \\
\text { conocimiento }\end{array}$ & $\begin{array}{l}\text { Buscamos } \\
\text { permanentemente nuevas } \\
\text { formas de hacer mejor las } \\
\text { cosas. Promovemos la } \\
\text { generación de } \\
\text { conocimiento y lo } \\
\text { compartimos en beneficio } \\
\text { de nuestros clientes, } \\
\text { nuestra gente y los } \\
\text { negocios del Grupo } \\
\text { Nutresa. }\end{array}$ & $\begin{array}{l}\text { - Propiciamos ambientes de trabajo que estimulen la } \\
\text { creatividad. } \\
\text { - Aprendemos de nuestros errores. } \\
\text { - Asumimos riesgos razonables en los procesos de } \\
\text { innovación. } \\
\text { - Facilitamos la generación, conservación, } \\
\text { transferencia y aplicación de conocimientos en toda } \\
\text { la organización. }\end{array}$ \\
\hline $\begin{array}{l}\text { Trabajo } \\
\text { colaborativo }\end{array}$ & $\begin{array}{l}\text { Estamos organizados } \\
\text { alrededor de procesos } \\
\text { para potencializar las } \\
\text { capacidades de nuestro } \\
\text { negocio y la de nuestros }\end{array}$ & $\begin{array}{l}\text { - Construimos conjuntamente las ofertas de valor } \\
\text { con nuestros clientes. } \\
\text { - Contribuimos con nuestro conocimiento de clientes } \\
\text { y shoppers para el desarrollo de las marcas. } \\
\text { - Generamos espacios de opinión, comunicación y } \\
\text { participación orientados al mejoramiento continuo. } \\
\text { - Compartimos e implementamos mejores prácticas }\end{array}$ \\
\hline
\end{tabular}




\begin{tabular}{l|l|l} 
& clientes. & $\begin{array}{l}\text { para enriquecer el desempeño. } \\
\text { Trabajamos en equipo por procesos con } \\
\text { entusiasmo y compromiso buscando el logro de } \\
\text { resultados. }\end{array}$ \\
\hline $\begin{array}{l}\text { Orientación } \\
\text { al logro }\end{array}$ & $\begin{array}{l}\text { Valoramos los comportamientos y resultados } \\
\text { sobresalientes propendiendo por el mejoramiento } \\
\text { continuo de nuestra gente, los clientes y los } \\
\text { negocios del GN. }\end{array}$ \\
& alcanzar las metas & $\begin{array}{l}\text { Somos rigurosos en la ejecución, medición y } \\
\text { seguimiento de nuestra gestión. } \\
\text { establecidas. }\end{array}$ \\
& $\begin{array}{l}\text { Desarrollamos líderes que orienten, acompañen y } \\
\text { reconozcan. }\end{array}$
\end{tabular}

Fuente: Elaboración propia en base a documentación oficial proporcionada por CN.

\subsubsection{Cultura Organizacional de Comercial Nutresa}

\subsubsection{Dimensiones de la Cultura Organizacional}

El modelo de gestión de $\mathrm{CN}$ se basa en la integración de tres ejes: el direccionamiento estratégico, la gestión por procesos y la gestión propiamente de la cultura. El primero busca orientar el rumbo de la organización y alcanzar los resultados. En él se encuentran contenidos los principios rectores de la gestión de la compañía. Se busca responder a las preguntas: ¿qué hacer? y ¿para qué? El segundo, el de la gestión por procesos, se encuentran las metas que se deben alcanzar en el día a día para lograr los resultados plateados por el direccionamiento estratégico. En este sentido, responde a la pregunta del ¿cómo? Por último, en la gestión de la cultura se identifican las habilidades y comportamientos que se deben desarrollar para alcanzar los resultados. En este componente se encuentran las formas de ser y de relacionarse de los individuos.

CN define la Cultura de la siguiente manera:

"Conjunto de principios, valores, presunciones, verdades, normas, costumbres y comportamientos, desarrollados, compartidos y validados por una organización, como producto de la solución continuada en el tiempo a los problemas para su 
supervivencia y que se entienden como la forma de pensar, sentir y actuar de esa organización".

El tema de la Cultura Organizacional está a cargo de la Gerencia de Cultura y Desarrollo Organizacional. Tiene como objetivo ofrecer y facilitar los distintos procesos que permitan a los empleados desarrollarse en el ser y transformarse como individuos. A este conjunto de procesos se le denomina la escuela de vida, dentro de la cual se busca el desarrollo de los empleados en cuatro dimensiones:

(1) Ser: Se busca que cada empleado se acerque a la realidad en forma cognitiva, para luego se adhiera a ella afectivamente. Para poder lograrlo, CN acompaña y ayuda al empleado a responderse a las siguientes preguntas; ¿quién soy yo?, ¿dónde estoy? y ¿para dónde voy? Para ello, se implementaron unos talleres llamados: Proyecto de vida con sentido. Junto con él, están otra serie de talleres, entre ellos el del Desarrollo de competencias conversacionales, que busca transformar la realidad organizacional mediante el desarrollo de habilidades para la comunicación a través de una conversación más eficaz y fluida. Lo que se busca es que los líderes fortalezcan sus competencias, sean flexibles, empoderados, desarrolladores de equipos, todo esto con la velocidad necesaria para lograr los objetivos.

(2) Hacer: Está en relación con la actividad que realiza cada empleado en las distintas áreas de la compañía, en donde se busca que cada uno se desempeñe con éxito y claridad. Por tal razón, esta dimensión está en estrecha relación con el componente propiamente técnico. Se inscriben aquí los siguientes programas: escuelas de ventas, escuela de líderes en logística y demás aspectos en donde se promueve la profesionalización de los empleados. Se encuentran también aquí el auxilio para empleados para realizar estudios formales de especializaciones, maestrías, etc. 
De manera transversal se encuentra el proceso de conversaciones sobre el desempeño. Es un espacio de diálogo sobre las metas cumplidas que permiten una retroalimentación y seguimiento de los compromisos adquiridos y de las competencias que la compañía necesita de cada empleado.

(3) Tener: Lo que busca CN es que sus empleados sean felices. Para ello, éstos deben tener claro cuáles son sus metas, su proyecto de vida, el norte para poder construirlo también dentro de la organización, no a expensas de ella. Se quiere que "[...] la empresa sea el medio para lograr lo que queremos hacer en la vida, con la familia y en el rol personal, enmarcado siempre en el compromiso y lealtad con nuestra Empresa" (D3).

CN brinda una serie de herramientas y auxilios económicos a los empleados para que logren concretar sus proyectos y alcanzar sus metas trazadas, con el objetivo que tengan una mejor calidad de vida. Algunas de estas herramientas o medios son: Pacto Colectivo, los créditos de vivienda, auxilios de educación y calamidad, los premios y redenciones que se obtienen a través del programa Apasionados, entre otros.

Así mismo, CN brinda auxilios que ayudan a los empleados a desempeñarse mejor en su quehacer como: auxilios de rodamiento, alimentación y comunicación. Por último, la empresa cuenta con tácticas de bienestar laboral, las cuales apuntan a que las familias de los empleados se autodesarrollen. Un ejemplo de ello son las alianzas con entidades especializadas para la formación en algún oficio o una destreza que les generen ingresos extras para su núcleo familiar.

Las actividades de bienestar laboral están encaminadas también, al autocuidado. El proceso de valoraciones médicas tiene el alcance del 100\% de la población y los resultados son el insumo para planes de mejoramiento 
de los empleados, en cuanto al manejo de hábitos alimenticios, de posturas, manejo de carga, entre otras. CN trabaja conjuntamente con la ARP (administradora de riesgos profesionales) para tener diagnósticos de los puestos de trabajo, con el fin de prevenir enfermedades. En ese sentido, se promueve el Copaso (Comité Paritario de Salud Ocupacional) para que trabaje con un presupuesto que logre mejorar las condiciones de trabajo, se hacen auditorias constantes en las bodegas para controlar los riesgos y evitar accidentes de trabajo. Además este organismo (Copaso) ayuda a vigilar el cumpliendo de la normatividad de la salud de los empleados.

(4) Trascender: El objetivo de CN es desarrollar un modelo gerencial en donde sus líderes pasen por un proceso de formación migratorio donde los jefes se conviertan en mentores y luego en maestros. Con el objetivo de trascender, es decir, dejar huella en lo que se hace, $\mathrm{CN}$ ha implementado una serie de tácticas con el fin de fortalecer el compromiso a sus colaboradores denominado Frente Comercial de los Socios de Nutresa, el cual busca que se desarrollen como socios más integrales y sostenibles a aquellos terceros que distribuyen sus productos.

Junto con lo anterior, están las escuelas de clientes que agrupan también a los tenderos, mayoristas y autoservicios. Todo esto se desarrolla y promueve por medio de la capacidad de conversar que impulsa la compañía como el medio para promover una cultura del diálogo.

En estas cuatro dimensiones están condensados todos los procesos y programas que desarrolla $\mathrm{CN}$, en donde la Cultura es el vehículo para que la estrategia de la compañía se cumpla. 


\subsubsection{Componentes de la Cultura Organizacional}

Los componentes son aquellos aspectos que ayudan a concretizar la Cultura Organizacional de CN. Éstos están en estrecha sintonía con los objetivos de la compañía (para el 2015) construidos a través de grupos focales de empleados en todo el país. Los componentes son los siguientes:

(1) Propósitos y significados comunes: la cultura es el vehículo para que los empleados se muevan alrededor de la estrategia. Por esta razón, este componente es el norte: visión, misión y valores.

(2) Estilo de liderazgo: CN busca tener líderes mentores, que se automotiven y autodesarrollen, ya que son los primeros que tienen que tener claro el sentido de su vida. Ser líder significa capacidad para reconocer, construir confianza, ser coherentes enseñando con el ejemplo, inspirando sueños y retos. Este componente está direccionado a desarrollar a los líderes en coherencia con la definición de liderazgo de GN.

(3) Comunicación y estilo direccionamiento: CN busca ser una organización que conversa de frente, cara a cara, con una comunicación cercana, participativa y constructiva. Las conversaciones entre jefes y empleados no son jerárquicas, son efectivas y de confianza, que logran resultados desde el componente humano y técnico. Asimismo, con los clientes externos, CN busca relacionarse de manera cálida, informal y respetuosa.

(4) Concepto del ser humano: Responde al ser, hacer, tener y trascender. Se busca que el ser humano se desarrolle de manera integral, trascendiendo sus acciones y buscando un sentido de vida. Se busca que los empleados se empoderen de su desarrollo y bienestar; y junto con la organización, se construya un ambiente socialmente sano y económicamente sostenible. 
(5) Forma de trabajo: La forma de trabajo de $\mathrm{CN}$ es colaborativa y en red. Para la compañía es importante que se tenga una visión estratégica del rol que cumple, y una visión sistémica de la compañía, transcendiendo las áreas, a la vez que busca contar con un conocimiento estratégico de los demás procesos.

(6) Valores compartidos: Se busca vivir los valores como hábitos. Para ello los equipos realizan procesos de autorreflexión, teniendo como referente los valores previamente definidos. Además, los líderes son legitimadores de los valores y buscan actuar en coherencia con los mismos.

\subsubsection{Evaluación de la Cultura Corporativa de Comercial Nutresa}

Una primera evaluación de la gestión de la Cultura de $\mathrm{CN}$ fue realizado por el Grupo Consultoría S.A. en junio de 2011. Este instrumento de medición de la Cultura fue aplicado a través de talleres donde participaron empleados de todos los niveles de la compañía. El análisis de la cultura en CN evidencia:

- Una compañía en desarrollo con un nivel alto de exigencia en la gestión de lo humano.

- Una cultura sana, personas libres para expresar sus percepciones, aspectos por mejorar socialmente y viables de gestionar.

- Una organización donde el liderazgo juega un rol preponderante en la construcción de su cultura y la movilización de las personas.

- Los componentes de la cultura menos desarrollados son: Forma de trabajo y comunicaciones y estilo de relacionamiento.

En cuanto a la estructura organizacional se evidencia una fragmentación en:

- La gestión de lo humano: presenta una fragmentación en lo humano, técnico y gerencial. El ser humano es una unidad y esa unidad es 
fragmentada en la gestión del día a día. La separación ocurre cuando se gerencia desde una perspectiva lineal en lugar de ser sistémica.

- La gestión de lo técnico: presenta una fisura en la medida que separa la interacción, la coordinación de acciones del sistema humano, de la implementación de métodos y prácticas técnicas del negocio.

- La gestión de lo humano, de lo técnico y lo gerencial ocurre en un mismo momento y es a partir de las situaciones cotidianas en donde se da la oportunidad para engranarlas.

En este mismo informe se evalúa un componente más, pertinente para la investigación: Identidad Cultural, en donde se le pregunta a los empleados: ¿Cuáles de los ritos y celebraciones que usted ha vivido le gustaría conservar que nos ayudaría a tener identidad propia? Los resultados son los siguientes:

\section{Gráfica 15: Ritos y celebraciones anteriores}

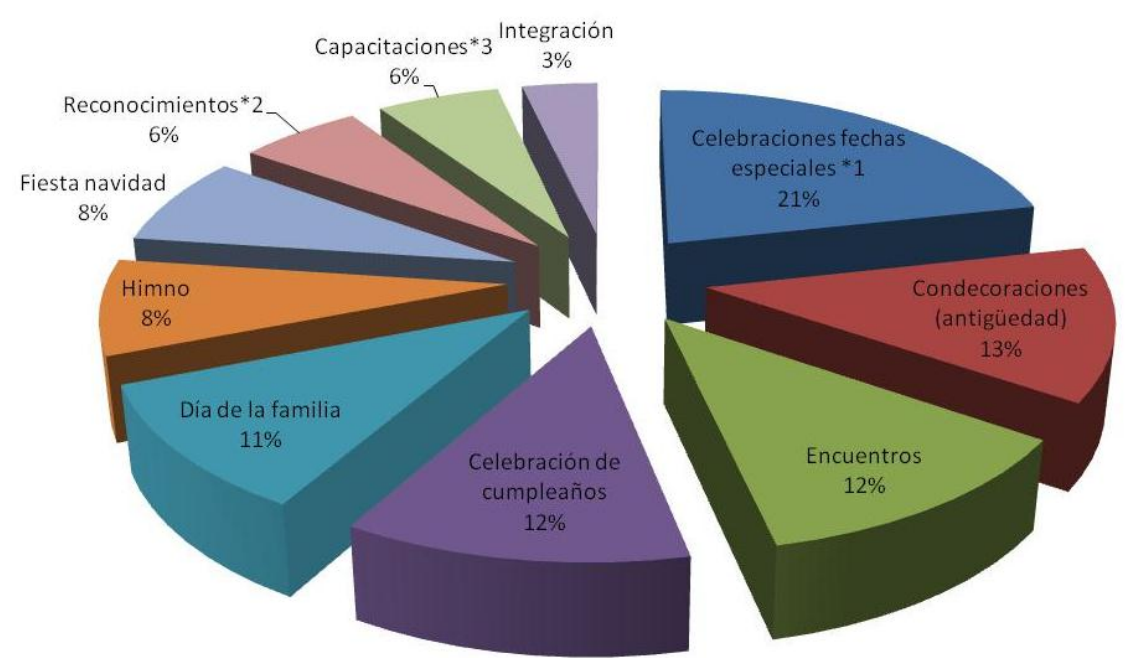

Fuente: Grupo Consultoría S.A. Informe sobre la Cultura de Comercial Nutresa, 2011.

Frente a la otra pregunta de este mismo componente: ¿Qué nuevos ritos o celebraciones le gustaría que tuviéramos que nos generen identidad propia y para usted es significativo? Los resultados fueron los siguientes: 


\section{Tabla 13: Ritos y celebraciones que desean vivir en la nueva cultura}

(1) Celebración de fechas especiales

- Día de la Familia - eventos familiares (28), halloween, navidad, día del niño, de la mujer, amor y amistad, madre.

(2) Celebraciones - Cumpleaños Nutresa (9), día del vendedor, especiales internas del ayudante de ventas, del equipo de trabajo, de la logística.

(3) Formación personal y profesional - Coaching, becas, intercambios, inglés, manualidades.

(4) Identidad Corporativa

- Uniforme, ritual, video, mascota, himno, slogan, campañas.

(5) Incentivos $\quad$ • Por resultados, tarde libre.

(6) Beneficios $\quad$ •Descuentos especiales en productos del GN.

(7) Encuentros $\quad$\begin{tabular}{l} 
- $\begin{array}{l}\text { Convenciones nacionales, comerciales, } \\
\text { logística. }\end{array}$ \\
\hline$\bullet$
\end{tabular}

(8) Condecoraciones

- Escudo por antigüedad.

Fuente: Grupo Consultoría S.A. Informe sobre la Cultura de Comercial Nutresa, 2011.

\subsubsection{Clima Organizacional}

Una primera evaluación del Clima organizacional de CN lo realizó la empresa CINCEL (Centro de Investigación en Comportamiento Organizacional), cuyo informe final fue entregado en febrero del 2012. El estudio sobre el diagnóstico del clima organizacional y el compromiso laboral fue realizado entre septiembre octubre de 2011 y diciembre de 2011 - febrero de 2012 a una población de 997 empleados en todo Colombia de los distintos niveles jerárquicos de la empresa. En términos generales, el perfil de clima organizacional de $\mathrm{CN}$ es muy positivo con puntuaciones que se encuentran por encima de los referentes empresariales utilizados para realizar dicha evaluación.

\subsubsection{Retos y desafíos}

La creación de la nueva empresa comercializadora del $\mathrm{GN}$, exigió una reestructuración de los procesos de comercialización implementados por las diversas compañías del grupo, las cuales venían operando mucho tiempo atrás, y tenían ya un mercado y una forma de trabajar consolidada. El personal de CN está 
conformado básicamente por dos de las principales compañías del grupo: Compañía Noel y Compañía Nacional de Chocolates. Esto trajo el reto de conformar una nueva Cultura e Identidad Organizacional bajo la sombra de dos reconocidas, legitimadas y consolidadas empresas dentro del territorio colombiano, claramente identificables y cuyos empleados se sentían muy identificados con cada una de ellas. Debido a esto, se realizó una caracterización de los empleados provenientes de las otras compañías del grupo, cuya proporción es la siguiente: $\mathrm{CNCH}, 52 \%$; Noel, $30 \%$, Doria, $10 \%$; otros $2 \%$.

Se presenta a continuación una breve caracterización de las culturas fuente de los trabajadores de CN realizada por la empresa de consultoría Team Resources, Inc., y presentada al comité de presidencia el día 25 de octubre de 2010. Para realizar esta caracterización la empresa consultora realizó entrevistas a los miembros del comité de presidencia y encuestas a los dos primeros niveles jerárquicos de la compañía. Los resultados se presentan en la tabla 14.

\section{Tabla 14: Caracterización de los empleados provenientes de diversas compañías del Grupo Nutresa}

\begin{tabular}{|c|c|c|}
\hline GRUPOS & ASPECTOS POSITIVOS & $\begin{array}{l}\text { ASPECTOS } \\
\text { NEGATIVOS }\end{array}$ \\
\hline Galletas & 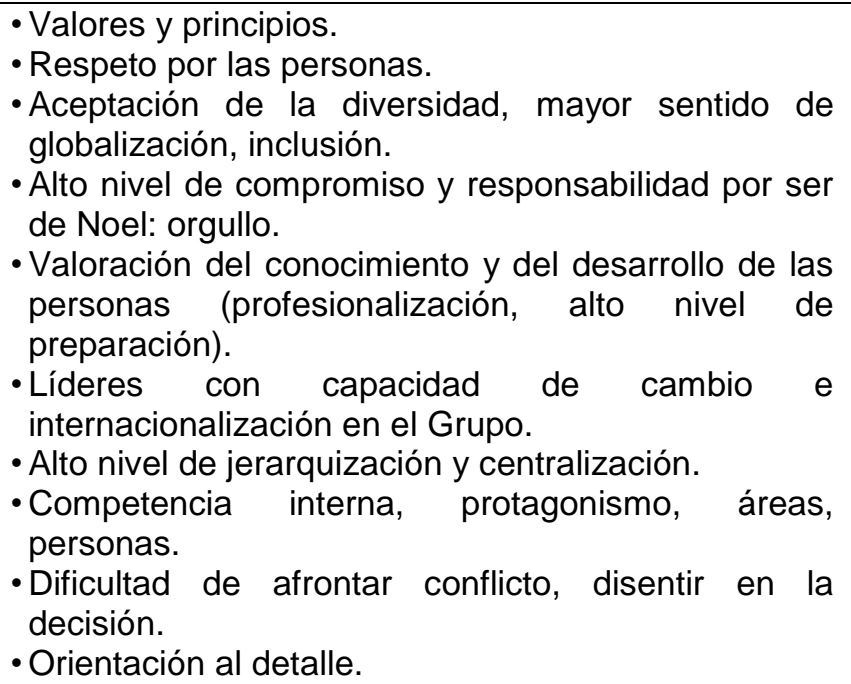 & $\begin{array}{l}\text { - Actitud de ser de otro } \\
\text { nivel, genera } \\
\text { diferencias y } \\
\text { distancias. } \\
\text { - Mucho power point; } \\
\text { Show off muestra un } \\
\text { alto nivel de } \\
\text { conceptualización vs. } \\
\text { aplicación práctica; } \\
\text { diagnóstico vs solución. } \\
\text { - Mayor orientación } \\
\text { conceptual que } \\
\text { relacional. Dificultad para } \\
\text { identificar prana } \\
\text { comunicación franca y } \\
\text { honesta: poco directo. }\end{array}$ \\
\hline
\end{tabular}




\begin{tabular}{|c|c|c|}
\hline Chocolates & $\begin{array}{l}\text { - Calidez y respeto por las personas e importancia de } \\
\text { la familia. } \\
\text { - Valores y principios muy fuertes. } \\
\text { - Capacidad de ejecución, alineación y obediencia } \\
\text { organizacional. } \\
\text { - Metodología, foco, procesos de trabajo simples y } \\
\text { enfocados. } \\
\text { - Alto nivel de seguimiento a la ejecución. } \\
\text { - Alto nivel de compromiso y responsabilidad, amor } \\
\text { por la camiseta. } \\
\text { - Alto nivel de participación en el desarrollo de las } \\
\text { soluciones y planes de acción. } \\
\text { - Paternalismo. } \\
\text { - Cultura jerárquica y baja capacidad de disentir con } \\
\text { el jefe. } \\
\text { - Falta trabajo en equipo, e involucramiento de los } \\
\text { niveles más bajos en la toma de decisiones y } \\
\text { preparación en los cargos. } \\
\text { - Falta coordinación y capacidad de acuerdo entre } \\
\text { áreas diferentes. } \\
\text { - Bajo nivel de riesgo y cambio. }\end{array}$ & $\begin{array}{l}\text { - Dificultad para manejar } \\
\text { la autocrítica, los } \\
\text { puntos de vista } \\
\text { externos por una } \\
\text { actitud prepotente o } \\
\text { arrogante. } \\
\text { - Difícil construir nuevas } \\
\text { soluciones porque se } \\
\text { asume que lo que se } \\
\text { tiene ya lo incluye o es } \\
\text { mejor (descalificación } \\
\text { de los demás). } \\
\text { - Respeto por la } \\
\text { jerarquía minimiza el } \\
\text { pensar distinto. } \\
\text { - El exceso de } \\
\text { paternalismo hace que } \\
\text { sea difícil trazar límites } \\
\text { sobre el bienestar y se } \\
\text { aplique una filosofía de } \\
\text { asistencialismo más } \\
\text { que de autonomía. }\end{array}$ \\
\hline Pastas & $\begin{array}{l}\text { - Alto nivel de respeto por las personas expresado en } \\
\text { términos de balance de vida y foco en la realización } \\
\text { personal. } \\
\text { - Altos niveles de comunicación y participación de los } \\
\text { funcionarios donde hay transparencia y confianza } \\
\text { en mostrar los errores y estar en desacuerdo. } \\
\text { - Trabajo en equipo y buen ambiente de trabajo. } \\
\text { - Humildad, capacidad de escucha y generación de } \\
\text { aprendizaje a partir de las ideas de los demás. } \\
\text { Altamente participativa. } \\
\text { - Orientación al resultado y percibidos como } \\
\text { guerreros. Conocimiento más limitado del cliente y el mercado } \\
\text { por el sistema de comercialización establecido. } \\
\text { - El proceso de culturización no está tan pronunciado } \\
\text { en todos los niveles por el tiempo del proceso vs. } \\
\text { otros. }\end{array}$ & $\begin{array}{l}\text { - Orientación excesiva al } \\
\text { detalle. } \\
\text { - Un enfoque más táctico } \\
\text { que estratégico. }\end{array}$ \\
\hline Cárnico & $\begin{array}{l}\text { - Orientación a resultados. } \\
\text { - Conocimiento y expertiz tecnológica. } \\
\text { - Principios y valores. } \\
\text { - Capacidad de creación de conocimiento conjunto. } \\
\text { - Estilo jerárquico y participativo al tiempo. } \\
\text { - Espontáneos al trabajar. }\end{array}$ & $\begin{array}{l}\text { - Cerrados, distintos, } \\
\text { lejanos, lo que genera } \\
\text { un bajo conocimiento } \\
\text { en el grupo. }\end{array}$ \\
\hline $\begin{array}{l}\text { Servicios } \\
\text { Comercial } \\
\text { Nutresa }\end{array}$ & $\begin{array}{l}\text { - Respeto por las personas. } \\
\text { - Orientación a los procesos y control. } \\
\text { - Bajo nivel de interacción entre funciones y áreas. } \\
\text { - Alto nivel de compromiso y responsabilidad con la } \\
\text { tarea pero no con el proceso completo. } \\
\text { - Bajo nivel de confrontación y conflicto. } \\
\text { - Estilos gerenciales y de liderazgo poco } \\
\text { homogéneos y consistentes. }\end{array}$ & $\begin{array}{l}\text { - No se entiende que es } \\
\text { servicio (gobierno vs. } \\
\text { servicio). } \\
\text { - Cultura fría. }\end{array}$ \\
\hline
\end{tabular}


Fuente: Team Resources, Inc. (2010).

La misma empresa consultora encuentra aspectos convergentes y divergentes en estas mismas compañías los cuales se muestran a continuación:

\section{Tabla 15: Similitudes y diferencias de los empleados provenientes de otras compañías del Grupo Nutresa}

\begin{tabular}{|c|c|}
\hline SIMILITUDES & DIFERENCIAS \\
\hline $\begin{array}{l}\text { - Respeto por las personas. } \\
\text { - Orientación a los resultados. } \\
\text { - Orgullo y sentido de pertenencia. } \\
\text { - Interiorización y actuación conforme a valores. } \\
\text { - Cercanía de las personas. } \\
\text { - Dificultad para llegar a acuerdos. } \\
\text { - Alta jerarquización en las culturas más } \\
\text { representativas. } \\
\text { - Bajo nivel de interacción entre funciones y } \\
\text { áreas. }\end{array}$ & $\begin{array}{l}\text { - Calidez en el trato y alegría en el trabajo. } \\
\text { - Causas y efectos de la dificultad para llegar a } \\
\text { acuerdos: imposición sobre el "más débil", } \\
\text { evitar el conflicto. } \\
\text { - Niveles de participación. } \\
\text { - Bienestar del trabajador, el qué y el cómo. } \\
\text { - Cambio entendido como riesgo. } \\
\text { - Culturas más sólidas y fuertes. } \\
\text { - Conocimiento del cliente y de los canales. }\end{array}$ \\
\hline
\end{tabular}

Fuente: Team Resources, Inc. (2010).

De otro lado, es pertinente resaltar que la figura sinérgica de la nueva comercializadora es clara. El anterior esquema de distribución contemplaba que por cada empresa existía un representante para promocionar el portafolio de productos de cada compañía. En el nuevo esquema, los empleados de CN tendrían a su cargo la promoción y venta de todos los productos secos del GN.

Junto con lo anterior, la conformación de la nueva compañía exigió una reorganización de las distintas estructuras en las regiones. Así, por ejemplo, aquel empleado que trabajaba para una compañía en concreto y tenía poder de decisión para negociar e intervenir en los procesos de negociación, en la nueva estructura tendrá que ofertar y ser responsable por todos los productos secos del grupo, para lo cual, perderá cierta autonomía ya que se convierte en un MM dentro del nuevo organigrama, en donde el jefe (gerente) se encuentra en la oficina central en Medellín, y frente al cual tendrá que rendir informes de las metas estipuladas. 
En relación con los MM, en opinión de un alto directivo de la compañía, existe un problema de entendimiento en la línea media de gestión. Esto hace que los MM se vuelvan más burocráticos por tratar de sostener las relaciones de poder que tienen, lo cual repercute en una lentitud en el servicio. En este sentido, no se ha logrado permear la manera propia en como CN quiere hacer las cosas. Es decir, la ejecución de los procesos en $\mathrm{CN}$ está aún influenciado por el estilo de las compañías de donde provienen los empleados. Así, si el jefe o gerente de un área específica que proviene de Noel, su accionar y direccionamiento lo hará como lo hacía en dicha compañía, con el añadido que este mismo jefe tiene a su cargo personal que no solo proviene de esta compañía sino de otras. A esto se le suma el hecho que se configurarán grupos de trabajo totalmente nuevos en donde ni siquiera los mismos jefes conocen a todo su equipo.

Hay un aspecto importante que vale la pena mencionar y es que desde la creación de compañía ha habido dos restructuraciones. Una se realizó en noviembre del 2011, y la segunda en marzo del 2012. Esta última fue el "dolor más grande que le hemos ocasionado a esta gente y que ha causado un sentir muy complejo" (D4). Ambas acciones respondieron a factores de competitividad de CN. La carga pensional con la cual se formó la compañía, los salarios, las prestaciones sociales y demás beneficios fueron muy altos, lo cual exigió una retroalimentación para evaluar que tan eficientes son y ver la posibilidad de aligerar la nómina. Junto con ello, la demanda comenzó a estacionarse, impactando en las ventas. Esta primera reestructuración estuvo a cargo de los gerentes y del presidente. Como política, no se despidió a ningún empleado de la parte operativa, ya que esta sostenía el negocio, sino que se tomaron decisiones de la mitad para arriba, de MM hacia arriba. En esta primera restructuración salieron 20 MM.

En la segunda restructuración (principios del 2012), se volvió a evaluar cómo iban a crecer las ventas. $Y$ se vuelve a experimentar que $C N$ no estaba aún lo suficientemente liviana y que las metas no se iban a cumplir. Se hizo un trabajo más profundo. Esto arrojó que las áreas de soporte ya no podían prescindir de 
más empleados. Es así que se analizó el modelo comercial, y se encontró que se estaban duplicando cargos en las distintas regiones. De esta manera, se agruparon regiones. Al hacer esto, los empleados que ocupaban cargos duplicados pertenecientes a las distintas gerencias dejaron la compañía. Esto fue un proceso de mucho mayor impacto porque salieron empleados de mucha trayectoria, tradición y que gozaban de mucho reconocimiento dentro del GN. En esta restructuración dejaron la compañía 30 MM.

Estas restructuraciones ha marcado mucho la cultura de CN. Hay cierta prevención y malestar ya que no se esperaban que esto pudiera llegar a suceder. Al provenir, en su gran mayoría de dos empresas insignes y de mucha tradición paternal como son Noel y $\mathrm{CNCH}$, los empleados no pensaron que podía suceder una restructuración de este tipo (en estas compañías no se suelen tomar este tipo de decisiones), mucho menos si en la conformación de CN hubo muchas promesas de seguridad y estabilidad laboral. Frente a esto, y para prevenir y evitar deteriorar el clima laboral, se implementó lo que se llama la agenda de cambio, que es un proceso de acompañamiento de salida para sopesar y manejar las repercusiones que esto podía traer. Estas restructuraciones fueron un hito histórico dentro del GN. Nunca antes se había tocado el modelo comercial. Salieron gerentes de mucha tradición con más de 25 años de servicio, faltándoles poco para jubilarse, lo cual generó mucho temor al interior de CN.

La conformación de la nueva comercializadora, exigió también la negociación de los beneficios que tenían los empleados en la compañía de origen, concretamente, una re-negociación con los sindicatos. Esto obligó a realizar un doble ejercicio de negociación de pacto colectivo y de convención colectiva. Esto se vió incrementado en las regionales en donde hay un mayor posicionamiento de las organizaciones sindicales (Bogotá y Bucaramanga).

A pesar de ser una política el hecho de mantener el $100 \%$ de los empleados del grupo en la conformación de la nueva compañía, estas restructuraciones 
implicaron una serie de nuevas contrataciones, lo cual generó gastos adicionales que no estaban previstos. Faltó una mayor comunicación para poder hacer una evaluación más clara de la situación del personal que iba a formar parte de CN.

\subsection{CONTEXTUALIZACIÓN DE LA PROBLEMÁTICA DEL ESTUDIO DE CASO EN COMERCIAL NUTRESA S.A.S.}

El modelo teórico-metodológico fue presentado y explicado en el capítulo dos. En este apartado, se retomó dicho modelo para aplicarlo a la realidad del caso estudiado de CN. En ese sentido, no se hará un desarrolló teórico del mismo, sino que se contextualizará y enmarcará la realidad estudiada a partir de él. De esta manera, los dos ejes, tanto a nivel temporal como relacional, servirán para identificar aspectos de $\mathrm{CN}$ que fueron considerados en el análisis de los datos. Así mismo, las categorías preliminares fueron clasificadas en cada una de las dimensiones de dicho modelo para ambos actores partícipes de la investigación (directivos-MM).

\subsubsection{Contextualización a partir de los ejes de referencia}

El modelo teórico-metodológico consta de tres ejes, el relacional, el temporal y el cultural. Este último, si bien fue considerado y explicado en el capítulo respectivo, no se tuvo en cuenta para el análisis de la información. Esto se debió básicamente a lo siguiente:

- A partir de la recolección y construcción de los datos, y a través de las estrategias utilizadas para los dos actores de la investigación (MM y directivos), el tema cultural no fue un aspecto relevante. Estuvo prácticamente ausente en cuanto a los procesos que desarrollaban los directivos para buscar crear o fabricar una 10 , o en el proceso de construcción identitaria por parte de los MM. 
- En casi todos los casos, tanto los MM como los directivos, no son oriundos de la región en donde trabajan, es decir, son asignados a lugares de trabajo distintos a sus ciudades de origen. En ese sentido, los FC están conformados por una confluencia de culturas en donde los elementos culturales que intervienen para fabricar una IO, si bien están presentes, no son un aspecto importante de las características de los FC.

- Hay ciertos aspectos culturales enmarcados en un ámbito regional en donde operan los FC, que no fueron relevantes para el análisis. De esta manera, las costumbres, la idiosincrasia, los códigos de conducta, los sistemas de creencias entre otros componentes culturales no constituyeron elementos diferenciadores a ser considerados en la interpretación de los datos, ya que si bien estuvieron presentes, su injerencia en la construcción de la IO no fueron importantes.

Como ya se mencionó en el capítulo correspondiente al marco teórico y conceptual (capítulo dos), la seguridad (MM) y la permanencia (directivos) constituyen el eje relacional; y la significación (MM) y el cambio (directivos), el eje temporal. En la gráfica 16 se muestra la conformación de las categorías preliminares con cada una de las dimensiones referidas de acuerdo con los actores sociales de la investigación, y por lo tanto, con los ejes definidos. 


\section{Gráfica 16: Categorías preliminares en relación con las dimensiones de los actores sociales de la investigación y la conformación de los ejes de}

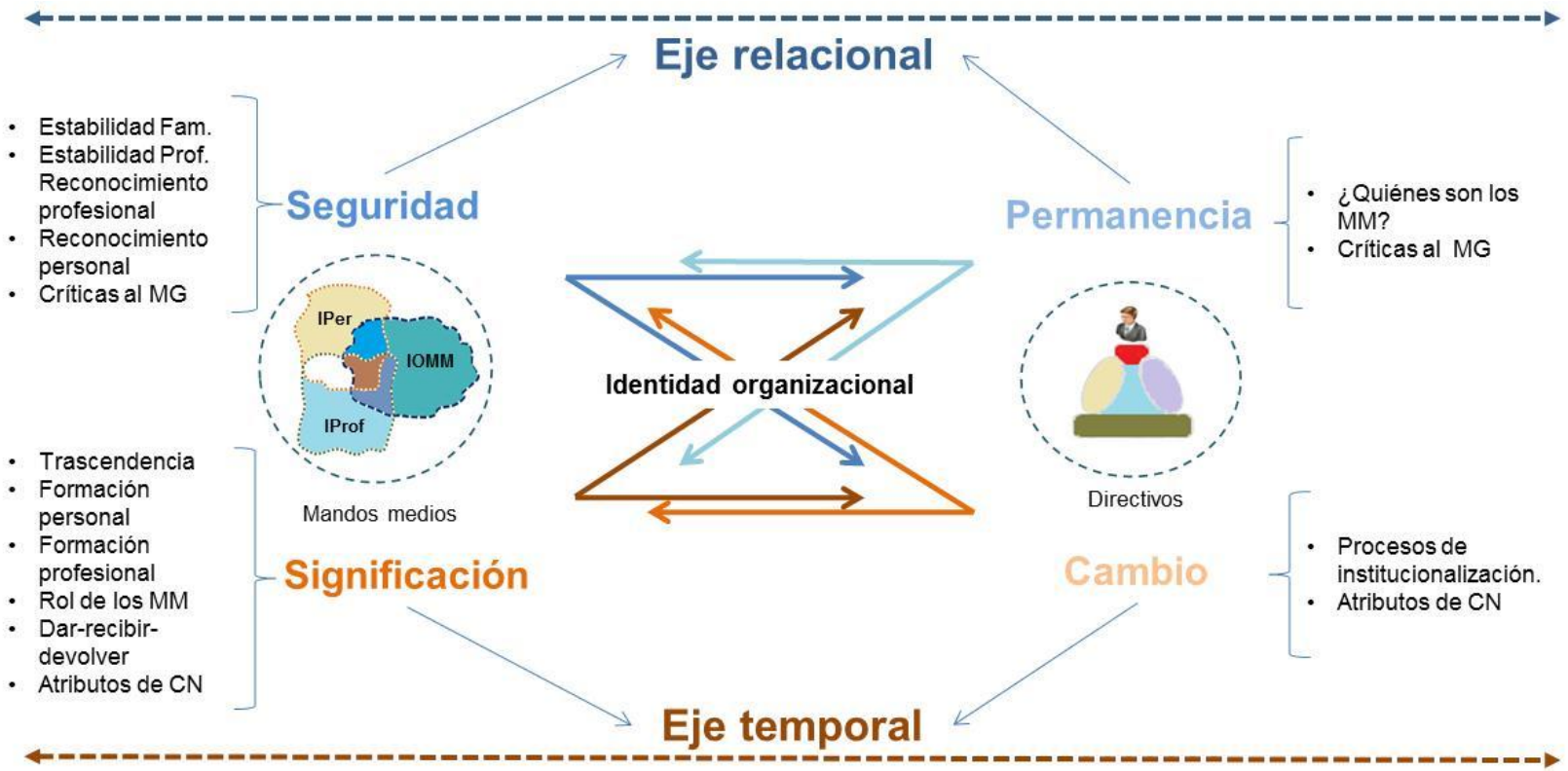

referencia

Fuente: Elaboración propia.

Conjugando las dimensiones tanto para los MM como para los directivos, con cada una de las categorías preliminares se forman los dos ejes de referencia, y por lo mismo, configuran el contexto en donde la construcción de la IO de los MM se desarrolla. En ese sentido, la construcción de IO por parte de los MM de CN, estará mediada necesariamente por estas circunstancias específicas enmarcando la investigación en un estudio de caso concreto, dentro de un determinado período de tiempo y situación histórica particular. Es así que se retoman los dos ejes contextuales para caracterizar, enmarcar y contextualizar el problema organizacional del estudio de caso que se vislumbra. A continuación se explicita qué elementos, hechos o circunstancias conforman cada uno de estos ejes. 


\section{Eje temporal (biográfico)}

- En el tiempo que lleva de creada la compañía $\mathrm{CN}$, se han realizado dos reestructuraciones, y $52 \mathrm{MM}$ han dejado de trabajar en la compañía, marcando un hito dentro de la historia del GN. La primera de ella se debió al ajuste estructural de cargos en el entendido que aquellos cargos que se encontraban repetidos fruto de la creación de $\mathrm{CN}$, fueron reducidos a uno solo. En la segunda, el criterio que primó fue el de la eficiencia y productividad.

- Las reestructuraciones no sólo obligaron al retiro de algunos cargos que estaban repetidos y a aplanar la estructura de la organización, sino que implicó la movilidad de cargos y puestos dentro de toda Colombia. Hubo traslados y se configuraron los FC de las regiones.

- El mercado tiene un fuerte resentimiento en el período en que se realiza la investigación. Utilizando una serie de instrumentos y herramientas audiovisuales, la dirección busca contrarrestar el pesimismo que se viene generando dentro de la compañía por las metas incumplidas. Sobre todo se busca que la situación económica no se convierta en escusa y razón para no cumplir con las metas propuestas por el GN para el 2013.

- En los últimos años ha ingresado competencia externa directa representada por multinacionales, a la vez que se ha fortalecido la competencia por parte de empresas nacionales.

- La gran mayoría de los MM llevan muchos años trabajando para el GN, por lo que están próximos a jubilarse. Aquellos que se encuentran en ese proceso se sienten comprometidos en formar y capacitar a la nueva generación de trabajadores. 
- Para los MM ha sido importante participar en la creación de la nueva compañía. Muchos de ellos se sienten orgullosos y se reconocen a sí mismos como fundadores de $\mathrm{CN}$.

\section{Eje espacial (relacional)}

- Los MM son jefes y subordinados a la vez. Dada la posición que ocupan dentro de la estructura jerárquica de la organización, los MM se encuentran en una situación de intermediación, por lo que sus funciones cobijarán estas dos dimensiones, su ser jefe, y al mismo tiempo, estar subordinados a un jefe inmediato superior.

- La conformación de CN se realizó mediante la integración de los departamentos de comercialización y ventas de algunas compañías del GN. Estas compañías (sobre todo Noel y $\mathrm{GNCH}$ ), tienen una gran trayectoria y reconocimiento en Colombia. Antes de la integración, en lo que se denominó Cordialsa Colombia previa a cambiar de nombre a $\mathrm{CN}^{66}$, estas dos empresas competían entre sí, no en los productos como tal, sino en el reconocimiento social, y luego de la integración, en el cumplimiento de indicadores de eficiencia. Esto generó una rivalidad previa a la constitución de $\mathrm{CN}$ entre los $\mathrm{MM}$ debido a la comparación reinante entre ambas empresas.

- Los FC están conformados en desigualdad de condiciones. El FC se estructura a partir de los representantes de cada una de las gerencias de $\mathrm{CN}$, en donde se incluyen aquellas referidas a lo comercial, y a las de soporte. Desde esta misma configuración se desprende una desigualdad en la capacidad de negociación y conciliación de cada uno de los miembros

\footnotetext{
${ }^{66}$ Se puede revisar el capítulo referido al estudio de caso (capítulo cuatro).
} 
del FC, manifestado básicamente del hecho que las áreas de soporte mantienen y garantizan la operación del negocio que es liderado por las áreas comerciales.

- El nuevo modelo comercial trae como correlato un nuevo modelo de gobierno. En este nuevo modelo, los roles de los MM ya no sólo se restringen a las funciones propias del cargo, sino que cumplen la labor de realizar un trabajo integrado y mancomunado con sus colegas en la toma de decisiones de la región.

- Dado que los directivos también provienen de compañías pertenecientes al GN (al igual que los MM, sobre todo de Noel y $\mathrm{NCH}$ ) las formas y modos de gerenciar están mediados por la experiencia adquirida en dichas compañías.

- Las OO se caracterizan por tener una gran estabilidad laboral (sobre todo $\mathrm{NCH}$ ). En ese sentido, los MM esperan que esta estabilidad perdure en la nueva compañía. Lo que se busca es mantener una relación estable y duradera con el nuevo empleador.

- Muchos de los MM fueron gerentes comerciales de las OO del GN. Luego de la creación de $\mathrm{CN}$, a partir de la integración de los departamentos respectivos, los gerentes se convirtieron en directores de algunas de las gerencias de $\mathrm{CN}$. Esto restringió sus funciones y las posibilidades de ejercer el poder que tenían.

- Las relaciones entre los MM y los directivos están soslayadas por cierta desconfianza de los primeros a las directrices que se les imparten. La relación se encuentra mitigada por promesas no cumplidas por parte de la dirección, entre ellas, las reestructuraciones. 
- Debido a estas reestructuraciones los FC se recompusieron en cuanto al personal que los constituía. Así, estos órganos de gobierno regionales quedaron constituidos por $\mathrm{MM}$ con tiempo de experiencia disímiles dentro del GN. Esto configuró un espacio de nuevas relaciones enmarcadas por la lucha por el reconocimiento, la experiencia y el ejercicio del poder.

\subsubsection{El frente comercial: el eslabón tensionante}

El espacio del FC se convierte en el lugar en donde los MM buscan construir una IO. Es el lugar en donde los que ocupan la línea media de gestión defienden lo que son, o quieren ser, frente a otros colegas, directivos y subordinados, que al igual que ellos buscan legitimarse. Dado que el FC se convierte en el órgano de gobierno, la dirección y el ejercicio del liderazgo recae sobre los MM que tienen que poner su criterio a consideración dentro de este órgano de gobierno democrático, ya que al no haber una cargo que los lidere formalmente, las disyuntivas no se dirimen por la autoridad o el ejercicio del poder legítimo, sino por medio de una democracia consensuada. En este sentido, hay algunos elementos que configuran y caracterizan al FC como un espacio tensionante en donde la identidad se construye y/o se busca defender:

- Cada MM representa a una gerencia en particular. Cada una de éstas tienen sus propios objetivos a cumplir mediante una serie de indicadores que le son definidos por la alta dirección, y por el cual son evaluados. Así, el espacio del FC ya es en sí mismo un lugar en donde los intereses de cada gerencia se enfrentan. Al no haber una cabeza visible que represente a la organización $(\mathrm{CN})$ como un todo, cada MM velará o buscará imponer sus propios puntos de vista en pos de cumplir con sus metas propias que están relacionadas y condicionadas con ciertos bonos económicos a entregarse al final del ejercicio contable. De esta manera, la coordinación entre las diferentes áreas, quizás la más ejemplar sería logística y alguna 
de las gerencias comerciales, tenderán a conflictuarse ya que sus indicadores y metas son diferentes. Un ejemplo de ello lo declara uno de los mismos directivos:

Desde que nosotros empezamos a trabajar en el diseño de esta organización uno de los temas más complejos que nos parecía y que nos sigue pareciendo es que nosotros diseñamos el cerebro de esta organización en función de la especialización, entonces decíamos: La especialización la vamos a tener desde el mercado, vamos a entender las diferencias que hay entre los distintos tipos de clientes, vamos a bajar unos clústers y a esos los vamos a llamar segmentos y vamos a cubrir lo que requieren esos segmentos. [...] Entonces dijimos ahí hay un tema complicado porque es que en las regiones son unas unidades que necesitan una dirección y un manto unificado y entonces lo primero por definir es que es que como no tenemos un gerente regional entonces tienen que ser un gobierno especializado y generamos las directrices del negocio de manera segmentada. La persona le tiene que dar la interpretación de alguna manera que él crea conveniente y va a manipular el modelo porque el modelo es puro. El autoservicio que piense como autoservicio, el de cadena como cadena y los tradicionales como los tradicionales, pero si eso llega aquí en la unidad de ejecución a una sola cabeza, para el tradicional es más fácil cumplir el presupuesto haciendo más énfasis en el tradicional, sacrificando autoservicios por ejemplo. Finalmente el de tradicional actúa y puede desbaratar todo este engranaje que se construyó con el modelo de la especialización. Entonces eso no puede llegar a pasar. Tenemos que replicar lo que tenemos en la oficina central en las regionales y entonces que exista un responsable de tradicional, que exista un responsable de autoservicio y que exista los soportes espejo de la oficina central. Entonces esto ahora si se puso bueno porque es que yo como logístico recibía órdenes de un comercial y yo sabía que mi costo por servir se me podía aumentar cuando el comercial me decía "salite de la ruta porque hay que entregarle este pedido a este señor". Ahora si el comercial me dice "salite de la ruta" yo le digo: "olvídese que yo me salgo de la ruta porque yo respondo por un coso por servir entonces yo lo programo para la ruta siguiente y como usted no es mi jefe sino que yo estoy al mismo nivel usted no me puede dar órdenes". Entonces cada uno termina siendo un dictadorcito en su proceso pero nadie en teoría está viendo el todo y nadie está viendo qué sacrificios hay que hacer para poder tener lo mejor. Entonces empiezan los conflictos. (D5).

- El FC es una reunión de gobierno que es conformada por un grupo de MM en desigualdad de condiciones. (1) Por un lado, no todas las gerencias están representadas en todos los FC. Esto quiere decir que no todas las áreas de la compañía tienen representatividad en la compañía. (2) Por otro lado, CN es una empresa de ventas y distribución, en ese sentido -y así se les considera oficialmente- las gerencias del canal tradicional, autoservicios y grandes cadenas, son las más importantes, ya que congregan en sus funciones la razón de ser del negocio. Las demás áreas son las de soporte, es decir, sostienen y ayudan a mantener la operacionalidad del negocio. En ese sentido, el FC pretende colocar al 
mismo nivel funciones que constitutivamente y esencialmente son distintas. (3) La experiencia y el mismo salario se ven enfrentados en el espacio del FC. Luego de las reestructuraciones, el FC quedó constituido por MM que tienen distinto tiempo (y experiencia) tanto en el área específica de desempeño, como en el GN. Curiosamente, los representantes de los canales de ventas, son los que mayor experiencia y tiempo llevan en la compañía, por lo que informalmente, y a pesar de que la dirección busque que esto no se dé, son los líderes naturales de los procesos. Los mismos MM describen su importancia dentro de la compañía de la siguiente manera:

Sí, nosotros, pues yo creo que los MM somos los que movemos esta compañía en todos los aspectos. Recibimos lineamientos, pero somos básicamente los que ejecutamos todo el movimiento de esta compañía. Somos el contacto directo con las personas de nuestros equipos, y tenemos la responsabilidad de esas personas, además nos miden por cómo respondemos ante esa responsabilidad, es decir, si alguien de mi equipo, yo debo prescindir de él, a mí me presionan. Yo creo que en los MM está la gran potencia de esta compañía. Está el conocimiento de la compañía, mucho más profundo que el de los altos mandos, porque los altos mandos toman las decisiones y dan la línea en esta compañía, pero quien sabe sí el pro, el contra de cómo se puede, si eso se puede, si eso no se puede, si eso es viable, si eso no es viable, pues eso son los jefes, los gerentes y los coordinadores de la compañía que son quienes finalmente cuestionan o ejecutan las cosas. Esa me parece es la principal característica de nosotros, y los MM casi que están resumidos en los frentes comerciales. (MM14).

- Un aspecto importante por anotar es que los directores del canal tradicional se desenvolvían como gerentes regionales. En este sentido, y para efectos de esta investigación (con las implicaciones que esto trae), pasaron de ser directivos de alto nivel, a MM. De controlar todos los procesos y todas las áreas en cada región se convirtieron en unos directores en donde tienen que centrar su trabajo sencillamente en una de las áreas de ventas, que en la gran mayoría de los directores entrevistados pertenece al canal tradicional. Es decir, en un mismo espacio de negociación se encuentran algunos $\mathrm{MM}$ que teniendo todo, lo perdieron al repartir sus funciones y tareas con otros MM. Junto con ello, para estos nuevos directores el FC es 
el lugar en donde negocian y pasan de ser jefes a colegas, y de colegas a subordinados, al tener que responder a una gerencia determinada.

- Hay otro aspecto importante por anotar: Es la falta de claridad por parte de los directivos en cuanto al papel que cumplen en los FC, incluso dentro de la estructura jerárquica expresada en el MG. Apegados al modelo proveniente de las $\mathrm{OO}$, realizan sus tareas con la experiencia que tienen, y a pesar de conocer y apostar por el nuevo MG, el resabio de la funcionalidad del modelo anterior aún se encuentra presente.

- A pesar de que en las regiones el órgano de gobierno es el FC, son los directores del canal tradicional los que tienen la iniciativa de dirigir las funciones y áreas. Son ellos los que reciben por ejemplo al investigador al llegar a las regiones para hacer el trabajo de campo, y son ellos los que resuelven cosas tan simples como la invitación del almuerzo. Junto con ello, hay un aspecto estético importante y es que la oficina del director tradicional es la más grande y dotada de todas las oficinas de las regionales de CN.

Con lo anterior se puede describir el FC como un espacio en donde reposan una serie de aspectos que tensionan la construcción de 10 por parte de los MM. Éstos recurrirán a sus $\mathrm{OO}$ para hacer resistencia, es decir, buscan no perder lo que eran o lo que tenían. Por parte de los directivos, éstos buscan gobernar bajo el manto de una experiencia y enfrentados a la falta de claridad que tiene aún por delante, lo cual los sumerge también dentro de un proceso de construcción identitario. Esto se ejemplifica en el siguiente comentario:

Yo creo que es un tema natural de resistencia al cambio. La gente se siente cómoda en lo que ya conoce y siente que $\mathrm{CN}$ no nació producto de una crisis donde llegó un momento en que las ventas se complicaron y por lo tanto hay un error en el modelo que ya no es vigente. Aquí lo que hicimos es prever un futuro en donde se pueda garantizar una diferencia competitiva que ha diferenciado a este grupo por ventas $y$ distribución. Entonces no fue producto de una crisis y la gente de una manera dice: 
"pero si nos venía yendo bien porque vamos a cambiar". El tema entonces es mucho de ese razonamiento. La gente no encuentra mucho sentido y puede eso llevar a generar dudas, entonces al no ver una necesidad no apremiante de las cosas, el modelo no es confiable. (D5).

\subsection{A MANERA DE CONCLUSIÓN}

La constitución de lo que en su época se llamó el Sindicato Antioqueño, hoy conocido como el Grupo Empresarial Antioqueño (GEA), el cual pretendió evitar el control de empresas antioqueñas por parte de capitales bogotanos, cobra una nueva razón al buscar proteger a las empresas del grupo del capital extranjero. La nueva compañía $(\mathrm{CN})$ no sólo tiene el reto de construir una IO propia por medio de empleados que tiene mucha tradición en el GN, sino que la cultura que se gesta en su interior se convierte en un espacio de confrontación por mantener un estilo y genera una lucha por tener una identidad propia, aun no construida.

El aprendizaje técnico de los nuevos portafolios implica una involucración con las marcas y con las compañías que si bien pertenecen al mismo grupo (GN), muchas se convierten a su vez, en fuente de envidias que ahora tendrán que ser asumidas como propias para los MM. A nivel de los clientes, el nuevo modelo comercial significó la adaptación a un nuevo modo de operar, en donde si bien seguía siendo la misma compañía y los mismos productos, las condiciones comerciales comenzaron a tener su propia dinámica en el entendido que se inició una fidelización de los clientes bajo el nuevo nombre de CN.

Si bien CN trata de implementar una cultura nueva, con definición de megas objetivos para el 2015, y construye una planeación ello, aún no tienen definido un estilo propio. Este estilo de dirección se encuentra en un proceso de construcción identitario diverso y complejo, en donde no se tiene claro, incluso a nivel directivo, aquellos aspectos que los hacen únicos, distintos y perdurables. 


\section{CAPÍTULO 5}

\section{RESULTADOS DE LA INVESTIGACIÓN DESDE EL PUNTO DE VISTA DE LOS DIRECTIVOS}

\section{INTRODUCCIÓN}

Se presenta el primer capítulo sobre los hallazgos de la investigación. En un principio se pensó en estructurar uno solo pero se tomó la decisión de separarlos, básicamente, para mantener la propuesta teórica, la cual concibe a la IO como un diálogo entre los directivos y los $\mathrm{MM}^{67}$. En este apartado se presentan los resultados de la investigación frente a la pregunta: ¿Qué dicen los directivos que son los MM?, para que en el capítulo siguiente se discuta la respuesta a la pregunta, ¿qué dicen los MM sobre sí mismos? Por tal razón, estas dos secciones bien pueden ser consideradas una unidad.

En este capítulo se presentan los resultados de la investigación desde la perspectiva de los directivos. En ese sentido, se busca explicar y comprender la noción que la alta dirección tiene de los MM de CN. La reflexión girará alrededor del proceso reificante al cual quieren someter a los MM. Los resultados permiten hacer una reflexión en relación con los alcance de la administración y plantear una nueva modalidad de intervención que busca fabricar y controlar un identidad del individuo en relación con la organización. Así, este tipo de acciones se inscriben dentro de una tendencia o conjunto de modas de los últimos tiempos en donde se busca tener injerencia en aspectos más internos del individuo.

${ }^{67}$ Con el fin de recordar el significado de las siglas, se pueden revisar las tablas correspondientes del comienzo. 
Debido a ello, se ha buscado profundizar en la racionalidad instrumental, que si bien ya ha sido estudiada en el ámbito administrativo, es pertinente volver a las fuentes para retomar sus postulados más importantes que permitan comprender los alcances de las prácticas administrativas. Dentro de este análisis se emplea el término instrumentalización para expresar el proceso histórico de la Modernidad y en particular de la llustración que denota una crítica expresada por la Escuela de Frankfurt hacia el carácter de una razón que pierde objetividad y conciencia de sí, y se presta a legalizar y justificar racionalmente preceptos particulares desmontando el pensamiento de su contenido cognitivo para privilegiar en su lugar, el cálculo de medios y fines, y que trae como resultado la pérdida del pensamiento reflexivo y crítico.

Lo anterior ha permitido hacer una reflexión crítica en cuanto a la razón de ser de la administración y los límites que tiene. A su vez, lo aquí descrito y analizado servirá para comprender cómo los MM construyen la $\mathrm{IO}$ a partir de los procesos de institucionalización a los que son sometidos.

Siguiendo el modelo teórico-metodológico, se iniciará la discusión con aquello que los directivos dicen que son los MM, aspecto que se convierte en uno de los aportes de la investigación consignado en este capítulo. Para una mayor comprensión del lector se presenta la gráfica 17 en donde se vuelve a mostrar las categorías emergentes y preliminares ya explicadas en el capítulo referido a la metodología. 


\section{Gráfica 17: Categorías preliminares y emergentes construidas a partir de los directivos}

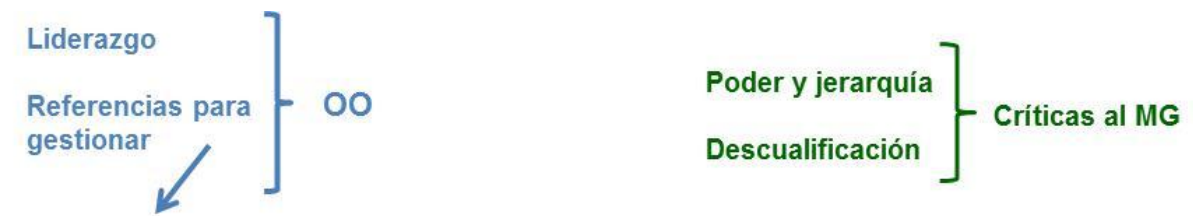

\section{¿Quiénes son los MM?}

¿Quiénes son los MM?

Buscar conductas determinadas

Estrategias de institucionalización

MODELO

EFICIENTE DE GOBIERNO

Críticas al MG Atributos de $\mathrm{CN}$
¿Quiénes son los MM?

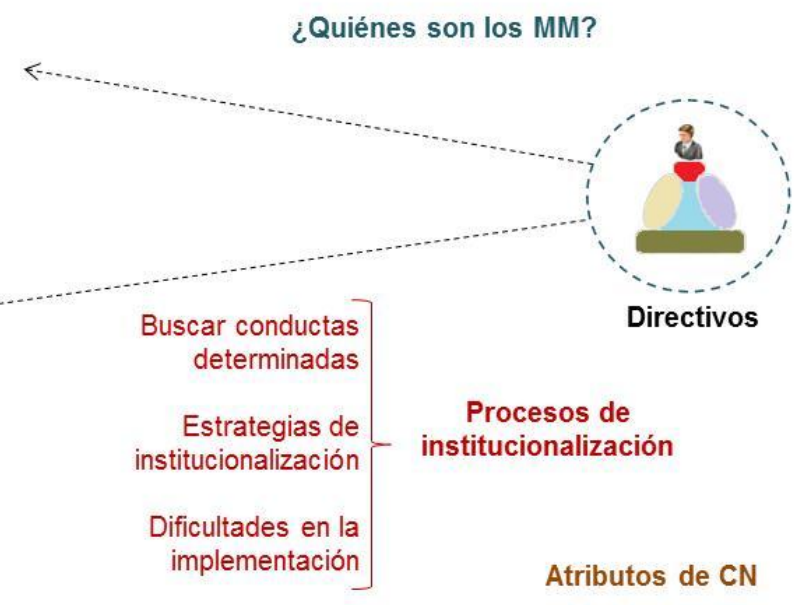

CN

Categoría emergente principal

Categorías emergentes

Categorias preliminares

Fuente: Elaboración propia.

\subsection{PARA LOS DIRECTIVOS, ¿QUIÉNES SON LOS MANDOS MEDIOS?}

A partir de los resultados de la investigación, lo que quieren los directivos que sean los MM se expresa tanto en las categorías preliminares como en las emergentes. A partir de las primeras se realiza una breve conceptualización y análisis a partir de los resultados de la investigación, resaltando los matices a partir de la teoría consultada. Las categorías emergentes se dividirán en dos: Aquellas que son transversales al proceso y se configuran como un elemento relevante para el análisis denominado Organizaciones de origen (OO), y la 
categoría emergente principal que es el Modelo eficiente de gobierno. Esta última, por contener en su interior aspectos importantes a considerar y reflexionar en relación con la Administración como tal, se tomará como un acápite separado.

\subsubsection{Categorías emergentes}

\subsubsection{Organizaciones de origen (00)}

Es la categoría que hace referencia a la influencia que tienen las organizaciones de origen en la concepción de los directivos de quiénes son los MM. Una respuesta a la siguiente pregunta lo ejemplifica: "Entrevistador: Vamos a construir una nueva silla. En esta construcción, ¿usted cree que hay todavía unos ciertos hábitos que vienen de las otras empresas? Entrevistado: "Yo creo que casi todos"' (PPD1). La concepción de quiénes son los MM está fuertemente influenciada por las $\mathrm{OO}$ de donde provienen los mismos directivos. Las $\mathrm{OO}$ se convierten en un punto de referencia para configurar un ideal o aspiración de quiénes deberían ser los MM para CN. Esta categoría se subdivide en otra, a su vez, que es caracterizada por lo siguiente:

\subsubsection{Liderazgo}

Se refiere a la influencia que tiene el líder para reproducir o incentivar conductas específicas, muchas de ellas a partir del mismo ejemplo de vida. En los resultados de la investigación hay una continua referencia a los jefes. Estos se convierten en referentes esenciales para el proceso de formación de los MM que no sólo se limita a los aspectos meramente profesionales sino también a los personales. Los mismos directivos se saben con esa capacidad de influencia sobre los MM.

Para aquellos que vienen de $\mathrm{NCH}$, la figura del jefe es sumamente importante, esto imposibilita un trabajo en equipo en las regiones dado que los integrantes del FC están acostumbrados a ver la presencia de una figura jerárquica que direccione el quehacer de la región. Cabe resaltar que la figura de jefe, sobre todo 
en la $\mathrm{NCH}$, era reconocido socialmente, es decir, el ascenso era un proceso normal dentro de la compañía y era legitimado como tal, ganándose el repecto de los demás.

Creo en la subcultura de la Nacional de Chocolates. Había un respeto absoluto por el jefe porque era una compañía que cuando nombraba un jefe era porque se había ganado ese puesto, ese cargo y la gente de abajo, en cierta forma, le reconocía a ese jefe ese puesto, por haberlo sudado, por estar ahí, por haber hecho el proceso. Eso representa el respeto y eso que tu sientes que hay un respeto hacia los gerentes es posible que venga de ahí. Lo mismo pasaba en Noel y lo mismo pasa en cualquiera, no es solamente una cosa de la Nacional de Chocolates sino que yo diría que es como la característica trasversal que está implícita en este modelo gerencial antioqueño. (D2).

Haciendo un énfasis en el concepto de liderazgo, para Grey (1997), no hay claridad en cuanto al cuerpo de conocimiento y técnicas para administrar, por lo que el administrador ${ }^{68}$ ha tenido que crear y regular así mismo una profesión. Para este mismo autor, la etiqueta de jefe es el resultado se separar ciertas tareas y funciones en categorías especiales y de valor, ignorando que muchas de éstas son desarrolladas por aquellos que no son administradores o jefes dentro o fuera de la organización. Ser administrador es pretender, por lo tanto, tener una identidad muy especial y valorada, como una identidad en el trabajo (Alvesson y Willmott, 2002). Para lograr esta identidad, es necesaria la existencia de la jerarquía y de la división del trabajo (Grey, 1999), como sucede en el caso del FC.

${ }^{68}$ El término administración está sujeto a múltiples connotaciones y definiciones. Los diferentes vocablos (gerenciar, gestionar, dirigir, gobernar, manejar, coordinar, etc.) asociados a dicho término, remiten al hacer, es decir, a una acción que debe ser ejecutada. Aktouf (1998) hace un breve desarrollo del término, afirma que las palabras gerente o gerenciar derivan de las palabras francesas ménager y ménagement. Se trata -a modo de entender del autor- de un parentesco indirecto entre el verbo inglés to manage y la raíz del francés ménager. Ambos tienen el significado de disponer, gobernar con sentido. Ya en el siglo XV aparece el sentido de administración, conducción o cuidado de una cosa, para luego derivar al significado explícito de la persona que administra, que gerencia o que cuida de bienes o patrimonios que se le confían y custodia con la misión de hacerlos fructificar, 0 al menos preservarlos. Actualmente el término francés ménagemente se define como conducción, dirección de una empresa, mientras que el correspondiente verbo manager toma el sentido de manejar, dirigir. Aparece en él una función complementaria, que es el manejo de las personas en el trabajo administrativo. En su raíz latina administrare, administración significa (tomado de la RAE): "Gobernar, ejercer la autoridad o el mando sobre un territorio y sobre las personas que lo habitan". Es una acción que requiere de un complemento en donde recaiga dicha acción. El individuo que realiza tal acción (sustantivo), es el administrador, quien tendrá la tarea de administrar, es decir, cuidar los bienes que se le confían con el objetivo de hacerlos fructificar o preservarlos. 
Sin embargo, los empleados buscan ser autónomos y tienen expectativa en poder auto-dirigirse como característica propia de su ser jefe, a su vez que buscan ser legitimados y reconocidos por sus colegas.

Es así, que para que los MM puedan asumir sus nuevas funciones, CN les brinda y los blinda de autoridad y jerarquía al estructurar un MG que les garantice cierta autonomía para cumplir eficientemente sus labores. En el caso estudiado, los MM están en el proceso de asumir su nuevo rol. Frente a esta situación, estos jefes se encuentran en el proceso de despojarse de su identidad anterior como subordinado, y tomar una nueva identidad como jefe. En este proceso se llega a ser un jefe, comenta Parker (2004), no será algo que se pueda alcanzar plenamente, por el contrario, será un proceso a ser trabajado en forma interminable. En ese sentido, alcanzar una nueva identidad requerirá necesariamente instaurarse en la nueva estructura organizada para ello; generar nuevas relaciones con los colegas pertenecientes al FC, y sostener una relación distinta con los nuevos subordinados. A esto se le tiene que agregar la participación en ciertos procesos de formación que la dirección ha implementado para ello. En otras palabras, la organización ha propiciado y configurado un nuevo espacio social en donde las funciones y los individuos que pertenecen a ella obligan a los $\mathrm{MM}$ a insertarse en una nueva travesía de identificaciones y afiliaciones, dentro del proceso de llegar a ser y constituir una identidad particular de jefe. Es un proceso en donde constantemente se tiene que tener el control y monitorear el trabajo de los demás por el nuevo puesto asumido.

Pero este proceso de llegar a ser busca responder a la pregunta por quiénes son los jefes, con el fin de encajar en el perfil corporativo que requiere la organización, y por lo mismo, garantizar su permanencia en la misma. En otras palabras, los jefes no pueden ser simplemente ellos mismos cuando se encuentran presionados y obligados a ser moldeados en los requisitos o perfiles que tienen que ocupar. Para Watson (2008), esta dicotomía o tensión se da a partir de un proceso en donde se mira tanto hacia adentro de la propia identidad, como en forma externa, 
es decir, hacia la identidad social. En este sentido, pareciera que "convertirse en un [jefe], al parecer, a veces puede significar dejar una vieja identidad como cuando una serpiente cambia de piel, o de asumir, e incluso llegar a cambiar de identidad, como lo haría un hombre lobo" (Kenny, Whittle y Willmott, 2011, p. 81).

La dirección no sólo quiere que los MM sean fieles representantes de las gerencias en los FC, sino que buscan que sean líderes. Esto remite necesariamente a discutir, al menos someramente, la diferencia entre estos dos términos (jefe-líder). Bratton, Callinam, Forshaw y Sawchuk (2010, p. 361) realizan una clasificación: El jefe o gerente: (1) Afronta las actividades del día a día, (2) se centra en la estabilidad y la eficiencia, (3) se basa en la autoridad jerárquica tradicional, (4) se basa en las técnicas de control de mando para garantizar el cumplimiento de las órdenes. El líder en cambio: (1) Afronta la gestión de la estrategia y la visión a largo plazo, (2) se centra en la innovación y el cambio, (3) basa su gestión a partir de la personalidad por medio de la persuasión, (4) se basa en la inspiración y la creación de valores positivos para asegurar el compromiso y el logro de los objetivos.

El tema del liderazgo se ha convertido en una característica más de las habilidades de dirección, incluso los así llamados líderes han buscado definir su rol, identidad y prácticas en términos de liderazgo (Carroll y Levy, 2008). Esto se ha acentuado en lo que algunos autores Ilaman la era del postfordismo, o postestructuralismo, caracterizada por el trabajo en equipo, el empoderamiento, las estructuras planas, la descentralización, el trabajo en red, etc. Este tipo de técnicas de gestión se aplican con el ánimo de facilitar la coordinación y el control. Pero, ¿cuáles son las diferencias entre los gerentes y los líderes? ¿Qué características identitarias personales son requeridas por los líderes que no las requieran los gerentes?

Los líderes suelen definirse en contraste con los jefes, y representan algo distinto (Carroll y Levy, 2008). Estos involucran diferentes tipos de identidad. Los jefes 
asumen la regla, orientan y controlan a diferentes tipos de personas. Por el contrario, se espera que los líderes sean visionarios, determinados, de ágil pensamiento, innovadores y carismáticos. Sobre esto, Carroll y Levy (2008) argumentan que para el desarrollo de una identidad (¿quién soy?), se requiere el desarrollo a su vez de una anti-identidad (¿quién no soy?). Justamente, estos autores al estudiar los MM descubren una transición del jefe al líder. La negativa de la anti-identidad permite una mayor claridad ya que el concepto de líder es sumamente vago. La concepción de líder es atractiva ya que connota cualidades asociadas al héroe: ser transformadores de la realidad, inspiradores, visionarios, motivadores, exitosos, etc.

Para los directivos de CN, los MM son los promotores y principales responsables de hacer funcionar el nuevo modelo de gobierno en la nueva compañía. Su tarea es buscar la eficiencia por medio de su condición de líder. Dada la coyuntura de los FC y el incumplimiento de las metas en ventas, el ambiente dentro de los FC es tenso. Los MM están a la defensiva y hay cierta desconfianza con la compañía porque las metas, que siempre fueron cumplidas desde su creación, para el año 2013 en definitiva no se darán. De ahí que la figura del líder sea tan apropiada y esperanzadora.

\subsubsection{Referencia para gestionar}

Las $\mathrm{OO}$ de donde provienen los directivos tienen una fuerte influencia en cómo estos se aproximan a los MM, o más concretamente, ¿cuál es la concepción que tienen de ellos?, y ¿qué es lo que quieren que sean? En ese sentido, volver al pasado se vuelve algo natural y difícil de manejar por parte de la dirección que ve en tal dinámica un obstáculo para poder construir la nueva IO de la compañía.

Culturalmente hay unas huellas muy profundas de los modelos que traíamos de las compañías que hicieron parte de la creación de CN. Dejar esas huellas es muy difícil y la tendencia a regresar al pasado es de alguna manera alta, entonces permanentemente hay que estar diciendo: un momentico, aquí estamos gerenciando con un nuevo modelo, hay que ser disciplinado en la ejecución de ese modelo. No regresemos al pasado. En algunos momentos, en algunas prácticas, y en algunas 
personas la inercia de mantener lo que se traía, se evidencia. Hay que estar permanentemente insistiendo y persistiendo. Decir: el nuevo modelo dicta esto, tengamos disciplina y de alguna manera la ortodoxia en la aplicación de ese modelo.

(D5).

Los directivos se encuentran aún anclados, por la seguridad y confianza que esto les genera en el modelo de gestión y de gobierno de las $\mathrm{OO}$ de donde ellos provienen. Esta referencia a las OO termina por generar una distorsión, ambigüedad y contradicción en cuanto a la gestión de CN a partir del nuevo MG. Así, la incidencia de las $\mathrm{OO}$ en lo que deben ser los MM muestra una contradicción estructural. Las OO están constituidas dentro de la concepción burocrática, por lo tanto, la jerarquía y los procesos están altamente especializados. Sin embargo, detrás del MG se encuentra un elemento de la forma de organización que es la especialización del trabajo y busca que las decisiones sean más flexibles y rápidas.

Al respecto, DiMaggio y Powell (1999) afirman que la burocracia sigue siendo la forma de organización más común, pero advierten que en la actualidad, el cambio estructural en las organizaciones aparece cada vez menos motivado por la competencia o por la necesidad de la eficiencia. En otras palabras —continúan los autores - la burocratización ocurre como resultado de un proceso que hace a las organizaciones más similares, pero no necesariamente más eficientes. En el caso estudiado, el MG fue creado para responder al dinamismo del mercado cada vez más competitivo, sin embargo, los mismo directivos impulsan a sus integrantes (MM) a una concepción burocrática, aspecto que lo tienen muy bien interiorizado, fruto de las $\mathrm{OO}$ de donde provienen.

Si bien CN y concretamente el FC, (espacio en donde los MM construyen la IO de la compañía) dejaron de pertenecer a las $\mathrm{OO}$, se percatan que los mismos directivos promueven un grado de isomorfismo en el entendido que su forma de comportarse en la nueva organización corresponde a la replicación del modo de gobernar y administrar de donde surgieron y estuvieron vinculados muchos años. 
Dentro de los tres mecanismos de cambio institucional isomórfico ${ }^{69}$ se considera que para el caso en discusión se da una forma mimética.

Cuando se entienden poco las tecnologías organizacionales [...], o cuando las metas son ambiguas o cuando el ambiente crea incertidumbre simbólica, las organizaciones pueden construirse siguiendo el modelo de otras organizaciones. Las ventajas de la conducta mimética son considerables; cuando una organización enfrenta un problema de causas ambiguas o soluciones poco claras, la búsqueda en otras organizaciones puede dar una solución viable con pocos gastos. El modelado es una respuesta a la incertidumbre. La organización de la que se toma el modelo puede no estar consciente de ello o puede no desear ser copiada; solamente sirve como una fuente conveniente de prácticas que la organización que las toma prestadas puede usar. (DiMaggio y Powell, 1999, pp. 111-112).

Esta tendencia al mimetismo por parte de directivos trae mucha seguridad, ya que replican una gestión de éxito, a la vez que gracias a su misma reputación y al reconocimiento adquirido a lo largo de muchos años se saben ellos mismos más seguros en su puesto de trabajo y se corre un menor riesgo de ser violentado o cuestionado. En este sentido, los directivos tienen que enfrentar otra circunstancia, y es que el mimetismo no sólo proviene de OO distintas, y por lo mismo, con estilos de gestión disímiles, sino que los cargos que tienen actualmente, al igual que lo tienen los MM (sobre esto se profundizará en el capítulo siguiente) está mediado por la concepción de la diferenciación del trabajo, o la especialización de la tarea. Así, los directivos ya no se encargan en forma global de las ventas, la logística, la planeación sino de un área específica. Esto no sólo quita margen de acción a su quehacer, porque se tienen que restringir a las funciones asignadas, sino que obliga a coordinar ciertas tareas con otros colegas. En este sentido, habrá una tensión desde la misma dirección al querer instaurar miméticamente el modelo de gestión de donde provenían. "Entonces el resetear para poder tener alineado el modelo es la mayor dificultad. Vamos avanzando, y lo vamos haciendo bien pero hay que tener en cuenta que la resistencia y la inercia que en algunos casos es importante, obliga a que hay que estar recordando permanentemente el tema" (D5).

69 Siguiendo a DiMaggio y Powell (1999) los otros dos mecanismos del cambio institucional isomórfico son: El coercitivo, referido a las influencias políticas y al problema de legitimidad; y el normativo, relacionado con la profesionalización. 
Es así como las $\mathrm{OO}$ influyen en los directivos en dos aspectos, de ahí que sean transversales a la concepción y que lo sean los MM: Por un lado estas OO han configurado a los directivos desde su rol de líderes, al hacer que ellos mismos busquen estas cualidades en los MM; y por otro, la manera de gestionar de los directivos está mediada por la forma en que lo hacían en las organizaciones de donde provienen, dando como resultado una gestión de tensión mimética en $\mathrm{CN}$. A continuación se presenta la categoría emergente principal de la investigación que no es otra cosa que considerar a los MM como gestores eficientes del modelo de gobierno recientemente implementado por la compañía.

\subsection{CATEGORÍA EMERGENTE PRINCIPAL: LA EFICIENCIA Y LA RACIONALIDAD INSTRUMENTAL DE LA ADMINISTRACIÓN EN EL TRABAJO HUMANO}

La respuesta a la pregunta ¿qué dicen que son los mandos medios? queda ejemplificada en la respuesta de uno de los entrevistados:

Entrevistador: ¿Qué características considera usted que deberían tener estos MM en este proceso de construcción identitaria de CN? Entrevistado: "Primero, entender muy bien el modelo; segundo, alinearse con el modelo; y tercero, ser un efectivo puente entre la dirección y operación". (D5).

Como se puede ver, la concepción en cuanto a lo que son los MM está mediada por la utilidad de estos para hacer que el MG funcione. La preocupación primordial se centra en el modelo, en la eficiencia, en la consecución de los objetivos organizacionales que están detrás de la buena operatividad del nuevo modelo propuesto. Esto tiene un trasfondo en cuanto a la concepción del individuo en el trabajo y la administración como tal, ya que se busca generar una IO para los MM de acuerdo con los requerimientos específicos que se necesitan para ello. Este aspecto es el hallazgo fundamental de la investigación en esta primera parte. Esto tiene una fuerte incidencia en la Administración y posee un trasfondo filosófico importante. Por tal razón se hará un recorrido por estos aspectos para terminar afirmando que se está frente a un nuevo modelo de control en las organizaciones 
con un enfoque más interno y que busca fabricar una subjetividad, al crear y con ello controlar, una IO específica en el individuo.

\subsubsection{La instrumentalización de la razón: Una revisión al concepto}

No es el objetivo de este apartado desarrollar la propuesta ni las denuncia de algunos miembros de la llamada Escuela de Frankfurt —concretamente desde la perspectiva de Max Horkheimer - sobre el proceso de instrumentalización de la razón, ya que tal tarea, de por sí interesante y retadora, no responde a los objetivos de la investigación. Sin embargo, dados los hallazgos de la investigación, se presentan sólo algunos conceptos que ayudan a comprender el proceso reificante $^{70}$ y cosificante al que los MM son sometidos desde la dirección de $\mathrm{CN}$, de allí que el desarrollo de este tema sea ilustrativo y pertinente para el análisis a partir de los datos construidos.

La categoría de razón está presente a lo largo de la historia del pensamiento y es considerada en algunos momentos como una facultad que permite el desarrollo de la humanidad, y en otros, como una categoría que marca un punto decisivo para las transformaciones tanto científicas como epistemológicas, sobre todo por el vínculo que en la modernidad se establece entre la razón, la ciencia y el desarrollo de la tecnología. "El vínculo entre estas [...] grandes fuerzas humanas es el rasgo distintivo de la Edad Moderna: ya [...] presente en las tesis de Francis Bacon y René Descartes" (Labastida, 2007, p. 16).

Es en la Modernidad ${ }^{71}$ en donde se inicia el proceso de instrumentalización de la razón. Se gesta una nueva etapa del pensamiento caracterizada por la autonomía

\footnotetext{
${ }^{70}$ El primero en abordar el concepto de reificación fue Georg Luckács. En su colección de ensayos: Historia y conciencia de clase publicada en 1925, forja este concepto mediante la recopilación de aportes de Karl Marx, Max Weber y Georg Simmel.

${ }^{71}$ Escondida en un discurso positivista, la idea de modernidad ha calado profundamente en el discurso administrativo. Definida por la eficacia de la racionalidad instrumental, el dominio del mundo por la ciencia y la técnica, la administración ha hecho eco de dichos principios para racionalizar la realidad en la cual interviene, exaltando la cosificación por medio del individualismo y la prosperidad material a la misma persona (Hopenhayn, 2001). El mismo Touraine (2002) en el
} 
absoluta de la razón. Las matemáticas y la geometría ejemplificarán el ideal del nuevo saber expresando el conocimiento en forma clara, evidente y tangible. Los números y la geometría aparecen como instrumentos que permiten describir y entender la realidad a partir de conceptos objetivos y empíricos.

"La Modernidad no es sólo cambio puro, sucesión de acontecimientos; es difusión de los productos de la actividad racional, científica, tecnológica y administrativa [gracias a los cuales] la idea de modernidad reemplaza, en el centro de la sociedad, a Dios por la ciencia y, en el mejor de los casos, deja las creencias religiosas para el seno de la vida privada" (Touraine, 2002, p. 17). Dentro de este proceso, la naturaleza, y con ella las características que definen la razón se van modificando, haciéndose más evidente un cambio de percepción de la realidad. El hombre alejado de la explicación metafísica y divina recurre a la ciencia, al método y a la experimentación para dar cuenta de sus descubrimientos y entender la realidad que lo rodea.

La construcción de la categoría de razón instrumental se abre camino en este período, concretamente en el de la llustración. Max Horkheimer y Theodor Adorno ubican que es en el momento de la exaltación de la razón cuando comienza un proceso que lleva a presentarla con independencia, subjetivación y pragmatismo. El concepto de razón instrumental parte de la crítica que realiza Horkheimer a la sociedad capitalista. Siguiendo el discurso de Carlos Marx, vislumbra el germen del individualismo, del poder exacerbado, del interés por lo material y en general, de un carácter de dominio frente a la naturaleza y la humanidad. En la Crítica de la Razón Instrumental publicada en Alemania en 1967, se preocupa por realizar una denuncia de "la homogenización de la cultura centrada en la aniquilación del individuo y de la capacidad de autodecidir su vida otorgándole un sentido propio" (Solares, 1998, p. 224).

plano social, afirmaba que la "imagen visible de la modernidad es la del vacío, la de un poder sin centro, en una palabra, la imagen de la sociedad moderna es la de una sociedad sin actores. Cuando más entramos en la modernidad más se separan el sujeto y los objetos, mientras que en las visiones pre-modernas estaban confundidos" (Touraine, 2002, p. 263). 
La crítica de Horkheimer a la sociedad capitalista llega a ser en aspectos esenciales una "crítica de la razón instrumental", juzgándose la instrumentalización de la razón que constatará Horkheimer - en el seno de la ciencia burguesa como una declaración de incapacidad frente a relaciones de dominio cada vez más totalizadoras, mientras que el principio de trueque de la sociedad burguesa se interpreta como la expresión más acabada de dicha razón instrumentalizada. (Wellmer, 1979, p. 145).

El capitalismo trae consigo los anhelos de la llustración con el creciente desarrollo de la industria, el intercambio comercial, el perfeccionamiento de la técnica, y la idea de progreso individual. Este sistema de producción contiene una serie de relaciones de dominio que fueron estudiadas por Horkheimer. Posteriormente, y bajo la dirección de la Escuela de Frankfurt, este pensador enfoca el problema de la modernidad al desarrollo de generalizaciones abstractas sobre la esencia humana partiendo del psicoanálisis. Es así que algunos frankfurtianos pasan de enarbolar los ideales socialistas de la filosofía de Marx para hallar en la propuesta de Freud una explicación al comportamiento humano, ya no histórico, sino inconsciente de los actos humanos ${ }^{72}$.

Para el crítico alemán, el carácter de dominio se expresa de manera evidente en el liberalismo económico y en el capitalismo ${ }^{73}$, los cuales a su juicio, vuelven al sujeto cada vez más egoísta y ajeno a las problemáticas que acontecen a su alrededor, pero sobre todo, lo separan cada vez más de su relación con el otro, del cual sólo se sirve teniendo en cuenta la conveniencia y necesidad. En este sentido, las relaciones sociales vinculan a los individuos sólo en su carácter

\footnotetext{
${ }^{72}$ Erich Fromm será uno de los integrantes de este movimiento que encontrará en el psicoanálisis de la sociedad la explicación de la crisis contemporánea. "[Fromm] entra en la década de 1930 al Instituto de Psicoanálisis de Frankfurt, donde se relaciona con Marcuse y Adorno. Desde esa época, se empeña en conciliar a Marx y Freud y trata de integrar los factores socioeconómicos a la explicación de la neurosis. Es considerado con K. Horney, H.S.Sullivan y otros, representante de la tendencia culturalista del psicoanálisis. Su obra es una protesta vigorosa contra las formas más diversas de totalitarismo y de alienación social". (Fromm Erich, citado por Chemama y Vandermersch, 2004, p. 287).

73 Para Erick Fromm: "Con el milagro de la producción y de los cambios avasalladores que devinieron del siglo XIX tales como la electricidad, la utilización del vapor y posteriormente del petróleo, el hombre atraviesa los océanos y los continentes, primero en semanas, después en días, ahora en horas. Parece vencer la ley de la gravedad, vuela por el aire; convierte los desiertos en tierras fértiles y hace la lluvia en vez de rezar para que se produzca. El milagro de la producción lleva al milagro del consumo. Ya no hay barreras tradicionales que impidan a nadie comprar lo que se le antoje. Todo lo que se necesita es dinero [...]" (Fromm, 1987, pp. 95-96).
} 
económico, en la medida en que las transacciones se hacen teniendo en cuenta intereses particulares ${ }^{74}$.

Para entender la categoría que le ocupa es necesario recordar que este filósofo alemán distingue dos tipos de razón: una objetiva y otra subjetiva. La razón objetiva está en los sistemas filosóficos desde Platón hasta Kant ${ }^{75}$ los cuales, conducidos por el principio clásico de la razón, pretenden guiar los pensamientos y acciones a la búsqueda de un bien supremo, a la construcción de una comunidad justa o a la realización de la felicidad humana.

Dicha visión afirmaba la existencia de la razón como una fuerza no sólo en la conciencia individual, sino también en el mundo objetivo, en las relaciones entre los hombres y las clases sociales, en la naturaleza y en sus manifestaciones. [...] La estructura objetiva de ésta, y no tan sólo el ser humano y sus fines debían ser el patrón de medida de los pensamientos y acciones individuales. [...] El énfasis era puesto más en los fines que en los medios. La aspiración máxima de este tipo de pensamiento era conciliar el orden objetivo de lo «racional», tal como lo concebía la filosofía, con la existencia humana, incluidos el interés propio y la auto conservación. (Horkheimer, 2002, p. 46).

Tal concepto de razón mantiene como prioritarios problemas tales como el bien supremo y el mejor modo posible de realización de los fines supremos, basados en la afirmación de que la racionalidad humana es sólo genuina cuando sus

74 Adam Smith comentaba al respecto lo siguiente: "El hombre está casi permanentemente necesitado de la ayuda de sus semejantes, y le resultará inútil esperarla exclusivamente de su benevolencia. Es más probable que la consiga si puede dirigir en su favor el propio interés de los demás, y mostrarles que el actuar según él demanda redundará en beneficio de ellos. [...] Todo trato es: dame esto que deseo y obtendrás esto otro que deseas tú; y de esta manera conseguimos mutuamente la mayor parte de los bienes que necesitamos. No es la benevolencia del carnicero, el cervecero o el panadero lo que nos procura nuestra cena, sino el cuidado que ponen ellos en su propio beneficio. No nos dirigimos a su humanidad sino a su propio interés, y jamás les hablamos de nuestras necesidades, sino de sus ventajas. $Y$ es que, como observamos: No es por el amor a nuestros vecinos o el amor a la humanidad que intentamos comportamientos virtuosos. Es por el amor a lo honorable y noble que tienen la grandeza, dignidad y superioridad que a nuestro carácter brinda la magnanimidad. Y ésta es la que nos dicta el hombre interno. [...] Es asunto de justicia y de razón, no de benevolencia" (Smith, 2004, pp. 45-46).

75 "Grandes sistemas filosóficos como los de Platón y Aristóteles, la Escolástica y el idealismo alemán tenían como fundamento una teoría objetiva de la razón. Su objetivo era el desarrollo de un sistema englobante o una jerarquía de la totalidad de los entes, incluidos el ser humano y sus fines. El grado de racionalidad de la vida de una persona podía ser determinado a partir de su armonía con esta totalidad" (Horkheimer, 2002, p. 46). 
acciones están organizadas de un modo más o menos técnico y lógico, armonizando los medios y fines, coordinándolos con el interés de la humanidad.

La razón subjetiva es aquella que considera que lo único que cuenta es el medio, "el funcionamiento abstracto del mecanismo del pensamiento" (Horkheimer, 2002, p. 45). Le confiere poca importancia a la pregunta por la racionalidad de los fines y basa sus acciones en el interés del sujeto en orden a su autoconservación ya sea tanto de manera individual como colectiva.

La razón subjetiva se revela en última instancia como la capacidad de calcular probabilidades y determinar los medios más adecuados para un fin dado. [...] la «razón» se utiliza más bien para caracterizar una cosa o pensamiento que un acto, ésta viene referida exclusivamente a la relación entre un objeto de este tipo o un concepto con un fin, no al objeto o al concepto mismo. Lo que significa que la cosa o el pensamiento sirven para algo distinto. No hay ningún fin racional en sí y, en consecuencia, carece de sentido discutir la preeminicencia de un fin respecto de otro desde la perspectiva de la razón. (Horkheimer, 2002, p. 47).

Como explica Horkheimer (2002), siempre existe una relación entre estos dos conceptos, la razón objetiva "jamás excluyó la razón subjetiva, sino que la consideró como expresión parcial y limitada de una racionalidad englobante, de la que eran derivados los criterios para todas las cosas y seres vivos" (p. 46). Es durante la Modernidad, específicamente en el periodo de la llustración, donde la razón subjetiva es privilegiada ${ }^{76}$, llevando así a la crisis contemporánea de la razón que implica que "el pensamiento o bien perdió por completo la capacidad de concebir tal objetividad, o bien comenzó a combatirla como un espejismo" (p. 48).

Este cambio afecta el contenido objetivo de toda concepción racional, para la que "finalmente no hay realidad singular alguna que pueda aparecer como racional per se; vaciados de su contenido, todos los conceptos fundamentales se han convertido en meras cáscaras formales" (p. 48). En la medida en que el pensamiento no posea dirección objetiva alguna y se ponga al servicio de

\footnotetext{
76 "Históricamente han estado operantes desde un principio ambos aspectos de la razón, el objetivo y el subjetivo, y sólo en el transcurso de un largo proceso tomó cuerpo la preeminencia de éste sobre aquel" (Horkheimer, 2002, p. 48).
} 
cualquier interés particular, dejan de tener sentido categorías tales como bondad o maldad, correcto o incorrecto, verdad o falsedad.

El fortalecimiento de esta razón subjetiva deriva en instrumentalización; pues si bien la razón nunca ha dirigido realmente la realidad social, en este momento: "ha sido tan depurada de toda tendencia o inclinación específica, que ha renunciado incluso a la tarea de enjuiciar acciones y modos de vida de los seres humanos. Tales cosas han sido dejadas por la razón a sanción definitiva de los intereses en pugna, a merced de los que parece estar hoy nuestro mundo" (Horkheimer, 2002, p. 49-50).

Esta instrumentalización tiene su fundamento en el egoísmo, ya que "[...] la idea de interés egoísta fue progresivamente convirtiéndose en hegemónica y relegó finalmente a un plano muy secundario a los otros motivos considerados como fundamentales para el funcionamiento de la sociedad [...]" (Horkheimer, 2002, p. 57). Es en el Renacimiento cuando ocurre un proceso de degradación de la razón objetiva, que da paso al surgimiento de la razón instrumental.

La razón en la que se basaban «las ideas de justicia, igualdad, felicidad, democracia y propiedad» fue convertida en mero instrumento: Es como si el pensamiento mismo hubiera quedado reducido al nivel del proceso industrial, como si se hubiera sometido a un plan exacto [...]: como si hubiera sido convertido en parte integrante y sólida de la producción. (Solares, 1998, p. 225).

Esta transformación provoca que conceptos epistemológicos centrales como el de verdad, sean susceptibles de ser manipulados por intereses particulares, centrándose en lo inmediatamente útil y funcional con vista a la obtención de un bien determinado para un sujeto particular ${ }^{77}$. Para Horkheimer (2002) esto implica que las cosas se vacíen de contenido, es decir, que la propia naturaleza humana pierda la capacidad para apreciar el sentido de la realidad.

77 "El complejo concepto de razón de Horkheimer abarca así el conjunto problemático de las contradicciones todas, espíritu y materia, y el fenómeno de su reducción racionalizante, que separa al hombre de la naturaleza bajo el fin de la auto-conservación hasta su adecuación cínica a un presente opresivo" (Solares, 1998, p. 225). 
Cuanto más se debilita el concepto de razón, tanto más fácilmente queda a merced de la manipulación ideológica y de la difusión de las mentiras más descaradas. El avance de la llustración disuelve la idea de razón objetiva, el dogmatismo y la superstición [...] Intereses creados, opuestos a los tradicionales valores humanitarios, acostumbran a reclamarse, en nombre del «sano sentido común», de la razón neutralizada, impotente. (p. 61).

En esta etapa del Renacimiento es cuando comienza la crisis moderna del pensamiento basada en la exaltación de la razón humana sobre todas las cosas, y surge "el carácter de dominio del objeto fundado en la concepción abstracta de humanidad transitada ya desde su origen de un pensamiento subjetivista, ordenador, egoísta" (Horkheimer, 2002, p. 227). Este afán de dominio sobre la humanidad y la naturaleza camina cegado por una idea de progreso, la cual desde la perspectiva del filósofo de Frankfurt es mera ilusión que conduce a la esclavitud humana. Desde ahí surge su crítica, cuando al cuestionar los desastres y tragedias de la Segunda Guerra Mundial reflexiona sobre la irracionalidad que pueden albergar la ciencia y la técnica al carecer de un carácter objetivo que conduzca las acciones a favor de un bienestar para la humanidad ${ }^{78}$.

Horkheimer develaba, desde el dolor de una cultura estallada, el luto escondido tras los intersticios de una racionalidad que naufragaba en su propio proyecto: el dominio de la naturaleza que sofocaba a la naturaleza misma del hombre. [...] La "razón iluminística", en fin, se convertía en su propia autotraición. (Waldman, 1998, p. 239).

Con este carácter de dominio y manipulación, la naturaleza es percibida como un objeto ajeno al hombre, puesto a su disposición. Al mismo tiempo, los hombres se

\footnotetext{
${ }^{78}$ Los pensamientos nihilistas y pesimistas de filósofos como Theodor Adorno, Max Horkheimer y Marcuse se explican por el gradual desencanto y desilusión que vivieron a partir del fracaso de la revolución alemana y el advenimiento del fascismo. El peligro constante en el que vivían, el exilio que sufrieron y las consecuencias que percibían de un creciente sistema capitalista. "Esta actitud intelectual, asumida como ejercicio crítico comprometido sólo consigo mismo extraía su fuerza de la capacidad para analizar el mundo moderno desde el ángulo de la negatividad [...] con respecto a la trágica inadecuación de una realidad que se disfrazaba de razón, o de una razón que ambicionaba reconocerse en la realidad y que había culminado en Auschwitz como expresión de las dimensiones más sombrías de la razón. Plasmado como antítesis de un mundo cuya "productividad destruye el libre desarrollo de la necesidad y las facultades humanas; un mundo que se mantiene en paz mediante la constante amenaza de guerra, cuyo crecimiento depende de la represión de las verdaderas posibilidades de pacificar la lucha por la existencia en el campo individual, nacional e internacional», el pensamiento crítico sólo podía existir como negación del proyecto iluminista que, en lugar de disipar las tinieblas, había desembocado en la subyugación de las conciencias y en la destrucción de la naturaleza" (Waldman, 1998, pp. 236-237).
} 
esfuerzan por sobrevivir dentro de un medio, que aunque creado por ellos, les exige relativizar los fines, llevando a identificar la razón con la capacidad de adaptación.

Las fuerzas económicas y sociales asumen el carácter de potencias naturales ciegas que el hombre ha de dominar, adaptándose a ellas para sobrevivir. Como resultado final del proceso tenemos por una parte el sí mismo, el yo abstracto, vaciado de toda substancia que no sea su intento de convertirlo todo, en el cielo y en la tierra, en un medio para su conservación y prevalecimiento; y, por otro, tenemos una naturaleza vacía, degradada a mero material, a mera materia primera, que ha de ser dominada sin otro fin ni objetivo que el del dominio mismo. (Horkheimer, 2002, p. 119).

Para Horkheimer el afán de dominio es una parte inseparable de la esencia de la razón, que explica el desarrollo de la humanidad y que se convierte en causa de la instrumentalización de la razón.

De hablarse de una enfermedad que afecta a la razón, ésta no debería ser entendida en el sentido de haber afectado a la razón en un momento histórico determinado, sino como inseparable de la esencia de la razón en la civilización, tal como la hemos conocido hasta la fecha. La enfermedad de la razón tiene sus raíces en su origen, en el afán del hombre de dominar la naturaleza [...] Desde la época en que la razón se convirtió en el instrumento del dominio de la naturaleza humana y extra humana por el hombre -esto es, desde los más tempranos comienzos-, su intención propia, la de descubrir la verdad, se ha visto frustrada. Lo cual debe atribuirse a su conversión de la naturaleza a mero objeto, y al hecho de haber fracasado en el empeño de descubrir la huella de sí misma en tal objetivación, en los conceptos de materia y de cosa no menos que en los de los dioses y del espíritu. (Horkheimer, 2002, p. 179).

Históricamente este proceso de instrumentalización se da en el momento en que Europa sufre grandes cambios. Con la revolución industrial, la manera de vivir y de percibir las cosas se modifica radicalmente; la utilización de los descubrimientos científicos hace que las ciudades se transformen, los sistemas de producción y transporte se multipliquen y agilicen, mientras que los intercambios comerciales hacen crecer ciudades enteras aumentando con ello su producción y riqueza. Horkheimer (2002) afirma que la idea de un progreso humano basado en el poder de la ciencia como principio regulador de la sociedad viene a señalar la forma en que la ciencia es la que suministra un dominio sobre la naturaleza; pues una vez que ésta ha perdido todo valor intrínseco es abandonada con el único fin de servir como proveedora para la conservación humana. 
La razón instrumental busca el dominio de la naturaleza, la convierte en objeto de explotación e intercambio comercial, alejándose cada vez más de algún vínculo que pudiera establecer con ella. "La nueva concepción del mundo natural como un campo de control y manipulación humana corresponde a una noción similar del hombre como objeto de dominación. [...] Para los ilustrados el hombre y la naturaleza sólo eran máquinas" (Marshall, 1997, p.44).

Horkheimer dirá al respecto que la voluntad de dominio que caracteriza a la naturaleza humana se arroja contra el mundo abandonando la vieja pretensión de captar la totalidad; pues en el ejercicio por depurar la razón, se elimina cualquier indicio metafísico o teológico. "La filosofía cifró todo su orgullo en ser el instrumento de la deducción, explicación y revelación del contenido de la razón en cuanto reflejo de la verdadera naturaleza de las cosas y de la recta conducción de la vida" (Horkheimer, 2002, pp. 53-54).

La razón instrumental crea una nueva ilusión de la autonomía del hombre y del esperanzador progreso de la humanidad. Se cree superado el mito y la superstición, pues "[...] la racionalidad afirmada como poder absoluto, hacía brotar de sí misma una ciega irracionalidad que provocaba la regresión a estados que la razón, calificándolos de «bárbaros», creía haber superado triunfalmente" (Waldman, 1998, pp. 238-239). Desde la perspectiva de Horkheimer, la misma confianza y exaltación que se le da al despliegue triunfal de la ciencia y la técnica durante la llustración es nuevamente un mito más que la razón crea con su creciente afán de crecimiento económico, mercantil e industrial. El hechizo de la idea del progreso social llevaba al poderío de una ciega fatalidad que esclavizaba al ser humano. El aumento de la productividad económica se transformaba en un instrumento de opresión.

La crisis se refleja en el hombre en la falta de individualidad, personalidad, reflexión y sentido. Una vez que la humanidad ha caminado hacia la ilusión de un futuro prometedor y técnicamente mejorado, abandona cualquier rastro de 
misticismo, superstición y metafísica se topa con que carente de referencias que orienten su existir, la complacencia se vuelve requisito de supervivencia.

[...] el hombre se [pierde] en el camino de la ciega irracionalidad. Desarraigado, no posee un lugar reconocido. En su debilidad, magnifica todo aquello que se le aparecía como omnipotente. En su soledad, renuncia a sí mismo para salvarse de cualquier amenaza. En su terror frente a fuerzas que le son incomprensibles, busca protección en entes superiores que le den sentido a su existir. (Waldman, 1998, p. 239-240).

Los fines objetivos bajo los cuales la humanidad supedita sus acciones, a falta de referencias, se relativizan, pues las actividades guiadas por la razón instrumental sólo son consideradas como racionales cuando poseen una finalidad práctica tangible. Toda acción considera al ser como mero instrumento que le permita al hombre acceder a circunstancias que brinden beneficios y satisfacciones. Lo que cumpla otra función deja de ser importante o prioritario para la vida ${ }^{79}$. Para Horkheimer (2002) la razón instrumental ya no determina ni comprende los fines, ahora simplemente se ocupa de los medios. "Es como si el pensamiento mismo se hubiese quedado reducido al nivel de los procesos industriales, sometido a un plan exacto y convertido, en una palabra, en un elemento fijo de la producción" (p. 59).

La estructura objetiva de la razón, la cual es la medida de los pensamientos y de las acciones, es consumida por la capacidad de calcular posibilidades y determinar los medios más adecuados para un fin particular.

La razón se utilizará más bien para caracterizar una cosa o pensamiento que un dato, ésta viene referida exclusivamente a la relación entre un objeto de este tipo o un concepto con un fin, no al objeto o al concepto mismo. [...] No hay ningún fin racional en sí, y, en consecuencia, carece de sentido discutir la preeminencia de un fin respecto de otro desde la perspectiva de la razón. (Horkheimer, 2002, p. 47).

\footnotetext{
79 "Siendo así como un paseo por el paisaje no resulta ya necesario; y de este modo el concepto de paisaje, tal como es experimentado por un caminante, se convierte en arbitrario y carente de sentido. El paisaje degenera a mera experiencia turística" (Horkheimer, 2002, p.72). Se ha perdido el significado intrínseco que pervivía en la mera experiencia estética, en la contemplación, admiración o asombro ante aquello que no genera interés fáctico alguno. Lo que ahora importa es consumir, tener, gastar y poseer artículos que se venden como indispensables para la vida moderna; pues dada la pérdida de sentido en los fines y la relativización de los medios ahora convertidos a fines, ya no cabe la consideración de que algo valga por sí mismo, incluso la propia razón y la verdad.
} 
El proceso de racionalización moderna se revela cada día más como un implacable proceso de instrumentalización, lo cual lleva a Horkheimer a describir la ruptura entre los dos tipos de razón, pero sobre todo a enfatizar el desbocamiento de la razón subjetiva y el afán de dominio sobre la naturaleza. El predominio de la razón subjetiva sobre las convicciones objetivas de la cultura occidental muestra que éstas son demasiado débiles y cerradas. La crítica recae sobre las consecuencias que se dieron en pos de ese progreso, señalando sobre todo el relativismo y la pragmatización del pensamiento, que sustituye la lógica de verdad por la lógica de la probabilidad y la relativización del lenguaje; del mismo modo que trae consigo el vaciamiento de los grandes ideales, los cuales son sustituidos por la opinión de la mayoría y la manipulación ideológica del poder.

Uno de los mayores peligros se halla en la pragmaticidad del pensamiento, en que éste llegue a un punto en el que pierda su capacidad objetiva y universal y quede reducido a instrumento. "Lo que teme Horkheimer es que la razón, el pensamiento autónomo/crítico - y no hay otro que merezca ese nombre - sea arrollado por la lógica disolvente del dominio y pierda su momento de verdad, la capacidad de «resistencia frente a la injusticia»" (Sánchez, 2002, p. 24). La crítica y la denuncia que realiza se dirigen a la instauración del individuo tecnócrata que se mueve dirigido por la razón instrumental ${ }^{80}$, y al individuo que una vez convertido en hombre-masa ${ }^{81}$, se mimetiza ${ }^{82}$ con la mayoría, transformando su pensamiento en un estereotipo que la lógica de mercado ha homogenizado y pervertido.

${ }^{80}$ El tema sobre la decadencia del individuo desde su reificación se tratará brevemente en los siguientes apartados. Sin embargo, ya se hace mención a él por considerarlo una consecuencia importante de este proceso, pues si bien la razón instrumental ha anulado a aquel que se supone la dirige, es de entender que todo el sistema se encuentre desbocado.

81 "Las masas, o bien adquieren los artículos de lujo como si se tratase de una necesidad, o bien los consideran como un medio para su recreo. Nada, ni si quiera el bienestar material, que según parece ha ocupado el lugar de la salvación del alma como objetivo supremo de ser humano, es valioso en sí mismo y por sí mismo, ningún objeto es, en cuanto tal, mejor que otro" (Horkheimer, 2002, pp. 74-75).

82 "Se inculca al individuo, desde sus primeros pasos, la idea de que sólo existe un camino para saber manejárselas en este mundo, el de abandonar la esperanza de una máxima autorrealización. Esto es algo que sólo puede ser logrado mediante la imitación. Actúa de continuo en consonancia 
Así, la categoría de razón instrumental sirve para explicar una percepción de la realidad carente de dirección y sentido objetivo, que es guiada por el afán de dominio, la conveniencia y el poder. La importancia que logra la razón subjetiva es presentada por Horkheimer como un proceso necesario ya que permite el progreso de la humanidad, el problema es que dicho proceso se sale de control al carecer de una dirección objetiva. Ahora bien, si esto es un proceso, es posible encauzarlo nuevamente logrando "[...] que la «tendencia de dominio» (y por lo tanto la instrumentalización de la razón) no sea un proceso «fatal», sino un proceso histórico que puede -y debe - ser reorientado en cuanto los hombres tomen conciencia de ello" (Sánchez, 2002, p. 15).

Teniendo esta conceptualización de la razón instrumental como precedente, se relaciona el tema de la racionalidad subjetiva con la administración, como fundamento conceptual para presentar una nueva forma de control a nivel administrativo que se inscribe en aspectos más internos del individuo, que no es otra cosa que el control identitario dentro de las organizaciones. Para llegar a este punto será necesario discutir algunos asuntos referidos al capitalismo y al trabajo, así como la administración en cuanto la gestión que realiza para promover e impulsar este tipo de control.

\subsubsection{El trabajo humano: escenario de paradojas y contradicciones}

El trabajo se configura como un espacio social que a la vez se convierte en objeto de múltiples investigaciones y reflexiones en torno a su desarrollo e incidencia dentro de la sociedad, particularmente luego de la Revolución industrial y de la influencia del protestantismo ${ }^{83}$. El trabajo es considerado como la actividad que

con lo que percibe en su entorno, y no sólo conscientemente, sino con todo su ser, compitiendo con los rasgos y los modos de comportamiento representativos para todos los colectivos en los que se ve involucrado" (Horkheimer, 2002, p. 153).

${ }^{83}$ La iglesia protestante surge a partir de la escisión de la Iglesia Católica en el siglo XVI. Sus principales representantes fueron Martín Lutero y Juan Calvino. Para el protestantismo, la única regla de fe es la Escritura interpretada privadamente, rechazando la jerarquía de la Iglesia Católica. Existen algunas diferencias entre ambos: Los luteranos no admiten visibilidad ni jerarquía alguna de la Iglesia, mientras que los calvinistas sostienen que la Iglesia es en parte visible y aceptan a 
transforma de manera consciente la naturaleza y al individuo mismo. Independiente del valor, será el trabajo el medio de creación de riqueza material e inmaterial, y el responsable de hacerla circular.

El trabajo tiene un componente objetivo y otro subjetivo. Lo objetivo está en relación con la riqueza, mas no así con las diversas connotaciones sociales que ésta tiene, de donde surge su componente subjetivo (De la Garza, 2002). Este carácter dual de lo objetivo y lo subjetivo del trabajo será la base de diversas discusiones dentro de las ciencias sociales. De hecho, De la Garza (2009), bajo esta misma óptica define el trabajo como "una forma de interacción entre hombres y entre estos con objetos materiales y simbólicos, que todo trabajo implica construcción e intercambio de significados" (p. 111).

En este marco de discusión propuesto para este capítulo, es pertinente destacar el planteamiento que frente al problema de la explotación del hombre-trabajador, hizo Marx. Para este filósofo alemán, no sólo el trabajo era el único origen del valor, sino que la ganancia capitalista provenía de un trabajo no remunerado, lo cual le permitía generar más valor (plusvalía) al capitalista. De esta manera, Marx centró su atención en el concepto de fuerza de trabajo y trabajo, o lo que es lo mismo, entre la capacidad de generar valor por la fuerza de trabajo y la cantidad de valor incorporada a la mercancía en el proceso productivo. Esta es la disputa esencial para Marx: El capitalista compra la fuerza de trabajo pero no especifica la cantidad de trabajo presente en la jornada laboral. De este modo, no sólo el trabajo sino también su producto y las relaciones productivas con otros individuos se encuentran alienados al capital.

Esta particularidad del trabajo en cuanto a su carácter subjetivo ha repercutido fuertemente en las organizaciones y, por lógica derivación, en el individuo y en sus

los presbíteros como delegados del pueblo cristiano. Ya en el plano más económico, los luteranos honraron el trabajo apreciando el oficio y el valor (no en el sentido monetario) que esto tenía para la comunidad. En cambio, para los calvinistas, el valor del trabajo se centraba en la capacidad de acumular dinero. Lo individual pasó a convertirse en algo deseado y socialmente aceptado. 
relaciones sociales. Las consecuencias del capitalismo presentan aspectos ambivalentes: Por un lado, una visión cosificante del trabajo que reduce al individuo a un mero capital, y por otro, entender el trabajo como factor de progreso y riqueza. Inspirado por la dialéctica hegeliana del progreso, Marx desarrolló el concepto de alienación en el texto Manuscritos Económicos y Filosóficos de 1844, para criticar el concepto de trabajo del capitalismo. De acuerdo con Marx (1978), el trabajo capitalista es alienante en cuatro sentidos: (1) El objeto producto del trabajo deja de pertenecer al trabajador ya que el capitalista es el dueño del capital. (2) Las actividades de los trabajadores llegan a ser una práctica alienada dado que el trabajo se convierte en una actividad forzada. (3) El trabajador se aliena a sí mismo al convertirse en un extraño para sí. La espontaneidad, la libertad de conciencia y conducta para realizar sus actividades de acuerdo con sus propósitos particulares, se pierden. Por lo que, "el trabajo enajenado, enajena la especie del hombre" (Marx, 1978, p. 75), lo que conduce a la deshumanización del trabajador (Schacht, 1970). (4) Como consecuencia de otras formas de alienación, la enajenación del hombre respecto a éste se produce debido a que el hombre es enfrentado a otros en el mercado laboral (Costas y Fleming, 2009).

De la Garza y Campillo (1998) retoman la concepción de Marx sobre el trabajo para afirmar que "en su aspecto más básico, el trabajo puede entenderse como la transformación de un objeto a partir de la actividad humana, utilizando determinados medios de producción para generar un producto con valor de uso y, en ciertas condiciones, con valor de cambio" (p. 117). El valor de cambio sólo dice que en la mercancía ${ }^{84}$ se ha invertido trabajo, independiente de los valores de uso que dichas mercancías tengan. La magnitud de valor reside en la cantidad de trabajo encerrada en ella, pudiéndose medir por el tiempo de duración. Así, lo que

\footnotetext{
${ }^{84}$ Marx (1984) define mercancía como un "objeto externo, una cosa apta para satisfacer necesidades humanas, de la clase que ellas sean" (p. 3). Las características intrínsecas a dichas mercancías permiten definir el uso que se les va a dar. Así, el valor de uso de un bien reside en su materialidad misma. La posibilidad de intercambiar el uso de un bien por el uso que se le podría dar constituye el valor de cambio.
} 
"determina la magnitud de valor de un objeto no es más que la cantidad de trabajo socialmente necesario para su producción" (Marx, 1984, p. 7$)^{85}$.

El trabajo se convierte hoy en día en fuente de división y espacio de desencuentro entre los individuos. Esta es una nueva faceta de la realidad humana que aparece en el escenario económico: El hombre es fundamentalmente un trabajador, y es en ese sentido que tiene un espacio social (Smith, 2004). Desde la economía clásica, la sociedad bien podría convertirse entonces en una sociedad de productores, y su orden interno estaría regido por leyes implacables e invisibles que regulan el funcionamiento y la evolución de la economía. Movidas por el interés individual, estas leyes pondrán las primeras piedras para cimentar el capitalismo e introducir los conceptos de competencia y libre mercado para tratar de explicar la rueda lógica económica por la cual la sociedad se rige (Aktouf, 1998).

Para Hegel, el trabajo es una actividad mediante la cual el espíritu desarrolla sus potencialidades y, al mismo tiempo, como la actividad en la cual el espíritu deviene en algo distinto de sí mismo. Esta paradoja, lógicamente enmarcada dentro del concepto dialéctico de dicho autor expresa, por un lado, que el trabajo actualiza y, por el otro, que aliena el ser. Sin el trabajo, el individuo no es nadie; pero mediante el trabajo el individuo deja de ser lo que era antes.

Como fuente de productividad, el trabajo está en la base de las relaciones humanas. La relación señor-siervo, o amo-esclavo, ayuda a comprender este aspecto. El siervo es esencialmente un trabajador; su misma vida es su trabajo, y éste está volcado sobre objetos que no le pertenecen. De esta forma, el siervo lleva una existencia que no le concierne y necesita del dueño de los objetos para

\footnotetext{
${ }^{85}$ Profundizando en esto, para el mismo autor, "la magnitud del valor de una mercancía cambia en razón directa a la cantidad y en razón inversa a la capacidad productiva del trabajo que en ella se invierte. Es decir, cuanto mayor sea la capacidad productiva del trabajo, tanto más corto el tiempo de trabajo necesario para la producción de un artículo, tanto menor la cantidad de trabajo cristalizada en él y tanto más reducido su valor" (Marx, 1984, p. 8).
} 
poder trabajar. Al estar encadenado a los objetos, el trabajo cosifica al siervo ya que su misma existencia consistirá en ser utilizada por otro. Así, el trabajador es tal gracias a su trabajo, en el cual forja una idea de sí mismo que depende de otra conciencia, la del amo (Hopenhayn, 2001).

El amo se crea una conciencia también distinta. Encarga y ordena los objetos que desea sin trabajar en ellos, compensando sus necesidades - a lo cual se le asocia su felicidad - mediante el trabajo ajeno. Al ejercer esos bienes hace uso de quien verdaderamente ha laborado en ellos: el siervo. Esto lo convierte en un ser dependiente de otro. Así, independientemente de ser señor o siervo, "en la relación donde interviene el trabajo, cada una de las partes reconoce que su identidad la alcanza a través del otro, y que su subjetividad es, mediante el trabajo, intersubjetividad" (Hopenhayn, 2001, p. 126).

Desde una perspectiva dialéctica, la alienación es concebida como necesaria y propia del dinamismo del espíritu del individuo. La alienación es volverse otro distinto a sí, depositando la misma existencia y la propia subjetividad en objetos que están fuera del ser, convirtiendo la existencia en una existencia productiva. Esta ya no se mide por sí misma, sino por los objetos con los que se vincula y por la forma en que el individuo se vincula a ellos.

Es así que el trabajo en el capitalismo industrial asume la forma de trabajo alienado. Esta alienación traspasa lo meramente personal para tener una connotación social. Siendo las mercancías el nexo de intercambio social, el individuo carece de control sobre sus propias posibilidades, siempre interdependientes de la regulación impersonal del mercado capitalista. La alienación para Marx se hace explícita en la imposibilidad de crecimiento y de decisión de los individuos, y también por el predominio de una superestructura que no responde a las necesidades de los individuos que la componen. 
Dentro de este aspecto social se encuentra también una dimensión humana. La oposición entre capital y trabajo tiene su efecto alienante del hombre con respecto del hombre. Los individuos se ven a sí mismos como competidores y participan en una carrera por adquirir mercancías y aumentar el poder del capital que poseen. Junto con esto, son las mercancías del capital las que determinan las relaciones entre los individuos, no viceversa.

Inmerso en la dinámica ya descrita de una economía asfixiante, impersonal y alienante, pareciera ser que el individuo no tiene otra posibilidad que regirse por una lógica externa en la que su misma humanidad corre el riesgo de ser relegada a un instrumento utilitario de carácter comercial. Pero no es sólo el trabajo y la lógica en que éste se inscribe los que promoverán cierto condicionamiento, sino que será también la administración la que buscará aplicar dichos preceptos capitalistas, al instaurar métodos y herramientas para potenciar una rentabilidad eficaz por medio del uso adecuado de los recursos.

Dentro de este contexto, se puede afirmar que se está frente a una lógica racionalizadora $^{86}$. El principal argumento del racionalismo ${ }^{87}$ es la impotencia del

\footnotetext{
${ }^{86}$ Las escuelas que representan el racionalismo son la griega y la moderna. En la primera se encuentra Parménides como su principal representante. Este filósofo afirma que el camino de la experiencia sólo conduce al error; sólo la razón conduce al sabio a la verdad. La primera verdad es el principio de identidad (el ser es y el no ser no es); así, niega el cambio y la diversidad de los seres; el ser es inmóvil y uno. Por otro lado, la moral estoica reposa en una metafísica del mismo tipo: el sabio debe ser indiferente, insensible a sus pasiones porque la felicidad es la virtud, que consiste en vivir según la razón. En la escuela de la filosofía moderna está Descartes. Con él aparece el racionalismo, que se expresa principalmente por la idea de la matemática universal y por la teoría de las ideas innatas. Las matemáticas son para él, el tipo de la ciencia: rigurosas y progresivas. Para que el conocimiento sea verdadero debe desarrollarse a priori, partir de ideas claras y distintas captadas por intuición y deducir las verdades por orden, como los teoremas de la geometría. La experiencia no proporciona ningún objeto a la ciencia. Con Kant, por influencia de Hume, el racionalismo se matiza y profundiza. El racionalismo kantiano radica enteramente en la distinción entre la materia y la forma del conocimiento. La forma es a priori, es decir, independiente de la experiencia, rige la conciencia, pues no se puede conocer nada sino es por las leyes de nuestro espíritu. La materia es a posteriori y nos es dada por la experiencia sensible. Es también necesaria, pues sin ella el pensamiento sería vacío. Pero el racionalismo tiene una importancia mayor, ya que la razón es la forma que constituye los objetos. Los sucesores de Kant no se han contentado con esta posición relativamente moderada y han llevado el racionalismo al absoluto, absorbiendo la materia del conocimiento en su forma, lo que quiere decir que han atribuido a la razón sola el conocimiento de la verdad.
} 
empirismo para explicar lo intelectual y especialmente el conocimiento científico. Pero el racionalismo no se limita a refutar a su adversario, sino que su argumentación tiene un valor positivo, presenta un único camino para llegar a la verdad.

El racionalismo tiene estrecha relación con el método económico. La idea cartesiana de la matemática universal define un método de saber independiente del objeto y trata de extenderlo a todos los ámbitos del conocimiento (es arbitrario). Esto tiene sus consecuencias en cuanto que va a influenciar la filosofía moderna y con ello al positivismo, al cientismo, a la fenomenología y por lo tanto, a Hegel y a Marx. Esto se verá en el postulado racionalista que negará la existencia de todo lo que podría escapar al método elegido y reconocerá la existencia de un elemento rebelde, dado por la experiencia, declarado irracional porque no se somete a la razón.

La realidad no es una idea exenta de materialidad. El hombre la crea y la construye configurando una existencia real y concreta a partir de esa experiencia. La pretensión racional de considerar lo objetivo por fuera de dicha experiencia subjetiva es reducir la vida misma del hombre a una idea inteligible, a la vez que universaliza la realidad particular a una teoría general. De ahí las grandes dificultades en los modelos y demás métodos llamados científicos en las ciencias sociales, en donde se inscribe la administración.

Esta racionalidad permitirá el surgimiento del llamado espíritu del capitalismo. Weber (2007) denota espíritu del capitalismo a aquella mentalidad que busca

${ }^{87}$ Los argumentos del racionalismo se pueden resumir en el pensamiento de Kant. Él apoya su racionalismo sobre el único argumento que le viene de Leibniz: la ciencia consiste en juicios necesarios y universales; estos no pueden fundarse en la experiencia, pues ésta sólo presenta hechos particulares y contingentes. En los juicios analíticos el predicado está incluido en el sujeto; por tanto, se le puede atribuir independientemente de toda experiencia. En los juicios sintéticos, el espíritu atribuye al sujeto un predicado que no está contenido en él. Cuando está fundado en la experiencia, no hay dificultad alguna, pues la experiencia nos la da el sujeto con este predicado. Pero hay juicios sintéticos necesarios y universales, que son a priori; su fundamento es la razón, ya sean las formas de la sensibilidad (juicios matemáticos), o las categorías del entendimiento (juicios de la física). 
obtener un lucro ejerciendo sistemáticamente una profesión, una ganancia racionalmente legítima, en donde la empresa capitalista se convierte en el espacio más apropiado para llevarse a cabo, y descubre en ese espíritu el más adecuado impulso espiritual.

En ese sentido, la doctrina de la Reforma Protestante "compaginó la subordinación al mandato divino con la acción e iniciativa personal, opuso la ética mercantil burguesa del siglo XV, que tenía la ganancia como finalidad, otra ética que, aunque religiosa, va a valorar aún más el proceso de acumulación capitalista" (Hopenhayn, 2001, p. 86). Pero el principal nexo entre el protestantismo y el espíritu del capitalismo lo establece la doctrina calvinista de la predestinación. Esta doctrina divide a los hombres entre los elegidos y los condenados, negando toda posible conmutabilidad entre ambos, es decir, se nace uno o lo otro. Se debe tener la suficiente autoconfianza de ser elegido mediante una intensa actividad productiva. Calvino desconfiaba de toda emoción y sentimiento. Para él la fe debía ponerse en evidencia por sus resultados objetivos, convirtiéndose así en una fe eficaz (Weber, 2007) ${ }^{88}$. La fe calvinista se traduce en signos y muestras individuales, hechas para rectificar a su ejecutor. No hay posibilidad de elemento solidario alguno.

Este concepto de predestinación que alberga un individualismo progresivo y egoísta, agrega un factor más: el tema del control. La posibilidad de saberse condenado o elegido sitúa al hombre en la inexorable encrucijada de adecuar su comportamiento y conducta a la realidad escatológica, definiendo así su vida y su comportamiento. La vida del hombre se convierte en una carrera maratónica para buscar confirmar su destino. Su conciencia estará abocada a tener presente en todo momento que por lo que haga o deje de hacer, será juzgado.

\footnotetext{
${ }^{88}$ Esta concepción de eficacia asociada a la idea del trabajo y a la predestinación terminó por asociar el trabajo con el bien, el ocio con la maldad, y considerar el mal uso del tiempo como actividades pecaminosas por estar desperdiciando un tiempo para dar gloria a Dios. Esto ayudó a manipular la concepción del trabajo moderno.
} 
De esta manera, Calvino buscó fundir lo mundano con lo divino. Las acciones tienen peso de eternidad o de condenación en la medida que éstas reflejen la elección del hombre. La profesión -entendida como actividad convocada por mandato divino - consiste en el ejercicio del trabajo que busca dar gloria a Dios mediante la acumulación de bienes y riqueza. Esto pone las bases de una concepción del trabajo distinta. Este control metódico del puritanismo ${ }^{89}$ convierte toda la vida del hombre en una actividad profesional. El trabajo no sólo es una construcción vital, sino también moral. El fruto de esta concepción del trabajo, que racionaliza toda acción, fue la acumulación intensiva de bienes de capital y de dinero destinado a la inversión.

Para Weber (2007) entonces, el efecto combinado de la austeridad frente al consumo y exaltación de acumular riqueza como signo de predestinación salvadora tendrá como efecto final la formación del capital. Ya que las utilidades no podían derrocharse había que invertirlas, terminando por redundar en una reinversión del ahorro en capital. Esta conducta racional que el puritanismo impulsó se tradujo en una formación de capitales, y esto fue la antesala del homo economicus (Hopenhayn, 2001). Teniendo esto presente, ¿puede ser el individuo autónomo, capaz de desarrollarse desligado y condicionado por esta realidad?

\subsubsection{La autonomía del hombre desde la Teoría Administrativa}

Proviene del griego auto (uno mismo) y nomos (norma). La palabra designa, en términos generales, la capacidad de controlar, afrontar y tomar por propia iniciativa decisiones personales acerca de cómo vivir de acuerdo con las normas y

\footnotetext{
${ }^{89}$ Se entiende aquí puritano no como el movimiento político y religioso surgido en la Inglaterra en el siglo XVII que defendía los preceptos anglicanos, sino como una actitud la cual busca comportarse de acuerdo con una extremada rigurosidad moral.
} 
preferencias propias así como de desarrollar las actividades básicas de la vida diaria ${ }^{90}$.

Lo que se entiende como autonomía, ya introducida desde la óptica económica, proviene de la filosofía y la psicología, la cual expresa la capacidad para normarse a uno mismo sin influencias externas o internas. En ese sentido, se opone a cierto determinismo que aboga por ejercer la libertad como característica intrínseca que particulariza al individuo como ser humano. Es pertinente recorrer tal concepción desde la llamada Teoría Administrativa para ver su desarrollo y las implicaciones que trajo para la administración como tal.

Con la Revolución Industrial en el siglo XVIII la razón cambia de propósito. De usar dicha razón en relación con la especulación, en el afán del hombre por comprender el argé ê $^{1}$, aquello inmutable y que por ende podría dar explicación de la realidad (Maritain, 1981); pasó a convertirse en el efecto multiplicador de las acciones técnicas, diversificándolas en extremo, para obrar en función de resultados. De esta manera, la razón queda al servicio de la eficacia como fin preciso de las técnicas, que busca un resultado, eliminando así todo tipo de especulación.

${ }^{90}$ Esta definición no es la única. Según la RAE, la palabra es utilizada recurrentemente como sinónimo de auto-organización. Se refiere entonces al proceso en el cual la organización interna de un sistema abierto aumentará la complejidad sin la necesidad de ser guiada por ningún agente externo. El término también designa aquella potestad que ostentan ciertos entes territoriales para regirse con normas propias en el marco de un Estado Mayor. La autonomía, en este sentido, constituye una forma de soberanía. Por otra parte, en el contexto del derecho, la palabra autonomía goza de una especial participación. Se le designa como la capacidad que tiene el individuo de dictarse sus propias normas morales. Finalmente, en el ámbito de la técnica, la autonomía es el tiempo que un dispositivo con una fuente de alimentación independiente puede permanecer activo hasta el agotamiento de su fuente de alimentación.

${ }^{91}$ Así por ejemplo: para Tales será el agua; para Anaximeno, el aire; para Heráclito, el fuego; para Anaximandro, el infinito (indeterminado, mezcla de todos los contrarios). Así, estos elementos son considerados como seres activos, vivos, animados, capaces - por una fuerza interior propia- de una fecundidad multiforme e ilimitada (Maritain, 1981). 
La administración surge desde una idea de razón cuyo sentido teleológico es claro: generar algún tipo de rentabilidad por medio de los recursos confiados ${ }^{92}$. Incluso, dicho imperativo económico se ha convertido en sí mismo en un símbolo administrativo, poniendo, ideológicamente como fin, la racionalidad privilegiada del lucro ${ }^{93}$, que la administración ha sabido asumir muy bien como su propio objetivo.

Esta racionalización ha sido aplicada de diversas maneras por los representantes y promotores más eximios de la $\mathrm{TA}^{94}$. La mano invisible de Adam Smith (17231790) ${ }^{95}$, de quien bien podría afirmarse que la administración encuentra en su propuesta económica uno de sus fundamentos, regula de manera implacable e invisible todo aquello que constituye la trama del funcionamiento y evolución de la economía. Adam Smith (2004) pone las primeras bases para cimentar el capitalismo e introduce los conceptos de competencia y libre mercado para tratar de explicar la rueda lógica económica por la cual la sociedad se rige. Haciendo énfasis en la división del trabajo, subdivide las tareas en las más elementales posibles, buscando con ello, no sólo acelerar la producción al incrementar las habilidades de las personas, sino que prepara el terreno para reducir y someter al ser humano a la fuerza invisible de la instrumentalización racional de la eficiencia.

92 En este proceso, el hombre mismo es considerado y reducido a un recurso privilegiado. El mismo término recurso da cuenta de ello. Proviene del latín resurgere, el cual significa: "volver a levantarse". El término implica la idea de algo disponible a lo que se puede recurrir cuando es necesario. En el ámbito administrativo, el hombre sería un recurso que se agota y por lo tanto es necesario reemplazarlo. Así como la batería se agota y deja de ser productiva, el reemplazo del recurso humano es necesario para evitar que la productividad se vea afectada.

${ }_{93} \mathrm{Al}$ respecto Alain Chanlat es contundente al afirmar lo siguiente: "Vivimos hoy en día en un mundo dominado por la ideología económica y los imperativos de la administración [...]. La racionalidad económica, con el desarrollo del mercado, se hace cada vez más autónoma frente a las otras racionalidades, y termina por imponer su propia lógica [...]. Esta racionalidad privilegia el lucro, la rentabilidad [...]; otorga un sitial preponderante al cálculo y a la medición" (citado por Aktouf, 1998, p. 7).

${ }^{94}$ Se desarrollarán, brevemente, los principales exponentes de la Teoría Administrativa. No se pretende abordar a profundidad este tema, tan sólo relacionar esta tecno-racionalización a modo de ilustración. Así mismo, y en relación con los fundamentos de la Administración se puede revisar: Merrill (2000), Podestá y Jurado (2003) y Bédard (2003, 2004), entre otros.

${ }^{95}$ Si bien, Adam Smith, no es propiamente uno de los representantes de la Teoría Administrativa, su propuesta económica sienta las bases para la racionalización del trabajo, aspecto para lo cual la administración propondrá una serie de prácticas e instrumentos para su fortalecimiento y divulgación. De ahí que se inicie esta reflexión haciendo una breve mención a su propuesta teórica. 
La dinámica de la competencia y el libre mercado dinamizan la satisfacción del interés personal haciendo que todos los individuos entren a competir. Pero dicha competencia es de por sí egoísta. La idea es que cada hombre debe ser libre de perseguir sus propios intereses para que así se alcancen los intereses colectivos de la sociedad. El Mercado es omnipresente y esta absolutización de la realidad permea las relaciones interpersonales así como las conciencias de las personas a un fin externo al hombre. La mirada está puesta en el mercado al convertirse en el fin último del trabajo humano, y a quien a su vez, le debe la existencia misma. El hombre queda sometido a una fuerza con carácter divino. No hay lugar a la réplica, sólo una obediencia radical e incondicional a su lógica le permite al individuo seguir compitiendo, y en ese sentido, seguir existiendo. Esta racionalidad superior tiene tras de sí, y contradictoriamente, una fuerte carga mítica: el Mercado y sus leyes deben seguir un libre curso, dado que la ley principal consiste en no seguir a ninguna.

Por otro lado, y siguiendo con las propuestas de los teóricos de la administración; Charles Babbage (1792-1871), plantea un principio de productividad fruto de la división del trabajo. Su postura radica principalmente en la necesidad de comprar la exacta cantidad y calidad del trabajo necesario para cada tarea precisa, permitiendo así, una mayor subdivisión del trabajo ${ }^{96}$.

Al contrario de la intención de Taylor (1856-1915), la llamada Administración Científica del Trabajo proporcionó un método de control sobre el empleado: individualizar, separar, desagregar, cronometrar e imponer un contenido de tareas

\footnotetext{
${ }^{96}$ Una extensión de este principio que reduce al ser humano a una parcialización humana se nota cuando Henry Ford expresa lo siguiente respecto a las 7.882 operaciones necesarias para la construcción de un automóvil modelo T: "[...] 949 exigen hombres vigorosos, robustos y prácticamente perfectos desde el punto de vista físico: 3.338 hombres de una fuerza física simplemente común; casi todo el resto puede ser confiado a mujeres y niños grandes: 670 operaciones pueden ser realizadas por lisiados; 2.637 por cojos; 2 por hombres amputados de ambos brazos; 715 por mancos, y 10 por ciegos" (Aktouf, 1998, p. 43). La integridad del ser humano desde su unidad y proyección se ve reducida a sus habilidades parciales no integradas, buscando que la simpleza y la especificidad le permita ser eficiente para responder a la exigencia rentable de un mercado que lo ha sometido a la impersonalidad y el anonimato.
} 
en donde este empleado no es sino una reserva energética de intercambiable voluntad (Aktouf, 1998). Es una visión mecanicista que se centró en los aspectos instrumentales del comportamiento humano, al considerarlo como un elemento de producción (Dávila, 2001).

Fundador de lo que se ha llamado one best way (la mejor manera de hacerlo), Taylor, retoma el concepto del homo economicus (Friedmann, 1956; Brown, 1963; Morin, 2005), para plantear la hipótesis de que la naturaleza humana sólo está motivada por el deseo de maximizar racionalmente las ganancias materiales. De esta manera, la calificación del individuo estará mediada por la capacidad de poder cuantificar un determinado valor a su humanidad, cuyos actos se condicionan por el incentivo de la utilidad y el interés (Marin, 2006). A pesar de que para Taylor (1961) la máxima prosperidad es el objeto de la administración y la eficiencia se da cuando una persona da su máximo rendimiento diario, Taylor buscó transformar cualquier esfuerzo de los empleados en reflejos condicionados, expresión última de la división técnica del trabajo y del entorpecimiento del trabajador $^{97}$.

Henri Fayol (1841-1925) se convierte en el segundo pilar del pensamiento administrativo. Basa su teoría en la sistematización del trabajo, organizando las experiencias empíricas del momento ${ }^{98}$. Para Fayol "[...] se le otorgaba demasiada importancia a cinco de las operaciones (técnicas, comerciales, financieras, de seguridad y contabilidad) realizadas en el marco de cualquier empresa frente a una sexta función que era seriamente descuidada, que no es otra que la función

${ }^{97}$ Cabe mencionar que se le puede atribuir a Taylor como el pionero en concebir el concepto de subordinación dentro de la organización. La división entre obreros y patrones, y la relación tan piramidal y jerárquica que se deja ver en sus textos expresa la autoridad y el sentido de obediencia que deben de poseer los obreros para poder realizar las tareas en forma científica. Dicha relación trasciende la esfera meramente práctica para trasladarse al plano de la naturaleza del obrero. En la división que hace Taylor entre los que piensan y los que hacen, se vislumbra también una estratificación que genera diferencias insalvables.

${ }^{98}$ Fayol (2003) desarrolló un concepto para el término organización (cuerpo social más cuerpo material) y en esa medida, además de su propuesta administrativa como tal y de sus complementariedades con la tayloriana, resultó ser pionero en la teorización en torno a la organización propiamente dicha como categoría aparte. 
administrativa" (Aktouf, 1998, p. 75). Esta última no entra en el marco de las anteriores sino que las engloba. Dicha función -la administrativa- tiene la misión de desarrollar el programa general de acción de la empresa, construir su cuerpo social, coordinar esfuerzos y armonizar los actos.

Buscando tal objetivo, Fayol establece recomendaciones para fijar el modo óptimo de la organización formal, basándose en principio ${ }^{99}$ (elabora 14), procedimientos y capacidades, buscando conformar un armazón funcional entre quienes dirigen los planes y quienes ejecutan las tareas. Según Fayol, "[...] en todo género de empresa, la capacidad esencial de los agentes inferiores es la capacidad profesional característica de la empresa, y la capacidad esencial de los altos jefes es la capacidad administrativa" (Fayol, 2003, p. 139).

Para el sociólogo y filósofo alemán Max Weber (1865-1920), la burocracia ${ }^{100}$ se interesa en mostrar cómo pueden ser superadas las posibilidades de decisión de los empleados mediante la utilización de técnicas racionales. La meta es llegar a un estado de previsibilidad pura la cual permita que todos los comportamientos de la organización sean fáciles de predecir (Weber, 1997). Morgan (1998) expresa esta idea al relacionar la organización con una máquina que busca ser eficiente, exacta y predecible ${ }^{101}$.

\footnotetext{
99 Al igual que Taylor, Fayol hace también una división entre aquellos que dirigen y los que obedecen. Dávila (2001) hace una clasificación de los 14 principios de Fayol y los agrupa en poder (7), agentes del cuerpo social (5) y trabajo y su remuneración (2). Hay que resaltar que la mayor subdivisión la tienen aquellos principios que hacen referencia al tema del poder. El tema de autoridad, disciplina, centralización y unidad de mando, aúnan - a la vez que refuerzan - la distancia entre los dirigentes y los obreros.

${ }^{100}$ La burocracia cobra vida a través de un cuerpo administrativo, por lo que es la forma (más moderna) de organización técnicamente más pura de dominación legal racional (organizacional y socialmente), cuyo fundamento se localiza en la racionalidad de las reglas.

${ }^{101}$ Ilustra mucho el trabajo que hace Marín (2006) con relación al desconocimiento de las personas a que lleva la burocracia. Afirma que: "En todo caso, frente a las características propias de la burocracia, sustentadas principalmente en la división del trabajo, la delimitación específica de tareas y competencias, la normalización de los procesos, la formalización jerárquica, la impersonalidad y afectividad neutra, el desarrollo de carrera y la estructura salarial según niveles escalares, el sujeto humano se encuentra anclado a un puesto al cual ha sido ajustado 'a la medida', como una pieza de rompecabezas encajable, gracias a que ha perdido su creatividad e
} 
Los trabajos de Elton Mayo (1880-1949) iniciarán desde los años 30, una nueva corriente administrativa moderna llamada: "Las ciencias del comportamiento organizacional". Esta buscará dar herramientas instrumentales al administrador con el objetivo de crear y mantener un clima laboral propicio para poder intervenir a las personas y buscar una mayor productividad, eficiencia y rentabilidad ${ }^{102}$.

De esta manera, el factor humano cobró gran importancia debido al surgimiento de los elementos de orden afectivo y emocional que eran tan importantes para la productividad como los incentivos materiales y/o económicos. Así, el ser humano no puede ser tratado como lo pretendía la Organización Científica del Trabajo (OCT en adelante), en donde como una pieza más del engranaje organizacional, el hombre tenía que trabajar especializándose en sus funciones buscando ser lo más eficiente posible. Ese factor humano tenía la necesidad de sentirse involucrado, considerado y motivado. Paradójicamente, Mayo y en especial sus seguidores ${ }^{103}$, verán al individuo no desde su individualidad, sino como un factor, lo cual hace que se le ponga al nivel de cosa o de objeto, tal como los autores de la OCT lo propiciaron ${ }^{104}$. Al movimiento de Mayo se le denominó humanización del trabajo y de la industria, pero muy pronto se derivó en una industrialización de lo humano ${ }^{105}$.

inventiva y a que ha quedado sometido a una rutinización progresiva, a una incapacidad disciplinada" (p. 149).

${ }^{102}$ Los trabajos de Hawthorne (1924-1928) se realizaron debido a un descenso en la productividad expresado sobre todo en el pesimismo y en el ausentismo.

${ }^{103}$ Los principales continuadores de Mayo fueron (en orden cronológico): Kurt Lewin, Abraham H. Maslow, Chris Argyris, Rensis Likert y Douglas McGregor.

${ }^{104}$ Esta racionalidad instrumental termina por desconocer al individuo dentro de la organización, lo que deriva en lo que algunos autores han llamado: "El lado inhumano de las organizaciones". Sobre este aspecto, de por sí interesante y pertinente con lo que se viene discutiendo, se puede consultar: Cruz Kronfly (2003, 2008), Marín (2007), Cruz Kronfly y Rojas (2008).

${ }^{105}$ Ejemplo de ello es la propuesta de Mayo en cuanto a la filosofía de la comunicación como espacio para satisfacer las necesidades del trabajador. Dicha filosofía se transforma en un espacio de propaganda al servicio de la organización. La comunicación empleados-dirigentes se convirtió en una operación de supervisión y cuasi espionaje de empleados, buscando descubrir a partir de las herramientas de Mayo, el grado de lealtad u hostilidad que tenían los empleados hacia la compañía. Junto con lo anterior, el tema de la participación como mecanismo de consulta devino en una práctica de manipulación destinada a aceptar mejor los cambios, las restricciones y demás 
Esta aparente preocupación por lo humano marca el inicio -entre 1925 y 1945- de un movimiento que daría inicio a la Teoría de la Organización (TO) ${ }^{106}$ : Las Relaciones Humanas (Ibarra y Montaño, 1990), pero sobre todo, a la inclusión de diversas áreas del saber, como la filosofía, la sociología, la antropología y la psicología buscando articular las variables o factores humanos presentes en la organización con el objetivo de lograr una mayor productividad (Ibarra, 2006). La búsqueda de un paliativo para poder remediar las insuficiencias que la complejidad del individuo trae elevará la búsqueda incesante -por parte de los dirigentes- de ciertas recetas de how to orientadas a satisfacer tales necesidades. Así, el movimiento de las Relaciones Humanas pondrá al servicio de los directivos el factor humano, condicionándolo como recurso operativo al servicio de la organización.

Este movimiento no contradice los planteamientos de la Administración Científica, ya que su aproximación al comportamiento humano como tal estará teñida por una aproximación técnico instrumental propia de una razón subjetivada y atada a los principios e ideales de la maximización de la riqueza del capital industrial. Así, la TO buscará proponer un debate acerca de las organizaciones mediante la combinación de una visión individual y las técnicas de producción ubicadas dentro de un contexto socio-histórico particular. "En resumen, la Teoría [Organizacional] es una práctica históricamente situada intelectualmente, dirigida a movilizar el montaje y material ideacional, y los recursos institucionales para legitimar las afirmaciones de conocimiento cierto y los proyectos políticos que se derivan de ellos" (Reed, 1996, p. 33).

Sin embargo, el tema de la racionalización subjetiva vigente en la Teoría Administrativa, estará aún presente en dichas corrientes. El racionalismo tendrá

medidas que sin estas participaciones habrían sido impopulares o difíciles de implementar (Aktouf, 1998)

${ }^{106}$ Para revisar un panorama sobre las diversas maneras de concebir el desarrollo de la Teoría de la Organización se puede consultar: Clegg, Hardy y Nord (1996); Clegg y Dunkerley (1980); Hall (1996); Hatch (1997); Ibarra y Montaño (1986 y 1992); Mouzelis (1975); Perrow (1991); Pfeffer (1992, 2000); Reed (1996); Silverman (1975), entre otros. 
una fuerte influencia en el desarrollo conceptual del análisis organizacional. Así, "[...] la organización se convierte en una herramienta o instrumento para la autorización y realización de metas colectivas a través del diseño y la gestión de estructuras dirigidas por la administración y la manipulación del comportamiento organizacional” (Reed, 1996, p. 36).

Para Montaño (2012) es la eficiencia la que dio inicio a la nueva disciplina llamada Administración. La división del trabajo se convierte en un aspecto importante de las distintas propuestas de la TA (como se ha querido mostrar) para lograr la eficiencia productiva. Para este mismo autor, la aparición del texto de Taylor es el inicio de la administración como ciencia de la eficiencia y ha marcado significativamente la evolución del mundo de las organizaciones y de la sociedad.

Teniendo esto como marco, ¿el tema identitario se ha convertido en un nuevo interés a ser gestionado? ¿La IO será una variable más de gestión, en donde las técnicas administrativas buscarán adecuar los procesos identitarios para buscar nuevamente una rentabilidad de los recursos confiados?

\subsection{4. ¿Una nueva modalidad de ergonomizar (controlar) el alma?}

Dentro de las organizaciones llamadas modernas, la concepción del trabajo, o más específicamente, del hombre trabajador ha tomado dimensiones distintas, y por lógica consecuencia, su administración ha variado, como se ha desarrollado en los acápites anteriores. La aplicación del conocido proceso administrativo (PODC), centrado sobre todo en el control de los procesos de trabajo se ha modificado para enfocarse en gestionar aspectos por fuera del horario laboral, e incluso dentro del ámbito interno (familiar o personal) del trabajador.

En muchas organizaciones contemporáneas, por ejemplo, el gerente se enfrenta a un desafío ético. Por un lado, la organización espera de él a un hombre nuevo (Linstead y Thomas, 2002) con un balance individual (Meriläinen S., Tienari, 
Thomas y Davis, 2004), que le permita pasar más tiempo con su familia y ayudar con las responsabilidades del hogar. Por otro lado, este mismo gerente busca ganarse un lugar en la organización, mostrando por medio de su trabajo que está comprometido, siempre disponible y dispuesto a trabajar horas extras a las jornadas laborales (Eräranta y Moisander, 2011).

Algunas investigaciones han buscado comprender este dilema de confrontaciones duales mediante la construcción de identidades. En este contexto, la gestión identitaria se convierte en una herramienta de control para mantener estas tensiones en su justa medida, pero sobre todo, y dentro del ámbito netamente organizacional, para que tal disyuntiva no vaya en desmedro de la eficiencia y el rendimiento del trabajador, al buscar una fidelización e identificación con la organización.

En relación con las distintas formas que han buscado controlar al individuo, Carson, Lanier, Carson y Guidry (2000) revisaron 16 modas de gestión en los últimos cinco decenios. Examinaron las relaciones entre los ciclos de vida y las variables económicas y de penetración para comprender el surgimiento, difusión y decaimiento de estas modas de gestión. Los resultados de la investigación sugieren que las modas más recientes tenían una mayor amplitud y alcance, pero de más corta duración y más difíciles de implementar para la alta dirección. A continuación se presentan cada una de las modas de gestión estudiadas por estos autores en las décadas respectivas: 
Tabla 16: Tendencias de gestión desde 1950 al 2000

\begin{tabular}{|c|c|c|c|c|}
\hline 1950 's & 1960 's & 1970 's & 1980 's & 1990 's \\
\hline 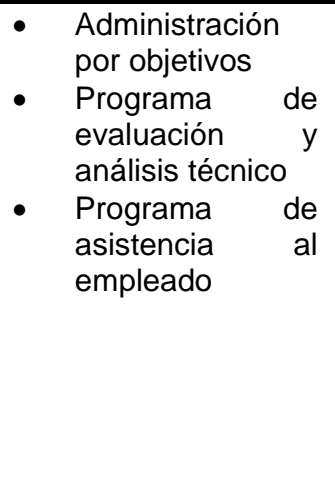 & $\begin{array}{l}\text { - Sensibilidad } \\
\text { y formación } \\
\text { de grupos T }\end{array}$ & $\begin{array}{l}\text { - Calidad de } \\
\text { los } \\
\text { programas } \\
\text { de la vida } \\
\text { social } \\
\text { Círculos de } \\
\text { calidad }\end{array}$ & $\begin{array}{ll}\text { - } & \text { Cultura } \\
& \text { corporativa } \\
\text { - } & \text { Gestión de } \\
\text { la calidad } \\
\text { total } \\
\text { - Estándares } \\
\text { internacional } \\
\text { es de } \\
\text { organización } \\
9000 \text { (ISO } \\
9000) \\
\text { - Evalución } \\
\text { corporativa }\end{array}$ & $\begin{array}{ll}\text { - } & \text { Empoderamiento } \\
& \text { de los empleados } \\
\text { - } & \text { Corporaciones } \\
& \text { horizontales } \\
\text { - } & \text { Visión } \\
\text { - } & \text { Reingeniería } \\
\text { - } & \text { Estratégias } \\
& \text { flexibles } \\
\text { - } & \text { Competencias } \\
& \text { básicas }\end{array}$ \\
\hline
\end{tabular}

Fuente. Carson, Lanier, Carson y Guidry (2000).

Vale la pena rescatar la presencia en este estudio de modas que tuvieron un fuerte impacto en la gestión como son la cultura corporativa, la reingeniería, la gestión de calidad. Junto con ello sólo resaltar que este tipo de prácticas administrativas están direccionadas a intervenir aspectos del individuo que abarcan su ámbito externo, muy en la línea de las propuestas tayloristas y fayolianas.

Carson, Lanier, Carson y Guidry (2000, p. 1143-1144) definen las tendencias o modas de gestión a partir de los siguientes criterios:

- Tienden a manifestarse como un contagio social, ya que estas modas son nuevas y se perciben como progresivas o preferibles a las tendencias ya existentes.

- Son o se perciben como innovadoras, racionales y funcionales.

- Están dirigidas a fomentar un mejor desempeño ya sea material o en forma simbólica.

- Son motivadas por un deseo de subsanar algunas deficiencias operacionales existentes o aprovechar las capacidades de mejora y, 
- Son consideradas por tener un valor transitorio ya que a pesar de tener un período de aceptación, ningún estudio sistemático y exhaustivo legitimiza su utilidad prolongada.

¿Es la construcción de 10 una nueva moda administrativa que se consolida a su vez como una nueva forma de control cuyas acciones están direccionadas a aspectos más interiores del hombre?

Las promesas de la modernidad de constituir una nueva condición humana no fueron cumplidas. Estas promesas estaban basadas en un entusiasmo desbordante por el conocimiento y la tecnología. Sin embargo:

Evidentemente que estas promesas no han sido cumplidas: el conflicto, en la escena mundial, es creciente y la fuerza bruta, dado el impresionante desarrollo tecnológico de la industria militar, es cada vez más mortífera. La cultura, en su sentido civilizatorio, es decir, como establecimiento de formas refinadas de convivencia que apaciguaran el temor al otro, debería haber sido una acompañante fiel en las andanzas de la modernidad, conteniendo los impulsos destructivos de los individuos. La cultura, en su sentido antropológico, mal leído desde el territorio organizacional, en tanto cultura corporativa, prometía la concordia mediante la inculcación de principios éticos y valores compartidos. (Montaño, 2008, p. 336).

Lo Modernidad, en el contexto administrativo, instrumentaliza al individuo a través del uso del conocimiento técnico-científico para lograr resultados predecibles medidos por la productividad y la solución de problemas técnicos, buscando con ello acceder a una buena vida económica y social, logrando la acumulación de riqueza por medio de la inversión y el consumo. Esto permite abordar el problema de la reificación de la identidad y la gestión administrativa que busca su control.

En este sentido, el control identitario se logra (o al menos eso se espera) mediante el diseño y la aplicación de estructuras, procedimientos, medidas y objetivos organizacionales. La resistencia a estos mecanismos (catalogados muchas veces como síntomas) busca ser rectificada mediante la reestructuración del personal o por medio de la implementación de un proceso formativo. Se trata de considerar el control como un ejercicio en donde se fabrica la subjetividad (Knights y Willmott, 
1989; Barker, 1999; Deetz, 1992, 1994 entre otros). Sin embargo, esta búsqueda por la regulación es una modalidad cada vez más intencional de control organizacional, sin decir con ello que éste sea eficaz al aumentar el compromiso o la lealtad de los empleados (Alvesson y Willmott, 2002). Incluso, el efecto que ésta produce, puede amplificar el cinismo, promover la disidencia o catalizar la resistencia (Ezzamel, Willmott y Worthington, 2000).

Las nuevas formas de control buscan procesar la subjetividad con el objetivo de constituir trabajadores no sólo más adaptables sino capaces de moverse rápidamente entre actividades y tareas con orientaciones diversas. Sin embargo, en la práctica, esta fluidez y fragmentación identitaria puede hacer que los empleados sean más vulnerables a la tipificación de las identificaciones corporativas. Es dentro de este contexto, en donde la fabricación identitaria se convierte en un aspecto más a gestionar dentro de las organizaciones.

Frente a la dificultad por constituir un equipo de trabajo cohesionado e involucrado con los nuevos retos de la compañía, los directivos implementan una serie de acciones buscando que los MM se identifiquen con su equipo de trabajo en los FC y sean eficientes en el funcionamiento del modelo de gobierno. En ese sentido, el individuo, y la misma identidad que él construya, la cual es inducida y controlada para evitar, entre otras cosas, seguir apegada a las OO, manifiesta la utilización del individuo como fin, posición inscrita en el racionalismo moderno instrumental, que no sólo se reduce a sus acciones, sino que sus relaciones, en donde se inscribe el proceso de construcción identitario también serán sometidos a la misma lógica instrumental. En ese sentido, la fabricación y control indentitarios se encuentran sometidos a una práctica reificante. En este punto vale la pena aclarar y puntualizar el concepto de reificación. Éste se entiende como:

[...] una clase de hábito de pensamiento, de perspectiva habitual petrificada, en virtud de cuya adopción los hombres pierden su capacidad de implicarse con interés en las personas y en los sucesos, y en consonancia con esta pérdida [...] los sujetos se transforman en observadores puramente pasivos a quienes no sólo su entorno social y físico, sino también su vida interior, les debe aparecer como un conjunto de 
entidades cósicas. Como podemos comprobar retrospectivamente, [...] la reificación es entonces tanto un proceso como un resultado; con ello se designa el proceso de una pérdida, concretamente de la sustitución de una actitud original correcta por otra secundaria, incorrecta, y el resultado de este proceso, es decir, una percepción o una forma de conducta reificada. (Honneth, 2005, pp. 84-85).

La reificación a la que están sometidos los sujetos es un proceso que tiene como base el desconocimiento del otro, el cual corre el riesgo de volverse un aspecto cultural dentro de la sociedad (Honneth, 2009). En este tenor, muchas investigaciones han buscado reconocer las prácticas institucionalizadas que llevan a una desvinculación del propósito de la observación social dentro de las organizaciones, o de esquemas de pensamiento socialmente efectivos que imponen una negación del reconocimiento previo del otro. La acción reificante no sólo se reduce a una cosificación o consideración del individuo, sino que involucra un proceso social en donde la construcción en sí misma es sujeta a una instrumentalización propiciando una cultura en donde la justificación por conseguir los fines permite todo tipo de desconocimiento de quién es el otro, tanto en su individualidad, como en los procesos sociales que realiza para desarrollarse en sociedad.

Mirado desde esta perspectiva, el estudio del comportamiento humano sirvió para la creación y aplicación de modelos, técnicas y herramientas con el fin de influir en el comportamiento del individuo. Es por eso que a la corriente del comportamiento humano dentro del estudio de las organizaciones se le denuncie como un campo heterogéneo que ha tenido un desarrollo aislado, dejando de lado las ciencias humanas. Esta nueva lógica racional impone como condición categórica eludir, a como dé lugar, discusiones sobre realidades singulares que puedan parecer como racionales por sí mismas. "La idea de razón queda sometida a la regulación de medios y fines, a la caracterización de un acto; a la vez que se vacía la posibilidad de determinar los límites de la acción humana" (Cruz y Rojas, 2008, p. 21). Así, el individuo será entendido como cosa, será reificado. 
Las prácticas administrativas han buscado desarrollar una serie de procesos para buscar el control del individuo, muchas veces manipulándolo a manera de cosa, otras veces, tratando de intervenir su entorno externo -así como sus aspectos internos - para que su productividad no decaiga. Siguiendo a Montaño (1987), estas prácticas promovidas por los llamados psicólogos sociales de la corriente de las Nuevas Relaciones Humanas ${ }^{107}$, buscarán una relación democrática falsa, en donde se impulsará la participación ilusoria de los individuos en el nivel conceptual y se promocionará su participación real en el desempeño de sus actividades.

\begin{abstract}
El comportamiento exigido en la organización requiere de un doble control: material e inmaterial. La verdadera intención de la Psicología Industrial, en sus diversas variantes, es el control de los aspectos incorpóreos del individuo: sus lazos afectivos, sus creencias y valores, su subjetividad. Todos los aspectos materiales son religiosamente deleznables: el individuo debe trabajar por objetivos sociales humanistas como los que dicen tener las grandes empresas progreso social, desarrollo de tecnologías en beneficio de la humanidad, atención de necesidades de las mayorías, en beneficio del país, etc.- Némesis organizacional que traiciona al hombre en la búsqueda de la verdad. (Montaño, 1987, p. 34).
\end{abstract}

Para Montaño (1987), estos psicólogos industriales son los ergónomos del alma, quienes buscan el control alternativo por medio de las máquinas. Este control se centra en lo inmaterial, en aquello que responde al fuero interno del individuo. En términos de McGregor (1972), -al igual que lo hace López (2009)- estas prácticas se pueden clasificar en dos: En primer lugar se registra en el contexto organizacional un estilo administrativo de corte vertical y autocrático. Esta dirección autoritaria busca ejercer desde afuera el control de los individuos dentro de la organización. En segundo lugar, es posible encontrar también otro estilo que ha venido promulgando una forma de gerencia humanista, expresada en el discurso de cambio organizacional y de la transformación personal de los individuos. Este estilo busca el control de los individuos desde adentro, es decir, a partir de la vigilancia de las dimensiones individuales y ajenas al mundo del trabajo, donde se inscriben las costumbres, los modos de vida, valores, etc.

\footnotetext{
${ }^{107}$ Al respecto se puede revisar los comentarios que hace Montaño (1991) en relación con las falsas promesas de los investigadores de las Nuevas Relaciones Humanas. Así mismo se puede consultar: McGregor (1972), Maslow (1970), Herzberg (1966), Likert (1961) y Argyris (1975).
} 
Este tipo de acciones tiene como relato la limitación y el alcance de las decisiones de los empleados. En ese sentido, la "libertad acotada es en realidad una libertad «relativa», o más bien la percepción de una libertad inexistente" (Montaño, 1991, p. 84). Al buscar controlar aspectos desde el interior del sujeto, se configura un ideal de bienestar y participación democrática que lo que busca es una identificación ideológica del individuo con las normas impuestas, más no un espacio de desarrollo y acción.

Las propuestas normativas desde adentro han compartido la idea de que los resultados y la consecución de los objetivos empresariales se alcanzan por la vía del supuesto énfasis en lo humano, es decir, a diferencia de las teorías desde afuera, que depositan su confianza en el énfasis en las tareas, los resultados, los procesos, etc., las prácticas desde adentro "[...] se enfocan en la afiliación, las relaciones interpersonales, el espacio para el intercambio de palabras y afectos, el trato amistoso para, supuestamente, generar motivación, entusiasmo y compromiso en el personal" (López, 2009, p. 254).

Pero estas propuestas orientadas desde adentro -llamadas también teorías $\mathrm{Y}, \mathrm{o}$ democráticas-, tienen cierta contradicción con la praxis. La intención y los predicamentos que anuncian, y las retóricas que promulgan la consideración y la satisfacción del sujeto en el trabajo no son más que sofisticados intentos de alienación. Lo anterior se vislumbra en la siguiente gráfica: 


\section{Gráfica 18: Formas de control}

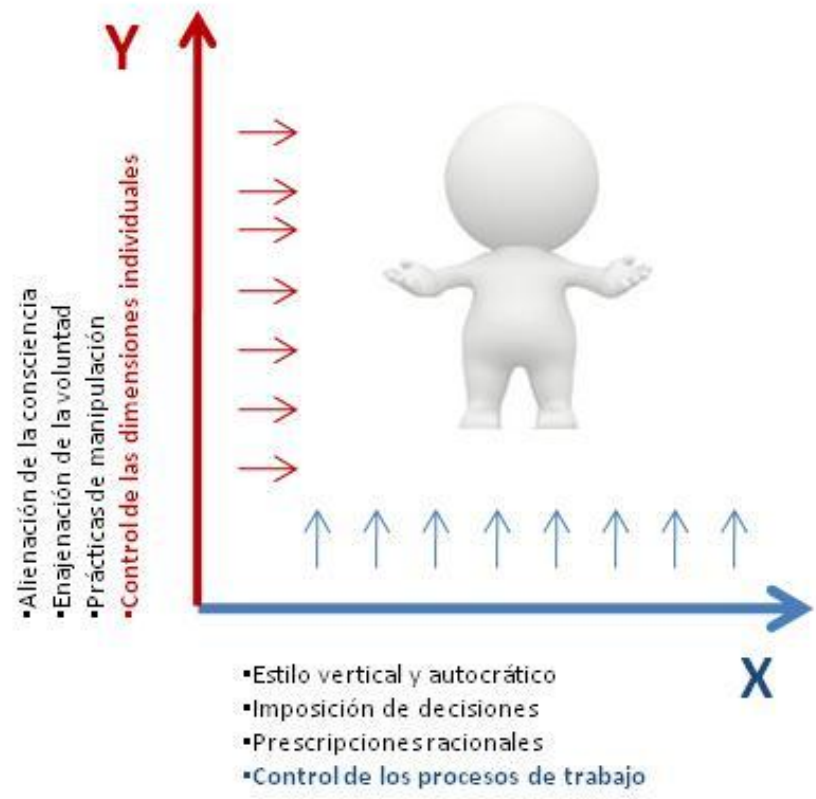

Fuente: Elaboración

propia.

Los estudios de la identidad - que tienen una influencia directa en el control de la organización - incluyen el análisis de fenómenos a nivel institucional y a otros fenómenos a nivel macro (Albert y Whetten, 1985; Christensen, 1995; Czarniawska-Joerges, 1994), así como los estudios que se concentran en los sujetos y las formas de identificación y subjetivación (Alvesson, 2000; Deetz, 1992). La regulación de la identidad abarca los efectos intencionales de las prácticas sociales en los procesos de construcción y reconstrucción de identidad, particularmente los procedimientos de inducción, capacitación y promoción en las organizaciones.

La identidad "no es un rasgo distintivo o incluso un conjunto de rasgos poseídos por el individuo. Es el sí mismo como reflejo comprendido por la persona... la propia identidad es continua (a través del tiempo y del espacio) como una interpretación reflexiva por parte del agente" (Giddens, 1991, p. 53). El trabajo de la identidad es relativamente inconsciente, dependiendo, claro está, del discurso, medio por el cual la identidad se reproduce. 
En ese sentido y siguiendo a Alvesson y Willmott (2002) se pueden agrupar las prácticas de control de la identidad por medio del discurso, en las siguientes: (1) Aquellas referidas al empleado. El empleado es definido por la misma organización, o es definido por medio de otros individuos. (2) Las orientaciones de la acción. Se definen a través de un vocabulario específico, explicando la moral y los valores o proporcionándole conocimientos y herramientas. (3) Las relaciones sociales. Se definen por medio de la pertenencia y la diferenciación. En ese sentido, se le categoriza dentro de un grupo el cual lo afilia, y se le establece dentro de un orden jerárquico específico. (4) La escena. Son aquellas regulaciones que indican el tipo de identidad que se ajusta al contexto social, al terreno organizativo y económico en el que el sujeto opera. Así, se definen a partir de la claridad y la distinción de las reglas de juego y a partir del contexto. Dentro de este marco, la fabricación y el control identitarios se les puede clasificar dentro del control que apunta a aspectos más internos, tipo $Y$.

\subsubsection{Una búsqueda de control identitario en negación}

Para los directivos de $\mathrm{CN}$ el proceso de construir o fabricar una $\mathrm{IO}$ está mediada irremediablemente por la imagen o el recuerdo que tienen de las $\mathrm{OO}$ de donde provenían. Concretamente por el referente en que se convierten dichas organizaciones en la forma de gestionar, y el liderazgo que estos mismos directivos ejercían con sus equipos de trabajo. En ese sentido, la concepción de la IO propia de $\mathrm{CN}$, desde la concepción de los directivos queda en entredicho. Para muchos de los dirigentes, no existe una IO propia de la compañía, sino que a la sombra de las $\mathrm{OO}$ de donde también provienen los $\mathrm{MM}$, se está en el proceso de configurar, crear o construir una nueva IO, o al menos esa es la pretensión.

Nosotros traemos una carga desde los negocios que nos siguen acompañando de alguna forma y yo diría que lo que está haciendo $\mathrm{CN}$ es la construcción de una compañía nueva, la cual para mí tiene mucho valor, porque no es la sumatoria de los negocios anteriores, ni siquiera coger lo mejor de cada uno de los mundos y aplicarlo sino la constitución o la construcción de una nueva identidad y a mí eso me apasiona, me parece que eso es muy importante. (D1). 
Los atributos de CN (entendido como aquellos aspectos constitutivos de la compañía) están relacionados con las $\mathrm{OO}$ de donde provienen. Al realizar tal comparación, las características propias de $\mathrm{CN}$, no existen como tal, sino que son la añoranza y el recuerdo de ver reflejado en la actual compañía ciertas características de las OO. A esto hay que agregar que dependiendo del directivo, las referencias a las $\mathrm{OO}$ estarán sesgadas por dicha procedencia. Junto con esta particularidad, en donde está contextualizado el proceso de institucionalización por parte de los directivos al buscar crear o fabricar una 10 propia, se encuentran una serie de críticas al MG que se implementó. Estas críticas son importantes ya que son aspectos que se buscan remediar o subsanar en el momento de configurar una $1 O$ particular, de ahí que sea necesario profundizar en ellas.

Una primera crítica, que a su vez configura e interviene en el proceso de institucionalización, está en relación con el poder. EI MG no sólo permite que los MM accedan a ejercer el poder, dada la estructura y la filosofía del gobierno como tal, sino que el poder que los mismos MM tenían, se limitó. Muchos de los MM antes de pasar a convertirse en directores y con ello, a ser miembros del FC, fueron, en la estructura antigua de gobierno, gerentes regionales de alguna de las compañías de GN previas a la integración. Esto lo expresa uno de los directivos: "Entrevistador: ¿Y cuáles son los problemas en la línea media? Entrevistado: "Para mí, ellos no han terminado de sanar la pérdida de poder" (D4). Los directivos tienen que mediar y considerar esta situación de los MM, lo cual hace que no tengan a su vez, el poder total de decisión porque ellos mismos tienen que negociar sus rangos de acción en los FC. Es por eso, que ellos mismos tienden a repetir la estructura de poder anterior, rompiendo el esquema del gobierno actual.

Entonces, partiendo de ahí, si vos me preguntás si se refleja lo que pasa en el comité de presidencia yo te digo que sí, y se refleja en ambos sentidos porque yo siento que acá a veces no hemos terminado todavía tampoco de dar la vuelta y nos cuesta trabajo ser independientes y nos cuesta trabajo medir fuerzas en la discrepancia con $\mathrm{X}$ y con $\mathrm{Y}$ porque son los dos líderes digamos, de mayor trayectoria y de mayor fuerza, entonces a veces siento que ahí no nos metemos de frente. (D4). 
La otra gran crítica por parte de los directivos no sólo se concentra en la descualificación de los MM sino en los mismos gerentes que ocupan el Comité de Presidencia, es decir consigo mismos. Los entrevistados hacen hincapié en cuestionar los mismos procesos administrativos del nuevo MG de CN. En ese sentido, la descualificación del modelo no sólo se remite a los problemas de ajuste y adaptación, sino a los mismos procesos que no están siendo acompañados por la alta dirección.

Existe una fuerte crítica al modelo y a la misma compañía donde ésta no ha puesto los medios suficientes para promocionar y hacerle seguimiento a este proceso, de ahí que muchos MM no hayan hecho el esfuerzo necesario para adaptarse a la nueva situación de CN. Los MM se han quedado más unidos a los directivos que a la parte operativa, y han recibido un poder que no están en la capacidad de asumir y ponerse al mismo nivel que los colegas que forman parte del FC que tienen más experiencia y conocimiento.

\begin{abstract}
Frente a las metas que tenemos en el año 2013 no vamos bien, vamos mal este año. Tenemos una ejecución presupuestal baja y ya empezamos a hacer una reflexión profunda y nos estamos dando cuenta de que la operación del modelo tiene fallas. Conceptualmente todos estamos claros pero cuando bajamos ya a lo que es la ejecución y la práctica nos estamos quedando cortos frente a las exigencias del modelo, entonces yo creo que esa mini crisis coyuntural que estamos viviendo en esta primera parte del año nos está sacudiendo [...] la gran conclusión es, primero esto no es de híbridos, no podemos quedarnos entre lo que teníamos y lo que tenemos. Como que le juego a unas cosas sí y a otras no. No, aquí ya estamos jugados, esto ya no lo podemos devolver entonces sí estamos jugados pues, y creemos en el modelo conceptual pues garanticemos la operacionalidad procesando el modelo. (D5).
\end{abstract}

Es así que los procesos de institucionalización, en donde se busca crear una IO, se encuentran en una etapa de implementación, en donde considerando estas circunstancias antes descritas, se caracteriza por lo siguiente:

Lo primero es que busca resolver una serie de dificultades que se han presentado, que tienen como correlato la fuerte referencia hacia las OO. Algunas de ellas son las siguientes: 
- El primero y más importante es la referencia continua a las OO, expresado en la comparación que se hace constantemente, en donde se manifiesta un bienestar mayor en las OO. Se busca, por tanto, que los MM rompan abruptamente con las culturas de donde provienen.

- El MG lleva a hacer acuerdos, que no sólo se refieren a aspectos meramente técnicos sino a los estilos de dirección, los cuales muchas veces no se respetan. Así, los acuerdos y negociaciones están direccionados no tanto a resolver aspectos técnicos u operativos, sino que se estructura un espacio para imponer un estilo, una filosofía de trabajo proveniente de las $\mathrm{OO}$.

- Los mismos directivos no se han apropiado aún el MG. Hay pugnas en cuanto a la preponderancia de los estilos de dirección, también a nivel directivo. Esto repercute fuertemente en los MM ya que genera inseguridad, desasosiego y desconfianza en sus quehaceres.

La construcción de IO por parte de los directivos busca un aspecto clave: Que los MM se despojen de las referencias de las OO. En ese sentido, la IO buscará ser construida negando una historia, que es obviar la misma organización. Será una construcción en negación que busca cortar los lazos que unen profesionalmente y sentimentalmente a las $\mathrm{OO}$.

Culturalmente hay unas huellas muy profundas de los modelos que traíamos de las compañías que hicieron parte de la creación de CN. Dejar esas huellas es muy difícil y la tendencia a regresar al pasado es de alguna manera alta, entonces permanentemente hay que estar diciendo: aquí estamos gerenciando con un nuevo modelo, hay que ser disciplinado en la ejecución de ese modelo, no regresemos al pasado. Resetear ese disco para poder tener alineado lo que es el modelo es la mayor dificultad. Vamos avanzando y lo vamos haciendo bien pero hay que tener en cuenta que la resistencia y la inercia que en algunos casos es importante. (D5).

Entrevistador: ¿Encuentra usted, sobre todo en los MM, una fricción por hacer la silla al estilo azul y al estilo rojo? ${ }^{108}$ Entrevistado: La preocupación mía es que la confrontación se acabó. Entrevistador: ¿Por qué la preocupación? Entrevistado: Pues porque no se va a construir, porque al final vuelve y queda el azul, porque nada más

${ }^{108}$ Como se explicó en el capítulo cuatro (referido al estudio de caso), el color rojo hace referencia a la Compañía de Galletas Noel, y el azul, a la Compañía Nacional de Chocolates. 
peligroso que las minorías silenciosas como decían los romanos, los vencidos. (PPD1).

Los procesos de institucionalización buscan conductas determinadas, concretamente, los directivos quieren resolver las críticas y las dificultades que se han presentado buscando que los MM:

- Lideren desde la inclusión y no sólo como ejercicio del poder que les proviene del cargo.

- Se hagan co-responsables de lo que suceda en su equipo de trabajo sin buscar culpables externos.

- Conozcan el sentido de su vida y lo proyecten en el trabajo.

- Sepan manejar o administrar las diferencias y conflictos. Para ello requieren criterio y carácter.

- Ser capaces de alejarse del poder que tenían en las OO.

Las estrategias específicas que se implementaron son las siguientes:

- Los distintos programas que implementa la compañía de manera formal. Entre ellos, vale la pena mencionar el taller: "Proyecto de vida con sentido", el cual busca que la persona sepa qué es lo que quiere de la vida para poder realizar un trabajo satisfactorio.

- En general, la apuesta está en los diversos programas de capacitación que CN tiene.

- Darles autonomía y empoderarlos de sus puestos de trabajo.

- Que no pierdan el contexto general de la empresa con la especialización que se les está pidiendo y que el nuevo MG impulsa.

- Buscar que repitan las conductas y la aproximación que tiene el Comité de Presidencia. 
- La estrategia de la Gerencia de Cultura y Desarrollo de la compañía como marco en donde se inscriben todas las demás acciones de intervención que buscan construir una IO específica.

- Tener a la gente correcta en el lugar correcto, de acuerdo con los requisitos requeridos.

Este tipo de acciones busca lograr un proyecto de vida con la intención de que dicho objetivo esté en sintonía con los de la empresa. Es buscar "cambiar desde adentro a la persona" (PPMM1). Al buscar lograr una relación complementaría, las aspiraciones y proyectos internos, todos desde una dimensión más interior, servirán para cumplir con los objetivos empresariales.

\footnotetext{
Una vez que tenga un proyecto de vida ya en el interior de la organización es muy fácil. A esas personas prácticamente no hay que estar permanentemente diciéndoles qué hacer porque si su reflexión da para que diga estoy haciendo lo que me gustaría y esto está en relación con el proyecto de la compañía, pues inmediatamente haces click entre lo que es el plan de negocio y el proyecto de vida personal. Eso entonces lo que hace es que esa persona desde su ser sienta que puede llegar a ser feliz y exitosa que son dos cosas distintas. (D5).
}

Como a la vez también me puedo desarrollar como persona pero también como trabajador o como persona laboralmente hablando, yo creo que esa auto realización definitivamente tiene que ser un balance entre las dos cosas porque yo creo que son muy pocos los casos en donde una persona es brillante laboralmente y terriblemente desastrosa en el tema, yo creo que esas dos cosas, normalmente el que es buen directivo es buen papá y buen hijo y en el lugar de influencia donde vive es una persona en que la gente ve un modelo, un referente. Yo creo que esas dos cosas normalmente son coherentes. (D4).

El ser y lo exitoso se relacionan. Este es el objetivo último de las acciones de intervención realizadas en $\mathrm{CN}$ : Que el individuo logre una $1 \mathrm{O}$ a partir de la relación con los objetivos específicos y lo de la empresa. En este proceso, se lucha contra la presencia e injerencia de las $\mathrm{OO}$, las cuales buscan que desaparezca.

\subsubsection{Una autonomía que se subordina}

Lo anterior posibilita el espacio para una reflexión sobre la administración. Desde sus inicios, la TA se ha orientado a encontrar respuestas efectivas para explicar el 
manejo de los recursos (en donde se incluye al individuo) dispuestos con un propósito específico. En ese sentido, la TA ha ofrecido -y continúa haciéndolosoluciones adecuadas para la aplicación del trabajo humano al alcance de la productividad, la efectividad y la eficiencia. En dicho afán, la gestión de los recursos se ha simplificado a cumplir con tales objetivos relegando las demandas explicativas a otros espacios, concentrándose en simplificar el concepto de organización de acuerdo con las necesidades pragmáticas y funcionalistas que le atañen a su misma naturaleza y acción.

Teniendo esto como precedente, ¿en qué se ha convertido esto que se está llamando organización? ¿Hasta qué punto es verdaderamente autónomo el hombre dentro de ella? Para discutir tales interrogantes no se puede quedar en la TA, ya que desde su teleología, sus objetivos están lejos de circunscribirse a lo comprensivo de los fenómenos sociales, sino que direccionada por lo pragmático y prescriptivo, la preocupación por el hombre reposa en un aspecto meramente instrumental. Por ello, es pertinente recurrir a otros campos del conocimiento para, desde un carácter interdisciplinar, aproximarse a la organización desde marcos distintos.

Así, se entiende a la organización como un espacio social. Al respecto Montaño (2007b) nos dice:

La organización [...] no sólo es un lugar de trabajo cuyo único destino sea hacerse eficaz y eficiente, sino un lugar donde se juegan diversas apuestas, tanto en el terreno social como personal. La organización, podríamos entonces pensar, es un espacio social con fronteras difusas, con múltiples centros dinámicos en el que se depositan esperanzas y desencantos, un espacio de encuentros y desencuentros, una figura amorosa y amenazadora, en la que, a veces sin saberlo, nos seguimos inventando como actores sociales. (p.18).

Sin embargo, la administración ha desvirtuado y olvidado que el concepto de organización remite o encuentra en su seno el aspecto fundante de la creación humana, y en ese sentido, la misma organización no debería ser un espacio en donde se promuevan y alienten prácticas que vayan en contra de la misma 
humanidad del hombre. Dentro de los diversos aspectos que se podrían mencionar, de cómo las prácticas administrativas han deshumanizado a la organización, vale la pena centrarse en el aspecto de la autonomía, o de cierta libertad que se ha visto cada vez más reducida y diezmada dentro del ámbito organizacional.

El constructo de acción colectiva permite redefinir los problemas y los campos de interacción de tal manera que los actores, en la búsqueda de sus propios intereses, no ponen en peligro los resultados de la organización, sino que incluso los mejoran (Crozier y Friedberg, 1990). En ese sentido, la acción colectiva le permite a este actor social cierto margen de libertad dentro de una relación de poder. Así, el sujeto (esto dependerá del lugar jerárquico que ocupe dentro de la organización) no estará completamente atado (determinado) a las normas o reglas organizacionales, sino que tendrá la posibilidad de elegir, logrando, lo que podríamos llamar, una autonomía acotada (Montaño, 2007a), encontrándose en una posición intermedia entre la libertad y la restricción.

Es entonces que esta nueva autonomía no es más que una nueva forma de control o de inculcar una autodisciplina ya que convierte al hombre -o dice convertirlo- en señor de su voluntad. De esta manera, las nuevas formas organizacionales modernas han manipulado perversamente este término para volver a la precariedad de la burocracia.

Esta autonomía, principalmente referida ahora a los cuadros administrativos, es en realidad ilusoria ya que la empresa les inculca una sensación muy fuerte de poder al proporcionarles una imagen grandiosa de la organización que estos incorporan en su aparato psíquico, hasta el punto de desvanecerse frente a dicha imagen: el individuo es la empresa, transfiriéndole la responsabilidad -y la oportunidad- de alcanzar los objetivos de esta. (Montaño, 2007a, p. 4).

El capitalismo ha endiosado el concepto de eficiencia, por el desempeño, la productividad, el rendimiento a corto plazo; reduciendo todos los esfuerzos a meras prácticas de control (Chanlat, 1994). De ahí que Aktouf (1992) denuncie que es necesario buscar las bases ideológicas que están detrás de las teorías del 
management para comprender los alcances y las consecuencias que éste posee. ¿Tiene algún sentido preocuparse por quién realiza la acción administrativa, cuando la razón de ser de dicha acción es cumplir con un objetivo externo a ambos, que en este caso es la producción rentable? ¿A mera instrumentalidad ha llegado a convertirse el hombre?

La pugna entre lo que Schvarstein (1991) llama lo instituido y lo instituyente ${ }^{109}$ caracterizará a la organización. "La fuerza instituyente que triunfa, a partir del desconocimiento del otro, se instituye y en ese mismo momento, por el simple efecto de su afirmación y consolidación, se transforma en instituido y convoca a su instituyente" (Schvarstein, 1991, p. 27). Así, el subordinador, a partir de prácticas y discursos administrativos, buscará desconocer al otro dentro de las relaciones de subordinación. De esta manera, intentará instituir en él el rol de subordinado. Inmediatamente ese otro se resistirá a ser instituido en tal rol, convocando una fuerza de rechazo o resistencia, buscando desde lo instituyente rechazar el ser instituido.

Dada esta dinámica, que inserta a las organizaciones dentro de la lógica capitalista y moderna, en donde no hay espacios para la cooperación, la autonomía es prácticamente dejada de lado y reemplazada, incluso con una presunción válida e incuestionable, por el cumplimiento de ciertas normas, con el fin de poder sobrevivir dentro de la organización. Al subordinar la autonomía, el papel del individuo queda relegado a un cumplimento de metas y objetivos que lo despersonalizan, oscureciendo su humanidad a mero factor productivo que trabaja y en donde la autonomía más que un aspecto que debe respetar, es un problema

${ }^{109}$ Lo instituido es aquello que está establecido. "Es el conjunto de normas y valores dominantes así como el sistema de roles que constituyen el sostén de todo orden social. Lo instituyente es una fuerza constituida como protesta y como negación de lo instituido" (Schvarstein, 1991, p. 26-27). También se puede revisar al respecto Lourau (2007) entre muchos otros. 
a controlar, o mejor dicho, una posibilidad que no debe ser expuesta, a costa de que se convierta en una rebelión ineficiente a futuro ${ }^{110}$.

El control es una de las funciones centrales de las llamadas ciencias de gestión, en especial sobre la conducta o el desempeño de los empleados. El control es un proceso que ayuda a mantener un comportamiento específico conforme al plan racional de la organización, la coordinación y el orden creado a partir de los diversos intereses y el comportamiento de sus miembros.

La naturaleza disfuncional del trabajo irónicamente crea sus propias formas de descontento en el desarrollo y la extensión de este discurso de la identidad. La sociabilidad de los individuos como dinamismo inherente de la condición humana es usada para gestionar, buscando con ella conseguir una legitimidad en una sociedad a través de inculcar atributos cada vez más personales de los trabajadores, especialmente aquellos que se relacionan emocionalmente con el trabajo. Esto podría ser visto como un paso progresivo hacia una sociedad libre, diversa e incluyente, preocupada por los aspectos más personales e internos de los individuos en las organizaciones, sin embargo, no es más que una extensión de la racionalidad instrumental administrativa. De hecho, el enfoque de propiciar ser uno mismo en el trabajo difiere de las antiguas prácticas administrativas, para centrarse en apropiarse, y por lo mismo de construirse parcialmente una gama de identidades con fines productivos.

Esta nueva modalidad de control identitario sirve para capturar la sociabilidad y la personalidad de los individuos a partir de la intervención en la dimensión emotiva del ser humano buscando con ello nuevas formas de ser y actuar de los

\footnotetext{
${ }^{110}$ Diversas perspectivas han buscado configurar la organización. Así, por ejemplo, la burocracia buscó definir claramente las funciones, los niveles de comunicación y las tareas y responsabilidades en busca de eficiencia y perdurabilidad. Por el contrario, la perspectiva de las anarquías organizacionales plantean la existencia de múltiples lógicas que se inscriben dentro de la dinámica organizacional que no sólo responden a los parámetros racionales modernos. Si bien esta última no buscó organizar propiamente el espacio social que estamos llamando organización, sí desvela y plantea puntos de vista divergentes para buscar comprenderlas.
} 
individuos. Este nuevo modismo administrativo tiene altas implicaciones y repercusiones en la comprensión de la autonomía de los empleados en y alrededor de este tipo de sistemas de control identitarios que bien se podrían llamar híbridos por la connotación y campo de acción que tienen.

\subsection{UNA MIRADA ÉTICA A LA ADMINISTRACIÓN}

Es evidente que todo individuo dentro de una organización se encuentra sujeto a fuerzas que coartan su libertad, y en ese sentido, restringen su autonomía. ¿Será entonces que esta autonomía está condenada a no ser reconocida, valorada y respetada, sino que por el contrario, será reificada y utilizada como mero instrumento a manipular e intervenir para lograr una gestión administrativa más eficaz?

Si se entiende que las normas, leyes y demás disposiciones son la autoridad, representadas por individuos, dentro de la organización, entonces se puede considerar que la autoridad no es extraña a esa forma de la otredad que es el diálogo. Es decir, que el cumplimiento de la ley no es que esté fundada en la razón argumentativa y que su acatamiento esté supeditado a la persuasión. A la ley se le acata y es desde el marco posibilitado por ésta que se despliegan la autoridad y la argumentación personal que pueden conducir, esfuerzo y lucha mediante una actitud colectiva que revoque el orden vigente. La ley y la norma son el principio fundacional del conjunto humano que cuando su agenciamiento no es autoritario, ella misma define los términos de su cuestionamiento posible. De ahí que la autonomía de un individuo no se cristaliza en el abandono de la ley, sino en el sometimiento a ella en términos de una oposición creativa que alcanza el reconocimiento, valga decir, la legitimación de los demás o de una parte significativa de ellos, y en donde haya espacio para una construcción del sujeto (Kant, 1989). 
Ser autónomo, es decir, ser mayor de edad que invocaba Kant (1989, 1996), es ser particular, creativo y crítico dentro de la ley. La obediencia a la ley no está supeditada al convencimiento racional que tenga el sujeto, éste debe desenvolverse en el marco de aquella mientras no logre transformarla a pesar de que su proceder apunte a lograr esto último.

\subsubsection{La administración y los actos del hombre}

Cuando ejecuta algún trabajo, el hombre comienza ensayando los instrumentos que tiene a su alcance para poder realizar tal tarea a fin de poder comprender bien el uso que de él puede hacer de acuerdo con una realidad específica a transformar. Para poder realizar tal tarea, la persona utiliza la razón. Examinando esta razón, el hombre puede sencillamente contemplar, es decir, conocer por conocer (orden de las ciencias especulativas); o puede examinar su razón, buscando darle algún tipo de utilidad para la vida misma por medio de la acción (orden de las ciencias prácticas). La administración, dada su naturaleza, se encuentra en esta segunda connotación. Es decir, no es interés de la administración el conocer por conocer, sino darle algún tipo de utilidad al hombre en su vida por medio de la razón.

Las ciencias prácticas no son verdaderas ciencias ya que no proceden de una manera demostrativa, reduciendo las conclusiones a sus principios. Más que ciencias son artes. Pero, ¿cuál es el carácter esencial del arte en su sentido más amplio? "Es el de dirigir una obra que se va a hacer, de modo que sea fabricada, modelada y dispuesta como debe serlo, y que se consiga así la perfección o la bondad, no ya del hombre que la trabaja, sino de la obra hecha por el hombre" (Maritain, 1981, p. 227).

Es así que el arte pertenece al orden práctico; regula la obra que se va a producir, prescindiendo del uso que se haga del libre albedrío y teniendo sólo en cuenta la 
manera de cómo la obra debe ser ejecutada. El arte, pues está en relación con el hacer, son los actos del hombre.

Este aspecto formal de obra a ejecutarse se encuentra principalmente en las obras materiales producidas o llevadas a cabo por el hombre. Pero no es posible establecer una teoría general de las artes y de la obra si no se sitúa desde el punto de vista de los conceptos y principios más universales y más elevados del conocimiento. Tal teoría cae necesariamente en los dominios de la filosofía. Así, las teorías administrativas ya comentadas en los apartados anteriores bien podrían tener una connotación filosófica, siempre y cuando cumplan con tener conceptos, reglas o normas más universales. De ahí que muchas veces sean consideradas como ciencia.

Esta parte de la filosofía así precisada es evidentemente práctica, ya que se ocupa de la obra a realizarse y trata de dirigir desde arriba a las ciencias o disciplinas prácticas. No obstante, por su carácter de ciencia propiamente dicha, no puede ser esencialmente práctica; así se mantienen en el orden puramente especulativo por su objeto y por su manera de proceder, permaneciendo más alejada de la operación misma; pues no sólo se mantiene extraña a la aplicación de las reglas artísticas a la obra particular que se realiza, sino que las reglas que dan son demasiado generales para ser inmediatamente aplicables a esa obra en concreto, aún para merecer el nombre de reglas artísticas propiamente dichas. No es sino impropia y muy perfectamente práctica. De tal manera, la administración no podrá tener esta connotación de ciencia (especulativa) ya que sus prácticas no guardan una distancia con la obra a realizar y sus reglas no son generales aplicadas universalmente sino en forma específica, más allá de tener la intención de prescribir y regular.

Sólo las diferentes artes (disciplinas esencialmente prácticas) poseen reglas suficientemente determinadas para ser aplicables al acto en la obra particular por realizar; y a ella sólo pertenece aplicar esas reglas. Las otras artes no contienen 
en sí nada del carácter universal propio de la filosofía, sino el hecho de que son artes. En ese sentido la administración es un arte propio y perfecto.

\subsubsection{La administración y los actos humanos}

La moral o ética es la ciencia práctica (siguiendo a Maritain, 1981) que tiende a procurar el bien puro y simple. No tiene como objeto propio la perfección de las obras elaboradas y producidas por el hombre, sino la bondad o la perfección misma del hombre que opera, o bien, el libre uso que hace de sus facultades hace que sea propiamente la ciencia del obrar, la ciencia de los actos humanos.

La ética es práctica, en el grado en que puede serlo una verdadera ciencia propiamente dicha, ya que enseña no sólo las reglas supremas aplicables de lejos, sino también las reglas próximas aplicables a los actos particulares. Al mismo tiempo, esta ciencia tiende, no ya a tal o cual fin secundario, sino al fin supremo (el bien absoluto del hombre), es decir, a la causa más elevada del orden práctico, por lo que se puede considerar una ciencia filosófica. La ética se convierte en el eslabón entre lo universal y lo práctico. No sólo se preocupa por designar las reglas universales, las cuáles regularán nuestra conducta, sino que buscará llegar hasta el mismo cómo hacer para cumplirlas.

Si se hiciera una relación con la administración, la ética -así entendida y definida - respondería a una preocupación por el hombre en cuanto tal, lo cual la llevaría a preocuparse por los actos que realiza para ello, llevándolo también desde la moralidad, a poder valorarlo como bueno o malo. Pero la administración se ha olvidado de estos aspectos, que desde la filosofía podrían darle un horizonte de reificación al humanismo, para reducirlo, a meros procesos evaluativos juzgando sus conductas desde apreciaciones de valor que tienen como referencia, no al hombre mismo, sino unos fines externos a él. El valor moral no es visto bajo los parámetros supremos del fin del hombre, sino como una materialidad 
económica reduccionista. La moral cambia porque su objeto, el hombre, es desconocido.

Aún más, siendo la ética una ciencia práctica, no debe detenerse en consideraciones universales; debe descender a la determinación más particular de los actos humanos y de sus reglas. De ahí el deber de estudiar de una manera más detallada las reglas que ordenan la conducta del hombre, primeramente en lo concerniente a su propio bien, luego, en lo que concierne al bien de los demás (virtud de la justicia). Esto introduce a lo que se llama derecho natural, refiriéndose primero a lo que el hombre le debe a Dios (religión natural); en segundo lugar, lo que debe a los demás hombres y los que afectan a los hombres como miembros de un todo natural, a cuyo bien común los individuos deben servir: sociedad, familia (derecho social). Las ciencias prácticas buscan el conocer, pero no por conocer, sino para procurar con las acciones el bien ${ }^{111}$ del hombre.

\subsubsection{Una reflexión que invita al diálogo}

El objetivo de la administración es la rentabilidad, el uso de los recursos de otro (al servicio de) con el fin de obtener una ganancia, un lucro. No es la preocupación de la persona que realiza la acción, sino de su obra. De tal forma que bajo este aspecto, es una administración de los actos del hombre, pero a diferencia de la filosofía del hacer o del arte, no se busca la perfección o la bondad de dicha obra, sino su producto, el fin. Se ha dicho entonces que la administración es un arte, pero un arte que no regula bajo los criterios antes descritos, ningún aspecto de la obra del hombre. No obstante, la administración no tiene, ni posee una teoría general, la cual le permita dirigir universalmente dichas prácticas. En tal sentido, se podría afirmar que por su objeto es un arte, más no un arte que pueda pretender connotaciones de ciencia.

\footnotetext{
${ }^{111}$ Se refiere a un bien del puro acto de conocer la verdad.
} 
Por otro lado, es preciso una reflexión de la administración en relación con el obrar. El objeto de dicha ciencia no es la perfección de las obras elaboradas o producidas por el hombre sino la perfección y la bondad del hombre que obra y hace libre uso de sus facultades. Es decir, es la ciencia de los actos humanos. Las empresas y organizaciones productivas difícilmente son constituidas buscando el bien del hombre. Tomado como un factor productivo, los individuos son medios, instrumentos o recursos para buscar el objetivo de rentabilidad. No obstante, la reflexión en torno a la ética, es un lugar recurrente en el ámbito administrativo.

La ética es una práctica porque enseña reglas particulares aplicables, pero es importante aclarar que forma parte de su naturaleza aplicarlas siempre en forma correcta. Tienen un objeto formal, que son los actos humanos que estudia buscando reducir verdades a sus principios, lo cual no implica que se lleven a la acción necesariamente. De esta manera, la administración no tiene cómo tomar a la ética que busca una preocupación por el hombre mismo, porque la ética es en sí misma insuficiente para buscar ese bien supremo que es la felicidad.

Por ende, la reflexión invita a generar consciencia de que la organización es un espacio social de desarrollo y crecimiento tanto a nivel individual como profesional para el individuo. La autonomía, como característica intrínseca del individuo queda expuesta constantemente a pretensiones de control y dominación. Sin embargo, la libertad no podrá ser totalmente coartada, y por ello el ejercicio autónomo siempre estará presente. Queda a la conciencia de la dirección y de la gestión en general, que los espacios organizacionales brinden las condiciones para la crítica y el desarrollo dialogal, que contemplando las normas, la autonomía del hombre pueda ser respetada.

\subsection{A MANERA DE CONCLUSIÓN}

El capítulo ha abordado críticamente las nuevas formas de control organizacional. El control, como aspecto característico del management, ha variado su campo de 
acción para pasar de los procesos laborales, a aspectos más íntimos del trabajador. De esta manera, el control por la productividad y eficiencia, ya no sólo se restringen a un horario laboral concreto, ni tampoco a las dimensiones físicas de las organizaciones, sino que trascienden esos límites para buscar influir en asuntos más personales e interiores de los individuos.

Esta forma de control, que se viene desarrollando desde los promotores y pensadores de la Escuela de la Nuevas Relaciones Humanas, si bien no es algo nuevo, tiene mucha importancia y es objeto de estudio e investigación en los últimos tiempos. En tal sentido, se ha presentado y fundamentado lo que se considera una nueva modalidad de gestión del individuo desde el punto de vista de la fabricación y control identitario.

Es por ello que se optó por profundizar en la racionalidad instrumental propugnada por la Escuela de Frankfurt, concretamente por Max Horkheimer, y las relaciones que tiene con la administración y el trabajo. En este mismo sentido se realizó una reflexión sobre las prácticas administrativas desde el punto de vista ético para profundizar en las acciones reificantes que buscan controlar aspectos del individuo en las organizaciones.

Por último, invitar a la reflexión crítica del mundo organizacional y a los fenómenos que desde la administración se inscriben dentro de ella. La mirada multidisciplinaria, la continua reflexión y mirada ética en cuanto a las consecuencias de las acciones se convierten en pilares para construir una gestión que no sólo vele por el buen desempeño de las organizaciones, sino que respete y propicie espacios de desarrollo para quienes las integran. 


\section{CAPÍTULO 6}

\section{RESULTADOS DE LA INVESTIGACIÓN DESDE EL PUNTO DE VISTA DE LOS MANDOS MEDIOS}

\section{INTRODUCCIÓN}

Como se anunció en la sección anterior, se optó por separar los resultados del trabajo en dos capítulos destinados a los hallazgos, a la vez que se mantiene el modelo teórico-metodológico construido para esta investigación. Así, en el apartado anterior se presentaron los resultados a partir de la pregunta de quiénes son los $\mathrm{MM}^{112}$ para los directivos. En el presente, se expone la respuesta a la pregunta: ¿Qué dicen que son los MM? La confluencia de estos dos interrogantes da como resultado la $1 \mathrm{O}$ que desde el punto de vista de los MM tiene CN. Aquí, no solo se explica esta 10 en concreto, sino que se muestran los componentes y el proceso de construcción que llevan a cabo los MM, objetivo principal de estudio.

Como característica, los EO recurren a diversas ciencias sociales para acercarse a la comprensión de los fenómenos sociales que se inscriben en las organizaciones (véase capítulo dos). Ya, bajo el título anterior, se planteó -con base en los resultados de la investigación- una nueva modalidad para controlar la identidad del individuo a partir de intervenir aspectos más interiores; se recurrió a la filosofía para enmarcar tales acciones y dar un sustento epistemológico que permita un mayor conocimiento del fenómeno organizacional estudiado. En este capítulo, se acude también a la filosofía y a la antropología para explicar los

${ }^{112}$ Con el fin de recordar el significado de las siglas, se pueden revisar las tablas correspondientes del comienzo. 
componentes o constructos teóricos que intervienen en el proceso de construcción identitario, desde el punto de vista de los MM. Estos son: el reconocimiento, la trascendencia y la seguridad.

Con base en la composición de estos tres constructos conceptuales se propone entender la construcción de la 10 como un espacio liminal. Esto se convierte en el hallazgo principal de la investigación, teniendo en cuenta el estudio de caso en $\mathrm{CN}$. No obstante, la metodología utilizada y la particularidad propia de los EO, de buscar comprender el fenómeno que se examina dentro de un contexto específico, al final de la sección se propone una reflexión más teórica de cómo concebir la IO como un equilibrio liminal constituido por dos niveles de análisis mutuamente necesarios: lo personal y lo organizacional. En tal sentido, las precategorías (identidad personal, profesional y organizacional) estructuran una relación de equilibrio sostenida por la seguridad que permite un reconocimiento y una trascendencia. Se configura así una identidad transicional que su no definición es aquello que la estructura como tal.

Los resultados del trabajo realizado permiten apreciar el énfasis en el proceso de construcción identitario de los $\mathrm{MM}$ y, en consecuencia, afirmar que la $\mathrm{IO}$ es un fenómeno de dinamismo social en cambio permanente, en el cual los procesos de resignificación involucran dos niveles de análisis: el personal y el organizacional. En ese sentido, y desde el procesualismo de Víctor Turner, la transicionalidad caracteriza a la IO; de allí que lo importante sea comprender sus componentes y las relaciones existentes entre ellos.

Al igual que en el capítulo anterior, en la primera parte de este se discuten brevemente las categorías emergentes: Hist Per-Prof-Org (historia personal profesional y organizacional) y $\mathrm{OO}$ (organizaciones de origen). Estas categorías permiten explicar el surgimiento de las tres categorías emergentes principales 0 hallazgos de los componentes que participan del proceso de construcción de la 10 de los MM: el reconocimiento, la trascendencia y la seguridad. En cada una de 
ellas se ha profundizado apoyándose en nociones importadas de otras disciplinas. De esta forma, se busca una mayor claridad conceptual y enriquecer la interpretación y posterior análisis de los datos.

Por tales consideraciones, el lector encontrará algunos apartes dedicados a presentar y explicar conceptos teóricos provenientes de otras disciplinas, concretamente de la filosofía y la antropología. Ahora bien, tales novedades no se incluyeron en el segundo capítulo, correspondiente al marco teórico, básicamente por dos razones. En primer lugar, se quiere evidenciar que en el proceso metodológico cualitativo, el análisis de los datos tiene un carácter circular y emergente, en tanto que es necesario regresar reiteradamente a los marcos conceptuales, debido a que los hallazgos de la investigación así lo exigen. De igual manera, con ello se muestra cómo el propio estudio conduce al investigador en el proceso comprensivo de los datos. Así pues, al construir las categorías emergentes principales, fue necesario recurrir a una nueva teoría que no estaba considerada al inicio del trabajo. La segunda explicación está en relación con la anterior: la teoría emergente se coloca antes del análisis buscando que el lector pueda comprender con mayor claridad y facilidad el proceso interpretativo que se expone, sin tener que recurrir a otros acápites que dificultarían tal proceso.

Aclarado lo anterior, se procede a explicar el proceso de construcción identitario, en donde se resaltan la interacción de los componentes antes mencionados. El análisis se centra en el caso de estudio específico en donde se realizó el trabajo de campo, los MM de CN. A partir de allí, se realiza la interpretación de los datos y se lleva la discusión a un nivel comprensivo distinto, sin que ello implique buscar una teoría o un discurso de otra índole, lo cual estaría en contravía con el espíritu de la investigación y de los EO, perspectiva teórica-metodológica en donde se inscribe esta investigación. 
A continuación se presentan las categorías preliminares y emergentes expuestas en el tercer capítulo, de tal manera que el lector pueda ubicarse más fácilmente en el desarrollo que se presenta con posterioridad.

\section{Gráfica 19: Categorías preliminares y emergentes construidas a partir de los mandos medios}

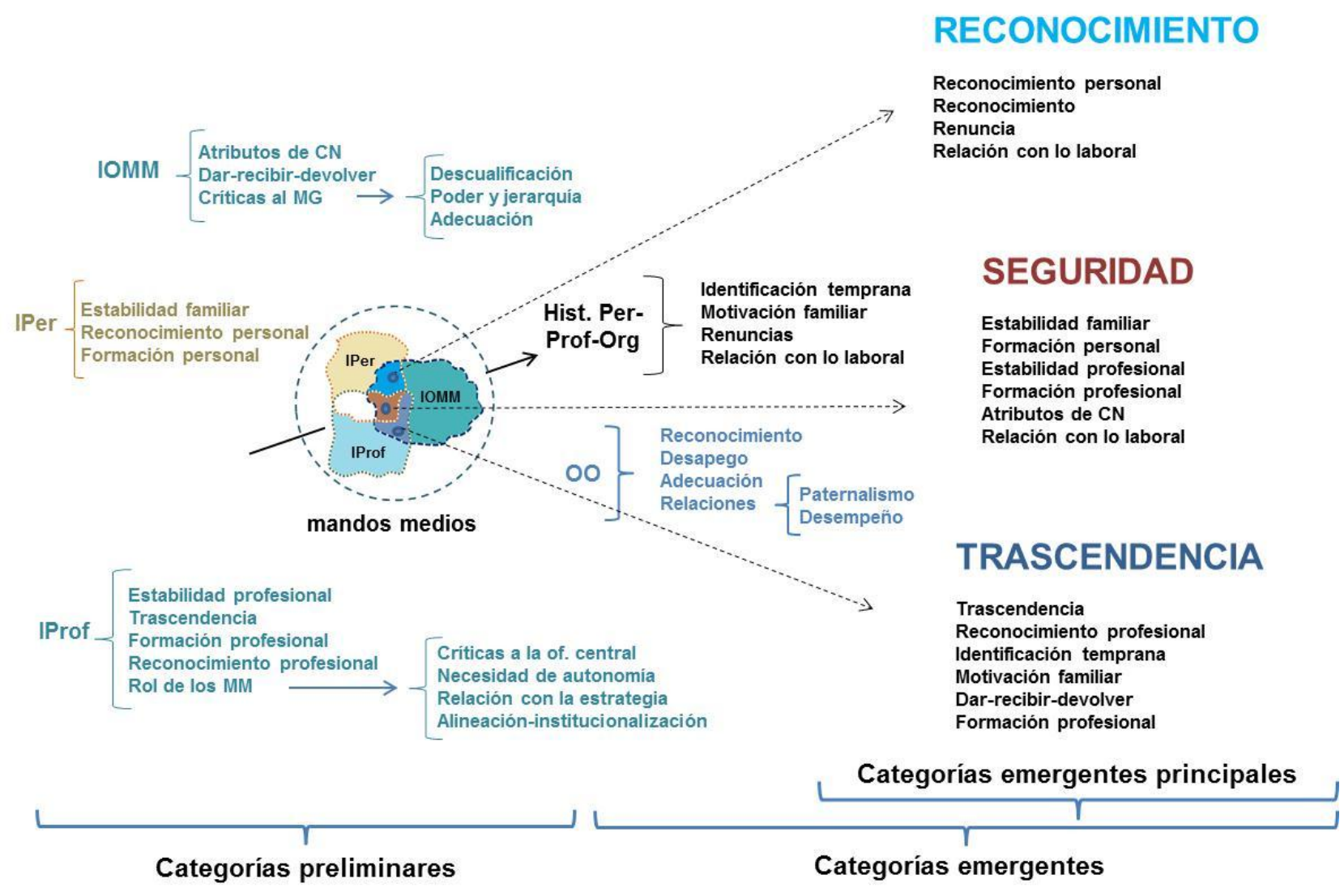

Fuente: Elaboración propia.

\section{1. ¿QUIÉNES SON LOS MANDOS MEDIOS?}

A continuación se exponen las categorías emergentes de la investigación. Todas ellas dan cuenta de quiénes son los MM y aportan en la comprensión de los componentes que intervienen en el proceso de construcción identitario. 


\subsubsection{Categorías emergentes}

\subsubsection{Organizaciones de origen $(00)^{113}$}

Esta categoría hace referencia a la influencia que tienen las organizaciones de donde provienen los MM en la actual construcción de IO de CN. Es una categoría nuclear y transversal junto con las otras dos preliminares que también la afectan y que ayudan a comprender el proceso de construcción identitario de los MM. Como es de esperarse, es un referente importante dentro de los hallazgos de la presente investigación en cuanto a las categorías emergentes o interpretativas. Esta alusión constante a las $\mathrm{OO}$ se expresa o manifiesta en un conjunto de subcategorías. En ese sentido, las $\mathrm{OO}$ que influencian también a los directivos en su accionar para fabricar una 10 particular, tiene connotaciones propias en los MM. En consecuencia, a continuación la categoría se discute a partir de los siguientes conceptos:

\subsection{Reconocimiento}

El reconocimiento no solo se refiere al orgullo de saberse originario de una compañía proveniente del GN, sino que es una respuesta de amor y respeto hacia ella. Es decir, el reconocimiento está fundado por un afecto, trasciende la relación entre el empleado y la empresa para expresarse en la valoración que la sociedad tiene al momento de nombrar a las $\mathrm{OO}$. El reconocimiento, por tanto, tiene una connotación personal y social, que se ha forjado a lo largo de la historia personal, profesional y organizacional de los $\mathrm{MM}$ de $\mathrm{CN}$.

\subsection{Desapego}

Tal reconocimiento y apego a las $\mathrm{OO}$ se expresa en la desvinculación afectiva que han tenido que enfrentar los $\mathrm{MM}$ al ingresar a CN. Existe una lucha constante por

${ }^{113}$ Las OO son las organizaciones de origen desde el punto de vista de los mandos medios (MM). Esta nomenclatura es la misma que se utiliza para los directivos, pero dado que son actores sociales distintos, su definición y delimitación serán diferentes. 
buscar desprenderse de las $\mathrm{O}$ ya que el aprecio está aún presente y es difícil de evitarlo. Uno de los aspectos importantes que mencionan los MM son las renuncias que han tenido que hacer luego de haber estado trabajando en algunas de las OO del GN. Sin embargo, en vez de ser un ejercicio que genere cierta nostalgia y tristeza, por el hecho de tener que apartarse y con ello romper con una identificación previa que marcó algunos aspectos de lo que ellos son como personas y profesionales, el ejercicio de desapego, motivado y exigido por la dirección de $\mathrm{CN}$ en cuanto al cumplimiento propio de sus cargos, les ha permitido a los MM, no solo darse cuenta de la estrecha relación aún presente con las $\mathrm{OO}$, sino que ha propiciado una serie de resistencias frente a las nuevas directrices que $\mathrm{CN}$ ha venido implementando para buscar construir una $\mathrm{IO}$ propia.

Este proceso de desapego no es nuevo para los MM. Sin bien este tiene una connotación distinta en el proceso de desprenderse de las OO, la vida de los MM a lo largo de su trayectoria profesional se ha caracterizado por ello. El desapego se manifiesta por medio de una serie de renuncias, ejemplificadas, en su mayoría, por los traslados y las implicaciones que estos contraen para su vida familiar. Dichas renuncias han permitido forjar una relación más duradera, a partir de esos sacrificios. Además, se suma otro tipo de renuncias: desarraigo a la propia cultura y costumbres, dificultad para frecuentar amigos y familiares, nuevas adaptaciones, suspensión o cancelación de estudios de posgrado, cambios en los proyectos de vida como el hecho de tener que suspender el matrimonio o la misma procreación, entre otros aspectos.

Esas renuncias, desarrolladas a lo largo de su carrera profesional, de una u otra manera han formado a los $\mathrm{MM}$ y les ha permitido gestar una fuerte identificación con las OO. En el proceso de tener que adaptarse al nuevo MG de $\mathrm{CN}$, la referencia a las $\mathrm{OO}$ se convierte en un obstáculo a manera de resistencia. Contradictoriamente, la mayor renuncia, que consiste en alejarse de la $\mathrm{OO}$ de donde provienen los MM y fueron reconocidos e identificados con la nueva organización (CN), aún no se logra. 
Otro elemento dentro de esta categoría, es la lucha por buscar el reconocimiento, la valoración y el trato personalizado. Sobre esto último, existe una desorientación que se manifiesta en el hecho de que en $\mathrm{CN}$ nadie sabe para quién trabaja, es decir, falta de claridad del MG que se busca implementar. Tal situación genera malestar, dolor, incluso cierta irritación y cólera debidos a ese desconocimiento. Por consiguiente, cuando esto sucede, se hace inevitable la comparación con lo vivido y experimentado en sus 00 . Esto es propio de los lazos afectivos generados previamente $\mathrm{y}$, también, por la inestabilidad que genera volver $a$ hacerse, a pensarse en una empresa nueva.

En el proceso de desapego, además, hay cierta inseguridad por conocer, enfrentarse e interactuar con pares nuevos; es volver a entrar en el terreno de la competencia por un puesto de trabajo y por un reconocimiento, aspectos que ya se habían ganado y consolidado en las OO. Desapego que está fuertemente vinculado a un duelo, enfocado sobre todo por el tema del poder que se tenía antes de la implementación del nuevo MG.

\subsection{Adecuación}

Esta categoría se refiere a aquellas condiciones que los $M M$ han tenido que cambiar y ante las cuales han de ajustarse en el nuevo MG de CN. Concretamente, los MM experimentan que aportan más desde el rol anterior, que en el actual. Para aquellos MM que pertenecen a las áreas de soporte y que se llaman asimismo transversales, les es difícil manejar las situaciones de pujas y controversias, sobre todo para aquellos que llevan más tiempo en el GN.

Para aquellos que llevan menos tiempo en la compañía, la adecuación al cambio es relativamente más sencilla, no es tan traumática, no hay tanta referencia como era de esperarse - al pasado. Para algunos, la adecuación al nuevo modelo comercial y de gobierno, no va a funcionar o se tienen dudas al respecto. Para ellos hay una fuerte presencia de las culturas anteriores en su obrar en cuanto a 
lograr que el nuevo MG funcione y sea eficiente. Otro elemento importante tiene que ver con que los MM, dentro del nuevo MG, están más orientados a la ejecución, ya que la estrategia viene definida por la dirección. En ese sentido, son más operativos que estratégicos. El siguiente comentario expresa esa visión: "yo pienso que la experiencia ha sido positiva más que negativa. Si a mí me dicen: ¿qué le ha traído negativo en lo personal?, de pronto, pensar un poco más estratégicamente, porque la estrategia viene montada, solo ejecuta. Eso, de alguna manera, pienso que ha sido una de las cosas negativas para mí" (MM5).

\subsection{Relaciones}

Se refiere básicamente, a las relaciones que las $\mathrm{OO}$ tenían con los empleados. Para muchos de ellos, existía una preocupación real por el bienestar, elemento que se ha perdido o se ha condicionado a los buenos resultados. La comparación toma como referente a Noel y $\mathrm{NCH}$. Hay dos aspectos que caracterizan a estas OO: el desempeño, ligado sobre todo a la cultura proveniente de Noel, y el paternalismo, palpable sobre todo en la compañía $\mathrm{NCH}$.

Por la importancia que esto tiene para los entrevistados, se describen esta dos sub-categorías por separado.

Paternalismo: Está marcado por el cuidado y proteccionismo a los empleados. Esto si bien, es algo característico del grupo como tal, es particular para quienes provienen de $\mathrm{NCH}$. Esta empresa se identifica por ser condescendiente, consentidora, con una gran capacidad de escucha. Tal es la involucración con los empleados que la misma empresa suele resolver problemas personales y familiares.

Desempeño: Tiene que ver con los logros y resultados que se obtengan, como expresión del estilo de dirección de la empresa Noel. La preocupación por el desempeño y la presión que se ejerce en torno a este, y que sirve a su vez para la 
evaluación del cargo de los empleados, son muy grandes, tanto que algunos MM no han visto jubilarse a nadie en esta empresa debido a que existe una amplia rotación de personal allí. En palabras de los entrevistados, Noel es la cultura del presupuesto, en donde la cifra tiene mayor importancia que la persona. Esta concepción se contradice, pues, con la categoría anterior, representativa de $\mathrm{NCH}$. Los MM provenientes de Noel son más jóvenes y mejor preparadas académicamente, con un mayor conocimiento en el uso de la tecnología.

\subsubsection{Historia personal-profesional-organizacional.}

Esta categoría hace referencia a las relaciones entre los aspectos personales y profesionales que tienen injerencia en la construcción de una 10 dentro de la organización. Se resaltan los siguientes componentes dentro de esta categoría:

\subsection{Identificación temprana}

Los MM han tenido una expectativa por estar vinculados al GN desde el inicio de su carrera profesional y laboral, por lo que la expectación y el posterior reconocimiento al ingresar a $\mathrm{CN}$ son aspectos importantes que influyen en el proceso de construcción identitaria.

En la gran mayoría de casos, los MM anhelan trabajar en el GN gracias al gran prestigio y reputación que este tiene en Colombia. Logran percibir algunas características propias de los miembros del GN; es decir, el deseo de querer formar parte de este viene por agentes externos, por las referencias positivas que les Ilegan. Los criterios para querer formar parte del GN giran en torno a la reputación y a la posibilidad de jubilarse luego de lograr una trayectoria dentro del grupo empresarial. 


\subsection{Motivación familiar}

Una de las mayores motivaciones de los MM para ingresar a algunas de las compañías del GN es la búsqueda de una mayor calidad de vida. La aspiración de tener una mejor situación económica que les permita gozar de una serie de comodidades y no padecer las dificultades vividas por sus familiares. Este es un aspecto importante que los MM tienen en cuenta y recurren a la memoria para afianzar el deseo de pertenecer al GN. No se quiere experimentar los mismos impedimentos y sacrificios vividos en su proceso de formación profesional, ya que debido a precarias o difíciles condiciones económicas, dicha situación fue, para muchos de ellos, muy compleja y difícil.

En general, se presenta una constante alusión y gratitud hacia sus padres, así como la responsabilidad de velar por la familia, de hacerse cargo de ella, de ayudar económicamente. De igual modo, se busca que la familia esté orgullosa con su trabajo. La estrecha relación con la familia (que forma parte de lo propiamente personal) pone en primer plano el aspecto de la seguridad en el proceso de construcción identitario, en el entendido que los comportamientos o conductas inducidas por la dirección que impidan el cumplimiento de las obligaciones de los MM con sus familias, será rechazada.

\subsection{Renuncias}

La historia laboral dentro del GN se ha caracterizado por una serie de renuncias, entendidas como sacrificios, tanto a nivel personal como familiar y profesional. El continuo cambio de ciudades por el trabajo, la postergación de algún plan familiar como la procreación de hijos o el matrimonio, independizarse, dejar la novia, o el tener que atrasar algún tipo de actualización de estudios formales, son algunos de los ejemplos. Si bien no hay quejas o comentarios que expresen cierto resentimiento al respecto, son aspectos coincidentes y reincidentes en las entrevistas realizadas. 


\subsection{Relación con lo laboral}

Esta categoría se refiere a cómo los aspectos de la vida personal, familiar y profesional se unen con lo laboral. Se puede afirmar que lo laboral está condicionado a que no interfiera con las condiciones propiamente personales de los MM como son las familiares. En otras palabras, los planes personales y profesionales se van moldeando de acuerdo a lo laboral, en donde la relación es tan fuerte que parecen fundirse. "Yo me he formado en la compañía profesional y personalmente, entonces como todos los aspectos están íntimamente relacionados, entonces están ligados con la experiencia laboral" (MM16). Por tal sentido, parece que la valoración en uno de los aspectos de la vida, tendrá que ser coherente con los demás. Es mediante lo laboral como se logran cumplir los proyectos y demás anhelos personales y profesionales.

Como a la vez, también me puedo desarrollar como persona pero también como trabajador o como persona laboralmente hablando. Yo creo que esa autorrealización definitivamente tiene que ser un balance entre las dos cosas porque yo creo que son muy pocos los casos en donde una persona es brillante laboralmente y terriblemente desastrosa en lo personal. Yo creo que el que es buen directivo es buen papá y buen hijo y en el lugar de influencia donde vive es un referente para la gente. (MM15).

La historia es importante. La procedencia de los actores, la realidad social de donde provienen, los hitos personales, etcétera, configuran un punto de referencia en donde los MM pueden entenderse, interpretarse, valorarse, tomar decisiones en el futuro y adentrarse en saber quiénes son hoy, a partir de quiénes fueron, o dicho de otro modo, quiénes son hoy, con base en el conocimiento de quiénes vienen siendo.

Para King, Felin y Whetten (2010, p. 6), "el resultado de una organización [como un actor social] depende de la trayectoria de la historia de la organización". En ausencia de tales antecedentes y ya que $\mathrm{CN}$ es una organización totalmente nueva, los MM se apoyan en su propia historia o en el conocimiento de otras organizaciones para decidir qué acciones desarrollar y qué compromisos asumir. Así pues, se encuentran elementos importantes del proceso de formación de la 
identidad que se refieren a la búsqueda del óptimo distintivo de lo esencial, es decir, del proceso de ser iguales y diferentes al mismo tiempo.

Las preguntas por el pasado denotan un estado, que presente en el hoy, evocan un ayer y esperan un futuro. La importancia del pasado, o en general de la historia, se ve reflejada en la capacidad que tienen los MM para recordar puntual y específicamente aquellos hechos que acontecieron en un tiempo y espacio determinados. Factor significativo es el proceso de cómo conocieron las $\mathrm{OO}$, pero, sobre todo, la posibilidad de proyectarse dentro de ellas. La decisión de entrar y participar, no solo está motivada por el prestigio y el reconocimiento de la empresa, en su trayectoria organizacional, sino por la proyección que le pueda brindar al trabajador.

Las categorías emergentes enunciadas ayudan a explicar y entender los tres conceptos principales que se convierten propiamente en los hallazgos de la investigación. Por esto, ha sido necesario hacer una breve conceptualización para poder dar cuenta en mayor profundidad del proceso de construcción identitario de los $\mathrm{MM}$ de $\mathrm{CN}$, el cual se construye a partir de los tres constructos encontrados: reconocimiento, trascendencia y seguridad. Tanto las organizaciones de origen (OO) como la historia personal, profesional y organizacional (Hist.per.prof.org) están presentes en la conformación de estas categorías principales pero en sentidos diferentes. Las $\mathrm{OO}$ se convierten en una tensión permanente que propicia una resistencia al cambio y, con ello, a adquirir una nueva 10 , pues aquellas siguen presentes como referentes para los MM. Por otro la lado, la Hist.per.prof.org es transversal a cada una de ellas.

En efecto, tales aspectos se desarrollarán con mayor profundidad y detalle al momento de explicar los constructos principales. Se puede revisar el tercer capítulo sobre los aspectos metodológicos y consultar el apartado ocho en donde se explica la construcción de las categorías emergentes principales. 


\subsubsection{Categorías emergentes principales}

A continuación se presentan las categorías emergentes principales de la investigación. En cada una de ellas se introducen aspectos teóricos novedosos, en el entendido de que no fueron desarrollados en el marco teórico y conceptual (proceso similar se hizo en los hallazgos referidos a los directivos). Con el fin de abordar conceptualmente cada uno de ellos, se recurrió a las ciencias sociales, concretamente a la filosofía y a la antropología, para precisar los conceptos, ampliar la comprensión y enlazar las relaciones con el proceso de construcción identitario. Esto no solo permitió un mejor análisis de los datos sino que su relación con la IO se convierte en uno de los aportes relevantes del estudio.

En ese orden de ideas, es conveniente aclarar lo siguiente: cada categoría emergente principal es analizada, según el caso, a partir de una nueva teoría específica. En consecuencia, con base en esta, en consonancia con los objetivos de la investigación y dentro del marco del modelo teórico-metodológico propuesto, se desarrolla la profundización correspondiente. Así, el análisis de los datos guarda una estrecha relación con la unidad de análisis de la indagación que es la construcción de la 10 de los MM de CN. Estos dos elementos (objetivo de la investigación y unidad de análisis), enmarcados dentro del modelo teóricometodológico, permiten que las reflexiones llevadas a cabo no caigan en cierto eclecticismo, es decir, que el análisis se base en múltiples teorías para obtener información complementaria en la interpretación de los datos. Con la teoría emergente no se busca, entonces, conciliar las diversas disciplinas, sino utilizar conceptos o marcos teóricos diversos que permitan ahondar en la problemática propuesta y enriquecer su comprensión, a la vez que abrir puentes y nuevas relaciones para el estudio de los fenómenos organizacionales. 


\subsubsection{Reconocimiento}

El reconocimiento es un aspecto crucial de los hallazgos de la investigación. Su análisis se vuelve indispensable para acercarse a la comprensión del proceso de construcción de $\mathrm{IO}$ de los MM. A continuación se presenta la teoría emergente, fundamentada en la propuesta de Axel Honneth.

\subsection{Reconocimiento como ideología, formas de reconocimiento y ofensas morales}

El tema del reconocimiento es tratado ampliamente por el actual director de la llamada Escuela de Frankfurt: Axel Honneth. Él nació en 1949 en Essen, cursó estudios de filosofía, sociología y germanística en las universidades de Bochum y de Bonn. En 1974, obtuvo su graduación en filosofía. Amplió sus estudios en la Universidad Libre de Berlín (1974-1976), en cuyo Instituto de Sociología desempeñó el cargo de asistente científico entre 1977 y 1982. Realizó su doctorado en el Instituto Max Planck de Ciencias Sociales bajo la dirección de Jürgen Habermas. En 1990 accedió a la habilitación en el área de filosofía por la Universidad de Fráncfort del Meno. Desde 2001 es director del Instituto de Investigaciones Sociales, más conocido como la Escuela de Frankfurt, centro de pensamiento neurálgico de la Teoría Crítica ${ }^{114}$. Según Hernández y Herzog (2011), Honneth puede ser considerado como la figura más relevante de la tercera generación de la Escuela de Frankfurt.

En este apartado no se trata de presentar la obra intelectual del influyente pensador alemán, tan solo de retomar algunas de sus propuestas teóricas y conceptuales para el análisis de los resultados de la investigación referidos concretamente al tema del reconocimiento. Por ello se explican brevemente

\footnotetext{
${ }^{114}$ El proyecto de Axel Honneth está asociado a revitalizar la Teoría Crítica por medio de la Teoría del Reconocimiento, cuyos planteamientos principales están expuestos en su obra La lucha por el reconocimiento (edición en alemán de 1992, en español de 1997). Su trabajo parte de una premisa antropológica fundamental: "El hombre es solamente hombre entre los hombres".
} 
algunos conceptos que deben ayudar a comprender el proceso de construcción identitaria de los $\mathrm{MM}$ de $\mathrm{CN}$ en donde interviene el reconocimiento.

Para iniciar, es conveniente partir por una crítica que el autor hace al tema del reconocimiento y las posibilidades que se tiene de considerarlo como una ideología. Honneth (2006, pp. 129-130) afirma que dicho término ha sido utilizado con un carácter meramente retórico y de sucedáneo, convirtiéndolo "en un instrumento de la política simbólica, cuya función subterránea es integrar a individuos o grupos sociales en el orden social dominante mediante la sugestión de una imagen positiva de sí mismo", por lo cual el reconocimiento social tan solo servirá para la generación de actitudes conformes al sistema, fortaleciendo su sometimiento por medio del reconocimiento mutuo.

El autor retoma el concepto marxista de Louis Althusser (del que luego tomará distancia) para afirmar que en la praxis del reconocimiento público se localiza el mecanismo estandarizado de todas las formas de ideología. Así, esta es concebida como el proceso mediante el cual los individuos se convierten en sujetos en el sentido de que adquieren una conciencia de las propias responsabilidades y derechos gracias a que son sometidos a un sistema de reglas y atribuciones sociales que les otorga identidad social. Para él:

Pierde repentinamente lo que podríamos denominar como reconocimiento toda connotación positiva y se convierte en el mecanismo central de toda ideología: reconocer a alguien significa inducirlo, en virtud de requerimientos repetidos y continuados de forma ritualizada, exactamente al tipo de autocomprensión que encaja adecuadamente en el sistema establecido de expectativas de comportamiento. (Honneth, 2006, p. 130).

Y con ello:

El reconocimiento social puede siempre tener la función de actuar como ideología generadora de conformidad: la repetición continuada de las mismas fórmulas de reconocimiento alcanza sin represión el objetivo de producir un tipo de autoestima que provee de las fuentes motivacionales para formas de sumisión voluntaria. (p. 131). 
Estas son las perspectivas netamente críticas en relación con la ideología que asientan las bases para la discusión desde el punto de vista del reconocimiento. Sin embargo, es necesario precisar el concepto desligado de las válidas presunciones antes descritas. Así, el reconocimiento hace referencia a actitudes o prácticas a través de las cuales los sujetos individuales o grupos sociales son ratificados en algunas de sus cualidades.

El reconocimiento debe ser concebido como género de diferentes formas de actitud práctica en la que cada vez se refleja el objetivo primario de una determinada afirmación del que está en frente. A diferencia de lo que Althusser sostuvo, tales comportamientos afirmadores poseen un carácter indudablemente positivo, porque permiten al destinatario identificarse con sus cualidades y con ello alcanzar una mayor autonomía; lejos de representar una mera ideología, el reconocimiento configura las condiciones previas intersubjetivas de la capacidad de realizar autónomamente los propios objetivos vitales. (Honneth, 2006, p.135).

Así, un elemento importante en la propuesta de Honneth (1997b) es el hecho de considerar que el reconocimiento humano comporta un conjunto de hábitos que, en el proceso de socialización, están vinculados con las razones capaces de constatar el valor de otras personas. A esta altura, es pertinente precisar un aspecto más: cuando se habla de ideología suele entendérsela como formaciones de consciencia o sistemas de enunciados evaluativos cuya fuente no es la relación intersubjetiva, sino reglas o acuerdos institucionales. Como se mencionó líneas arriba, la premisa antropológica clave de Honneth es la relación intersubjetiva que hace al hombre tal. Entonces, ¿cómo se logra o significa que se pueda dar un reconocimiento no solo por parte de personas sino también a nivel institucional? La respuesta, es clara: "[...] también las regulaciones y prácticas institucionales pueden contener representaciones acerca de qué cualidades de valor de los seres humanos deben alcanzar reconocimiento de modo específico" (Honneth, 2006, p. 138).

La propuesta de Honneth a este respecto, por tanto, se basa en la posibilidad de una forma racional, adecuada, de reconocimiento que consiste en hacer valer públicamente, de modo performativo, cualidades de valor ya existentes en los 
seres humanos. Así, y en relación con Kant, reconocer a alguien significa percibir en él una cualidad de valor que motiva intrínsecamente a comportarse no de manera egocéntrica sino adecuada a los propósitos, deseos o necesidades de los demás. Es así como el reconocimiento debe constituir una acción moral porque se determina por el valor de las otras personas; el comportamiento de reconocimiento no se orienta según los propios propósitos, sino según las cualidades evaluativas de los demás. ${ }^{115}$

Es claro que para Honneth las formas de reconocimiento social no pueden poseer solo una función ideológica. Las ideologías de reconocimiento proporcionan la disposición emocional para cumplir sin resistencia las tareas y obligaciones esperadas. Para que estos sistemas de persuasión no puedan ser considerados como ideologías deben caracterizarse por lo siguiente (Honneth, 2006, pp. 140142):

a) La cualidad debe expresar el valor positivo de un sujeto o grupo de sujetos. La función que se espera de ellos solo pueden cumplirla si se les da la oportunidad de referirse a sí mismos de manera positiva de tal modo que se vean alentados a la asunción voluntaria de determinadas tareas. Se excluyen aquellas declaraciones discriminadoras. Las ideologías deben ser efectivas en virtud del reconocimiento social al integrar, no para excluir.

b) Los sistemas de persuasión indagados deben ser dignos de crédito para los propios afectados. La función performativa se pierde cuando las personas apeladas no encuentran ninguna buena razón para identificarse con la declaración valorativa vigente para ellos. Hay un criterio de credibilidad. Las ideologías del reconocimiento solo pueden utilizar las declaraciones valorativas

\footnotetext{
${ }^{115}$ A partir de ello, Honneth distingue tres formas de acción moral, correspondientes a las formas diferenciadas de reconocimiento del mundo, ya que, para él, el horizonte de valores de la sociedad moderna está marcado por la representación de lo que los seres humanos deben recibir al menos como seres necesitados, con iguales derechos de su autonomía, al cual corresponden las distintas formas de comportamiento de reconocimiento: amor, respeto jurídico, valoración social (Honneth, 1997a).
} 
que de alguna manera están a la altura del vocabulario evaluativo de cada individuo. Por el contrario, aquellas declaraciones que señalan como visibles cualidades de valor que han caído en descrédito, serán percibidas como carentes de credibilidad.

c) Las declaraciones valorativas deben ser contrastantes en el sentido de que en cada caso deben expresar nuevos valores o capacidades específicas. Esta condición se deriva de que los individuos solo tienen la posibilidad de identificarse con las determinaciones válidas para ellos cuando pueden experimentarse como distinguidos, de ahí que estas declaraciones valorativas deben de mostrar un contraste en comparación con el pasado o con el orden social circundante, lo cual ofrece una garantía para la experimentación de distinciones positivas específicas.

En efecto, las ideologías del reconocimiento podrán promover una relación individual consigo mismo que motive la asunción voluntaria de tareas y funciones cuando las declaraciones cumplan al mismo tiempo con estas tres condiciones: sean positivas, dignas de crédito y contrastantes. A ello, Honneth (2006, p. 146) le agrega un cuarto aspecto de vital importancia:

El reconocimiento no debe de agotarse en meras palabras o manifestaciones simbólicas, sino que debe acompañarse de acciones acreditadoras: un acto de reconocimiento queda de alguna manera incompleto mientras no desemboque en modos de conducta que pongan de manifiesto también de forma efectiva el valor articulado.

Aunque el reconocimiento institucional generalizado se traduce, a largo plazo, en formas modificadas de hábito, la fuente primaria de su cumplimiento reside en el cambio hacia nuevas formas de reconocimiento social generalizadas, transformadas en disposiciones jurídicas y representadas en forma material. En otras palabras, la brecha entre la promesa evaluativa y el cumplimiento material se debe de cerrar. Ello implica generar toda una estructura que proporcione las condiciones materiales bajo las cuales son realizables las nuevas cualidades de 
valor de las personas afectadas. Si no se cumple esto, efectivamente los modelos institucionales de reconocimiento serán considerados como ideologías.

Ahora bien, a partir de la propuesta del filósofo alemán y sobre la base de tener claro cómo el reconocimiento y las formas institucionalizadas concretas que se apoyan en él pueden o no convertirse en un una ideología, a continuación se explica la relación entre el reconocimiento y la obligación moral, otro elemento importante para la posterior interpretación de los datos.

Honneth (1997b, pp. 242-243) plantea la relación entre el reconocimiento no obtenido o denegado y una falta moral. La conciencia de no ser reconocido en la propia autocomprensión es lo que constituye una condición de ofensa moral. Con el propósito de explicar tal relación, el autor expone una serie de premisas que, tomadas en conjunto, esclarecen la relación constitutiva entre ofensa moral y reconocimiento no obtenido. Estas son las siguientes:

a) Solo puede ofenderse moralmente a aquellos individuos que se refieren reflexivamente a su propia vida, en el entendido que les importa su propio bienestar. Sin la referencia a patrones cualitativos acerca de la propia vida, no se puede explicar qué es lo que realmente daña o lastima a una persona.

b) La condición de posibilidad para que exista un daño moral requiere de las reacciones aprobatorias o afirmativas de otros sujetos. Sin la referencia a estas presuposiciones intersubjetivas no se puede llegar a comprender por qué se le daña a una persona cuando mediante determinadas acciones, declaraciones 0 circunstancias, se destruye un aspecto específico de su autocomprensión.

c) Si la ofensa moral consiste en que a través de ella una persona es menospreciada en algunos aspectos de su autorrelación positiva, de los cuales requiere de una confirmación intersubjetiva, entonces esto se esclarece en una experiencia psicológica. La experiencia de una injusticia moral implica una 
perturbación psíquica en la medida en que el sujeto es decepcionado en alguna expectativa cuyo cumplimiento es parte de su propia identidad. En ese sentido, cada ofensa moral es un acto de daño personal porque destruye un supuesto esencial de la capacidad de acción del individuo.

Honneth continúa afirmando con su argumentación que si bien estas premisas aclaran en líneas generales en qué medida la particularidad de las ofensas morales reside en la ausencia o negación del reconocimiento, también es posible diferenciar las distintas formas de injusticia. Para ello usa el siguiente criterio: "[...] las ofensas morales serán consideradas más graves según sea más elemental el tipo de autorrelación que perjudican o destruyen" (Honneth, 1997b, p. 243). A partir de estas consideraciones es posible esbozar una tipología que subdivida el espectro de ofensas morales según el punto de vista de los respectivos niveles de autorrelación implicados. Para el filósofo alemán, a cada nivel de la autorrelación práctica le corresponderá un tipo especial de injusticia, a la vez que le concierne un grado específico de daño psíquico. Es preciso, entonces, definir estos niveles que comprenden la relación práctica con uno mismo. El autor distingue tres fases de autorrelación práctica ${ }^{116}$ :

- Primer nivel o forma de autorrelación: Nivel primario. Los sujetos se refieren a sí mismos de tal modo que conciben sus necesidades físicas y sus deseos como parte articulable de su propia personalidad. El autor alemán acuña, de acuerdo con Erikson, el concepto de autoconfianza como el tipo se seguridad elemental sobre el valor de la propia indigencia.

- Segundo nivel o forma de autorrelación. Ser un sujeto moralmente responsable de sus propios actos. El filósofo, recurriendo al kantismo, llama autorrespeto a este tipo de seguridad sobre el valor de la propia formación de juicios.

\footnotetext{
${ }^{116}$ Por autorrelación se entiende la conciencia o el sentimiento que cada persona tiene de sí misma con respecto a las capacidades y los derechos que le corresponden. Solo se puede alcanzar esta autorrelación en la medida en que se ven confirmados o reconocidos por otros el valor de determinadas capacidades y derechos.
} 
- Tercer nivel o forma de autorrelación. Se manifiesta en la conciencia de poseer capacidades buenas o valiosas. Se le denomina como autoestima.

A estos niveles de autorrelación, Honneth le asigna el tipo de ofensas morales y la forma de reconocimiento respectivo, como aparece en la tabla 17:

\section{Tabla 17: Formas de autorrelación y reconocimiento. Tipo de ofensas morales correspondientes}

\begin{tabular}{|c|c|c|}
\hline Niveles o formas de & Tipos de ofensas morales & Formas de reconocimiento \\
\hline Primer nivel: Autoconfianza & $\begin{array}{l}\text { Aquellas que privan a la } \\
\text { persona de seguridad para } \\
\text { disponer de su propio bienestar } \\
\text { psíquico. Actos de este tipo } \\
\text { destruyen la confianza en el } \\
\text { valor de quien goza la propia } \\
\text { indigencia. Ejemplos: maltrato } \\
\text { físico, tortura, violación. }\end{array}$ & $\begin{array}{l}\text { El individuo es reconocido como } \\
\text { una persona cuyas necesidades } \\
\text { y deseos son de valor singular } \\
\text { para otra persona. Es un tipo de } \\
\text { entrega incondicional. Se } \\
\text { emplean conceptos como los de } \\
\text { cuidado y amor. }\end{array}$ \\
\hline Segundo nivel: Autorrespeto & $\begin{array}{l}\text { Aquellas que menosprecian la } \\
\text { responsabilidad moral de las } \\
\text { personas. Esta se afecta a } \\
\text { través de tales; incluso, se } \\
\text { destruye la autoestima cuando } \\
\text { otras personas no reconocen el } \\
\text { valor de los propios juicios. } \\
\text { Ejemplos: engaño y fraude, } \\
\text { discriminación. }\end{array}$ & $\begin{array}{l}\text { El individuo es reconocido como } \\
\text { una persona a la que le } \\
\text { corresponde la misma } \\
\text { responsabilidad moral que a } \\
\text { todos los seres humanos. Es un } \\
\text { trato universalmente igualitario, } \\
\text { para el cual se emplea el } \\
\text { concepto de respeto moral. }\end{array}$ \\
\hline Tercer nivel: Autoestima & $\begin{array}{l}\text { Casos en los que se } \\
\text { demuestra, a través de la } \\
\text { humillación o falta de respeto a } \\
\text { una o más personas, que sus } \\
\text { capacidades no gozan de } \\
\text { reconocimiento. Actos de este } \\
\text { tipo dañan el sentimiento de } \\
\text { poseer importancia social en el } \\
\text { seno de una comunidad } \\
\text { concreta. Ejemplos: Quitar el } \\
\text { saludo infligir } \\
\text { estigmatización. o }\end{array}$ & $\begin{array}{l}\text { El individuo es reconocido como } \\
\text { una persona cuyas capacidades } \\
\text { tienen un valor constitutivo para } \\
\text { una comunidad concreta. Se } \\
\text { utiliza el concepto de solidaridad } \\
\text { o lealtad. }\end{array}$ \\
\hline
\end{tabular}

Fuente: Adaptación a partir de Honneth (1997b, 2009).

Con las anteriores definiciones se esclarece el sentido intersubjetivo del hombre. Se requiere del otro para ser reconocido. Además, llegado a este punto, es pertinente definir el concepto de moral: 
Los seres humanos pueden ser ofendidos en una manera específica que llamamos «moral» porque deben su identidad a la construcción de una autorrelación práctica que desde el primer momento depende de la cooperación y la aceptación de parte de otros hombres. [...] La moral comprende el conjunto de actitudes que estamos obligados a adoptar recíprocamente para asegurar en común las condiciones de nuestra identidad personal. (Honneth, 1997b, pp. 246-247).

En este sentido, las distintas actitudes son introducidas por referencia a un estado considerado deseable, en la medida que sirve (de ahí su carácter netamente teleológico) al bienestar humano. Así, la moral es un mecanismo colectivo que asegura la identidad personal.

Con las formas de reconocimiento explicadas, quedan nombradas las actitudes morales que, tomadas en conjunto, constituyen el punto de vista cuya asunción asegura las condiciones de la integridad personal. Sin embargo, las asimetrías reinantes en estos niveles traen una consecuencia paradójica: el punto de vista moral describe una perspectiva que obliga a los sujetos a adoptar actitudes distintas según sea el tipo de la relación intersubjetiva en que se hallen involucrados.

El vínculo entre los deberes y derechos es lo que permite hablar específicamente de una moral del reconocimiento. Estas obligaciones recíprocas consisten en el trato igualitario universal; todos los sujetos tienen mutuamente el deber de tratarse y respetarse como personas a las que les corresponde la misma responsabilidad moral. El filósofo alemán termina así de explicar este tema:

La teoría moral que hemos venido desarrollando encierra una idea que difiere en un punto decisivo de todas las interpretaciones tradicionales, a saber, que entre las tres formas de reconocimiento que, tomadas en conjunto, constituyen un punto de vista moral, no puede darse una relación armónica, sino debe existir una relación de tensión constante. (Honneth, 1997b, p. 251).

Vale la pena aclarar que para este autor, los tres modelos de reconocimiento designan actitudes morales que no tienen por qué entrar en conflicto unas con otras en la medida que poseen carácter vinculante solo en el marco de una forma específica de relación social. Así, en situaciones específicas, se está obligado a 
actos de reconocimiento en función de las relaciones sociales. Sin embargo, en circunstancias de conflicto, según otros parámetros, se debe decidir a cuáles de los compromisos se le concede supremacía. No obstante, y dado el carácter universalista en donde se debe reconocer a todos los seres humanos como personas que disfrutan de un mismo derecho a la autonomía, no se estará moralmente permitido optar por relaciones sociales cuya realización implique una lesión de dichas pretensiones.

A continuación se procede a analizar esta categoría principal, con base en lo expuesto por Axel Honneth y los marcos teóricos ya explicados en el capítulo dos.

\subsection{Un reconocimiento con tinte ideológico}

Es importante determinar si el reconocimiento para los $\mathrm{MM}$ de $\mathrm{CN}$ es una construcción ideológica $^{117}$, con la cual se pretende que el individuo disponga de una estructura emocional que le impulse y permita cumplir sus compromisos mitigando la resistencia, de tal manera que esté sometido, a la vez, a encajar adecuadamente en un sistema establecido de antemano y lo lleve a cumplir con una serie de comportamientos específicos.

Por tanto, se evaluarán las condiciones o requisitos que propone Axel Honneth para considerar el reconocimiento como una ideología. Las declaraciones positivas que buscan hacer públicas las cualidades de valor existentes en los individuos podrán ser pensadas como ideológicas si no cumplen con tres condiciones: ser positivas, dignas de crédito y contrastantes. A estas, el mismo autor agrega una más: ha de tener representación material efectiva, es decir (y para el caso específico de análisis), se deben dar, a nivel organizacional, los

$117 \mathrm{Si}$ bien este aspecto se pude relacionar, y en ese sentido analizar a partir del nuevo institucionalismo o la misma llamada cultura corporativa, aquí se examina desde el marco propuesto, pues comporta un mayor vínculo con la identidad. Asimismo, este estudio permite nuevas maneras de aproximarse a los fenómenos organizacionales, más allá de los comúnmente conocidos. 
medios para que dichas valoraciones se cumplan y no queden en meras elucubraciones.

Se entiende, además, que en el marco del modelo teórico-metodológico, la 10 funciona como un diálogo entre los MM y los directivos. Implícitamente, se reconoce la necesidad de la intersubjetividad para hablar de un proceso de construcción identitario. En ese sentido, el modelo de análisis propuesto está en sintonía con la premisa antropológica fundamental de Honneth de considerar al hombre como tal, únicamente si es capaz de entrar en relación con otros.

En efecto, el valor que los directivos manifiestan a los MM está encaminado a afirmar y declarar que estos son imprescindibles para la operatividad del negocio y con ello, para la eficiencia de todo el ejercicio, el cual, no solo se circunscribe a CN sino a todo el GN. Como se comentó en el capítulo anterior, se está, entones, frente a una reificación del sujeto, fruto de una clara racionalidad instrumental. No obstante, las proclamaciones de valor son positivas en el entendido de que alientan a los MM a realizar sus funciones, es decir, son un aliciente para el cumplimiento de sus tareas. Si bien existen palabras de aliento y expresiones en donde se resaltan sus capacidades en cuanto su disposición y gran incidencia en la estrategia de la compañía, la razón de este tipo de términos se funda en un modelo que no es totalmente compartido por los directivos, lo que significa que no cuenta con la aprobación y credibilidad de quienes emiten o expresan tales aseveraciones valorativas. Por consiguiente, se traduce en un apoyo verbal sostenido en una creencia ambigua y en algunos casos ficticia.

La segunda condición demanda que las declaraciones sean dignas de crédito, que cumplan con el criterio de credibilidad. Esto es, justamente, lo que queda en entredicho, gracias a la ambigüedad del MG que contradice el discurso profesado por la dirección. En otras palabras, la búsqueda de que los MM posean una autonomía inexistente, la falta de condiciones estructurales y estratégicas de los cargos para tomar decisiones democráticas, el desbalance de la experiencia y el 
inadecuado salario de los miembros del FC, entre otros aspectos ${ }^{118}$, hacen que la credibilidad en cuanto a las capacidades para ser ejecutores de la estrategia del negocio, así como la responsabilidad en cuanto a la eficiencia del modelo, caiga en descrédito. En tales condiciones, pues, los elogios y manifestaciones positivas no tienen dónde desarrollarse como tales, por lo que dicho discurso es considerado sin contenido por parte de los MM.

La tercera condición propende por que haya un contraste efectivo que permita mostrar una diferencia entre el ayer y el hoy de las declaraciones positivas. Con respecto a este asunto, en concreto, se presenta una decepción entre los MM al recordar la relación y los reconocimientos positivos que recibían de sus $\mathrm{OO}$. Si bien se encuentran afirmaciones positivas en donde se reconoce la autonomía de los sujetos, estas no demuestran un contraste significativo con las emitidas por las compañías de donde provinieron. Incluso, las antiguas declaraciones tenían un grado mayor de valoración, o así las perciben los MM.

Por último, la cuarta condición viene a convertirse en el sostén o garantía de que dichos actos declarativos positivos sobre el sujeto realmente se lleven a la práctica, o aquello que enuncian tengan un sentido asertivo en la realidad y se concreten efectivamente. El cambio debería de manifestarse en la creación de espacios de reconocimiento dentro de la organización. En el caso de CN se pueden distinguir algunos procesos en los cuales se dan condiciones para llevar a la práctica los reconocimientos $\mathrm{y}$, en consecuencia, ser coherentes con las declaraciones mencionadas. Uno de esos procesos es el plan de carrera. El contraste es evidente: mientras los MM pasan de tener muchas posibilidades de ascenso dentro de las compañías de donde provenían, aquí entran en una dinámica estructural mucho más cerrada y competitiva. Ya no solo rivalizan con los miembros de su área, sino también con sus colegas e iguales de las otras compañías del GN. De esta manera, se les dificulta optar por un ascenso ya que

\footnotetext{
${ }^{118}$ El lector se puede remitir al capítulo cuatro para retomar dichas consideraciones.
} 
incluso las vacancias son poco comunes. A todo esto se le agrega una política reciente, con la cual las convocatorias para acceder a ciertos cargos directivos o importantes ya no solo se llevarán a cabo dentro de la $\mathrm{CN}$, sino que los aspirantes deberán competir con los de todas las empresas del GN. De este modo se evidencia la carencia de una estructura, política o estrategia que permita considerar que los valores positivos declarados a los MM puedan materializarse de forma efectiva.

El reconocimiento es una expresión valorativa positiva de un individuo o de un grupo a otro. Es el realce de las cualidades apreciadas y confirmadas en sociedad, las cuales propician identificación del individuo con ellas, lo que permite a este conocerse un poco más y favorecer la autonomía que se desprende de la confianza que dichos enunciados generan en el quehacer cotidiano. Esta dimensión del reconocimiento resalta su aspecto social, dialogal y comunitario. Las cualidades son expresadas por otro, y en ese sentido, coloca al individuo como ser social, en donde la alteridad se vuelve algo constitutivo y necesario para su desarrollo y crecimiento.

Así pues, las ofensas morales, que no son otra cosa que el no-reconocimiento, generan en el individuo una autocomprensión de quién es, pues advierten y propician una reflexión sobre sí que es impulsada por la ausencia de declaraciones que registren y valoren las cualidades propias. Un reconocimiento ideológico, que busca generar una serie de conductas dentro de un proceso de adaptación al sistema, con una clara concepción reificante, que ubique al individuo dentro de un proceso productivo en específico, no solo va en contravía de respetar la propia autonomía, sino que la capacidad de acción se verá paradójicamente mermada.

Al realizar, pues, el análisis a partir de la propuesta de Honneth, se puede afirmar que el reconocimiento brindado por los directivos tiene un tinte ideológico. Lo que se busca es la constitución de un sujeto conforme a una estructura de gobierno 
creada para buscar una eficiencia productiva. Las valoraciones sobre el actuar y las capacidades que tienen los MM no buscan el bienestar de estos y, por lo mismo, no constituyen un reconocimiento real de quiénes son, sino que fungen como un dispositivo de instrumentalización identitario. Por consiguiente, tal reconocimiento no reconoce en el sentido estricto del concepto aquí definido ni es una categoría de respeto; se convierte en un instrumento de enajenación.

\subsection{La respuesta de los MM}

Luego de esta discusión y por lo desarrollado en el capítulo anterior, se concluye entonces que los MM se enfrentan a un proceso ideológico reificante. Surgen así varias preguntas: ¿Cómo construyen los MM una IO? ¿Qué elementos intervienen en dicho proceso? ¿Cómo hacen frente al condicionamiento incesante por instaurar en ellos una IO particular?

Desde el punto de vista del reconocimiento, hay tres elementos que intervienen y por lo mismo son importantes para los $\mathrm{MM}$, en el entendido que configuran ciertas condiciones intersubjetivas para realizar autónomamente sus acciones.

En primer lugar, el reconocimiento es personal. Si bien cada cargo es importante dentro de la estructura organizativa de $\mathrm{CN}$, las cualidades positivas que se reconocen a los $\mathrm{MM}$ se refieren a quienes ocupan tales cargos. Es la valoración positiva del sujeto en su individualidad, por fuera de su relación netamente laboral en donde tal declaración se realiza, se concreta. El MM es reconocido como una persona en su singularidad, cuyas necesidades y deseos son importantes y relevantes para el otro. Queda relegado a un plano inferior el reconocimiento direccionado únicamente a resaltar las cualidades que estén en relación con sus 
capacidades y habilidades productivas, para dar paso a los valores no sujetos a criterios de eficiencia y rentabilidad $^{119}$.

Esta singularidad interroga el equilibrio organizacional existente en donde, a pesar de que los intereses de los individuos y de la organización no necesariamente coinciden, ambos actores mantienen una relación que les es útil para lograr sus propios intereses. De este modo se configura una relación de conveniencia. La valoración y el reconocimiento a partir de afirmaciones positivas exigen considerar al individuo en una dimensión más profunda y personal, rompiendo la relación utilitarista de mutua necesidad. Se manifiestan aspectos propios del sujeto que van más allá de un cinismo, o cierto protocolo, que busca sostener la relación en el equilibrio de dependencia mutua.

Dichas enunciaciones positivas se pueden convertir en procesos reificantes, pues al utilizarlas como medios para buscar fines productivos, no son reconocimientos valorativos de las cualidades del individuo, sino mecanismos de adaptación a un sistema particular. No obstante, tal reconocimiento parte de observar una serie de calidades en el otro, lo cual implica una preocupación por él, un descubrir cierta identidad que especifica la realidad del individuo en relación con los demás. Si bien esas declaraciones pueden ser manipuladas con objetivos egoístas, su construcción implica la intersubjetividad y el reconocimiento desde la individualidad, dándole al hecho un carácter humanizante.

Un segundo aspecto es que el reconocimiento se sostiene gracias a que los MM se saben importantes y valiosos para la organización. Las capacidades y habilidades son respetadas y registradas como aspectos constituyentes de la organización en donde trabajan. Esto es valorado por los MM cuya retribución o respuesta es un afecto y agradecimiento hacia la compañía, pero no a CN sino a las OO. En este sentido, los MM se saben valiosos para las organizaciones de

${ }^{119}$ Esta es la única subcategoría que forma parte de las categorías preliminares o precategorías (IProf). El resto de elementos conforman parte de las categorías emergentes, tanto de la Hist.PerProf-Org como de las OO. 
donde llegaron, no para la que laboran en la actualidad. Así, y siguiendo la propuesta de Honneth (1997b, 2009), hay una lealtad y solidaridad que las OO le manifestaron a los MM, pero que no está presente o, al menos, no es reconocida como tal en $\mathrm{CN}$.

Ahora bien, el no-reconocimiento, considerado por Honneth (1997b) como una ofensa moral, se manifiesta en el conjunto de declaraciones positivas que les fueron denegadas a los MM en la compañía en donde trabajan. Según el cuadro 19 , este tipo de ofensa moral se encuentra en el nivel de la autoestima en tanto que las capacidades de los individuos no gozan de reconocimiento dentro de la nueva comunidad de CN. Esto se manifiesta en las contradicciones provenientes de la dirección en cuanto a los procesos a seguir dentro del MG.

Muchos MM perciben como una falta de lealtad por parte del GN el cambiarles las condiciones laborales y obligarles a formar parte de la nueva compañía. Fruto del cambio, ellos se han apegado al reconocimiento que tenían en las OO. La historia construida a nivel personal, familiar y profesional, al lado de las organizaciones que los vieron crecer como personas y como profesionales, ha generado una relación afectiva muy fuerte. El reconocimiento entonces proviene de las OO; curiosamente, a pesar de no recibirlo de estas, pues en la actualidad no hay relación laboral, los MM rememoran su experiencia pasada y en el presente hacen la comparación. Es la referencia del pasado y esas vivencias lo que marcan las posibilidades de construcción identitaria que tiene los MM.

Un tercer elemento es el aspecto de las renuncias. Los MM, a lo largo de su historia con el GN, han tenido que realizar sacrificios tanto a nivel personal como familiar y profesional. Estos aspectos —ya se dijo- han forjado y hacen parte del proceso de formación de los MM en su tránsito y peregrinar por el GN. Sin embargo, subsiste un aspecto importante: el sacrificio se vio retribuido por los ascensos y el mejoramiento de la calidad de vida en las $\mathrm{OO}$ de donde provienen. Ha existido un trato igualitario, que se ha visto recompensado por la mejor 
posición económica y profesional con la cual han sido beneficiados y, por tanto, ahora buscan que se les respete y mantenga.

Por todo lo anterior, los tres aspectos enunciados (reconocimiento personal, importancia para la organización y sacrificios retribuidos) se integran en la historia de vida de cada individuo. El reconocimiento tiene una connotación de perdurabilidad, en el entendido que busca prolongarse en el tiempo. La historia de vida (para esta investigación) se conforma por el recorrido personal, profesional y organizacional de cada uno. Los individuos, a lo largo de su vida, requieren de declaraciones positivas acerca de lo que hacen, piensan o sienten, como manera de afirmarse en el mundo y construir una identidad propia. Así, la historia de vida estará llena de acciones reconocidas y no reconocidas por otros, en estas tres facetas de la identidad del individuo. Se entiende, desde el punto de vista temporal, que la historia personal inicia antes que la profesional y esta última antes de la propiamente organizacional. Así, la 10 es una historia que si bien empieza con la vinculación laboral del individuo, se construye sobre la base de una identidad personal y profesional que se viene estructurando desde tiempo atrás.

Si bien estas tres historias se dan en paralelo, y comienzan en distintos puntos de la línea del tiempo, no son incoherentes entre sí, es decir, el reconocimiento que buscan los MM se nutre de las historias personales, donde la familia se convierte en el espacio en el cual ellos aluden las muestras de reconocimiento recibidas en el trabajo. El reconocimiento abarca estas tres dimensiones de la historia del individuo. Las declaraciones positivas y muestras de estima y de respeto dadas en la organización enorgullecen la vida profesional y repercuten positivamente en las historias de vida personales.

Hay una unidad y estrecha relación entre dichos contextos. Se podría afirmar entonces que es un reconocimiento completo, unitario, en donde participan las tres dimensiones y el reconocimiento las integra en el tiempo, en donde la 10 forma 
parte y ayuda a cohesionarlas. Los esfuerzos de los miembros para dar sentido a su realidad organizacional está influenciada por la necesidad de preservar un concepto de sí mismos (Dutton y Dukerich, 1991). De esta manera, no habrá una satisfacción entre los MM si en el trabajo, o en la vida organizacional, se les exime de las muestras de reconocimiento, mientras en el hogar se les reconoce por su labor.

\subsubsection{Trascendencia}

La trascendencia es la segunda categoría emergente principal como componente neurálgico en el proceso de construcción identitario de los MM. Tiene relación con el deseo de estos de que su obra permanezca, continúe en el tiempo. Dejar un legado es la expresión de permanecer en el tiempo como representación no solo de las obras sino también de los individuos que las realizaron. Tales ejecuciones no se restringen al interior de la organización, pues se pretende que ellas superen los límites propiamente organizacionales para dejar su impronta en la sociedad.

La trascendencia está constituida por dos aspectos. Uno, en relación con las actividades que realiza, y en ese sentido es la obra la que busca permanecer en el tiempo; otro, en cuanto relaciones e imagen que se busca dejar en la compañía como un legado. Este último factor está ligado al deseo que tienen los MM de dejar una huella como personas en la organización. Dado que la búsqueda de trascender requiere tener una importancia para la compañía y que la obra y sus relaciones impacten positivamente, hay algunos MM que se sienten subutilizados y quieren irse a otro puesto o a una región más importante, para poder figurar y poder trascender. La estructura más jerárquica y colaborativa de $\mathrm{CN}$ está motivando este tipo de acciones:

Mi proyecto de vida, [es] seguir siendo un maestro con mi equipo y seguir siendo un referente para mis hermanos. Creo que a través del ejemplo he construido mucho con mi familia y a través de ser un maestro he construido también mucho con mi equipo. Yo creo que cuando uno se da la oportunidad de ser maestro es que se quiere dar la oportunidad de ser alumno porque termina uno siendo más alumno que maestro. (MM11). 
La trascendencia lleva a los MM a actuar para dejar un legado, para que la historia de la compañía sea construida contando la historia individual o, dicho de otra manera, la trascendencia implica que el recuerdo del camino recorrido por los MM sea considerado y quede inscrito, por el impacto que tiene para ella, en la leyenda de la organización. Las dimensiones espacio temporales representadas por los dos ejes contextuales (relacional y biográfico) configuran un espacio de posibilidad para que los MM trasciendan por medio de su actuar. De este modo, el obrar implica una acción transformadora por parte del individuo, en la realidad concreta que le circunscribe. Al personaje se le ofrecen múltiples y diversas formas de gestión, que enmarcadas dentro del propio ámbito espacio temporal, pueden ser catalogadas como posibles en el entendido que dichas acciones son elaboradas dentro de una diversidad de posibilidades.

En esa dirección se vislumbra aquí una dinámica de buscar mediante el actuar, la trascendencia del individuo. Este proceso de conquista permite que la persona se haga en sus propios actos. Sin embargo, la clave de estas ejecuciones trascendentes no solo se centra en las acciones en sí mismas y el deseo que las motiva, sino en el motor o causa que las produce. El reconocimiento recibido por parte de las OO, impulsan la acción de los MM a trascender como un gesto de gratitud por las oportunidades recibidas en el proceso de formación y de vida que llevan. En ese sentido, la causa o el motor que inspira la trascendencia reside en el reconocimiento obtenido a lo largo de la trayectoria laboral y expresada en la necesidad de retribuir lo alcanzado.

Este aspecto, que para la investigación se denominó con la categoría de darrecibir-devolver, encuentra en la propuesta del antropólogo francés Marcel Mauss (2009) luces para su comprensión. En su "Ensayo sobre el don. Forma y función de intercambio en las sociedades arcaicas", el autor profundiza sobre el don y su devolución entre otros importantes temas. El sociólogo y antropólogo francés nació el 10 de mayo de 1872 y estudió filosofía en la Universidad de Burdeos y en la École Pratique de Hautes Études de París. Fue discípulo de E. Durkheim y 
colaborador de la revista L'Année Sociologique. Catedrático de historia de las religiones de los pueblos no civilizados e inspirador de la escuela estructuralista francesa. Murió en París el 11 de febrero de 1950.

Marcel Mauss reflexionó sobre la antropología económica al mostrar que el don es agonista, porque el vínculo mercantil genera un lazo social obligante para quien lo recibe. De esta manera, el don crea nexos sociales que obligan a las personas y pueblos que reciben el don. ¿Cuál es la norma de derecho y de interés que ha impuesto en las sociedades de tipo arcaico que el regalo recibido haya de ser obligatoriamente devuelto? ¿Qué fuerza tiene la cosa que se da, que exige al donatario a devolverla? Mauss plantea que la cosa ofrecida tiene alma. Por eso, la obligación por la cosa es una obligación entre almas (entre las almas de las personas que se encuentran relacionadas en el intercambio) ${ }^{120}$, pues ofrecer una cosa a alguien es brindar algo propio, algo de la misma alma. Aceptar algo de alguien significa asentir la esencia espiritual de su alma. La cosa que se sirve no es algo inerte, otorga un poder especial, es animada y a veces individualizada, tiende a producir la devolución a su lugar de origen o a producir un equivalente que la reemplace (Mauss, 2009).

En las sociedades donde se realiza el intercambio se produce un constante dar y tomar. Esta relación está atravesada por una corriente continua que se extiende en todos los sentidos, de dádivas que se entregan y se reciben obligatoriamente, por interés, por benevolencia o por razón de servicios prestados. La riqueza que se regala y se recibe es uno de los principales instrumentos de la organización social, del poder del jefe y de los lazos de parentesco sanguíneo o matrimonial.

${ }^{120}$ Mauss (2009, p. 78) compara el intercambio con los realizados en la ceremonia del Potlatch ("principio de rivalidad o antagonismo que enfrenta a sus jefes en diferentes prácticas hasta darles muerte. Así es que las entiende como prestaciones totales de tipo agonístico".), resaltando el honor como un factor trascendente dentro de los intercambios que se dan en este rito. El anfitrión busca, mediante el acto de regalar sus posesiones a su invitado, mostrar su potencial económico, procurando con ello que quien las reciba vea que su riqueza es tan vasta que puede permitirse regalársela. También desea, de este modo, conservar una autoridad sobre la tribu y su pueblo, porque es mediante el derroche de los recursos como demuestra que sigue favorecido por los espíritus. 
La obligación esencial es dar: el jefe da por sí mismo, por su hijo, su yerno o su hija y por sus muertos. Solo conservará su autoridad entre su pueblo, y mantendrá su rango entre los jefes, si demuestra que está perseguido y favorecido por los espíritus y la fortuna, que está poseído por ella y que él la posee, y solo puede demostrar esta fortuna, gastándola, distribuyéndola, humillando a los otros, poniendo a los demás a la sombra de su nombre. (Mauss, 2009, p. 204).

En la reflexión de este autor, el don no se puede rechazar porque se pondría de manifiesto el temor de tener que devolver y, por ende, se correría el riesgo de quedar rebajado socialmente hasta la reposición. Sería declararse vencido de antemano, aunque en algunos casos se consideraría vencedor o invencible. La obligación de devolver es dignamente imperativa.

La trascendencia en el proceso de dar-recibir-devolver hace referencia precisamente a la relación que los $\mathrm{MM}$ confieren a la responsabilidad de recompensar, como algo imperativo, las oportunidades brindadas por el GN al abrirles las puertas de este grupo empresarial para trabajar. Este tipo de devolución parte de un compromiso, de una responsabilidad con carácter forzoso que tienen los MM con la compañía. Se traduce en un sentimiento de deuda, pero con la característica de buscar retribuir o reponer en mayor cuantía (que no solo se refiere a lo meramente monetario) lo recibido.

Por un lado, esta categoría tiene relación con la OO, ya que la retribución no se realiza en memoria de $\mathrm{CN}$ como tal, debido básicamente al poco tiempo de su existencia, sino a todo un proceso a lo largo de la historia personal y profesional. De este modo, el reconocimiento impulsa la acción de trascender que se ve fundamentada en las $\mathrm{OO}$, para buscar que en la nueva organización $(\mathrm{CN})$ se vean reflejadas en el futuro las acciones trascendentes de los MM.

Por otro lado, la categoría de dar-recibir-devolver se basa en las condiciones que tuvieron muchos de los MM de acceder a un mejor estatus de vida, el cual no solo se refiere a lo meramente laboral y económico, sino a los espacios de formación intelectual, conformación de una familia, conocer otras culturas y regiones, entre otros aspectos. Estas consideraciones llevan a los entrevistados a devolver lo 
recibido, como expresión de gratitud por las posibilidades y oportunidades brindadas. El paso de un estado de calidad de vida a otro está vinculado con la estabilidad, aspecto del cual se está agradecido. Se presenta, entonces, una relación de correspondencia - yo doy y vos me das-, a través de la cual yo devuelvo con creses lo recibido. Esta restitución, como acción trascendente, se manifiesta sobre todo por medio de la enseñanza, en términos de que los MM quieren compartir la experiencia vivida y con ello formar el relevo generacional.

A continuación se profundiza en esos elementos y se presentan ejemplos.

- Dar: Se refiere a aquellas cosas o aspectos que los MM han entregado al GN. Acción caracterizada por el conocimiento y los sacrificios personales que tuvieron que asumir, como la postergación de ciertos planes o el traslado a otras regiones; el tiempo que llevan en la compañía, entendido como lealtad; las esperanzas puestas en que el modelo comercial funcionará, por lo que no aceptaron otras oportunidades laborales durante el proceso de creación de $\mathrm{CN}$.

- Recibir: Agrupa todo aquello que los MM han aceptado de parte del GN. Ellos destacan la formación profesional recibida de los líderes, capacitaciones formales, experiencia; rescatan en este último aspecto el orgullo de estar vinculados a alguna de las compañías del GN, por el prestigio que ello les significa en la sociedad.

- Devolver: Tiene que ver con la retribución que los MM llevan a cabo como contraprestación por lo recibido. Se refiere en propiedad a los actos de trascendencia que buscan darse en $\mathrm{CN}$. Como aspecto particular de estas acciones, los MM no buscan algún tipo de recompensa adicional; no esperan algún tipo de retorno por lo realizado; ellos dan en forma gratuita y generosa. En otras palabras, hay una disposición para sacrificarse por la compañía. 
Así las cosas, se constituye una relación en donde las oportunidades recibidas por parte de los MM son retribuidas por estos de diversas formas, en busca de trascendencia.

\begin{abstract}
Yo creo que esto ha sido de toma y dame, porque yo a la compañía me le he entregado mucho, me le he dado mucho. Considero que soy una persona muy productiva para la compañía. Soy una persona orientada mucho al logro, incluso una de las debilidades que yo tenía era que era muy orientado al logro y poco a las personas. Yo he ido aprendiendo mucho acá, orientarme mucho al ser humano, a las personas porque sin las personas no se alcanzan las cosas. Entonces, primero viene el ser humano y después viene el resultado. Yo creo que la compañía se ha beneficiado mucho en todo lo que yo he hecho por ella, en las cosas de implementación, en la ejecución de las estrategias, en la disciplina en el trabajo, la responsabilidad en el trabajo. Pero yo también he recibido mucho de esta compañía. Todo lo que tengo en mi parte económica se lo debo a esta compañía. Mi parte como profesional, mi desarrollo como ser humano se lo debo a esta compañía que ha sido un toma y dame; yo diría que está a la par, parte y parte. (MM9).
\end{abstract}

[...] bueno, a nivel profesional la empresa me ha dado mucho. ¿Me entiende?, pero yo cuando llegué aquí vine para aportar. La compañía se ha beneficiado de mi conocimiento y de mi experiencia. Yo aquí vine a formar y enseñar y a corregir cosas. (MM4).

Simon (1988) afirma al respecto que en una organización existen varios propósitos, además de las finalidades personales de cada individuo: "El objetivo de la organización es, indirectamente, un objetivo personal de todos los participantes. Es el medio por el que sus actividades organizativas se ligan para satisfacer sus diversos móviles personales" (p. 18). De esta forma, se logra un equilibrio en la organización, en donde las perspectivas organizacionales han de tener, al menos de algún modo, relación con los objetivos personales. En el momento en que los primeros se alejen de los segundos, la relación entre la organización y el individuo comenzará a deteriorarse, llegando incluso a quebrarse el nexo laboral existente.

En efecto, la trascendencia se convierte en un elemento esencial para los MM dentro de la realidad organizacional en la cual se encuentran. Esta realidad supera la experiencia humana. Es cierto que el mundo es limitado, pero no completamente establecido, sino que es un mundo con fronteras relativamente abiertas. Es limitado en la medida que los individuos no pueden experimentar 
totalmente su extensión y alcance, pues solo captan fragmentos de la realidad, y con ello de las organizaciones. Tampoco se aprende en forma completa: siempre se entiende bajo aspectos delimitados. Contradictoriamente, a pesar de que el individuo es consciente de tal limitación, quiere ir más allá. Se pregunta continuamente, tiene nuevas experiencias, busca otros horizontes, entiende diversos contenidos y atraviesa por nuevas relaciones.

La experiencia trasciende consecutivamente las difusas pero reales fronteras. La vivencia, constituida por la historia personal, profesional y organizacional, es un movimiento trascendente; sin embargo, no se puede descubrir ni demostrar en forma aislada y simultánea la trascendencia del ser, prescindiendo de la realidad esencial por medio de las acciones. Es decir, la trascendencia acontece en la inmanencia experimental, así como la consustancialidad del mundo experimental trasciende esencialmente a sí mismo. Por tanto, la trascendencia viene dada de un modo asistemático en la experiencia cotidiana sin convertirse explícitamente en un objeto experimentable. No obstante, en la medida en que ese acontecimiento trascendente entra constitutivamente en la realización de la experiencia, esta se convierte en una realidad trascendental.

Empero, en algunas ocasiones dicha experiencia pierde su cuota esperanzadora y se convierte en una carrera por lograr una eficiencia que termina por asfixiar. Al respecto, según Aubert y De Gaulejac (1993), el paso de una sociedad autoritaria a una sociedad individualista y narcisista se refleja en una mutación en el modo de funcionamiento interno de las organizaciones y en el tipo de sujeto que contribuye a formar. Un signo de esas transformaciones es el surgimiento de una patología individual intermedia entre neurosis y psicosis, que puede llevar, en casos extremos, hasta el suicidio; es la llamada quemadura interna o enfermedad de la excelencia. Esta ocurre como un proceso gradual a nivel psíquico y organizacional, desde el momento en que el sujeto llega a la empresa y es empujado a adaptarse a su forma de ser y actuar para progresar y triunfar en la misma, a cambio de reconocimiento, pertenencia y otros satisfactores. Se 
establece entonces un contrato donde el sujeto, al obtener reconocimiento de la organización, es cada vez más captado por el ideal organizacional.

Así, cuando un determinado modelo de gestión ha sido interiorizado y el funcionamiento psíquico y organizacional se encuentra institucionalizado, el sujeto vive de acuerdo con las exigencias que le impone la estructura. El problema se hace evidente cuando el individuo ya no puede seguir el ritmo que se le exige o deja de identificarse con algún aspecto de la organización: viene la ruptura y el sujeto recurre a un yo casi desaparecido, consumido o moribundo y resiente un efecto angustiante que lo lleva a la depresión profunda. La organización ha antepuesto sus objetivos y estrategias en la búsqueda de la eficiencia y la competitividad. Se encuentra así a un sujeto bajo un dominio sutil, a quien es posible que la organización le transfiera el modelo y las prácticas (incluyendo sus componentes ideológicos y psicológicos; sus valores y mitos) que más le convenga.

En el caso que se estudia, sin embargo, la experiencia de la realidad organizacional no llega a tener las características que mencionan Aubert y De Gaulejac (1993), sino que lleva a los MM a devolver lo recibido en la empresa donde actualmente desarrollan sus labores. Esa devolución tiene una cuota de sacrificio, porque va más allá del deber, es una retribución con fuertes rasgos de solidaridad por todo lo recibido. Las acciones de reintegro por las posibilidades y oportunidades recibidas se tienen que materializar en el futuro, en un tiempo posterior. Junto con ello, la trascendencia evoca un sentido de perdurabilidad, por lo que la obra y el impacto que esto genera en las personas buscarán perpetuarse.

\subsubsection{Seguridad}

Esta es otra categoría emergente principal. Como tal, es fruto de la confluencia de las tres categorías preliminares o precategorías: identidad personal (IPer), identidad profesional (IProf) e identidad organizacional de los mandos medios (IO). 
Como resultado de la investigación, esta categoría se estructura a partir de la intersección de estos tres constructos teóricos (véase el capítulo sobre los aspectos metodológicos).

El hallazgo no se había considerado inicialmente en el modelo teóricometodológico, ya que se buscaba analizar las relaciones de la identidad personal y profesional con la identidad organizacional. No obstante, y buscando ser coherentes con los resultados y el análisis de los datos, se construyó esta categoría a partir de las preliminares, dado que los datos así lo determinaron.

Esta categoría emergente se convierte, pues, en el constructo principal que sostiene el proceso de construcción identitario. Su comprensión exigió involucrar conceptos y reflexiones desde las ciencias sociales para su interpretación, estableciendo una relación entre las tres categorías preliminares con los aspectos propiamente administrativos y organizacionales que se articulan con la identidad. Por consiguiente, las definiciones que se presentan complementan lo expuesto en el marco teórico y conceptual. A continuación se profundiza en dichas relaciones, no sin antes hacer mención a cada una de ellas a partir de los datos analizados.

\subsection{Identidad personal}

Para iniciar, esta no es estática sino dinámica; se va adecuando a unas dimensiones espacio-temporales específicas en donde el individuo se sitúa.

La identidad no es lo que permanece necesariamente «idéntico», sino el resultado de una «identificación» contingente. Es el resultado de una doble operación lingüística: diferenciación y generalización. La primera es la que tiende definir la diferencia, la que incide en la singularidad de algo o de alguien en relación con los otros: la identidad es la diferencia. La segunda es la que busca definir el nexo común a una serie de elementos diferentes de otros: la identidad es la pertenencia común. Estas dos operaciones están en el origen de la paradoja de la identidad: lo que hay de único es lo que hay de compartido. (Dubar, 2002a, p. 11).

No hay, pues, identidad sin alteridad. Al igual que las alteridades, las identidades varían históricamente y dependen del contexto para su definición. En ese sentido 
no se puede hablar de una identidad única sino de una afiliación a muchas, de acuerdo con el contexto del individuo. Como lo propone Goffman (2010), la identidad personal es un carné de identidad social organizado a partir de una identificación principal.

Es así como se puede considerar que la identidad es aquello más valioso de un individuo pero es, a su vez, multirreferencial y contextual: hay elementos esenciales de la identidad personal, como también cambiantes. Es decir, la identidad personal se relaciona con el supuesto de que el individuo puede diferenciarse de todos los demás (de ahí su dimensión esencialista), y que alrededor de este medio de diferenciación se adhieren y entrelazan diversos aspectos o hechos históricos (su dimensión cambiante), los cuales configuran una adecuación a la realidad particular de la persona.

\subsection{Identidad profesional}

La sociología de las profesiones considera que estas no son el producto de las técnicas o conocimientos específicos de un grupo de personas, sino más bien, el resultado de un proyecto por medio del cual un grupo de trabajadores construye para sí mismos una exclusiva, valiosa y muy bien pagada ocupación (Macdonald, 1995). Por ejemplo, los consultores administrativos han estado durante muchos años tratando de reconocerse a ellos mismos como una profesión legítima (Grob y Kieser, 2006). Las profesiones son, simplemente en este sentido, aquellos colectivos que han tenido éxito en la organización de la defensa y regulación del grupo. Desde la perspectiva de la identidad, este se involucra en el proyecto de profesionalización debido a que ayuda a asegurar las recompensas sociales y psicológicas en términos de un estatus social elevado y el sentido de la propia valía (Macdonald, 1995, p. 55).

La identidad del profesional no es algo que meramente sucede cuando una persona entra en una ocupación, como un abogado, contador o profesor. Tiene 
que aprender a convertirse en un profesional a través de procesos de inducción, capacitación y socialización. La idea de una identidad profesional actúa para disciplinar a aquellos que quieren alcanzar dicha identidad (Fournier, 1999). En otras palabras, la profesión, y la identidad que se asocia con ella, es el ejercicio de un oficio que busca ser institucionalizado.

Por eso se dice (Korica y Molloy, 2010) que las profesiones no son estáticas, y el poder y la autonomía son conceptos relativos en donde la identidad profesional es una condición humana dinámica y compleja, en permanente estado de conversión y configuración; se vuelve a las prácticas anteriores y se reconceptualizan en forma permanente. Para Kerfoot (2003), por su parte, el profesionalismo es una identidad discursivamente construida, abierta a la resistencia y a la alteración. La identidad profesional tiene una aproximación postestructuralista en donde se le considera como construcción discursiva, donde lo profesional estará siempre configurado como proceso que da sentido a las diversas acciones emprendidas por el sujeto para demostrar el dominio de un ideal profesional en específico (Rumens y Kerfoot, 2009).

\subsection{Identidad organizacional en relación con la seguridad}

Bédard (2004) plantea concebir la organización como un sistema o un todo integrado que reposa sobre tres pilares o funciones esenciales y complementarias: a. (1) La producción y la creación, (2) la protección y la seguridad, y (3) el gobierno y el interés general. Para efectos de la investigación, es pertinente detenerse sobre la segunda.

La organización no solo es un conjunto de departamentos que cumplen una función específica; cada organización se presenta como un grupo social determinado, con la voluntad de resistir o eliminar las amenazas internas o externas. Bédard argumenta que el sentido general de la organización es la protección y seguridad, con el ánimo de garantizar la perennidad del grupo a partir 
de estos dos aspectos. A este tenor, la seguridad, desde el punto de vista de la organización, debe propender y garantizar:

Un ambiente humano exento de temor, de angustia, de miedo o de inquietud causados por el sentimiento de un peligro o de un mal por venir. En un sentido positivo, esta función general designa toda actividad que se enfoque a consolidar y reforzar el grupo social, interna y externamente.

[...] La protección y la seguridad comprenden tres grandes roles que, respectivamente, apuntan a cada una de las funciones. El primer rol respecto de la producción, consiste en proteger a los miembros de la organización o del grupo y los bienes que les pertenecen, de suerte que las condiciones favorables para la vida (la vitalidad) sean preservadas. El segundo rol, específico para la función de protección, es garantizar la seguridad interna y externa. La seguridad interna se obtiene por la concordia y la armonía colectiva, haciendo reinar el orden y observando el respeto por las reglas, convenciones y otras formalidades. El civismo hace parte de la seguridad interna. Por su parte, la seguridad externa resulta del establecimiento de relaciones amistosas o de ser buen vecino con los colegas o amigos (la diplomacia) o del desarrollo de estrategias que tienen como eje la fuerza y la defensa (la guerra). EI tercer rol de la protección y de la seguridad frente al gobierno es proteger la autoridad legítima, el sistema y las instituciones, así como el patrimonio colectivo. (Bédard, 2004, p. 98).

En efecto, de acuerdo con los resultados de la investigación, la seguridad organizacional tiene las connotaciones propuestas por este autor. CN debe garantizar los términos, espacios, acuerdos y demás aspectos para que los MM tengan las garantías de participar de un proceso de construcción de una nueva IO. Sin la seguridad, el desarrollo de tal construcción se trunca, porque los individuos buscan su integridad y permanencia laborales.

En consecuencia, algunas actividades que responden a la necesidad enunciada de seguridad, que estuvieron presentes o se implementaron, son las siguientes:

- Un pacto colectivo.

- Un plan de salarios nivelado de acuerdo con las mejores condiciones de las OO.

- La promesa de la no desvinculación de ningún trabajador luego de la creación de CN. 
- Un acompañamiento desde el área de Cultura y Desarrollo a los FC de las regiones para asistir al proceso de adecuación.

- La puesta en marcha de una serie de talleres de formación y conocimiento personal, así como capacitaciones que promuevan el diálogo y la escucha entre los empleados y los equipos de trabajo.

- El compromiso de promover los ascensos dentro de la misma compañía.

No obstante lo anterior, surgió un hecho que generó incredibilidad y desconfianza por parte de los MM hacia la compañía. La seguridad se quebró y generó en resentimiento y desengaño con $\mathrm{CN}$ porque no se respetó (desde el punto de vista de los MM) lo pactado: nadie sería retirado de la organización luego de su creación y a partir de la integración de los departamentos de ventas y distribución de algunas compañías del GN.

\begin{abstract}
En lo comercial, los mandos medios en este momento tienen muchas expectativas e inquietudes con respecto a su estabilidad y a su desarrollo. Son dos ideas que las tienen muy marcadas en su mente, estabilidad por decisiones que hemos tenido que tomar en otro momento y que los han puesto a cuestionarse; bueno, qué va pasar conmigo. Y la segunda es referida al desarrollo de oportunidades. Ellos están viendo que llevamos varios años con oportunidades muy estancadas. [...] Hay que destacar que estos MM son personas que quieren hacer las cosas muy bien y quieren progresar dentro de la organización y se interesan y trabajan para poderlo lograr. (MM11).
\end{abstract}

A continuación se explica la relación de la seguridad con el proceso de construcción identitario.

\title{
6.1.2.3.4. La seguridad y el proceso de construcción identitaria
}

La categoría emergente principal de la seguridad se configura a partir de las tres categorías preliminares antes expuestas. De esta relación, existe una serie de aspectos que caracterizan el proceso de construcción identitario en relación con la seguridad. Estos son los siguientes: 
- Los aspectos personales y profesionales se dan a un nivel individual; en cambio, los propiamente organizacionales tienen un nivel social o grupal, pues la organización los define. Así, en la categoría de la seguridad se conjugan o están presentes los dos niveles de análisis, tanto el personal como el organizacional.

- La seguridad es la categoría que permite y sostiene el conjunto de entramados de significados que intervienen en la construcción de una identidad personal y profesional, a la luz de la vida organizacional del individuo. En ese sentido, la seguridad garantiza el proceso identitario y lo sostiene en el tiempo.

- Se conjuga aquí un primer equilibro organizacional estructurado por la tensión existente entre la pretensión por mantener los aspectos personales y profesionales y los aspectos netamente organizacionales nivelados. Es claro que hay una jerarquización por parte de los individuos en priorizar aquellos aspectos personales ligados íntimamente a los profesionales, sobre los organizacionales, de ahí que la pugna se dé entre los intereses personales-profesionales y los objetivos organizacionales. El individuo estará sometido a diversas fuerzas y estrategias que buscan direccionarlo para cumplir con los objetivos de la firma. Desde la libertad relativa o acotada que posee, los MM optan por tomar las decisiones pertinentes para que los aspectos propiamente personales no se frustren o corran el peligro de no llevarse a cabo. En el caso de no garantizarse lo personal, este primer equilibrio se quebrará.

- La seguridad permite generar vínculos que mantienen la relación en equilibrio e impiden que los individuos rompan el vínculo laboral. En ese orden, la seguridad propicia una estabilidad laboral y disminuye la rotación 
del personal, configurando una forma de ser y operar propia de cada organización.

- Lo ontológico, aquello que los MM han construido a lo largo de su trayectoria profesional y de una $u$ otra manera han tratado de descifrar sobre ellos mismos, encuentra en la organización un espacio para profundizar en su comprensión. Si bien los niveles de desarrollo y de ampliación son distintos y muchas veces los grados de consciencia no son iguales, hay un proceso de conocimiento personal que se liga necesariamente a la organización, debido a la estrecha relación que el individuo genera con esta.

- La seguridad garantiza que la IO se pueda seguir construyendo. Junto con ello, permite que el reconocimiento no se convierta en una ideología, cuando muestre, mediante acciones específicas por parte de la organización, que las declaraciones positivas motivan un cambio en concreto y son respaldadas en la práctica.

- La profesión es en sí misma una construcción identitaria en el entendido que el conocimiento técnico requiere ser reconocido y legitimado por una comunidad particular.

Forma tenor de estas observaciones, cuando un individuo ingresa a una organización y con ello se comienza a gestar o construir una IO específica, es claro que ello constituye la continuación de un proceso ya iniciado en el tiempo a partir de la estructuración de una identidad personal, y una identidad profesional. Por tal razón, la identidad personal comienza su configuración y estructuración desde muy temprana edad en el individuo. En ese trayecto, el MM comienza a adquirir una identidad profesional gracias al estudio de una carrera determinada, la cual cuenta con la propia identidad personal. Luego, cuando el individuo ingresa a 
una organización se inicia el proceso de construcción identitario con respecto a la organización, la cual tiene que contar necesariamente con las otras dos identidades que han iniciado el proceso.

Es así, pues, como el proceso de construcción identitario se inicia en un tiempo determinado, cuando confluyen dos procesos de construcción identitarios ya iniciados: el personal y el profesional. Por tanto, la organización no podrá controlar los sentidos y significados con que cuenta el individuo y que hacen parte importante de la significación que para él tienen al vincularse a la organización. La gráfica 20 ilustra dicho proceso.

\section{Gráfica 20: Identidad personal, profesional y organizacional en el tiempo}

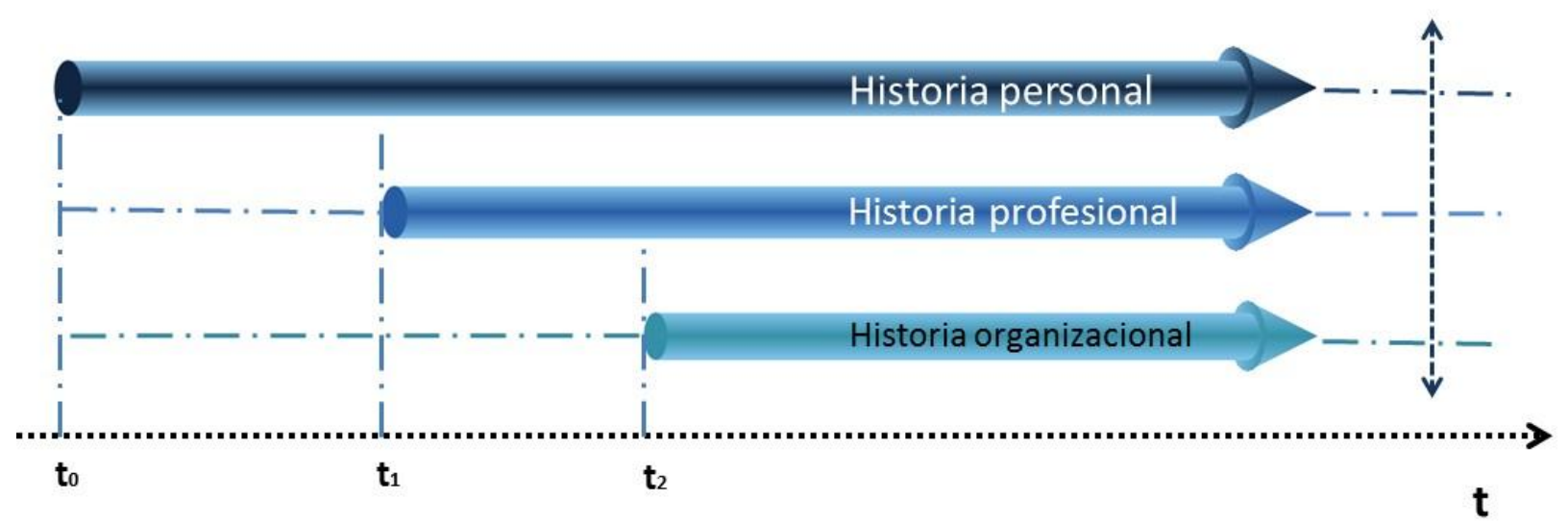

Fuente: Elaboración propia.

Hasta aquí se han desarrollado las categorías emergentes principales de la investigación. Se las ha definido desde su relación con la organización. Dicha relación se ha sustentado a partir de una teoría emergente, con el objetivo de poder realizar un análisis más profundo y, por lo tanto, posibilitar la comprensión del proceso de construcción identitario de los MM. A continuación, se procede a relacionar los tres constructos y a responder en propiedad a la pregunta planteada por la investigación: ¿Cómo es el proceso de construcción de la identidad organizacional de los mandos medios en Comercial Nutresa? 


\subsection{CONSTRUCCIÓN DE IDENTIDAD ORGANIZACIONAL DE LOS MANDOS MEDIOS}

Según lo que se ha discutido, la construcción de la 10 de los MM se caracteriza por la búsqueda de un reconocimiento, la trascendencia de la obra ejecutada y la seguridad que garantiza, propicia y permite la estabilidad, tanto a nivel personal, como estructural del proceso en sí mismo. Este desarrollo, tal como se concibió en el modelo teórico-metodológico, se cimenta a partir del diálogo entre los MM y la dirección que busca producir una IO. El proceso de construcción identitario es dialéctico y da primacía al propio proceso. En términos de Clegg y Hardy (1996), la respuesta a la pregunta-estudio enfoca la reflexión y los hallazgos en el organizing, en el proceso social en donde los componentes se integran para estructurar una forma de organización que es propia para la organización empresa en donde se realizó la investigación.

La $1 O$ es el resultado de un juego interno de relaciones que, en última instancia, constituyen las cosas, a pesar de que aparentemente pueda parecer que los componentes (MM y directivos) tengan una independencia. Es decir, la 10 -en tanto dialéctica- no es fija ni determinada de una vez por siempre, sino que está en un constante proceso de transformación y cambio, cuyo motor es, a la par, tanto su interna contradicción, su limitación y desajuste en consonancia con su exigencia e intención de totalidad, infinitud y absoluto, como la interna relación en que está con otra realidad, que aparece como su contrario.

En este apartado se mostrarán las relaciones que subyacen tras este proceso de construcción, en donde se subrayan las paradojas constitutivas, así como las fuerzas que se manifiestan en resistencia a adquirir una IO particular. Los MM, así, se hallan inmersos en un estado liminal en donde pugnan por resolver el reconocimiento recibido y construido en sus $\mathrm{OO}$ y la firmeza de no querer adoptar una IO, promocionada e impuesta por la alta dirección. 


\subsubsection{Una construcción identitaria que se resiste a ser fabricada}

Una definición de poder ampliamente utilizada dentro del ámbito de los EO, es la de Robert A. Dahl (1957, pp. 202-203): "A tiene poder sobre B en la medida en que puede conseguir que $\mathrm{B}$ haga algo que no haría de otra manera".

\footnotetext{
Esta definición aparentemente simple, que presenta aspectos más negativos que positivos del poder, ha sido cuestionada, modificada, criticada, difundida y rechazada a lo largo de los años, pero, sin embargo, sigue siendo el punto de partida de un notable cuerpo diverso de la literatura. (Clegg y Hardy, 1999, p. 369).
}

Así, a pesar de algunos investigadores (Ailon, 2006) que cuestionan esta definición, al argumentar que no se sabe lo que $B$ haría, y lo que esto implicaría para el análisis organizacional, aquí se desarrolla la reflexión en relación con la reificación, a partir de la resistencia que dicho poder genera en $B(\mathrm{MM})$.

Otra manera de definir poder es la siguiente: el poder del actor A sobre el actor B es la cantidad de resistencia por parte de $B$ que puede ser potencialmente vencida por A. El poder se manifiesta en su ejercicio mismo al ser capaz de vencer la resistencia de B. En este sentido, la perspectiva de poder está en estrecha relación con la resistencia, en donde cualitativamente no habría diferencia, ya que la resistencia es una parte integral del poder (Thomas y Davis, 2005; Fleming y Spicer, 2003). Por su parte, Weedon (1987) va más allá y afirma que todo lo relacionado con la subjetividad puede ser clasificado como resistencia ya que el individuo hará prevalecer lo individual dentro de un entorno social. En otras palabras, la resistencia es la acción en contra del acto o ejercicio mismo de poder que permite que este último se manifieste como tal. En dicho ejercicio, lo individual tiene una participación activa ya que el sujeto realiza una reflexividad como aspecto característico de la resistencia previa a cambiar de conducta o dejarse someter por el poder manifiesto, vale decir, la resistencia se opone al ejercicio del poder. 
Por tanto, este poder es una relación interpersonal (o intergrupal) en medio de la cual un individuo (o grupo) puede provocar que otro individuo (o grupo) lleve a cabo una acción que de otra manera no realizaría (López y Gonzales, 2010). E poder busca que una persona modifique su comportamiento o conducta. En la mayoría de las situaciones se habla de una fuerza implícita, no de una fuerza real. Así, el sujeto $A$ tiene poder sobre un sujeto $B$ si este cree que el primero puede forzarlo a él a cumplir los deseos de aquel.

$A$ tiene que ejercer una fuerza sobre $B$ capaz de quebrar la resistencia de este. Al momento de lograr que $B$ realice lo que $A$ desea, a pesar de no querer hacerlo (expresado en dicha resistencia), se podrá afirmar que $A$ tiene poder sobre $B$. En consecuencia, la resistencia es inherente al poder; sin ella, el poder no existiría. Dentro del ámbito de la investigación que se expone, la producción de la identidad es una estrategia de dominación, impuesta por la alta dirección, que pretende construir una subjetividad específica. La resistencia del individuo radica en buscar un equilibrio entre aquello que los directivos se proponen y lo que él está dispuesto a ceder para permanecer en la organización sin quebrantar la relación laboral.

El ejercicio del poder en $\mathrm{CN}$ está encaminado a fabricar una $1 \mathrm{O}$ específica, conducente a lograr mayor lealtad y, por ende, mayor productividad y eficiencia. En tal orden de ideas, el poder

[...] puede ser considerado como una relación social, ello significa, por una parte, que el poder fluye solamente dentro de una relación social, y por otra parte, que si bien el ejercicio del poder es ejercido por y entre individuos, su efecto no recae sobre el individuo mismo sino sobre sus acciones, es decir, lo que se trata de modificar es la conducta del individuo, no al individuo mismo. (De la Rosa Albuquerque A., 2008, p. 10).

La fabricación de una 10 pasa por cosificar al sujeto y, en consecuencia, el cambio no se busca solo en un nivel meramente conductual sino en un aspecto más interno e íntimo del sujeto ya que entra a relacionarse con lo personal y profesional. Esta es una pretensión más ontológica, por lo cual las relaciones de 
poder, expresadas en la imposición y coerción, alcanzan alturas distintas. La resistencia individual se concentra en impedir la injerencia de elementos más personales e íntimos como es la propia identidad. Esto no quiere decir que en aspectos comportamentales más externos no se genere una resistencia; en este estadio, la dinámica propia del trabajo y las relaciones de poder que se inscriben en él, propician un cambio de procedimiento más explícito.

La resistencia al ejercicio del poder, expresa, entonces, por parte del sujeto, una respuesta negativa a someterse a tal dominación. Por ello, se puede considerar que la resistencia es una forma de contra-discurso, pues cuestiona los nuevos poderes y la forma como el individuo es definido, etiquetado y clasificado (Meriläinen S., Tienari, Thomas y Davis, 2004). Se manifiesta asi, una resistencia a la dominación por medio de la gestión administrativa, mediante la contraidentificación y la des-identificación con la organización. La re-articulación del rol de MM forma parte de una de las tareas de la organización, mediante la cual se le invoca una identidad que establece y legitima una posición servil dentro de la organización (Holmer-Nadesan, 1996), ante lo cual el individuo se resiste.

La acción individual tiene lugar en un mundo social de relaciones de poder que no se puede entender completamente sin una comprensión general de la dinámica de la sociedad que produce sus verdades de manera regulada y normatizada. En ese contexto, es importante ver cómo esas verdades funcionan en relacion con las estructuras de poder dominantes en cada sociedad (McNay, 1992). Los discursos están socio-culturalmente presentes en ambientes determinados y muchas veces son condicionados por la sociedad. En ese sentido, esta contradicción es crucial para la comprensión de significados vinculados a identidades específicas.

Por tales consideraciones, impulsar o generar sentido de identidad y pertenencia en los empleados ha generado un creciente interés investigativo, enfocado en el concepto de des-identificación en el lugar de trabajo (en tanto expresión de resistencia), como una táctica de los individuos para oponerse a la dominación. 
Los estudios muestran que la des-identificación puede tomar múltiples formas, tales como el cinismo ${ }^{121}$, el escepticismo y la ironía, que se han venido extendiendo en diferentes sentidos (Costas y Fleming, 2009). Como parte de la cultura del management, estos mecanismos de des-identificación permiten a los empleados, en su afán de mantener el sentido de autenticidad, superar las tensiones entre aquello que sienten que realmente son y lo que tienen que ser en el puesto trabajo (Sturdy, 1998; Whittle, 2005).

La cultura retórica de la gestión de relaciones humanas basadas en la autonomía del empleo, genera disfunciones en los controles culturales. Esto se debe a la sensación de falta de autenticidad que experimentan muchos empleados cuando son obligados a identificarse con la empresa o con el cliente bajo creencias 0 sentimientos previamente definidos por la organización (Fleming y Sturdy, 2011). Esto también tiene relación con lo planteado por Ainsworth y Hardy (2008), quienes afirman que el control tecnocrático a través de la estandarización y supervisión busca influir en las creencias de los trabajadores.

Al forzar a los empleados a realizar actividades con las que están en desacuerdo, se genera una autoreflexión sobre sus acciones y de ese modo se propicia resistencia que se traduce en cinismo o distanciamiento $y$, por ende, agotamiento y limitación en el compromiso que tienen con la organización. Se pone así, en tela de juicio, la lealtad de los funcionarios hacia la organización. La naturaleza contraproducente de los dispositivos de control identitario favorece, y mantiene a su vez, una tensión en el equilibrio organizacional, el cual se comienza a quebrantar si no se pueden sostener tales acciones cínicas previamente fabricadas por la organización.

Tenemos que tener claro el modelo y también qué es lo que queremos, [nosotras] somos las que jalonamos el modelo de gobierno junto con los de Servicios Comerciales, pero somos nosotras las que imponemos la cultura, las que ponemos las

121 El cinismo sirve como nueva forma de autodefensa, con la cual se hace frente a los pensamientos de sumisión y los sentimientos de decepción derivados de la gestión y las medidas adoptadas por la organización (Reichers, Wanous y Austin, 1997). 
alertas y las ayudas para imponer esa identidad que quiere tener la organización. [...] Siento que somos unos actores importantes en la región para que eso se jalone. (MM7).

Esta no-colonización reserva de alguna manera la individualidad de los sujetos y les permite sobrevivir a los violentos intentos de control e imposición de conductas establecidas por la organización. Lo importante del concepto de des-identificación es la capacidad que tiene de explicar mejor las relaciones de dominación empresarial dirigidas hacia las personas como un recurso estratégico. En este contexto, la reificación de la identidad se podría considerar como una extensión del control de los sistemas direccionados hacia la identidad (Ray, 1986). Por medio de la des-identificación, los empleados toman distancia o protegen ciertos aspectos de su personalidad fuera del alcance normativo de las empresas, como son la llamada cultura corporativa, el empoderamiento y los programas de fidelización, en boga actualmente (Brown y Humphreys, 2006; Mumby, 2005; Trethewey, 1997).

Tal situación se expresa en el apego que tienen los MM a las OO. El recuerdo y el afecto que manifiestan en la rememoración de las experiencias anteriores en su paso por las organizaciones de donde provienen y en donde fueron forjados a nivel profesional, sirve como una des-identificación y un rechazo a la nocolonización de una 10 específica. Frente a la imposición de una IO, los MM recurren al pasado para realizar una especie de contraofensiva, que si bien pareciera estar sustentada en el capricho, ya que no están formalmente vinculados a $\mathrm{OO}$ sino a la nueva organización $(\mathrm{CN})$, se escudan en una $1 \mathrm{O}$ pretérita que si bien existe y es válida, actualmente es inviable.

La resistencia por parte de los $\mathrm{MM}$, por fuera del ámbito meramente identitario, es expresión de una demanda de reconocimiento igualitario, con la cual la particularidad busca ser valorada y la vida en común es un anhelo de relaciones que procuran construir por fuera de las lógicas de la eficiencia y la rentabilidad. El literato argentino Ernesto Sábato lo expresa en forma clara: 
La primera tragedia que debe ser urgentemente reparada es la desvalorización de sí mismo que siente el hombre, y que conforma el paso previo al sometimiento y la masificación. Hoy el hombre no se siente un pecador, se cree un engranaje, lo que es trágicamente peor. Y esta profanación puede ser únicamente sanada con la mirada que cada uno dirige a los demás, no para evaluar los méritos de su realización personal ni analizar sus actos, sino al modo de un abrazo que nos puede dar la alegría de pertenecer a una obra grande que nos incluya. (Sábato, 2013, p. 86).

La resistencia entonces está relacionada con la amenaza a la identidad; va en pos de preservar la dignidad y la autonomía del individuo. Resistencia es sinónimo de oposición o rechazo a las prácticas discursivas manageriales. En términos postmodernos, la identidad social, aplicada al ámbito organizacional, es múltiple, flexible, fragmentada y transformada. No existe, por tanto, en forma pura en ninguna parte, como si no estuviera contaminada por las ansiedades e inseguridades que emanan del deseo de controlar las identidades individuales (Linstead, 2004).

\subsubsection{Lo liminal dentro del ámbito organizacional}

En el campo de los EO se ha desarrollado una literatura que da cuenta de la identidad como un proceso de construcción y reconstrucción a través de una interacción dinámica en la que un individuo es moldeado bajo una determinada identidad por otros (Karreman y Alvesson, 2001). En tal sentido, busca proyectar una identidad hacia el mundo exterior (Brown, 2001) y asume (o promulga) comportamientos, símbolos e historias de identidad (Sims, 2003). Estas prácticas implican un diálogo en el que la propia identidad interna se ve influida por la identidad social externa (Watson, 2009). Así, la identidad social se compone de las proyecciones de los demás hacia uno mismo, de las proyecciones del yo hacia los demás y las reacciones a las proyecciones recibidas (Beech, 2008). La identidad social es, por consiguiente, un espacio, un lugar en el que se imponen a los individuos discursos externos, y la identidad propia es la visión interiorizada del sí mismo en que las personas tratan de "mantener una narrativa particular [de sí mismo]" (Watson, 2009, p. 431). 
Bajo estas premisas, la construcción de la $\mathrm{IO}$ de los $\mathrm{MM}$, para el caso específico estudiado de $\mathrm{CN}$, es un proceso liminal. Por eso aborda el concepto de construcción de IO cuando las personas están dentro de dos establecimientos de identidad, es decir cuando no son ni una cosa ni la otra (Beech, 2011). La noción de liminalidad (ni una cosa ni la otra) ha sido expuesta por la antropología social (Turner, 1967) e introducida por algunos investigadores en el ámbito propiamente organizacional (Sturdy, Schwarz y Spicer, 2006; Tempest y Starkey, 2004), con el objetivo de ampliar y desarrollar el concepto de liminalidad dentro de la construcción de identidad (Sveningsson y Alvesson, 2003). El presente trabajo se inscribe dentro de esta perspectiva y busca aportar a la discusión en dicho ámbito temático.

El proceso de construcción identitario puede ser considerado como parte de la versión de la estructura del agente, en donde este constituye y está constituido por su entorno social y los discursos sociales que lo rodean (Ybema, Keenoy, Oswick, Beverungen, Ellis y Sabelis, 2009). También es denominado como proceso de reconstrucción identitario (Thornborrow y Brown, 2009; Alvesson y Robertson, 2006; Watson, 2009). Según Thomas y Linstead (2002), igual que Thornborrow (2009), dicha construcción puede ser parcial o incompleta. En este desarrollo, la IO se encuentra parcialmente estructurada, o en proceso de, lo que hace retomar el concepto de prácticas liminales que ocurren en la intersección entre la estructura y la agencia, para explicar la evolución identitaria a partir de los resultados de la investigación. Para ello se invocará la propuesta procesualista del antropólogo Víctor Turner.

Víctor Turner (1920-1983) fue un antropólogo estudioso de los símbolos y de los ritos en sociedades tribales. En su texto The ritual process: structure and antistructure (2008), este autor estudia los rituales de los Ndembu en Zambia. Allí desarrolla sus ideas sobre la liminalidad, como una situación o espacio en donde el sujeto se convierte en un "ser transicional que estructuralmente resulta indefinible" (Turner, 1980, p. 106). Con base en esta marginalidad, reflexiona en 
torno a los conceptos de estructura y antiestructura que se presentan en uno de los ritos, concretamente, en el rito de paso. Ahí, el investigador despliega una serie de conceptos en su afán de encontrar una interpretación y comprensión de los fenómenos sociales.

A su vez, Gennep (1960) expuso otra teoría de los ritos de paso: una persona transita de un estado de identidad a otro (por ejemplo: niño a hombre, soltera a novia) en tres fases: a) separación, que se caracteriza por los símbolos de desprendimiento; b) liminalidad, en la que el sujeto del ritual o liminar es ambiguo y se mueve a través de un proceso que tiene pocos o ninguno de los atributos de los estados antes y después, y c) la agregación, que no es otra cosa que la consumación del pasaje. En esta etapa, lo liminar ha alcanzado una nueva identidad y se espera la adopción de determinadas normas.

En general, el proceso liminal es ritualista, es decir, sucede a partir de un evento de activación y transcurre durante un periodo específico. Esta conceptualización fue ampliada por Turner al concebir la persona liminal como interestructural, en un estado de camino o transición entre las posiciones que ocupan los puntos de separación y agregación. Según el autor, la posición interestructural tiene ciertas características: en primer lugar, lo liminal, físicamente invisible, es un aspecto social que connota ambigüedad por el significado exterior que conlleva; por ejemplo, "las definiciones seculares de una sociedad no permiten la existencia de un no-niño, un no-hombre, que es lo que un novato en un rito de la pubertad masculina es (si es que puede decirse que es nada)" (Turner, 1967, p. 95). En segundo lugar, hay un enlace con la muerte; el liminar está estructuralmente muerto y es considerado como impuro, por lo que su contacto está prohibido o restringido durante la liminalidad para que no contamine a los que no han sido inoculados contra él. En tercer lugar, durante la liminalidad, lo liminar no tiene derechos y su relación con las personas mayores es de una completa obediencia. En cuarto lugar, Turner también ve la liminalidad como una fase en donde se 
reflexiona acerca de la sociedad y el cosmos, con el fin de regresar a la sociedad con una nueva identidad con renovadas responsabilidades y poderes.

En esa dirección apuntan también Noble y Walker (1997, p. 31): "La liminalidad, perturba significativamente el propio sentido interno de uno mismo o dentro de un sistema social". En ese contexto, la liminalidad se puede definir como una reconstrucción de la identidad (en donde el sentido de sí mismo se interrumpe de manera significativa), de tal manera que la nueva identidad es significativa para el individuo y para la organización.

En cuanto a la literatura referida al ámbito organizacional, el concepto de liminalidad se asume, con frecuencia, para designar una situación de ambigüedad e incertidumbre, estar entre lo uno y lo otro (Chreim, 2002). Si bien esto se corresponde con una parte del concepto de Turner, en este caso no se suelen incluir, por ejemplo, las fases procesales. Lo liminal se utiliza indistintamente como una forma de clasificar a las personas (Garsten, 1999), las ocupaciones (Czarniawska y Mazza, 2003), los roles jerárquicos (Eriksson-Zetterquist, 2002), las organizaciones (Tempest y Starkey, 2004) y los eventos y espacios (Sturdy, Schwarz y Spicer, 2006) ${ }^{122}$. El concepto hace hincapié en la naturaleza cambiante de estos temas, los múltiples significados que pueden coexistir y las consecuencias psicológicas negativas de la liminalidad extendida.

Así, el término liminal dentro del ámbito propiamente organizacional fue desarrollado por varios investigadores. Garsten (1999) ve a los trabajadores temporales como en un estado alargado de liminalidad, en la periferia de las organizaciones, donde experimentan baja autoestima (solo soy un temporal) como se esperaría de un liminal (Noble y Walker, 1997). Sin embargo, no se llega a la fase de agregación, por lo que Garsten enfatiza en el desprendimiento de la organización por parte de los trabajadores temporales que fueran considerados

${ }^{122}$ Ellis e Ybema (2010), por ejemplo, analizan la experiencia liminal de directores de redes interorganizacionales, ya que oscilan entre y a través de las fronteras organizacionales. 
como sustituibles y prescindibles, no ajustándose, en este caso, al uso del término desde un punto de vista antropológico.

En otro sentido, Czarniawska y Mazza (2003) consideran los consultores como liminales por estar constantemente en medio del cambio organizacional. Enfatizan en el contexto liminal de trabajo, donde los empleados permanecen en circunstancias cambiantes. Del mismo modo, Tempest y Starkey (2004) investigaron los trabajadores independientes en la industria de la televisión y encontraron que las carreras son cada vez más liminales, con motivos contractuales de los equipos de trabajo y de los proyectos que crean y recrean las redes dentro y entre organizaciones.

En otras palabras, cuando se aplica a las organizaciones, la definición de liminalidad incorpora inestabilidades en el contexto social, la ambigüedad permanente y la multiplicidad de significados, la falta de resolución (o agregación) y la posibilidad de sustitución del individuo considerado como liminal. La liminalidad se puede entender en el sentido antropológico como una transición temporal a través de la cual se reconstruye la identidad, y puede ser pensada como una experiencia más longitudinal de ambigüedad dentro de un entorno cambiante.

Para Turner, los ritos de paso forman parte de una estructura social. En relación con la Administración, esta ha introducido (creado) una serie de ritos con el ánimo de controlar o buscar crear, en forma coercitiva, un comportamiento particular, cuyo objetivo último es la eficiencia a costa del respeto a la singularidad del individuo. Este tipo de controles es más frecuente y recurrente en los MM, dado su acceso al poder y el papel que juegan dentro de las organizaciones.

Otro concepto importante por rescatar del procesualista inglés es el de estado. Con este hace referencia a una situación relativamente estable, en donde se incluyen constantes sociales como el status legal, la profesión, el oficio, rango o 
grado. La noción también se utiliza para designar la situación de las personas con respecto a un grupo social, y puede denotar, a su vez, las condiciones ecológicas, físicas o mentales en que una persona 0 un determinado grupo pueden encontrarse en un momento concreto. Así, "«estado», en definitiva, es un término mucho más amplio que «status» o que «oficio», y hace referencia a cualquier tipo de situación estable o recurrente, culturalmente reconocida" (Turner, 1980, p. 104).

De acuerdo con lo expuesto, los ritos de paso y la definición de estado remiten a la idea de transacionalidad ${ }^{123}$. Lo importante del concepto es la idea de proceso, de transición. Para Turner, entonces, este proceso, el paso de un estado a otro, el movimiento de la potencia al acto, tiene atributos culturales que le son propios. Este llegar a ser, constituye un elemento fundante de su propuesta teórica; el llegar a ser configura un estado permanente, de ahí su importancia.

Ahora bien, desde la perspectiva de Víctor Turner (1980) y el procesualismo, la transacionalidad está dividida en tres fases que vale la pena precisar. La primera, de separación, comprende el comportamiento simbólico de la desvinculación individual o del grupo del estatus que tenía (antes del ritual) prefijado en la estructura social. La segunda, de liminalidad, es más confusa o ambigua; las características del ritual pasan a una esfera o dimensión en la que no se posee

${ }^{123}$ Una definición que ayuda a comprender con mayor claridad este concepto es la que expone Aristóteles sobre los conceptos de acto y potencia. Para el gran pensador griego, cuya influencia constituye uno de los pilares de Occidente, el cambio se explica a partir de tales conceptos. La potencia es lo que está por hacer, como la materia prima o la base, mientras que el acto es lo que está acabado. "El ser no solo se toma en el sentido de sustancia, de cualidad, de cuantidad, sino que hay también el ser en potencia y el ser en acto, el ser relativamente a la acción" (Aristóteles, 1997 , p. IX - 1). De esta manera, la potencia es aquella que tiene la capacidad para, pero aún se encuentra dormida, es decir, posee aquellos elementos constitutivos que le permiten mutar o realizar la esencia de su existencia y sin embargo todavía no se realiza, aún no se desarrolla. El acto es la realización concreta de la potencia, su perfeccionamiento, es su culmen. Aquellos elementos constitutivos que lo caracterizan y lo individualizan, se realizan, se despliegan, llegan a ser aquello que estaban llamados a ser. A manera de ejemplo ilustrativo se podría decir que en una oruga se encuentra una mariposa en potencia. Así, en la oruga se hallan todos los elementos constitutivos que la hacen ser una mariposa, pero todavía no lo es. Luego que ocurren una seria de procesos naturales y se dan las condiciones pertinentes y particulares, la oruga pasa al acto y se transforma en una mariposa. La mariposa en este sentido es el acto, la realización del culmen del proceso metamórfico iniciado por la oruga. 
ningún (o muy pocos) atributos del estatus pasado o del futuro. En la tercera, de agregación o reincorporación, el rito es consumado y se retorna a la estabilidad; en virtud de ello, se regresa a una situación donde los individuos recuperan derechos y obligaciones en cuanto retoman un estatus claramente definido en la estructura social del grupo.

A continuación, los conceptos expuestos se aplican al tema de estudio de la presente investigación: la IO. Queda claro, pero no está por demás subrayarlo, que lo liminal hace referencia a buscar la comprensión del proceso de construcción de la IO; no se trata de relacionarlo ni con lo MM no con algún otro aspecto. Así, se puede afirmar que los $\mathrm{MM}$ de $\mathrm{CN}$ están en un proceso de transición identitario, es decir, se encuentran en el proceso liminal caracterizado por lo siguiente:

- El evento de activación que propicia e inicia el proceso de separación e introduce a los MM en el estado liminal de construcción identitario es la constitución de $\mathrm{CN}$, a partir de los departamentos de ventas y distribución de algunas compañías del GN, particularmente de $\mathrm{NCH}$ y Noel. Este proceso implicó la desvinculación, por parte de los MM, de sus OO. Si bien se les respetaron todas sus condiciones laborales, e incluso recibieron una serie de beneficios económicos, pues se nivelaron las prestaciones sociales extralegales tomando como referente la compañía que más prestaciones económicas brindaba, los MM dejaron de estar vinculados a las $\mathrm{OO}$ que los vieron crecer como profesionales. La desvinculación se realizó materialmente: se ejecutó un cambio de contrato y por lo mismo de vinculación laboral. También, simbólicamente, tuvo un efecto importante: el reconocimiento y el prestigio ganado a lo largo de los años así como el legado construido y la seguridad en cuanto a su proyección y bienestar se vieron truncados ya que se reiniciaron en otra organización, bajo parámetros y condiciones distintas. Junto con ello, el nombre de $\mathrm{CN}$ no es conocido en el medio comercial. Como es una empresa nueva, los clientes 
y proveedores aún no la legitiman, a pesar de que proviene de compañías muy reconocidas socialmente. En muchos casos, los $\mathrm{MM}$ se siguen presentando como si estuvieran vinculados a sus $\mathrm{OO}$.

- El reconocimiento de los MM fue otorgado por las OO. Si bien los MM se encuentran en una nueva organización (CN), no terminan por desprenderse de las afirmaciones positivas que recibían, y lo que significaba para ellos. En ese sentido, el reconocimiento es uno de los dinamismos que impide que los MM transiten hacia una nueva IO. Se convierte en la fuerza de resistencia que los ata a las realidades organizaciones de donde provinieron.

Tal resistencia o negativa a adquirir una nueva $1 \mathrm{O}$ se ve incrementada por algunos aspectos internos que caracterizan el mismo proceso identitario, y en el cual los MM se encuentran inmersos. Por ejemplo, la contradicción interna reflejada en los FC: los MM no se encuentran en igualdad de condiciones para poder conformar un equipo de trabajo autónomo y democrático en cuanto a la toma de decisiones en las regiones de Colombia. Otro caso tiene que ver con las contradicciones que les llegan a los MM desde el Comité de Presidencia: Al no haber claridad en cuanto al proceso en sí, los mismos directivos caen en contradicciones y contraórdenes, aspecto que los MM tienen que resolver entre ellos, con la consecuente generación de mayor tensión en el ambiente de los FC.

Por último, la rivalidad preexistente entre las organizaciones que configuran $\mathrm{CN}$ : esta competencia genera una autoafirmación identitaria por parte de los $\mathrm{MM}$ con sus $\mathrm{OO}$, al reforzar y subrayar, por medio de comparaciones, la procedencia que tienen, y cómo llevaban los procesos administrativos en aquellas empresas. 
- La pertenencia a CN obliga a los MM a ubicarse en un nuevo espacio en donde tendrán que reinventar o reiniciar el proceso de construcción identitario que ya tenían consolidado en sus OO. Por eso, como categoría fundamental que interviene en el proceso de construcción identitario, la trascendencia se proyecta en $\mathrm{CN}$, es decir, al final del rito de paso. (Se entiende que no tiene que haber un tiempo específico para ello, pero el proceso debe culminar, ya que la transacionalidad tiene un inicio y un fin). La agregación da la posibilidad de aceptar la nueva condición y empezar a desligarse afectivamente de las $\mathrm{OO}$. En ese sentido, si el reconocimiento ataba a los MM a sus respectivas $\bigcirc O$ y generaba una tensión o resistencia que impedía su movimiento hacia la reincorporación, la trascendencia los impulsa o atrae hacia el final del proceso. Este representa la esperanza que el legado permanezca y que el reconocimiento y respeto adquirido en una tradición laboral pueda consolidarse en el futuro.

- La seguridad sostiene todo el proceso de construcción identitaria y permite que este se concrete. Lo liminal en el proceso está sujeto a dos tensiones: por un lado, la fuerza resistente de no querer desprenderse de las OO, y, por otro, el impulso esperanzador de encontrar en la nueva organización (CN) los espacios para hacerse a un lugar, lo que abre las puertas para que la IO de los MM se reconstruya.

La tensión se mantiene gracias a que existe una serie de garantías. Es decir, la seguridad tiene connotaciones garantes que se manifiestan a dos niveles: 1) En el plano psicológico; la seguridad de saberse necesario e importante para la nueva organización mantiene a los $\mathrm{MM}$ dentro del proceso. El hecho de estar vinculados a CN expresa que la organización los requiere. 2) Existe una seguridad representada en aspectos estructurales, como las políticas que se implementaron para la constitución de $\mathrm{CN}$, así como los beneficios extralegales que se otorgaron a los MM. A todo esto se 
le suman las garantías y los recursos brindados por CN para estructurar el nuevo MG.

En el proceso de construcción identitario, denominado liminal, subyace un marco teórico muchas veces difícil de comprender por la complejidad del significado que encierra. Para facilitar su entendimiento se remite a la gráfica 21.

\section{Gráfica 21: Construcción identitaria de los MM como proceso liminal}

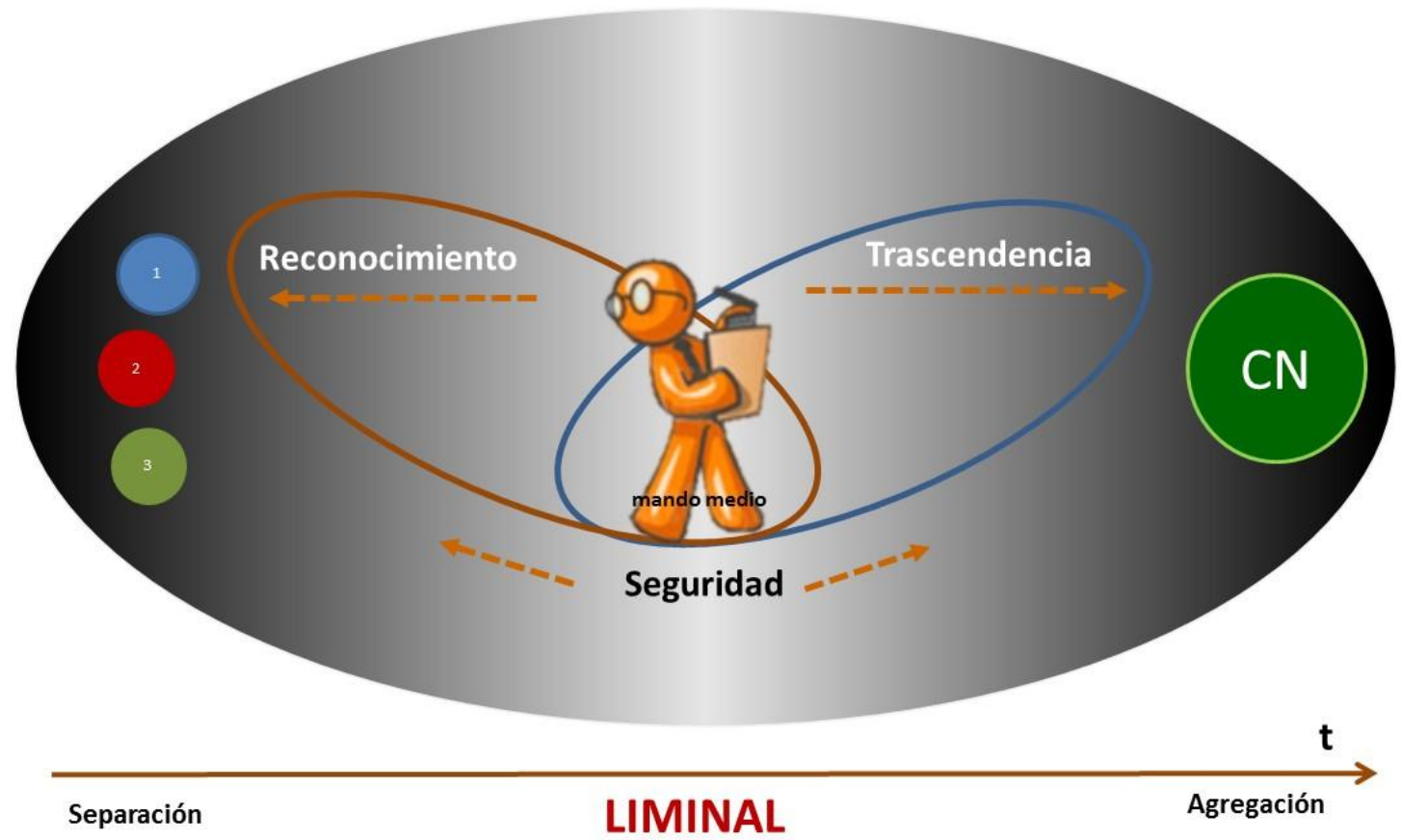

Fuente: Elaboración propia.

El MM, luego de pasar por esta secuencia de ritos, alcanza un estado nuevo, en virtud del cual ${ }^{124}$ "adquiere derechos y obligaciones de tipo estructural claramente definido, esperándose de él que se comporte de acuerdo con ciertas normas de uso y patrones éticos" (Turner, 1980, p. 104). En consecuencia, los MM, al superar

${ }^{124}$ Para Turner (1980, p. 105), los ritos de paso "se usan también para marcar el acceso a un nuevo status adquirido, tanto si se trata de una posición política como de la pertenencia a determinado club exclusivo o sociedad secreta". 
la etapa liminal de este proceso de construcción, se estarían adaptando a las condiciones deseadas por la dirección.

Ahora bien, los ritos de paso no dejan de tener una característica peculiar ya que los MM se encuentran en la fase liminar; es decir, la construcción de la IO de estos empleados es transicional, como resultado de la estructura misma de este componente organizacional, según la definición ya discutida que Mintzberg hace de los MM. Para decirlo de otro modo, la transacionalidad se caracteriza por una consecución de ritos transformativos y de ceremonias que buscan confirmar y sellar una determinada identidad. Los ritos expresan la presencia de fuerzas que resisten el paso en la transición, a la vez que lo impulsan. El reconocimiento y la trascendencia se vuelven cómplices y configuran un proceso liminal que resalta el desarrollo de una construcción identitaria en particular ${ }^{125}$.

Por otro lado, la designación del nombre que se emplea para referirse a los MM, pareciera que busca caracterizar la situación transicional en vez de los estados particulares entre los que esa transición tiene lugar. El nombre mando medio, puede ser interpretado de distintas maneras: ejecutivos medios, directores, gerentes de línea, coordinadores e incluso supervisores. Depende de la organización, la nomenclatura cambia, de acuerdo con su estructura o funciones particulares; sin embargo, lo común a todos los MM es que esta denominación sigue referenciando un lugar: el medio. Así pues, el significante expresa una realidad que en sí misma concuerda con el proceso de transición. El cargo formal tiene relación con la realidad de sentido y proceso de construcción identitario al que se remite.

125 Trabajos como los de Luis H. Méndez demuestran la aplicación de estos conceptos para explicar fenómenos organizacionales. El autor presenta un ensayo interpretativo del fenómeno de la maquila en la frontera norte de México. Allí analiza y expone dos elementos que, para él, han estado inalterables: los ritos de paso truncos que viven los trabajadores de la maquila y las identidades difusas que ahí se dejan ver. Él utiliza los conceptos y la teoría turneriana para demostrar cómo el proceso por el que atraviesan estos obreros son ritos de paso, pero truncos. Así, estos ritos truncos los define "como momentos de presentes alargados, o como situaciones disfuncionales de un rito que genera el inmóvil movimiento en este tipo de sociedad" (Méndez, 2005, p. 36). 
En efecto, desde el punto de vista de la identidad, "la invisibilidad estructural de las personas liminales tiene un doble carácter. Ya no están clasificados y, al mismo tiempo, todavía no están clasificados" (Turner, 1980, p. 106). Su característica es entonces la de la ambigüedad y la paradoja. Confundido entre fuerzas de presión, su situación es poco clara, o en términos de Mary Douglas (1973), están sucios, o sea, agentes contaminantes. En este sentido se tendría que considerar la identidad de los MM como seres

[...] contaminantes puesto que no son ni una cosa ni la otra, o tal vez ambas al mismo tiempo; o quizás no estén aquí ni allí; o incluso no están en ningún sitio, y están, en último término, "entre y en la mitad de» todos los puntos reconocibles del espaciotiempo de la clasificación estructural. (Turner, 1980, p. 108).

¿En qué sentido contaminante? En cuanto los MM no tienen una estructura identitaria definida. Definitivamente se encuentran estructurados y limitados en sus funciones, en las comunicaciones y en las mismas relaciones de poder que tienen, pero las tensiones a las que se encuentran sujetados y la inseguridad por encontrarse en el proceso de transición hace que se conviertan en referentes negativos para sus colegas. Con mayor razón si muchos tienen fuertes críticas al MG y se resisten a ingresar en la dinámica planteada. De ahí que para muchos directivos la manera de solucionar el problema sea apartándolos de la organización. De esta forma, bien se podría afirmar que esencialmente son actores en donde su 10 no está estructurada y con ello deben ser considerados como un factor contaminante para la organización, en la situación particular que el estudio de caso presenta.

Además, otro aspecto liminal en la construcción de $I O$ de los $M M$ es la coincidencia de procesos y unidades de opuestos en una misma representación: lo que no es ni una cosa ni la otra, pero es, al mismo tiempo, ambas. Dicha unidad se refleja en que los MM generan una comunidad particular. Por un lado existe cierta camaradería, pero resalta un individualismo que busca una diferenciación que no los aleje del poder al cual pueden acceder en los FC. Los MM tienden a mantener la estructura en donde se encuentran inmersos, a la vez que buscan 
romper las normas que los sujetan a ella, para generar lazos políticos y mantener una distancia social a manera de esquemas de defensa y supervivencia (Montaño, 2007a).

Un último elemento a considerar es el concepto de communitas. Esta noción la introduce Turner en relación estrecha con la liminalidad. Expresa la relación que un individuo o un colectivo establece con la estructura social. En la liminalidad emerge la communitas y, a su vez, es en esta fase del rito de paso donde se crea la communitas permitiendo el funcionamiento y dirección de la estructura. En otras palabras, se podría decir que la experiencia de cada uno (experiencia antiestructural) termina reforzando y legitimando la estructura:

Parece como si existieran aquí dos «modelos» principales de interacción humana, yuxtapuestos y alternativos. El primero es el que presenta a la sociedad como un sistema estructurado, diferenciado, y a menudo jerárquico, de posiciones políticasjurídicas-económicas con múltiples criterios de evaluación, que separan a los hombres en términos de «más» 0 «menos». El segundo, que surge de forma reconocible durante el periodo liminal es el de la sociedad en cuanto communitas, comunidad, o incluso comunión, sin estructurar o rudimentariamente estructurada, y relativamente indiferenciada, de individuos iguales que se someten a la autoridad de los ancianos que controlan el ritual. (Turner, 1988, p. 103).

El segundo modelo creado en la fase liminal contempla una forma de sociedad representada así:

El que está arriba no podría estar arriba de no existir el que estuviese abajo, y que quien está arriba debe experimentar lo que es estar abajo [y, por lo tanto] para los individuos como para los grupos la vida social es un tipo de proceso dialéctico que comprende una vivencia sucesiva de lo alto y lo bajo, de la communitas y la estructura, de la homogeneidad y la diferenciación, de la igualdad y la desigualdad. (Turner, 1988, p. 104).

Como se observa, para Turner queda claro que la communitas es un momento necesario de la estructura; no solo es lo opuesto sino que forma parte de la dinámica misma de estructuración.

En ese sentido, la communitas, como aspecto ambiguo y característico del proceso liminal como tal, abre la posibilidad para la fabricación de una 10 
específica. El proceso de construcción pasa necesariamente por el sentido y significación que los individuos realizan cuenta partir de su propia historia y la estructura de los componentes antes descritos. Esto genera una serie de tensiones que propician una indefinición. Por ello, la IO es susceptible de ser moldeada o fabricada.

Con esta visión, la contradicción, la dialéctica misma de la construcción identitaria, es la communitas, la expresión que identifica la dicotomía existente entre una estructura particular que se intenta implementar y la situación anárquica que responde a una resistencia que se opone al control y a la homogeneización. Paradójicamente, estructura y communitas no pueden entenderse una sin la otra. La presencia de una, justifica la otra. En ese sentido, la 10 es un momento indefinido, no estructurado, cuando la anarquía supone un proceso decisorio entre optar por asumir una nueva IO, o resistirse a ella. El momento de reflexividad, cuando los MM interiorizan con mayor profundidad la pregunta: ¿Quiénes somos? La respuesta está sujeta a los afectos por las $\mathrm{OO}$ y a la necesidad de pertenecer ahora y, con ello, someterse a asumir una nueva IO. Esto es lo que caracteriza la construcción identitaria; es decir, la transaccionalidad explica y permite comprender la construcción identitaria al poner el énfasis en el espacio constituido entre la entrada y salida del individuo en medio de un ámbito estructural organizacional.

Yo creo que nos falta todavía como compañía y a veces lo cuestiono dentro de la compañía y a veces con fuerza y a veces no me miran muy bien por eso, pero yo lo hago porque me parece que nosotros en un momento dado renunciamos muy fuertemente a la herencia de cada una de las compañías porque queríamos crear una nueva cultura pero hoy le decimos a la gente usted no puede ser como era en Noel, pero la gente tampoco es como es $\mathrm{CN}$, o sea, no somos lo que éramos pero tampoco somos la realidad de ahora. Ese es como mi gran cuestionamiento, porque le borramos a la gente o le intentamos borrar de un plumazo a la gente su historia. Es mal visto aquí, que se hable, yo soy Chocolates, yo soy Noel, de una te corrigen y te dicen tú no eres Chocolates, tú no eres Noel, tú eres CN, pero a CN le falta identidad. (MM14).

Para el representante de la antropología procesualista, el trasfondo de la vida social es la indeterminación, no aquello que se encuentra estructurado o definido 
claramente. Por eso concibe la sociedad como un fluir constante, definida por el devenir; ${ }^{126}$ de ahí que se busque rescatar y poner énfasis en el proceso mismo, en la estrecha relación de lo liminal con los hallazgos de la investigación.

Así concibe Turner la vida social, como un espacio agónico o agonístico, es decir, un espacio en donde constantemente se presentan luchas, confrontaciones y diferencias. ${ }^{127}$ Con el propósito de abordar los fenómenos que allí se presentan, el filósofo propone el concepto-metáfora de drama social como una técnica para describir y analizar las situaciones agonísticas. Es lo que refleja en la propia constitución de CN. Los MM provienen mayoritariamente de dos organizaciones que pueden considerarse antagónicas ( $\mathrm{NCH}$ y Noel) y, en ese sentido, estos empleados se enfrentan a una 10 proveniente de dichas organizaciones, con las cualesya no tienen, pero tuvieron que luchar para afirmarse debido a la rivalidad entre ellas. La situación cambia cuando, al momento de tener que construir una nueva $1 \mathrm{O}$ en $\mathrm{CN}$, la competencia a la cual estaban acostumbrados o iniciados, ya no es tal. Estacircunstancia les genera cierta inseguridad, ya que el hecho de existir una lucha por afirmarse en alguna de las dos compañías, los obligaba a tener una identificación fuerte y con ello, una claridad que les permitía difrenciarse

${ }^{126}$ Como se dijo up supra, el tema del devenir, colocado de nuevo, en el centro, por Víctor Turner, es un problema de vieja data. Los filósofos de la naturaleza ya lo habían abordado: el hombre comienza a preguntarse el porqué de los fenómenos, buscando respuestas a su realidad, con el fin de comprender y en esa dinámica poder ser el dueño y señor de la naturaleza que lo rodea. Su necesidad de descifrar su entorno se traduce en la búsqueda de una explicación a su propia existencia. Es lo que se aprecia con mayor fuerza en Heráclito, Demócrito y Anaxágoras. Para el primero, el arge es el cambio, el devenir. Él observa que todas las cosas se transforman de tantas maneras que proclama que todo es cambio. "En el momento que llevamos la mano a una cosa, esta ha dejado ya de ser lo que era. Lo que existe, cambia, por el hecho de ser" (Maritain, 1981, p. 36). Demócrito busca algo fijo y estable y lo encuentra en la cantidad geométrica pura, sin cualidades (sin color, sin olor, sin sabor) y que solo contiene la extensión en las tres dimensiones del espacio. Todo se explica por el lleno que confunde con el ser y por el no-lleno que es el vacío. Anaxágoras, por su parte, nota que el principio material que constituye todas las cosas debe estar compuesto por toda la diversidad de seres que de él se han de formar: si todo no estuviera en todo, nada podría provenir de nada. Por lo tanto, cree que ese principio consiste en una mezcla infinita de todas las naturalezas y de todas las cualidades, de modo que cada partícula corpórea contiene en sí elementos de todos los demás.

${ }^{127}$ Si se relaciona esta apreciación con el concepto de lo liminal, la vida social sería un espacio transaccional que abarcaría la vida misma del hombre. El autor lo hace explícito cuando señala, citando a Warner, "«la trayectoria del hombre a lo largo de su vida, desde la situación placentaria en el seno de su madre, hasta su muerte y último emplazamiento en su tumba como organismo muerto»" (Warner, citado por Turner, 1980, p. 104). 
(es lo que Sainsaulieu (1996) llama códigos de identificaciones anteriores). Por ello, bien se podría afirmar que los MM se encuentran en un drama social, inmersos en el cual afrontan una serie de procesos de ritualización que vale la pena destacar.

El proceso de ritualización no es exclusivo de las sociedades triviales:

\begin{abstract}
Si la dimensión mística resulta del estilo de contenido múltiple de vincular posiciones sociales, y si la función atribuida a la ritualización es la de segregar roles en un sistema jerárquico de posiciones y relaciones, entonces no hay razón de peso alguna para sostener que la ritualización sea exclusiva de las sociedades tribales: en las complejas también existen demarcadores altamente convencionalizados para segregar roles, para enfatizar la naturaleza jerárquica de un sistema de posiciones y relaciones, no exentas estas últimas, en todos los casos, de contenido múltiple.
\end{abstract}

[Entendiendo la ritualización como la] forma de actuar por medio de la cual se pretende no solo distinguir, estratégicamente, unas acciones sociales de otras, sino también privilegiar, en un espacio acotado, aquello que se hace o dice: focaliza o centra la atención. (Díaz, 1998, p. 198).

De acuerdo con esta apreciación, y para el análisis del caso en concreto, la ritualización se inició desde las $\mathrm{OO}$, motivo por el cual se podría pensar que hacer a un lado o coaccionar a través de distintas estrategias la no presencia de la $\mathrm{OO}$, en la construcción de una nueva IO, es no reconocer un componente neurálgico y, además, promover una mayor resistencia y des-identificación.

En tanto que la ritualización es un aspecto social que se encuentra enraizado en las distintas acciones de los individuos, los MM son objeto de ritualizaciones constantes para intentar imponerles una IO particular. Estos mecanismos coercitivos no solo se remiten o se circunscriben a la utilización de objetos o artefactos sino también a aspectos emotivos, con los cuales se busca distinguir o focalizar conductas y personas como parte de las estrategias implementadas. 


\subsection{LA IDENTIDAD ORGANIZACIONAL EN EQUILIBRIO LIMINAL}

La exposición en los apartados anteriores ha mostrado y explicado el proceso de construcción identitaria de los MM dentro de la compañía colombiana Comercial Nutresa S.A.S., a partir de la tipificación de los componentes y las relaciones que se establecen entre ellos. Para el efecto, se ha seguido la perspectiva comprensiva y pluridisciplinaria de los EO y se ha buscado dar respuesta a la pregunta de planteada en la investigación. A diferencia de esto, en la sección que se inicia se presenta un análisis que, dejando de lado el caso de estudio específico, reflexiona sobre los hallazgos a partir de este. No se trata de teorizar, sino de expandir y elevar la discusión a otros niveles a partir de lo aprendido. Con ello, no solo se procura ahondar en la conversación de los fenómenos organizacionales, sino propiciar nuevos diálogos con base en dichas consideraciones. En ese sentido, este apartado es una continuación del anterior.

Como se comentó líneas arriba, no es algo nuevo para los EO retomar el concepto de lo liminal. Víctor Turner (1980, p. 122) exhortó a los estudiosos para profundizar en la transicionalidad, como un elemento importante en la reflexión de los procesos sociales:

Terminaré este estudio con una invitación a los investigadores del ritual para que centren su atención en los fenómenos y procesos relacionados con los periodos de transición. Son estos en mi opinión, los que de manera paradójica exponen los fundamentos de la cultura justamente en el tiempo que transcurre entre la salida y el ingreso en el ámbito estructural.

Desde la perspectiva de la construcción social, los cambios en la identidad implican alteraciones en los significados que se asocian con una persona, no son simplemente ubicados en los sujetos sino en la relación entre el individuo y la organización o la sociedad. Esto puede ser pensado desde un enfoque dialógico, entre lo que el sujeto dice que es (internalización de la identidad) y aquello que los otros dicen que es el sujeto (exterioridad de la identidad). Estas percepciones de lo que el sujeto dice que es, remite a consideraciones positivas sobre sí mismo en 
el reconocimiento propio que tiene en cuenta la valoración de lo que los otros dicen. Por el contrario, la exterioridad de la identidad es el proceso por el cual el sujeto sale de sí para darse a conocer a los demás.

Por un lado, la construcción de la 10 responde a un diálogo entre el yo y los demás que se responden mutuamente a partir de un cambio interno en el individuo, producto de las influencias y acciones que recaen sobre él, derivadas de la organización y realizadas por esta con el ánimo de promover, construir o fabricar un entendimiento del individuo con respecto a su participación en la compañía. Como consecuencia, el individuo busca construir una identidad en proyección hacia el exterior, en tanto una persona que persigue afirmar una identidad deseada y con el fin de influir en la forma como los demás lo considera. Sin embargo, el mismo individuo será más sensible a reaccionar ante influencias externas en donde se le imponga una identidad en concreto. La liminalidad de la identidad en el ámbito organizacional se asemeja a un diálogo que incorpora el ser interior, tanto como el exterior de la identidad social. Pero, como en todo diálogo, la orientación puede variar de acuerdo al énfasis de lo externo a lo interno, una mayor uniformidad del juego entre los dos o un mayor énfasis de lo interno hacia lo externo.

Por otro lado, la conceptualización de la 10 como liminal, hace referencia a las prácticas que surgen de las diferentes circunstancias dialógicas. En ese sentido, el yo se pone a prueba al buscar una identidad nueva o modificada en la orientación de adentro hacia afuera. Ejemplo de ello es la des-identificación, proceso en el cual, luego de la resistencia inicial, se pasa a una fase de experimentación en donde el individuo busca diversas formas de vinculación temporal al grupo, a las identidades organizadas o personales. En este tránsito, la desvinculación identitaria, contradictoriamente, busca afianzarse en otras realidades, con el fin de avanzar hacia una identidad deseada o como expresión y acción, para resistirse a una identidad no deseada. 
Una orientación dialógica en el otro sentido, es decir, de afuera hacia adentro, se practica por medio del reconocimiento, en el entendido de que el individuo se da cuenta de una realidad distinta a partir de un hecho o evento que suscita o propicia un punto de inflexión conducente a configurar un nuevo significado. Tal punto de inflexión, en términos de Strauss (1996), impulsa un cambio de identidad cuando hay una desalineación, sorpresa, disgusto, ansiedad, tensión, desconcierto o cuestionamiento de sí mismo, y una persona se ve obligada a reconocer que no es la misma que era, como solía serlo ${ }^{128}$.

Alternativamente, los reconocimientos pueden venir, en conjunto, como una revelación de cómo es visto el individuo en la organización. En estos casos, la IO incorpora prácticas tanto de afuera hacia adentro como viceversa, constituyendo un diálogo internalizado, propio de la reflexión. Esto implica un autocuestionamiento y la posibilidad de ingresar en un proceso de cambio, a la vez que abre la oportunidad de asumir o interiorizar influencias y percepciones externas. El autocuestionamiento puede ser un proceso principalmente interno y el auto-cambio puede ser un trabajo de cómo se debe proyectar el individuo hacia la sociedad. En este sentido, la reflexión, como proceso de interrelación identitario en las organizaciones, puede ser considerada como parte de la noción antropológica de la liminalidad.

[La] liminalidad puede describirse en parte, como una etapa de reflexión. [...] Liminalidad es el reino de la hipótesis primitiva, donde hay una cierta libertad de hacer malabares con los factores de la existencia [...] existe una mezcla promiscua y alternativa de las categorías de evento, experiencia y conocimiento, con una intención pedagógica. (Turner, 1967, pp. 105-106).

El autocuestionamiento activo, cómo se ve el sujeto y cómo lo ven los demás, es la esencia de una construcción dialógica del yo.

${ }^{128}$ Goffman (1974) la describe como una experiencia en la que el individuo muta el énfasis del significado de un acto por algún aspecto de primer plano al que se atribuye mayor importancia, permitiéndole tomar conciencia de lo que sucede. 
En ese orden de ideas, entonces, se propone que la liminalidad en el proceso de construcción identitario puede estar constituida por una o más de estas prácticas: la trascendencia, en la que lo liminal construye y proyecta una identidad; la reflexión, cuando lo liminal considera las opiniones de los demás y las preguntas de sí mismo en un presente, y el reconocimiento, en donde lo liminal reacciona a una identidad que se proyecta a partir de una historia pasada.

El reconocimiento así como la trascendencia tienen una connotación netamente individual. Son dinamismos personales que entran en relación con lo propiamente organizacional a través de la seguridad. Esta categoría, a diferencia de las dos primeras, recae en el ámbito netamente organizacional en cuanto a su aplicación o ejecución. De este modo, las posibilidades que tiene la organización para intervenir en el proceso de construcción identitario se dan, gracias a las garantías que ofrezcan seguridad al proceso como tal. Si bien hay una historia personal y profesional escrita paralelamente a la organización, la construcción de sentido y los significados que los MM interpretan y asimilan, se dan gracias a que existen las condiciones para ello.

En tales circunstancias, y relacionándola con los aspectos personales y profesionales, se puede afirmar que la construcción identitaria está permeada por dos niveles de análisis anclados por la seguridad que la organización propicia para garantizar el proceso de construcción identitario. El primer nivel de equilibrio está dado por las tensiones entre los aspectos personales y profesionales con respecto a los organizacionales. Las contradicciones que pudieran surgir entre estos dos polos desequilibran la balanza y ponen en peligro la estabilidad laboral y la continuidad del trabajador, ya que este podría optar por romper las relaciones y retirarse de la empresa. El nivel de equilibro está caracterizado por aspectos personales de la vida del individuo que se encuentran con los organizacionales. En ese sentido, la construcción identitaria pasa por un primer análisis de lo individual, por medio del cual la persona contrapone lo particular y profesional a los intereses de la organización. 
Lo anterior sugiere que el equilibrio organizacional está estructurado mediante una relación egoísta de conveniencia mutua: los individuos permanecen en la organización, no necesariamente porque los intereses de ambas partes se identifiquen sino porque la relación misma les es útil, es decir, al estar en la organización, los individuos pueden valerse de los beneficios que ellas les brinda para cumplir con sus propios objetivos e intereses. De la misma manera, la organización se vale de las habilidades y de los conocimientos de los empleados para cumplir con los objetivos que se propone, a pesar de que estos muchas veces no coincidan con los de los trabajadores. Se estructura así una relación interesada que busca las condiciones que la otra parte pueda proporcionar para mantener una vinculación laboral. Si estas condiciones no se dan en algún caso, alguna de las partes romperá la relación.

Un segundo nivel de equilibrio se configura a partir de los aspectos propiamente organizacionales, enmarcados por las condiciones espacio-temporales específicos a cada compañía. La reputación, el prestigio, las funciones, las dinámicas culturales, el desarrollo de la estrategia, entre otros aspectos, influyen en la construcción de sentido por parte de los individuos. Tales componentes están sostenidos por la seguridad que la empresa pueda brindar en lo referente a garantizar las condiciones mínimas de permanencia y autonomía para poder realizar el proceso de asimilación y apropiación de una nueva $I O$.

En este segundo equilibro se expresa, a su vez, un segundo nivel de análisis que es la presencia de lo organizacional en la construcción de la IO. Si bien, la categoría de seguridad le corresponde a la organización en cuanto a su cumplimiento y desarrollo, los aspectos personales y profesionales se encuentran situados en una dimensión particular del individuo. Por el contrario, el reconocimiento y la trascendencia se constituyen y configuran en sí mismos gracias a la relación con la organización. De esta manera, la tensión del individuo entre lo que quiere ser y lo que fue se ve mediada por la organización que es garante de seguridad del proceso de construcción identitario. 
En conclusión, el proceso de construcción identitario de los individuos se configura a partir de los dos niveles de análisis. Hay una unidad en la dinámica de construcción, en donde lo personal no se desliga de lo organizacional, lo supone, se requiere y constituye sentido a partir de él. El establecimiento de la liminal identidad requiere considerar estas dos dimensiones y los componentes que intervienen allí. No obstante, esta construcción privilegia los aspectos personales, de ahí que la primera situación de equilibrio se convierta en condicionante para la segunda, es decir, tiene una importancia mayor para que el proceso de construcción se realice o continúe. Junto con ello, es claro que el control que puede ejercer la organización dentro del proceso de construcción se podría centrar en el segundo espacio de equilibro, es decir en lo referido a lo propiamente organizacional, ya que en los aspectos personales, no tiene ningún tipo de injerencia.

De esta manera, la construcción de la IO contiene unos componentes que se integran en dos niveles de análisis cohesionados por la participación de la organización como garante del proceso. La estabilidad de este, junto con la seguridad que pueda brindar la organización, se sostiene por las tensiones inherentes a su desarrollo. Vale decir, el proceso de construcción identitaria se sustenta en las tensiones existentes, no es una relación exenta de controversias, desencuentros, incumplimientos o frustraciones; es un proceso que se recompone de acuerdo con los intereses de las partes, es agónico, lo cual genera acuerdos explícitos e implícitos, y provoca una tensión que se reescribe y se reconfigura en el dinamismo social y continuo de la experiencia organizacional y de los factores que en ella intervienen, situación que se refleja en la gráfica 22. 


\section{Gráfica 22: La construcción de la IO como un equilibrio liminal}

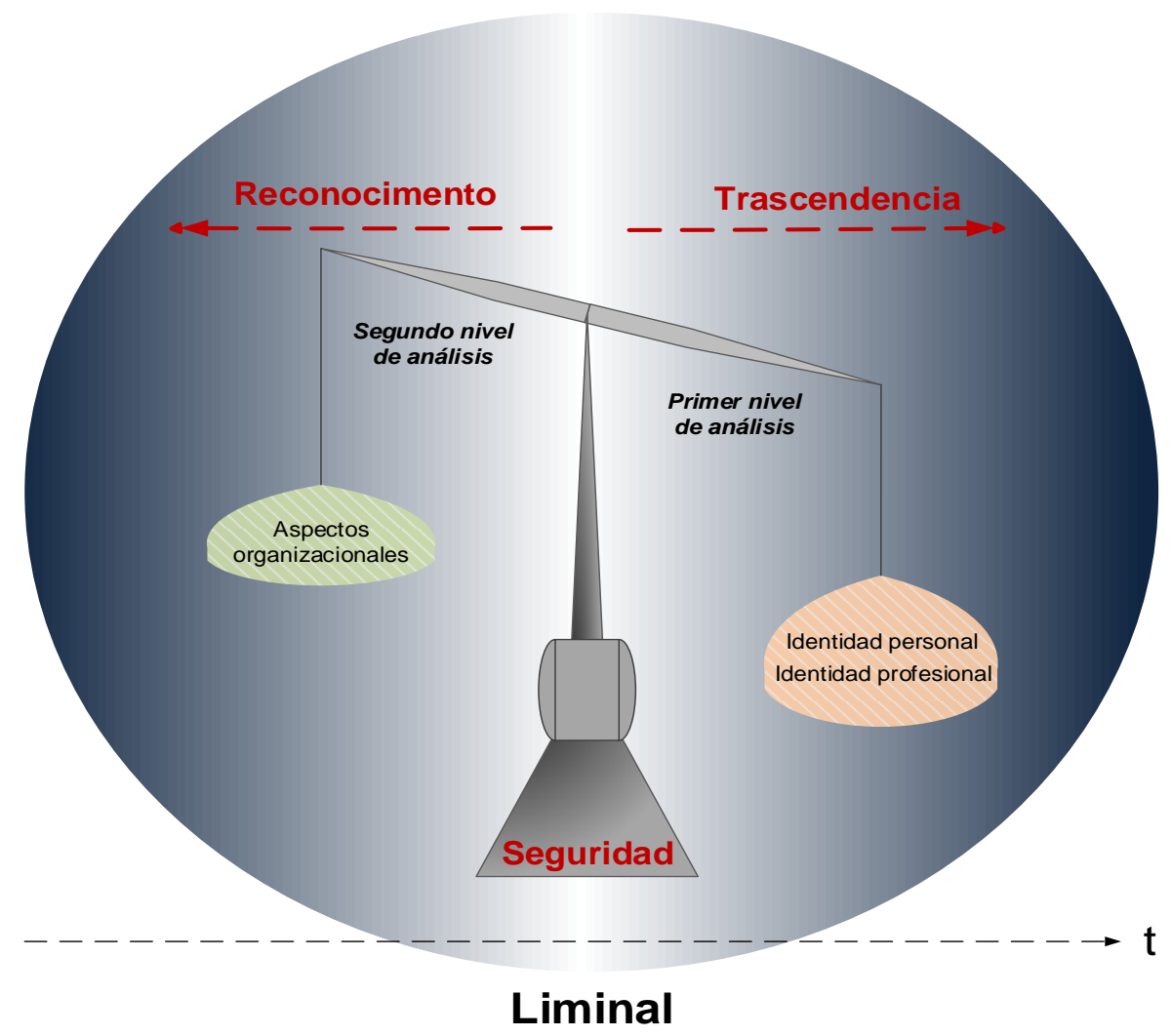

Fuente: Elaboración propia.

La balanza busca expresar el equilibrio entre los dos componentes mencionados: la identidad personal y profesional, y los aspectos organizacionales. La IO se sostiene por la seguridad que les otorga la organización a los individuos, en el proceso de construcción de una IO específica. Lo personal del individuo (la identidad personal y profesional) tiene una importancia mayor para él, de ahí que la balanza esté inclinada. Del otro lado se encuentran los aspectos organizacionales propios de la organización. Esta balanza, que busca estar en equilibrio y se va adecuando y reacomodando constantemente, se encuentra en un estado liminal, en una situación de no-estructuración. Es el communitas, caracterizado por las fuerzas contrarias de reconocimiento y trascendencia, que mirando al pasado y al futuro, respectivamente, delimitan un estado de 
construcción de sentido del individuo en donde no siendo, buscan definirse a sí mismos en relación con la organización.

La balanza sostenida por la seguridad, aspecto que solo puede ser propiciada y garantizada por la organización, soporta en sus dos brazos los componentes del proceso de construcción identitario como tal. Se configuran así dos tensiones provenientes de los dos extremos de la balanza, las cuales deben ser mantenidas adecuadamente por la organización. Si una de ellas se rompe, el proceso de construcción se interrumpe. Junto con ello, se establecen dos niveles de análisis que articulan indisolublemente lo individual y lo organizacional dentro del proceso.

La dinámica de la balanza denota también el estado de continuo movimiento a partir del equilibrio de fuerzas. El modelo no es estático sino dinámico y expresa el proceso en sí, donde la regulación, la resistencia y la construcción de sentido se presentan en forma constante. La 10 no es algo que ya posee el individuo, no es algo distintivo, es la construcción entre lo que el sí mismo comprende en un contexto determinado por el tiempo y las circunstancias específicas que lo componen. La construcción es continua como una interpretación reflexiva por parte del individuo; la 10 es un proceso fundado en la alteridad entre quien construye sentido y se pregunta quién es para la organización, y un otro que dice quién debe ser para esta.

Como se puede inferir, los resultados de la investigación permiten afirmar que la IO puede ser considerada un proceso liminal. Este, sujeto a tensiones entre lo organizacional y personal, configura un espacio social para el individuo. Allí, las fronteras son difusas y la pregunta por la propia identidad de los individuos dentro de las organizaciones está mediada por contradicciones, frustraciones, pero también por sueños, agradecimientos, esperanzas y anhelos. Lo liminal se convierte en expresión de lo dialéctico, es su manifestación, en donde el foco está puesto en el proceso como tal. En ese sentido, y relacionándolo con los paradigmas expuesto en el capítulo referente a la revisión de la literatura (capítulo 
uno), la investigación se basa en el modelo de la construcción social, a la vez que propone que lo liminal puede ser tomado como una temática importante dentro del ámbito de la $\mathrm{IO}$ en los EO.

Un tema, no menos importante, queda aún por resolver; se desprende de todo este proceso que se ha tratado de describir y explicar. El desarrollo de la construcción identitaria evoca un movimiento en el tiempo. Los componentes dilucidados son tomados como estáticos, circunscritos a un contexto en específico; entonces, ¿cómo explicar en el tiempo una realidad que toma del pasado y mira hacia el futuro en una tensión que mantiene constante y presente el proceso?

Para responder tal interrogante, se recurre a las reflexiones del santo de Ipona sobre el problema del tiempo. Agustín se plantea la pregunta siguiente. ¿Qué es el tiempo? Para el Obispo de Ipona, el tiempo encierra una aporía, una paradoja del ser del tiempo, que consiste en que este está compuesto por los modos del pasado, presente y futuro.

\begin{abstract}
Sin embargo, cuando lo queremos aferrar, el pasado ya no es, porque ha pasado, el futuro aún no ha sucedido y el presente parece, por su divisibilidad infinita, no tener extensión. [...] Hablamos de tiempo presente como si fuera real, como si estuviera ante nosotros, pero se puede ver rápidamente que ese mismo uso deriva en cierta perplejidad. Cuando se habla de periodos de tiempo largos o breves, se asume una duración temporal como real. Sin embargo el presente, bajo las premisas de transcurrir constante del tiempo del futuro hacia el pasado, parece no tener duración, no poder asirse como unidad. (Corti, 2011, p. 19-20).
\end{abstract}

La alternativa que utiliza Agustín para atrapar el tiempo es recurrir a la experiencia cotidiana. A través de esta, en el transcurso de los tiempos, se tienen noticias de la duración del tiempo. A partir de esta experiencia se puede hablar de lo pasado, presente y futuro, en cuanto su accesibilidad a la experiencia, es decir, ya no se pregunta si estas dimensiones del tiempo son, sino cómo son accesibles a la experiencia en tanto pasado, presente y futuro. Así pues, aquello que es, tiene que ser accesible a la experiencia, deber ser presente. Por lo tanto, ser accesible o estar a disposición no tiene relación exclusiva a ser en el tiempo presente. 
En concreto, el modo temporal del pasado y las huellas que este deja en la memoria se encuentran en el presente. El futuro existe hoy en una representación de una imagen que está en el futuro.

Más propiamente debiera decirse que los tiempos son tres: presente de lo pasado, presente de lo presente y presente de lo futuro. En efecto, estos tres modos «son" de algún modo en el alma y no veo otra forma de comprenderlo: el presente de lo pasado es la memoria; el presente de lo presente es la atención; el presente de lo futuro, la expectación. (Agustín, 1984, p. 228).

Solo a través de la experiencia (o de la actividad del alma) se puede afirmar la existencia de los tiempos. En esa experiencia, lo pasado, lo presente y lo futuro son accesibles como tiempo, gracias a la actividad triple del alma (entendida como psiqué) que recuerda, atiende y espera.

Si lo dicho se tiene presente, el equilibro liminal de la construcción de la IO es una experiencia que se estructura a partir de memorias y recuerdos del pasado, los cuales brindan un reconocimiento a los individuos por las experiencias vividas y hacen que exista un apego de las $\mathrm{OO}$ en el presente. Así mismo, el dinamismo trascendente impulsa a los individuos a mirar al futuro. La posibilidad de llegar a ser, de perfeccionarse como seres humanos, propicia una espera que los mantiene vinculados a la organización por la promesa esperanzadora que en un futuro, el despliegue de lo que son signifique para la organización. Por último, la seguridad es lo que permite que las tensiones antes descritas existan y el proceso de construcción identitario se desarrolle. La seguridad como garante es el presente, es la experiencia del cumplimiento de una promesa que permite confiar en el futuro y compararse con el pasado. De esta manera, el proceso confluye en el presente a partir de esa experiencia, e integra los modos del tiempo en él.

\subsection{A MANERA DE CONCLUSIÓN}

En este capítulo se ha respondido con propiedad a la pregunta de la investigación: ¿Cómo es el proceso de construcción identitario de los MM? En su desarrollo se ha buscado esclarecer y explicar el proceso mediante el cual los MM construyen 
una $\mathrm{IO}$, así como los componentes que interviene en dicho proceso. Son las categorías emergentes principales, desde el punto de vista de los MM: el reconocimiento, la trascendencia y la seguridad. Fundamentado en esas conceptualizaciones y la relación que las categorías tienen con la teoría, la revisión de la bibliografía y el sentido, el investigador encontró los resultados de la investigación y presenta la respuesta a la pregunta planteada.

A lo largo del capítulo se han detallado y esclarecido las situaciones específicas para el caso de $\mathrm{CN}$; no obstante, se ha tratado de proponer teóricamente la 10 como un proceso de construcción en un equilibrio liminal en donde se conjugan dos niveles de análisis, el personal y el organizacional. De esta manera, los resultados de la investigación han permitido realizar aportes a nivel teórico, para acercarse a comprender en mayor profundidad la temática de la IO como liminal.

Por otro lado, y resaltando la pluridisciplinariedad de los EO, los hallazgos se han fundamentado y amparado en algunas ciencias sociales, cocretamente en la filosofía y en la antropología. Se evidenció, además, la necesidad de tender lazos con otras disciplinas para poder comprender al individuo como ser social y, por lo mismo, inmerso en dinámicas y procesos sociales. Esta mirada comprensiva no busca dar soluciones logarítmicas, pragmáticas y funcionales, sino que se propone acercarse al fenómeno social para comprenderlo y explicarlo.

La propuesta de Turner en cuanto a los ritos de paso y al proceso de ritualización, posibilitaron profundizar en distintos aspectos por los que atraviesan los individuos que buscan construir una IO específica. La realización de tal ejercicio ha dado pie para acercarse a las ciencias sociales, enriqueciendo la mirada a este fenómeno -la construcción de la IO de los MM entendidos como un proceso liminal-que poco se ha investigado en las organizaciones. 
De otra parte, y luego de lo discutido, es válido resaltar aquellos aspectos, tanto a nivel epistemológico como metodológico, que la mirada pluridisciplinar aporta para la comprensión de la realidad organizacional.

- Los MM se encuentran en una situación de conflicto permanente por las rivalidades y los juegos de poder ya descritos. Por eso, la fase de reajuste identificada por Turner se convierte también en espacio y oportunidad para la reflexividad, es decir, para la mirada autocrítica de las acciones. La reflexividad supone de alguna manera una interrupción en ese proceso transicional, en ese devenir. Por lo tanto, será también un espacio para mostrar cuáles son los límites que tiene la subjetividad, en el sentido de que el individuo busca tomar decisiones a partir de la realidad que le toca definir y delimitar. Con esto, no se quiere decir que exista una única realidad, sino lo real que el sujeto descifra para sí.

- Si la administración no ha de ser una ciencia, y mucho menos una ciencia de carácter técnico-instrumental; si ha de entenderse como una parte de la acción humana, un territorio mucho más ambiguo e incierto que el tradicionalmente transitado, se debe buscar la comprensión como prolegómeno a toda teorización, a toda concepción instrumental, a toda enseñanza y a toda práctica administrativa como tal. Se ha resaltado la palabra comprensión porque ella marca la postura final, para llevar a un plano diferente el debate disciplinar que tradicionalmente se ha circunscrito a lo epistemológico.

- La atención se ha tratado de centrar en una mirada comprensiva, en una perspectiva de humanidad como medio de comprensión de la naturaleza humana y sus finalidades. Paradójicamente, el problema de la administración deberá buscarse fuera de ella (ad extra), sin que esto quiera decir que la administración como disciplina de gestión de recursos de las 
personas no pueda comprenderse ad intra. Es solo que quien administra deberá trascender los estrechos límites de la racionalidad instrumental en su ejercicio. Para ello es necesario una formación comprensiva (para no decir hermenéutica) que le dé un horizonte de visión y criterios de interpretación y acción más amplios que los adquiridos en una educación (o más bien, una instrucción) profesional meramente técnica.

Se ha transitado en compañía de otros marcos teóricos dentro de las ciencias sociales para acercarse a la gran e inconmensurable realidad organizacional desde la perspectiva de la IO. Faltan aún muchos puentes por tender, pero este trabajo es prueba factible y evidente de su posibilidad, gracias al apoyo de las ciencias sociales, aspecto característico de los EO. Junto con ello, y por los hallazgos encontrados, bien se podría considerar a la 10 como un marco de análisis en sí mismo desligándolo del tema de la cultura, al cual se le asocia comúnmente. 


\section{CAPÍTULO 7}

\section{RECAPITULACIÓN Y REFLEXIONES FINALES}

\subsection{COMENTARIOS GENERALES}

En los capítulos precedentes se presentaron y discutieron los resultados de la investigación; se interpretaron y analizaron los datos a la luz del modelo teóricometodológico diseñado previamente. Ahora corresponde exponer las reflexiones conclusivas de todo el proceso.

Lo primero por resaltar es el rol de los $\mathrm{EO}^{129}$. En efecto, estos, como campo de conocimiento especializado en el estudio de las organizaciones, retoman de las ciencias sociales la conceptualización de categorías de análisis para penetrar en la comprensión de los fenómenos sociales que se inscriben en las organizaciones. Los aportes tomados de la psicología, la filosofía, la antropología y la sociología acompañan gran parte de la reflexión del estudio realizado. Por lo demás, los EO comprenden un ámbito pluridisciplinario que permite tender puentes con otras ramas del conocimiento para estudiar los fenómenos sociales vinculados a las organizaciones. Esto se evidenció en las posibilidades de integrar conceptos como identidad personal, identidad profesional e identidad organizacional, categorías nucleares del modelo propuesto. Sin la ayuda de las ciencias sociales no se hubiera podido analizar e interpretar los datos obtenidos y construidos ni profundizar adecuadamente.

${ }^{129}$ Con el fin de recordar el significado de las siglas, se pueden revisar las tablas correspondientes del comienzo. 
Otro elemento a rescatar, relacionado con lo antedicho, es la construcción de un modelo teórico-metodológico para abordar el análisis de los datos. Modelo aplicado a la realidad organizacional estudiada, concebido, no para buscar una generalización u universalización de los resultados, sino para resaltar lo importante del estudio del caso circunscrito a los aspectos organizacionales en su particularidad. Por ello se definió y argumentó una propia definición de IO, a la vez que se construyó un modelo teórico que permitiera el análisis de los datos en concordancia con dicha definición. Sin duda, este recurso se convierte en uno de los principales aportes de la investigación.

Se destaca la concepción metodológica con la que se transitó a lo largo de la investigación, con el fin de mostrar el proceso de construcción como tal. En otras palabras, se buscó presentar la articulación y las relaciones de las categorías preliminares y emergentes de la investigación en conformidad con el modelo propuesto. En la práctica, la construcción metodológica en su originalidad, particularidad, profundidad y complejidad se transformó en el trabajo investigativo como tal. El camino recorrido permitió adquirir coherencia y rigor metodológicos, y por lo mismo, ser garante de la fiabilidad de los hallazgos. Junto con ello, el proceso descrito se puede convertir en un referente de consulta para quienes se preguntan por el cómo, y no tanto -sin ser excluyentes- por los resultados del trabajo investigativo.

En el marco del preámbulo que antecede, a continuación se presentan algunas reflexiones finales de la investigación. Están agrupadas en tres niveles: teórico, metodológico y organizacional. Es esta última se incluyen los aspectos propios del estudio de caso. Todas las conclusiones están en sintonía con los objetivos general y específicos propuestos para el trabajo; su cumplimiento expresa la coherencia y consistencia de la metodología empleada. 


\subsection{A NIVEL TEÓRICO}

- Luego de un poco más de un cuarto de siglo desde su conceptualización, el término IO no está lo suficientemente definido ni acabada la discusión sobre sus alcances o modelos propuestos. En el campo organizacional han proliferado definiciones que van desde el nivel individual hasta percepciones de lo que es la organización; todas, basadas en perspectivas institucionalistas o esencialistas con las cuales se busca identificar las características propias de la organización. Esto ha redundado en una cacofonía y polisemia de su definición y en sus aportes al ámbito organizacional; ha llegado incluso a generar una contradictoria y consecuente situación en donde pareciera que todo es identidad y, simultáneamente, nada lo es.

- El tema de la $1 O$ es importante a nivel teórico, toda vez que proporciona elementos valiosos para los análisis empíricos. Brinda formas creativas para comprender una amplia variedad de contextos y fenómenos organizacionales. Además, también ha sido planteado como perspectiva teórica de análisis y como objeto de estudio. En otras palabras, existe una preocupación por lo que «se es», en tanto forma cultural e histórica, y una propensión a tomar la IO como perspectiva para comprender los problemas y fenómenos sociales presentes en las organizaciones.

- Tanto la filosofía, los estudios culturales y la teoría literaria, como la psicología, la sociología y la antropología han desarrollado a su manera el concepto de IO. Por ello, estas ramas del conocimiento se convierten en sus fundamentos disciplinares y no sorprende que el concepto de IO haya encontrado en los EO un espacio para su interrogación y utilización. 
- Los fundamentos ontológicos de la 10 descansan en su concepción como metáfora o como realidad. Desde la primera pespectiva, se buscó explicar cómo las organizaciones son similares y diferentes entre los individuos y la colectividad, a la vez que se pretende entender las dimensiones simbólicas de la vida organizacional. Desde la segunda postura, se advierte a la organización como un fenómeno experimentado por los miembros de la organización, percibida por quienes están por fuera de ella, convirtiéndose en primordial para los procesos sociales dentro de los contextos organizacionales.

- Los cimientos epistemológicos se levantan en la concepción de la IO como construcción social o como nucleo esencial. Desde esta última, la IO es un fenómeno contingente, cuyo núcleo o esencia es el resultado de los procesos de construcción social. Conceptualizar la organización como una construcción social permanente que se lleva a cabo entre sus miembros, posibilita influir y acceder a los individuos, grupos, equipos de alta dirección y de otros colectivos. En contraste, el otro punto de vista sobre este tema trata la IO como una característica o propiedad que de alguna manera se encuentra dentro de ella misma, es decir, se conceptualiza a la IO como un actor social.

- En cuanto a la conceptualización de la 10 se presenta un conjunto de convergencias y divergencias. Se la definió como aquello que captura y da sentido y significado a sus miembros. Es la autorreferenciación, donde el yo es el colectivo. Esta autorreferenciación puede ser tácita o explícita, propia o cedida, o estar más o menos presente en los individuos. La IO sirve también de contexto y es inherentemente comparativa. Esta identidad está típicamente contextualizada en términos de la posición del actor o del rol establecidos por un sector industrial específico, por el marco social y el laboral; a la vez, envuelve un conjunto de significados compartidos por la colectividad, de ahí que tenga un nivel de construcción colectiva. Así pues, la IO se aleja de las 
definiciones que la asimilan a la identidad corporativa, la imagen organizacional y la reputación o la confunden con dichos conceptos.

- Después de una revisión de la literatura sobre el tema de la 10 , se lograron identificar tres paradigmas -esencialista, constructivista, discursivo-, cinco perspectivas teóricas -regulación y resistencia, estabilidad y cambio, construcción identitaria, narración y discurso, audiencia e identidad- y distintas discusiones en relación con el concepto mismo de IO. Ahora, en el contexto de la presente investigación, el concepto de 10 se inscribe en el paradigma constructivista y encuentra cabida dentro de un tema específico poco estudiado en el ámbito de los EO como es lo liminal. Esta determinación se convierte también en uno de los principales aportes de la investigación.

- La construcción de la 10 —no sobra recalcarlo- es un trabajo que se realiza en las prácticas situadas, al participar, de cierta manera, en las actividades y, simultáneamente, en el pensamiento, como un habla interna y la generación de un sí mismo capaz de orquestar distintas voces. La construcción de la identidad es un proceso de autoformación al contribuir y entrar en contacto con las prácticas y significados culturales. En la medida en que se conocen más ámbitos de la experiencia, se generan nuevas capacidades de ser y pensar que se entroncan y posibilitan apropiarse de los mundos culturales. De este modo, las personas y las actividades que se efectúan en lugares específicos proporcionan recursos identitarios a los sujetos que buscan configurar una IO.

- A partir de la documentación revisada, causa cierto asombro que el tema de la IO, prácticamente, no está ligado a la temática cultural. No hay referencias o desarrollos en donde se relacionen la 10 con la cultura organizacional, más allá de que los investigadores citen textos o investigaciones sobre el asunto. Además, se suma la gran variedad de temas y marcos teóricos en los cuales se toma la 10 como objeto de estudio, así como perspectiva teórica para el 
análisis de los fenómenos organizacionales. De ahí se podría inferir que la 10 tendría la importancia y la relevancia suficientes para que se la considere como una corriente de estudio en sí misma dentro de los EO.

- El marco teórico de la investigación está constiuido a partir de los EO, campo especializado en el estudio de las organizaciones que se caracaterizó con base en sus aspectos ontológicos, epistemológicos y metodológicos. De igual modo, se presentaron algunas de las controversias y diferencias que lo circundan, a la vez que se mostraron las particularidades que se consideran como propias. $\mathrm{Si}$ bien los EO están todavía en construcción y muchos investigadores se acercan a ellos con definiciones aún inacabadas, es posible afirmar que se trata de una nueva perspectiva para la comprensión de los fenómenos organizacionales. Su riqueza se encuentra en su pluridisciplinariedad y en su perspectiva crítica, factores notables tanto para la investigación como para la intervención organizacional. Bajo tal visión, los EO se convierten en un campo reflexivo y crítico que puede abonar a la formación en Administración, al considerar no solo los aspectos técnicos de la organización sino también al centrar la atención en los efectos sociales que produce su operación.

- La diversidad de perspectivas teóricas lleva a delimitar los EO como un campo de conocimiento que se vale de las ciencias sociales para la comprensión de los fenómenos sociales que se inscriben en las organizaciones. En este sentido, es un campo abierto, un receptor de múltiples racionalidades, las cuales permitan explicar y comprender antes que resolver problemas organizacionales específicos de corte operativo y funcional. Esto es coherente con la misma definición de estudios. No se busca una sola teoría o un gran único discurso, sino que el término denota en sí mismo la pluralidad con la cual diversas perspectivas teóricas ayudan a comprender más profundamente el fenómeno estudiado. Se afirma que por su historia, surgimiento y sus dimensiones epistemológicas y metodológicas, los EO son un campo inclusivo, 
en donde la pluridisciplinariedad complementa y aporta en el concimiento de los fenómenos organizacionales examinados.

- Tanto la Teoría Crítica como el Posmodernismo pueden considerarse como perspectivas que comparten aspectos convergentes y divergentes para entender las organizaciones. La TC, en sentido amplio, constituye un cuestionamiento radical a la sociedad contemporánea, caracterizada por la explotación, la represión, las relaciones asimétricas de poder, la comunicación distorsionada y la falta de conciencia. En sentido estricto, se refiere a la llamada Escuela de Frankfurt. Por su parte, el PM es mucho más difícil de delimitar. Dentro de las ciencias sociales, el término describe un estado de ánimo social, un período histórico lleno de grandes cambios sociales y organizacionales, y un conjunto de enfoques.

- Mandos medios (MM), construcción de identidad organizacional e identidad personal y grupal, en la cual se inscribe la identidad profesional, son los conceptos principales de la investigación, los cuales fueron delimitados y precisados por esta. Por MM se entiende a aquellos empleados localizados por debajo de los directivos y son la primera línea de supervisión jerárquica de las empresas. Los MM, de acuerdo con el lugar que ocupan en la organización, permanecen atrapados en el medio o propician un conflicto entre las demandas que la organización les exige y la necesidad de buscar, al mismo tiempo, cooperación de los subordinados para llevar a cabo sus funciones. Tal situación los lleva a experimentar falta de poder para realizar las acciones competitivas que incumben a sus responsabilidades.

- La identidad personal, para efectos de esta investigación, es definida como aquella que hace único a alguien. Unicidad que se concibe como aquello que soporta una identidad, tal como la representanción fotográfica que los demás hacen de un individuo, o el conocimiento de su ubicación espacial dentro de 
una red de parentesco. Solo un sujeto a la vez puede encajar dentro de la imagen que otra persona puede estar examinando, y quien llena los requisitos del pasado tanto como los actuales. Además, la noción de unicidad también se refiere a que si bien la mayoría de los episodios aplicables a un personaje se pueden destinar a otro, se advierte que en ninguna otra persona se encuentra combinada la totalidad de los hechos que caracterizan a dicho individuo como tal.

- La identidad profesional tiene que ver con las normas identitarias que distinguen a un colectivo dentro de un sistema de acción laboral específico, pero también biográfico, de acuerdo con la trayectoria que sus miembros tengan dentro de su vida laboral. Las identidades profesionales son, para los individuos, formas socialmente aceptadas de reconocerse mutuamente en el ámbito laboral. Es así como la pertenencia a una profesión influye en la autodefinición y en las formas cómo los demás piensen de una persona. Por lo tanto, se puede definir la identidad profesional como el conjunto de atributos, creencias y valores que las personas utilizan para definirse a sí mismas en tareas y habilidades especializadas, y la educación basada en profesiones o vocaciones.

- La construcción de la 10 es un proceso cognitivo permanente, iterativo, encarnado por los empleados, quienes se basan en múltiples modalidades para asimilar la situación de la organización, con la capacidad de acercarse a ella de diversas maneras, a través de información que evoca diferentes trayectorias de experiencia. La construcción de 10 por un miembro de la organización se fundamenta en el procesamiento, examen, interpretación y expresión de la información incorporada, que es formal y no formal, oficial y no oficial, simbólica y material, así como la información que se comparte es colectiva, interpersonal y específica para ese individuo. Junto con esto, la conceptualización de lo que es la $\mathrm{IO}$, por parte del individuo, se funda no solo 
en estímulos físicos y experiencias, sino también en hábitos socialmente construidos, y en acciones intencionales de gestión con el fin de elaborar ciertas creencias acerca de lo que es una organización.

- Para Gioia, Price, Hamilton y Thomas (2010) no existe ningún estudio exhaustivo acerca de cómo se construyen las identidades organizacionales en sus inicios. Para estos autores, solo tres trabajos han estudiado la formación de la IO per se: Clegg, Rhodes y Kornberger (2007); Corley y Gioia (2004), y Czarniawska y Wolff (1998). Cada una de las obras aborda tan solo algunos aspectos de la construcción de la IO, pero, en su conjunto, son un buen punto de partida para una consideración más holística de la construcción de la IO. Los resultados de la presente investigación contribuyen en esta temática en concreto ya que se exponen los componentes y las relaciones que se generan en los MM durante el proceso de construcción de una 10 en específica.

\subsection{A NIVEL METODOLÓGICO}

- Con la creación de un modelo teórico-metodológico se pretendió integrar a los dos actores sociales involucrados - los MM y los directivos- en los dinamismos de permanencia y despliegue propios de los MM y en la realidad permanente y cambiante de la organización, en figura de sus directivos. El modelo busca expresar un dinamismo de mutua relación entre los aspectos mencionados que se caracterizan por la forma en cómo se integran y permiten dar sentido al proceso de construcción como tal. En ese marco, para la investigación, la 10 es un fenómeno cultural que se inscribe dentro de las organizaciones, es decir, es posible explicarla por los miembros de la organización. Empero, no se parte de considerar esencias particulares ni inamovibles de la identidad sino como construcciones sociales. En este sentido, no se puede hablar de una identidad sino de identidades, en la medida en que cada sujeto esclarece aquello que es central, distintivo y perdurable en la organización. 
- El modelo teórico-metodológico permitió definir las categorías preliminares luego de una revisión documental sobre el tema de la IO. El proceso de construcción identitario se basa en esas categorías. En sí mismo, la configuración y definición de estas dentro del modelo implicaron una claridad conceptual, de ahí que se pueda afirmar que lo teórico no está ausente de lo propiamente metodológico. Por otra parte, lo metodológico requiere del sostén teórico para su viabilidad y claridad procedimental en la recopilación y construcción de la información y el posterior análisis.

- La investigación se afrontó desde una postura interpretativa que contrasta con la mirada funcionalista. Es así como, rescatando la dinámica propia del sujeto que construye y da sentido a la realidad organizacional en la cual se encuentra inmerso, la IO se erige como una construcción dialéctica, resultante del diálogo entre el enfoque funcionalista con pretensiones de regulación por parte de la dirección, y la construcción de sentido desde el punto de vista de los sujetos (MM).

- El carácter dialéctico — se entiende- no significa que solo tenga una relación interna sino, más profundamente aún, que cada cosa es lo que es en un proceso continuo (Adorno, 1974). Es decir, la realidad —en tanto dialécticano es fija ni determinada de una vez y para siempre; está en un constante proceso de transformación, cuyo motor es, al mismo tiempo, su contradicción interna, su limitación y desajuste en relación con su exigencia e intención de totalidad, infinitud y absoluto, como la relación interna en que está con otra realidad, que aparece como su contrario. La realidad, en cuanto dialéctica, está regida y movida por la contradicción, internamente relacionada y constituida como oposición unitaria de contrarios. Si se tiene presente lo anterior, la propuesta teórica concibe la 10 como un proceso de construcción dialéctica entre los directivos y los MM. 
- La tesis se fundamenta en los procesos de institucionalización a los que son sometidos los MM. Se puede concebir la organización como una institución en sí misma en la medida en que las prácticas organizacionales se transmiten socialmente, a la vez que facilitan comprender la trasferencia y legitimación de las normas y los procesos internos. Los directivos de la organización buscan institucionalizar ciertos procedimientos referidos a la identidad, como una forma de regulación organizacional.

- La antítesis está construida por los MM. Las normas, reglas y demás directrices son interpeladas, asimiladas y dotadas de sentido. Al proceso que se desarrolla dentro de este diálogo se le llama construcción. Gracias a esta, los MM tienen la posibilidad de elegir, a pesar de estar limitados muchas veces por la estructura social, y los convierte en personajes activos, no simplemente en individuos reactivos. En este sentido, los MM pueden ordenar jerárquicamente las identidades de acuerdo con una relevancia o compromiso para cada relación en la que se encuentren. Por consiguiente, la IO de los MM está mediada por la organización y por las relaciones que en ella se produzcan y actúen como referentes. La construcción de sentido para los MM es la conciencia de las vivencias que les propician las acciones que tratan de promover en ellos una IO. Tal identidad está conformada por el conjunto de experiencias suscitadas gracias al tipo de acciones de la organización que los MM interpretan y configuran.

- La IO no se implementa per se, es la síntesis. Es fruto de un diálogo con los actores sociales (MM). Ellos buscan darle sentido a las diversas manifestaciones que la dirección propone e impone. Aquí es donde se estructura una $\mathrm{IO}$, la cual requiere de una interpretación y dotación de sentido. Se sugiere, entonces, que la misma IO es una dialéctica constante, resultado de una visión sintética entre la organización y los sujetos (MM, entre otros). En 
este caso, no se puede hablar de una única IO sino de una conglomeración de significados compartidos que vislumbran una serie de características particulares y comunes.

- La IO se concibe como un proceso de construcción social que se realiza en las organizaciones gracias a la interacción de los sujetos sociales inscritos en ellas. La investigación enfatizó que hay grados de permanencia y cambio y, en consecuencia, se pueden encontrar elementos que están más predispuestos a permanecer y otros a cambiar, sin que esto sea insalvable. La identidad es un proceso como tal -es lo que se es-, en presente, pero, a su vez, es expresión de un desarrollo constructivo que deviene del pasado. La identidad, pues, es la construcción de sentido autorreferencial, que encuentra sus bases en el pasado para expresarse en el presente. Así, la IO se construye por antonomasia.

- El modelo de la IO que se creó es psicodinámico emergente. En ese sentido, la IO se estudia para comprender procesos sociales, tales como la identidad, y para entender cómo se satisfacen las necesidades psicológicas y emocionales. El modelo propicia el conocimiento de los recursos que los individuos están utilizando para satisfacer ese tipo de necesidades. Así, en el sujeto se vislumbran dos fuerzas o dinamismos que configuran una identidad: la seguridad psicológica y la necesidad de significación.

- Desde el punto de vista de la organización, hay aspectos que permanecen y otros que cambian. Las normas, los procesos de control, el mismo código laboral tienen una tendencia a permanecer en el tiempo. Por el contrario, otros aspectos - muchos de ellos propiciados por el mercado o por las mismas estrategias internas - tienden a cambiar. En otras palabras, concebir que la organización está representada por sus directivos desde las dimensiones temporales de permanencia y cambio es subrayar que el análisis de la 
construcción de una 10 es dinámico; al tiempo, se asume una postura que se aleja de una visión esencialista de la IO.

- El modelo está relacionado con la configuración identitaria propuesta por Dubar (2000), donde las dimensiones de seguridad y permanencia conforman el eje relacional, y las de significación y cambio el eje temporal. De esta manera, sendos aspectos, tanto a nivel individual (seguridad y significación) como organizacional (permanencia y cambio), se entrecruzan mutua y constantemente. Para la investigación es claro que el modelo procura ser dinámico, en tanto integra, en la medida de lo posible, los componentes que hacen parte de la construcción de la IO de una organización determinada.

- La identidad organizacional del individuo se estructura de forma latente y constante junto con la identidad personal y profesional. Al hablar de identidad individual, los diversos enfoques se activan en una situación social concreta. La identidad es una combinación de aspectos más que una totalidad integral, es decir, lo individual incluye concepciones sobre uno mismo, vinculadas a las circunstancias sociales del entorno. La identidad del individuo se compone de las características personales y de las categorías sociales. De este modo, algunos aspectos interdependientes de la identidad personal se pueden integrar a los aspectos de la 10 , mientras que otros pueden ser diferenciados o excluidos.

- De acuerdo con lo anterior, el diseño de la propuesta de investigación se desarrolló desde un enfoque cualitativo, por considerarlo el más apropiado para responder a la pregunta de investigación planteada. Al lado de esto, la propia pregunta auspició la utilización del constructivismo como lente epistemológico, lo que luego se vió reflejado en los aspectos metodológicos. Se consideró que la estrategia global del estudio de caso era la más pertinente para realizar la investigación, ya que se centra en la individualidad como una 
conquista creativa, discursivamente estructurada, históricamente contextualizada y socialmente producida, reproducida y trasmitida (Galeano, 2009).

- La investigación se realizó mediante la modalidad descrita, en la compañía Comercial Nutresa S.A.S., empresa dedicada a la venta y distribución de productos no perecederos del Grupo Nutresa. La elección para realizar el estudio de caso se debió a un criterio de facilidad de acceso a la información, como aspecto fundamental. Además, y según Stake (1995), el criterio de maximizar el aprendizaje a partir del estudio de caso es también sumamente importante. Este aprendizaje se adquiere de situaciones atípicas, en donde aquello que se sale de lo normalmente establecido o predecible, se convierte en fuente de conocimiento y comprensión, a tal punto que incluso puede llevar a modificar ciertas generalidades teóricas previas (Galeano, 2009; Stake, 1995).

- La unidad de análisis y el objeto de estudio se encuentran íntimamente relacionados. Por medio de la primera se llega a estudiar el segundo, o visto de otra manera, en la unidad de análisis se encuentra el objeto de estudio. Además, el marco teórico, que es la 10 , se convierte en la perspectiva de análisis para abordar la investigación, a la vez que conforma parte de su objeto de estudio. Al estudiar la IO de los MM, la perspectiva teórica es lente y objeto de estudio a la vez. A través del caso particular de CN se buscó recomprender, entonces, el concepto de IO.

\subsection{SOBRE LO ORGANIZACIONAL}

- El estudio de caso se realizó en CN. Esta empresa pertenece a la Compañía Nacional de Chocolates (posteriormente Grupo Nutresa) y su objetivo es encargarse de la distribución y venta de los productos secos de cinco compañías del Grupo: Noel, Nacional de Chocolates, Colcafé, Pastas Doria y 
Pastas Comarrico. La nueva compañía se constituyó a partir del modelo de planeación estratégica con oferta de valor diferenciada. Su estructura está definida de la siguiente manera: tres gerencias dedicadas a ventas en los tres canales (Tradicional, Autoservicios y Grandes Cadenas), y cinco gerencias de soporte (Logística Comercial, Desarrollo de Clientes, Servicios Comerciales, Cultura y Desarrollo Organizacional, y Planeación Comercial).

- El espacio del FC se convirtió en el lugar donde los MM buscan construir una IO. Es el ámbito donde quienes ocupan la línea media de gestión defienden lo que son, o quieren ser, frente a otros colegas, directivos y subordinados, quienes, al igual que ellos, también buscan legitimarse. Dado que el FC se convierte en el órgano de gobierno, la dirección y el ejercicio del liderazgo recae sobre los $\mathrm{MM}$ que tienen que poner su criterio a consideración dentro de este órgano de gobierno democrático, ya que al no haber un cargo que los lidere formalmente, las disyuntivas no se dirimen por la autoridad o el ejercicio del poder legítimo, sino por medio de una democracia consensuada.

- El FC es una reunión de gobierno conformada por un grupo de MM en desigualdad de condiciones: 1) no todas las gerencias están representadas en todos los FC; lo que quiere decir que no todas las áreas de la compañía tienen representatividad en el FC. 2) CN es una empresa de ventas y distribución, de tal modo que - así se les considera oficialmente - las gerencias de los tres canales mencionados - tradicional, autoservicios y grandes cadenas-son los más importantes, ya que congregan en sus funciones la razón de ser del negocio. Las demás áreas son las de soporte, es decir, aquellas que sostienen y ayudan a mantener la operacionalidad del negocio. Así las cosas, el FC pretende colocar al mismo nivel funciones que constitutiva y esencialmente son distintas. 3) La experiencia y el salario se ven enfrentados en el espacio del FC. Luego de las reestructuraciones, el FC quedó constituido por MM que tienen diferentes experiencias, tanto en el área específica de desempeño como 
en el GN. Curiosamente, los representantes de los canales de ventas tienen más tiempo de permanencia en la compañía, y, en tales circunstancias, informalmente, y a pesar de las discrepancias de la dirección, fungen como los líderes naturales de los procesos.

- Para los directivos de CN, los MM son los promotores y principales responsables de hacer funcionar el nuevo modelo de gobierno en la recién creada compañía. Su tarea es buscar la eficiencia por medio de su condición de líder. Dada la coyuntura de los FC y el incumplimiento de las metas en ventas, el ambiente de trabajo se tornó tenso. Los MM están a la defensiva y hay cierta desconfianza con la compañía porque las metas, que siempre fueron cumplidas desde el comienzo, no se alanzarán a lograr para el año 2013. De ahí que la figura del líder sea tan apropiada y esperanzadora.

- Los directivos se encuentran aún anclados a sus funciones anteriores, debido a la seguridad y confianza que les genera el modelo de gestión y de gobierno de las $\mathrm{OO}$ de donde provienen. La referencia a las $\mathrm{OO}$ termina por generar distorsión, ambigüedad y contradicción en cuanto a la gestión de $\mathrm{CN}$, en cuanto al nuevo MG. Al mismo tiempo, la incidencia de las $\mathrm{OO}$ en lo que deben ser los MM muestra una contradicción estructural: las $O O$ están constituidas dentro de la concepción burocrática, por lo tanto, la jerarquía y los procesos están altamente especializados. Sin embargo, detrás del MG se encuentra la especialización del trabajo como forma de organización, a la vez que busca mayor flexibilidad y rapidez en las decisiones.

- Las nuevas formas de control procesan la subjetividad con el propósito de formar trabajadores más adaptables y capaces de moverse rápidamente entre actividades y tareas con orientaciones diversas. No obstante, esa fluidez y fragmentación identitaria pueden hacer que los empleados, en la práctica, sean más vulnerables a la tipificación de las identificaciones corporativas. En este 
contexto, la fabricación identitaria se convierte en un aspecto más a gestionar dentro de las organizaciones.

- La reificación a la que están sometidos los sujetos es un proceso que tiene como cimiento el desconocimiento del otro, por lo que se corre el riesgo de volverla un aspecto cultural dentro de la sociedad (Honneth, 2009). La acción reificante no solo se reduce a una cosificación o consideración del individuo, también involucra un proceso social mediante el cual la construcción en sí misma está sujeta a una instrumentalización. Además, propicia una cultura en donde la justificación por conseguir los fines permite todo tipo de desconocimiento de quién es el otro, tanto en su individualidad, como en los procesos sociales que realiza para desarrollarse en sociedad.

- Las prácticas administrativas buscan desarrollar una serie de procesos que persiguen el control del individuo, muchas veces manipulándolo a manera de cosa; en otras ocasiones, se trata de intervenir su entorno externo - así como sus aspectos internos - para que su productividad no decaiga. De acuerdo con Montaño (1987), estas prácticas, promovidas por los llamados psicólogos sociales de la corriente de las Nuevas Relaciones Humanas, pretenden una relación democrática falsa, por medio de la cual se impulsa la participación ilusoria de los sujetos en el nivel conceptual y se promociona su participación real en el desempeño de las actividades.

- Para Montaño (1987), estos psicólogos industriales son los ergónomos del alma, pues persiguen el control alternativo por medio de las máquinas. Dicho control se centra en lo inmaterial, en aquello que responde al fuero interno de la persona. En términos de McGregor (1972) -al igual que lo hace López (2009)-, tales prácticas se pueden clasificar en dos: en primer lugar, en el entorno organizacional se registra un estilo administrativo de corte vertical $y$ autocrático. La dirección autoritaria, dentro de la organización, se propone ejercer el control de los individuos desde afuera. En segundo lugar, también es 
posible encontrar otro estilo que viene promulgando una forma de gerencia humanista, expresada en el discurso de cambio organizacional y de la transformación personal de los individuos. Este enfoque propone el control de las personas desde adentro, es decir, a partir de la vigilancia de las dimensiones individuales y ajenas al mundo del trabajo, donde se inscriben las costumbres, los modos de vida, valores, etc.

- La construcción de IO, por parte de los directivos, busca un aspecto clave: que los MM se despojen de las referencias a las OO. Por lo tanto, se tratará de construir la 10 negando una historia, lo que significa obviar la misma organización. Se producirá una construcción en negación que pretende cortar los lazos que unen a los MM, profesional y sentimentalmente, con las $\mathrm{OO}$.

- El objetivo de la administración es la rentabilidad, el uso de los recursos de otro (al servicio de), con el fin de obtener una ganancia, un lucro. Lo que preocupa no es, por tanto, la persona que ejecuta la actividad sino la obra que ella produce. De tal forma que bajo esta concepción, lo que se administra son los actos del hombre; a diferencia de la filosofía del hacer o del arte, no se busca la perfección o la bondad de dicha obra sino su producto, el fin. Se dice que la administración es un arte, pero un arte que no regula ningún aspecto de la obra del hombre bajo los criterios descritos. Sin embargo, la administración no tiene ni posee una teoría general que le permita dirigir universalmente dichas prácticas. En consecuencia, se podría afirmar que, por su objeto, es un arte, más no un arte que pueda pretender connotaciones de ciencia.

- Las tres categorías emergentes principales de la investigación son: reconocimiento, trascendencia y seguridad. Cada una se analizó, según el caso, a partir de una teoría específica no contemplada en la revisión inicial. En consecuencia, con base en esta, en consonancia con los objetivos propuestos y dentro del marco del modelo teórico-metodológico diseñado, se llevó a cabo 
la profundización correspondiente. Así, el análisis de los datos guarda una estrecha relación con la unidad de análisis de la investigación que es la construcción de la IO de los MM en CN.

- El reconocimiento (primera categoría emergente principal) tiene una connotación de perdurabilidad, en el entendido que busca prolongarse en el tiempo. La historia de vida concuerda con el recorrido personal, profesional y organizacional de cada sujeto. Los individuos, a lo largo de su vida, requieren de declaraciones positivas acerca de lo que hacen, piensan o sienten, como forma de afirmarse en el mundo y construir una identidad propia. La historia de vida está llena de acciones reconocidas y no reconocidas por otros, en aquellas tres facetas de la identidad del individuo. Se entiende, desde el punto de vista temporal, que la historia personal inicia antes que la profesional y esta última antes de la propiamente organizacional. Así, la $\mathrm{IO}$ es una historia que si bien empieza con la vinculación laboral del individuo, se construye sobre la base de una identidad personal y profesional que se viene estructurando desde tiempo atrás.

- La trascendencia es la segunda categoría emergente principal que opera como componente neurálgico en el proceso de construcción identitario de los MM. Tiene relación con el deseo de permanencia en el tiempo de su obra, de dejar un legado como representación de su actividad y también de los individuos que la realizan. Tal repercusión de sus ejecuciones no se restringe a las fronteras de la organización, pues los MM pretenden que superen los límites propiamente organizacionales para marcar su impronta en la sociedad.

- La seguridad, como tercera categoría emergente principal, permite y sostiene el conjunto de entramados de significados que intervienen en la construcción de una identidad personal y profesional, a la luz de la vida organizacional del 
individuo. En ese sentido, la seguridad garantiza el proceso identitario y lo sostiene en el tiempo.

- Los resultados de la investigación centraron la atención en el desarrollo de construcción identitaria desde un punto de vista comprensivo. En ese sentido, el fenómeno social estudiado permite entender lo organizacional como un proceso, y cómo los componentes de su construcción se organizan para configurar una realidad organizacional específica. De ese modo, el proceso social inscrito en la dinámica social organizacional se convirtió en el marco bajo el cual se concibió el objeto de estudio de la investigación.

- En ese contexto, la organización puede entenderse como una construcción ambigua, en la cual sus componentes y procesos plenamente estructurados y delimitados permiten su estudio gracias al proceso de acomodación en que se encuentra. De ese modo, lo que se está organizando u organizándose, permite muchas posibilidades de estudio y reflexión, ya que la transición en que se encuentra la organización facilita examinar sus factores y componentes en el proceso que está por estructurarse.

- La organización es un entretejido de situaciones diversas, que lejos de buscar un común denominador, a manera de cierta universalización, presenta rasgos determinados, propios, ya que está circunscrita por una historia y un tiempo específicos. Su carácter social hace que en la organización se entrecrucen diversas lógicas de acción y múltiples actores propugnen por disímiles proyectos sociales; por lo mismo, distintas interpretaciones del sentido institucional, como reflejo de intereses particulares, de ilusiones, fantasías y angustias (Montaño, 2004). Como se deduce, el significado de la organización no es perceptible, pues los fenómenos que subyacen ahí se convierten en lo ininteligible, en lo que pugna por sobresalir, pero que, tras la dinámica de la creación humana, sigue latente. El esfuerzo académico se concentró, 
entonces, en hacerlo inteligible $y$, en efecto, hacer comprensible 10 organizacional.

- El proceso mediante el cual se establece la organización, se desenvuelve en una constante pero inestable situación de equilibrio. El dinamismo que el mismo proceso expresa se caracteriza por las fuerzas que configuran su desarrollo como tal. La presión que estas realizan en diferentes direcciones, independiente de su magnitud, ha de mantener el equilibrio. Si este no se logra, la relación laboral se quiebra y la organización, en tanto proceso social, se suspende.

- Tanto quienes tienen la función de dirección como el resto de empleados ven la organización como un conjunto de contradicciones. La falta de claridad en cuanto a las disposiciones emitidas y la aplicación de políticas que garanticen el cumplimiento de los objetivos organizacionales, impulsan a la organización a moverse en un constante proceso de adaptación y ajuste, rescatando de esta manera los procesos sociales que participan de tal dinámica.

- La organización es la síntesis de la confluencia en el presente de una historia que pasó y de una que está por suceder. En la experiencia del hoy se estructura una realidad cambiante y dinámica de lo que fue y lo que será. En ese sentido, todo estudio de un proceso dado y dándose, encuentra en la experiencia del presente el punto de análisis para comprender una realidad en constante transformación. Y la organización, entonces, puede entenderse como un entretejido de historias pasadas que estructuran en el presente las proyecciones a futuro.

- La construcción de la 10 responde a un diálogo entre el yo y los demás. Sus interlocuciones surgen a partir del cambio interno en el individuo, producto de las influencias y acciones que recaen sobre él, derivadas de la organización y 
realizadas por esta con el ánimo de promover, construir o fabricar un entendimiento del sujeto con respecto a su participación en la compañía. Como consecuencia, la persona busca construir una identidad en proyección hacia el exterior. Sin embargo, el individuo tiende a reaccionar más sensiblemente ante influencias externas, cuando se trate de imponerle una identidad en concreto. La liminalidad de la identidad en el ámbito organizacional se asemeja a un diálogo que incorpora en simultánea el ser interior y el exterior de la identidad social. Pero, como en todo diálogo, la orientación puede variar de acuerdo al énfasis de lo externo frente a lo interno, una mayor uniformidad del juego entre los dos o un mayor énfasis de lo interno hacia lo externo.

- La conceptualización de la 10 como liminal hace referencia a las prácticas que surgen de las diferentes circunstancias dialógicas. Es así como el yo se pone a prueba al buscar una identidad nueva o modificada en la orientación de adentro hacia afuera. Ejemplo de ello es la desidentificación, proceso en el cual, luego de la resistencia inicial, se pasa a una fase de experimentación en donde el individuo busca diversas formas de vinculación temporal al grupo, a las identidades organizadas o personales. En este tránsito, la desvinculación identitaria, contradictoriamente, busca afianzarse en otras realidades, con el fin de avanzar hacia una identidad deseada o como expresión y acción, para resistirse a una identidad no deseada.

- El reconocimiento así como la trascendencia tienen una connotación netamente individual. Son dinamismos personales que entran en relación con lo propiamente organizacional a través de la seguridad. Esta categoría, a diferencia de las dos primeras, recae en el ámbito organizacional. De este modo, gracias a las garantías que ofrezcan seguridad al proceso como tal, se abren las posibilidades para la organización de intervenir en el proceso de construcción identitario. Si bien existe una historia personal y profesional en 
desarrollo paralelo a la organización, la construcción de sentido que interpretan y asimilan los MM se dan porque concurren las condiciones para ello.

- El equilibrio organizacional está estructurado mediante una relación egoísta de mutua conveniencia: los individuos permanecen en la organización, no porque necesariamente se identifiquen los intereses de ambas partes, sino porque la relación les es útil a sendos participantes. Es decir, al mantenerse en la empresa, los empleados pueden valerse de los beneficios que aquella les brinda para cumplir con los objetivos e intereses organizacionales. De la misma manera, la organización se vale de las habilidades y de los conocimientos de los empleados para cumplir con los objetivos que se propone, a pesar de que estos muchas veces no coincidan con los de los empleados. Se estructura así una relación interesada que busca las condiciones que la otra parte pueda proporcionar para mantener una vinculación laboral. Si estas condiciones no se dan en algún caso, una de las partes romperá la relación.

- Un segundo nivel de equilibrio se configura a partir de los aspectos propiamente organizacionales, enmarcados por las condiciones espaciotemporales de cada organización. La reputación, el prestigio, las funciones, las dinámicas culturales, el desarrollo de la estrategia, entre otros aspectos, influyen en la construcción de sentido por parte de los empleados. Tales componentes están sostenidos por la seguridad que la empresa pueda brindar en lo referente a garantizar las condiciones mínimas de permanencia y autonomía para poder realizar el proceso de asimilación y apropiación de una nueva IO.

- En conclusión, el proceso de construcción identitario de los individuos se configura a partir de los dos niveles de análisis. Hay una unidad en la dinámica constructiva, en donde lo personal no se desliga de lo organizacional, lo supone, lo requiere y constituye sentido a partir de esto. El establecimiento de 
la liminal identidad necesita considerar estas dos dimensiones y los componentes que intervienen allí. No obstante, esta construcción privilegia los aspectos personales; de ahí que la primera situación de equilibrio se convierta en condicionante para la segunda, es decir, tiene una importancia mayor para que el proceso de construcción se realice o continúe. Junto con ello, es claro que el control que puede ejercer la organización dentro del proceso de construcción se podría centrar en el segundo espacio de equilibro, es decir en lo referido a lo propiamente organizacional, ya que en los aspectos personales no tiene ningún tipo de injerencia.

\subsection{LIMITACIONES Y POSIBILIDADES DE INVESTIGACIÓN FUTURAS}

Los resultados de la investigación llevan a considerar que se está frente a una nueva modalidad de control direccionada a aspectos más interiores del individuo. A su vez, desvela una identidad organizacional considerada como una variable de gestión, sujeta y susceptible de ser gestionada, diseñada, planificada y controlada. Empero esta pretensión por parte de la alta dirección, los miembros de la organización (para este caso los $\mathrm{MM}$ ) resignifican tales pretensiones y le dan un sentido, permitiendo con ello, mantener el equilibrio laboral. Así, se puede afirmar que hay otra modalidad de identidad organizacional que emerge con base en la interpretación de la realidad de los miembros de la organización. Esta dicotomía se asemeja a la discusión entre cultura organizacional y cultura corporativa, que en términos identitarios estaría nombrada como identidad organizacional e identidad corporativa. Este es un aspecto importante por estudiar y profundizar.

Los resultados de la investigación condujeron a concebir que los procesos de institucionalización a la que son sometidos los MM, son promovidos básicamente por la dirección, en el entendido que al ejercer la autoridad formal o legítima, los MM se ven envueltos en una relación de poder ante la cual están obligados a acceder y obedecer las disposiciones impuestas. Sin embargo, la alta dirección no es el único estamento que puede propiciar la construcción de una IO en concreto. 
Los subordinados y los mismos colegas son actores que influencian el accionar de los MM. En otras palabras, la injerencia de los otros estamentos de la organización en la implementación de una IO es un aspecto importante aún por explorar.

Luego de la revisión documental, y fruto de esta investigación, se afirma que el concepto de 10 puede ser considerado como un marco de análisis para aproximarse a comprender los fenómenos sociales que se inscriben en las organizaciones. El modelo teórico-metodológico, apoyado y sustentado en conceptos provenientes de las ciencias sociales, justifica y soporta la posibilidad que la $1 O$ tenga un espacio propio desligado del tema cultural. Este constructo que se viene discutiendo desde la definición seminal de Albert y Whetten (1985), permite una comprensión dinámica de los componentes que lo integran, en donde lo personal y lo colectivo se enlazan para desvelar lo complejo de la interacción humana. En ese sentido, este modelo propuesto falta aún por ser validado en otros estamentos organizacionales por fuera de los MM, adaptando y reapropiando, como es obvio, los componentes que lo estructuran y las dimensiones espacio-temporales (ejes de referencia) que lo enmarca.

Los hallazgos de la investigación, sintetizados en las categorías emergentes principales desde el punto de vista de los mandos medios: reconocimiento, trascendencia y seguridad, se sustentaron y apoyaron, para su profundización, en las ciencias sociales. En ese sentido, la investigación y con ella, los EO, dialogaron con otras disciplinas para profundizar en la problemática organizacional que se estudió. La concreción del estudio de caso permitió apreciar cómo las ciencias sociales abonan a los EO, no obstante, hay también una relación que se devuelve, en el entendido de preguntarse: ¿cómo aporta el estudio de caso a la conceptualización de los constructos conceptualizados a partir de otras disciplinas? ¿Cómo lo liminal, el reconocimiento y la trascendencia, por ejemplo, aportan a la filosofía y a la antropología? El estudio de caso permite, entre otras cosas, concretar los marcos teóricos en una realidad de análisis concreta, de ahí que su aplicación posibilita los cuestionamientos sobre los marcos que la analizan. 
Los resultados de la investigación sugieren considerar a la 10 como un espacio liminal. En ese sentido, y desde el marco de los EO, la reflexión concibió a la organización a partir de los procesos sociales que se estructuran en su interior. Esto abre la posibilidad de utilizar la riqueza de este concepto para afrontar otras problemáticas organizacionales que se caracterizan por ser un proceso, una dinámica que se construye en forma constante. Entre ellas se pueden anotar: la resistencia a los procesos de dominación, los proceso de identificación en fusiones, la constitución de una organización dentro de un conflicto social, las implicaciones para los individuos debido a la maquinización de los procesos productivos, la virtualidad como componente organizacional, etc.

Se ha discutido la aparición de nuevas formas de control que apuntan a regular dimensiones más interiores del individuo, entre ellas, la regulación de la 10 por parte de las organizaciones con el objetivo de buscar una mayor identificación y por ende, productividad, a partir de una supuesta fidelización. Este tipo de acciones, a las cuáles se les puede sumar otras, muy de boga hoy en día como el coaching ontológico, la programación neurolingüística, o la llamada gerencia espiritual, ¿tienen un parámetro común de intervención? ¿Se podrían identificar los supuestos epistemológicos y metodológicos que las agrupan? Diversas investigaciones han criticado las implicaciones que tienen para el individuo las prácticas basadas en el control de aspectos externos del individuo. Esta investigación abre una veta para profundizar en las consecuencias de tales pretensiones de regulación a un nivel más interior. 


\section{REFERENCIAS}

Abramson, N. R., \& Senyshyn, Y. (2010). Effective punishment through forgiveness: rediscovering Kierkegaard's knight of faith in the Abraham story. Organization Studies, 31(5), 555-581.

Adorno, T. (1974). Tres estudios sobre Hegel. Madrid: Taurus.

Agustin, S. (1984). Confesiones. Madrid: Sarpe

Ailon, G. (2006). What B Wolud otherwise do: a critique of conceptualizations of "power" in organizational theory. Organizations, 13(6), 771-800.

Ainsworth, S., \& Hardy, C. (2008). The enterprising self: An unsuitable job for an older worker. Organization, 15(3), 389-405.

Ainsworth, S., Grant, D., \& ledema, R. (2009). Keeping things moving: space and the construction of middle management identity in a post-NPM organization. Discourse \& Communication, 3(1), 5-25.

Aktouf, O. (1998). La administración: entre tradición y renovación (3 ed.). Cali: Artes gráficas del Valle.

Albert, S., \& Whetten, D. (1985). Organizational identity. En L. L. Cummings, \& M. M. Staw (Edits.), Research in organizational behavior (págs. 263-295). Greenwich, CT: JAI.

Albert, S., Ashforth, B. E., \& Dutton, J. E. (2000). Organizational identity and identification: Charting new waters and building new bridges. Academy of Management Review, 25(1), 13-17.

Alvarado, S. V. (1993). La construcción de categorías teóricas a partir de los datos empíricos, como base del acercamiento metodológico en la investigación cualitativa. En Investigación Cualitativa. Confrontación y prospectiva. (págs. 271-278). Medellín: Universidad de Antioquia.

Álvarez Morales, V. (2003). De las sociedades de negocios al "Sindicato Antioqueño". En C. Dávila L. de Guevara, Empresas y empresarios en la historia de Colombia. Siglos XIX-XX (págs. 213-246). Bogotá: Norma y UNIANDES. 
Alvesson, M. (1990). Organization: From substance to image? Organization Studies, 11(3), 373-394.

Alvesson, M. (2000). Social identity and the problem of loyalty in knowledgeintensive companies. Journal of Management Studies, 37(6), 1101-1123.

Alvesson, M. (2011). Interpreting interviews. London: SAGE.

Alvesson, M., \& Berg, P. O. (1992). Corporate culture and organizational symbolism. Berlin: De Gruyter.

Alvesson, M., \& Deetz, S. (1999). Critical theory and postmodernism: approaches to Organizational Studies. En S. R. Clegg, \& C. Hardy (Edits.), Studying Organization. Theory \& Method (págs. 185-211). London: SAGE.

Alvesson, M., \& Deetz, S. (2000). Doing Critical Management Research. London: SAGE.

Alvesson, M., \& Robertson, M. (2006). The best and the brightest: the construction, significance and effects of elite identities in consulting firms. Organization, 13(2), 195-224.

Alvesson, M., \& Willmott, H. (1996). Making sense of Management. London: SAGE.

Alvesson, M., \& Willmott, H. (2002). Identity regulations as organizational control: producing the appropriate individual. Journal of Management Studies, 39(5), 619-644.

Alvesson, M., \& Willmott, H. (Edits.). (2003). Studying Management Critically. London: SAGE.

Alvesson, M., Ashcraft, L. K., \& Thomas, R. (2008). Identity Matters: Reflections on the construction of identity scholarship in Organization Studies. Organization, 15(1), 5-28.

Amalric, J.-L. (2012). Ricoeur, Derrida. el desafío de la metáfora. (J. Rivera, \& F. Pineda, Trads.) Bogotá: Universidad Externado de Colombia, République Francaise, Universidad del Valle, Unversidad del Bosque.

Argyris, C. (1975/1971). The impact of the Formal Organization upon the individual. En D. Pugh, Organization Theory (págs. 261-278). London: Penguin Books. 
Aristóteles. (1997). Metafísica (Segunda edición ed., Vol. I). Madrid, España: Gredos.

Arnott, D. (2002). El culto a la empresa. El engañoso atractivo de la organización devoradora. Buenos Aires: Paidos Argentina.

Ashforth, B. E. (2001). Role transitions in organizational life: An identity-based perspective. Mahwah, NJ: Lawrence Erlbaum Associates.

Ashforth, B. E., \& Johnson, S. A. (2001). Which hat to wear? The relative salience of multiple identities in organizational contexts. En M. A. Hogg, \& D. J. Terry (Edits.), Social identity processes in organizational contexts (págs. 31-48). Ann Arbor, MI: Taylor \& Francis.

Ashforth, B. E., \& Mael, F. (1989). Social Identity Theory and the organization. Academy of Management Review, 14(1), 20-39.

Ashforth, B. E., Rogers, K. M., \& Corley, K. G. (2011). Identity in Organizations: Exploring cross-level dynamics. Organization Science, 22(5), 1144-1156.

Aubert, Nicole, \& Gaulejac, V. d. (1993). El coste de la excelencia. Barcelona: Paidós.

Ball, K., \& Wilson, D. (2000). Power, control and computer-based performance monitoring: Repertoires, resistance and subjectivities. Organization Studies, 21(3), 539-565.

Barba Álvarez, A., Montaño Hirose, L., \& Solís Pérez, P. (1999). Perspectivas internacionales de los Estudios Organizacionales. Memorias del III Foro de Investigación en las disciplinas financiero-administrativas. (págs. 75-87). México: Universidad Autónoma de México.

Barba Álvarez, A., Montoya Flores, M. T., \& Vázquez García, A. (2010). Comunidad, individuo e identidades profesionales, análisis a partir de dos resultados de investigación. VIII Congreso Internacional de Análisis Organizacional: "Individuo y Sociedad: Redes y formas emergentes de organización", (pág. 16). México, D.F.

Barker, J. (1999). The Discipline of Teamwork. London: SAGE.

Barnard, C. I. (1948). Concepts of Organization. En C. I. Barnard, Organization and Management. Selected Papers. Cambridge: The Harvard University Press. 
Barney, J. (1998). Kotch Industries: Organizational Identity as moral philosophy. En D. Whetten, \& P. Godfrey (Edits.), Identity in Organizations: Developing Theory throug conversations (págs. 106-109). Thousand Oaks: SAGE.

Bauman, Z. (2010). Identidad. (D. Sarasola, Trad.) Buenos Aires: Losada.

Bédard, R. (2003). Los fundamentos del pensamiento y las prácticas administrativas. El rombo y las cuatro dimensiones filosóficas. Revista $A D$ MINISTER, 3, 68-87.

Bédard, R. (2004). Los fundamentos del pensamiento y las prácticas administrativas: La trilogía administrativa. Revista Ad Minister 4, 80-108.

Beech, N. (2008). On the Nature of Dialogic Identity Work. Organization, 15(1), 51 74.

Beech, N. (2011). Liminality and the practices of identity reconstruction. Human Relations, 64(2), 285-302.

Bendle, M. F. (2002). The crisis of identity in high modernity. British Journal of Sociology, 53(1), 1-18.

Berger, P., \& Luckmann, T. (2008). La construcción social de la realidad. Argentina: Amorrortu.

Blau, P. M., \& Scott, W. R. (1962). Formal Organization: A comparative Approach. San Francisco: Chandler.

Blau, P., \& Schoenherr, P. A. (1971). The Structure of Organizations. New York: Basic Books.

Boal, K. B., Hunt, J. G., \& Jaros, S. J. (2003). Order is free: On the Ontological Status of Organizations. En R. Westwood, \& S. Clegg (Edits.), Debating Organization (págs. 84-98). Oxford: Blackwell.

Boltanski, L. (1982). Les Cadres. La formation d'un groupe social. Paris: Les éditions de minuit.

Bratton, J., Callinam, M., Forshaw, C., \& Sawchuk, P. (2010). Work and Organizational Behaviour: Understanding the Workplace. (2 ed.). Basingstoke: Palgrave Macmillan. 
Brewer, M. B., \& Gardner, W. (1996). Who is this "We"? Levels of Collective Identity and Self Representations. Journal of Personality and Social Psychology, 71(1), 83-93.

Breweton, P., \& Millward, L. (2001). Organizational Research Methods. A guide for Students and Researchers. London: SAGE.

Brickson, S. L. (2000). The impact of the identity orientation on individual and organizational outcomes in demographically diverse settings. Academy of Management Review, 25(1), 82-101.

Brown, A. D. (2001). Organization studies and identity: Towards a research agenda. Human Relations, 54(1), 113-121.

Brown, A. D. (2006). A narrative approach to collective identities. Journal of Management Studies, 43(4), 731-753.

Brown, A. D., \& Lewis, M. A. (2011). Identities, discipline and routines. Organization Studies, 32(7), 871-895.

Brown, A. D., \& Starkey, K. (2000). Organizational identity and learning: A psychodynamic perspective. Academy of Management Review, 25(1), 102120.

Brown, A., \& Humphreys, M. (2006). Organizational identity and place: A discursive exploration of hegemony and resistance. Journal of Management Studies, 43(2), 231-257.

Brown, J. A. (1963). La psicología social en la industria. México: Fondo de Cultura Económica.

Bruner, J. (1991). Actos de significado: Más allá de la revolución cognitiva. Madrid: Alianza.

Brunstein, I. (1999). L'homme à l'échine pliée: réflexions sur le stress professionnel. Paris: Desclée de Brouwer.

Bryman, A. (1989). Quantity and quality in social research. London: Unwin Hyman.

Burke, P. J. (1991). Identity processes and social stress. American Sociological Review, 56(6), 836-849.

Burke, P. J., \& Stets. (1999). Trust and commitment through self-verification. Social Psychology, 62(4), 347-366. 
Burns, T., \& Stalker, G. M. (1961). The management of innovation. Great Britain: Oxford University Press.

Burrel, G. (1979). Pandemonium. London: SAGE.

Burrel, G. (1996). Normal science, paradigms, metaphors, discourses and genealogies of analysis. En S. R. Clegg, C. Hardy, W. R. Nord, S. R. Clegg, C. Hardy, \& W. R. Nord (Edits.), Handbook of Organization Studies (págs. 31-56). London: SAGE.

Burrell, G., \& Morgan, G. (1979). Sociological Paradigms and Organizational Analysis. Elements of the Sociology of Corporate. London: Heinemann.

Callon, M. (1986). Some elements of a sociology of translation: domestication of the scallops and the fishermen of St. Brieuc Bay. En J. Law (Ed.), Power, action and belief- (págs. 196-233). London: Routledge.

Carrol, B., \& Levy, L. (2008). Defaulting to management: leadership defined by what it is not. Organization, 15(1), 75-96.

Carson, P. P., Lanier, P. A., Carson, K. D., \& Guidry, B. N. (2000). Clearing a Path through the Management fashion jungle: some preliminary trailblazing. The Academy of Management Journal., 43(6), 1143-1158.

Carter, C., \& Mueller, F. (2002). The "long march" of the management modernizers: Ritual, rhetoric and rationality. Human Relations, 55(11), 13251354.

Carvajal Orozco, J. G. (2005). El problema de la existencia y la identidad de las organizaciones. INNOVAR, 15(25), 25-35.

Case, P. (2003). From Objectivity to Subjectivity: Pursuing Subjective Authenticity in Organizational Research. En R. Westwood, \& S. Clegg, Debating Organization. Point-Counterpoint in Organization Studies (págs. 156-179). London: Blackwell.

Casey, C. (1995). Work, self and society. London: Routledge.

Chanlat, J. (1994). Hacia una Antropología de la Organización. Gestión y Políticas Públicas, 3 (2), 317-363.

Chemama, R., \& Vandermersch, B. (2004). Diccionario de Psicoanálisis. Estados Unidos: Amorrortu. 
Cheney, G., \& Christensen, L. T. (2001). Organizational Identity: Linkages between internal and external communication. En F. Jablin, \& L. Putman (Edits.), Handbook of Organizational Communications. London: SAGE.

Chia, R. (1996). Organizational analysis as deconstructive practice. Berlin: Walter de Gruyter.

Chia, R. (2003). Ontology: Organization as "World-making". En R. Westwood, \& S. Clegg, Debating Organization. Point-Counterpoint in Organization Studies (págs. 98-113). London: Blackwell.

Chreim, S. (2002). Influencing organizational identification during a major change: A communication based perspective. Human Relations, 55(9), 1117-1137.

Chreim, S. (2005). The continuity-change duality in narrative texts of organizational identity. Journal of Management Studies, 42(3), 567-593.

Christensen, L. (1995). Buffering organizational identity in the marketing culture. Organization Studies, 16(4), 651-672.

Clarke, C., Brown, A. D., \& Hope Hailey, V. (2009). Working identities? Antagonistc discursive resources and managerial identity. Human Relations, 62(3), 323352.

Clegg, S. (1990). Modern Organizations. Organization Studies in the Postmodern world. London: SAGE.

Clegg, S. R., \& Dunkerley, D. (1980). Organization. Class and Control. London: Routledge \& Kegan Paul.

Clegg, S. R., \& Hardy, C. (1996). Introduction. Organizations, Organization and Organizing. En S. R. Clegg, C. Hardy, \& W. R. Nord (Edits.), Handbook of Organization Studies (págs. 1-28). London: SAGE.

Clegg, S. R., \& Hardy, C. (1999). Representations. En S. R. Clegg, \& C. Hardy (Edits.), Studying Organization (págs. 422-452). London: SAGE.

Clegg, S. R., Hardy, C., \& Nord, W. R. (Edits.). (1996). Handbook of Organization Studies. London: SAGE.

Clegg, S. R., Rhodes, C., \& Kornberger, M. (2007). Desperately Seeking Legitimacy: Organizational Identity and Emerging Industries. Organization Studies, 28(4), 495-513. 
Clegg, S., Kornberger, M., \& Rhodes, C. (2005). Learning/organizing/becoming. Organization, 12(2), 147-168.

Collinson, D. (2005). Dialectics of leadership. Human Relations, 58(11), 14191443.

Comte, A. (1853). The Positivist Philosophy I. (H. Martineau, Trad.) London: Chapman.

Contreras Manrique, J. C., \& De la Rosa Alburquerque, A. (2013). Organizaciones y políticas públicas. Elementos para trabajar una perspectiva organizacional de las políticas públicas. Documento de trabajo. México: Seminario: "Organizaciones y políticas públicas: hacia una perspectiva organizacional de las políticas públicas". UAM-COLSAN.

Cooley, C. (1902). Human nature and the social order. Ney York: Charles Scribner's Sons.

Cooley, C. H. (1964). Society and the Individual. New York: Charles Scribner's Sons.

Corley, K. (2005). Examining the dynamics of organizational identity: Key dimensions. Arizona State University: Tempe.

Corley, K. G. (2004). Defined by our strategy or our culture? Hierarchical differences in perceptions of organizational identity and change. Human Relations, 57(9), 1145-1177.

Corley, K. G., \& Gioia, D. A. (2003). Semantic learning as change enabler: Relating organizational identity \& organizational learning. En M. Easterby-Smith, \& M. Lyles (Edits.), Handbook of organizational learning and knowledge management (págs. 621-636). London: Basil Blackwell.

Corley, K. G., \& Gioia, D. A. (2004). Identity ambiguity and change in the wake of a corporate spin-off. Administrative Science Quarterly, 49(2), 173-208.

Corley, K. G., Harquail, C. V., Pratt, M. G., Glynn, M. A., Fiol, C. M., \& Hatch, M. J. (2006). Guiding Organizational Identity through aged adolescence. Journal of Management Inquiry, 15(2), 85-99.

Cornelissen, J. P. (2002a). The merit and mischief of metaphor: A reply to Gioia, Schultz and Corley. British Journal of Management, 13(3), 277-280. 
Cornelissen, J. P. (2002b). On the "Organizational Identity" metaphor. British Journal of Management, 13(3), 259-268.

Cornelissen, J. P. (2006). Making sense of theory construction: Metaphor and disciplined imagination. Organization Studies, 27(11), 1579-1597.

Corti, Agustín. (2011). Introducción. En Agustín de Hipona, Qué es el tiempo (págs. 9-36). Madrid: Trotta.

Costas, J., \& Fleming, P. (2009). Beyond dis-identification: A discursive approach to self-alienation in contemporary organizations. Human Relations, 62(3), 353-378.

Coupland, C., \& Brown, A. D. (2004). Constructing organizational identities on the web: A case study of Royal Dutch Shell. Journal of Management Studies, 41(8), 1325-1348.

Cruz Kronfly, F. (2008). Del hombre como fin al hombre como medio de producción. En F. Cruz Kronfly (Ed.), Racionalidad Instrumental y gestión (págs. 67-90). Cali: Artes Gráficas Univalle.

Cruz Kronfly, F., \& Rojas, R. W. (2008). La noción de inhumanidad y culturas híbridas en algunas organizaciones colombianas. En F. Cruz Kronfly (Ed.), Racionalidad Instrumental y gestión (págs. 13-66). Cali: Artes Gráficas Univalle.

Cruz Kronly, F. (2003). La presencia de lo inhumano en la cultura y en las organizaciones. En F. Cruz Kronfly, \& O. Aktouf, El lado inhumano de las organizaciones (págs. 15-64). Cali: Facultad de Ciencias de la Administración.

Cunliffe, A. (2002). Social poetics as management inquiry: A dialogical approach. Journal of Management Inquiry, 11(2), 128-146.

Czarniawska B., \& Mazza, C. (2003). Consulting as a liminal space. Human Relations, 56(3), 267-290.

Czarniawska, B. (1997a). Narratives of Individual and Organizational Identities. Communication Yearbook, 17, 193-221.

Czarniawska, B. (2003). Social Constructionism and Organization Studies. En R. Westwood, \& S. Clegg (Edits.), Debating Organization. Point-Counterpoint in Organization Studies (págs. 128-139). London: Blackwell. 
Czarniawska, B., \& Wolff, R. (1998). Constructing new identities in established organization fields. International Studies of Management and Organization, 28(3), 35-56.

Czarniawska-Joerges, B. (1994). Narratives of individual and organizational identities. En S. Deetz, Communication Yearbook (Vol. 17). Newbury: SAGE.

Czarniawska-Joerges, B. (1997b). Narrating the organization: Dramas of institutional identity. Chicago: Universityof Chicago Press.

Dahl, R. A. (1957). The concept of Power. Behavioral Science, 2(3), 201-215.

Dávila, C. (2001). Teorías organizacionales y administración. Bogotá: Mc GrawHill.

De la Garza Toledo, E. (2001). La epistemología crítica y el concepto de configuración. Revista Mexicana de Sociología.

De la Garza Toledo, E. (2002). Tratado Latinoamericano de la Sociología del Trabajo. Ciudad de México: Fondo de Cultura Económica.

De la Garza Toledo, E. (2009). Hacia un concepto ampliado de trabajo. En E. De la Garza Toledo, J. C. Neffa, \& L. Muñiz Terra (Edits.), Trabajo, empleo, calificaciones profesionales, relaciones de trabajo e identidades laborales (págs. 111-140). Buenos Aires: CLACSO.

De la Garza Toledo, E., \& Campillo, M. (Set-Oct de 1998). ¿Hacia dónde va el trabajo humano? Nueva Sociedad 157, 1-21.

De la Rosa Albuquerque, A. (2008). Organización y poder: Un marco analítico para su estudio. Análisis Organizacional, 1(1), 1-27.

De la Rosa Alburquerque, A. (2007). La micro, pequeña y mediana organización en la perspectiva de los estudios organizacionales. Una mirada al caso de una microorganización desde la óptica del poder. Tesis Doctoral en Estudios Organizacionales. México: UAM-I.

De la Rosa Alburquerque, A. (2011). Entre la teoría de la Organización y los Estudios Organizacionales: una aproximación al esclarecimiento del término "organizacional". Congreso Nacional de ciencias sociales sujetos $y$ espacios: Retos locales, globales y regionales. (pág. 12). Morelos: Universidad Autónoma del Estado de Morelos. 
De la Rosa Alburquerque, A., \& Contreras Manrique, J. C. (2007). El partido político: entre la ciencia política y los Estudios Organizacionales. Polis, 2(3), 17-67.

Deaux, K. (1993). Reconstructing social identity. Personality and Social Psychology Bulletin, 19(1), 4-12.

Deetz, S. (1992). Democracy in an Age of Corporate Colonization: Developments in Communication and the politics of Everyday life. Albany: State University of New York Press.

Deetz, S. (1994). The micro-politics of identity formation: the case of a knowledge intensive firm. Human Studies, 17(1), 23-44.

Deetz, S. (2000). Putting the community into organizational science: exploring the construction of knowledge claims. Organization Science, 11(6), 732-738.

Delmestri, G. (2006). Streams of inconsistent institutional influences: Middle managers as carriers of multiple identities. Human Relations, 59(11), 15151541.

Delmestri, G., \& Walgenbach, P. (2005). Mastering Techniques or Brokerin Knowledge? Middle Managers in germany, Great Britain and Italy. Organizations Studies, 26(2), 197-220.

Denissen, A. M. (2010). The right tools for the job: Constructing gender meanings and identities in the male-dominated building trades. Human Relations, 63(7), 1051-1069.

Díaz Cruz, R. (1998). Archipiélago de rituales. Teorías antropológicas del ritual. Barcelona: Anthropos; UAM-I.

DiMaggio, P. J., \& Powell, W. W. (1983). The iron cage revisited: Institutional isomorphism and collective rationality in organizational fields. American Sociological Review, 48(2), 147-160.

DiMaggio, P. J., \& Powell, W. W. (1999). Retorno a la jaula de hierro: el isomorfismo institucional y la racionalidad colectiva en los campos organizacionales. En P. J. DiMaggio, \& W. W. Powell (Edits.), El nuevo institucionalismo en el análisis organizacional (págs. 104-125). Ciudad de México: Colegio Nacional de Ciencias Políticas y Administración Pública, Universidad Autónoma del Estado de México y Fondo de Cultura Económica. 
Donaldson, L. (2003). Position Statement for Positivism. En R. Westwood, \& S. Clegg (Edits.), Debating Organization (págs. 116-127). Oxford: Blackwell.

Dopson, S., \& Stewart, R. (1990). What is happening o middle management? British Journal of Management, 1(1), 3-16.

Douglas, M. (1973). Pureza y peligro. Madrid: Siglo XXI.

Down, S., \& Revely, J. (2009). Between narration and interaction: Situating firstline supervisor identity work. Human Relations, 62(3), 379-401.

Driver, M. (2009). Struggling with Lack: A Lacanian Perspective on Organizational Identity. Organizations Studies, 30(1), 55-72.

Dubar, C. (2002a). La crisis de las identidades. La interpretación de una mutuación. Barcelona: Edicions Bellaterra.

Dubar, C. (2002b). La socialization. Construction des identités sociales eh professionelles. París: A. Colin.

Dupuy, F. (2006). La fatiga de las élites. El capitalismo y sus ejecutivos. (H. Pons, Trad.) Buenos Aires: Manantial.

Dutton, J. E., Dukerich, J. M., \& Harquail, C. V. (1994). Organizational images and member identification. Administrative Science Quarterly, 39(2), 239-263.

Dutton, J., \& Dukerich, J. (1991). Keeping an eye on the mirror: Image and identity in organizational adaptation. Academy of Management Journal, 34(3), 517554.

Eisenhardt, K. M. (1989). Building theories from Case Study Research. Academy of Management Review, 14(4), 532-550.

Eisenhardt, K. M., \& Graebner, M. E. (2007). Theory building from cases: opportunities and challenges. Academy of Management Journal, 50(1), 2532.

Eisenhardt, K., \& Bourgeois, L. (1988). Politics of strategic decision making in highvelocity environments: Toward a midrange theory. Academy of Management Journal, 31(4), 737-770.

Ellis, N., \& Ybema, S. (2010). Marketing Identities: Shifting circles of identification in inter-organizational relationships. Organizations Studies, 31(3), 279-305. 
Elsbach, K. D. (2002). Intraorganizational institutions. En J. Baum (Ed.), Companion to organizations. (págs. 37-57). Oxford: Blackwell.

Elsbach, K. D., \& Kramer, R. M. (1996). "Members" responses to organizational identity threats: Encountering and countering the business week rankings. Administrative Science Quarterly, 41(3), 442-476.

Enriquez, E. (2007). Clinique du pouvoir. Les figures du maitre. Paris: Érès.

Eräranta, K., \& Moisander, J. (2011). Psychological regimes of truth and father identity: challenges for work/life integration. Organization Srudies, 32(4), 509-526.

Eriksson-Zetterquist, U. (2002). Gender construction in corporations. En B. Czarniawska, \& H. Hopfl (Edits.), Casting the Other: Production and maintenance of inequality in organizations. (págs. 89-103). London: Rautledge.

Essers, C., \& Benschop, Y. (2007). Enterprising Identities: Female entrepreneurs of Moroccan or Turkish origin in the Netherlands. Organization Studies, 28(1), 49-69.

Etkin, J., \& Schvarstein, L. (1997). Identidad de las organizaciones. Invarianza y cambio. Buenos Aires: Paidos.

Etzioni, A. (1986). Organizaciones modernas. México: UTEHA.

Ezzamel, M., Willmott, H., \& Worthington, F. (2000). Control and Resistance in "The Factory that Tiem Forgot". Working Paper.

Farh, C. I., Bartol, K. M., Shapiro, D. L., \& Shin, J. (2010). Networking abroad: a process model of how expatriates form ties to facilitate adjustement. The Academy of Management Review, 35(3), 434-454.

Fayol, H. (2003). Administración industrial y general. Bogotá: Adigrama.

Fernández Rodríguez, C. J. (2007). Postmodernidad y Teoría Crítica de la empresa: Una presentación de los Critical Management Studies. En C. J. Fernández Rodríguez (Ed.), Vigilar y Organizar. Una introducción a los Critical Management Studies (págs. 1-24). Madrid, España: Siglo XXI.

Fernández, L. M. (2013). Instituciones educativas. Dinámicas institucionales en situaciones críticas. Buenos Aires: Paidos. 
Ferrater Mora, J. (1994). Diccionario de Filosofía. España: Ariel.

Ferreira, F. V. (2010). Potencialidades da análise histórica nos estudos organizacionais brasileiros. Revista de Administración de Empresas, 50(1), 37-47.

Fiol, C. M. (1991). Managing culture as a competitive resource: An identity-based view of sustainable competitive advantaje. Journal of Management, 17(1), 191-211.

Fiol, C. M. (2001). Revisiting an identity- based view of sustainable competitive advantage. Journal of Management, 27(6), 691-699.

Fiol, C. M. (2002). Capitalizing on paradox: The role of language in transforming organizational identities. Organizational Science, 13(6), 653-666.

Fiol, C. M., \& Huff, A. S. (1992). Maps for manager: Where are we? Where do we go from here? Journal of Management Studies, 29(3), 267-285.

Fiol, C. M., Pratt, M. G., \& O'Connor, E. J. (2009). Managing intractable identity conflicts. Academy of Management Review, 34(1), 32-55.

Fleetwood, S. (2005). Ontology in Organization and Management Studies: A critical realist perspective. Organization, 12(2), 197-222.

Fleming, P., \& Spicer, A. (2003). Working at a cynical distance: implicantions for subjectivity, power and resistance. Organization, 10(1), 157-179.

Fleming, P., \& Sturdy, A. (2011). "Being yourself" in the electronic sweatshop: New forms of normative control. Human Relations, 64(2), 177-200.

Flick, U. (2008a). Managing quality in qualitative research. . London: SAGE.

Flick, U. (2008b). Designing qualitative research. London: SAGE.

Fombrum, C. J., \& Shanley, M. (1990). What's in a name? Reputation building and corporate strategy. Academy of Management Journal, 33(2), 253-258.

Fombrun, C. J. (1996). Reputation: Realizing value from the corporate image. Harvard Businness School Press.

Foote, N. N. (1951). Identification as the basis for a theory of motivation. American Sociological Review, 16(1), 14-21. 
Foreman, P., \& Whetten, D. A. (2002). Members's identification with multiple identity organizations. Organization Science, 13(6), 618-635.

Foucault, M. (1999). El cuidado de la verdad. En M. Foucault, Obras esenciales. Estética, ética y hermenéutica. (Vol. II). Barcelona: Paidos.

Fournier, V. (1999). The appreal to "professionalism" as a disciplinary mechanism. Sociological Review, 47(2), 280-307.

Fraiberg, A. M. (2010). "With edges of rage and despair": Anger and the poetry of office life. Journal of Management Inquiry, 19(3), 196-207.

Friedman, G. (1956). Problemas humanos del maquinismo industrial. Buenos Aires: Sudamérica.

Fromm, E. (1987). Psicoanálisis de la sociedad contemporánea. México: Fondo de Cultura Económica.

Fuller, J. B., Hester, K., Barnett, T., Frey, L., Relyea, C., \& Beu, D. (2006). Perceived external prestige and internal respect: New insights into the organizational identification process. Human Relations, 59(6), 815-846.

Gabriel, Y. (1999). Beyond happy families: A critical reevaluation of the controlresistance-identity triangle. Human Relations, 52(2), 179-203.

Gabriel, Y. (2003). Your home, my exile: Boundaries and "Otherness" in antiquity and now. Organization Studies, 24(4), 619-632.

Galeano Marín, M. E. (2004). Diseño de proyectos en la investigación cualitativa. Medellín: Universidad EAFIT.

Galeano Marín, M. E. (2009). Estrategias de Investigación Social Cualitativa. El giro de la mirada. Medellín: La Carreta Editores.

Galeano Marín, M. E., \& Aristizabal Salazar, M. N. (2008). Cómo se construye un sistema categorial. Estudios de Derecho, 65(145), 162-187.

Galimberti, U. (2002). Diccionario de Psicología. Buenos Aires, Argentina: Siglo XXI editores S.A.

Gallo Machado, G. (28 de Agosto de 2011). Así nació el Sindicato Antioqueño. El Colombiano, pág. 38.

García de la Torre, C. (2007). Estudio sobre la Identidad y la Cultura en América Latina. Cuadernos de Administración, julio-diciembre(38), 21-51. 
Garsten, C. (1999). Betwixt and between: Temporary employees as liminal subjects in flexible organizations. Organization Studies, 20(4), 601-617.

Gecas, V., \& Burke, P. J. (1995). Self and Identity. En K. S. Cook, G. A. Fine, \& J. S. House (Edits.), Sociological Perspectives on Social Psychology (págs. 336-338). Needham Heights, MA: Allyn and Bacon.

Gennep, A. v. (1960). The rites of passage. London: Routledge \& Kegan Paul.

Gergen, K. J. (1992). El yo saturado. Dilemas de identidad en el mundo contemporáneo. Barcelona: Paidós.

Gibson, C. B., Gibbs, J. L., Stanko, T. L., Tesluk, P., \& Cohen, S. G. (2011). Including the "I" in virtuality and modern job design: extending the job characteristics model to include the moderating effect of individual experiences of electronic dependence and copresence. Organization Science, 22(6), 1481-1499.

Giddens, A. (1991). Modernity and Self-Identity. Cambridge: Polity Press.

Giddens, A. (1998). La constitución de la sociedad. Bases para la teoría de la estructuración social. Buenos Aires: Amorrortu.

Giménez, G. (1996). La identidad social o retorno del sujeto en sociología. En Identidad III Coloquio P. Kirschhoff (págs. 11-24). México: UNAM.

Giménez, G. (2000). Materiales para una teoría de las identidades sociales. En J. M. Valenzuela (Ed.), Decadencia y auge de las identidades (págs. 45-78). México: CFN y plaza y Valdéz.

Ginzel, L. E., Kramer, R. M., \& Sutton, R. I. (1993). Organizational impression Management as a Reciprocal Influence Process: The Neglected Role of the Organizational Audience. Research in Organizational Behavior, 15, 227266.

Gioia, D. A. (1998). From individual to organizational identity. En D. Whetten, \& P. Godfrey, Identity in organizations: Developing theory through conversations (págs. 17-31). Thousand Oaks, CA: SAGE.

Gioia, D. A., \& Chittipeddi, K. (1991). Sensemaking and sensegiving in strategic change initiation. Strategic Management Journal, 12(6), 443-458. 
Gioia, D. A., \& Thomas, J. B. (1996). Identity, image and issue interpretation: Sensemaking during strategic change in academia. Administrative Science Quarterly, 4(3), 370-403.

Gioia, D. A., Price, K. N., Hamilton, A. L., \& Thomas, J. B. (2010). Forging and Identity: An insider-outsider study of processes involved in the formation of organizational identity. Administrative Science Quarterly, 55(1), 1-46.

Gioia, D. A., Schultz, M., \& Corley, K. (2000). Organizational identity, image and adaptative instability. Academy of Journal Management, 25(1), 63-82.

Glaser, B., \& Strauss, A. (1967). The discovery of grounted theory: strategies for qualitative research. Chicago: Aldine.

Glynn, M. A. (2000). When cymbals become symbols: Conflicto over organizational identity within a symphony orchestra. Organization Science, 11(3), 285-298.

Glynn, M. A., \& Abzug, R. (2002). Institutionalizing identity: Symbolic isomorphism and organizational names. Academy of Management Journal, 45(1), 267280.

Glynn, M. A., \& Abzug, R. A. (1998). Isomorphism competitive differentiation in the organizational game. En J. A. Baum (Ed.), Advances in strategic management (Vol. 15, págs. 105-128). Greenwich, CT: JAI.

Glynn, M. A., Barr, P. S., \& Dancing, M. T. (2000). Pluralism and the problem of variety. Academy of Management Review, 25(4), 726-734.

Goffman, E. (1974). Frame Analysis. New York: Harper and Row.

Goffman, E. (1989). La presentación de la persona en la vida cotidiana. Buenos Aires: Amorrortu.

Goffman, E. (2010). Estigma. La identidad deteriorada. Buenos Aires: Amorrortu editores.

Golden Biddle, K., \& Rao, H. (1997). Breaches in the boardroom: Organizational identity and conflicts of commitment in a nonprofit organization. Organization Science, 8(6), 593-609.

Gómez, M.-L., \& Bouty, I. (2011). The emergence of an influential practice: food for thought. Organization Studies, 32(7), 921-940. 
Gonzales-Miranda, D. R. (2012). Identidad Organizacional: marco teórico para el análisis organizacional. Estudios Interdisciplinarios de la Organización., 1(2), 35-63.

Gonzales-Miranda, D. R., Gentilin, M. y Ocampo, C.A. (2014) La identidad organizacional. ¿En qué va la conversación? Perspectivas y Controversias. En proceso de evaluación.

Gonzales-Miranda, D. R., Gentilin, M., Ocampo Salazar, C., \& Sierra Echeverry, A. (2012). Investigadores, temáticas y tendencias en el Estudio de las Organizaciones. Informe de Investigación. Proyectos Internos EAFIT 2012, Medellín.

González, F. (2014). Los Negroides (Ensayo sobre la Gran Colombia). Medellín: Fondo Editorial Universidad EAFIT, Corporación Otraparte.

Gotsi, M., Andriopoulos, C., Lewis, M. W., \& Ingram, A. E. (2010). Managing creatives: Paradoxical approaches to identity regulation. Human Relations, 63(6), pp. 781-805.

Graafsma, T., Bosma, H., Grotevant, H., \& De Levita, D. (1994). Identity and development: An interdisciplinary view. En H. A. Bosma, H. D. Graafsma, Grovetant, \& D.J. de Levita (Edits.), Identity and development: An interdisciplinary approach. (págs. 159-174). Thousand Oaks, CA: SAGE.

Grey, C. (1997). Management as technical practice: professionalization or responsibilization? Systemic Practice and Action Research, 10(6), 703-726.

Grey, C. (1999). We are all managers now; we always were. On the emergence and demise of management. Journal of Management Studies, 36(5), 561586.

Grey, C., \& Willmott, H. (Edits.). (2005). Critical Management Studies. A reader. New York: Oxford.

Grison, M., \& Worland, D. (2000). Managers in the middle: Employee Involvement Effects in a Federal Goverment Agency. Journal of Industrial Relations, 42(4), 573-581.

Grob, C., \& Kieser, A. (2006). Consultants on the way ti professionalization? En R. Greenwood, \& R. Suddaby (Edits.), Research in the Sociology of Organizations (págs. 69-100). Bingley: Emerald. 
Guba, E. G., \& Lincoln, Y. S. (1994). Competing paradigms in qualitative research. En N. K. Denzin, \& Y. S. Lincoln (Edits.), Handbook of qualitative research (págs. 105-117). London: SAGE.

Gunderman Kröll, H. (2008). El método de los estudios de caso. En M. L. Tarrés (Ed.), Observar, escuchar y comprender (págs. 251-288). Ciudad de México: FLACSO; El Colegio de México, Miguel Ángel Porrúa.

Gunderman, H. K. (2001). El método de los estudios de caso. En L. Tarrés (Ed.), Observar, escuchar y comprender: Sobre la tradición cualititativa en la investigación social. (págs. 251-288). México: Porrúa.

Gustafson, L., \& Reger, R. (August de 1998). Organizational Identity: Am empirical investigation of unresolved issues. Paper presentado a la Academy of Management. San Diego, CA.

Gutiérrez, J., \& Delgado, J. M. (1999). Teoría de la observación. En J. Gutiérrez, \& J. M. Delgado (Edits.). Madrid: Síntesis.

Habermas, J. (1972). Knowledge and human interests. London: Heinemann.

Habermas, J. (1984). The Theory of Communicative Action. Reason and the Rationilization of Society. (Vol. 1). (T. McCarthy, Trad.) Boston: Beacon.

Hackley, C., \& Kover, A. (2007). The trouble with creatives: Negotiating creative in advertising agencies. International Journal of Advertising, 26(1), 63-78.

Hall, S. (1996). Who Needs "Identity"? En S. Hall, \& P. du Gay (Edits.), Questions of Cultural identity. London: SAGE.

Ham Juárez, C. (2001). Lenguaje y subjetividad en el pensamiento de Emmanuel Levinas. Iztapalapa, 24(50), 297-320.

Hancké, B. (2009). Intelligent research design. A guide for beginning researchers in the social sciences. Oxford: Oxford University Press.

Hannan, M. T., \& Freeman, J. (1989). Organizational Ecology. Cambridge: Harvard University Press.

Harding, N. (2007). On Lacan and the "Becoming-ness" of Organizations/Selves. Organization Studies, 28(11), 1761-1773. 
Hardy, C., Lawrence, T. B., \& Grant, D. (2005). Discourse and collaboration: The role of conversations and collective identity. Academy of Management Review, 30(1), 58-77.

Harquail, C. V. (2004). Book Review of Moingeon, B and Soenen, G (Eds). Corporate and organizational identity: Integrating strategy. Marketing. Communication and organizational perspectives. Administrative Science Quarterly, 49(1), 141-144.

Harquail, C. V., \& King, A. W. (2010). Construing Organizational Identity: The role of embodied cognition. Organization Studies, 31(12), 1619-1648.

Harquail, C., \& King, A. (August de 2003). Organizational identity and embodied cognition: A multi-level conceptual framework. Paper presentado a la Academy of Management. Seattle, WA.

Haslam, S. A., \& Ellemers, N. (2005). Social identity in industrial and organizational psychology: Concepts, controversies and contributions. En G. P. Hodgkinson (Ed.), International Review of industrial and organizational psychology (Vol. 20, págs. 39-118). Chichester: Wiley.

Hatch, M. J. (1997). Organization Theory. Modern, symbolic and postmodern perspectives. Great Britain: Oxford University Press.

Hatch, M. J. (2005). Identity Organizational. En N. Nicholson, P. G. Audio, \& M. Pillutla (Edits.), The blackwell encyclopedia of management. London: Basil Blackwell.

Hatch, M. J., \& Schultz, M. (1997). Relations between organizational culture, identity and image. European Journal of Marketing, 31(5/6), 356-365.

Hatch, M. J., \& Schultz, M. (2002). The dynamics of organizational identity. Human Relations, 55, 989-1019.

Hatch, M., \& Schultz, M. (2004). Organizational Identity. A reader. Ney York: Oxford University Press Inc.

Hegel, G. (2005). Enciclopedia de las Ciencias Filosóficas. Madrid: Alianza editorial.

Heise, D. R. (1977). Social action as the control of affect. Behavioral Science, (22), 163-177. 
Heracleous, L., \& Jacobs, C. D. (2008). Understanding organizations through embodied metaphors. Organization Studies, 29(1), 45-78.

Hernández González, J. (2008). El trabajo sobre la identidad en estudiantes de bachillerato. Reflexividad, voces y marcos morales. México: Universidad Pedagógica Nacional.

Hernández i Dobon, F., \& Herzog, B. (2011). Axel Honneth: Estaciones hacia una Teoría Crítica de la Sociedad del desprecio. En A. Honneth, La sociedad del desprecio (págs. 9-25). Madrid: Trotta.

Herzberg, F. (1966). Work and the nature of man. New York: Thomas Y. Crowell Company.

Hickson, D., \& Kieser, A. (1988). Editorial. Organization Studies, 9(1), 1.

Holmer-Nadesan, M. (1996). Organizational identity and space of action. Organizationa Studies, 17(1), 49-81.

Holstein, J., \& Gubrium, J. (2000). The self we live by: Narrative identity in a posmodern world. Oxford: Oxford University Press.

Honneth, A. (1997a). La lucha por el reconocimiento. Por una gramática moral de los conflictos sociales. (M. Ballesteros, Trad.) Barcelina: CRÍTICA.

Honneth, A. (1997b). Reconocimiento y obligación moral. Areté, 9(2), 235-252.

Honneth, A. (2005). Reificación. Un estudio en la Teoría del Reconocimiento. (G. Calderón, Trad.) Buenos Aires: Katz Editores.

Honneth, A. (2006). El reconocimineto como ideología. ISEGORÍA, juliodiciembre(35), 29-150.

Honneth,A. (2009). Crítica del agravio moral. Patalogías de la sociedad contemporánea. (P. Storandt Diller, Trad.) Buenos Aires: Fondo de Cultura Económica, Universidad Autónoma Metropolitana.

Hopenhayn, M. (2001). Repensar el trabajo. Buenos Aires: Norma.

Horkheimer, M. (2002). Crítica de la razón instrumental. (J. Muñoz, Trad.) Madrid: Trotta.

Horkheimer, M., \& Adorno, T. (1979). The Dialectics of Enlightement . London: Verso. 
Hsu, G., \& Hannan, M. T. (2005). Identities, genres, and organizational forms. Organizations Science, 16(5), 474-490.

Huber, G., \& Power, D. (1985). Retrospective reports of strategic-level managers: Guidelines for increasing their accuracy. Strategic Management Journal, 6(2), 171-180.

Humphreys, M., \& Brown, A. D. (2002a). Narratives of Organizational Identiy and Identification: A case Study o Hegemony and Resistance. Organization Studies, 23(3), 421-447.

Humphreys, M., \& Brown, A. D. (2002b). Dress and identity: A Turkish case study. Journal of Management Studies, 39(7), 927-952.

Ibarra Colado, E. (2003). Teoría de la Organización. Mapa conceptual de un territorio en disputa. En E. De la Garza Toledo, Tratado Latinoamericano de Sociología de la Empresa (págs. 245-284). Ciudad de México: El Colegio de México, Facultad Latinaoamericana de Ciencias Sociales, UAM, Fondo de Cultura Económica.

Ibarra Colado, E. (2006). ¿Estudios Organizacionales en América Latina? Transitando del centro a las orillas. En E. De la Garza Toledo (Ed.), Teorías Sociales y Estudios del Trabajo. Nuevos Enfoques (págs. 88-107). Ciudad de México, México: Anthropos, UAM-I.

Ibarra Colado, E., \& Montaño Hirose, L. (1990). Teoría de la Organización: Desarrollo histórico, debate actual y perspectivas. En E. Ibarra Colado, \& L. Montaño Hirose (Edits.), Teoría de la Organización: fundamentos y controversias. (págs. vii-xxvi). México: UAM-I.

Ibarra Colado, E., \& Montaño Hirose, L. (1992). Mito y poder en las Organizaciones. México: Trillas.

Ibarra, H. (1999). Provisional seves: Experimenting with image and identity in professional adaptation. Administrative Science Quarterly, 44(4), 764-791.

James, L., \& Sells, S. (1981). Psychological climate: Theoretical perspectives and empirical research. En D. Magnussen (Ed.), Toward a Psychology of situations: An international perspectives (págs. 275-295). Hillsdale: Lawrence Erlbaum. 
Jay, M. (1974). La imaginación dialéctica. Una historia de la Escuela de Frankfurt y el Instituto de Investigación Social (1923-1950). (J. C. Curutchet, Trad.) Madrid: Taurus.

Jenkins, R. (2004 (1996)). Social identity (2 ed.). London: Routledge.

Jepperson, R. (2001). Instituciones, efectos institucionales e institucionalismo. En W. W. Powell, \& P. J. DiMaggio (Edits.). México: Fondo de Cultura Económica, Colegio Nacional de Ciencias Políticas y Administración Pública, Universidad Autónoma del Estado de México.

Kant, I. (1989). La metafísica de las costumbres. Madrid: Tecnos.

Kant, I. (1996). Fundamentación de la metafísica de las costumbres. México: Miguel Ángel Porrúa.

Karreman, D., \& Alvesson, M. (2001). Making newsmakers. Organization Studies, 22(1), 59-90.

Karreman, D., \& Alvesson, M. (2004). Cages in tandem: Management control, social identity, and identification in a knowledge-intensive firm. Organization, 11(1), 149-175.

Kelemen, M., \& Hassard, J. (2003). Paradigm Plurality: Exploring Past, Present, and Future Trends. En R. Westwood, \& S. Clegg (Edits.), Debating Organization. Point-Counterpoint in Organization Studies (págs. 73-82). London: Blackwell.

Kelemen, M., \& Kostera, M. (Edits.). (2002). Critical Management Research in Eastern Europe. Managing the Transition. New York: Palgrave Macmillan.

Kelman, H. C. (2006). Interests, relationships, identities: Three central issues for individuals and groups in negotiating their social environment. Annual Review of Psychology, 57(1), 1-26.

Kenny, K., Whittle, A., \& Willmott, H. (2011). Understanding Identity \& Organizations. London: SAGE.

Kerfoot, D. (2003). The problematic professional: Gender and the transgression of "professional" identity. En J. Barry, M. Dent, \& M. O’Neill (Edits.), Gender, professionalism and managerial change. (págs. 205-217). London: Rautledge. 
Khapova, S. N., \& Arthur, M. B. (2011). Interdisciplinary approaches to contemporary career studies. Human Relations, 64(1), 3-17.

King, B. G., Felin, T., \& Whetten, D. A. (2010). Finding the organization in organizational theory: A metatheory of the organization as a social actor. Organization Science, 21(1), pp. 290-305.

Knights, D., \& Willmott, H. (1989). Power and subjectivity at work. Sociology, 29, 761-782.

Knights, D., \& Willmott, H. (1992). Conceptualising leadership processes: A study of senior managers in a financial services company. Journal of Management Studies, 29(6), pp. 767-783.

Knorr Cetina, K. (2005). La fabricación del conocimiento: un ensayo sobre el carácter constructivista y contextual de la ciencia. Buenos Aires: Universidad Nacional de Quilmes.

Korica, M., \& Molloy, E. (2010). Making sense of professional identities: Stories of medical professionals and new technologies. Human Relations, 63(12), 1879-1901.

Kornberger, M., \& Brown, A. (2007). "Ethics" as a Discursive Resource for Identity Work. Human Relations, 60(3), 497-518.

Kosmala, K., \& Herrbach, O. (2006). The ambivalence of professional identity: On cynicism and jouissance in audit firms. Human Relations, 59(10), 13931428.

Kreiner, G. E., \& Ashforth, B. E. (2004). Evidence toward an expanded model of organizational identification. Journal of Organizational Behavior, 25(1), 1-27.

Kreiner, G. E., Hollensensbe, E. C., \& Sheep, M. L. (2006a). Where is the "me" among the "we"? Identity work and the search for optimal balance. Academy of Management Journal, 49(5), 1031-1057.

Kreiner, G. E., Hollensensbe, E. C., \& Sheep, M. L. (2006b). On the edge of identity: Boundary dynamics at the interface of individual and organizational identities. Human Relations, 59(10), 1315-1341.

Kuhn, T. S. (1970). The Structure of Scientific Revolutions (2 ed.). Chicago: University of Chicago.

Kunda, G. (1992). Engineering culture. Philadelphia: Temple University Press. 
Labastida, J. (2007). El edificio de la razón. México: Siglo XXI, Universidad Nacional Autónoma de México.

Labianca, G., Fairbank, J. F., Thomas, J. B., Gioia, D. A., \& Umphress, E. E. (2001). Emulation in Academia: Balancing structure and identity. Organization Science, 12(3), 312-330.

Lash, S. (1988). Discourse or figure? Postmodernism as a "Regime of Signification". Theory, Culture \& Society, 5(2), 311-336.

Latour, B., \& Woolgar, S. (1979). Laboratory Life. The Social Construction of Scientific Facts. Beverly Hills: SAGE.

Lattuca, L. R. (2001). Creating interdisciplinarity: Interdisciplinary research and reaching among college and university faculty. Nashville: Vanderbilt University Press.

Lawrence, P. R., \& Lorsh. (1973). Organización y ambiente. México: Editorial Labor S.A.

Leyva, G. (2005). Presentación. En G. Leyva (Ed.), La Teoría Crítica y las tareas actuales de la crítica (págs. 7-14). Cuidad de México, México: Anthropos, UAM-I.

Likert, R. (1961). New Patterns of management. Tokyo: Mc Graw Hill; Kogakusha Company.

Lincoln, Y. S., \& Guba, E. G. (1985). Naturalistic Inquiry. Beverlu Hills, CA: SAGE.

Linstead, S. (2004). Organization Theory and Postmodern Thought. London: SAGE.

Linstead, S., \& Thomas, R. (2002). "What do you want from me?" A poststructuralist feminist reading of middle managers' identities. Culture and Organization, 8(1), 355-362.

Londoño, C. (2004). Grupo Empresarial Antioqueño. Evolución de políticas y estrategias, 1978-2002. EIA, 1(1), 47-62.

López Gallego, F., \& Gonzales Miranda, D. R. (2010). El poder y conflicto en las organizaciones: Una mirada desde los libros de texto funcionalistas. En R. Muñoz Grisales, S. Arcand, J. Facal, \& J. P. Dupuis (Edits.), Sociología de la empresa: Del marco histórico a las dinámicas internas (págs. 207-235). 
Medellín: Fondo editorial Universidad EAFIT, Universidad del Valle, Siglo del hombre editores.

López, F. (2009). El coaching ontológico: o una arremetida de gestión totalitaria. En R. Carvajal Baeza (Ed.), Gestión Crítica Alternativa (págs. 249-265). Cali: Universidad del Valle, Facultad de Ciencias de la Administración.

Lourau, R. (2007). El análisis institucional. (N. Fiorito de Labrune, Trad.) Buenos Aires: Amorrortu.

Macdonald, K. (1995). The Sociology of the Professions. London: SAGE.

MacKinnon, N. J. (1994). Symbolic interactions as effect control. Albany, NY: State University of New York Press.

Maitlis, S., \& Lawrence, B. (2003). Orchestral manoeuvres in the dark: Understanding failure in organizational strategizing. Journal of Management Studies, 40(1), 109-139.

March, J. G. (2007). The study of organizations and organizing since 1945. Organizations Studies, 28(1), 9-19.

March, J. G., \& Simon, H. A. (1977). Teoría de la organización. Barcelona: Ariel.

March, J., \& Simon, H. A. (1958). Organizations. New York: Wiley.

Marcus, A. A., \& Goodman, R. S. (1991). Victims and shareholders: The dilemmas of presenting corporate policy during a crisis. Academy of Management Journal, 34(2), 281-305.

Marín Idárraga, D. (2006). El sujeto humano en la administración. Una mirada crítica. Cuadernos de Administración, 19(32), 135-156.

Marín Idárraga, D. A. (2007). Administración y racionalidad. Sotavento (14), 8-41.

Maritain, J. (1981). Introducción a la Filosofía. Buenos Aires: Club de lectores.

Markus, H., \& Wurf, E. (1987). The Dynamic Self-Concept: A social psychological perspective. Annual review of psychology, 38(1), 299-337.

Marshall, B. (1997). Todo lo sólido se desvanece en el aire. En S. Arriarán, Filosofía de la posmodernidad. Crítica a la modernidad desde América Latina. México: Universidad Nacional Autónoma de México. 
Martínez Miguélez, M. (s.f.). Uso del programa computacional Atlas ti de Thomas Mühr (Univ. De Berlin) en la estructuración teórica de "datos cualitativos. Recuperado el 22 de junio de 2010, de http://prof.usb.ve/miguelm/estructuracionteorica\%203.html

Martins, L. L. (2005). A model of the effects of reputational rankings on organizational change. Organization Science, 16(6), 701-720.

Marx, C. (1984). El Capital: Crítica de la Economía Política. Ciudad de México: Fondo de Cultura Económica.

Marx, K. (1978). Economic and philosophical manuscripts of 1844. En R. Tucker (Ed.), The Marx-Engels reader. (Vol. 1, págs. 66-125). London: Pelican.

Maslow, A. (1970). Motivation and personality. New York: Harper \& Row Publishers.

Mauss, M. (2009). Ensayo sobre el don. Forma y función del intercambio en las sociedades arcaicas. Madrid: Katz.

McAdams, P. (1996). Personality, modernity and the storied self: A contemporary framework for studying persons. Psychological Inquiry, 7(4), 295-321.

McCall, G. J., \& Simmons, J. L. (1966). Identities and interaction. New York: Free Press.

McGregor, D. (1972). El aspecto humano de las empresas. México: Editorial Diana.

McKelvey, B. (1997). Quasi-natural organization science. Organization Science, 8(4), 352-380.

McKelvey, B. (2003). From Fields to Science: Can Organization Studies make the Transition? En R. Westwood, \& S. Clegg (Edits.), Debating Organization. Point-Counterpoint in Organization Studies (págs. 47-73). London: Blackwell.

McKendrick, D. G., Jaffee, J., Carroll, G. R., \& Khessina, O. M. (2003). In the bud? Disk array producers as a (possibly) emergent organizational form. Administrative Science Quaterly, 48(1), 60-93.

McNay, L. (1992). Foucault and Feminism. Cambridge: Polity.

Mead, G. H. (1934). Espíritu, persona y sociedad. Barcelona: Paidós. 
Meeth, L. R. (1978). Interdisciplinary Studies: A matter of definition. Change: The Magazine of higher Learning, 10(7), 10.

Melucci, A. (1989). Nomads of the present: Social movements and individual needs in contemporary society. Philadelphia: Temple University Press.

Méndez B., L. H. (2005). Ritos de paso truncos: El territorio simbólico maquilador fronterizo. Ciudad de México: Ediciones y Gráficos EÓN, UAMAzcapotzalco.

Mendizabal, N. (2006). En I. Vasilachis de Gialdino (Ed.), Estrategias de investigación cualitativa (págs. 65-106). Barcelona: Gedisa S.A.

Meriläinen, S., Tienari, J., Thomas, R., \& Davis, A. (2004). Management consultant talk: A cross-cultural comparison of normalizing discourse and resistance. Organization, 11(4), 539-564.

Merril, H. F. (2000). Clásicos de la Administración. México: Limusa.

Messner, M., Clegg, S., \& Kornberger, M. (2008). Critical Practices in Organizations. Journal of Management Inquiry, 17(2), 68-82.

Meyer, A. D., Tsui, A. S., \& Hinings, C. R. (1993). Configurational approaches to organizational analysis. Academy of Management Journal, 36(6), 11751195.

Mills. (1970). The Sociological Imagination. Harmondsworth: Penguin.

Mintzberg, H. (1992). El poder de las organizaciones. Barcelona: Ariel.

Mintzberg, H. (2000). La estructuración de las organizaciones. Barcelona: Ariel.

Montaño Hirose, L. (1991). Las nuevas relaciones humanas: un falso reto a la democracia. En E. Ibarra Colado, \& L. Motaño Hirose, Ensayos críticos para el estudio de las organizaciones en México. (págs. 69-102). México: UAM-I; Miguel Ángel Porrúa.

Montaño Hirose, L. (1994). Modernidad, postmodernismo y organización. Una reflexión acerca de la noción de estructura postburocrática. En L. Montaño Hirose (Ed.), Argumentos para un debate sobre la modernidad. Aspectos organizacionales y económicos. (págs. 67-91). UAM-I.

Montaño Hirose, L. (2001). La razón, el efecto y la palabra: Reflexiones en torno al sujeto en la organización. Iztapalapa(50), 191-212. 
Montaño Hirose, L. (2004). El estudio de las organizaciones en México, una perspectiva social. En L. Montaño Hirose (Ed.), Los estudios organizacionales en México. Cambio, poder, conocimiento e identidad. (págs. 9-39). México: UAM-I, Universidad de Occidente, Miguel Ángel Porrúa.

Montaño Hirose, L. (2007a). Autonomía y distancia social en una organización pública mexicana. En M. Rendón Cobian (Ed.), Organización y Cultura. Tradición, poder y modernidad en México (págs. 127-171). México: Universidad Autónoma Metropolitana - Iztapalapa.

Montaño Hirose, L. (2007b). El análisis organizacional. Un modelo para armar. Reflexiones en torno a la perspectiva de Eugène Enriquez. México: UAM-I, Red Mexicana de Investigadores en Estudios Organizacionales.

Montaño Hirose, L. (2012). El sentido de la existencia social frente a los embates de la eficiencia. Estudios Interdisciplinarios de la Organización, 1(1), 35-49.

Montaño Hirose, L. (2013). Los Estudios Organizacionales. Revisando el papel de la crítica en la administración. En R. Carvajal Baeza (Ed.), Estudios críticos de la organización: qué son y cuál es su utilidad. (págs. 21-52). Cali: Universidad del Valle.

Montaño Hirose, L. (24 de Noviembre de 1987). Ergónomos del alma. El mundo, págs. 33-34.

Moore, G. E. (1903 / 1922). The refutation of idealism. En G. E. Moore (Ed.), Philosophical Studies (págs. 1-30). London: Trench Trubner.

Morgan, G. (1998). Imágenes de la organización. México: Alfaomega.

Morin, E. (2005). El método V: la humanidad de la humanidad. La identidad humana. Madrid: Cátedra.

Mouzelis, N. P. (1975). Organización y burocracia: Un análisis de las teorías modernas sobre organizaciones sociales. (1967 ed.). Barcelona: Ediciones Península.

Mumby, D. (2005). Theorizing resistance in organization studies. Management Communication Quarterly, 19(1), 19-44.

Myrdal, G. (1958). Value en Social Theory. London: Rautledge. 
Nag, R. K., Corley, K. G., \& Gioia, D. A. (2007). The intersection of organizational identity, knowledge, and practice: Attemping strategic change via knowledge grafting. Academy of Management Journal, 50(4), 821-847.

Nayak, A. (2008). On the way to theory: A processual approach. Organization Studies, 29(2), 173-190.

Noble, C., \& Walker, B. (1997). Exploring the relationships among liminal transitions. Symbolic consumption and the extended self. Psychology and Marketing, 14(1), 29-47.

Noorderhaven, N. G., Benders, J., \& Keizer, A. B. (2007). Comprehensiveness versus pragmatism: consensus at the Japanese-Dutch interface. Journal of Management Studies, 44(8), 1349-1370.

Pacheco Espejel, A., \& Cruz Estrada, M. C. (2010). Metodología Crítica de la Investigación. México: Patria.

Pàges, M., Bonetti, M., De Gaulejac, V., \& Descendre, D. (1979). L'emprise de I'organisation. Paris: Presses Universitaires de France.

Palmer, D., Dick, B., \& Freiburger, N. (2009). Rigor and Relevance in Organization Studies. Journal of Management Inquiry, 18(4), 265-272.

Parker, M. (2004). Becoming manager - or, the were wolf looks anxiously in the mirror, checking for unusual facial hair. Management Learning, 35(1), 45-59.

Parkinson, M. (2003). Aplicación de la psicología en los negocios. Ciudad de México: Mc Graw Hill.

Pérez Serrano, G. (1994). Investigación Cualitativa. Retos e Interrogantes. I. Métodos (Vol. I.). Madrid: La Muralla.

Perrow, C. (1991). Sociología de las Organizaciones. Madrid: Mc Graw Hill.

Pfeffer, J. (1992). Organizaciones y teoría de las organizaciones. México: Fondo de Cultura Económica.

Pfeffer, J. (2000). Nuevos rumbos de la Teoría de la Organización. México: Oxford University Press.

Podestá, P., \& Jurado, J. C. (2003). Fundamentos del Saber Administrativo. Cuadernos de difusión, 15, 81-100. 
Polletta, F., \& Jasper. (2001). Collective identity and social movements. Annual Review of Sociology, 27(1), 283-305.

Potosky, D. (2008). A conceptual framework for the role of the administration medium in the personnel assessment proecess. Academy of Management Review, 33(3), 629-648.

Pratt, M. (2000). The good, the bad and the ambivalent: Managing identification among amway distributors. Administrative Science Quarterly, 45(3), 456493.

Pratt, M. G. (1998). To be or not to be: Central questions in organizational identification. En D. A. Whetten, \& P. Godfrey (Edits.), Identity in organizations: Developing theory through conversations (págs. 171-207). Thousand Oaks: SAGE.

Pratt, M. G. (2003). Disentangling collective identity. En J. T. Polzer, E. Mannix, \& M. Neale (Edits.), Research on managing groups and teams (Vol. 5, págs. 161-188). Greenwich: JAl.

Pratt, M. G., \& Foreman, P. O. (2000). Classifying managerial responses to multiple organizational identities. Academy of Management Review, 25(1), 18-42.

Pratt, M. G., \& Rafaeli, A. (1997). Organizational dress as a symbol of multilayered social identities. Academy of Management Journal, 40(4), 868-898.

Pratt, M. G., \& Rosa, J. A. (2003). Transforming work-family conflict into commitment in network marketing organizations. Academy of Management Journal, 46(4), 395-418.

Pugh, D. S. (1997). Does context determine form? En D. S. Pugh, OrganizationTheory. London: Penguin Books.

Pugh, D. S., Hickson, D. J., Hinings, C. R., Lupton, K. M., Mcdonald, K. M., Turner, C., \& Lupton, T. (1963). A conceptual scheme for organizational analysis. Administrative Science Quarterly, 8(3), 289-315.

Racinero, L. (1994). Oriente y Occidente. Filosofía oriental y dilemas occidentales. España: Anagrama.

Raes, A. M., Heijltjes, M. G., Glunk, U., \& Roe, R. A. (2011). The intreface of the top management team and middle managers: a process model. Academy of Management Review, 36(1), 102-126. 
Ravasi, D., \& Schultz, M. (2006). Responding to organizational identity threats: exploring the role of organizational culture. Academy of Management Journal, 49(3), 433-458.

Ravasi, D., \& van Rekom, J. (2003). Key issues in organizational identity and identification theory. Corporate Republication Review, 6(2), 118-132.

Ray, C. (1986). Corporate Culture: The last frontier of control? Journal of Management Studies, 23(3), 187-297.

Reed, M. (1996). Organizations Theorizing: a historically contested terrain. En S. R. Clegg, C. Hardy, \& W. R. Nord, Handbook of Organization Studies (págs. 31-56). London: SAGE.

Reger, R. K., Gustafson, L. T., DeMarie, S. M., \& Mullane, J. V. (1994). Reframing the organization: When implementing total quality is easier said than done. Academy of Management Review, 19(3), 565-584.

Reichers, A. E., \& Schneider, B. (1990). Climate and culture: An evolutions of constructs. En B. Schneider (Ed.), Organizational climate and culture (págs. 5-39). San Francisco: Jossey-Bass.

Reichers, A. E., Wanous, J. P., \& Austin, J. T. (1997). Understanding and managing cynicism about organizational change. Academy of Management Executive, 11(1), 48-59.

Repko, A. E. (2012). Interdisciplinary Research. Process and Theory. (2 ed.). London: SAGE.

Repko, A. F., Szoztak, R., \& Buchberger, M. P. (2013). Introduction to Interdisciplinary Studies. London: SAGE.

Ricoeur, P. (1996). El sí mismo como otro. México: Siglo XXI.

Riege, A., \& Zulpo, M. (2007). Knowledge Transfer Process Cycle: Between Factory Floor and Middle Management. Australian Journal of Management, 32(2), 293-314.

Rios, M. (2003). Reapropiación de modelos y construcción de identidad organizacional. Ciencias Sociales y Humanas, 24(55), 69-100.

Ritzer, G. (2003). Teoría sociológica moderna. México: McGraw-Hill. 
Roberts, J. (2005). The power of the "imaginary" in disciplinary processes. Organizations, 12(5), 619-642.

Rodrigues, S. B., \& Child, J. (2008). The development of corporate identity: A political perspective. Journal of Management Studies, 45(5), 885-911.

Rodríguez Gómez, G., Gil Flores, J., \& García J., E. (1996). Metodología de la investigación cualitativa. Málaga: Aljibe.

Rousseau, D. M. (1998). Why workers still identify with organizations. Journal of Organizational Behavior, 19(3), 217-233.

Ruiz, O. (2007). Metodología de la investigación cualitativa. Bilbao: Universidad de Deusto.

Rumens, N., \& Kerfoot, D. (2009). Gay men at work: (Re)constructing the self as professional. Human Relations, 62(5), 763-786.

Russell, B. (1929). Our knowledge of the extrenal world. New York: New American Library.

Sábato, E. (2013). La resistencia. Bogotá: Planeta.

Sainsaulieu, R. (1996). Lídentité au travail. Paris: Presses de Sciences Po.

Sánchez Serrano, R. (2001). La observación participante como escenario y configuración de la diversidad de significados. En M. L. Tarrés, Observar, escuchar y comprender: Sobre la tradición cualitativa en la investigación social. (págs. 97-131). México: FLACSO,El Colegio de México, Miguel Ángel Porrúa.

Sánchez, J. (2002). Presentación de la Crítica a la razón instrumental. En M. Horkheimer, Crítica de la razón instrumental. Madrid: Trotta.

Schacht, R. (1970). Alienation. London: George Allen \& Unwin.

Schipani, A. (25 de Noviembre de 2012). El producto de exportación más importante de Colombia. El Espectador, pág. 32.

Schutz, A. (1995/1974). El problema de la realidad social. Buenos Aires: Amorrortu.

Schvarstein, L. (1991). Psicología Social de las Organizaciones. Nuevos aportes. Buenos Aires: Paidos. 
Schwartz, H. S. (1987). Anti social actions of Committed Organizational Participants: An existential Psychoanalytic Perspective. Organization Studies, 8(4), 327-340.

Scott, S. G., \& Lane, V. R. (2000a). Fluid, fractured, and distintive? In search of a definition of organization identity. Academy of Management Review, 25(1), 143-144.

Scott, S. G., \& Lane, V. R. (2000b). A stakeholder approach to organizational identity. Academy of Managemet Review, 25(1), 43-62.

Scott, W. R. (1992). Organizations Rational. Natural and open systems. New Jersey: Pretince Hall.

Scott, W. R. (2003). Organizations: Rational, natural, and open systems. Upper Saddle River, NJ: Prentice Hall.

Selznick, P. (1957). Leadership in administration. New York: Harper \& Row.

Selznick, P. (2000). TVA and the Grass Roots. A study of politics and organization. Berkeley: University of California Press.

Serrano Blasco, J. (1997). Estudio de casos. En Á. Batzán (Ed.), Etnografía. Metodología cualtitativa en la investigación sociocultural. México: Alfaomega.

Shankar Pawar, B. (2009). Theory Building for Hypothesis Specification in Organizational Studies. London: SAGE.

Shi, W., Markoczy, L., \& Dess, G. G. (2009). The role of Midle Management in the Strategy Process: Group Affiliation, Structural Holes, and Tertius lungens. Journal of Management, 35(6), 1453-1480.

Sillince, J. A., \& Brown, A. D. (2009). Multiple organizational identities and legitimacy: The rhetoric of police websites. Human Relations, 62(12), 18291856.

Silverman, D. (1975). Teoría de las Organizaciones. Buenos Aires: Nueva Visión.

Simon, H. A. (1988). El comportamiento administrativo. Estudio de los procesos decisorios en la organización administrativa. Buenos Aires: Aguilar.

Simpson, B., \& Carroll, B. (2008). Re-viewing "Role" in processes of Identity Construction. Organization, 15(1), 29-50. 
Sims, D. (2003). Between the millstones: A narrative account of the vulnerability of middle managers's storying. Human Relations, 56(10), 1095-1121.

Slay, H. S., \& Smith, D. A. (2011). Professional identity construction: using narrative to understand the negotiation of professional and stigmatized cultural identities. Human Relations, 64(1), 85-107.

Sluss, D. M., \& Ashforth, B. E. (2007). Relational identity and identification: defining ourselves through work relationships. Academy of Management Review, 32(1), 9-32.

Smith, A. (1997). La teoría de los sentimientos morales. Madrid: Alianza Editorial.

Smith, A. (2004). La riqueza de las naciones. Madrid: Alianza.

Smith-Lovin, L., \& Heise, D. R. (Edits.). (1988). Analyzing social interaction: research advances in affect control theory. New York: Gordon \& Breach.

Snow, D. A., \& Anderson, L. (1987). Identity work among the homeless: The verbal construction and avowal of personal identities. American Journal of Sociology., 92(6), 1336-1371.

Solares, B. (1998). Max Horkheimer o el anhelo de lo completamente otro. En G. Zabludovsky (Ed.), Teoría sociológica y modernidad. México: Plaza y Valdéz, Universidad Nacional Autónoma de México.

Stablein, R. (1996). Data in Organization Studies. En C. Clegg, C. Hardy, \& W. R. Nord (Edits.), Handbook of Organization Studies (págs. 509-525). London: SAGE.

Stake, R. E. (1994). Case Studies. En D. Norman, \& Y. Lincoln (Edits.), Handbook of qualitative research (págs. 236-247). London: SAGE.

Stake, R. E. (1995). Investigación con estudio de casos. Madrid: Morata.

Strauss, A. (1996). Mirrors and Masks: The Search for Identity. New Brunswick, $\mathrm{NJ}$ : Transaction Publishers.

Strauss, A., \& Corbin, J. (2008). Basics of Qualitative Research. Thousand Oaks, CA: SAGE.

Stryker, S. (1980). Symbolic interationism: A social structural version. Menlo Park, CA: Benjamin Cummings. 
Stryker, S. (1987). The vitalization of symbolic interactionism. Social Psychology Quarterly, 50(1), 83-94.

Stryker, S. (1991). Exploring the relevance of social cognition for the relationship of self and society: Linking the cognitive prespective and identity theory. En J. A. Howard, \& P. L. Callero, The self-society dynamic: Cognition, emotion, and action (págs. 19-54). New York: Cambridge University Press.

Stryker, S., \& Statham, A. (1985). Symbolic interaction and role theory. En L. Gardner, \& E. Aronson (Edits.), Handbook of social psychology (3 ed., págs. 311-378).

Sturdy, A. (1998). Customer care in a customer society: Smiling and sometimes meaning it? Organization, 5(1), 27-53.

Sturdy, A., Schwarz, M., \& Spicer, A. (2006). Guess who's coming to dinner? Structures and uses of liminality in strategic management consultancy. Human Relations, 59(7), 929-960.

Suddaby, R., \& Greenwood, R. (2005). Rhetorical strategies of legitimacy. Administartive Science Quarterly, 50(35), 35-67.

Sveningsson, S., \& Alvesson, M. (2003). Managing managerial identities: Organizational fragmentation, discourse and identity struggle. Human Relations, 56(10), 1163-1193.

Taijfel, H., \& Turner, J. (1979). An integrative Theory of Intergroup Conflict. En W. G. Austin, \& S. Worchel (Edits.), The Social Psychology of Intergroup Relations (págs. 33-47). Monterey, CA: Brooks/Cole.

Tajfel, H. (1981). Human groups and social categories: Studies in social psychology. Cambridge: Cambridge University Press.

Tajfel, H., \& Turner, J. C. (1986). The social identity theory of intergroup behavior. En W. G. Austin, \& S. Worchel (Edits.), The social Psychology of intergroup relations. (págs. 7-24). Monterey, CA: Brooks/Cole.

Taylor, C. (1989). Explorando la condición humana: Sources of the self. Cambrigde: Harvard University Press.

Taylor, F. (1961). Principios de Administración Científica. México: Herrero Hermanos. 
Taylor, S. J., \& Bogdan, R. (1996). Introducción a los métodos cualitativos de investigación. La búsqueda de significados. España: Paidós.

Tempest, S., \& Starkey, K. (2004). The effects of liminality on individual and organizational learning. Organization Studies, 27(7), 507-527.

Thoits, P. A., \& Virshup, L. K. (1997). Me's and we's: Forms and functions of social identities. En R. D. Ashmore, \& L. Jussim (Edits.), Self and identity: Fundamental issues (Vol. 1, págs. 106-133). Ney York: Oxford University Press.

Thomas, R., \& Davies, A. (2005). Theorising the Micro-Politics of Resistance: Discourses of change and professional identities in the UK Public Services. Organization Studies, 26(5), 683-706.

Thomas, R., \& Linstead, A. (2002). Losing the Plot? Middle managers and identity. Organization, 9(1), pp. 71-93.

Thornborrow, T., \& Brown, A. D. (2009). 'Being regimented': Aspiration, discipline and identity. Organization Studies, 30(4), 1-22.

Touraine, A. (2002). Crítica a la Modernidad. México: Fondo de Cultura Económica.

Trethewey, A. (1997). Resistence, identity, and empowerment: A postmodern feminist analysis in a human service organization. Communication Monographs, 64(4), 281-301.

Tsoukas, H., \& Chia, R. (2002). On organizational becoming: Rethinking organizational change. Organization Science, 13(5), 567-582.

Turner, J. C., Hogg, M. A., Oakes, P. J., Reicher, S. D., \& Wetherell, M. S. (1987). Rediscovering the social group: A self-categorization theory. Oxford, UK: Basil Blackwell.

Turner, V. (1967). The Forest of Symbols: Aspects of Ndembu Ritual. Ithaca, NY: Cornell University Press.

Turner, V. (1980). La selva de los símbolos. Madrid: Siglo XXI editores.

Turner, V. (1988). El proceso ritual: estructura y antiestructura. Madrid: Taurus.

Turner, V. (2008). The ritual process: structure and anti-structure. New Jersey: Berrue Circle. 
Uribe, B. (2006). La objetivación del cuerpo, un dispositivo de poder en las organizaciones. Medellín: Universidad EAFIT.

Vaara, E., Kleymann, B., \& Seristo, H. (2004). Strategies as discursive constructions: the case of airline alliances. Journal of Management Studies, 41(1), 1-35.

Vaara, E., Tienari, J., Piekkari, R., \& Santti, R. (2005). Language and the circuits of power in a merging multinational corporation. Journal of Management Studies., 42(3), 595-623.

Velez, O. L., \& Galeano, M. E. (2000). Investigación cualitativa: estado del arte. Medellín: Digital Express.

Voss, Z. G., Cable, D. M., \& Voss, G. B. (2006). Organizational identity and firm performance: What happens when leaders disagree about "Who we are?". Organization Science, 17(6), 741-755.

Waldman, G. (1998). Max Horkheimer: un diálogo inconcluso. En G. Zabludovsky, Teoría sociológica y modernidad. México: Plaza y Valdéz, Universidad Autónoma de México.

Walliser, B. (2002). Los modelos económicos. En G. Cohen-Tannoudji, N. Bouleau, B. Walliser, E. Picavet, \& A. Utaker, El concepto de Modelo (R. Zapata Cano, Trad., págs. 38-48). Medellín, Colombia: Universidad EAFIT.

Watson, T. (1994). In Search of Management. London: Routledge.

Watson, T. (2008). Managing Identity: identity work, personal predicaments and structural circumstances. Organization, 15(1), 121-143.

Watson, T. (2009). Narrative, life story and manager identity. Human Relations, 63(3), 425-452.

Weber, M. (1997). Economía y Sociedad (1922 ed.). México: Fondo de Cultura Económica.

Weber, M. (2007). La ética protestante y el espíritu del capitalismo. Ciudad de México: Colofón.

Weedon, C. (1987). Feminist practice and poststructuralist theory. Oxford: Basil Blackwell. 
Wellmer, A. (1979). Teoría crítica de la sociedad y positivismo. (G. Hernández Ortega, Trad.) Barcelona: Ariel.

Westwood, R., \& Clegg, S. (2003). The Discourse of Organization Studies: Dissensus, Politics and Paradigms. En R. Westwood, \& S. Clegg (Edits.), Debating Organization: Point-Counterpoint in Organization Studies (págs. 142). London: Blackwell.

Whetten, D. A. (2006). Albert and Whetten Revisted Strengthening the Concept of Organizational Identity. Journal of Management Inquiry, 15(3), 219-234.

Whetten, D. A., \& Mackey, A. (2002). A social actor conception or organizational identity and its implications for the study of organizational reputation. Business \& Society, 41(4), 393-414.

Whetten, D., \& Godfrey, P. (1998). Identity in organizations. Building theory through conversations. London: SAGE.

Whittle, A. (2005). Preaching and practising flexibility: Implications for theories of subjectivity at work. Human Relations, 58(10), 1301-1322.

Wiggershaus, R. (2010). La Escuela de Fráncfort. (M. Romano Hassán, Trad.) México: Fondo de Cultura Económica, Universidad Autónoma Metropolitana-I.

Wood, M., \& Brown, S. (2011). Lines of flight: everyday resistance along England's backbone. Organization, 18(4), 517-539.

Woodward, J. (1975). Management and technology. En D. S. Pugh, Organization Theory (págs. 56-71). London: Penguin Books.

Wooldridge, B., Schmid, T., \& Floyd, S. W. (2008). The Middle Management Perspective on Strategy Process: Contributions, Synthesis, and Future Research. Jornal of Management, 34(6), 1190-1221.

Ybema, S. (2010). Talk of change: Temporal contrasts and collective identities. Organizations Studies, 31(4), 481-503.

Ybema, S., Keenoy, T., Oswick, C., Beverungen, A., Ellis, N., \& Sabelis, I. (2009). Articulating identities. Human Relations, 62(3), 299-322.

Yin, R. K. (1994). Case study research: Design and Methods. California: SAGE, Thousand Oaks. 
Zucker, L. (2001). El papel de la institucionalización en la persistencia cultural. En W. W. Powell, \& P. J. DiMaggio (Edits.), El nuevo institucionalismo en el análisis organizacional. (págs. 126-153). México: FCE, Colegio Nacional de Ciencias Políticas y Administración Pública, Universidad Autónoma del Estado de México.

Zuckerman, E. W., Kim, T. Y., Ukanwa, K., \& von Rittmann, J. (2003). Robust identities or nonentities? Typecasting in the feature-film market. American Journal of Sociology, 108(5), 1018-1074.

\section{CIBERGRAFÍA}

GRUPO NUTRESA. (26 de 12 de 2012). Historia. Obtenido de http://www.grupochocolates.com/es/content/estructura-del-grupo

\section{DOCUMENTOS OFICIALES}

Grupo Consultoría S.A. (2011) Informe sobre la Cultura de Comercial Nutresa.

Consultora Team Resources, Inc. (2010). Caracterización de los empleados provenientes de diversas compañías del Grupo Nutresa. 
CONSTRUCCION DE IDENTIDAD

ORGANIZACIONAL DE LOS MANDOS MEDTOS COMO ESPACIO LIMINAL. UN ESTUDIO DE CASO.

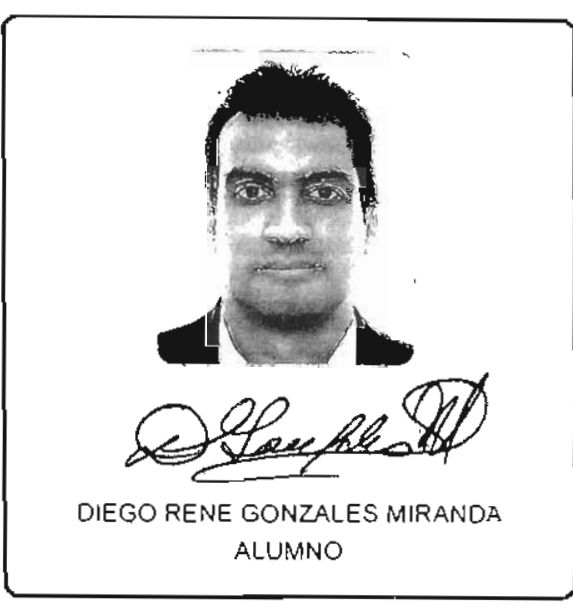

REVISO

LIC JULIO CESAR DE LARA ISASSI DIRECTOR DE SISTEMAS ESCOLARES
En México, D.F., se presentaron a las ll:od horas del día 9 del mes de julio del año 2014 en la Unzdad Iztapalapa de Ia Universidad Autónoma Metropolitana, los suscricos miembros del jurado:

DR. IUIS MONTANNO HIROSE

DR. ANTONIO BARBA ALVAREZ

DR. FRANCISCO LOPEZ GALLEGO

Bajola presidencia del primero $y$ don caracter de Secretario el ullimo, se reunieron a la presentación de la Disertación fública cuya denominación aparece al margen. para la ob́ención del grado de:

DOCTOR EN ESTUDIOS ORGANIZACIONALES

DE: DIEGO RENE GONZALES MTRANDA

$y$ de acuerdo con e: articulo 78 fracción IV/del Reglamento de Estudios Siperiores de la Universidad Autonoma Metropolitana, ios niembros del jurado resolvieron:

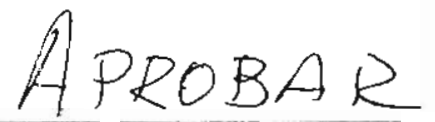

Acto continuo, el presidente del jurado comunicó al interesado el resultado de la evaluación $y$, en caso aprobatorio. le fue tomada la protesta.

DIRECTORA DE LA OIVISIÓN DE CSH

DRA JUANA JUAREZ ROMERO

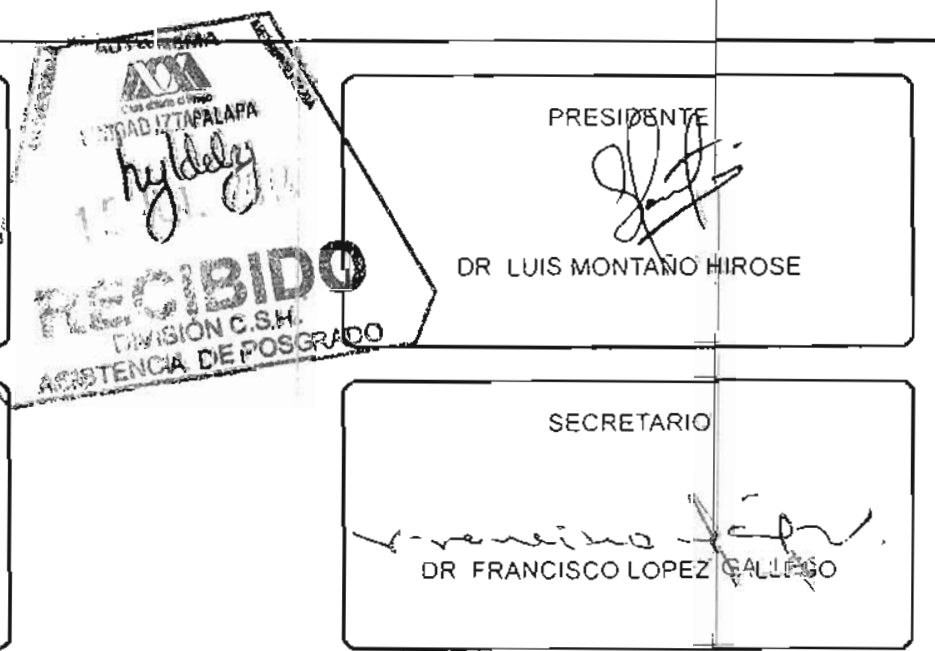

